\title{
MASTER
}

ORNL/SUB-7317/1

S\&W J.O. NO. 12977

\section{Cogeneration Feasibility Study in the Gulf States Utilities Service Area}

\author{
Work performed by the \\ Stone and Webster Engineering Corporation \\ Under Subcontract Number 7317 \\ for \\ Oak Ridge National Laboratory
}

OPERATED BY

UNION CARBIDE CORPORATION FOR THE UNITED STATES DEPARTMENT OF ENERGY 


\section{DISCLAIMER}

This report was prepared as an account of work sponsored by an agency of the United States Government. Neither the United States Government nor any agency Thereof, nor any of their employees, makes any warranty, express or implied, or assumes any legal liability or responsibility for the accuracy, completeness, or usefulness of any information, apparatus, product, or process disclosed, or represents that its use would not infringe privately owned rights. Reference herein to any specific commercial product, process, or service by trade name, trademark, manufacturer, or otherwise does not necessarily constitute or imply its endorsement, recommendation, or favoring by the United States Government or any agency thereof. The views and opinions of authors expressed herein do not necessarily state or reflect those of the United States Government or any agency thereof. 


\section{DISCLAIMER}

Portions of this document may be illegible in electronic image products. Images are produced from the best available original document. 


\section{Printed in the United States of America. Available from National Technical Information Service \\ U.S. Department of Commerce \\ 5285 Port Royal Road, Springfield, Virginia 22161 NTIS price codes-Printed Copy: A23 Microfiche A01}

This report was prepared as an account of work sponsored by an agency of the United States Government. Neither the United States nor any agency thereof, nor any of their employees, makes any warranty, expressed or implied, or assumes any legal liability or responsibility for any third party's use or the results of such use of any information, apparatus, product or process disclosed in this report, or represents that its use by such third party would not infringe privately owned rights. 
ORNL/SUB-7317/1

MASTER

S\&W J.O. NO. 12977

JULY 1979

\section{COGENERATION FEASIBILITY STUDY IN THE GULF STATES UTILITIES SERVICE AREA}

Date Published: December 1979

Work performed by the

Stone and Webster Engineering Corporation Únder Subcontract Number 7317

for

OAK RIDGE NATIONAL LABORATORY

Oak Ridge, Tennessee 37830

operated by

UNION CARBIDE CORPORATION

for the

DEPARTMENT OF ENERGY

Contract No. W-7405-eng-26

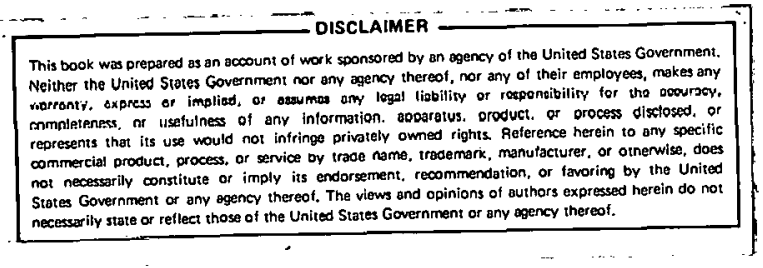

DISTRIBUTIOA OF THIS DOCUMENT IS UNLIMITED 
EXECUTIVE SOMMARY

1.1

1.2

1.3

1.4

1.5

1.6

1.7

1.8

1.9

1.10

1.11

1.12

1.13

1.14

2

2.1

2.2

3

3.1

3.2

3.3

3.4

3.5

3.6

4

4.1

4.2

4.3

4.4

5

5.1

5.2

6

6.1

6.2

6.3

6.4
Introduction

objectives

Site Selection

Heat cycle Optimization

Plant Descriptions

Capital cost Estimates

Economic hrialysis

Reliability - Fossil Fuel and Nuclear Plants

Provisions for Condensing Capabilities

Effect of plant Size and Process Steari Requirements

Sequential Construction of plants

General Conclusions

Implementation

Energy Savings

INTRODUCTION

Objectives and scope

Methodology

Figure

SITE SELECTION

Introuluction

Site Selection Procedures

Characteristics of Candidate Regions.

Location of Candidate sites

Siting Criteria

Candidate Site Evaluations

1-1

$1-1$

$1-2$

$1-2$

$1-2$

$1-5$

$1-5$

$1-9$

$1-10$

$1-10$

$1-11$

$1-11$

$1-13$

$1-14$

$2-1$

$2-3$

3-1

3-1

$3-27$

$3-29$

3-37

$3-39$

PLANT DESCRIPTIONS

Projected Users ' Demands

Heat Cycle Optimization - Orange and

Geismar Sites

Orange Site

Geismar Site

4-1

4-4

$4-10$

4-47

COST ESTIMIATES

Orange Site

$5-2$

Geismar Site

Tables

$5-10$

$6-1$

$6-13$

$6-18$

$6-24$

ECONOMIC ANALYSIS

Econoluic Assumptions

Economic Comparisons

Reliability - Fossil fuel and Nuclear

Plants - Orange and Geismar

Economics Considering Advanced Technology

Condensing Capabilities 
6.5 Sequential Installation of the High Temperature Gas-Cooled Reactor and Consolidated Nuclear steam system Figures

7 CONCLUSIONS

7.1 Site selection

7.2

Site Selection

7.3

Current Techiology

7.4

Advanced Technology Under Development -

$7-2$

$7-2$

High Temperature Gas-Cooled Reactor and

Consolidated Nuclear Steam System

7.5

8.6

Future Advanced rechnologies

$7-4$

$7-4$

$7-8$

plant Size and Steam Conditions

$7-8$

Condensing Capabilities

7.8

$7-9$

7.9 lemperature Gas-cooled Reactor and Consolidated Nuclear Steam System

7.10 Comparison with Existing Plants

7.11

Sensitivity

Figures

8 PLANT SCHEDULE ANO IMPLEMENTATION

8.1

Construction Schedules

8.2

Proposed Strategies for Implementation

of Plant Systern Concepts

$8-1$

$8-1$

9

REFERENCES

9-1

APPENDIX A - Application of Siting Considerations to Candicate Sites

APPENDIX B - Iist of Drawings

APPENDIX C - Discounted Cash Flow Analysis 


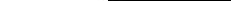




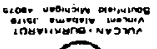

(3) 


\section{SECTION 1}

\section{EXECUTIVE SUMMARY}

TABLE OF CONTENTS

Page

1 INTRODUCTION 1-1

1.2 OBJECTIVES 1 1-1

1.3 SITE SELECTION 1-2

1.4 HEAT CYCLE OPTIMIZATION 1-2

1.5 PLANT DESCRIPTIONS 1-2

1.6 CAPITAL COST ESTIMATES 1-5

1.7 ECONOMIC ANALYSIS 1-5

1.8 RELIABILITY - FOSSIL FUEL AND NUCLEAR PLANTS $1-7$

1.9 PROVISIONS FOR CONDENSING CAPAEIIITIES

1.10 EFFECT OF PLANT SIZE AND PROCESS STEAM REQUIREMENTS $1-10$

1.11 SEQUENTIAL CONSTRUCTION OF PLANTS 1-11

1.12 GENERAI CONCLUSIONS 1-11

1.13 IMPLEMENTATION 1-13

$\begin{array}{ll}1.14 & \text { ENERGY SAVINGS }\end{array}$

TABLES

1-1 Summary of Estimated Capital Costs 1-8

1-2 Cost of Cogeneration Plant Process Steam 1-9

1-3 Comparison of Steam Costs 1-16

1-4 Present Value of Steam Costs Net-of-Taxes 1-17 
SECTION 1

EXECUTIVE SUMMARY

\subsection{INTRODUCTION}

Stone $\mathcal{E}$ Webster Engineering Corporation was retained as a subcontractor by Union Carbide Corporation, Nuclear Division, to perform an extensive cogeneration feasibility study utilizing several alternative steam sources. The study was funded by the Energy Research and Development Administration (ERDA), which is now part of the Department of Energy (DOE). The study considers sites in the Gulf States Utilities (GSU) service area at orange, Texas, and Geismar, Lake, Charles, and North Baton Rouge, Louisiana. The sources of steam considered include oil, coal, high temperature gas-cooled nuclear reactor (HTGR) steamers, consolidated nuclear, steam system (CNSS), atmospheric fluidized-bed coal combustion, and coal gasification.

A companion institutional study, which complements this engineering study, is being performed by stone $\varepsilon$ Webster Management Consultants. Their report appears separately.

Concepts concerning cogeneration fuel systems were categorized by technical applicability as: current technology (pulverized coal-fired boilers and fuel oil-fired boilers), advanced technology under development (HTGR steamers and the CNSS), and advanced technology for future development (atmospheric fluidized-bed (AFB) boilers and coal gasification).

The fuel.chargeable to power (FCP) in a cogeneration plant is on the order of half the heat rate of a fossil-fired power-only station. In addition to substantial net energy savings, the cogeneration alternatives studied would replace large amounts of scarce gas or oil with coal and nuclear fuel.

\subsection{OBJECTIVES}

In addition to providing data on cogeneration plants generally useful in the United States, the study determined the technical and economic feasibility of steam and electric power cogeneration using coal and nuclear fuels for localized industrial complexes. It also includes technical and economic studies associated: with the atmospheric fluidized-bed boiler and coal gasification in conjunction with onventional gas-fired boilers, gas turbine combined cycle, and fuel cells. Such multicompany thermal grids should provide sufficient demand to make a large cogeneration plant attractive, both for lower capital investment and lower operating costs, when compared to a 
program where each industrial plant would expand independently.

The scope of the study includes the tasks of selecting two sites most suitable for the cogeneration concept, developing and optimizing heat cycles, developing plant and equipment descriptions, determining capital and operating costs, evaluating alternatives, and presenting conclusions based on technical and economic factors.

\subsection{SITE SELECTION}

The siting objective of the study was achieved by comprehensively screening ten sites within the proposed four. regions and applying specific siting parameters. Based on assigned "scores," sites at Orange, Texas, and Geismar, Louisiana, were selected as being the two best suited for both coal and nuclear cogeneration plants. This selection does not indicate that the other sites are not suitable. merely that they are less suitable to some degree.

\subsection{HEAT CYCLE OPTIMIZATION}

Utilizing heat balances and cost estimates, it was determined that economic benefits improved with higher steam operating pressures. Following the trend away from supercritical pressures, 2,400. psig was, selected as the design operating pressure.

Maximum work is theoretically obtained with an infinite number of feedwater heaters. Final designs and heat balances generally include two closed feedwater heaters in series with the deaerator which balances capital costs against theoretical performance.

The most economic selection of turbine generators is the one that generates maximum power. In accordance with this criterion, straight noncondensing steam turbines were used where possible and practical. Extraction points increase turbine cost and reduce efficiency.

\subsection{PLANT DESCRIPTIONS}

All of the cogeneration plant designs were based on the total steam requirements projected for 1985 by the industrial users at the two specific sites. Generally, the proposed cogeneration plants at that time would have no excess capacity available for industrial expansion. The backup steam supply is assumed to be from users" facilities which must be maintained and expanded, as necessary, during construction of the cogeneration plant to provide, at a minimum, 100 percent of the users' backup requirements. Although the users at orange required essentially four 
operating pressures, steam from the cogeneration plant is distributed at two levels. The three distribution pressures at Geismar meet the three steam process pressures required by the users in that area. Projected 1985 steam demands are:

Process Steam Flows $(1 \mathrm{~b} / \mathrm{hr} \times 1,000)$

970 psia 690 psia 640 psia 290 psia Total

$\begin{array}{lccccr}\text { Geismar } & 370 & 5,020 & - & 450 & 5,840 \\ \text { Orange } & - & - & 1,450 & 745 & 2,195\end{array}$

The equipment in conventional fossil-fired plants and nuclear plants is typical of power generating stations except for use of noncondensing turbines and the electrical and steam distribution systems. Generally speaking and where applicable, the plant arrangements include boiler feedwater heating and pumping, fuel handling, ash handling, precipitators and scrubbers, water and wastewater systems, and the necessary buildings and structures. The atmospheric fluidized-bed plant is similar except for the steam generator and limestone handling system.

Cogeneration plants employing coal gasification are more complex and contain a considerable amount of process equipment. Briefly, these plants include gasifiers, sulfur and ammonia removal equipment, tar-fired boilers, gas-fired boilers, air compressors, air separation equipment, ash handling, and waste gas treating systems. In addition, the basic systems are also required for coal handling, water and wastewater treatment, and the like.

At both Orange and Geismar, the fossil-fired plants are designed with two 50-percent capacity boilers. Choice of two boilers was made on the basis of minimum initial capital cost with reasonable operating flexibility.

The HTGR and CNSS plants are designed around intermediate sized nuclear units rated at 1200 MWt. Heat input requires two units in all cases except for the HTGR at Geismar where three units are necessary. Use of standard size units results in an excess steam generating capacity in all of the nuclear plants.

Unlike the CNSS, the HTGR is capable of generating process steam at the required pressure and temperature. Because of this, oil-fired superheaters must be used in conjunction with the CNSS. Also, the 970 psia steam required at Geismar must be generated in a conventional oil-fired boiler. 
The following summary provides a general comparison of the various plant arrangements considered:

ORANGE

Eastern $\mathcal{E}$ Western Coals

No. 6 Fuel Oil

HTGR

CNSS without Condensing

CNSS with Condensing

GEISMAR Eastern \& Western
Coals

No. 6 Fuel Oil

HTGR

CNSS without Condensing

CNSS with Condensing

Fustel-Whieelés AFB

Babcock \& Wilcox AFB

Coal Gasification with Conventional Boiler (Air-Blown)

Conventional Boiler (Oxygen-Blown) Combined Cycle (Unlimited Elec.) Combined Cycle (Limited Elec.)

Fuel Cell (Unlimited Elec.)

Fuel Cell

(Limited Elec.)
Operating

Pressure

(psia)

2415

2415

2415

640

640

2415

.2415

2415

690

690

2415

2415

2415

2415

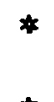

$\star$

$\star$

*
Heat Input (MWt)

989.360

989.360

1007.363

1315.560

$152 \cdot 3$

148.6

155.2

164.6

23.8
871.083

352.2

369.7

400

38.4

183.2

$344 \cdot 3$

339.9

2630.958

474.7

476.7

1854

352

$2701: 3$

352

\$970/690/290 psia. 


\subsection{CAPITAI COST ESTIMATES}

Order of magnitude cost estimates were prepared for each type of. cogeneration plant using vendor information and in-house costing data. Costs covered the complete plants outlined and described in section 4. Land and right-of-way costs, licensing, environmental impact studies, relocation of existing facilities, and dismantling costs at the end of the useful plant life were excluded. No allowance is made for related equipment and construction costs required by users in their plants to utilize the steam and electric power. A summary of the capital costs is shown in Table 1-1.

Estimates are for costs as of January 1978 escalated through 60 percent of the construction period. Interest during construction was calculated at simple interest for the final 40 percent of construction. Cost estimates and related analyses for the advanced technology concepts categorized as future development were prepared for the Geismar site only.

\subsection{ECONOMIC ANALYSIS}

The economic comparisons outlined in section 1.7 .1 below have been made utilizing levelized. steam costs based on utility-type fixed charges that provide a nominal rate of return of 10 percent. All of the net operating costs were developed using the same construction starting dates. In addition to having different initial operating dates caused by varying construction requirements, the anticipated operating life of the plants were 30 years for all of the fossil-fired plants versus 35 years for nuclear plants.

Since the possibility for ownership by an entity other than a utility does exist, an expense center cost analysis was made for discount rates of 10, 15, and 20 percent and fuel costs varying from 90 to 200 percent of the best estimate. Also, the discounted cash flows were determined based on all plants having the same startup date by delaying construction where applicable. A summary of the discounted cash flow analysis is covered in section 1.7.2.

\subsubsection{Economic Comparisons}

Because. steam is the primary product of the subject cogeneration plants, the final economic evaluations are based on the net operating cost per thousand pounds of process steam. This figure was determined from the annual operating cost comprising fixed charges (taxes, insurance, and debt service), operating and maintenance costs; and fuel costs, with a credit allowed for the net electric power exported. Total yearly process stean is based on maximum projected demand for 7,884 hours. 
Except for the fixed charges, the annual operating costs and the credit for electric power are escalated to the service date of each particular plant and levelized for projected plant life. The costs per thousand pounds of process steam in levelized dollars are summarized in Table 1-2.

As shown by the table, eastern coal is the least expensive of the current technology concepts in terms of process steam costs but only slightly less than western coal. Within the advanced nuclear technologies considered to be under development, the HTGR is far better economically than the CNSS. Atmospheric fluidized-bed combustion is the economic choice within future development concepts. Considering all three categories, the HTGR provides steam considerably lower in cost than any of the other schemes. Other factors aside, it emerges as the best economic choice among technologies. The addition of condensing capabilities in the CNSS plants reduces steam cost by 28 percent at Orange and 12 percent at Geismar .

\subsubsection{Discounted Cash Flow Analysis}

The expense center cost analysis determined the present value of the net cash outflow, discounted to 1979, for each of the proposed cogeneration plants, taking into account the cash requirements for capital investment, fuel storage capacity, fuel costs, operating and maintenance costs, credit for in-plant electric power generation, credit for taxes and depreciation. For comparison, the present value of operating expenses for continued operation of existing facilities was calculated. Values were calculated for three discount rates and four fuel costs for both Orange and Geismar.

The resulting present values have been utilized to develop the costs per thousand pounds of steam, which are a more meaningful and understandable basis for an economic evaluation. The following steam costs are summarized in Table $1-3$ for a 10 percent discount rate and 100 percent fuel costs.

(1) Minimum Revenue Requirement (MRR) Steam Costs

These steam costs provide the minimum rate of return of 10 percent used as the basis to determine results in Tables $6-4$ and 6-5. However, steam costs have been recalculated based on the longest construction period and a plant operating life of 30 years. The total study period is 37 years in all cases to agree with the DCF analysis.

(2) Levelized Steam Costs After Taxes 
These stearn costs were derived using results of the DCF study and the appropriate discount rate and plant life.

(3) DCF Break-Even Purchase Prices

These are the prices that could be paid to purchase steam to give the same levelized after-tax costs described in (2) above.

Tables 6-17 and 6-18 can be used to compare steam costs for other assumed values for the rate of return and fuel costs. It can be seen that at a 10 percent discount rate, the HTGR provides the lowest steam cost, and eastern coal is second. The same results occur as did in Tables $6-4$ and $6-5$ with western coal, the CNSS and No. 6 fuel oil following in that order.

The order is essentially the same at a discount rate of 15 percent, except at fuel costs of 90 and 100 percent where the HTGR loses most or all of its advantage over eastern coal.

At a 20 percent discount rate, eastern and western coal steam costs are lowest with the other alternate plants changing in order of costs depending on the fuel costs assumed.

The CNSS, at a fuel cost of 90 percent, is competitive with eastern coal plants at fuel costs from 150 to 200 percent, depending on the discount rate.

The study does point out that a definite economic advantage exists for an industrial user to purchase steam from an entity having a rate of return limited by regulation.

Although steam costo levelized over a 30-ycar period beginning in 1986 are good for comparison of alternates. they are difficult to relate to and compare with present day costs. Table 6-20 contains present day steam costs based on the DCF study for all of the alternates at two different escalation rates and the three discount rates. For a escalation rates and the three discount rates. For a present value steam costs for a 10 percent rate of return and a 7 percent escalation rate.

Al1 of these are below the 1979 operating costs for the existing plants. This advantage disappears as the discount rate increases to 20 percent. 
TABLE 1-1

SUMMARY OF ESTIMATED CAPITAL COSTS

$$
(\$ \times 1,000)
$$

Type of Cogeneration Plant

Eastern Coal Fired

Western Coal Fired

No. 6 Fuel Oil Fired

HTGR

CNSS (Without condensing)

CNSS (with condensing)

Foster-Wheeler AFB

Babcock $\varepsilon$ Wilcox AFB

Coal Gasification with

Conventional Boilers (Air-Blown)

Conventional Boilers (Oxygen-Blown)

Combined Cycle (Unlimited

Elec:)

Combined Cycle (Limited Elec.)

Fuel Cell (Unlimited Elec.)

Fuel Cell (Limited Elec.)

\begin{tabular}{lc} 
& Orange, Texas \\
\hline January & Including Escala- \\
1978 & tion and Interest \\
Dollars & During Construction
\end{tabular}

\begin{tabular}{ll} 
Geismar, Louisiana \\
\hline January & Including Escala- \\
1978 & tion and Interest \\
Dollars & During Construction
\end{tabular}

292.620

485,738
489,677
382.255
729,787
677.812
755,062

294,993

247,286

410,000

380,800

424,200

755,062
715.491

717,514

636,172

$1,127,000$

844,700

888,900

626,202

751,828

$1.297,086$

$1,473,439$

$2,976,000$

$1,600,000$

$2,797,230$

$1,179,100$
$1,184,368$

$1,191,045$

983,394

$2,006,025$

$1,503,539$

$1,582,214$

$1,309,471$

$1,248,005$

$2,153,113$

$2,445,853$

$4,940,046$

$2,655,939$

$4,643,295$

$1,957,260$ 
TABLE 1-2

COST OF COGENERATION PLANT PROCESS STEAM (Levelized $\$ / 1000$ lb)

Current Technology

Eastern Coal-Fired

Western Coal-Fired

No. 6 Fuel oil-Fired

Advanced Technology - Under Development

HTGR

CNSS without Condensing

CNSS with Condensing
Orange Geismar

$\begin{array}{rr}6.19 & 6.39 \\ 6.69 & 6.88 \\ 10.76 & 11.17\end{array}$

Advanced Technology - Future Development

Foster-Wheeler AFB

5.84

Babcock \& Wilcox AFB

6.62

Coal Gasification with:

Conventional Boilers (Air-Blown)

13.13

Conventional Boilers (Oxygen-Blown)

14.42

Combined Cycle (Unlimited Elec.)

14.56

Combined Cycle (Limited Elec.)

16.48

Fuel Cell (Unlimited Elec..)

9.91

Fuel Cell (Limited Elec.)

13.46

\subsection{RELIABILITY - FOSSIL FUEL AND NUCLEAR PLANTS}

A reliability study using availability factors extracted from published data indicates that spare steam generating equipment can be economically justified for certain concepts. Justification was determined by comparing the annual fixed oharges attributable to the increased capital cost for the purchase and installation of additional equipment with the resulting savings in fuel costs. Steam capacity not generated in the cogeneration plant due to the unavailability of steam generating equipment was assumed to be generated by the users backup boilers burning No. 2 fuel oil. The improvement in availability with the addition of spare or backup equipment reduced the users' operating time and thus reduced the overall operating costs. Variations in credit for electric power generated by the cogeneration plant are also a factor affecting the total operating costs and were considered.

At Geismar, spare steam generating equipment is justified for both coal-fired plants and the CNSS, while the HTGR provides only a marginal return on investment. A spare boiler for the 970 psia process steam required to supplement the CNSS cannot be justified. 
At Orange, spare units were found to be only marginally warranted for both coal-fired plants. Spare nuclear steam generators cannot be economically justified.

\subsection{PROVISIONS FOR CONDENSIING CAPABILITIES}

Economic analyses have shown that the use of excess steam generating capacity (that above process steam requirements) to increase electric power generation justifies installation of the additional equipment needed to incorporate a condensing turbine generator. The HTGR and CNSS plants have inherent excess capacity due to standard size increments of steam generators and would require only the suitable steam turbine generator and the related condensing and cooling water equipment.

Since the CNSS is a viable option, a detailed analysis using condensing facilities was made which confirmed that the added capital costs were more than justified by the credit received for the resulting increase in power generation. Although the steam costs were not reduced enough to compete with the coal-fired plants, they are more attractive when comparing costs with an oil-fired cogeneration plant or continued operations of the present facilities.

Spare steam generating capacity or redundant capacity in any type cogeneration plant warrants an investigation of the costs associated with the addition of condensing facilities. Generally, it appears that additional equipment is justified provided demand for electric power is flexible.

\subsection{EFFECT OF PLANT SIZE AND PROCESS STEAM REOUIREMENTS}

Comparison of the steam costs indicates that plant size, based on the steam generated, has no effect on the economic selection of the type of cogeneration plant. Even though Orange is half the size of Geismar, the arvantages and disadvantages of each type of plant are similar. The same order of preference exists for both sites. At both sites, the eastern coal-fired plant proves to be the best choice under current technology and the HTGR is the better choice under advanced technology.

Net costs per thousand pounds of process steam are not lower for the larger plant at Geismar because plant size is not the governing factor. Before credit for power, the larger plant has the lower operating costs. This result is expected and indicates that utilization of the steam has an impact on net costs. At Geismar, higher process steam requirements reduce energy utilization and thus reduce the electric output per unit of process steam. 


\subsection{SEQUENTIAL CONSTRUCTION OF PLANTS}

The option of installing two or three nuclear steam generators at 5-year intervals in the UTGR and CNSS plants was investigated and found economically unattractive. Installation of the required capacity during the initial construction provides lower total operating costs over the life of the plant.

An alternative that would only install two HTGRs initially and omit the third unit totally yielded lower operating cost for a short period of time. When considering the full life of the plant, the base option with three HTGRs still provided the least total cost in present worth dollars.

\subsection{GENERAL CONCLUSIONS}

All of the economic comparisons were made assuming nth-of-a-kind plants for the alternatives investigated. In addition, the final conclusions and recommendations have taken into consideration technical factors and present state of the art. The results of this study are site specific but may be common for other locations; however, a general application cannot be assumed valid and should be avoided. Each potential cogeneration site must be evaluated on its own merits for specific steam and electric power requirements.

The coal-fired cogeneration plant is recommended to meet the immediate needs of an industrial complex based on both economics and current technology. Such a plant can be built now with confidence because the technology has been well developed and performance can be predicted. with a high degree of accuracy. Also, use of coal agrees favorably with the present national energy program emphasizing utilization of U.S. coal reserves.

Eastern coal emerged as the economic choice with the cost of process steam marginally less than that of western coal. Basically, this is the result of the selection of assumptions. For this reason, a detailed review should be undertaken for any contemplated cogeneration plant. To achieve maximum flexibility and ensure against uncertainties in fuel supplies, it is recommended that a coal-fired plant be designed to accomrnodate both typer of coal. Flue gas scrubbers should be designed to handle the high sulfur eastern coals. The boilers and all their related auxiliaries and coal and ash handing facilities should be sized to utilize the lower Btu western coals.

Scrubbers have been included in the fossil-fired plants to meet the updated New source performance standards (NSPS) which call for "full scrubbing." The scrubber equipment is 
a significant part of the estimated capital costs with the investment varying from 14 percent for eastern coal to 16 percent for oil-fired plants. The operating and maintenance costs for scrubbers amount to about 25 percent of the total for western coal and about 40 percent for the oil and eastern coal-fired plants.

The HTGR, which is categorized as an advanced technology under development, provides the lowest process steam cost but because of limited successful operating experience in the United States cannot be considered as an immediate candidate plant.

All of the concepts considered to be advanced technology. future development, were defined, costed, and economically compared; but none can be seriously considered for application in cogeneration plants at this time.

An atmospheric fluidized-bed boiler used to generate steam results in net process steam costs similar to those of pulverized coal-fired plants when considering designs and cost data of two manufacturers. Present ongoing development anticipates commercial operation of large-scale utility plants by the end of the century. Continued development of the $\mathrm{AFB}$ is recommended because it offers the potential for utilizing vast low-grade coal resources in an environmentally acceptable manner.

The coal gasification process was considered as the fuel gas source for three plant configurations, all of which generate process steam at a lifylite uiit cost than pulverized coal-fired plants. This conclusion is due to the overall lower thermal efficiency, high initial capital costs, and high operating and maintenance costs. While coal gasifiers represent commercial or near commercial technology, developmental work presently in progress should yield an improved and reliable process within the next 10 years.

One concept studied utilizes the production of coal gas from either an air-blown or oxygen-blown gasifier in a cogeneration plant with conventional gas-fired boilers. Both alternates result in steam costs of approximately twice that of a pulverized coal plant and therefore are not competitive with coal firing and limestone flue gas

scrubbing.

The use of the gas turbine combined cycle in conjunction with a coal gasifier is not suited for the cogeneration plants studied. This is true because utilization of all the coal gas from the coal gasification plant in the combined cycle system to generate required process steam results in the generation of a great quantity of electric power (about five times that of the standard coal-fired plant). To limit 
electric power output requires the addition of gas-fired boilers to generate steam while limiting electric power and reducing fuel input. Steam costs for both cases are extremely high.

Fuel cells used in conjunction with coal gasification are similar to the combined cycle with regards to high electric power generation and, within the constraints of the present study, will not fit the requirements for a cogeneration plant with process steam as the prime commodity. Limiting electric output requires the addition of coal gas-fired boilers to generate the required process steam. Steam costs are slightly lower than the combined cycle plant but still considered high.

\subsection{IMPLEMENTATION}

Engineering and construction of the recommended coal-fired cogeneration plant can start immediately, and it can be in commercial operation in 6 years. There are no technical constraints to deter progress. If the project becomes a reality, the initial engineering phase should begin with a detailed economic evaluation to determine the number and size of boilers to obtain optimum reliability. Also, consideration should be given to the merits of including condensing capabilities to increase electric power generation. This may hinge entirely on plant ownership and the ability of the owner or owners to use or sell the resulting additional power.

At Geismar, during the construction of the cogeneration plant, the users must maintain and expand their steam generating facilities to meet their projected demands. This will automatically provide 100 percent backup to the cogeneration plant and ensure continuity of operations. Projected steam demands at Orangc indicate expansion of users" facilities is unnecessary. Like Geismar, they must maintain their steam generating facilities through the construction period of the cogeneration plant, thus providing 100 percent backup for the cogeneration plant.

Since the HTGR can provide the required process steam and the fuel costs are low, it is economically attractive. However, based on experience to date, the HTGR has not progressed technically to a point to be considered a viable option for a cogeneration plant. Technical acceptance may be 10 to 20 years away. Development of the HTGR for utility use may eventually produce a reactor suitable for industrial cogeneration.

For the two applications in this study, the cNss does not meet the specific steam requirements of the cogeneration plants without the addition of reboilers, superheaters, and 
a fossil-fired boiler at Geismar. This additional equipment increases operating costs and makes it economically unattractive as a candidate plant. Nothing further is recommended for use of a cNSS at Orange or Geismar. It should not be assumed, however, that the CNSS is unsuitable for other potential cogeneration sites. The CNSS may be applicable and more attractive for cogeneration plants providing heating steam for hospital, residential, and commercial areas. Some industrial complexes may also have needs within the limits of the CNSS.

Atmospheric fluidized-bed boilers, with the capability of burning low-grade coals in an environmentally acceptable nanner, offer potential benefits. Ongoing development efforts appear to be adequate and should continue.

Coal gasification is not specifically suited to meet the basic parameters of the plants studied and no development work can be justified on that basis. However, there appears to be a potential, when used with the gas turbine combined cycle or the fuel cell, for applications requiring high electrical output. Because of this potential, studies scheduled and in progress should continue.

\section{14 ENERGY SAVINGS}

Cogeneration, in this site-specific study, results in global energy savings for all current technology classified plants. Similarly, the nuclear plants also yield a reduction in total energy input. Energy savings, which are based on a comparisun will existiny operalions, result from improved operating efficiency and the lower heat rate chargeable to cogenerated electric power. Only the AFB provides an energy savings among the cogeneration plants considered as advanced technology, future development. The net energy savings, or loss, per operating hour for the various cogeneration options are:

\section{Energy Savings (Loss)-Btu $\times 106 / \mathrm{hr}$}

Cogeneration Plant

Coal-Fired

Oil-Fired

HTGR

CNSS

Foster-Wheeler AFB

Babcock \& Wilcox AFB

Coal Gasification with

Conventional Boiler (Air-Blown)

Conventional Boiler (Oxygen-Blown)

Combined Cycle (Limited Elec.)

Fuel Cell (Limited Elec.)
Orange Geismar

1246.2

1334.7

1923.4

820.2

3284.6

3471.6

5073.0

2001.1

3426.2

3133.8

$(1319.5)$

$(1561.2)$

$(2077.6)$

$(1591.5)$ 
The use of coal or a nuclear fuel as the energy source would replace about 3,603 million Btus per hour of oil or gas used by the industrial facilities at orange. This is equivalent to $25,000 \mathrm{gph}$ of oil. At Geismar, an alternate fuel would replace 9,963 million Btus per hour (equivalent to $70,000 \mathrm{gph}$ of oil): The reduction of oil would be less for the CNSS by 3,200 gph and 9,800 gph at Orange and Geismar, respectively, because of the use of oil to fire the superheaters and boiler required in the plant system. 


\section{TABLE 1-3}

COMPARISON OF STEAM COSTS(1)

$\begin{array}{lll} & \text { LSC After Taxes } & \text { DCF Break-Even (3) } \\ \text { MRR Steam Costs } & \text { Based on the DCF } & \text { Purchase Price } \\ (\$ / 1000 \mathrm{Lb}) & (\$ / 1000 \mathrm{Lb}) & (\$ / 1000 \mathrm{Lb})\end{array}$

\section{Orange}

$\$ / 1000 \mathrm{Lb})$

$(\$ / 1000 \mathrm{Lb})$

$(\$ / 1000$ Ib)

Eastern Coal

Western Coal

No. 6 Fuel Oil

HTGR

CNSS

$$
\begin{array}{r}
6.55 \\
7.06 \\
12.28 \\
3.33 \\
9 . .29
\end{array}
$$

-
$3: 62$

3.91

6.84
2.105

$8 \cdot 25$

3.41

3.58

6.63

2.05

4.76

$6: 72$
6.70

7.24

12.67

3.80

9.51

15.28

Geismar

Western Coal

Nn. 6 Fuel Oil

7.27

12.75

4.07
9.40

CNSS

Existing Plantso2
6.56

7.08

12.75

3.94

9.15

12.92

(1) Levelized for 30 years starting in 1986

( 2) Operating costs only

(3) Income Tax rate 46 percent at Orange; 48 percent at Geismar. 
TABLE: $\quad \mathbf{1 - 4}$

PRESENT VALUE STEAM COSTS NET-OF-TAXES( 1 )

$(1979 \$ / 1000 \mathrm{LB})$

Orange

Eastern Coal

Western Coal

Nu. 6 Fuel Oil

HTGR

CNSS

Existing Plants( 2$)$
1.13

1.22

2.14

0.64

1.61

2.73

Geismar

(1) Based on 7 percent escalation rate and 10 nercent discount rate.

(2) Operating costs only for No. 2 fuel oil. 


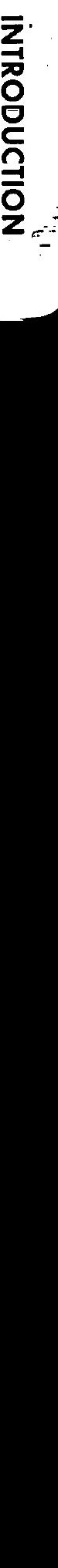




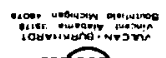

(4)

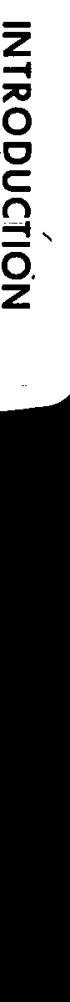


SECTION 2

INTRODUCTION

TABLE OF CONTENTS

Page

2.1 OBJ̄ECTIVES AND SCOPE

$2-1$

2.2 METHODOLOGY

$2-3$

FIGURE

Figure 2-1 Location of the Four Proposed Regions 


\section{SECTION 2}

\section{INTRODUCTION}

The study described in this report was undertaken by stone $\varepsilon$ Webster Engineering Corporation (SEW) under subcontract to the Oak Ridge National Laboratory operated by Union Carbide Corporation. Economic and engineering factors were considered by SEW to evaluate the feasibility of the development in the 1980's of a cogeneration plant in the Gulf States Utilities (GSU) service area. This section of the report briefly indicates the scope of the work carried out by SEW and the approach taken.

\section{$2: 1$ OBJECTIVES AND SCOPE}

The objectives of the cogeneration study were to determine:

Technical and economic feasibility of steam and electric power cogeneration alternatives using coal and nuclear fuels for industrial plants located in the general area of Gulf States Utilities.

- Technical and economic data on cogeneration plants generally useful in the United States.

- Technical and economic feasibility of steam and electric power cogeneration using atmospheric fluidized-bed boilers.

Technical and economic feasibility of steam and electric cogeneration utilizing gasified coal in conventional boilers, fuel cells, and gas turbines.

This report considers current and advanced technology steam and electric generating configurations for application at two locations determined to have the best potential for utilization of the cogeneration concept. The projected 1985 industrial steam and electric loads for the two locations were used as the basis for determining the capacity of the proposed plants.

The following current technology alternatives were considered for each of the two selected sites:

Low-sulfur western coal with conventional boilers and stack-gas desulfurization system.

High-sulfur eastern coal with conventional boilers and stack-gas desulfurization system: 
No. 6 oil-fired boilers, with precipitator and stack-gas desulfurization systems, were also considered for reference and comparison.

Alternatives categorized as advanced technologies under development were also considerea for both sites:

- Consolidated nuclear steam supply (400 MWe) as proposed by Babcock \& Wilcox Company.

- High-temperature gas reactor (400 MWe) as proposed by General Atomic Company.

In addition, the following advanced technology schemes, considered as future developments, were developed for only one selected site:

- Eastern coal atmospheric fluidized-bed boilers.

- Eastern coal gasification utilizing conventional boilers, gas turbines with waste heat boilers, and fuel cells.

The following investigations were made to achieve the study objectives:

1. For the Geismar, Lake Charles, North Baton Rouge, Louisiana; and Orange, Texas regions, the two sites best suited for a coal and/or nuclear cogeneration plant were determined considering the following contraints:

- Air pollution standards

- Availability of cooling water

Ability of alternatives to meet siting constraints.

Figure 2-1 shows the general location of the four proposed regions.

2. Steam and electrical requirements were determined for the industrial users at the two selected sites.

3. Heat cycles were developed for each cogeneration plant optimizing steam pressure, feedwater heating, and electric power generation.

4. Capital and operating cost estimates were prepared to permit economic comparison of the net operating cost for each alternate. Analysis was based on 
escalated and levelized costs for the projected life of the individual plants.

5. Applicability of the atmospheric fluidized-bed boiler to cogeneration plants was determined, utilizing eastern coal and considering present-day technology, availability of equipment, and costs.

6. Applicability of the coal gasification concept to cogeneration was determined, utilizing eastern coal and present-day technology. Coal gas generated in the coal gasification plant would be used to produce steam and generate electricity by:

- Direct combustion of the gas in conventional boilers with electric power generation from noncondensing steam turbine generators.

- Gas turbine generator electric power generation with waste heat boiler steam generation.

- Fuel cell electric power generation with waste heat boiler steam generation.

7. Reliability of steam-generating equipment was determined for the various arrangements and economic justification for backup.

8. Construction schedules were prepared for possible implementation of the current technology alternatives using coal and the advanced technology alternatives incorporating the HTGR and CNSS.

Section 2.2 describes the methodology used by S\&W to perform each of these tasks.

\subsection{METHODOLOGY}

The general approach taken to achieve study objectives included:

- Developing basic economic and technical criteria

- Selecting two candidate sites

- Preparing heat balances and diagrams

- Developing plant description and cost estimates

- Analyzing results

- Presenting conclusions and recommendations. 
The first requirement of the study was to define economic input needed to determine the capital and operating costs for the various cogeneration plant concepts. The assumptions for capital costs, fuel costs, operating and maintenance costs, rates of return, escalation factors, etc., were derived from various sources and approval obtained from the parties involved.

Because of the different operating dates established for the plants, the use of levelized costs for the life of the plants is an appropriate method of economic comparison. Factors for determining levelized cost are projected plant life, rate of return, and inflation rate.

Concurrently, while developing the economic assumptions, the four suggested plant sites were investigated and evaluated using weighted siting parameters to determine the two sites best suited for a cogeneration plant. Once sites were selected, the steam and electric requirements for the two selected sites were developed to establish plant design parameters. The steam flows projected by the industrial users for 1985 were used as the required capacity for each of the plants. Although the sites presently use steam at four and five different operating pressures, distribution from the cogeneration plants was established at a maximum of three pressure levels to minimize the size of the distribution system. Further control of steam pressures was left to the responsibility of each user.

Utilizing preliminary cost estimates, heat cycles were optimized for operating pressure and feedwater heating. Based on results of this optimization, heat balances were developed for all of the concepts considered as current technology and advanced technology under development; i.e., fossil fuel-fired plants and nuclear plants. The heat balances are basic and do not include consideration of pressure drops, heat losses, leakage, and blowdown. For the purpose of this study, comparative data are required and more detailed heat cycle analysis is not necessary.

Steam generating equipment, water treatment, turbine generators, structures, and other major plant equipment were investigated and developed for both fossil fuel and nuclear plants. General descriptions for each type of plant at each site were then prepared. Plot plans were also prepared to show site locations and the diagrammatic routing of the steam distribution piping and electric power.

Similarly, atmospheric fluidized-bed and six coal gasification schemes,' considered as advanced technology (future development) were developed and described with 
supporting drawings and diagrams. Information from published reports was utilized where possible in the preparation of this report and referenced accordingly.

Utilizing heat cycles, descriptions, and published data, an order-of-magnitude capital cost estimate was prepared for each site confiquration. Costs for fuel, operation, and maintenance were calculated using the appropriate economic factors and heat input data. Operating costs were also developed for the users "facilities to permit comparisons with the cogeneration plant and for input when studying the various modes of operation.

This costing data was used to develop the annual operating costs taking into account the credit received for exported electric power. Net operating costs in levelized dollars per thousand pounds of process steam, assuming the maximum steam flow for 7,884 hours per year, were used to make direct comparisons.

Economic analyses made on the basis of Nth-of-a-kind plants were made within each category of technology, and the best results of each then compared to arrive at the best overall economic choice. Further analysis of other factors impacting the type of plant best suited for cogeneration within an industrial complex, now and in the future, determined final recommendations concerning plant type.

Other factors having possible impact on the implementation of this study were also investigated. The factors considered were:

- Size of plant with respect to costs

- Sequential installation of steam generators

- Provisions for condensing capabilities

- Reliability.

Backup data and conclusions were included, and engineering and construction schedules developed for coal-fired and nuclear plants.

After reaching conclusions, recommendations and implementation strategies were presented for the various concepts.

The information and data contained in the remainder of this report are presented in a logical sequence, each section being independent of the previous section. That is, for each site and/or topic, the sections are complete within themselves and can be read without reference to other 
sections. This procecure presents some duplication of material but is necessary to permit continuity in review and study of the data. It also enables individuals to concentrate their efforts in areas of specific interest. The process developed to evaluate suitable plant sites and the sites finally selected as candidate sites are described in section 3 . 


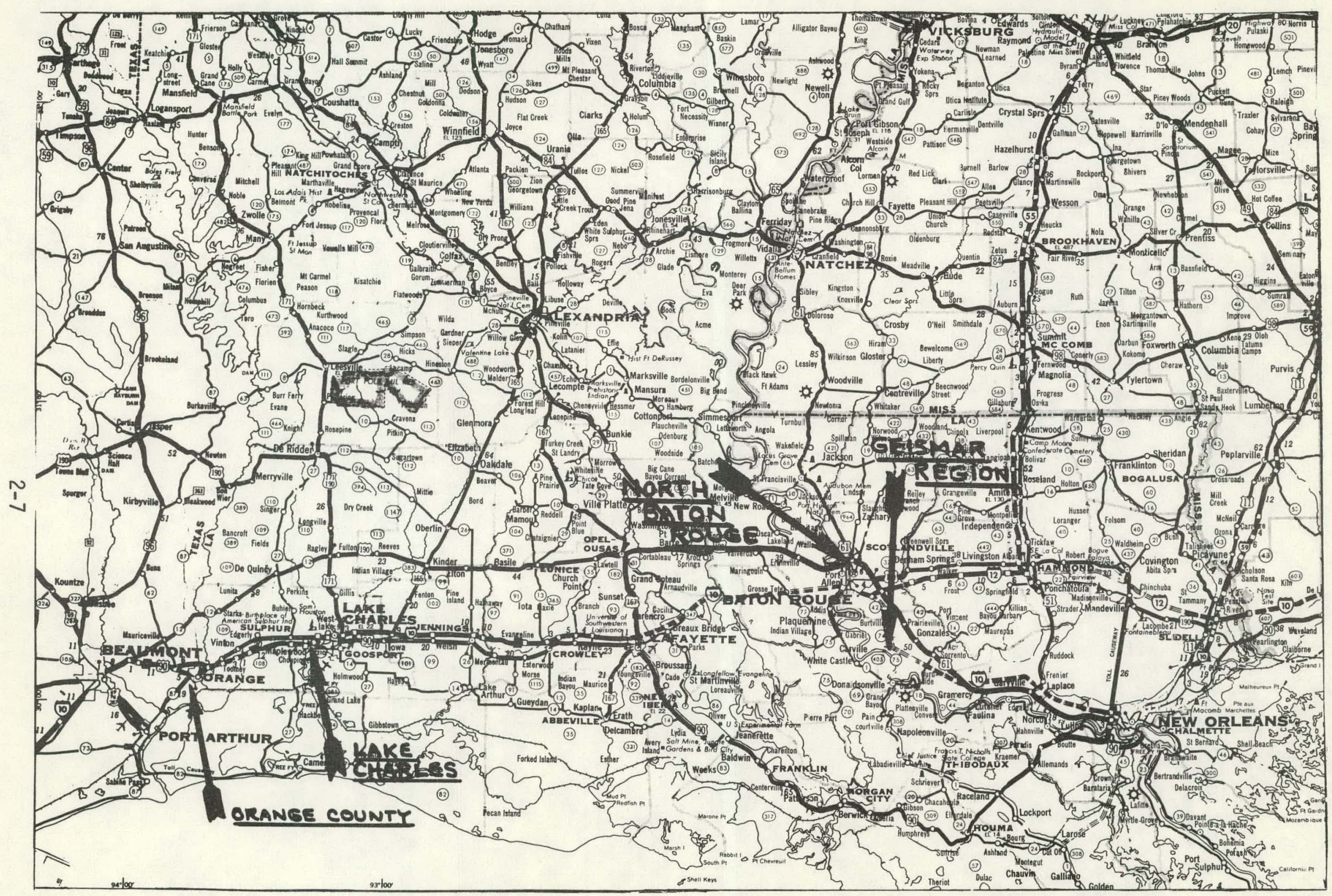

FIGURE 2-1. LOCATION OF THE FOUR PROPOSED REGIONS 
"xi:

(3)

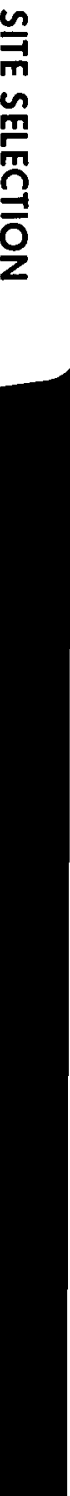




\section{SECTION 3}

SITE SELECTION

TABLE OF CONTENTS

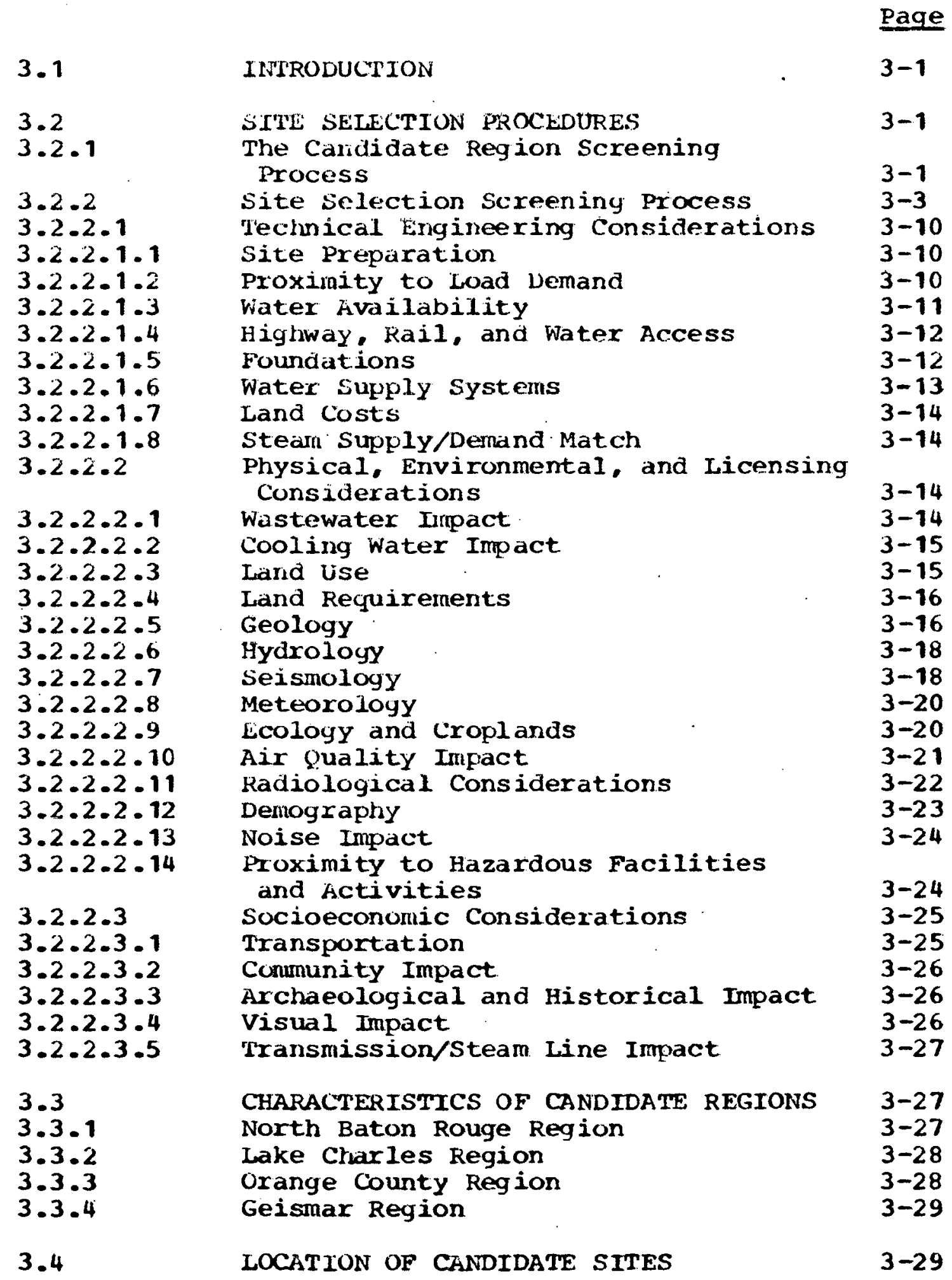


3.4 .1

3.4 .2

3.4 .3

3.4 .4

3.5

3.5 .1

3.5 .2

3.6

3.6 .1

3.6 .2

3-1

3-2

3-3

3-1

3-2

3-3

3-4

3-5

3-6

3-7

North Baton Rouge Sites $A$ and $B$

$3-29$

Lake Charles Sites A, B, and C

$3-30$

Orange Sites $A$ and $B$

$3-33$

Geismar Sites A through D

3-35

SIPING CRITERIA.

3-37

Siting Natrix Weighting Factors

3-37

siting Criteria Limits

$3-37$

CANDIDATE SITE EVALUATIONS

3-39

Site Ranking

Selection of Two Sites

3-39

$3-42$

\section{TABLES}

Major Evaluative Criteria

$3-5$

Emission Standards for New Stationary Source

Site Selection Matrix - Nuclear Site

$3-21$

site Selection Matrix - Fossil Site

$3-40$

$3-41$

\section{FIGURES}

General siting procedures

Selection of Candidate Regions

Selection of Candidate Sites

$3-2$

North Baton Rouge Sites $A$ and $B$

$3-4$

$3-8$

Iake Charles Sites $A, B$, and $C$

$3-31$

orange County Sites $A$ and $B$

$3-32$

Geismar Region Sites A, B, C, and D

$3-34$

$3-36$ 


\subsection{INTRODUCTION}

The objective of the siting portion of this study is to identify two candidate sites where a fossil-fueled or nuclear cogeneration plant may be located in the GSU service area. Information available from ERDA and GSU was employed in the site appraisal. When these sources could not provide sufficient information. Stone and Webster secured the required information from alternate sources. In accordance with the scope of work, no new siting data were developed from field studies.

The site selection process is designied to identify a number of realistic siting options. Four site regions consistent with the need for cogeneration were first designated by ERDA/GSU. A comprehensive screening process was then employed to identify those regions and sites that best fulfilled predetermined siting criteria. A reasonable balance of siting parameters was selected with special emphasis given to the unique considerations required for cogeneration plant siting. For example, realistic load demand distances and process steam/electric generation ratios were determined. other important technical/ engineering criteria such as water availability; highway, rail, and water access; proximity to hazardous materials: and land requirements were analyzed, as were a cross section of environmental/licensing and socioeconomic considerations.

Recommendation of selected sites does not foreclose the potential use of other closely ranked sites. Secondarily ranked sites are only less suitable when comparing all parameters in the siting study. "Secondary sites may serve as a reserve for developing future energy production alternatives.

\subsection{SITE SELECTION PROCEDURES}

\subsubsection{THE CANDIDATE REGION SCREENING PROCESS}

Proximate location of the site to industrial steam users is a major constraint in locating a cogeneration plant. With regard to this requirement, the four site regions initially screened were geographicaliy constrained to areas where steam demand either presently or potentially exists.

The siting procedure shown in Figure 3-1 is a progressive, iterative process of site region comparison and evaluation. The first phase of the siting procedure is designed to 


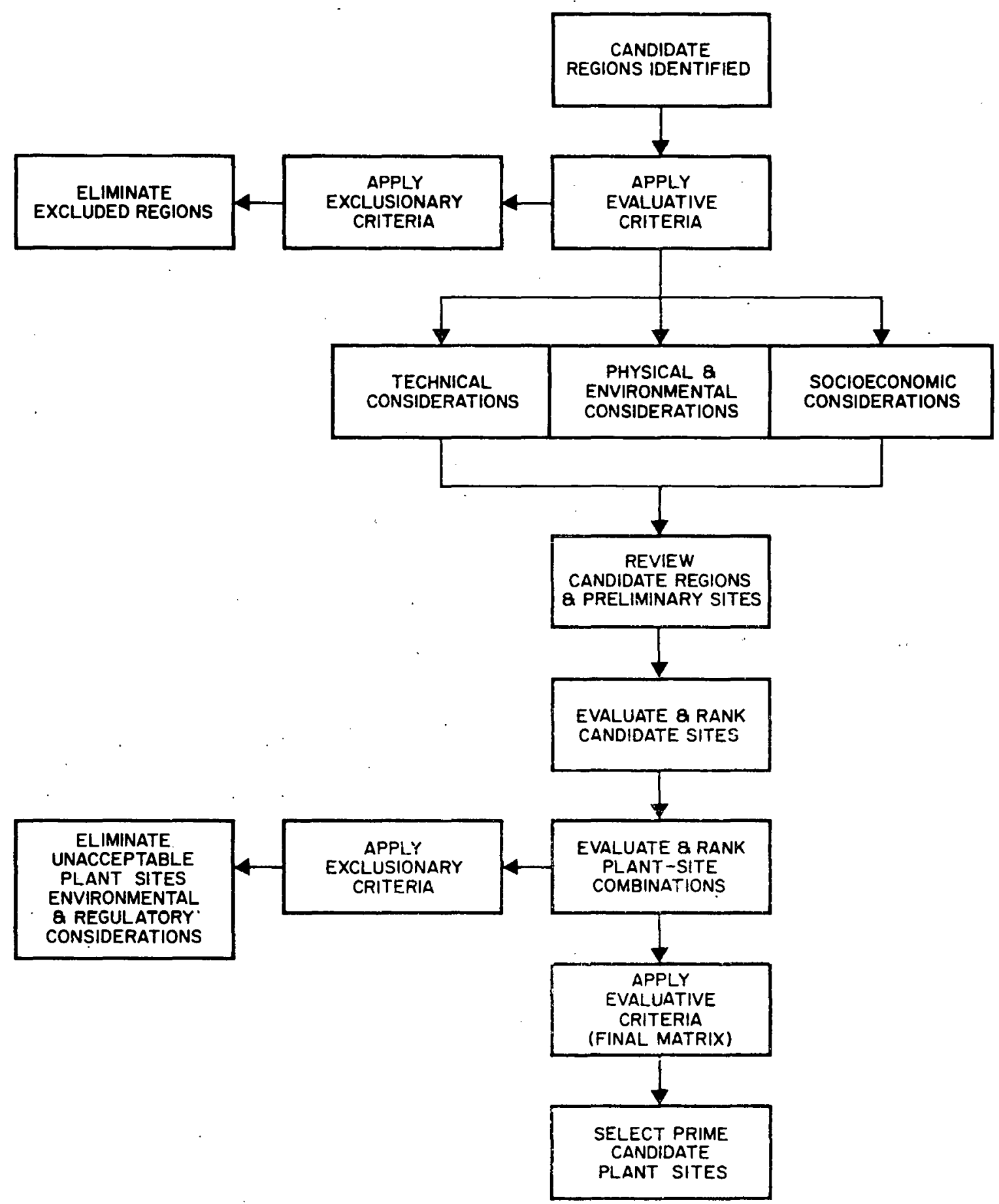

FIGURE 3-1. MAJOR EVALUATIVE CRITERIA 
identify the optimum candidate regions and preliminary sites within these regions for siting either a nuclear or fossil cogeneration plant. The second phase is a refined screening of the preliminary sites identified in the first phase. The third phase consists of detailed analyses and relative economic comparisons to select the final candidate plant sites. Each candidate region is comprehensively reviewed using an evaluative/exclusionary screening technique that includes licensing, environmental, socioeconomic, and technical/engineering considerations,-

During Phase $I$, the basic geographical regions are defined, and specific evaluative/exclusionary screening criteria are applied to identify the candidate regions. A candidate region is one in which preliminary sites may be found. In order to screen candidate regions, specific technical/ engineering and environmental/1icensing criteria are applied to exclude or defer unsuitable land areas. Figure 3-1 conceptually illustrates the overall siting procedure; Figure 3-2 shows the approach taken in Phase I. Criteria used to screen a region of interest for nuclear and fossil facilities are also shown in Figure 3-2. Following this Phase I screening, remaining candidate areas are further evaluated in Phase II.

Fs indicated in Figure 3-2, exclusionary criteria principally associated with nuclear facility safety-related issues include considerations such as geology/seismology, demography, and proximity to hazardous facilities. Both nuclear and fossil facilities' exclusionary criteria include incompatible land use; i.e.. proximity to national forests, major wetlands, and wildiffe refuges. These criteria are considered exclusionary because they define areas that can be eliminated from further consideration. Deferral criteria, on the other hand, can be applied to identify areas of technical/engineering or environmental/licensing suitability; i.e., land or water availability. Areas unable to support the required type and size facility are deferred for possible use in siting an advanced cogeneration plant.

Coincident with identification of the candidate regions in Phase I, the preliminary sites within the candidate regions are also determined for further screening and analysis in Phases II and III.

\subsubsection{SITE SELECTION SCREENING PROCESS}

The preliminary sites identified in phase I are further analyzed in phase II by applying detailed evaluative criteria consisting of technical/engineering considerations, physical and environmental/icensing considerations, and socioeconomic considerations. A complete breakdown of these criteria evaluated on the basis of difficulty/qualitative cost/acceptability is contained in Table 3-1. 


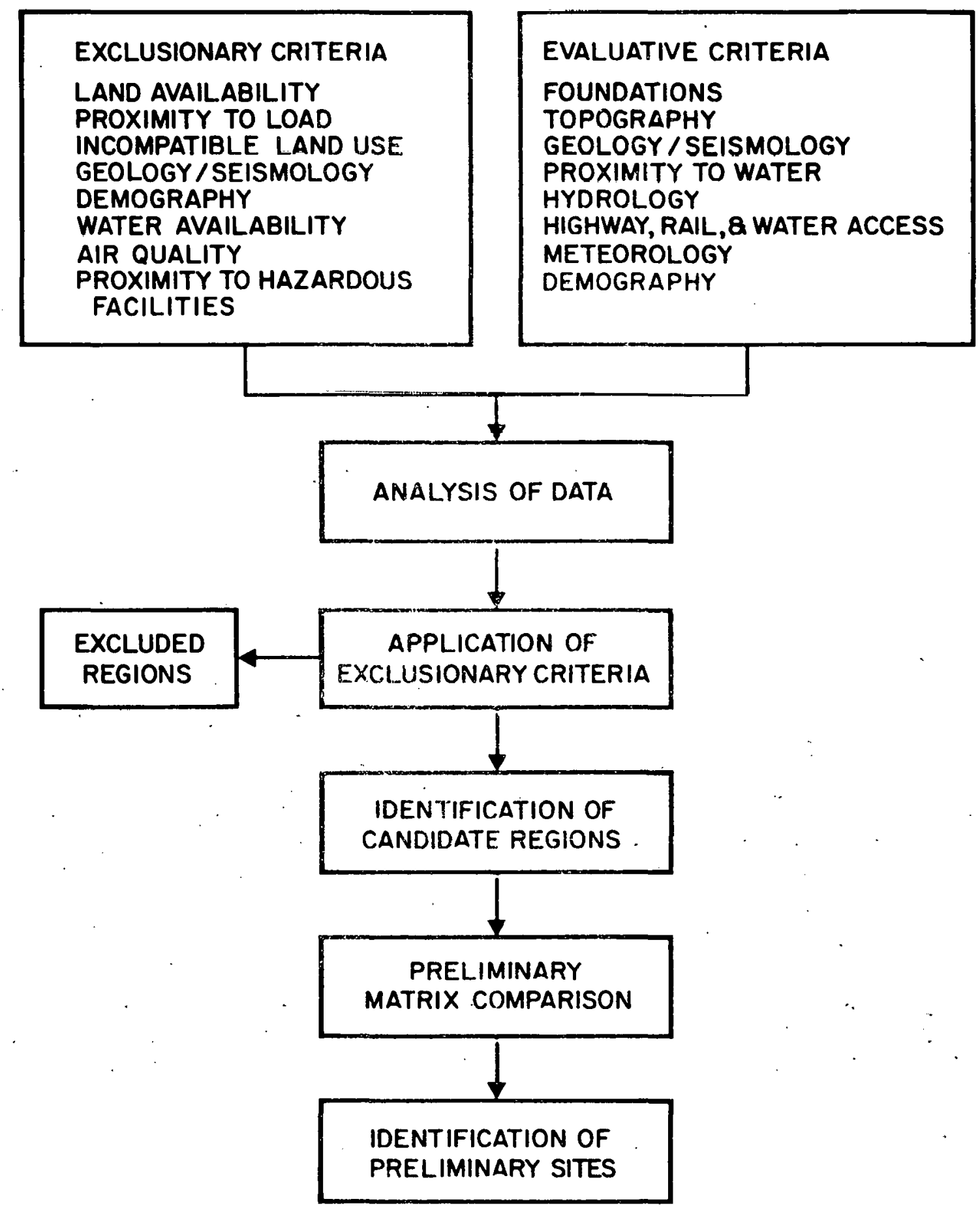

FIGURE 3-2. SELECTION OF CANDIDATE REGIONS 
TABLE $\quad 3-1$

MAJOR EVALUATIVE CRITERIA

Technical/Engineering Considerations

Site Preparation - Considerations such as excavation, dewatering during construction, site grading, berms, and drainage.

Proximity to Load Demand - Maximum and average distance to process steam/electric power users.

Water Availabjlity - Maximum, average, and minimum stream flow.

Highway, Railroad, and Water Access - Availability of each mode for fuel and waste transportation.

Foundations - Existing stratigraphy and the effects of seismology of the area, location of groundwater, soil improvement, and pile or caisson requirements. The liquefaction phenomenon is also considered for nuclear plant siting.

water Supply Systems - Construction requirements for circulating and service water systems.

Land Costs - Qualitative land cost comparison of all sites. Steam Supply/Demand Match - Relationship between the available power plant steam supply systems and steam demand requirements.

Physical and Environmental/Licensing Considerations

Wastewater Impact - Environmental impact of blowdown, cooling tower effluent, or other wastewater discharges.

Cooling Water Impact - Effect of consumptive water use, percentage of minimum stream flow.

Land Use - Present utilization of the site area and adjacent land (i.e.. commercial, industrial, state preserve, etc.).

Land Requirements - Amount of available land for plant construction, operation, fuel storage, and transmission/steam lines.

Geology - Structural geology, geological history, seismology, subsidence. 


\section{TABLE 3-1 (Cont)}

Hydrology - Flooa probability, upstream water impoundments and feasibility of groundwater for consumbtive use, groundwater contamination, drainage patterns.

Seismology - Basis for seismic design criteria.

Meteorology - Monthly average wind speed, wind direction, atmospheric stability, joint frequency, rainfall, storm severity, determination of area atmospheric diffusion.

Ecology and Croplands - Proximity to croplands, crop types, determination of unique or endangered ecological species, area ecology.

Radiological Considerations (Nuclear) - Determination of exclusion area, low population zone, and population center distance.

Air Quality Impact (Fossil) - Impact of gaseous effluent, area atmospheric diffusion, state and federal requirements.

Demography (Nuclear) - Current population of adjacent communities to 30 miles $(50$ miles if no town is within 30 miles), population density surrounding the site to 30 miles, population projections.

Noise Impact - Probable noise levels and impact on area industry and residences within 5 miles of the site.

Proximity to Hazardous Facilities (Nuclear) - Consideration of accidents at nearby industrial, military, and transportation facilities that may affect the safety of the plant.

\section{Socioeconomic Considerations}

Transportation - Irapact of fuel and waste transportation on nearby communities and transportation corridors.

Community Impact - Effect of construction workers and their families on adjacent community housing, services, utilities, etc.

Archaeological and Historical Impact - Determination of areas on or near the site listed in the National Registry of Natural Landmarks and the National Registry of Historic Places.

Visual Impact - Assessment of the visual effects of the station and transmission/steam lines on nearby valued cultural, scenic, historic, park, and recreation areas. 


\section{TABLE 3-1 (Cont)}

Transmission/Steam Iine Impact - Assessment of the potential impact exposure will have on area ecology and communities.

'l'he two major steps of phase II are:

1. Site Identification - Evaluat1ve/exclusionary criteria including technical, environmental $/$ icensing. and socioeconomic considerations.

2. Site Comparison - Suitability/constraint criteria and matrix analysis.

Figure 3-3 illustrates the phase II approach. 'l'he first step involves the application of further detailed evaluative/exclusionary criteria to the candidate areas described for Phase I. Some of the criteria shown on Table 3-1 are used as Phase II evaluative or comparison criteria and exclusionary or constraint criteria. Once defined, these criteria are analyzed and the resultant refined candidate areas are subjected to a matrix analysis. To perform a comparative analysis, a series of matrix weighting factors was developed to provide the appropriate impact of a specific siting criterion. These siting matrix weighting factors are discussed further in section 3.5.1.

Technical/engineering and environmental/licensing requirements are integrated into the siting matrix. For example. in defining a technical/engineering parameter such as foundations, the following site-specific criteria would be explored: existing stratigraphy and seismology, location of groundwater, soil improvement, and pile or caisson requirements.

During Phase II, site development qualitative/cost considerations are initiated. Site-specific parameters are utilized to rank and select the best candidate sites for cost evaluation, site-specific environmental impacts, and socioeconomic assessment. The selection of candidate sites should therefore result in sites exhibiting maximum technical/engineering suitability and minimum overall environmental/licensing constraints. Preselecting candidate sites from a list of preliminary sites minimizes detailed site-specific Phase III investigations. The remaining potential sites can be placed in a site bank for future consideration.

The final selection of two plant sites from the list of candidates is similar to selecting candidate sites from preliminary sites in the site comparison stage of Phase II. Two major differences are the degree of detail and the integration of technical/engineering, environmental/ licensing, qualitative, and cost considerations. 


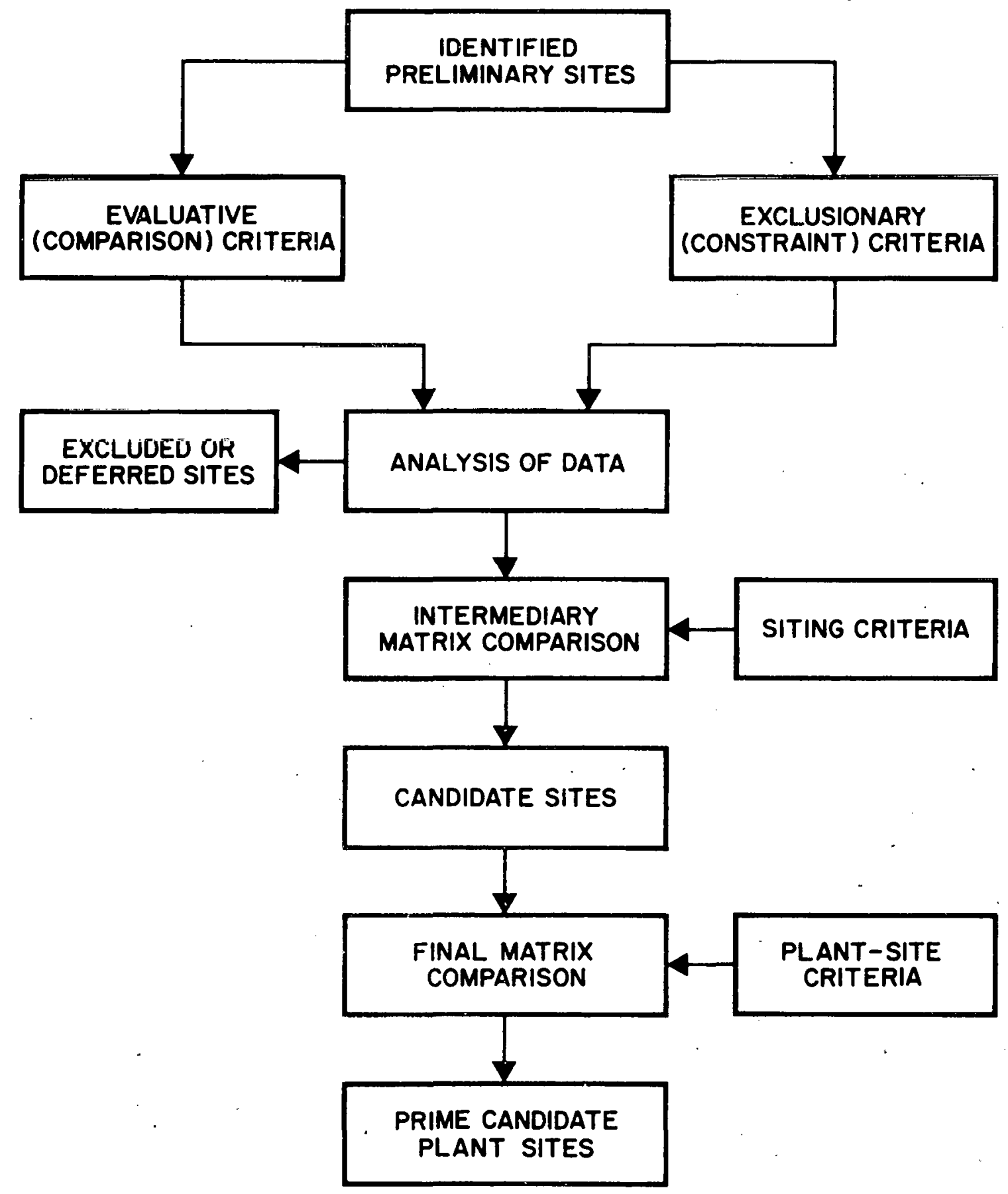

FIGURE 3-3. SELECTION OF CANDIDATE SITES 
Some of the criteria compared on a cost basis include steam supply transmission cost, required steam demand, flood protection, foundations, site grading, hazard design (nuclear). land acquisition, and emission controls.

Factors which cannot be reasonably quantified or comparatively evaluated by site are ranked and weighted qualitatively by professional, experienced personnel. Some important nonmonetary factors include:

- General licensing issues and anticipated trends in regulations.

- Engineexing factors with insufficient available data for definitive cost evaluation.

- Potential environmental impacts for which present data are insufficient to allow evaluation of cost control measures.

- Aesthetics.

- Institutional concerns.

Niore specifically, Phase III methodology includes the following:

Preparation of a comparative (economic) site ranking for those engineering factors which will vary from site to site; e.g., site development, steam transmission, environmental controls, etc.

- Environinental and socioeconomic assessment for each canaidate site. These assessments (nonmoretary) are qualitatively transformed into a subjective ranking system using rating and weighting factors.

Identification of environmental, socioeconomic, institutional, and political issues which are expected to have a significant impact on facility licensing for each site.

The use of a matrix analysis incorporating rating and weighting factors is applied. Nonmonetary considerations are transformed into a qualitative rating scale while weighting factors are established by the group consensus technique. Candidate plant sites can then be ranked in terms of qualitative/cost (QC) and suitability/constraint (SC) to establish whether a site with higher costs and SC scores is preferred over one with lower costs and SC scores. 
Care is exercised to appropriately integrate applicable licensing issues auring the ranking process.

\subsubsection{Technical Engineering Considerations}

\subsection{Site Preparation}

During the evaluation of the geographical regions and specific sites, assessment of site preparation includes:

- Existing topography relative to probable design flood levels.

- Extent of site clearing and grading required.

- Presence of drainage swales and/or ditches on property.

- Proximity to swampy terrain.

- Depth to groundwater table (of potential importance if a deep excavation should require dewatering) •

- Excavation/backfill requirements.

Some of the factors delineated above are interrelated to other evaluation areas such as Foundations and Geology, inasmuch as these directly affect the extent of excavation and the amount of construction dewatering required.

Because site conditions vary, there is great variability in costs of site preparation. For example, when comparing costs of fossil plant design, considerations such as liquefaction (nuclear) and pile foundation (fossil) can make the costs of either higher and tend to equalize the assigned matrix weighting factors. A matrix weighting factor of 10 was assigned for site preparation of both fossil and nuclear plants.

\subsection{Proximity to Load Demand}

A primary consideration is the distribution of steam to potential users from the proposed cogeneration sites. It is assumed that the distribution of electric power will not change the ratings based on the distribution of steam.

The optimal size of the steam distribution pipes can be determined from an economic tradeoff between the capital cost of the installed pipe (which increases with pipe diameter) and the loss of electric power production because of fluid friction (which decreases with pipe diameter). Preliminary calculations indicate that distribution of steam is feasible up to a distance of 5 miles. proposed sites 
requiring steam distribution lines longer than 5 miles were rated zero under Proximity to Load Demand.

The importance of steam distribution in evaluating cogeneration plant sites warranted a matrix weighting of 25 points for both fossil and nuclear plants.

\subsection{Water Availability}

Power plants require water for condenser cooling and process purposes as well as for potable use. The water supply source must be reliable since the need for water is critical for efficient plant operation and safety. The sites were evaluated on the availability of water from the closest major source (river, stream, canal, etc.).

The water availability segment. of the site evaluation is based on relative sources, flow rates, and guality. The minimum, average, and maximum flows available must be considered with respect to the maximum flow requirements of the station. One frequently used criterion is that water usage should not exceed 50 percent of the minimum flow for any year. The Nuclear Regulatory Commission (NRC) Regulatory Guidelines set 25 percent 10 -day low flow over a 7-year period as the limiting factor. (1)

The quality of the water must also be considered. It must be compatible with plant use so that excessive costs will not be incurred to improve the quality to usage standards.

NRC Regulatory Guide 1.27 requires that the heat sink of a nuclear plant serve two principal safety functions: (1) dissipation of residual heat after reactor shutdown and (2) dissipation of residual heat after an accident.(2) The sink's capacity should be sufficient to provide cooling for the time required to evaluate the situation and take corrective action. A 30-day period is considered adequate for these purposes. Two sinks acceptable to the NRC include large rivers and large lakes.

As indicated in section 3.2.2.1.8, the use of a condensing cycle was avoided; thus, circulating cooling water requirements are a slightly less critical siting constraint. A value of 20 was assigned as the weighting factor in the matrix. The consumption of cooling water for the service water system is of secondary importance when compared to power boiler makeup use. As indicated in section 4.4.1.1.7, it is assumed that 50 percent of the steam generated will be returned for reuse in the form of condensate of unknown quality. Therefore, maximum consumption will be for makeup purposes. It is also assumed that geohydraulic conditions will not support the use of groundwater. 
No limiting criteria have been set since the "offset" principle, that is, compensating principle, has been applied to earh industrial complex. Since steam and water consumption requirements within each industrial area complex are presently being satisfied, the net steam and consequent water consumptions should be equal to or less than present consumption. Thus, no limiting criteria were applied.

\subsection{Highway, Rail, and Water Access}

Fossil and nuclear plant sites must be accessible to transportation; the reliability, ease, and cost of transportation affects the construction and operation of power plants. In addition to supplies, heavy equipment, and plant wastes, personnel must also be transported to the site. Rail, water, highway, and pipeline are the generally used transportation systems. Transportation to fossil sites is heavier in order to meet demanding fuel supply needs and, therefore, must be reliable.

Sites located near a navigable waterway may be conducive to barge loading and unloading. A navigable waterway is defined as any body of water, inland river, lake, canal, or other man-made or natural right-of-way with at least the following parameters: a mean low-water depth of not less than 6 feet, a minimum channel width of 50 feet, and a minimum clear vertical unobstructed height of 30 feet above mean-low-water. (3)

Each site was evaluated on its relative overall transportation corridor accessibility and/or the cost impact to ensure adequate access. Matrix weighting factors of 5 and 25 were assigned for nuclear and fossil plants. respectively.

\subsection{Foundations}

Primary consideration was given to the depth to firm bearing soil when evaluating foundation conditions in the regions. Fossil-fueled plants are likely to require pile or caisson foundations at all of the proposed sites. Alternatively, if the depth to firm bearing soil is not too great, consideration can be given to excavating the looser, soft soils and replacing them with well-compacted backfill. Economics and schedule considerations dictate the final choice.

The current state of the art in evaluating the potential loss of lateral support for pile foundations during earthquakes typically discourages using piles for nuclear power plant Category I structures. Interaction between piles and the surrounding soil under dynamic loads is an exceedingly complex, somewhat subjective analysis. Thus, 
although pile foundations are technically feasible according to current NRC licensing positions, where loose or soft soils underlie a proposed commercial nuclear plant they are usually overexcavated and replaced with a well-compacted backfill.

Accordingly, when evaluating foundation conditions for nuclear plants in the proposed regions, consideration is given only to the amount of excavation and backfill that would be required to replace existing poor soil conditions. It must be emphasized that predicting foundation conditions at any of the proposed sites without the benefit of onsite soil borings may be speculative. Extrapolation of subsurface information from nearby soil borings can be misleading, particularly in areas wliere solls have been placed in their present locations by the geologic process of river deposition. A few of the proposed sites" subsurface foundation conditions were assessed using borings obtained several miles from the respective sites.

Iiquefaction is a physical phenomenon that can occur in loose cohesionless silts and fine sands during large earthquakes. Soils that are susceptible to liquefaction lose their shear strength during large earthquakes and behave like a fluid. Obviously, structures founded on such soils would suffer massive damage. To preclude this, analyses are made to determine the susceptibility to liquefaction of soils at any proposed site. If it is determined that existing soils beneath a proposed site are susceptible to liquefaction, remerial measures such as densification or excavation and replacement with well-compacted soils must be undertaken.

Matrix weighting factors of 15 and 10 were assigned for nuclear and fossil plant foundatiops, respectively. This weighting was based on the cost impact of foundation support systems (i.e., compacted backfill or pile foundations) and the relative degree of difficulty in installing foundations.

\subsection{Water Supply Systems}

Construction requirements for transporting water to the station must be assessed in addition to assurance of an adequate water supply. Pumphouse construction, pipe sizes and routings, distances to potable water systems, etc., must be evaluated. For example, intake structures must be designed to prohibit fish from entering the system. Trash racks and traveling water screens may also be desired.

Each site was evaluated relative to known construction impediments and distance from water sources. Based on these criteria, a matrix weighting factor of 10 was assigned for both nuclear and fossil plants. 


\section{$3.2 \cdot 2 \cdot 1.7$ Land Costs}

Imposing upon the total cost of a power plant is the cost of land. Generally, urban areas are more expensive than rural areas, and high-level ground is more expensive than low-lying or swampy ground. A matrix weighting factor of 5 for both nuclear and fossil plants was applied since land costs, while important, represent a small percentage of the total installed cost of a power plant. Individual sites were analyzed relative to present land use and future possibilities.

\subsection{Steam Supply/Demand Match}

A project management decision made at the outset of the study requires that no electric power generation be independent of steam produced for distribution. This precludes the use of steam turbine generators with condensers. Since stearn demand in each region is such that the industrial comiunity would be defioient in electric power and would have to import power from the GSU grid, the problem of matching steam supply and demand involves the availability of steam generators to produce the required steam.

The availability of coal-fired boilers in a wide range of sizes has prompted the relatively low steam supply/demand match matrix weighting of 10 for fossil plants. The match between supply and demand is more difficult for nuclear cogeneration plants and was given a weighting of 15 . The proposed intermediate-size light water reactors (LWR) have thermal ratings of approximately 1000 to $1200 \mathrm{MW}$.

3.2.2.2 Physical, Environmental, and Isicensing Considerations

\subsection{Wastewater Impact}

The environmental impact of service water cooling tower blowdown and other wastewater discharges must be considered so that effluent quality will be consistent with water quality standards. The most desirable areas from a water quality standpoint are sites which will not have an adverse impact on existing water quality.

While every effort will be made to close the water/wastewater cycle, the quality of return condensate from each industrial plant is indeterminate at this point. An accurate determination of wastewater quality should be made at a later date. It has been resolved that wastewater flows will be minimal (less than one percent of the water intake) and approximately the same quality for each site investigated. Accordingly, contributing factors in the 
assessment of wastewater impact become the maximum, average, and minimum flows of the receiving body of water.

Due to the introduction of a larger quantity of wastewater from a fossil plant (coal pile runoff, ash transport water, etc.), wastewater impact is weighted more heavily. Iiquid waste from either plant will meet all applicable regulatory agency requirements. A matrix weighting factor of $b$ was assigned to a nuclear plant and 10 to a fossil plant.

\subsection{Cooling Water Impact}

As described in sections 3.2.2.1.3 and 3.2.2.1.8, a design decision has precluded the use of power condensers; thus, condenser cooling water will not be required. However, NRC requires emergency cooling capabilities for nuclear plants. Emergency water use for a nuclear plant is about 120 cfs for each intermediate reactor. Since this water consumption occurs only under emergency conditions, the impact is of relatively minor importance; however, it has been recognized and must be assessed. The NRC requirement does not apply to fossil plants; hence, cooling water impact is not a consideration.

Where sources of cooling water are scarce or where other constraints exist, cooling ponds, reservoirs, or cooling towers for emergency cooling may be required. During emergency cooling, makeup water requirements are less than 5 cfs, a fraction of river flow. The combined effect of added costs, water consumption, and/or additional space requirements were assessed for each site under this category, and a matrix rating of 5 was assigned.

\section{$3.2 \cdot 2 \cdot 2 \cdot 3$ Land Use}

In general, land areas suitable for power plant siting are areas that generate greater economic benefit if developed for power generation rather than for an alternate use. Preferred areas are vacant, not previously designated for use, and adjacent to industry.

The land use of an area selected for a power plant site must be compatible with surrounding and adjacent land use. This is determined by zoning regulations, official long-range municipal community plans for the area, and public opinion concerning the adequacy of the land for power producing purposes.

Exclusionary criteria applied to the candidate sites relate to their proximity to the following: (1) active military installations, (2) major commercial airports, (3) national and state parks anc forests, (4) wildlife refuges, and (5) major wetlands. 
A matrix weighting factor of 10 was applied for both nuclear and fossil plants.

\section{$3.2 \cdot 2 \cdot 2.4$ Land Requirements}

Land requirements pertain to the amount of land available for plant construction ana operation. To determine the area required for a cogeneration plant, the following items must be taken into account: boiler (steam generator), turbine, fuel storage, tuel handling equipment, rail lines and/or barge unloading equipment, waste handling equipment, wastewater ponds, and switchyard, etc.

More land is required for the construction and operation of a.fossil-fueled plant than for a nuclear-fueled plant. Therefore, the matrix weighting factor is higher for fossil(25) than nuclear-fueled (20) plants.

The overall land requirement for constructing a nuclear unit is approximately 100 acres. This ared is sufficlent to accommodate switchyard, cooling tower, railroad sidings, and security fencing.

Siting two fossil units (coal- or oil-fired) would require approximately 300 acres. The area would accomodate fuel handling and storage, ash handling equipment, railroad sidings, wastewater handling equipment, switchyard, and security fencing. This estimate is based on land requirements not exceeding the following acreade: a 60-day fuel storage area of 20 acres, a sludge treatment area of 5 acres, a 5-acre switchyard, and a boiler plant complex of 20 acres.

\section{$3.2 .2 .2 \cdot 5$ Geology}

Historical and structural geology directly affect the foundation requirements for siting nuclear and, to a lesser degree, fossil plants; indirectly they can alter the amount of site preparation required. Structural geology, as used herein, incluces the broad consideration of tectonic structures that necessitate thorough evaluations for nuclear plant siting. Since the depth to bedrock exceeds several thousand feet at all four reviewed regions, any plant located within these regions would be founded on soil.

Knowledge of geologic origins and the age of ceposition can play a significant role in the feasible siting of nuclear plants. The NRC is particularly concerned with geologic faults in close proximity to any nuclear site. When it has been determined that a fault (or other geologic feature) is within 5 miles of a proposed nuclear plant site, a study must be made to ascertain whether movements have occurred along the fault recently.(4,5) At that time, the origin and 
age of the deposition of soils overlying the faults can serve as tools in determining the geologic time that movement last occurred along the fault. The soil stratigraphy offsite as well as onsite may have to be studied using soil borings to determine whether the younger soils have suffered any displacements attributed to previous earthquakes along a fault in question.

The NRC defines an incapable fault as one which has not experienced either a single movement within the last 35,000 years or multiple movements within the last 500,000 years. Conversely, if studies indicate that movements within the 35,000 - or 500,000-year criteria cannot be ruled out, a fault may be termed capable. $(4,5)$ It is then presumed that an earthquake could recur along the fault and thereby result in additional displacernents in the near-surface soils.

In addition to the concern for nearby faults and their classification as capable or incapable, other geologic factors affecting power plant siting are subsidence and/or liquefaction. When large amounts of fluids such as oil and water are extracted from below proposed sites, the overall ground surface can subside, leading to concerns for flood potential and differential movements between buildings. Another cause of subsidence prevalent in the Gulf coast region and the Mississippi River area is the downwarping of soil deposits caused by the ongoing process of soil deposition in the ocean and in river valleys. The vast amount of sediment carried by the Mississippi River is continuously deposited at its mouth. The additional weight of soils on existing deposits causes consolidation of the underlying layers and bending of deeply-buried strata. Due to constantly increasing overburden pressure tending to warp the underlying strata,. slump faults are often formed trending in directions perpendicular to the axis of the river. Thus, slump faults trending generally east-west are abundant through southern. Louisiana and Texas. Although these faults are not due to or capable of generating earthquakes, the NRC is concerned with their proximity to any proposed site inasmuch as they are definitive markers of potential differential subsidence and ground rupture.

Salt domes are common geologic structures throughout Louisiana and Texas.(6) They are often flanked by petroleum deposits and are of special. interest to the petroleum industry. Thus, the exploration and development of oil and gas is prevalent in the vicinity of an identified salt dome. Accordingly, the proximity of salt domes to the regions under consideration is significant because of their association with oil and gas withdrawal and the related concern for subsidence. 
It is evident that nuclear site licensability is highly dependent on geologic considerations so a matrix weighting factor of 25 was assigned. Although a fossil plant!s requirements are less restrictive, geology does affect related factors; i.e., foundation considerations. Therefore, a matrir weighting factor of 15 was assigned.

\subsection{Hydrology}

Hydrology criteria addressed include flood probability, upstream water impoundnents, and drainage patterns: Areas located above the maximum recorded flood level are most desirable. Recently, an Executive order on. Floodplain Management ( 7$)$ directed all federal agencies to take measures to avoid, to the extent possible, the long- and short-term adverse effects associated with the occupancy and modification of floodplains and to avoid direct or indirect support of floodplain development where there is a practical alternative. Each agency was directed to provide leadership and to take action to reduce the risk of 1 lood loss: to minimize the impact of floods on human safety, health and welfare; and to restore and preserve the natural and beneficial values served by floodplains.

Nuclear sites should be in compliance with Regulatory Guide 1.59.(B) Sites located in floodplains may be difficult to license if construction of the facility results in alteration of the floodplain or drainage patterns. The consumption of groundwater has little impact on site evaluation since all water for consumption will be derived from rivers and streams. It is also expected that groundwater contamination will not be a factor since the facility is designed to preclude any possible contamination.

Drainage is a minimal factor in site evaluation. The flow of streams in candidate areas consists primarily of immediate and subsequent surface runoff during periods of precipitation. Sites will be graded to minimize local flooding due to poor drainage patterns. For these reasons, hydrology matrix weighting factors of 20 and 15 were assigned to nuclear and fossil plants, respectively.

\section{2 .2 .2 .7 Seismology}

Seismology is assessed independently of Geology (Section 3.2.2.2.5) because of its importance in determining the seismic design basis for all plants. Fossil plant seismology is frequently treated by incorporating a seismic zone factor in the plant design criteria. This factor is usually delineated in a local building code and reflects the largest earthquakes experienced in the particular region. 
Geologic or seismo-tectonic provinces are determined by studying the earthquake history and structural geology of a given area. Previous earthquakes are assumed to have occurred along a specific fault or within a specific seismotectonic province. The largest earthquake ever generated along that fault or within that geologic province is expected to be able to occur again within the design life of a nuclear plant. However, to provide additional margins of safety, the maximum recorded earthquake is assumed to recur along the fault or along the boundary of the seismo-tectonic province at its closest approach to the proposed site. Thus, previous earthquakes are postulated as recurring and generating the greatest intensity, acceleration, or other measure of damage potential at the proposed site.

The safe shutdown earthquake (SSE) is defined as the largest earthquake that could occur at the site. It represents the seismic motion the plant can undergo and retain the capability to be safely shutdown. The SSE is determined by examining the history of all earthquakes that have occurred and could conceivably recur at an epicentral location closer to the proposed site than the actual epicenter.

The NRC has established minimum values of horizontal acceleration due to an SSE. Currently, this minimum value of SSE horizontal acceleration is $0.10 \mathrm{~g}$ where $\mathrm{g}$ is the acceleration of gravity. The prospective Louisiana/Texas regions lie within the confines of a relatively seismically inactive portion of the United States. Thus, it should be necessary to design any proposed nuclear plants only for the minimum SSE acceleration values allowed by the NRC.

For nuclear power plants, the operating basis earthquake (OBE) is determined as the largest earthquake expected to be felt at the proposed site during plant life.(5) In many respects, the OBE corresponds to the design basis earthquake upon which building codes are based. Typically, the NRC stipulates that the OBE acceleration level must be at least equal to one-half the SSE acceleration.

Seismology also results in indirect plant construction costs. For example, as regional seismicity increases, foundations and equipment support members can increase in size to provide adequate margins of safety against failure during postulated earthquakes. Accordingly, seismic zone factors in building codes affect fossil plant costs, and SSE and OBE accelerations affect nuclear plant costs. Maximum weighting factors of 20 and 10 points were assigned for nuclear and fossil plants, respectively. 


\subsection{Meteorology}

This section details the climatological features of the sites. Meteorological data include wind speed, wind direction, rainfall, storm severity and determination of area atmospheric diffusion. Atmospheric diffusion is defined as the ability of the atmosphere to disperse gases and particles emitted into the air. The diffusion is governed primarily by the motions of the atmosphere and the vertical temperature profile which are site-specific and depend, in part, on wind and topography.

The release rate of radioactive effluents from a nuclear plant can be designed to accommodate less than favorable dispersive qualities at a particular site. Therefore, exclusion criteria were not applied based on less than desirable meteorological or topographic conditions.

Preferred fossil plant sites exhibit adequate dispersive qualities allowing boiler stack emissions to have an insignificant impact at ground level.

Due to the proximity of candidate regions, the meteorological conditions are essentially the same, and the most important factor becomes the location of the site relative to prevailing wind direction and residential areas. For this reason, a matrix weighting factor of 15 for both nuclear and fossil plants was designated. (See also Air Quality Impact, Section 3.2.2.2.10.)

\subsection{Ecology and Croplands}

Desirable areas for power plants are those areas which do not support rare, endangered, or unique floral or faunal species, nor are they highly productive ecologic areas. They are distant from wildiife sanctuaries, refuges, or management areas, and do not support major populations of commercially valuable game birds or mammals. From the standpoint of terrestrial ecology, the most desirable area for locating a power generating facility is agricultural land under monoculture practices. Large, homogeneous tracts of cropland, in general, provide the minimum of habitat (food and cover) for wildlife species.

Desirable locations for a power plant, when concerned with aquatic or marine ecology, feature low marine life productivity and are distant from important spawning, nursery, or fishing grounds for commercial species of fish and shellfish. Similarly, areas which do not support rare or endangered species or important sport fisheries would be preferred. $(9,10,11)$ 
No sites were excluded based on ecology and cropland factors; however, a detailed inventory and analysis should be conducted coincident with a site-specific preconstruction study. A matrix weighting factor of 10 was applied to both nuclear and fossil plants.

\subsection{Air Quality Impact}

The meteorology of candidate sites should exhibit adequate dispersive qualities so that boiler stack emissions have an insignificant impact at ground level. These sites should also be located where ambient air quality standards are not in danger of being violated.

As a resuit of a recent EPA interpretive ruling (December 21, 1976) for implementation of the requirements of 40 CFR 51.18 for preconstruction review of stationary air pollution sources, major new fossil-fueled facilities (which include power generating units) may not be constructed in nonattainment areas unless specific conditions are met.(12) As a result of the imposition of this interpretation, a nonattainment status represents a constraint to the present siting of a new power facility. A solution is to obtain more than one-for-one legally enforceable emission reduction (offset) from existing sources in the area (whether or not under the same ownership) so as to represent reasonable progress toward achievement of the National Ambient Air Quality Standards.

On December 23, 1974, EPA promulgated the National Performance Standards for new stationary sources. As a new source the new power plant will comply with all performance standards covered in the latest issue of these regulations. These performance standards are listed in Table 3-2:

\section{TABLE 3-2}

EMISSION STANDARDS FOR NEW STATIONARY SOURCE

Sulfur Dioxide Nitrogen Oxides Suspended Particulate

\author{
Lb/106 Btu Heat Input* \\ 1.20 \\ 0.70 \\ 0.10
}

*When solid fossil fuel is burned.

The Clean Air Act Amendments of 1977 specified Class I areas for prevention of significant deterioration (PSD) . There are no Class I areas within 100 miles of the reviewed sites.

It is noted that all four candidate areas come under the jurisdiction of the Southern Louisiana/Southeastern Texas 
Interstate Air Quality Control Region. All sites are within areas designated as nonattainment areas for photochemical oxidants (generally associated with hydrocarbons produced by petroleum refineries, petrochemical process plants, and oil burning power boilers). It is recognized that coal-fired power plants do not contribute to hydrocarbon levels and could conceivably reduce hydrocarbon levels by the "offset" principle. Air quality impact is not a consideration for nuclear licensing but must be heavily weighed for fossil plants. Accordingly, a matrix factor of 20 was assigned to fossil air quality impact.

\subsection{Radiological Considerations}

Iight water reactor nuclear power plant licensing requires that there be assurance that dose limit guidelines of 10CFR100 will not be exceeded in the event of a design basis accident. The NRC has further specified lower dose limits in Regulatory Guides $1: 3$ and 1.4 . The limit must be met at the construction permit stage to ensure that changes in the design or in meteorology do not result in calculated doses in excess of 10CFR100 guidelines.

A nuclear power plant, with a combination of engineered safety features to mitigate the conseguences of an accident and located sufficiently distant from the population to allow for dispersion of radioactivity, must show that calculated doses are within predetermined limits.

The criteria used in this evaluation are based on distance from population concentrations. These requirements are either explicitly stated in 10CFR100 or based on past experience. The calculated doses will be determined when the plant design, including engineered safety features, is established and site specific meteorological data are available. The distances used in this evaluation are as follows :

Exclusion Area Boundary $(E A B)$ : Based on past experience, the NRC has found that a minimum distance to EAB for an LWR of approximately $3000 \mathrm{MWt}$ is $0.4 \mathrm{miles.(13)}$ This assumes unfavorable design basis atmospheric dispersion characteristics and usually provides assurance that engineered safety features can be designed to bring the calculated dose from a postulated accident within the guidelines of 10CFR 100. Stone $\varepsilon$ Webster's siting/licensing experience confirms the guideline distance of 0.4 miles. It should be noted that when siting a smaller power plant of approximately $1200 \mathrm{MWt}$ the $0.4-\mathrm{mile}$ guideline may not be applicable. 
Low Population Zone (LPZ): The NRC guideline, which was based on past siting experience, indicates that a distance of 3 miles to the outer boundary of the LPZ is sufficient to provide 30-day doses within the guidelines of 10CFR100. Also, the NRC requires population density within the LPZ be limited to less than 500 people per square mile.

Fopulation Center Distance: The distarice from the outer boundary of the IPZ to the boundary of a population center of greater than 25,000 persons must be at least $11 / 3$ greater than the distance to the LPZ outer boundary from the reactor. $(14)$

It should be noted that nuclear plants have been licensed Iur sites with $\mathrm{EAB}$ less than $0.4 \mathrm{mlles}$ or IDZ less than 3 miles, since it is the dose criterion that ultimately governs. Thus, a site is not absolutely precluded on the basis of distance alone. Due to the licensing requirements related to radiological considerations, a matrix weighting factor of 25 was assigned.

\subsection{Demography}

Areas of low population density are preferred for siting power plants, particularly a nuclear plant. High population densities projected for any period during the lifetime of a station are considered by the NRC and the public hearing phases of the licensing process. Should population densities at the proposed sites not be acceptably low, alternate sites might be needed to fulfill the regulatory requirements.

If the population density (including weighted transient population) projected at the time of initial operation of the plant exceeds 500 persons per square mile (averaged over a radial distance to 30 miles), alternate sites may be required to satisfy regulatory requirements. These requirements prevail if the projected population density over the lifetime of the plant exceeds:1,000 persons per square mile averaged over any radial distance out to 30 miles.(13)

The population density for a 5 -mile and 30 -mile radius from the site center was calculated by summing the present population of the towns within the radius and dividing the sum by the total area. Present population statistics were used since they are least restrictive and most documentable. Data will be gathered from federal and state census bureaus.

Those sites with a population density greater than 1,000 persons per square mile are excluded for nuclear plant considerations. Sites with a population density between 500 and 1,000 persons per square mile are constrained. Sites 
with a population density less than 500 persons per square mile are acceptable (no constraint).

The impact of demographic considerations on the licensing process resulted in a matrix weighting factor of 25 for nuclear plants.

\section{2 .2 .2 .13 Noise Impact}

The impact of noise from the power plant has to be assessed regarding its effect on the surrounding community.(1) The probable noise levels and impact on area industries and residences within 5 miles of the site were investigated. A nuclear plant without cooling tower has a minor noise impact. Fossil plants have a higher noise level due to outside coal handling equipment. It is expected that noise created by a fossil plant will represent a minor contribution to the ambient noise level due to the proximity of industrial complexes. Each site was evaluated with regard to its proximity to residential communities. A matrix weighting factor of 10 was assianed to fossil plants. a factor of 5 to nuclear plants.

\subsection{Proximity to Hazardous Facilities and Activities}

Potential accidents at nearby industrial, military, and transportation facilities may affect the safety of a nuclear plant. This factor is considered a siting constraint. For instance, the site under review should not be selected if, in the event of an accident, plant safety is significantly impacted, or if it is not possible for nearby facilities to alter their mode of operation to reduce the severity of these types of potential accidents.

In the event of an accident at a nearby industrial facility such as a chemical plant, refinery, gas, or petroleum processing and product storage installation; it is possible that missiles, shock waves, flammable vapor clouds, toxic chemicals, or incendiary fragments may result. This may directly affect the plant or plant operators and jeopardize plant safety.

An accident during the transport of hazardous materials (e.g.. by waterway, railroad, highway, or pipeline) near a nuclear plant may generate shock waves, missiles, and toxic or corrosive gas that also can impact the safe operation of the plant. The consequences of hazardous accidents depend upon. the proximity of the transportation vehicle or industrial facility, the nature and maximum quantity of the hazardous material, and the layout of the plant. 
Generally, potentially hazardous facilities and activities within 5 miles of the proposed site are considerations. Stone $\varepsilon$ webster has conducted detailed analyses on the potential impact of "hazardous accidents" and has successfully supported license applications for a number of nuclear power plants. Stone $\mathcal{E}$ Webster's experience in this area indicates that the plant can usually be designed so that its safety will not be affected by a hazardous accident, if the distances to these facilities and activities are no less than the following (based on a 3000-MWt nuclear power plant): 2,600 feet from railroad tracks; 1,800 feet from a major highway; 1,300 feet from a navigable river; 2,600 feet from gas or oil pipelines; and 2,600 feet from chlorine and other types of toxic chemical storage. of course, specified site related analyses would have to be conducted to determine accurately the distances to hazardous materials, especially concerning shipment and storage of liquified material gas and railroad and highway accidents. Because of the relative importance of the siting criterion, a matrix weighting factor of 20 was assigned.

\subsubsection{Socioeconomic Considerations}

Socioeconomic issues are important reterminants of siting policy. It is difficult both to assess the nature of the impacts involved and to determine value schemes for predicting the level or the acceptability of potential impacts.

The siting, construction, and operation of a power plant may have significant impact on the socioeconomic structure of a conmunity and nay place stress on the local labor supply, transportation facilities, and community services in general. There may be changes in the tax basis and in community expenditures.(14) problems may occur in determining equitable compensation for any required relocation of persons or facilities as a result of plant siting. Evaluation of the suitability of a site should, therefore, include consideration of these potential socioeconomic impacts.

In addition, certain communities in a site area may be subject to unusual impacts that would be costly to mitigate. For example, some towns have distinct cultural characteristics; i.e.. places of historic interest; unusual industry, or unique archaeological or scenic characteristics that must be considered during the siting process.

\subsection{Transportation}

Transportation-related impacts occur during the construction and operation of a power plant. Movement of heavy equipment during construction could impact roads, underpasses, 
briages, etc., on land routes; and bridges, docks, etc.. over water routes. During plant operation, the transportation requirements of a fossil plant involve large, continuous shipments of coal; nuclear plants involve radioactive fuel and waste shipment. Both construction and operation require adequate and available roads for transporting construction workers and employee commuting. Transportation considerations are less critical than other siting parameters and were assigned a matrix weighting factor of 5 for nuclear and 15 for fossil olants.

\subsection{Community Impact}

During construction and operation of the plant, workers and employees may affect nearby community infrastructures; e.g., additional housing requirements, utilities, police, fire, entertainment, and hospital facilities. Since the work force during construction and operation of the plant is expected to be a small percentage of the population of the adjacent communities, a matrix weighting factor of 10 wao assigned.

\subsection{Archaeological and Historical Impact}

Areas valued for their historic and archaeological significance may be affected by siting a plant on or proximate to these areas. Those properties included in the National Registry of Historic Places that may be affected by the station, its associated facilities, and steam and electric transmission lines were reviewed. Potential archaeological sites in the plant site areas were confirmed. Mitigation or avoidance of historical and archaeological impact can be achieved. Therefore, a matrix weighting factor of 5 was assigned.

\section{$3 \cdot 2 \cdot 2 \cdot 3 \cdot 4$ Visual Impact}

Many visual and scenic detriments of the plant and its auxiliary facilities can be avoided or reduced by appropriate design and execution. Aesthetic impacts can also be mitigated by selecting sites where existing topography or environment, such as industry, effectively screen or ameliorate the presence of the station. Generally, the design of a nuclear plant is more aesthetically acceptable than a coal plant. Because the candidate sites are located in industrial areas, low matrix weighting factors of 5 and 10 were assigned for nuclear and fossil plants, respectively. 


\subsection{Transmission/Steam Line Impact}

Transmission/steam line impact is an assessment of the potential effect that exposure of the lines (pipes) will have on area ecology and adjacent communities.

Transmission lines are generally run in the same corridor as steam lines with no cross connection to the area electrification grid. Cogeneration plants are assumed energy deficient, and a matrix weighting factor of 5 was assigned due to the assessment of Iimited impact.

The following section describes the characteristics of the four regions designated for evaluation of cogeneration plant location by ERDA (DOE)/GSU.

\subsection{CHARACTERISTICS OF CANDIDATE REGIONS}

\subsubsection{NORTH BATON ROUGE REGION}

The North Baton Rouge region comprises the area encompassing the City of Baton Rouge, Louisiana, and its contiguous suburbs. The region is located in south central Louisiana in the Mississippi River floodplain which consists of relatively low flatland. The population of Baton Rouge was 165,963 in 1970, is currently about 209,000, and is projected to reach 473,000 by 2020 .

The humid subtropical climate of the region is influenced to a large degree by the proximity of the Gulf of Mexico. Prevailing southeasterly winds combined with warm air from the Gulf of Mexico provide mild, humid weather during most of the year. Throughout the year, the water modifies the relative humidity and temperature by decreasing the range between extremes. Relative humidities of less than 50 percent occur each month; however, they are less frequent in the summer than during the remainder of the year. Air from the interior occasionally brings drier and usually cooler weather, but air of continental origin generally influences the area very little during the summer, and only part of the time during other seasons.(15, 16)

The summer climate is warm and humid. Daily mean and maximum temperatures average $82 \mathrm{~F}$ and $92 \mathrm{~F}$, respectively. Precipitation averages 5 inches per month. Afternoon thundershowers, which account for much of the rainfall, occur about one day in three during the summer months.

The winter climate is pleasant due to mild temperatures and moderate precipitation. Daily mean and maximum temperatures average $54 \mathrm{~F}$ and $64 \mathrm{~F}$, respectively, and freezing temperatures occur on an average of one night in four. 


\subsubsection{LAKE CHARLES REGION}

Lake Charles region is located on the east side of the city of Lake Charles and the Calcasieu River, which runs through the lake on its way to the Gulf of Mexico. The city is in the southwest corner of Louisiana, approximately 30 miles north of the Gulf of Mexico. Iake Charles had a 1970 population of 77,998 and a 2020 projected population of 116,500. Much of the Lake Charles terrain is level coastal plain. Most of the area to the south is marshland and bayous. Higher elevations around lake charles are cultivated with rice and soybeans. The remaining land is pasture and timberland.

The climate is humid subtropical. Prevailing winds are southerly 38 percent of the time, northerly 22 percent of the time, and easterly and westerly 40 percent of the tine. (17) Winds are rather light with 80 percent wind speed nbservations during the year recording $12 \mathrm{mph}$ or less. The average minimum and maximum temperatures are $43 \mathrm{~F}$ and $y_{1} \mathrm{~F}$, respectively; annual mean temperature is $68 \mathrm{~F}$. The average annual rainfall is 56 inches.

The Port of Lake Charles is a fully-equipped, general cargo, deep sea terminal and is one of the major rice shipping ports in the worla. Due to deep sea transportation. mila climate, and numerous oil and natural gas wells, a large industrial complex has developed in the area.

\subsubsection{ORANGE COUNTY REGION}

The Orange County region is located on the Texas-Louisiana border in the extreme southeast corner of Texas, approximately 40 miles inland from the Gulf of Mexico.. Much of the terrain is level coastal plain; the area to the south is prairie land whereas much of the area to the west is timberland. The climate of this region is semi-tropical. The population of Orange county is about 88,000 and is expected to reach 199,000 by 2020 .

Orange is the crossroads for water transportation in that area. Ocean-going vessels and intracoastal barge lines operate from the Port of Orange.

Many chemical plants such as E.I. DuPont de NeMours $\varepsilon$ Company, Owens-Illinois, Phillips Petroleum, Allied Chemicals, Goodrich Chemicals, Gulf Chemicals, Firestone Petrochemicals, and Crown Zellerbach are located along what is known as "chemical row". 


\subsubsection{GEISMAR REGION}

The Geismar region is located in south central Louisiana in the Mississippi River floodplain comprised of relatively low flatland. Geismar is a small village located on the Mississippi River approximately 16 miles southeast of Baton Rouge. Among the major companies located in Geismar are: BASF/Wyandotte, Monochem, Shell Chemical, Vulcan Chemical, Ciba-Geigy, and Allied Chemical.

The nearest population concentration is Gonzales, which had a 1970 population of 4,512 and a 2020 projected population of about 17,000 .

The climate of the region is humid subtropical. The prevailing southeasterly winds combined with the moisture and warm air from the Gulf of Mexico provide mild, humid weather throughout most of the year.

The summer climate is warm and humid. Daily mean and maximum temperatures average $82 \mathrm{~F}$ and $92 \mathrm{~F}$, respectively. Rainfall averages about 5 inches per month. Afternoon thundershowers, which account for most of the rainfall, occur on about one day out of three during the summer months.

The winter climate is pleasant due to mild temperatures and moderate precipitation. Daily mean and maximum temperatures average $54 \mathrm{~F}$ and $64 \mathrm{~F}$, respectively, and freezing temperatures occur on the average of one night in four.

Using the methodology described in section 3.2 for selecting specific sites, 11 possible locations within the four candidate regions were designated. The following section discusses their positions within the region and some of their relative merits. Section 3.5 is devoted to the in-depth analysis that ultimately defines the most desirable plant sites by weighted rank ordering.

\subsection{LOCATION OF CANDIDATE SITES}

\subsubsection{NORTH BATON ROUGE SITES A AND B}

Two potential plant sites were designated in the North Baton Rouge Region, within the boundaries of the City of Baton Rouge. Site $A$, the northern parcel, contains 220 acres; Site $B$, to the south, contains 30 acres. Because they are separated by a distance of only 8,400 feet, the sites were evaluated together.

As shown in Figure 3-4, both are bordered on the west by the Mississippi River, which qualifies as a navigable waterway 
and handles considerable barge tonnage annually; ocean freight goes as far as the Baton Rouge Port to the north.

Plants at either site could be located approximately 600 feet from the river. Site $A$ is presently a buffer zone between industrial complexes at the south and southern University to the north. Site $B$ is located in the middle of the industrial complex area.

Each site has easy access to all transportation means, is sufficiently near steam users, and has common environmental and engineering variables. The $A / B$ sites are, however, collocated near an extreme bend in the Mississippi River, presenting hazards to river navigation and requiring further study of the suitability of the site for unloading fuel from barges.

\subsubsection{LAKE CHARLES SITES A, B, AND C}

The three Lake Charles sites, shown on Figure 3-5, are located in the southwest corner of Louisiana. Site $A$ is approximately $5 \mathrm{miles}$ from the City of Lake Charles, and about 10,000 feet from the Calcasieu River. This latter distance would require building additional channels, if barges were to be used for transporting fuel.

Because of the relatively flat terrain embanking the river, Site $A$ and Site $B$, which are contiguous with the Calcasieu Ship Channel, might be prone to floods. Site $C$ is some distance from the mainstream of the river and the channel and would not be subject to potential flooding. 


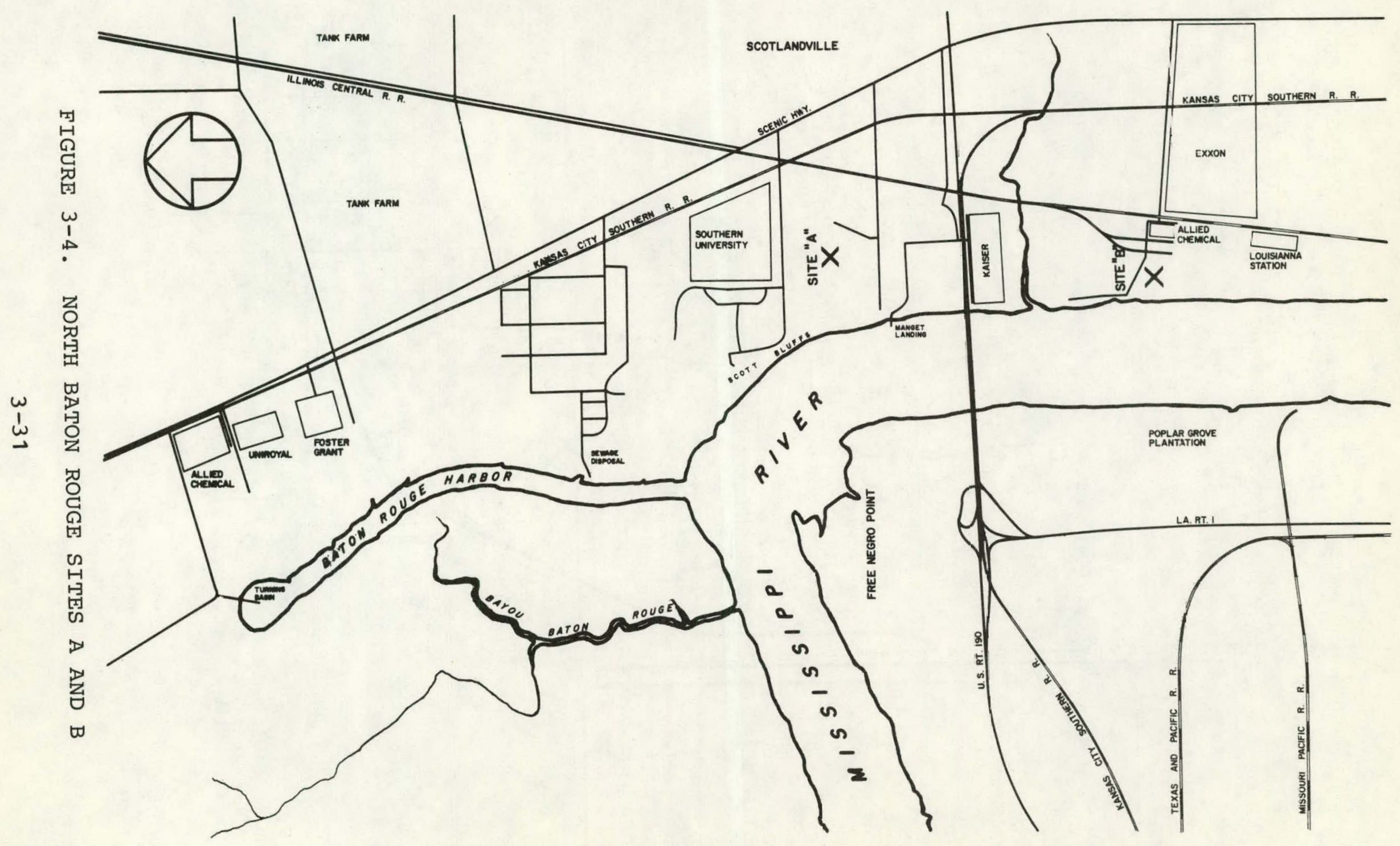




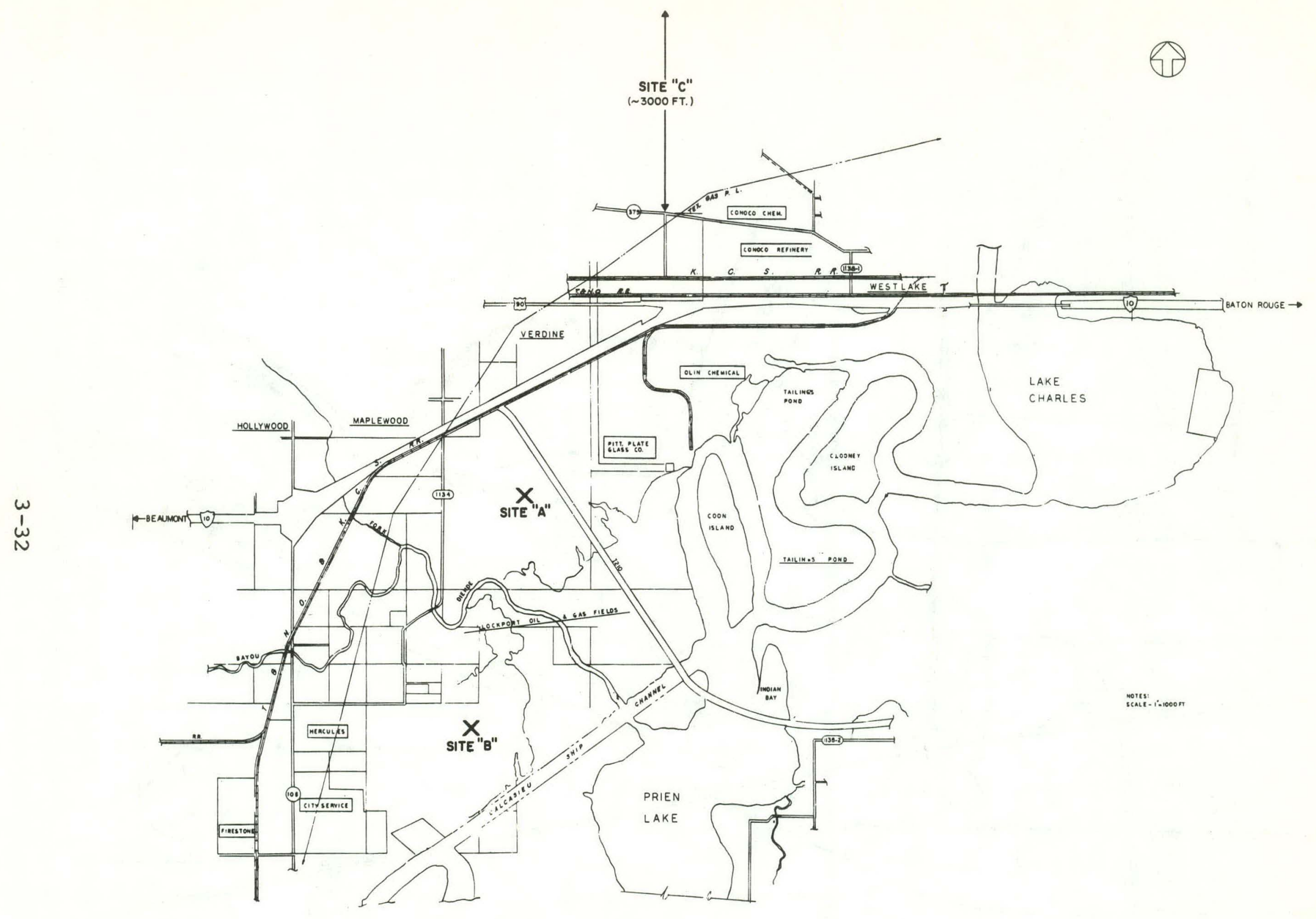

FIGURE 3-5. LAKE CHARLES SITES A, B, AND C 
Site $A$, the smallest of the three sites at Lake Charles, contains 400 acres, sufficient for either fossil or nuclear plants. Steam customers are widely dispersed in this area: Site A is most closely located to a major portion of them. Because of its high elevation compared to site B; proximity to railroads, interstate highways, the City of Maplewood; and industrial complexes and residential area, Site A's land is suitable for aevelopinent and thus could be costly.

The 600-acre site B, zoned industrial-commercial, is also located adjacent to an industrial complex. Its favorable access to the Calcasieu ship Channel allows barge transportation of coal for a fossil plant; however, its lower elevation offsets the higher land costs that could exist because of its direct proximity. Cust also would be positively affected by site B's greater distance from the Hollywood and Maplewood developed areas. In most engineering and environmental respects, site $B$ is similar to site $A$, except that its lower elevation increases the likelihood of flooding.

Although site $C$ is also approximately 5 miles from the City of Lake Charles and 2 miles from nearby developed areas (i.e... Westlake), its 700-landlocked acres are nearly 7 miles from the Calcasieu River, preventing its sharing a number of features with the other two sites. Site c's chief water source is the Houston River, which is cleaner than the channel but unsuitable for barge unloading. Elevation is higher, flooding unlikely, and because of its remoteness from industry and residences, its desirability for land development is less. However, Site cis distance of 5 miles from major steam consumers presents a significant piping distribution problem.

\subsubsection{ORANGE SITES A AND B}

Two plant sites are located about 15 miles northeast of Port Arthur in the Orange county Region (see Figure 3-6). This region is part of the flat Texas coast that extends along the Gulf of Mexico. Both sites are adjacent to swampy terrain along the Sabine River, the border between Texas and Louisiana, and are connected with the Sabine by a network of canals. There is thus adequate water source for each site, but barge fuel transport does not seem economical.

The Gulf Intercoastal Waterway intercepts the Sabine River south of the Port of Oxange, providing the port with a deep channel link to the Gulf. Other means of transportation are also accessible to the two sites.

Because steam consumers are clustered in a relatively small chemical industrial complex, the sites are located from 5,000 to 10,000 feet from customers. Site B is located within 8,000 feet of all steam users. 
(1)

ORANGE

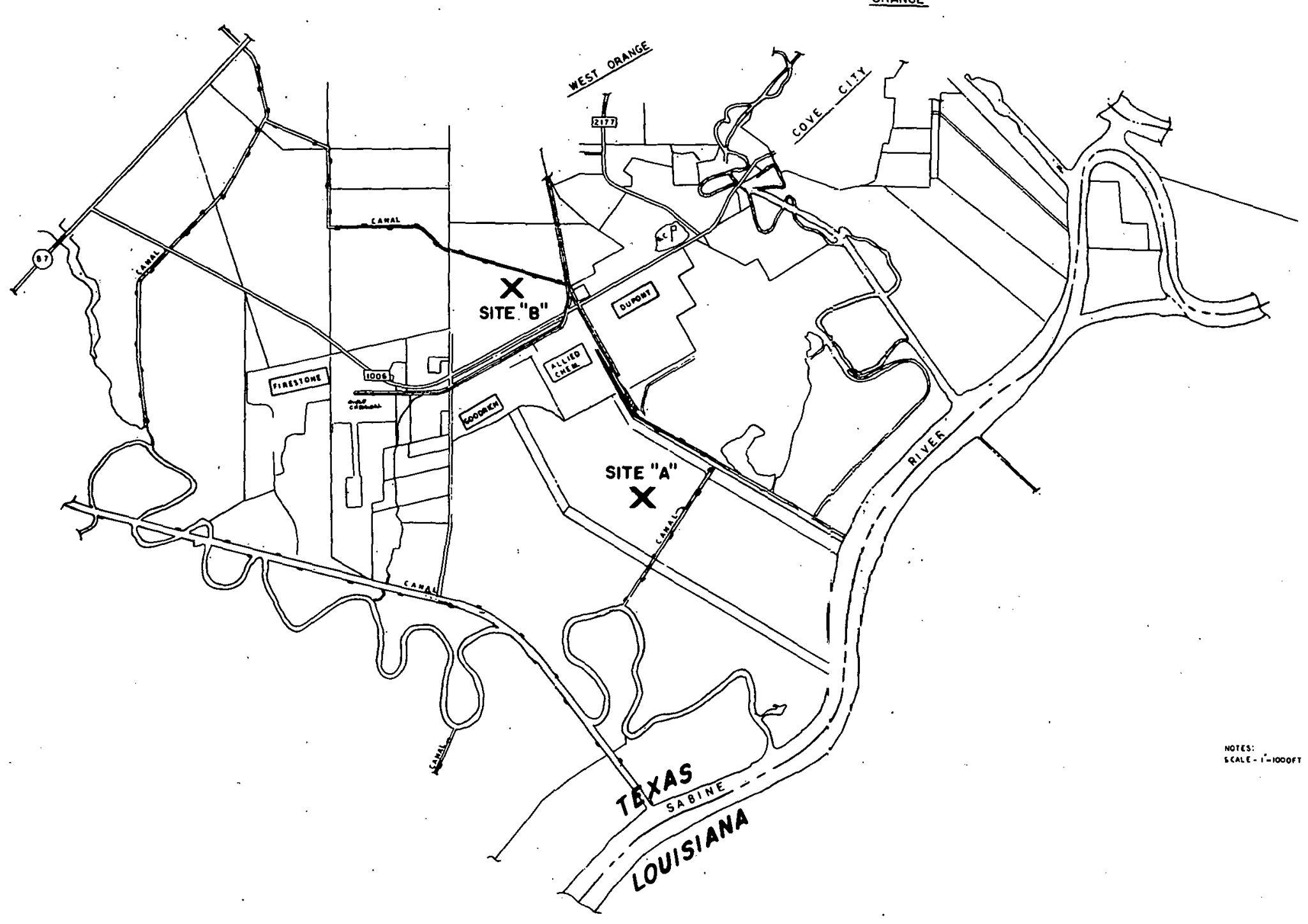

FIGURE 3-6. ORANGE COUNTY SITES A AND B 
The two sites differ mainly in size, Site A containing approximately 300 acres, Site B 580 acres. Both are adequate for either type of cogeneration plant. Site $B$, however, is landlocked, thus inaccessible to water transport and requiring piping water at greater costs. Cost factors slightly favor site B, however, because of its higher elevation; both sites are approximately 2 miles from the developed area of West orange.

\subsubsection{GEISMAR SITES A THROUGH D}

Four locations for plants exist on relatively flat land dipping slightly away from the Mississippi River in the Geismar region. All would require overexcavation and replacement with well-compacted backfill for nuclear plants.

Sites A, B, and D contain wooded and grazing lands; Site C is cleared. As shown in Figure 3-7, Sites A to $D$, located from north to south, are all fronted by the Mississippi River which offers each source of water and water transport. Rail and principal highways link the sites to the Baton Rouge area 16 miles to the northwest. Sites $A, C$, and D are collocated with a major industrial complex; nearby population centers are Gonzales and Donaldsonvilie.

Site $A$ is located near a major river bend creating problems for barge traffic. Furthermore, because of its 64-acre size, which will not support either type of plant, site A was eliminated from further consideration at this time.

Site B, the largest site in the Geismar Region is approximately 600 acres, lying north of the industrial complex. Its distance to steam consumers varies between 5,000 and 22,000 feet. A second advantage is site $B$ 's lower position on the river, making it possible to utilize existing dock facilities for fuel unloading.

All steam users lie within 10,000 feet of Geismar Site C, which consists of 500 acres suitable for either plant. Its closeness to the Belle Helene Plantation presents historical and visual interference problems. Site D lies south of all steam customers with distances from 8,000 to 18,000 feet. Its narrow configuration and limited size (100 acres) makes it unsuitable for current state-of-the-art nuclear or fossil plants.

As seen from this discussion, even preliminary definition of potential sites indicates criteria which could preclude present serious consideration of some sites. Further screening is achieved by employing the Phase II procedures described in section 3.2.2. The next section explains the development of the site comparison matrix in detail. 


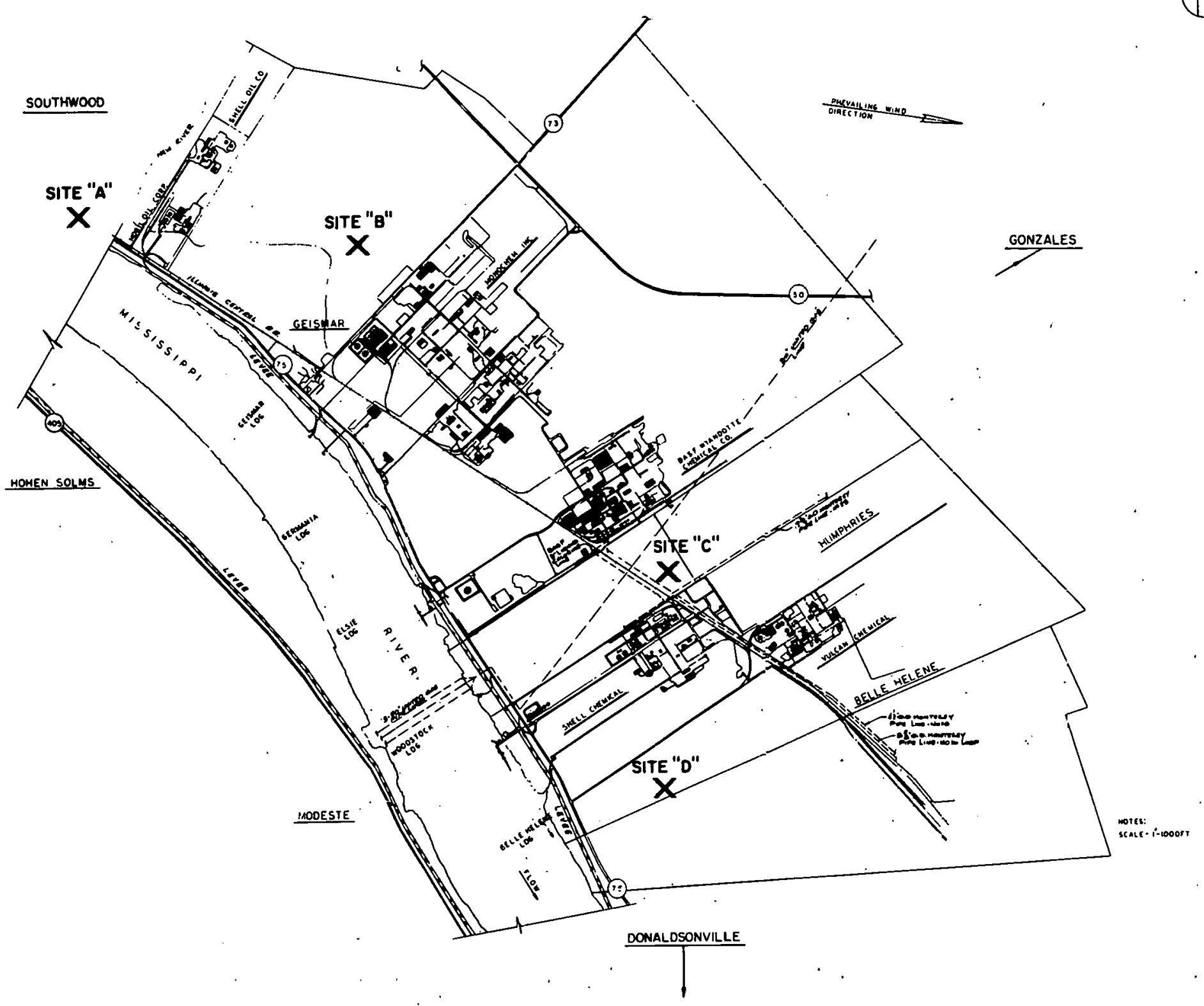

FIGURE 3-7. GEISMAR REGION SITES A, B, C, AND D 


\subsection{SITING CRITERIF}

\subsubsection{SITING MÄTRIX WEIGHTING FACTORS}

As mentioned in section 3.2.2, a method was developer to provide the appropriate impact of specific siting criteria during the site comparison process (see Figure 3-1). Each siting consideration was assigned a numerical value that was proportional to its burden on plant engineering, 'licensing, and environmental impact. This numerical value was designated as the matrix weighting factor.

The numerical variance assigned permits a realistic comparison of each of the elements of the sjting study. It also provides an integrated method of comparing the proportionate value of any one siting element related to a nuclear plant site versus a fossil plant site. For example; demographic considerations in nuclear siting are more critical from a licensability standpoint than wastewater considerations. The rationale behind this assumption is based on the significantly higher cost to increase engineered safeguards for calculated radiation doses to population versus the cost to comply with water pollution regulatory standards.

In addition, strict regulatory criteria have been promulgated for demographic totals and population density that, if exceeded, could completely exclude a site. Consequently, a matrix weighting factor of 25 was assigned in considering demography, whereas a matrix weighting factor of 5 was assigned to wastewater impact.

Similar reasoning prevails for the identical matrix weighting factor regarding the nuclear plant site versus the fossil plant site. For example, the consideration of highway, rail, and water access is significantly more important for a fossil plant site than a nuclear plant site. The impact of continuous large shipments of coal compared to the periodic small shipments of uranium fuel presents a substantially more sensitive effect on the siting concerns. Therefore, a matrix weighting factor of 25 was assigned to fossil and 5 to nuclear plants.

Consistent with the above description, each of the siting elements was analyzed for its proportional impact on the siting process, and matrix weighting factors were assigned.

\subsubsection{SITING CRITERIA LIMITS}

A quantitative ranking system was devised to compare all potential nuclear and fossil plant sites. The numerical values, called matrix ratings, assigned to the individual siting considerations were developed based on 
suitability/constraint criteria. This system consists of five basicheadings with corresponding numerical ranges. Each siting consideration was reviewed and specific criteria established for each of the headings. For example, the headings and numerical ranges of demography are:

\section{Heading}

Constraint

Less Constraint

No Constraint

Siltable

Very suitable
Numerical Range

$$
\begin{array}{r}
0 \\
1-15 \\
16-19 \\
20-23 \\
24-25
\end{array}
$$

The following demographic criteria were utilized to screen primary and candidate sites for a nuclear plant:(18)

\section{Matrix Rating}

0

$1-15$

$16-19$

$20-23$

$24-25$

\section{Demographic Criteria}

Sites with a present population density greater than 1,000 persons per square mile for a 5 -mile radius or 500 persons per square mile for a 30-mile radius.

Sites with a present population density greater than 500 persons per square mile for a 5-mile radius or less than 500 persons per square mile for a $30-\mathrm{mile}$ radius.

Sites with a present population density less than 500 persons per square mile for a 5 - or $30-$ mile radius.

Sites with a present population density less than 300 persons per square mile for a 30 -mile radius.

Sites with a present population density less than 150 persons per square mile for a $30-$ mile radius.

As indicated above, each consideration for the sites was assigned a matrix rating. Then matrix ratings were totaled for the three major siting categories (technical/ engineering, physical, environmental/licensing, and socioeconomic). Finally, a combined total score for each site was obtained by summing the resulting three categories and a relative site ranking was derived.

Table 3-3, Site Selection Matrix - Nuclear.Plant Site and Fossil plant Site, summarizes the matrix ratings for each 
site in the three major siting categories. The lengthy step-by-step analytic process from which these ratings were derived is provided for reference in Appendix A. Application of Siting Criteria to - Candidate sites. The respective ranking of the sites is discussed next.

\subsection{CANDIDATE SITE EVALUATIONS}

\subsubsection{SITE RANKING}

The cumulative weighting factor for nuclear plant sites is 340. including technical/engineering scores of 105, physical/icensing scores of 205, and socioeconomic totals of 30 points. Fossil fuel combined score is 300 with technical, physical, and social considerations totaling 115, 140, and 145, respectively.

Ranking the 10 designated sites by high score for both nuclear and fossil sites provides the following order:

Nuclear Plant Sites

\section{Technical/}

Engineering

1. Geismar B

2. Geismar C

3. Orange $B$

4. Orange $A$

5. Lake Charles C

6. Geismar A

7. Lake Charles B

8. Geismar D

9. Lake Charles B

10. North Baton Rouge $A / B$
81

86

90

84

56

72

64

71

64

91
Physical/

Environ-

mental
Socio-

economic Total

Fossil Fuel Plant Sites

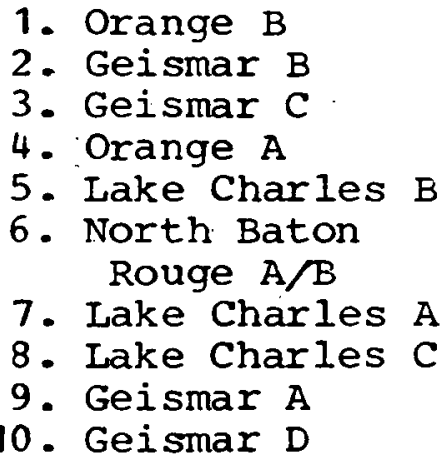

1. Orange B

Gejsmar B

5. Lake Charles B

7. Lake Charles A

8. Lake Charles C

10. Geismar D
104

91

78

105

83

6.2

77

89
177

170

162

162

175

154

154

154

154

128
30

28

30

30

28

30

28

25

28

26

288

284

282

276

259

256

246

250

246

245 
TABLE 3-3

SITE SELECTION MATRIX - NUCLEAR P_ANT SITE

\begin{tabular}{|c|c|c|c|c|c|c|c|c|c|c|c|c|c|c|c|c|c|c|c|c|c|c|c|c|c|c|c|c|c|c|c|}
\hline & \multicolumn{8}{|c|}{ TECHMICAL/ENEIMEERING CONSIDERATIONS } & \multirow[b]{2}{*}{ 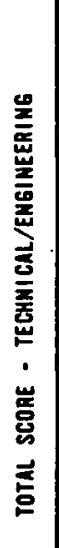 } & \multicolumn{13}{|c|}{$\begin{array}{l}\text { PHYSICAL ANO ENYIROMAENTAL/ } \\
\text { LICENSING CONSIOEBATIOKS }\end{array}$} & \multirow[b]{2}{*}{ 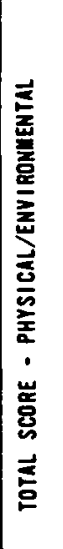 } & \multicolumn{5}{|c|}{$\begin{array}{l}\text { SOCIOECONOWIC } \\
\text { CONSIOERATIOWS }\end{array}$} & \multirow[b]{2}{*}{ 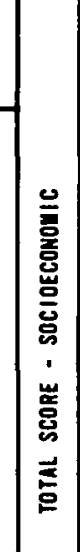 } & \multirow[b]{2}{*}{ 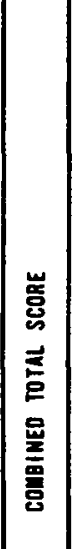 } & \\
\hline DESIONATEO SI TE & 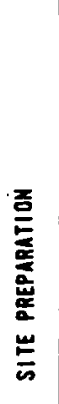 & 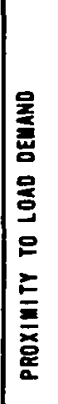 & 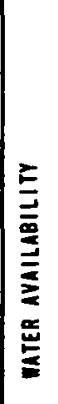 & 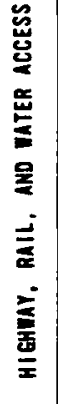 & 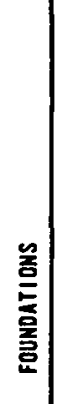 & 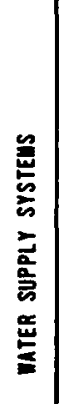 & 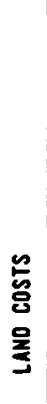 & 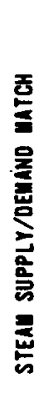 & & 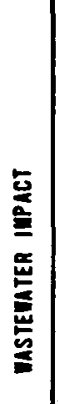 & 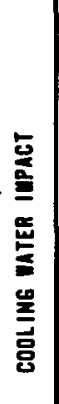 & $\begin{array}{l}\text { 岁 } \\
\text { 号 } \\
\frac{z_{3}}{2}\end{array}$ & 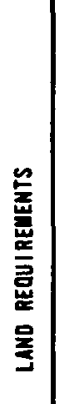 & $\begin{array}{l}\text { ঢ్ } \\
\text { 总 }\end{array}$ & $\begin{array}{l}\text { 离 } \\
\text { 蒂 } \\
\text { 旁 }\end{array}$ & 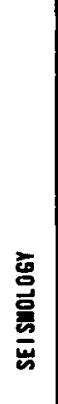 & 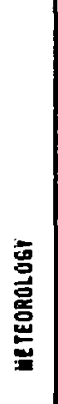 & 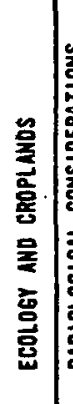 & 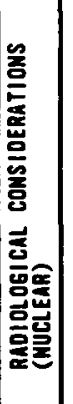 & 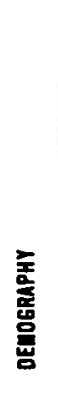 & 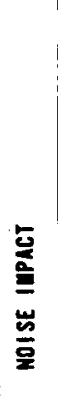 & 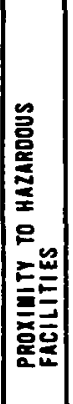 & & 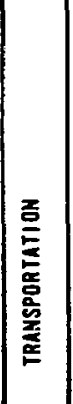 & 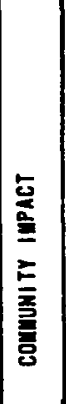 & 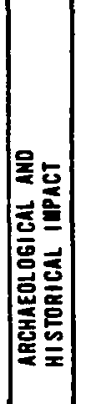 & 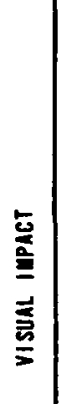 & 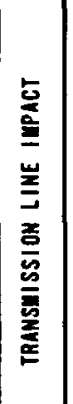 & & & 辤 \\
\hline 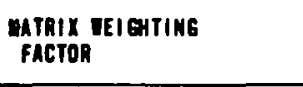 & 10 & 25 & 20 & 5 & 15 & 10 & 5 & 15 & 105 & 5 & 5 & 10 & 20 & 25 & 20 & 20 & 15. & 10 & 25 & 29 & 5 & 20 & 205 & 5 & 10 & 5 & 5 & 5 & 30 & 340 & \\
\hline MORTH BATON ROUGE - N/B & 7 & 25 & 20 & 5 & 12 & 10 & 2 & 10 & 91 & 5 & 5 & 8 & 20 & 20 & 20 & 20 & 11 & 10 & 5 & 0 & 4 & 2 & 128 & 5 & 6 & 5 & 5 & 5 & 26 & 245 & 10 \\
\hline LAKE GAARLES - 1 & 7 & 20 & 10 & 5 & $\theta$ & 8 & 3 & 10 & 69 & 3 & 3 & 8 & 20 & 15 & 20 & 20 & $\mathbf{s}$ & 10 & 10 & 18 & 4 & 15 & 156 & 5 & 8 & 5 & 5 & 5 & 28 & 253 & 7 \\
\hline LAKE CHARLES - B & 7 & $15^{\circ}$ & 10 & 5 & 8 & 6 & 3 & 10 & 64 & 3 & 3 & 8 & 20 & 15 & 16 & 20 & $n$ & 10 & 10 & 19 & 4 & 15 & 154 & 5 & 8 & 5 & 5 & 5 & $2 B$ & 246 & 9 \\
\hline LAKE CHARLES - C & 10 & 0 & 7 & 5 & 12 & 7 & 5 & 10 & 58 & 3 & 3 & 10 & 20 & 11 & 20 & 20 & 3 & 10 & 20 & 18 & 4 & 20 & 175 & 5 & 8 & 5 & 5 & 5 & 28 & 259 & 5 \\
\hline ORAMBE - A & 7 & 20 & 15 & 5 & 11 & 8 & 3 & 15 & 84 & 4 & 4 & 10 & 20 & 15 & 20 & 17 & 15 & 10 & 10 & 20 & 5 & 12 & 162 & 5 & 10 & 5 & 5 & 5 & 30 & 276 & 4 \\
\hline ORAMGE - B & 7 & 25 & 15 & 5 & 11 & 1 & 5 & 15 & 90 & 4 & 4 & 10 & 20 & 15 & 20 & 17 & 15 & 10 & 10 & 20 & 5 & 12 & 162 & 5 & 10 & 5 & 5 & 5 & 30 & 282 & 3 \\
\hline GEI SUAR - A & 5 & 10 & 20 & 5 & $\theta$ & $\theta$ & 4 & 12 & 72 & 5 & 5 & 9 & 1 & 15 & 18 & 20 & 18 & 8 & 25 & 25 & 5 & - & 154 & 5 & 10 & 5 & 5 & 5 & 30 & 256 & 6 \\
\hline GEISUAR - B & 5 & 20 & 20 & 5 & $\theta$ & 8 & 3 & 12 & 01 & 5 & 5 & 9 & 20 & 15 & 16 & 20 & 18 & 8 & 25 & 25 & 5 & 12 & 177 & 5 & 10 & 5 & 5 & 5 & 30 & 280 & 1 \\
\hline GEI SWAR - C & 5 & 25 & 20 & 5 & 8 & 8 & 3 & 12 & 86 & 5 & 5 & 9 & 20 & 15 & 18 & 20 & $1 !$ & 8 & 25 & 25 & 5 & 5 & 170 & 5 & 10 & 4 & 4 & 5 & 28 & 284 & 2 \\
\hline GEI SUAR - D & 5 & 10 & 20 & 5 & $\theta$ & 8 & 3 & 12 & 71 & 5 & 5 & 8 & 2 & 15 & 18 & 20 & $1 .:$ & 8 & 25 & 25 & 5 & 10 & 154 & 5 & 10 & 2 & 3 & 5 & 25 & 250 & 8 \\
\hline
\end{tabular}


TABLE $3-3 \quad\left(C^{\prime} O N T^{\prime} D\right)$

SITE SELECTION MATRIX - FOSSIL PLANT SITE

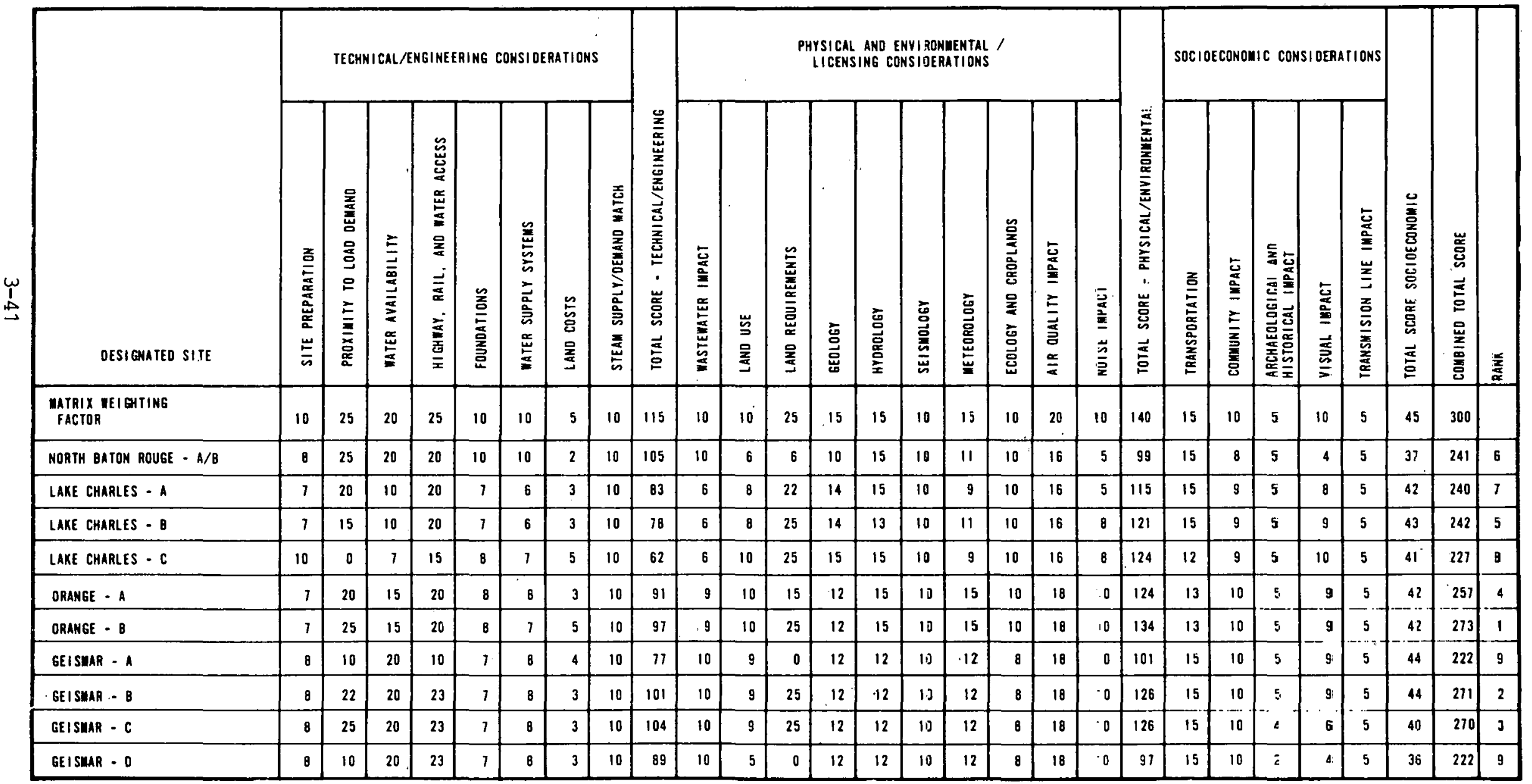


Geismar B is one of the two highest in each site category. Orange $B$ ranks first as a fossil fuel plant site and third as a nuclear site; Geismar C ranks second as a nuclear and third as a fossil-fuel plant site. In our analysis, the first/third combination would slightly favor the Orange $B$ site but could not be considered decisive. A further rationale used to arrive at only two sites suitable for both plants is explained in the following section.

\subsubsection{SELECTION OF TWO SITES}

Combining scores in the two plant categories presents the following rank:

\begin{tabular}{|c|c|c|c|c|}
\hline & $\begin{array}{l}\text { Technical/ } \\
\text { Engineering }\end{array}$ & $\begin{array}{l}\text { Physical/ } \\
\text { Environ- } \\
\text { mental } \\
\end{array}$ & $\begin{array}{l}\text { Socio- } \\
\text { economic }\end{array}$ & Total \\
\hline $\begin{array}{l}\text { 1. Geismar B } \\
\text { 2. Geismar C } \\
\text { 3. Orange B }\end{array}$ & $\begin{array}{l}182 \\
190 \\
187\end{array}$ & $\begin{array}{l}303 \\
296 \\
296\end{array}$ & $\begin{array}{l}74 \\
68 \\
72\end{array}$ & $\begin{array}{l}559 \\
554 \\
555\end{array}$ \\
\hline
\end{tabular}

Geismar $B$ remains first in combined score, followed by Orange $B$, with Geismar $C$ being third. A difference of one point is hardly significant, since technical and physical considerations can often be compensated for by innovative design or cost trade-offs. However, Geismar C's closeness to the historic Belle Helene Plantation presents social factors not controllable by design engineering, and makes orange site $B$ with its marginal one point difference the more desirable of the two sites for both types of plants.

Thus, the analysis has pinpointed Geismar Site B and orange Site $B$ as the two preferred candidates for the erection of either a nuclear or fossil fuel cogeneration plant.

Section 4 describes alternative fossil fuel (i.e., oil- and coal-fired), nuclear (consolidated nuclear steam system and high temperature gas-cooled reactor steamer), and advanced technology (fluidized-bed boiler, coal gasification, and combined cycle gas turbine) plants that could feasibly be built on the selected sites. 
1

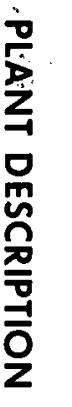




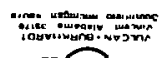

(3) 
SECTION 4

PLFINT DESCRIPTIONS

TABLE OF CONIENTS

Page

4.1

4.1 .1

4.1 .1 .1

4.1 .1 .2

$4 \cdot 1 \cdot 1.3$

4.1 .2

4.7 .2 .1

4.1 .2 .2

4.1 .2 .3

4.2

4.2 .1

4.2 .2

$4.2 \cdot 3$

4.3

4.3 .1

4.3 .1 .1

4.3.1.1.1

4.3.1.1.2

$4 \cdot 3 \cdot 1 \cdot 1 \cdot 3$

4.3 .1 .1 .4

4.3 .1 .1 .5

$4.3 \cdot 1 \cdot 1.6$

$4.3 \cdot 1.1 .7$

4.3.1.1.8

$4.3 \cdot 1.1 .9$

$4 \cdot 3 \cdot 1 \cdot 1 \cdot 10$

4.3 .1 .2

4.3 .1 .2 .1

$4 \cdot 3 \cdot 1 \cdot 2 \cdot 2$

$4 \cdot 3 \cdot 1.2 .3$

$4 \cdot 3 \cdot 1.2 .4$

$4 \cdot 3 \cdot 1.2 .5$

4.3 .1 .2 .6

4.3 .1 .2 .7

$4.3 \cdot 1.2 .8$

$4.3 \cdot 1.2 .9$

$4 \cdot 3 \cdot 1 \cdot 2 \cdot 10$

4.3 .2

4.3 .2 .1

$4 \cdot 3 \cdot 2 \cdot 1.1$

$4 \cdot 3 \cdot 2 \cdot 1 \cdot 2$
PROJECTED USERS' DEMANDS

Orange Region

stearn kequirements

Electrical Requirements

Backup Stear Source

Geismar Region

Steam Requirements

Electrical kequirements

Backup steam Source

HEAT CYCLE OPTIMIZATION - ORANGE

AND GEISMAR SITES

Stearn Pressure Determination

steam Turbine Selection

Number of Feedwater Heaters

ORANGE SITE

Fossil Fuel plants

Oil-Fired Plant (Reference plant)

Steam Generators

Boilex Feedwater system

Turbine Generators

Fuel Handing System

Ash Handling

Precipitators and Scrubbers

Water Treatment system

Waste Ireatment System

blectrical system

Structural Criteria

Coal-Fired Plant

Stean Genexators

Boiler Feedwater system

Turbine Generators

Fuel Handling System

A.sh Handling

Precipitators and Scrubbers

water Ireatment system

waste Treatment system

Electrical systen

Structural Criteria

Nuclear Plants - Advanced Technology

Under Development

Consolidated Nuclear Steam Supply

System (CNSS Plant)

Nuclear Steam Supply system (NSSS)

Thermal Cycle
4-1

4-1

4-1

4-1

4-2

4-2

4-2

$4-3$

4-3

4-4

4-4

4-7

4-8

4-10

4-10

4-10

4-10

4-10

4-11

4-11

$4-12$

4-12

4-13

4-13

4-14

4-15

4-16

4- -16

4-17

4-17

4- 18

4-18

4-20

4-20

$4-21$

$4-22$

$4-23$

$4-24$

4-24

$4-24$

4-25 
$4 \cdot 3 \cdot 2 \cdot 1 \cdot 3$

$4 \cdot 3 \cdot 2 \cdot 1.4$

4.3 .2 .1 .5

$4 \cdot 3 \cdot 2 \cdot 1.6$

$4 \cdot 3 \cdot 2 \cdot 1.7$

4.3 .2 .1 .8

4.3.2.1.9

4.3 .2 .1 .10

$4.3 .2 \cdot 1.11$

4.3 .2 .2

4.3 .2 .2 .1

4.3 .2 .2 .2

4.3 .2 .2 .3

4.3 .2 .2 .4

4.3 .2 .2 .5

4.3 .2 .2 .6

4.3 .2 .2 .7

4.3 .2 .2 .8

4.3 .2 .2 .9

4.3 .2 .2 .10

4.3 .2 .2 .11

$4.3 \cdot 2 \cdot 2 \cdot 12$

4.4

4.4 .1

4.4 .1 .1

4.4.1.1.1

$4.4 \cdot 1 \cdot 1.2$

$4.4 \cdot 1.1 .3$

4.4 .1 .1 .4

4.4 .1 .1 .5

4.4 .1 .1 .6

4.4.1.1.7

4.4 .1 .1 .8

$4.4-1.1 .9$

$4.4-1.1 .10$

4.4 .1 .2

$4.4 \cdot 1.2 .1$

4.4 .1 .2 .2

$4.4 \cdot 1.2 .3$

4.4 .1 .2 .4

$4.4 \cdot 1.2 .5$

4.4.1.2.6.

4.4 .1 .2 .7

4.4 .1 .2 .8

4.4.1.2.9

$4 \cdot 4 \cdot 1.2 \cdot 10$

4.4 .2

4.4 .2 .1
Plant frrangement

Reactor Containment

Fuel Handling System

'Turbine Generator and Steam Cycle

Radwaste Systen

vltimate leat Sink

Water Treatment System

Electrical system

Structural Criteria

High Telmuerature Gas-Cooled Reactor

steaner (HTGR Steamer)

Heat Cycle optimization

Nuclear Steam Supply System (NSSS)

Plant Arrangement

Reactor Containment

Fuel Handling System

Turbine Generator and stean cycle

Electrical System

Radwaste System

water Treatment System

Ultiniate Heat Sink

Buildings and other structures

other structural Criteria

GEISMAR SITE

Fossil Fuel plants

Oil-Fired Plant (Reference Plant)

Steam Generators

Boiler Feedwater system

Turbine Generators

Fuel Handling System

Ash Handling

Precipitators and Scrubbers

Water Treatuent System

Waste Treatment System

Electrical system

Structural Criteria

Coal-Firea Plant

Steam Generators

Boiler Feedwater system

Turbine Generators

Fuel Handling System

Ash Handling System

Precipitators and Scrubbers

Water Treatment System

Waste Treatment System

Electrical system

Structural Criteria

Nuclear Plants - Advanced Technology

Under Development

Consolidated Nuclear steam Supply

Systern (CNSS plant)
$4-27$
$4-27$
$4-28$
$4-29$
$4-29$
$4-30$
$4-30$
$4-31$
$4-32$
$4-32$
$4-32$
$4-33$
$4-34$
$4-34$
$4-35$
$4-35$
$4-36$
$4-38$
$4-39$
$4-40$
$4-40$
$4-46$
$4-47$
$4-47$
$4-47$
$4-47$
$4-47$
$4-48$
$4-48$
$4-49$
$4-49$
$4-50$
$4-50$
$4-51$
$4-52$
$4-53$
$4-53$
$4-54$
$4-54$
$4-55$
$4-55$
$4-56$
$4-56$
$4-57$
$4-58$
$4-59$
$4-60$
4 


$$
\begin{aligned}
& 4.4 .2 .1 .1 \\
& 4.4 .2 .1 .2 \\
& 4.4 \cdot 2 \cdot 1.3 \\
& 4.4 .2 .1 .4 \\
& 4.4 .2 .1 .5 \\
& 4.4 .2 .1 .6 \\
& 4.4 .2 .1 .7 \\
& 4.4 .2 .1 .8 \\
& 4.4 .2 .1 .9 \\
& 4.4 .2 .1 .10 \\
& 4.4 .2 .1 .11 \\
& 4.4 .2 .2
\end{aligned}
$$$$
4.4 .2 .2 .1
$$$$
4.4 .2 .2 .2
$$$$
4.4 \cdot 2 \cdot 2.3
$$$$
4.4 .2 .2 .4
$$$$
4.4 .2 .2 .5
$$$$
4.4 .2 .2 .6
$$$$
4.4 .2 .2 .7
$$$$
4.4 .2 .2 .8
$$$$
4.4 .2 .2 .9
$$$$
4.4 \cdot 2.2 \cdot 10
$$$$
4.4 .2 .2 .11
$$$$
4 \cdot 4 \cdot 2 \cdot 2 \cdot 12
$$$$
4 \cdot 4 \cdot 3
$$$$
4 \cdot 4 \cdot 3 \cdot 1
$$$$
4.4 .3 .1 .1
$$$$
4.4 .3 .1 .2
$$

$4 \cdot 4 \cdot 3 \cdot 1.3$

$4.4 \cdot 3 \cdot 1.4$

4.4 .3 .1 .5

$4.4 \cdot 3 \cdot 1.6$

4.4 .3 .2

$4.4 \cdot 3.2 .1$

$4 \cdot 4 \cdot 3.2 \cdot 2$

$4.4 .3 .2 \cdot 3$
Nuclear Steam Supply System (NSSS)

Therma1 Cycle

plant Arrangement

Reactor Containment

Fuel Handling System

Turbine Generator and steam Cycle

Radwaste System

Ultimate Heat Sink

Water ireatment System

Electrical system

Structural criteria

High Temperature Gas-Cooled Reactor

Steaner (HTGR Steamer)

Heat Cycle optimization

Nuclear Steam Supply System (NSSS)

Plant arranyement

Reactor Coutainment.

Fuel Handing System.

Turbine Generator and Steam Cycle

Electrical System

Radwaste System

Water Ireatnent. System

Ultimate Heat Sink

Buildings and other structures

Other structural Criteria

Advanced Fossil Fuel Technology -

Future Development

Eastern Coal Fluidized-Bed Boilers

Conventional Cogeneration Plant Boilers Fluidized-Bed Boiler General

Specifications

Boiler Equipment Differences

Balance of Plant Differences

Boiler control Flexibility

Continued Development and Potential

Eastern Coal Gasification

Eastern Coal Gasification with

Conventional boilers

Eastern Coal Gasification with

Combined Cycle Gas Turbines

Fuel Cell with Coal Gasification
$4-61$

$4=62$

$4-63$

$4-64$

$4-64$

$4-65$

$4-66$

$4-67$

$4-67$

$4-67$

$4-68$

$4-68$

$4-68$

4-70

4-71

4-71

4-71

4-71

4-72

$4-75$

4-75

4-77

4-77

4-82

4-83

4-83

4-84

4-84

4-84

4-86

4-87

4-88

$4-90$

4-96

4-96

4-98

\section{TABLES}

4-1

4-2

4-3

$4-4$

4-5

4-6
Stearn Requirements - MM Lb/Mr 4-1

Electrical Requirements - MW 4-1

Steam Requirements - MM Lb/Hr

Electrical Requirements - (1978) - MW 4-3

Coal Characteristics

Comparison of Four Cycles for HTGR

steamer 
Page

4-7

$4-8$

4-9

$4-10$

4-11

$4-12$

$4-13$

4-14

$4-15$

Safety classification of Structures

$4-42$ Comparison of Four Cycles for HIGR

Steamer

Safety classification of structures

Department of Energy Atmospheric

Fluidizeä-Bed Projects

coal Characteristics

Size, Capacity, and Performance of

Various Gasifiers

Characteristics and status of

Phosphoric and Molten Carbonate

Fuel cells

Forecast of Fuel Cell Development

Predicted Cost and Performance

Parameters for Fuel Cell Power System

4-69

$4-78$

$4-89$

$4-92$

$4-93$

$4-100$

$4-101$

$4-102$

\section{FIGURES}

4-1

Relationship Among Throttle Pressure, Exhaust Pressure, and kWh/1,000 Lbs of Steain

Generation irom Feedwater Heating System 
This section provides a general description of the cogeneration plants and the major systems and equipment reviewed and costed in this study. Site arrangenent drawings ard fundamental flow diagrams are included in Appendix $B$ for further clarification.

4.1 PROJECTED USERS - DEMANDS

4.1.1 ORANGE REGION

\subsubsection{Steam Reouirements}

The total requirements for steam projected for consumers in the Orange region are shown in Table 4-1:

TARLF 4-1

$$
\text { STEAM REQUIREMENTS - MM LB/HR }
$$

Pressure, psig

Temperature, $F$

1980

1985

1990

\begin{tabular}{ccccc}
$T$ & $F$ & $F$ & $H$ & $E$ \\
600 & 450 & 100 & 220 & 430 \\
761 & $\underline{600}$ & $\underline{350}$ & $\underline{440}$ & $\underline{580}$ \\
\hline
\end{tabular}

$\begin{array}{llllll}1.0 & .18 & .045 & .53 & .27 & 2.025\end{array}$

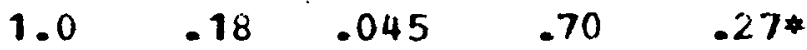

$.80 \quad .27 *$
Total

2.195

2.295

* Projected steam usage not available, initial demand held constant.

\subsubsection{Electrical RGquirements}

The total electrical requirements projected for consumers in the Orange region are shown in Table 4-2:

TABLE' 4-2

ELECTRICAL REQUIREMENTS - MW

$\begin{array}{llllll}\text { Year } & \underline{T} & \underline{F} & \underline{H} & \underline{E} & \text { Total } \\ 1980 & 88 & 54 & 20 & 35.5 & 197.5 \\ 1985 & 90 & 54 & 26 & \text { NA } & 205.5 \\ 1990 & 95 & 54 & 30 & \text { NA } & 214.5\end{array}$


The cogeneration plants (fossil and nuclear) at orange, T'exas, are designed to neet the steam demand projected to 1985 of Firestone. GuIf Chemical. B.F. Goodrich, and Dupont. with no reserve capacity. Reserve and backup capacity would be the resporsibility of each user. It has been assumed that up until the commercial operating date of the cogeneration plant, each user will continue to maintain and expand, if necessary, its steam-generating facilities to meet process needs. On this basis, in 1985 the steam-generating capacity contained in each user's plant will provide a ninimum of 100-percent backup. This assumption appreciably reduces the initial capital investinent (particularly for the nuclear units), assures users of process steam under all circumstances, allows sufficient time to debug the cogeneration plant without loss of productivity, and permits time for the cogeneration plant to yain the confidence of the industrlal users.

The projected stear requirements for this site indicate minimal expansion after 1985. From the standpoint of reliability and present tuel and equipment costs, a third coal-fired boiler can be maxginally justified but a nuclear steam generator for the CNSS and HTKR cannot. It is reconmended that fuel ana equipment costs for the addition of backup equipment be reviewed at the conception of cogeneration plant planning.

Users: plant expansions and increases in steam requirements beyond 1985 should be reviewed yearly to determine the steam-generating facilities that wonld be the most economical, reliable, and flexible. Factors such as timing of future expansions. Fuel costs, cost of maintaining users. stean-generating facilities and process downtime costs should all be consiaered. At each review, the inclusion of the backup steam-generating capacity should be evaluated with the projected steam requirements.

\subsubsection{GEISMAR REGION}

\subsubsection{Steam Requirements}

The total requirements for steam projected for consumers in the Geismar region are shown in rable 4-3: 
TABLE 4-3

STEAM REQUIREMENTS - MM LB/HR

\begin{tabular}{cllllll} 
& $E$ & $L$ & $H$ & $H$ & $N$ & \\
Pressure,psig & 640 & 650 & 640 & 950 & 250 & \\
Permperature, F & $\underline{740}$ & $\underline{740}$ & $\underline{740}$ & $\underline{850}$ & NA & TotaI \\
\hline 1981 & 1.76 & .75 & .90 & $.37 *$ & .36 & 4.14 \\
1982 & 2.035 & .77 & .95 & .37 & .37 & 4.495 \\
1983 & 2.22 & .775 & 1.05 & .37 & .43 & 4.85 \\
1984 & 2.22 & 1.0 & 1.15 & .37 & .44 & 5.18 \\
1985 & 2.32 & 1.5 & 1.2 & .37 & .45 & 5.84 \\
1986 & 2.32 & 1.6 & 1.25 & .37 & .46 & 6.0 \\
1987 & 2.35 & 1.7 & 1.3 & .37 & .47 & 6.19 \\
1988 & 2.38 & 1.8 & 1.35 & .37 & .48 & 6.38 \\
1989 & 2.44 & 1.9 & 1.45 & .37 & .49 & 6.65 \\
1990 & 2.5 & 2.0 & 1.55 & .37 & .5 & 6.92
\end{tabular}

* Projected steam usage not available, initial demand held - constant.

\subsubsection{Electrical Reguirements}

The present (1978) electrical requirements for the consumers in the Geismar region are shown in Table 4-4:

TABLE 4-4

EIECTRICAL REQUIKEMENTS (1978) - MN

E I $\quad$ H $\quad$ N Total

$\begin{array}{lllll}150 & 16 * & 96 & 78 & 340\end{array}$

*Will soon be increased to $24 \mathrm{MW}$.

Projections indicate more than a 50 percent increase in electrical power consunption by 1985 .

\subsubsection{Backup Steam Source}

The cogeneration plants at Geismar, Louisiana, are designed to meet the steam demands projected to 1985 of BASF, Shell. Vulcan, and Monochem with no reserve capacity - Reserve or backup capacity would be the responsibility of each user. It has been assumed that up until the commercial operating date of the cogeneration plant, each user will continue to maintain and expand its present steam-generating facilities to meet process demands. A comparison of the present-day installed steam-generating capacity to the projected steam demands indicates that three of the users must add 
facilities in the 1979-1981 time period. On this basis, in 1985, the steam-generating capacity contained in each user's plant will provide a minimum of 100-percent backup. This assumption appreciably reduces the initial capital investment (particularly for the nuclear units), assures users of process steam under all circumstances, allows sufficient time to debug the cogeneration plant without loss of productivity, and permits time for the cogeneration concelt to gain the confidence of the industrial users.

Although eacli plant scheme has been optimized on the basis of providing 100 percent of 1985 users' requirements, a reliability analysis indicates that a third 50-percent capacity stean yenerator, for backup, could possibly be justified for the coal-fired plants and the CNSS. A spare for the HIGR plant would be marginal (see section 6.3) - On the basis of this analysis, it is recommended that when plans to construct a cogeneration plant are being developed. the economics of an additional steam generator be evaluated to determine the most economial, reliable, and flexible plant configuration. Timing of future expansions, fuel costs, operating and naintenance costs, size and condition of users steam generation facilities, and cost attributable to process downtime are the major factors that should be considered.

Users' projected steala requirements should be reviewed yearly to deterrine future needs. At each review. consideration should be given to incorporating backup steam-generating capacity in future expansion of the cogeneration plant. Inclusion of backup capacity in plant expansions may be economically justified by the retirement of old boilers in the users' plants.

\subsection{GEAT CYCLE OPTIMIZATION - ORANGE AND GEISMAR SITES}

\subsubsection{STEAM PRESSURL DETERMINATION}

Industrial cogeneration plants have historically operated with steam turbine inlet pressures of 1.450 or lower psig. Figure 4-1 shows the relationship between throttle pressure. exhaust pressure, and $\mathrm{kWh}$ per 1.000 pounds of steam, indicating that electric generation can be increased by as much as 40 percent by increasing the steam throttle pressure from 1,450 to $2,400 \mathrm{psig}$ for a number of exhaust pressures. The 2400-psig pressure is typical of current utilities practice. pressures higher than current industrial practice, which yield maximum $\mathrm{kWh}$ per 1,000 pounds of steam. must ve considered practical for a community plant which may be operated under contract by a utility. Turbine throttle conditions of 2,400 psig and 1,000\% and 1,800 psig and $950^{\circ} \mathrm{F}$ were selected for comparison for the fossil-fired cogeneration plants at both Geismar. Louisiana, and Orange. 
Texas. The basic feedwater heating cycle included a deaerator. operating at 45 psia, and one stage of closed feedwater heating supplied with steam at 290 psia.

For conparison purroses, budgetary capital, fuel, and operating costs were estimated for the two operating pressures at each site. Similarily, the net electric power outputs were determined for edch pressure to provide a basis for evaluation. The ratios of capital cost and net power output shown below represent the increase in capital cost to utilize 2.400 psig. rather than $1.800 \mathrm{psig}$, and the resulting increase in power output.

\section{Plant Capital Cost Ratio Net Power Ratio}

Orange

1.049

1.198

Geismar

1.052

1.223

These figures indicate that a 5 percent increase in capital expenditures provides a plant that produces about 20 percent more electric power.

other analyses show that the ratio of differential heat input to differential net work is about $2.360 \mathrm{Btu} / \mathrm{kWh}$ for both plant sites. Also, the ratio of differential cost to differential net work is $\$ 576$ per $\mathrm{kW}$ at Orange and $\$ 459$ per $\mathrm{kW}$ at Geismar in 1977 dollars.

A comparison of the fixed charges and levelized operating costs for the 1,800 and 2,400 psig plants was made assuming 1985 initial operation. Both plants supply the same quantity of process steam, and recoverable heat from this steam is virtually the same. At both orange and Geismar the total annual cost for the 2,400 psig plant is approximately 8 percent less than the cost of the 1,800 psig plant when credit is taken for the power produced. The break-even cost of purchased power is $\$ 0.024$ per $\mathrm{kWh}$ which is about one-third of the estirnated levelized cost of power from GSU over the life of the plant. 


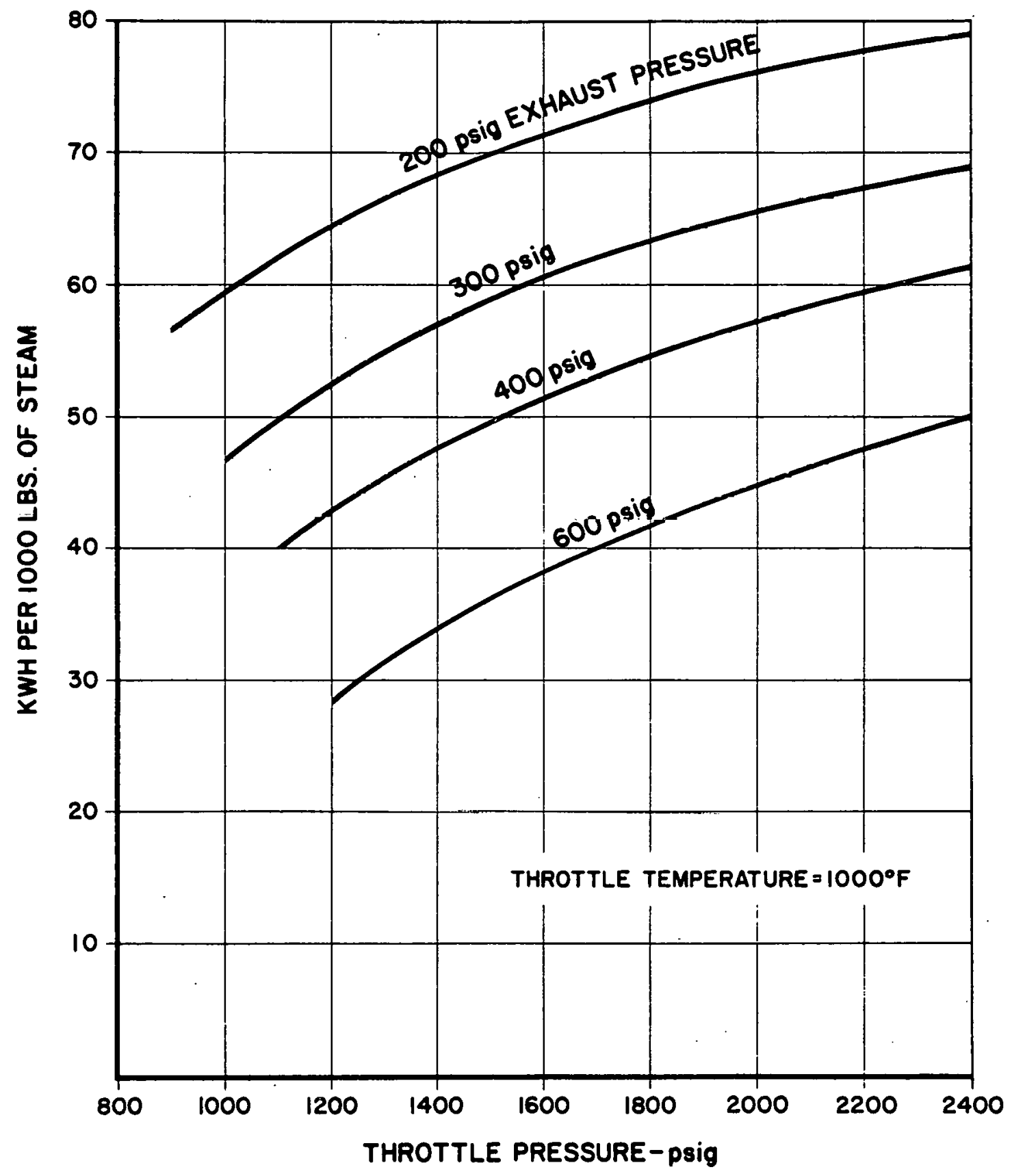

FIGURE 4-1. RELATIONSHIP AMONG THROTTLE PRESSURE, EXHAUST PRESSURE, \& $\mathrm{kWh} / 1,000 \mathrm{LB}$ STEAM 
The above comparison clearly indicates that throttle pressure of 2,400 psig is the more economic choice when compared to $1,800 \mathrm{psig}$. To have equal annual operating costs, the capital cost of the 1,800-psig plant would have to be about 80 percent of the cost of the 2,400-psig plant. It is evident that the optimum throttie pressure lies above 1.800 psig. Because the trend in central station practice is away from the supercritical pressures aforementioned, these were ruled out in this study, and a steam pressure of 2,400 psig was selected for the fossil-fired plants at both Orange and Geismar.

\subsubsection{STEAM TURBINE SELECTION}

'lhree straight noncondensing steam turbines were selected for the Orange plant. Two turbines operate at 2.415 psia throttle pressure: one turbine exhausts at 640 psia and one exhausts at 290 psia. The third turbine operates at a throttle pressure of 290 psia and exhausts at 45 psia to provide deaerating steam. Hecause the flow rate to the deaerator is relatively low, it was impossible to justify turbine operation at 2,415 psia throttle pressure.

Because automatic extraction points increase turbine costs and reduce turbine efficiency, turbine selection was developed using the following rationale. For evaluation purposes, two duplicate double-automatic extraction turbines were selected for comparison with three straight noncondensing units. It was found that the extraction turbines would generate on the order of 10 percent less power than the three straight noncondensing turbines. With a fixed charge rate of 15 percent. 7.884 hours of operation per year, and a levelized power cost of $\$ 0.0757$ per $\mathrm{kWh}$, the capitalized value of a power differential of $15 \mathrm{MW}$ amounts to approximately $\$ 59,700,000$. This cost is nearly twice the installed cost of the two turbines, including inflation and interest during construction. It becomes evident that the most economic selection is the one that generates maximum power.

Three straight noncondensing steam turbines and one automatic extraction steam turbine operating at 2.415 psia throttle pressure were selected for the Geismar plant. Two turbines exhaust at 690 psia, one exhausts at 290 psia, and a single automatic extraction turbine supplying $370,000 \mathrm{Ib} / \mathrm{hr}$ of process steam at 970 psia exhausts to the deaerator at $45 \mathrm{psia}$. An alternate arrangement was considered using three turbines with automatic extractions at 690 and $290 \mathrm{psia}$. (The latter unit would have been a prototype triple automatic noncondensing turbine-) The alternate arrangement produced on the order of $30 \mathrm{MW}$ less than the turbines selected, and also resulted in being more expensive. 


\subsubsection{NUMBER OF FEEDWATER HEATERS}

The stearn used for feedwater heating generates electric power by expanding it through a turbine to heater supply pressure. The anount of electric power generated is a function of the flow and temperature of the treated condersate and makeup water, the number of stages of feedwater heating, the final feedwater temperature, and the turbine performance.

For given initial and final feedwater temperatures, the maximum work is obtained with an infinite number of stages of feedwater heating. Figure 4-2 shows this theoretical work in kWh per 1,000 pounds of condensate and makeup at $68 \mathrm{~F}$ for the turbine conditions listed. In practice, a deaerator operates at above atmospheric pressure and is used to reduce the dissolved oxygen contained in the feedwater to acceptable linits. Feedwater pumps take suction from the deaerator: permitting varying stages of closed feedwater heating to be employea.

In the base case, the deaerator pressure was set at 45 psia and one stage of feedwater heating employed with stean supplied at 290 psia. For comparison, an alternate was evaluated with two stages of closed feedwater heating. At the orange plant, the second-stage heater operates at $640 \mathrm{psia}$. With two feedwater heaters, steam flow to the turbine increased 10 percent and the net electric power increased 8 percent. The second-stage heater at the Geismar plant operates at $690 \mathrm{psia}$. With two feedwater heaters the steam flow to the turbine increased 11 percent and the net power increased 9 percent.

A comparison of fixed charges and levelized operating costs for the plants with one and two stages of closed feedwater heating was made assuming the year of initial operation as 1985. The comparison showed the two stages of feedwater heating to be the nost economic choice if the increase in capital cost over one stage is less than 7 percent at Orange and less than 9 percent at Geismar.

On the basis of the above criteria, a second stage of closed feedwater heating can be economically justified at both Orange and Geismar. 


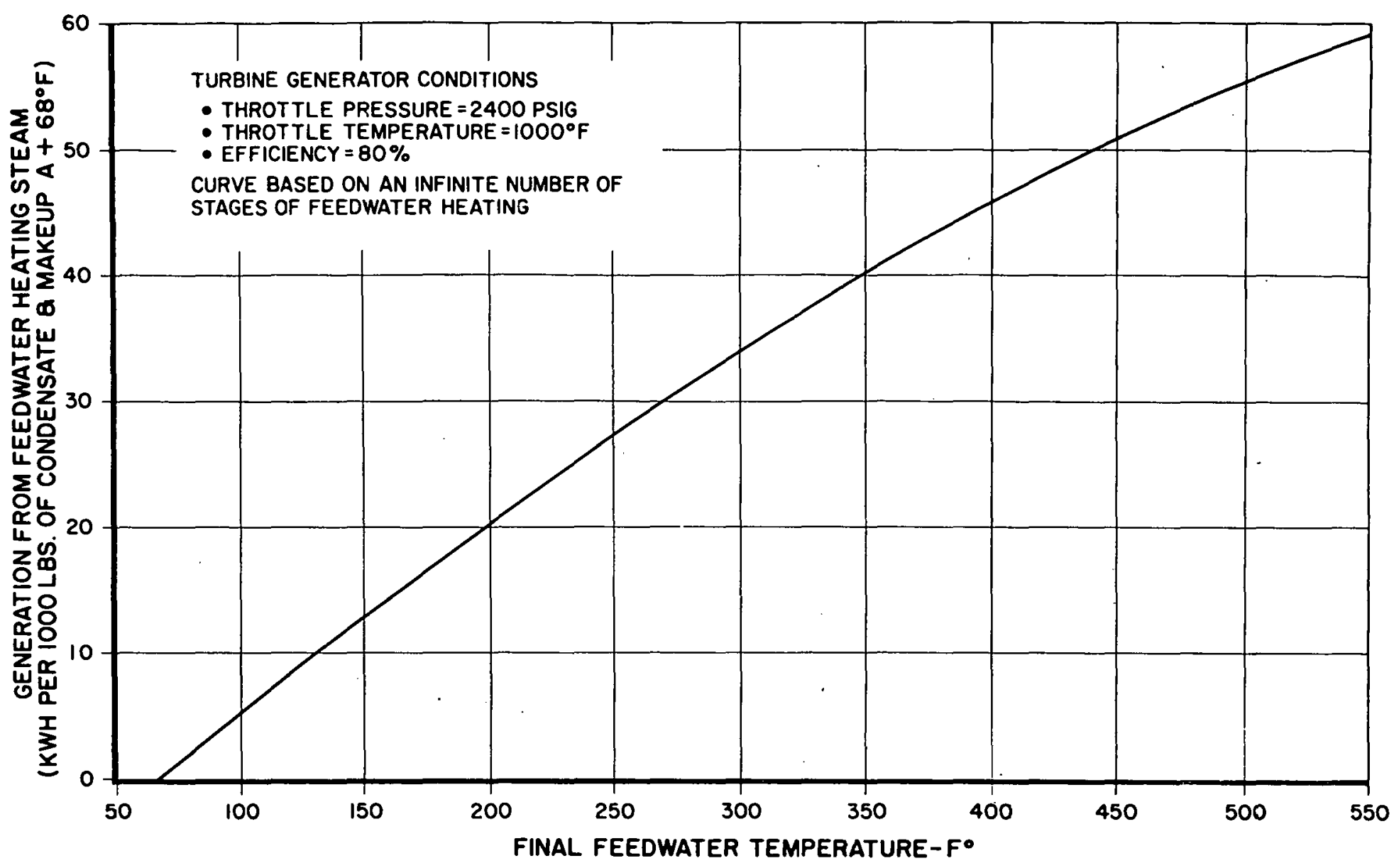

FIGURE 4-2. GENERATION FROM FEEDWATER HEATING SYSTEM 


\subsection{ORANGE SITE}

\subsubsection{FOSSIL FUEL PLANTS}

\subsubsection{Oil-Fired Plant (Reference Plant)}

\subsection{Steam Generators}

Two 50-percent capacity, oil-fired boilers are included in this arrangement. Each boiler is rated at $1,800,000$ lbs of steam per hour at 2,415 psia and 1,000 degrees FTT. This capacity pemits continuous production for the projected 1985 combined demand of Firestone, Gulf Chemical, B.F. Goodrich, and DuPont. Backup steam for each plant is provided by steam-generating facilities presently contained in each plant.

Design features of the steam generators include:

- Ore vertical-shart air prelieater per boiler.

- One 100-percent capacity forced, and one 100-percent capacity induced, draft fan per boiler.

- Retractable soot blowers.

- Electronic combustion controls.

- Solid state automatic controls.

\subsection{Boiler Feedwater System}

The arrangement of the feedwater system is illustrated on Drawing No. 12977-EP-2E located in Appendix B. The steam cycle has been designed to provide process steam at the projected 1985 demana level of the four process plants to be served.

The basic equipment contained in this system is:

Two deaerators, each operating at 45 psia and $248,100 \mathrm{lb} / \mathrm{hr}$. Deaerating steam is supplied from 45 psia turbine extraction.

- Three (2 operating and 1 spare) 50-percent capacity, motor-driven, feedwater pumps arranged in parallel. Motor drivers were selected to reduce first cost.

- Two strings of two closed feedwater heaters arranged in parallel. Each of the second-stage units is rated at $161.484 \mathrm{Ib} / \mathrm{Mr}$ and operates on extraction steam from the $640 \mathrm{psia}$ header. The 
first-stage heaters are each rated at $213,605 \mathrm{lb} / \mathrm{hr}$ and operate on extraction steam from the 290 psia header. Heater arains flow to the deaerator.

\subsection{Turbine Generators}

Study is based on a total of three noncondensing steam turbines of double-shell construction with backpressure governors.

A brief description of the turbine generators follows:

- One noncondensing stean turbine with backpressure governor for operation with inlet steam of 290 psia and 496.206 1b/inr throttle flow and 45 psia exhaust pressure. The turbine is connected to an air-cooled generator rated at $20.6 \mathrm{MVA}, 0.9 \mathrm{PF}, 22 \mathrm{kV}$ with static excitation system.

- One noncondensing steam turbine with backpressure governor for operation with inlet steam of 2.415 psia and 1,000 degrees FTT, 1,668,415 $\mathrm{lb} / \mathrm{hr}$ throttle flow and 290 usia exhaust pressure. The turbine is connected to a hydrogen-cooled gerierator rated at 107.6 MVA, 0.9 PF. $22 \mathrm{kV}$ with static excitation system.

- One noncondensing steam turbine with backpressure governor for operation with inlet steam of 2.415 psia and 1,000 degrees FIT. 1,772,967 $1 \mathrm{~b} / \mathrm{mr}$ throttle flow and 640 psia exhaust pressure. The turbine is connected to a hydrogen-cooled generator rated for 77.7 MVA, 0.9 PF, $22 \mathrm{kV}$.

\subsection{Fuel Handling System}

This system contains the equipment required to receive, store, and deliver No. 6 fuel oil to the boilers. The fuel oil was assumed to have the following composition:

\begin{tabular}{|c|c|}
\hline & Weight \\
\hline Sulfur & 2.3 \\
\hline Hydrogen & 9.7 \\
\hline Carbon & 85.6 \\
\hline Nitrogen and Oxygen & 2.0 \\
\hline $\begin{array}{l}\text { Ash } \\
\text { Water and sediment, Vol. } \% \\
\text { Heating value (Btu/lb) }\end{array}$ & $\begin{array}{r}0.12 \\
0.74 \\
18.300\end{array}$ \\
\hline
\end{tabular}

The fuel oil systern supplies oil to the station from the railroad tank car unloading facility. Three unloading pumps, located in the fuel oil pumphouse, transport fuel oil 
from tank cars to the storage tanks. Two storage tanks with a combined storage capacity of 43,500,000 gallons, store fuel oil equivalent to a 60 -day burning rate.

Mree 100-percent capacity pumps, one per boiler plus one common spare, are also located in the fuel oil pumphouse. These pumps transport fuel oil from the storage tanks to the boilers.

A 15-foot earth dike has been includeo around each tank for fire protection.

\subsection{Ash Handling}

Boilers are designeà primarily for oil firing and no provisions have been included for future coal firing except that adequate headroon has been provided beneath the boiler to permit future installation of a bottom ash hopper.

For oil firing, the bottom of the boiler is sealed off with a steel plate which can be unbolted at scheduled outages for manual removal of ash accumulations. Oil soot accumulations under precipitator hoppers and other points are removed on a continuous basis through eductors and reinjected into the boiler. This system operates under positive pressure.

The arrangeinent is illustrated on Drawing No. 12977-EP-2D located in Appendix $B$.

\subsection{Precipitators and Scrubbers}

Precipitators: Two precipitators, one per boiler, are included in the cost estimate. Included in the precipitator costs are supporting structures, transformers, controls, and model study.

Precipitators were selected to comply with both state and federal regulations, which limit particulate matter emissions to $0.11 \mathrm{~b} / 10^{\circ} \mathrm{Btu}$ heat input.

Scrubbers: Two scrubbers, one per boiler, are included in the cost estimate. Each scrubbing system consists of supporting steel; demister/absorber; limestone storage and handling equipment; limestone slurry tanks: thickener; miscellaneous pumps, tanks, piping, and duct work; controls: and a sludge handiling system.

Scrubbers were selected to comply with proposed regulations which will soon require 90 percent removal of $\mathrm{SO} 2$ from the flue gas. Complete duplication of all scrubber equipment was eliminated by utilizing some equipment for both scrubbers. 


\subsection{Water Treatuent System}

The makeup water supply passes through two clarifiers arranged in parallel, each operating at one-quarter of total plant requirements (50 percent retums are anticipated not requiring clarification). Underflow from the clarifier is pumped to a thickener.

Clarifier effluent flows by gravity to sand gravity filters. Filter backwash is recycled to the clarifier. Filter effluent is pumped through full-flow pressure carbon filters to a demineralizing system.

Dissolved solids are removed by demineralizer trains consisting of cation exchangers, vacuum degasifiers, anion exchangers, and mixed-bed exchangers. Demineralizer trains are followed by a battery of mixed-bed polishing units. Blowdown from the demineralizing system is discharged to the holding basin.

The condensate returns are put into the system ahead of the carbon filter after passing through oil removal equipment. The choice of oil removal facilities depends upor the form of oil; i.e., dissolved, suspended, or emulsified. The study design includes deep-bed precoat oil removal filters containing anthracite. The filter bed is precoated with an alum-soda ash uix and has a small continuous body feed.

A fundamental flow diagram of the system is shown on Drawing No. 12977-EP-2B located in Appendix B.

4.3.1.1.8 Waste Treatment System

In the October 8, 1974, Federal Register, EPA reported final effluent guidelines for the stean/electric power generating industry. The wastewater treatment described below complies with these new source performance standards.

liquid wastes from the station include water treatment wastes (suspended solids, acid, caustic, oil). steam plant wastes (floor ärainage, equipment washing wastes, boiler chemical cleaning wastes, boiler blowdown). storm drainage (yard and roof drainage), and sanitary systems.

The water treatment plant clarifier underflow is pumped to a thickener. Thickener solids are dewatered and sent to a disposal site. The overflow is recycled to the clarifier. Water from the vacuun filter is returned to the thickener.

An impervious holding or equalization basin is utilized to collect all other waste flows. These flows include floor drainage and internittent high-flow wastes, which are high in suspended solids and dissolved metals. Equipment washing 
wastes, boiler chemical cleaning wastes, and yard and roof drainage are typical examples. The basin is sized to accontiodate wastes from eguipment, washing and boiler chemical cleaning when heavy rainfall could result in a large amount of yard drainage.

The basin effluent flows to a treatment system consisting of a settling chanber with chelaical feed and neutralization to control $\mathrm{pH}$ within allowable linits for discharge into the river. The effluent is recirculated back to the water treatnient system clarifier when total solids content and other conditions permit.

Sludge from the setting chanber is pumped to the dewatering equipment, and the oil is collected and sent to disposal. A bypass system is provided for abnormal conditions.

Sanitary wastes are treated in a package plant providing secondary biological treatment and chlorination of the treated effluent prior to discharge.

A fundamental flow diagram of the system is shown on Drawing No. 12977-EP-2B Iocated in Appendix B.

4.3.1.1.9 Electrical system

The proposed oil-fired cogeneration facility generates approximately $185.3 \mathrm{MW}$ (yross) of electrical power: allowing for generator losses and plant auxiliaries, the net electrical output of the plant is 155.2 MWe.

Existing substations located at each user's plant will be retained and modified as necessary to allow integration of the cogenerated electrical power with the present supply from GSU. The distribution system between the cogeneration plant and the users is capable of delivering 100 percent of the electrical requirements to any user. The distribution of power among the users should be apportioned by a specific formula developed by them.

Distribution voltage is $138 \mathrm{kV}$ or $69 \mathrm{kV}$ according to present user service. Power is transmitted from the plant via overhead lines supported on wood pole-line structures.

As shown on Drawing No - 12977-EM-1F, located in Appendix B. electrical distribution follows the piping right-of-way to each user. The switchyards of Gulf and Goodrich serve as tie points for the distribution circuit.

Reliability is achieved by maintaining power availability from GSU in the event of a failure of the cogeneration plant generator or distribution circuit. 
Power is generated at $22 \mathrm{kv}, 3$ phase, $60 \mathrm{~Hz}$ and connected to two step-up power transformers with isolated-phase bus. One transformer, rated $90 \mathrm{MVA}$, delivers $69 \mathrm{kV}$ to the plant switchyard for distribution to Goodrich, Gulf, and Firestone. The second transformer, rated 75 MVA, delivers $138 \mathrm{kV}$ to the plant switchyard for distribution to Dupont.

A tap from the isolated-phase bus connects to the plant auxiliary transformer rated $40 \mathrm{MVA}, 22 \mathrm{kV}-4160 \mathrm{~V}$ and supplies all plant electrical equipment. Power for startup of the plant and reserve supply for auxiliaries is provided by means of a $138-\mathrm{kV}$ tie from GSU to the plant switchyard and then to a. 40-MVA, $22-3 V-4160-V$ reserve transformer. This connection assures reliability of steam production in the event of a generator or transformer failure.

Plant electrical auxiliary equipment consists of:

- 4-kV metal-clad switchgear rated 350 MVA.

- 1500-kVA load center unit substations for 480-V loads.

- 480-V motor control centers with circuit breaker combination starters.

A wiring system composed of copper conductor, flame-retardant cable installed in a raceway system of aluminum ladder tray or rigid steel conduit.

A lighting system utilizing flworescent fixtures, incandescent lamps, or high bay lighting as required.

- A common grounding system throughout the plant.

- A cormunications/paging system.

- An emergency dc supply system derived from 125-V station batteries for small. critical loads and switchgear breaker operations.

\subsection{Structural Criteria}

Foundations: Available soil information for the proposed plant indicates that drilled caisson or pile foundations may be required for major structures and equipment. The cost estimate includes pile foundations for all plant structures. piperacks, water treatment facilities, and other small buildings. Fuel oil tanks are supported on select compacted backfill. No ringwall foundation is included. 
Yardwork: The cost estimate includes clearing and grubbing the site, local excavation and spoiling of undesirable material, railroad trackwork, permanent plant roads, and fencing. Also included are the costs for relocation of the existing canal, construction of two bridge structures over the canal for roadway and railroad, earth dikes for the fuel oil tanks, a waste holding basin, and various other hydraulic structures.

Buildings and uther structures: Cost estimates of auxiliary buildings are based on a semi-outdoor design. They include two exposed boilers with enclosures over fronts and tops. Small enclosures are provided for each of the force draft fans. Cormon to the boilers is a 275-foot concrete stack erected on a concrete mat supported by piles. The stack is provided with steel liner, ladder, platforms, and aircraft lights.

The water treatruent plant also will be outdoors, except for a single-story laboratory and control building of steti frame with insulated metal siding constructed on a concrete slab on grade. A similar building will provide office and warehouse space.

The turbine building is a steel-frame structure enclosed with uninsulated metal siding, metal roof deck with insulated built-up asphalt, and gravel roofing. It has a concrete operating floor and ground floor. Galvanized steel grating supported by steel framing is used in general for other floors, walkways, stair treads, and intermediate landings. The turbine generators are supported on concrete pedestals extending from operating floor level to below grade. The turbine building contains a control roam. various switch and cable roorns, and a 50-ton capacity overhead crane to service the turbine generators.

\subsubsection{Coal-Fired Plant}

\subsection{Steam Generators}

Two 50-percent capacity, pulverized coal-fired boilers are included in this arrangement. Each boiler provides $1.800,000$ pounds of steam per hour at 2.415 psia and 1,000 degrees F'I'. 'lihis capacity permits continuous production for the projected 1985 combined demand of Firestone, Gulf Chemical, B.F. Goodrich, and DuPont. Backup steam is provided by the existing steam-generating facilities contained in each plant. 
Design features of the steam generators include:

- One vertical-shaft air preheater per boiler.

Two 50-percent capacity forced, and two 50-percent induced, draft fans per boller.

- Retractable suot bluwers.

- Electronic corubustion controls.

- Solid state automatic burner safety controls.

- Three bal1-type pulverizers with primary air fan.

4.3.1.2.2 Boiler Feecouater system

The arrangement of the feedwater system is illustrated on Drawing No. 12977-EP-2E located in Appendix B. The steam cycle was designed to provide process steam at the projected 1985 demand level of the four process plants being served.

The basic equipment contained in this system is:

- Two deaerators, each operating at 45 psia and $248,100 \mathrm{lb} / \mathrm{hr}$. Deaerating steam is supplied from 45 psia turbine extraction.

- Three ( 2 operating and 1 spare) 50-percent capacity feedwater pumps, arranged in parallel. Motor drivers were selected to reduce first cost.

- Two strings of two closed feedwater heaters arranged in paralle1. Each of the second-stage units is rated at $161,484 \mathrm{lb} / \mathrm{Mr}$ and operates on extraction steam from the 640 psia header. The first-stage heater is rated at $213,6051 \mathrm{~b} / \mathrm{Mr}$. Heater drains flow to the deaerator.

\subsection{Turbine Generators}

The study is based on a total of three noncondensing steam turbines of double-shell construction with backpressure yovernors.

A brief description of the turbine generators follows:

- One noncondensing steam turbine with backpressure governor for operation with inlet steam of 2,415 psia $496.206 \mathrm{lb} / \mathrm{hr}$ throttle flow and $45 \mathrm{psia}$ exhaust pressure. The turbine is connected to an air-cooled generator rated at $20.6 \mathrm{MVA}, 0.9 \mathrm{PF}, 22 \mathrm{kV}$ with static excitation system. 
- One nonoondensing steam turbine with backpressure yovernor for uperation with inlet steam of 2.415 psia and 1,000 degrees FTr, 1,668,415 $\mathrm{lb} / \mathrm{hr}$ throttle flow and 290 psia exhaust pressure. The turbine is connected to a. hyorogen-cooled generator rated for $107.6 \mathrm{MVA}, 0.9 \mathrm{PF}$, $22 \mathrm{kV}$ with static excitation system.

- One noncondensing steam turbine with backpressure governor for operation with inlet steam of 2.415 psia and 1,000 degrees FTT, 1,772,967 lb/ $\mathrm{hr}$ throttle flow and 640 usia exhaust kaessure. The turbine is connected to a hyärogen-cooled generator rated for 77.7 MVA, 0.9 PF, $22 \mathrm{kV}$ with static excitation system.

\subsection{Fuel Handling system}

This system contains the equipment required to receive, store, and deliver coal to the boiler house silos. The characteristics of the cuals considered in this study are shown in Table 4-5.

Based on the low heating value, coal consumption of the two units is estimated at 3,734 tons per day for hlabama coal and 5.671 tons per day for Wyoming cual. On a continuous basis, this amounts to 78 tons per hour per boiler for Alabama coal and 118 tons per hour per boiler for wyoming coal. Cual will be delivered to the plant by unit train. positioned over the track hoppers, and dumped by a rotary car dumper. A general configuration of the coal handling system is shown on Drawing No. 12977-SK-1A located in Appendix B.

\subsection{Ash Handing}

There are basically two ash handling systems: one for the bottom ash and one for fly ash removal.

The bottom ash system is hydraulic, using a jet pump to convey ash to dewatering storage bins for removal by truck to an offsite disposal area. To conserve water, a closed recirculating water system containing storage and settling tanks is employed. This system permits the particles which escape from the dewatering bin to drop out of suspension and be recovered as sluage. The water is finally drained into a storage tank for reuse in filling ash hoppers and for conveying ash.

Fly ash is removed from the gas system hoppers pneumatically and conveyed to a silo where it is stored ary: When removed from the silo for final disposal, the fly ash is mixed with water and discharged to a truck for removal to an offsite disposal area. 
TABIE $4-5$

COAL CHARACTERISTICS

Alabama Coal (Jefferson County. Pratt Seam)

Proximate Analysis

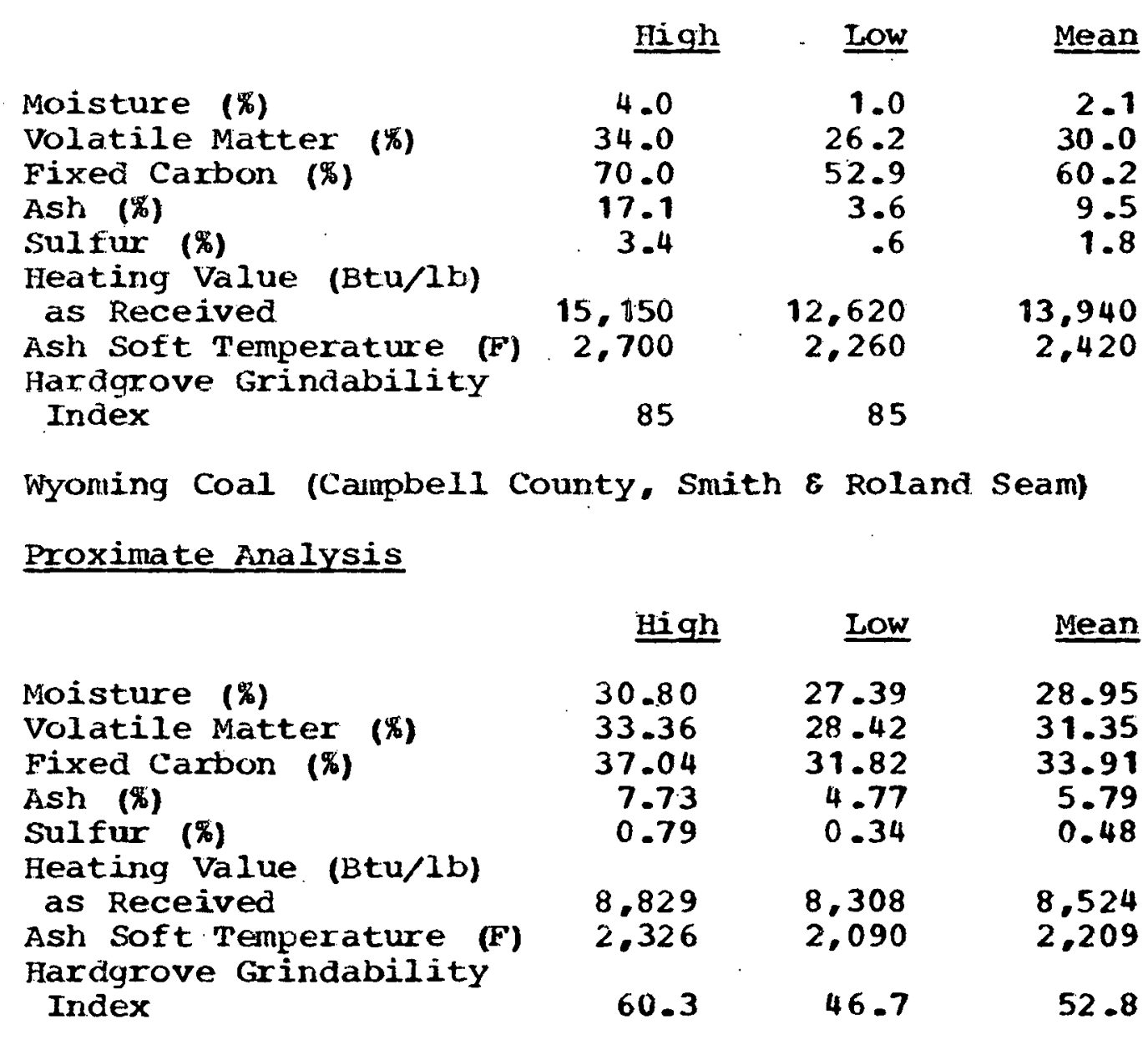


Arrangeluent of the system is illustrated in Drawing No. 12977-EP-2C located in Appendix B.

\subsection{Precipitators and Scrubbers}

Precipitators: Two precipitators, one per boiler, are included in the cost estinate. Included in the precipitator costs are supporting structures, transformers, controls, and irodel study.

Precipitators were selected to comply with both state and rederal regulations, which limit particulate matter emissions to $0.11 \mathrm{~b} / 10^{6} \mathrm{Btu}$ heat input.

Scrubbers: Two scrubbers, one per boiler, are included in the cost estimate. Each scrubbing system consists of supporting steel; demister/absorber; limestone storage and handling equipment: limestone slurry tanks: thickener: miscellaneous pumps, tanks, piping and duct work; controls: and a sludge hardining system.

Scrubbers were selected to comply with proposed regulations which will soon require 90 percent removal of 502 from the flue gas. Complete duplication of all scrubber equipment was eliminated by utilizing some equipment for both scrubbers.

4.3.1.2.7 Water Trea Jment System

The makeup water supply passes through two clarifiers arranged in parallel, each operating at one-quarter of total plant requirements $(50$ percent of the returns not requiring clarification are anticipated). Underflow from the clarifier is pumped to a thickener.

The clarifier effluent flows by gravity to sand gravity filters. Filter backwash is recycled to the clarifier. The filter eftluent is pumped through full-flow, pressure-type carbon filters to a demineralizing system.

The dissolved solids are removed by demineralizer trains consisting of cation exchangers, vacuum degasifiers, anion exchangers, and mixed-bed exchangers. The demineralizer trains are followed by a battery of mixed-bed polishing units. Blowdown from the demineralizing system is discharged to the holding basin.

Condensate returns are put into the system ahead of the carbon filter after passing through oil removal equipment. The choice of oil removal facilities is dependent upon the form of oil; i.e., dissolved, suspended, or enulsified. The study design includes deep-bed precoat oil removal filters 
containing anthracite. The filter bed is precoated with an alum-soda ash inix anç has a small continuous body feed.

A fundamental flow diagrain of the system is shown on Drawing No. 12977 EF-2A located in Appendix B.

\subsection{Waste Treatuent System}

In the Cctober 8, 1974, Federal Reqister, EPA reported final effluent guidelines for the steam/electric power generating industry. The wastewater treatment described below complies with these new source performance standards.

Liquid wastes from the station include water treatment wastes (suspended solids, acid, caustic, oil) steam plant wastes (floor drainage, equipment washing wastes, boiler chemical cleaning wastes, boiler blowdown). storm drainage (yard and roof drainage, coal pile runoff), and sanitary systems.

For coal-fired operation, the bottom ash sluicing is a closed recirculating systen incorporating dewatering bins and a clarifier with makeup from the wastewater system.

The water treatinent plant clarifier underflow is pumped to a thickener. Thickener solids are dewatered and sent to a disposal site. The overflow is recycled to the clarifier. water from the vacuun filter is returned to the thickener.

An impervious holding, or equalization, basin is utilized to collect all other waste flows. These wastes include floor drainage and intermittent high-flow wastes, which are high in suspended solids and dissolved metals. Coal pile runoff, equipment washing wastes, boiler chemical cleaning wastes. and yard and roof drainaye are typical examples. The basin is sized to accommodate wastes from equipment washing and boiler chemical cleaning when heavy rainfall could result in large coal pile ruroff and yarä drainage.

The basin effluent flows to a treatment system consisting of a settling chamber with chemical feed and neutralization to control pH within the allowable limits for discharge into the river. The effluent is used as makeup to the ash handling system, where applicable, and also may be recirculated back to the water treatment system clarifier.

Sludge from the settling chamber is pumped to the dewatering equipment, oil is collected and sent to disposal: a bypass system is provided for abnormal conditions.

Sanitary wastes are treated in a packaye plant providing secondary biological treatment and chlorination of the treated effluent prior to discharge.

$$
4-21
$$


The sulfur dioxide scrubber wastewater system is a closed system incorporating complete recirculation and requiring disposal of solids only - The three major system components are the scrubber, reaction tank, and thickener.

A limestone/water slurry passes through the scrubber where it reacts with the $\mathrm{SO}_{2}$ laden flue gas. The reacted solution is discharged into the reaction tank where chemical reactions go to conpletion yielding discardable precipitates. These precipitates are settled in a thickener and removed for disposal. The clarified thickener water is returned to the scrubber along with the reusable scrubbing slurry from the reaction tank.

A fundamental flow diagram of the system is shown on Drawing No. 12977-EP-2A Located in Appendix B.

4.3.1.2.9 Electrical System

The proposed coal-fired cogeneration facility generates approximately $185.3 \mathrm{MW}$ (gross) of electrical power. Allowing generator losses and plant auxiliaries, the net electrical output of the plant is 148.6 MWe.

bxisting substations located at each user's plant will be retained and modified, as necessary, to allow integration of the cogenerated electrical power with the present supply from GSU. The distribution system between the cogeneration plant and the users is capable of delivering 100 percent of the electrical requirentents to any user. The distribution of power among the users should be apportioned by a specific tormula developed by them.

Distribution voltage is $138 \mathrm{kV}$ or $69 \mathrm{kV}$ according to present user service. Power is transmitted from the plant via overhead lines supported on wood pole-line structures.

As shown on Drawing 1No. 12977-EM-1D, located in Appendix B, electrical distribution follows the piping right-of-way to each user. The switchyards of Gulf and Goodrich serve as tie points for the distribution circuit.

Reliability is achieved by maintaining power availability from GSU in the event of a failure of the cogeneration plant generator or distribution circuit.

Power is generated at $22 \mathrm{kV}, 3$ phase, $60 \mathrm{~Hz}$ and connected to two step-up power transformers with isolated-phase bus. One transformer, rated $90 \mathrm{MVA}$, delivers $69 \mathrm{kV}$ to the plant switchyard for distribution to Goodrich, Gulf, and Firestone. The second transformer, rated 75 MVA, delivers $138 \mathrm{kV}$ to the plant switchyard for distribution to Dupont. 
A tap from the isolated-phase bus connects to the plant auxiliary transformer rated 40 MVA, $22 \mathrm{kV}-4160 \mathrm{~V}$ and supplies all plant electrical equipment.

Power for startup of the plant and reserve supply for auxiliaries is provided by means of a 138-kV tie from GSU to the plant switchyard and then to a 40-MVA, 22-kV - 4160-V reserve transforner. This connection will also assure reliability of steam production in the event of a generator or transformer failure.

Plant electrical auxiliary equipment consists of:

- 4-kV metal-clad switchgear rated $350 \mathrm{MVA}$.

- 1500-kVA load center unit substations for 480-V loads.

- 480-V motor control centers with circuit breaker combination starters.

- A wiring systern composed of copper conductor. flame-retardant cable installed in a raceway system of aluminum ladder tray or rigid steel conduit.

- A lighting system utilizing fluorescent fixtures, incandescent lamps, or high bay lighting. as required.

- A common grounding system throughout the plant.

- A comunications/paging system.

- An emergency dc supply system derived from 125-V station batteries for sinall critical loads and switchgear breaker operations.

\subsection{Structural Criteria}

Foundations: Available soil information for the proposed plant indicates that arilled caisson or pile foundations may be required for major structures and equipment. The cost estimate includes pile foundations for all plant structures, piperacks, water treatment facilities, and other smali buildings. Fuel oil tanks are supported on select compacted backfill. No ringwall foundation is included.

Yardwork: The cost estimate includes clearing and grubbing the site. local excavation and spoiling of undesirable material, railroad trackwork, permanent plant roads, and fencing. Also included are the costs for relocation of the existing canal, construction of two bridge structures over the canal for roadway and railroad, earth dikes for the fuel

$$
\text { 4-23 }
$$


oil tanks, a waste holding basin, and various other hydraulic structures.

Buildings and other structures: Cost estimates of auxiliary buildings are based on a semi-outdoor design. They include two exposed boilers with enclosures over fronts and tops. Small enclosures are provided for each of the force draft fans. Conmon to the boilers is a 275-foot concrete stack erected on a concrete mat supported by piles. The stack is provided with steel liner, ladder, platforms, and aircraft lights.

The water treatment plant also will be outdoors, except for a single-story laboratory and control building of steel frame with insulated metal siding constructed on a concrete slab on grade. As sinilar building will provide office and warehouse space.

The turbine building is a steel-frame structure enclosed with uninsulated metal siding. metal ioul deck with insulated built-up asphalt and gravel roofing. It has a concrete operating floor and ground floor. Galvanized steel grating supported by steel framing is used in general for other floors, walkways, stair treads, and intermediate landings. The turbine generators are supported on concrete pedestals extending from operating floor level to below grade. The turbine building contains a control room, various switch and cable rooms, and a 50-ton capacity overhead crane to service the turbine generators.

\subsubsection{NUCLEAR PLANTS - ADVANCED TECHNOLOGY UNDER DEVELOP- MENT}

\subsubsection{Consolidated Nuclear Steam Supoly System (CNSS Plant)}

The CNSS is a 1200-Mwt nuclear steam supply system developed by the Babcock and Wilcox Company (BEW). BEW has prepared a conceputal design to utilize the CNSS for dual purpose steam/electric power generation.(19) This conceptual design study. done under contract for Union Carbide lOak Ridge National Laboratory) and the U. S. Finergy Research and Development Aduinistration, was derived from nuclear nerchant ship propulsion steam systems. It is distinctly different in detail and incorporates steam generators within the reactor pressure vessel. This section reviews the highlights of the CNSS design. In addition, modifications or additions to the CNSS design which are required for this site are identified and described in sufficient detail to allow the cost estimates developed by $B E W$ to be appropriately adjusted. 
The CNSS is a pressurized water reactor system with both the reactor core and the steam generators located inside the reactor pressure vessel. The reactor consists of 97 fuel assemblies each consisting of 208 fuel rods, 16 control rod guide tubes, and one instrumentation tube arranged in a $15 \times 15$ array. The fuel is uranium, enriched to about $3.43 \mathrm{wt}$. $\mathrm{u}^{235}$. The total core loading is 37 metric tons of uranium. The core is water cooled and water moderated.

The cNSS utilizes a straight-tube, tube-and-shell, once-through steam generator (OTSG) which, in the referenced study. was an integral part of the reactor pressure vesse1. primary fluid (reactor coolant) flows inside the tubes and generates steam on the shell side. At full power the CNSS produces $5,290,000 \mathrm{lb} / \mathrm{hr}$ of saturated steam at 935 psia and $536.5 \mathrm{~F}$. More recent designs utilize ten modular replacement units withir the reactor vessel. It is also possible to isolate these units individually.

Eight reactor coolant pumps circulate renctor coolant through the core and the once-through steam generator. The pumps are vertically nounted on penetrations in the reactor pressure vessel head.

Core reactivity is controlled by a combination of fixed burnable poison, soluble poison (boric acid) in the primary coolant and movable control rods. A chemical addition and boron recovery systen is utilized to control the concentration of soluble poison in the primary coolant. Thirty-seven control rod arive mechanisms are used to position control roc assemblies within the reactor core. The control rod drive mechanisms are mounted on penetrations in the reactor pressure vessel head.

A pressurizer is utilized to control reactor coolant system pressure at about 2,250 psia. The pressurizer is a vertical cylinarical vessel connected to the reactor pressure vessel by four parallel surge lines and one spray line. Electric heating elements in the lower section of the pressurizer along with a water spray nozzle in the upper section maintain the water/steam system at a saturation pressure corresponding to the desired reactor coolant pressure.

4.3.2.1.2 Thermal Cycle

The conceptual design of the CNSS cogeneration plant was based on two major assumptions:

1. A reboiler is necessary to reduce the probability of radioactive steam being released to the industrial customers.

2. Process stean must be superheated. 
A precedent for the use of a reboiler for supplying process steam using a pressured water reactor (PWR) NSSS has been set at the Midland plant.(20) rhis plant is a joint venture of the Consumers Power Company and Dow Chemical Company and will utilize two $B G W$ pressured water reactors as heat sources. The reboiler will be capable of supplying $4 \times 10^{6} 1 \mathrm{~b} / \mathrm{Mr}$ of steam for Dow Chemical process use.

The use of a reboiler serves as a second barrier to the radioactive primary coolant, the first being the OTSG. Without the reboiler, relatively minor oTsG leaks would result in shutaown for repair unless there was provision for control of radioactive stearn and condensate throughout the customers plants. It is assumed that this method would not be acceptable to industrial customers nor economically justifiable.

Cogenerating without the reboiler would require either:

1. A sophisticated process radiation muniluring sehenc to terminate steam to customers in the event of a tube leak in the OTSG.

2. An elaborate monitoring and control system for potentially radioactive steam/condensate throughout the customers" plants.

Ilternate 1. would result in low plant reliability because relatively ninor OTSG tube leaks would result in plant shutaown. Alternate 2. would be costly, require continuous maintenance, and be impractical for industrial users.

At each of the plants under consideration there is a demand for superheated stean. Much of this demand could be shifted to lower pressures by replacing mechanical driven turbines with electric motors. For the purpose of this study. however, it was assumed that all alternative plants should be designed to satisfy the existing process steam requirements. To meet these requirements an oil-fired superheater was included in the thermal cycle.

Heat balance for the CNSS cogeneration plant at the orange, Texas, site is shown on Drawing No. 12977 EP-2G located in Appendix B. Process steam at 640 psia and $700 \mathrm{~F}$ is supplied directly to the turbine generator and users from the reboiler and superheater. A single automatic extraction steam turbine supplies process steam at 290 psia and deaerating steam at 45 psia. Electric generation is approximately $43 \mathrm{MW}$ (gross), anounting to 4.7 percent of the heat input to the cycle. Generation could be increased to 5.5 percent through the use of a closed feedwater heater 
operating at 290 psia. Econonic analysis, however. indicates this method cannot be justified.

4.3.2.1.3 Plant Arrangement

The B\&W study includes a plot plan and building arrangement drawings for a 400-WWe central generating plant located at a standard hypothetical site. The plot plan would have to be modified to conform to the specifics of this particular site and to reflect the plant's use for cogeneration rather than central station electric generation.

Modifications to the plant arrangement would include: elimination of the circulating water intake structure and piping: addition of oil-fired superheater with precipltator. scrubber, and stack; a fuel oil storage tank; a pumphouse; and a cooling tower. Reboilers, deaerator, and boiler feed pumps would be located in the turbine building.

The major changes from the B\&W study are the addition of the following:

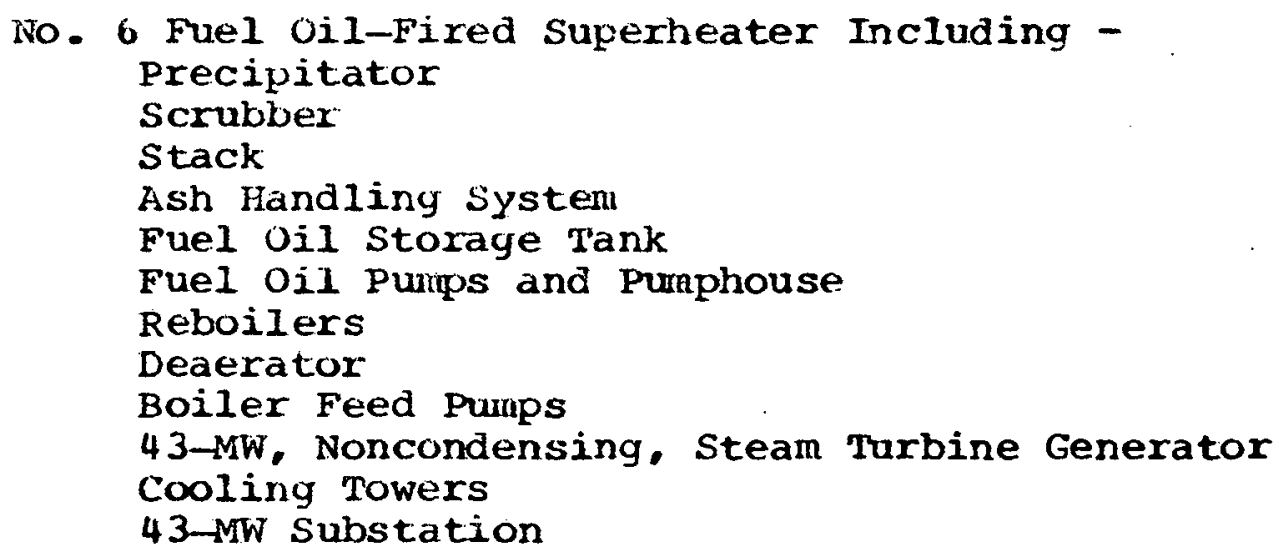

Deletion of the following:

400-Mw, Condensing, Steam Turbine Generator

Condenser

Circulating Water system

Circulating Water Intake Structure

400-MW Substation

\subsection{Reactor Containment}

The CNSS reactor containment is a free-standing, bottomsupported steel vessel 45 feet in diameter and 95 feet high. The containment is further enclosed in a 4-foot thick concrete biological shield having an outside diameter of 57 feet. The containment is housed in the reactor service building. 
The reactor cortainnent in the reference design is a pressure-suppression type which utilizes a pool of water to condense steam resulting from a postulated loss of coolant accident (LOCA). The design basis LOCA for the CNSS is a double-ended rupture of one of the 3.5 -inch inside dianeter pressurizer surge lines. The resulting coolant loss rate is relatively slow compared to the design basis LOCA in loop-type pressurized water reactors and makes the use of pressure-suppression contaiment feasible. Condensing the steam fron! the postulated LOCA allows the containment to be relatively small while maintaining a reasonable design pressure of approximately $105 \mathrm{psig}$. More recent studies by BEW found that the LOCh can be handled with a dry containment.

The concrete biological shield provides radiation shielding and, in conjuriction wath the reactor service building ventilation systern, an additional barrier to uncontrolled release of leakage from the containment.

\subsection{Fuel Handling system}

The fuel handling system for the CNSS is similar to that for other pressurized water reactors. Spent fuel is handled under borated water as it is transferred from the reactor pressure vessel to the spent fuel pool where it is allowed to cool for approximately orie year. The spent fuel can thus be loaded, still wader water, into casts for shipment to offsite storage or to a reprocessing facility.

The BEW study includes a detailed description of the various components of the fuel handling equipment and associated procedures. A critical path analysis of the refueling procedure is provided and indicates that the procedure can be completed in 392 hours (16.3 days). For the economic analysis $B E W$ assureo a 50-day refueling outage.

Two refueling schemes were investigated by $B \& W$; a 12-month and 15-month fuel cycle. The economic analysis presented by $B E W$ shows a small difference in the fuel cost of the two schemes level cost of 58.5 cents/106 Btu for the 12-month cycle and 61.2 cents/10 ${ }^{\circ}$ Btu for the 15-month cyclel. While the actual cycle chosen depends on many factors, basically the 15-month cycle represents higher plant availability but results in refueling during all guarters of the year while the 12 -month cycle permits refueling during a given quarter of the year, year after year. S\&W based its evaluation on the 12-month cycle because we believe it would be more attractive to industrial users. The cost difference between the two refueling schemes is so small that going to a 15-month cycle would negligibly affect the results of the study. 


\subsection{Turbine Gerierator and steam Cycle}

Drawing No. $12977 \mathrm{EP}-2 \mathrm{G}$, located in Appendix B, illustrates the heat cycle and fundamental flow diagram for the CNSS. Basically, the steam from the CNSS is utilized as the heat source for reboilers which generate process steam to meet the projected 1985 conbined demand of Firestone, Gulf Chemical, B.F. Goodrich, and Dupont. Backup steam is provided by stearngenerating facilities presently contained in each plant. Steam from the reboiler is sent via an oil-firea superheater to the industrial users and expanded through a steam turbine. The exhaust from the turbine is utilized in a deaerator to preheat condensate which is either returied from the industrial users or supplied as makeup. Steam is extracted at 290 psia for industrial user consumption.

The noncondensing stean turbine with backpressure control operates with inlet stean of $640 \mathrm{psia}$ and 700 degrees FTT, $1,245,872 \mathrm{lb} / \mathrm{hr}$ throttle flow and 45 psia exhaust pressure. rrocess stearn is extracted at 290 psia at a rate of $745.000 \mathrm{lb} / \mathrm{hr}$. The turbine is connected to a hydrogen-cooled generator rated at $47.6 \mathrm{MVA}, 0.9 \mathrm{PF}, 22 \mathrm{kV}$ with static excitation.

$A$ deaerator is included in the heat cycle. It operates at $45 \mathrm{psia}$ and $500,872 \mathrm{lb} / \mathrm{hr}$. Deaerating steam is supplied from the 45 psia turbine extraction.

Two $(1$ operating and 1 spare) 100-percent capacity, motor-driven, boiler feed pumps arranged in parallel are also included in the heat cycle.

One No. 6 fuel oil-fired superheater is included to raise the temperature of $2,695,872 \mathrm{lb} / \mathrm{Mr}$ of steam from $494.9 \mathrm{~F}$ to $700 \mathrm{~F}$ to meet users ' requirements.

\subsection{Radwaste Systern}

The CNSS radwaste system is actually composed of five separate systems:

- Reactor Coolant (RC) Waste system

- Liquid Waste Systeni

- Waste Evaporator System

- Solia Waste Disposal System

- Gaseous Waste System

The RC waste system contains and collects liquid and gaseous waste from normal plant letdown, pressurizer relief valve discharge, leakage, and maintenance drainage. These wastes are routed to the liquid or gaseous waste systems or recycled to the prinary system as appropriate. 
The liquid radwaste systen receives and shares liquid waste from the $R C$ and auxiliary systems. Depending on the activity and chemical content, the wastes are routed to the waste evaporator system or the liquid waste demineralizer. Waste of low enough activity is discharged to the environment through radioactivity monitors. Gases evolved from stored liquias are routed through vent headers to the gaseous waste systen.

The waste evaporator system separates liquid waste into distillate and concentrated solutions. The distillate, if pure enough, is stored for reuse or dicharged. If not, it is reprocessed through the waste evaporator. The concentrate is either transferred to concentrated boric acid storage or to the solid waste disposal system depending on the results of an analysis.

The solid waste disposal system provides for packaging. storage, and offsite shipment of solid and semi-solid radioactive waste. The solia waste system is used to process low-level wastes such as contaminated rags, papers, filter cartridges, etc., and high-level wastes such as spent demineralizer resins and concentrate from the waste evaporator.

The gajseous waste systems collect waste gases from reactor plant systems in their separate vent headers: low-activity. nitrogen-rich, and hydrogen-rich. The low-activity gaseous wastes are vented through filters and the plant stack to the atmosphere. The H2-rich gases are processed through a recombiner to reduce the quantity of $\mathrm{H} 2$. The gases are then compressed and stored in decoy tanks for subsequent discharge.

The BEW report includes additional description and flow diagrams for each radioactive waste system.

4.3.2.1.8 Ultimate Heat Sink

Since this site does not have ready access to an adequate supply of river water, two 100 -percent capacity (one for redundancy) cooling towers have been incorporated in BEW's design. Cooling towers will serve to remove decay heat from the reactor on shutdown.

4.3.2.1.9. Water Treatment System

Due to lack of information in the $B \& W$ report, it is not possible to elaborate on plant water treating system and equipment. 
The electrical system for the CNSS is basically composed of four major parts; i.e.. safety-related (Class IE), balance of plant, generation, and distribution systerns.

Due to lack of information in the $B \in W$ report on safety-related systemis and balance of plant systems, it is not possible to elaborate on these electrical systerns and equipment. The generation equipment was described in Section 4.3.2.1.6. The following discussion is devoted to the distribution system and the apportionment of output to users.

The proposed CNSS cogeneration facility produces approximately $42 \mathrm{NW}$ of electrical power. A total of $18 \mathrm{MWe}$ will be used for plant auxiliaries leaving 24 MWe net output available to the users.

Existing substations located at each user's plant will be retained and modified as necessary to allow integration of the cogenerated electrical power with the present supply from GSU. The distribution system between the cogeneration plant and the users is capable of delivering 100 percent of the electrical requirements to any user. The distribution of power among the users should be apportioned by a specific formula developed by them.

Distribution voltage is $138 \mathrm{kV}$ or $69 \mathrm{kV}$ according to present user service. Power is transmitted from the plant via overhead lines supported on wood pole-line structures.

As shown on Drawing No. 12977-EM-1E, located in Appendix $B$. electrical distribution follows the piping right-of-way to each user. The switchyards of Gulf and Goodrich serve as tie points for the distribution circuit.

Reliability is achieved by maintaining power availability from GSU in the event of a failure of the cogeneration plant generator or distribution circuit.

power is generated at $22 \mathrm{kV}, 3$ phase, $60 \mathrm{~Hz}$ and connected to two step-up power transformers with isolated-phase bus. One transformer, rated $15 \mathrm{MVA}$, delivers $69 \mathrm{kV}$ to the plant switchyard for distribution to Goodrich, Gulf, and Firestone. The second transformer, rated 11 MVA, delivers $138 \mathrm{kV}$ to the plant switchyard for distribution to Dupont.

A tap from the isolated-phase bus connects to the plant normal station service transformer is rated $21 \mathrm{MVA}$. $22 \mathrm{kV}-4160 \mathrm{~V}$ and supplies all plant electrical equipment.

Power for startup of the plant and reserve supply for auxiliaries is provided by means of a $138-\mathrm{kV}$ tie from GSU to the plant switchyard and then to a 21-MVA, 22-kV - 4160-V 
reserve station service transformex. This connection will also assure reliability of steam production in the event of a generator or transtorrier failure.

4.3.2.1.11 Structural Criteria

Due to lack of information in the B\&W report, it is not possible to elaborate on plant structural considerations and criteria.

4.3.2.2 High Temperature Gas-Cooled Reactor steamer (HTGK Steamer)

The HTGR steamer is a 1200-MWt modification of the Fort St. Vrain nuclear steam supply system designed and constructed by General Atomic Company (GA).(21) This section presents the highlights of the EIGR steamer design. One steamer is recomended for this site.

4.3.2.2.1 Heat Cycle Optimization

Steam Fressure Determination: Three cycles were developed. initially, by General Atomic company to determine the optimum operating pressure. A fourth scheme was later developed to improve the heat cycle and increase power generation. Table $4-6$ compares these cycles.

TABLE $4-6$

COMPARISON OF FOUR CYCLES FOR HTGR STEAMER

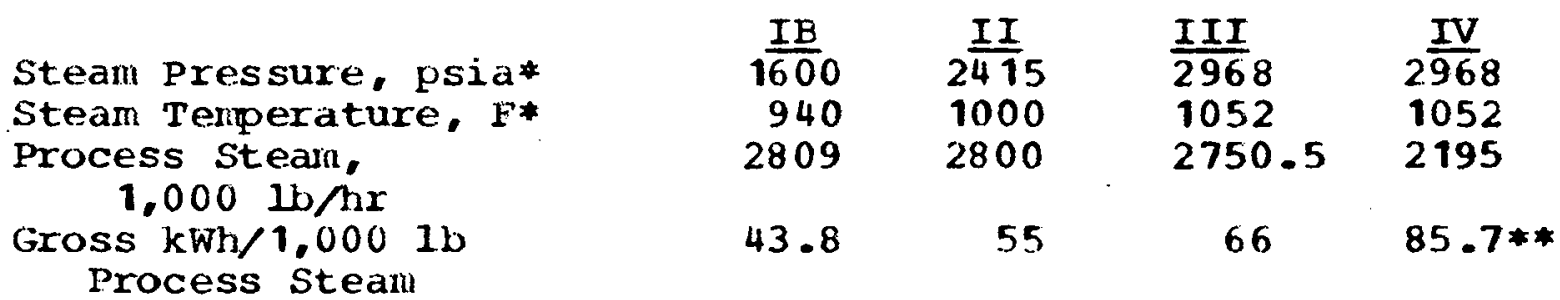

* Leaving the superheaters of the steam generators.

**Generation based on SEW assumed efficiencies and calculations.

For a given process steam flow. Cycle II produces 25.5 percent more power than Cycle IB, and Cycle III produces 20 percent more power than Cycle II. The levelized net credit for power over the life of the plant. after taking into account the operating costs, is projected to be on the order of $80 \mathrm{mills} / \mathrm{kWh}$. This yields a capitalized value for $1 \mathrm{~kW}$ of about $\$ 3,900$, (escalated capital cost plus interest during construction) assuming 7,884 hours of operation per year and a fixed charge rate of 16 percent. It is estimated that the differential capital cost per $k w$ 
between the cycles is less than this; hence, Cycle III energes as the most economical choice. The increased power generation in cycle IV justifies installation of the additional feedwater heating equipment.

Steam Turbine Selection: At orange, Cycle IV is applicable without modification. Steam leaving the helium circulating turbines is supplied at $2,415 \mathrm{psia}$ and $1,000 \mathrm{~F}$ to two straight noncondensing turbines, one exhausting at 640 psia and the other at $290 \mathrm{psia}$. Together these turbines produce about $141.6 \mathrm{MW}$. A single automatic extraction turbine would produce less power and could not be economically justified.

About 58 percent of the 640 psia steam is expanded through a third turbine to generate about $46.6 \mathrm{MW}$ (gross) of electric power while providing feedwater wheating steam at 381.3, 105.3, and 37.9 psia through uncontrolled extraction and an exhaust of 8.42 psia.

Number of Feedwater Heaters: The final feedwater temperature selected by the General Atomic Company is $435 \mathrm{~F}$. To provide this temperature, two low-pressure heaters, a deareator operating at $100 \mathrm{psia}$, and one high-pressure heater are used. Utilizing the steam required to achieve the proposed final feedwater temperature increases the power generated by about $3 \mathrm{MW}$ over the fossil-fired plant. closed heaters operating under vacuum introduce some complications in a noncondensing cycle, but the resulting additional power makes it worth considering.

\subsection{Nuclear Steam Supply System (NSSS)}

The HTGR steamer is a high temperature gas-cooled reactor with the reactor core, steam generator, and helium circulators all located within a prestressed concrete reactor vessel (P(TiV). The active core is helium cooled and contains 1.482 fuel eletuents in a closely packed hexagonal array, 74 control roà elements, and 37 control rod drives. Fissile $0^{235}$ and fertile $T_{1} 232$ fuel particles contained within bonded carbonaceous rods are inserted into the hexagonal graphite moderator structures.

The HTGR has unique flexibility because it can utilize both the proliferation-proof low-enriched uranium/thorium cycle and the previously described highly enriched uxanium/thorium cycle. It is important that these cycles be essentially interchangeable, so that the HIGR steamer can start with one cycle and change to another later with little operational perralty and/or modification to the reactor plant.

Two independent subsystems control core reactivity. Normal reactor control is accomplished by the 37 control rod arives 
mounted in top head penetrations. Fach operates a pair of control roäs. In independent reserve system utilizing boronated graphite pellets is designed to scran the reactor in the event of normal control system malfunction. Pellets are aropped into the core through a guide tube to retard core activity.

Four steam turbine-driven helium circulators pump primary coolant through the cure from the top of the steam generator. The circulators are mounted in penetrations on the PCRV in the pleriun area under the core.

The HTGR steamer employs four steam generators to produce superheated steam used to drive the helium circulators and turbire generaturs. They are also mounted in penetrations on the PCRV in the plenum area under the core. Hot helium flows down over the single helically coiled steam generator bundie counter to the flow of stearn and out the bottom of the shroud. Feedwater entering the steam generator flows up through parallel helical cuils to the top of the bunale. through a 180 degree turnaround, and down the center to the superheater coils. At full power, with $435 \mathrm{~F}$ feedwater. each HTGR steainer produces $3,910,820 \mathrm{lb} / \mathrm{hr}$ of primary steam at 2.968 psia and $1,052 \mathrm{~F}$. After expansion of the primary steam in the helium circulator turbines, it is available at 2.415 psia and $1.000 \mathrm{~F}$ for further expansion through turbine generators to provide process steam at the required pressures.

\subsubsection{3 plant Arrangement}

The General Atomic study includes a steamer plant layout, which requires modifications to adapt it to the specific site. The reactor containment building houses the reactor, prestressed concrete reactor vessel, steam generators, heliun circulators, and auxiliary systems for startup and emergency cooling.

The turbine building contains the turbine generators and other heat cycle equipment. other buildings include facilities for helium storage, fuel storage, radioactive waste treatment, diesel generators, and plant controls.

\subsection{Reactor Containment}

The PCRV serves the cual function of containing the coolant and providing radiological shielding. This protection is provided by walls with a nominal thickness of 9 feet and heads that are nominally 15-feet thick. The PCRV, which houses the steam generators, circulators, and core, has an internal diameter of 31 feet and an internal height of 67 feet. Its exterior dimensions are 55 feet diameter and 98.8 feet high. The prestressing system employs a

$$
4-34
$$


combination of interral vertical tendons and 360 degree wire-wrapped circunferential tendons that are in molded channels on the outside surface of the PCRV. In the top head are penetrations and wells to house the helium purification system and neutron chamber as well as the control rod drives. Penetrations in the bottom head include those for the four steam generators and the four helium circulators.

\subsection{Fuel Handling System}

Refueling of the IITGR steamer is accomplished during shutdown and depressurized conditions while maintaining the gas-tight integrity of the prestressed concrete reactor vessel. Control rod drives are removed in an auxiliary service cask. The fuel handling equipment then removes spent fuel and installs new fuel through the control rod drive penetrations. Approximately one-quarter of the core is replaced each year. The time required for replacement of ahout 500 fuel elements is estimated to be 10 days.

\subsection{Turbine Generator and Steam Cycle}

Drawing No. $12977 \mathrm{EP}-2 J$. located in Appendix B, illustrates the heat cycle and fundamental flow diagram for the HTGR steamer. Basically, steam generated by the HIGR is utilized to drive the four helium circulators and three steam turbine generators and provide the process steam required to meet the 1985 demand of Firestone, Gulf Chemical, B. F. Goodrich, and Dupont.

The major equipment contained in this plant consists of:

Two noncondensing steam turbine generators rated at $3,600 \mathrm{rpm}$ with backpressure governor for operation with inlet steam at 2.415 psia and 1,000 deyrees FTT. One unit requires a throttle flow of $2,494,239 \mathrm{lb} / \mathrm{hr}$ exhaust to $640 \mathrm{psia}$ and is connected to a hydrogen-cooled generator rated at 109.3 MVA, $0.9 \mathrm{PF}, 13.8 \mathrm{kV}$ with static excitation system. The other unit requires a throttle flow of $745.000 \mathrm{lb} / \mathrm{hr}$. exhausts to $290 \mathrm{psia}$, and is connected to a hydrogen-cooled generator rated at $48 \mathrm{MVA}, 0.9 \mathrm{PF}, 13.8 \mathrm{kV}$ with static excitation system.

One noncondensing steam turbine generator rated at $3.600 \mathrm{rpm}$ with backpressure governor for operation with inlet steam at 640 psia and 663.3 degrees FTT. Required throttle flow is $1,044,239 \mathrm{lb} / \mathrm{hr}$ with exhaust at 8.42 psia connected to a feedwater heater. Extractions from this turbine at 381.3 . 105.3. and 37.9 psia are utilized in a deaerator, a 
low-pressure heater, and a high-pressure heater for feedwater heating. The turbine is connected to a hydrogen-cooled generator rated at $51.7 \mathrm{MVA}$, $0.09 \mathrm{PF}, 13.8 \mathrm{kV}$ with static excitation.

- One feedwater heater operating at 8 psia and $266,96410 / \mathrm{hr}$.

One feedwater heater operating at 36 psia and $214.5381 \mathrm{~b} / \mathrm{hr}$.

One dearating feedwater heater operating at 100 psia and $213,152 \mathrm{lb} / \mathrm{hr}$.

Ore feedwater heater operating at 362.2 psia and $349.585 \mathrm{lb} / \mathrm{hr}$.

Two tull-size, motor-driven feed pumps.

One low-pressure heater drain pump.

4.3.2.2.7 Electrical System

The proposed HTGK cogeneration facility will produce approximately $188.2 \mathrm{MW}$ of electrical power. A total of $19 \mathrm{MW}$ will be used for plant auxiliaries leaving $169 \mathrm{MW}$ net output available to the users.

The electrical systen for the HTGR cogeneration facility is composed of four parts: i.e., safety-related (Class IE), balance of plant, generation, and distribution systems.

Safety-Related (Class IE) Electrical system: The Class IE electrical systeru provides a reliable source of electrical power. for safe reactor shutdown under emergency conditions and/or auring loss of offsite power. Major portions of the Class IE electrical system are:

- Standby power supply consisting of one or more diesel generators capable of supplying full power to the 4160-V safety-related buses.

- 4160-V safety-related distribution system consisting of switchgear, buswork, cable, and associated controls.

- 480-V safety-related distribution system consisting of load center substations, motor control centers. power panels, buswork cable, and associated controls.

- 120/208-V uninterruptible power supply. 
- $250 / 125-\mathrm{V}$ do system consisting of station batteries and chargers.

- Raceway system.

Balance of Plant Electrical system: whis portion of the plant electrical systeli is aesigned to supply reliable and sately controlled powei to turbines, redclors, anä miscellaneous plant auxiliaries during all modes of normal plant operation and shutaow conditions. Major portions of this system arre:

- 4160-V nornial distribution systen consisting of switchyear, buswurk, cable, and associated controls for noisalety-related Loads.

- 480-V nomal distiibution systern consisting of loaä center sutstations, wotor control centers, power panels, buswork, cable, and associated controls for nonsaiety-related loàis.

- $250 / 125-V$ ac systea consisting of station batteries and chirgers ror supply of dc power to emergency loads of the turbine generator, feedwater, punps. switchyear, control and instrument functions, and lightiriy.

- 120-V reguiáted instrament power system.

- Raceway systein.

- Flant ijghting systen.

- Intrapiant conmunications and paging system.

- Grounding systen.

Generation System: Llectrical power will be generated at $13.8 \mathrm{kV}, 3$ phase, $60 \mathrm{~Hz}$. The 109.3-MVh, 48-MVA, and 51.7-MVA generators will each be connected to a step-up power transforater by an isolated-phase bus. The transformers, rated $5 j \mathrm{MNA}, 47 \mathrm{MVA}$, and $34 \mathrm{MVH}$. respectively, will supply $138 \mathrm{kV}$ to the plant switchyard for distribution to the users. The second transfomer, rated $57 \mathrm{NVH}$, will supply $138 \mathrm{kV}$ to the plant switchyard for distribution to DuPont.

A tap from the isoläted-phase bus will connect to the plant normal station service transformer rated 24 MVA. $13.8 \mathrm{kV}-4160 \mathrm{~V}$ which supplies all of the plant auxiliary equipuent. 
Offsite power for plant startup and reserve will be supplied irom the 138-kV switchyard through a $24-M V A$ reserve station service transforner. This transformer will supply the 4160-V buses during plant startup, shutdown, or emergency upexation.

Distribution Systen: txisting substations located at each user's plant will be retained and modified as necessary to allow integration of the cogenerated electrical power with the present supply from GSU. The distribution system between the cogenexation plant and the users is capabie of delivering 100 percent of the electrical requirements to any user. The distribution of power among the users should be apportioned by a specific formula developed by them.

Distribution voltage is $138 \mathrm{kV}$. Power is transmitted from the plant via overhead lines supported on wood pole-line structures. bupont will require new service equipment to accept $138 \mathrm{kV}$.

As Shown on Drawing No. 12977-EM-1E, located in Appendix B, electrical distribution follows the piping right-of-way to each user. The switchyards of Gulf and Goodrich serve as tie points for the alstribution circuit.

Reliability is achievea by maintaining power availability from GSU in the event of a failure of the plant generator or distribution circuit.

\subsection{Radwaste Systen}

The radioactive waste system of the FIGR steamer includes liquid and gas waste systelus and is designed to preclude the release of activity from the plant in excess of allowable limits. Since the HI'GR does not produce significant amounts of solid wastes as a result of normal operations, an elaborate hanciling systera is not required. Solid wastes that are generated are packaged in drums and shipped of site for disposal.

Radioactive liquias will not be produced by the HTGR steamer in suivstantial quarititıes during normal operation. However. there is a liquid waste system for handing radioactive liquids generated by infrequent evolutions such as decontamination and potential accident situations (steam generator tube failure). Low-level liquid waste is collected in a sump and pumped through a filter to a liquid waste receiver for sampling and subsequent discharge through radioactivity monitors. High-level liquid waste such as that produced during decontamination operations are prefiltered in the decontamination system before transfer to the liquid waste receivers. 
Gases generated in the liquid waste receivers are vented to the gaseous waste systeru. Radioactive gaseous wastes from the helium purification systein, fuel storage lacility purge and exhaust systeris, ana the liquid waste receivers are collected and directed to either the low-activity inlet header or the high-activity inlet header for processing. Low-activity gases are filtered to remove particulate matter and ionine betore release through the reactur plant exhaust system. High-activity gases are accumulated in storage tanks, isolated and analyzed for isotopic composition, then released at a controlled rate to the reactor plant exhaust system.

\subsection{Water freatuent System}

The nonsafety-class water treatment system consists of the equiment required for condensate demineralization, feedwater treatiant, and inakeup water treatment. The quality of feedwater required is similar to that for a once-through steam generating system.

The nuclear steam system does not have any planned consumption of high purity water. Bearing water drains from the main circulator service system are normally returned to the heat cycle and the quantity so drained is replenished by a makeup stream from the teedwater pump discharge. Leakage from bearing water puwip shaft seals and valve stems is expected to be insignificant under nomal care and maintenance. Duxing any conditions involving combined turbine trip and loss of outside electric power, steam relief to atmosphere for linited periods would result in a denand on the storage of condensate.

The full-flow denineralizer systen design is based on plant requirements. The system consists of mixed-bed demineralizers: full turbine load can be carried while one mixed-bed demineralizer is being regenerated or on standby. Post-filters are provided duwnstream of the demineralizers to prevent carryover of fines to the steam generators. Condensate, atter passing through the gland steam condenser. flows through the mixed beds and filters and then on to the low-pressure feedwater heaters. A full-flow bypass is provided for energency operation.

The makeup pretreatment and demineralizer system for the entire two-unit plant consists of a clarifier with sodium hypochlorite, lime, ferrous sulfate, and spare chemical feeders followed by two gravity filters and a filtered water clearwell with transfer pumps. The demineralizer section consists of two trains, each containing a carbon filtex. cation, anion. and mixed-bed unit followed by $a$ demineralized water storage tank with sufficient capacity to regenerate one complete train. Demineralized water transfer

$$
4-39
$$


puraps feed to the conciensers for deaeration and then to the condensate sturage tanks of both units.

The regeneration systerin consists of sulfuric acid and sodiun hyüroxide storage tariks, automatically controlled metering punps, and the riecessary piping. valves, and contruls.

The regenerant waste disposal system accepts regeneration wastes trom both the condensate polishing and nakeup demineralizing systems. Ihis system consists of a newtralizing tark, recixculation pump, mixer, and pH control for addition of acio or caustic to neutralize the regenerant wastes. 'The nelutalized wastes are then bled at a controlled rate intu the cooling tower blowdown discharge.

Ihe pretreatment waste disposal system accepts blowdown and backwash from the clarifiex, gravity filters, and carbon filters. This system consists of a compartmented sludge lagoon. The individuil corpartments can be successively fillod and accunted with the decaril wäles üsaintë at a contrulled rate into the couling tower blowdown discharge.

Gily wastes trom the turbine room sumps and deluge water are drained irito a surye pond followed by an oil/water separatox. The separated oil and sludge is transportea for of Isite disposal and the water is degraded in an oxiajation lond before disposal at a controlled rate into the cooling tower blowdown discharge.

4.3.2.2.10 Ultiriate Heat sink

This site does not have ready access to an adequate supply of river water. Two luo-percent capacity lone for reaundancyl cooling towers have been incorporated into the vlant desigr. The cuoling towers will serve to remove decay heat from the reactor on shutabwn.

\subsection{Buildings and Othex Structures}

This section desciibes the major structures of an Hiti nuclear power station. rable 4-7 lists the safety classifications of these structures. Safety classes are in conformance with present-day nuclear safety criteria.

Prestressed concrete Reactor Vessel: The PCRV contains and slifelds the reactor core and the entire primary coolant system, including the stean generators and helium circulators. It functions as the primary coolant system pressure boundary. The conplete PCRV is composed of: an internal steei liner acting as a sealing membrane; a theribi irarrier and cooling systen to limit concrete temperatures: penetrations and closures to provide access to the vessel cavities; and high-strength concrete with bonded reinforcing

$$
4-40
$$


steel and prestressing systems to provide strength. The entire asselably is mounted on a support structure. The 1iner, concrete, reinforcing steel, and prestressing systems function as a composite structural system.

Keactor Containuent builazry: The reactor contairunent building is a Safety Class 2 . Seistaic Category I structure which provicues a ledkage barriex against significant fission product release to the atrosphere following an accident. The reactor containuent builaing allows the atuospheric deisity in the FCKV to be maintained as required for adequate core cooling following a design basis accident. The concrete structure also provides shielding from tission products which cuvld be arrborne within the building urider acciỏent concitions. 
TAELE 4-7

SAFETY CLASSTFICARION OF STRUCTURES

Structure

Safety* Safety* Safety* No Safety*

Class 1 Class 2 Class 3

class

Fieactor Containnent

Builaing. Penetra-

tiuns, and Hatches

$\mathbf{x}$

Reactor service

Building

$\mathbf{X}$

Control Builüing

$\mathbf{x}$

Penetration

building

$\mathbf{X}$

Auxilialy Cilculatui

Power Supply Builaings

$\mathrm{X}$

Diesel Generator

Building

$\mathbf{x}$

rurbine Euilding

$x$

Helium Storage

Euilding

$\mathrm{X}$

Aciä and Caustic

Storage structure

$\mathrm{x}$

Raw Water Intake

Buil 10ing

$\mathbf{X}$

Reactor Containment

Iuilaing Interior

Structures

$\mathrm{x}$

Substation

Structires

$\mathrm{x}$

sewage Treatment

plant

$\mathrm{x}$

Water Treatuent

Builaing

$\mathbf{x}$

Office and Service

Building

$\mathbf{x}$ 


\begin{tabular}{|c|c|c|c|c|c|}
\hline Structure & $\begin{array}{l}\text { Safety } \\
\text { class } 1\end{array}$ & $\begin{array}{l}\text { Safety* } \\
\text { Class } 2\end{array}$ & $\begin{array}{l}\text { Safety } \\
\text { Class } 3 \\
\end{array}$ & No & $\begin{array}{l}\text { Safety** } \\
\text { Class }\end{array}$ \\
\hline $\begin{array}{l}\text { Auxiliary Builex } \\
\text { Aouse }\end{array}$ & & & & & $X$ \\
\hline $\begin{array}{l}\text { Circulating Water } \\
\text { Puniphouse }\end{array}$ & & & & & $X$ \\
\hline Guard House & & & & & $x$ \\
\hline Warehouse & & & & & $x$ \\
\hline
\end{tabular}

* Also Seismic Category I structures.

* Also nonseismic category structures.

The reactor contaimment building is a cylindrical. prestressed concrete structure bearing on sound soil. The foundation mat has convertional steel reinforcing. The cylindrical walls are prestressed with a post-tensioning tendon systela in the vertical and horizontal directions. The oime is prestressed utilizing a three-way post-tensioning tencion system. Anchorages for the lower vertical tendon are located in a tendon gallery. Hoop tendons are anchored to three buttresses. The top vertical tendon anchorage and the dowe tendon anchorage are located in the ring gircier area. For easy accessibility, the PCRV tendon gallery and the reactor containment building tendon gallery have been cross-connected.

The inside surface of the reactor containment building is lined with carbon steel liner plate with stiffeners to ensure a high degree of leak-tightness for the containment. Leak chase channels are provided for the bottom liner plate and for inaccessible areas.

The polar crane with main and auxiliary hooks will be supported from the vertical builaing walls.

Reactor Service Builaing: The Safety class 2, Seismic Category I reactor service building houses new and used fuel storage facilities and reactor auxiliary systems not located in the reactor containinent building.

The primary activity in the reactor service building will be refueling. The reactur will be refueled via the reactor service building through the access door connecting the refueling floor of the reactor containment building to the 
reactor service builuirig. Both new and spent fuel are hardlea through this opering. Refueling equipment is norinally stored in the reactor service buildirg and will be tramsportea into the containment through the equipment: batch, when reguired.

The fuel storage concrete worolith contains the spent fuel elements. This iuassive structure comprises the inner core of the reactor service builaing and is also used for storage of radioactive touls, coritrol rods, and other equiprient. The remairilug portion of the reactor service building below the refueling floor huuses the fuel inspection and sealing lacility. equipment service facility, fuel shipping racility. shipping cask transporter parking and service areä, and other auxillary systems.

A crane sounted on the top of the reactor service builaing riakes a 11 lifts necessary for storing fuel in the monolith and tränsterring iuel to the reactor. Also, along with its auxiliary lusst, linis cratie performic all necessary mainterance lifts. ruel is transferred to the reactor in a trässfer cask.

The reactor service builaing, a raltistory structure beside the reactor contaiment building. is structurally independent of the other buildings. The foundation is a reintorced concrete riat on sound soil.

Control Building: rijis is a safety class 2. Seismic Category I structure housing the control room, auxiliary electrical equipsuent, ventilation equipment, controlled access area, and the rëactor plant cooling water system. The tollowirig tunctional areas comprise the control builaing:

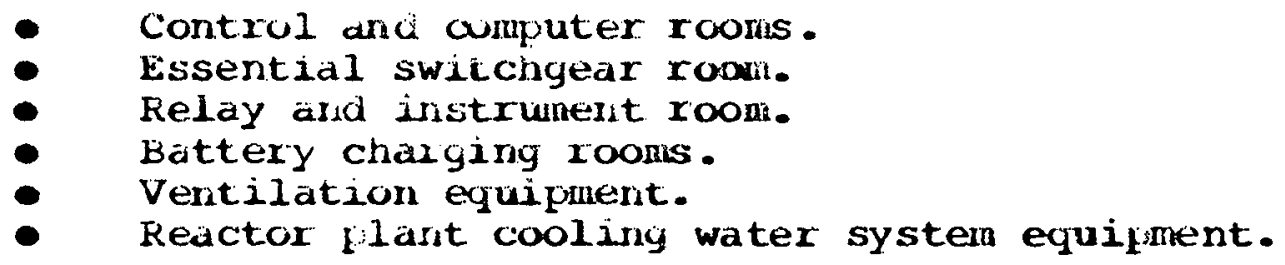

The control building has reinforced concrete floor slabs. walls, and roof. The building is protected from possible missile damage since it contäins safety-related equipuent.

Interior walls are reinforced concrete including elevator and stairwell enclosures, thus neeting fire resistance criteria. Walls, floor slab, and ceiling around the control access filters and ewergency charcoal filters are reinforced concrete for biological shielding. 
Peretration Euiluing: The süfety class 2, Seismic Category I penetration building protects both satety- and nonsafety-related fenetrations. The building consists of a turnel housing electrical control and power cables and valve pits housirg nain steari line stop valves. It is laid out so that it completely surrounds the reactor containmerit burlaing, thereby protecting toe containment penetrations at different locations around the perimeter of the containwent structure.

auxiliary Circulator Fower supply Buildina: The safety Class 2, Seismic Category I auxiliary circulator power supply building huuses the three auxiliary circulator power suptiles. The building is located on the perimeter of the electrical tunnel. iuxiliary circulator power supplies are placed 60 degrees apart within the building. Walls, roof. and mat of tisis structure are designed to withstand the infact of tornacio-gentrated rissiles.

Diesel Generator Euilding: The Safety class 2, seismic Category I diesel yenfrator. building houses standby power supplies, consistiny of three diesel generators for each unit. Fill walls, interior and exterior, and the roof slab are reinforced concrete. The founcation mat is of reinfurced concrete and bears on sound soil.

The diesel generator building is designed to withstand short-term tornacio loading including impact of tornado-generated missiles. Openings are providea with gratings to protect against wissiles.

Turbine Building: Mie turbine building is a nonsafety-class, nonseisnic-category structure that contains the curbine generatur and other equipment related to the conventional portion of the plant.

The turbine builaing is a multistory steel-frame structure. The roof is constructed of built-up roofing, rigid insulation, and steel deck supported by roof puriins and steel fraues. The side walls are constructed of insulated nietal sidirg. All ilours are of reinforced concrete.

The turbire generatur peciestal is a massive reinforced concrete structure designea to support the turbine generator with no objectionable detlections. Its natural frequency is above the dyramic vibration frequency of the turbine generator. The turline generator pedestal is isolated from the turbine buildiag and is supported on adequate subsoil mäterial.

A bridge crane is provided to service the turbine building and has access to the laydown area and the railroad access bäy .

$$
4-45
$$


Felium storaue Euildins: The helium storage building is a pretengineerea steel and metal-siding structure. This nonsafety-clasis, nonseisnic-category structure houses the primary coolant helium storage bottles.

Acid and Caustic stopaje structure: This nonsafety-class, nonseisulc-cintegory structure provides storage for acid and caustic required tor plant operation. This building is a lean-to of steel and metal siding.

Raw Vlater Intake buildzny: This nonsafety-class, nonseismic category structure houses equipment required for supply water from a natural source adjacent to the plant. It is a partially suograde structure. It includes a raw watex purploom housing the law water puaps, a fire purap pool, and a screening area housung the screening equipment.

The bottom fluor slab is a reinforced concrete mat bearing an sound soil. Vialls are reinforced concrete. A diesel ongine, cngino housing, pumps, and miscellaneous equipment are supported by a reinforcea concrete floor slab.

Miscellaneous Euilaings: The water treatment plant will be outdooxs, except for a. small laboratory and control building. Also included is a building for office and wareholise space. The builoings will be single-story. steel-framea structures with insulated metal siding built on a concrete slab on grade.

\subsection{Other Structural Criteria}

Foundations: Eused on available soils information for the proposed site, it may be necessary to remove a significant arnount of existing soil down to an adequate soil bearing stratua in the axea of the main plant. If so, a select compacted backfill will be used to replace the removed soil. All significant structures will be supported on reinforced concrete mat tourdations. other structures and equipment will be supported on reinforced concrete spread footings or pile fuurdations.

Due to the grounciwater level anticipated at the proposed site, extensive dewatering operations will be necessary during construction of the foundations.

Yardwork: 'rhe cost estimate includes clearing and grubbing the site, excavation and spoiling of undesirable material. railroad trackwork, permanent plant roads, and fencing. isso includea are the relocation of the existing canal and the construction of two bridge structwres over the canal for roadway and railuoad. 
4. 4 GEIGMAR SITE

4.4.1 FOSSLL FUEL FIANTS

4.4.1.1 Oil-Fired Pläit (Reference Plant)

4.4.1.1.1 Steam Generators

Two 50-pexcent capacity, oil-fired boilers are included in this arrangenent. bach boiler is rated at 4,700,000 pounds of stean per hour at 2.475 psia and 1.000 FTT. This capacity permits continuous production for the projected 1985 combiried steau deluarid of Monochem, Incorporated, BAsF Wyandotte chemical Company, shell chemical, and Vulcan Chemical. Bāckup steäm for each plant would be providea by the steam-generating facilities presently contained in each plant.

Design features of the steam generators include:

- Two vertical-shaft air preheaters per boiler.

- Two 50-percent capacity forced. and two 50-percent capacity induceä, draft fans per boiler.

- Retractable soot blowers.

- Ëlectronic corabustion controls.

- Solia state automatic burner safety controls.

\subsection{Boiler Feectwater system}

The arrangement of the feedwater system is illustrated on Drawing No. 12977-EP-2F located in Appendix B. The stean cycle was designea to provide process steam at the projected 1985 demand level of the four process plants being served.

The basic equipment contained in this system is:

Two deaerators, each operating at 45 psia and $655,7331 \mathrm{~b} / \mathrm{hr}$. Leaerating steam is supplied from 45 psià turbine exhaust.

- Three (2 operating and 1 spare) 50-percent capacity. wotor-ariven feedwater pumps arranged in parallel. Motor drivers were selected to reduce first cost. 
- Two strinys, one for each boiler, of three closed feedwater heaters arranged in parallel. The seconci-stage heaters are each rated at $475.4941 \mathrm{~b} / \mathrm{hI}$ ard operate on extraction steam from the 090 psic header. Four quarter-size first-stage heaters, ratea at $283,681 \mathrm{lb} / \mathrm{Mr}$ each, operate on extraction stean from the 290 psia header. Heater drains flow to the deaerator.

4.4.1.1.3 Turbine Generators

The study is based on lour roncondensing steam turbines of double sheil construction with backpressure governors.

is briel description of the curbine generators follows:

- Ore nonconciensung stean turbine with backpressure goverror for opelation with inlet steam of 2.415 psia and 1,000 degrees FIT, 1.584.724 1b/hr throttle flow and 290 usia exilaust pressure, connected to d hydroger-cuoled generator rated at $102.2 \mathrm{MVA}, 0.9 \mathrm{PF}$. 22. $\mathrm{kV}$ with static excitation systen.

- One noncondensing stean turbine with backpressure governor and 970 esia extraction for operation with inlet stean of $2,415 \mathrm{psia}$ and 1,000 degrees FTT. $1.681 .466 \mathrm{lb} / \mathrm{hr}$ throttle 1 low and 45 psia exhaust pressure. Whe turbine is connected to a hydrogen-cooled generator rated for $147.7 \mathrm{MVA}, 0.9 \mathrm{PF}, 22 \mathrm{kV}$ with static excitation systera. Extraction flow is $370,000 \mathrm{lb} / \mathrm{hr}$.

- Two nuricondensiry stean turbines with backpressure governors tor operation with inlet steam of 2.415 psia and 1,000 deyrees FTr. $2.985,494 \mathrm{lb} / \mathrm{hr}$ throttle flow and 690 psia exhaust pressure. Each is connected to a hyarogen-cooled generator rated for $124.3 \mathrm{MVA}, 0.9 \mathrm{PF}$. $22 \mathrm{kV}$ with static excitation syster.

4.4.1.1.4 Fuel Häraling System

This system contains the equiprent required to receive. store. and deliver no. 6 fuel oil to the boilers. The fuel oil was assumed to have the following composition:

\begin{tabular}{lc} 
& $\frac{\text { Weight }}{\%}$ \\
\cline { 2 - 2 } Sulfur & 2.3 \\
Hydrogen & 9.7 \\
Carbon & 85.6 \\
Nitrogen and Oxygen & 2.0 \\
Hsh & 0.12 \\
Water and sediment, Vol. 8 & 0.74 \\
Heating value (Btu/lb) & 18.300
\end{tabular}


The fuel oil system supplies oil to the station from a railroad tank car unloaâing facility. Three unloading puaps, located in the fuel oil pumghouse, transport fuel oil from tank caxs to the storage tanks. Four storage tanks. with a conbined storage capacity of 114,000,000 gallons, store fuel oil equivalent to a 60 -day burning rate.

Three 100-percent capacity punps, one per boiler plus one common spare. are also located in the fuel oil puaphouse. These purys transjort tuel oil from the storage tanks to the boilers.

A 15-foot earth dike has been incluoiel around each tank for fire protection.

4.4.1.1.5 7.sh Hanaling

loilers are designted primarily for oil firing and no provisiors have been incluated for future coal firing except that adexuate headruai has been frovided beneath the boilex to permit future installation of a bottom ash hopper.

For oil tiring, the buttom of the boiler is sealed off. with a steel plate which can be unbolted at scheduled ontages for manual renoval of ash accunulations. Oil soot accunulations under precipitator hoppers and other points are removed on a continuous basis trirough eductors and reinjected into the toiler. This systelin operates under positive pressure.

The system is illustrated on Drawing No. 12977-EP-2D located in Appendix B.

4.4.1.1.6 Precipitacors and Scrubbers

Precipitators: iwo precipitators, one per boiler, are included in the cust estimate. Included in the precipitator costs are supporting structures, transformers, controls, and moüel study.

Precipitators were selectea to comply with both state and federal regulations, which linit particulate matter emissions to $0.120 s / 10^{\circ}$ Etu heat input.

Scrubbers: Two scrubivers, one per boiler, are included in the cost estimace. Lach scrubbing system consists of supporting steel; denister/absorber: limestone storage and handling equipment: linestone slurry tanks; thickerer: miscellaneous pwips, tanks, piping and duct work; controls: and a sludge havdling system. 
Scrubbers were selected to comply with proposed regulations. which will suon rejuire 90 percent renoval of 502 from the tlue gass. Complete duplication of all scrubber equipment was elininated by utilizing some equipment for both scrubluers.

4.4.1.1.7 water ireatment System

The rakcup water supply passes through two clarifiers arranged in parallel, each operating at one-quarter of total plant requirements $(30$-percent returns not requiring clarification are ariticipated). Underflow from the rlarifier is pumper to a thickener.

Clarifier effluent flows by gravity to sand gravity filters. Filter backwash is recyclea to the clarifier. Filter effluent is punped through full-flow pressure carbon filters to a demineralizing system.

Dissolved soliüs are removed by demineralizer trains consisting of cation exchangers, vacuun degasifiers, anion exchangers, and mixeä-bed exchangers. The denineralizer trains are followed by a battery of nixed-bed polishing units. Blowdown from the demineralizing system is discharyed to the holäing basin.

The cordensate returns are put into the system ahead of the carban filter aiter jussing tirough oil removal equipment. The choice of oil rentoval facilities depends upon the form of oil: i.e.. dissolved, suspended, or emulsified. The study design includes deep-bed precoat oil removal filters containing anthracite. The tilter bed is precoated with an alum-soda ash wix and has a shall continuous body feed.

A fundamental flow diayram of the system is shown on Drawing No. 12977-EP-2B located in Appendix B.

4.4.1.1.8 Waste Treatment System

In the Octuber 8, 1974, Federal Register, EPA reparted Iinal effluent guidelines for the steam electric power generating industry. The wastewater treatment described below complies with these new source perfornance standards.

Liquid wastes frora the station include water treatment wastes (suspended sulids, acid, caustic, oil). steam plant wastes (flloor drainage, equipment washing wastes, boiler chemical cleaning wastes, boiler blow-down). storm drainage (yard and roof drainaye), and sanitary systems. 
The water treatment plant clarifier underflow is pumped to a thickener. Thickener solids are dewatered and sent tu a disposal site. the overtiow is recycled to the clarifier. water from the vacuun filter is returned to the thickerer.

in inpervious holàing or equalization basin is utilized to collect all other waste flows. inese flows include floor drainage and intenaittent high-flow wastes, which are high in suspendea solids and dissolved metals. Equipment washing wastes, boiler chemical cleaning wastes, and yard and roof drainaye are typical examples. The basin is sized to accombodate wastes from equipment washing and boiler chemical cleaning when heavy rainfall could result in a large amount of yara cirainage.

The basin effluent flows to a treatment system consisting of a settling chamber with chemical feed and neutralization to control $\mathrm{pH}$ within the allowable linits for discharge into the iiver. The effluent is recirculated back to the watex treatrent system claxitier when the solids content and otinex conditions permit.

sludge trom the settling chamber is pumped to the dewatering equipment and the oil is collected and sent to disposal. A bypass systern is provided for abnormal conditions.

Sanitary wastes are treated in a package plant providing secondary biological treatment and chlorination of the treated effluent prior to discharge.

A fundamental low diagram of the system is shown on Drawing No. 12977-EP-2B located in Appendix B.

\subsection{Electrical system}

The proposed oil-fired cogeneration facility generates approximately $448.6 \mathrm{MW}$ (gross) of electrical power. Allowing for plant generator losses and plant auxiliaries, the net electrical output is 369.7 MWe.

Existing substations located at each user's plant will be retained and wodified as necessary to allow integration of the cogenerated electrical power with the present supply from GSU. The distribution of power among the users should be apportioned by a specific formula developed by them. Distribution voltage is $138 \mathrm{kV}$ or according to present user service. Power is transinitted from the plant via overhead lines supportea on wood pole-line structures.

As shown on frawing No. 12977-EM-K, electrical distribution follows the piping right-of-way to each user. The switchyards of each user serve as tie points for the distribution circuit. 
Reliability is achieved by faintaining power availability from GSU in the event of a failure of the plant gererator: or distrioution cancuit.

Powex is genexated at $22 \mathrm{kV}, 3$ phase, $60 \mathrm{kz}$ and connected to a $395-\mathrm{kVA}, 22-138-\mathrm{kV}$ step-up power transformer through isolated-fhase bus. The transformer will deliver $138 \mathrm{kV}$ to the: plant swltchyara tor distribution to the four users.

1. tap from the isolited-phase bus connects to the plant auxiliary transtorner rated $105 \mathrm{MVA}, 22 \mathrm{kV}-4160 \mathrm{~V}$ and supplies ali plant electrical equipment.

Power for stimcup of the plant and reserve supply for auxiliaries is provideri by means of a $136-\mathrm{kV}$ tie from GSU to the plant: switchyard and then to a 105-MVA, 22-kV - 4160-V reserve transiulatex. rinis connection also assures reliability oi stear production in the event of a generator or transtormex failure.

Plant electrical auxiliary equipment consists of:

- 4-kV metai-clad switchgear rated 350 MVA.

- 1500-kVa load certer unit substations for 480-V loads.

- 480-V intor control centers with circuit breaker coribination starteis.

- Ir wiring system couposed of copper conductor. flane-retarcant cable installed in a raceway systen of alunirum laūder tray or rigid steel conduit.

- A lighting system utilizing fluorescent fixtures. incanciescent lanpsi, or high bay lighting as requireä.

- A carmon grounding system throughout the plant.

- I conaunications/paging system.

- Ar entigency dc supply system derived from 125-V station batteries tor small, critical loads and switchyear breakex operations.

\subsection{Structural Criteria}

Foundations: Inailable soil information for the proposed plant indicates that pile foundations may be required for major structures and equipment. The cost estimate includes pile foundations for all plant structures, piperacks, water treatment facilities, and other small builaings. Fuel oil

$$
4-52
$$


tanks are supportec on select compacted backfill. No ringwall foundation is included.

Yarawork: The cost estimate iricludes clearing and grubbiny the site. lucal excavation and spoiling of undesirable naterial. railroad trackwork, permanent plant roads, ana rencing. Also included are the costs for construction of two bridge structures over the New River for roadway and railroad, earth dikes for the fuel oil tanks, a waste holding basin, and various othex hydraulic structures.

Buildings and other structures: cost estinates of auxiliary builiangs are based on a semi-outdoor design. They include two exposed boilers with enciosures over fronts and tops. Snall enclosures are provided tor each of the force draft fans. Common to the boilex's is a 275-foot concrete stack erected on a concrete mat supported by piles. The stack is frovided with steel liner, ladder, platform, and aircraft lights.

The water treatnient plant also will be outdoors, except for a single-story laboratory and control building of steel frame with insulated retal siding constructed on a concrete slab on grade. A similar building wịll provide office and warehouse space.

The turbine builaing is a steel-frame structure enciosed with uninsulated metal siding, wetal roof deck with insulated built-up asphalt, and gravel roofing. It has a concrete operating floor and ground floor. Galvanized steel grating supported by steel traming is used in general for other flocars, walkways, stair treads, and intermediate landings. The turbire generators are supported on concrete pedestals extending from operating floor level to below grade. The turbine builaing contains a control room. various switch and cable rcoms, and a 50-ton capacity overhead crame to service the turbine generators.

4.4.1.2 Coal-Fired Plant

4.4.1.2.1 Steam Generators

Two 50-percent capacity, pulverized coal-fired boilers are included in this arrangement. Each boiler is rated at $4.700,000 \mathrm{lb}$ of steam per hour at 2,415 psia and 1,000 FIT. This capacity permits continuous production for the projected 1985 combined demands of Monochem Inc.. BASF Wyandotte Chemical Company, Shell Chemical, and Vulcan Chemical: backup steam is provided by the existing steam generating tacilities contained in each plant. 
Design features of the stearn generators include:

- Two vertical shaft air preheaters per boiler.

- 'Two 50-percent capacity forced, and two 50-percent capacity induced, draft fans per boiler.

- Retractable soot blowers.

- Electronic conaustion controls.

- Solid state automatic burner safety controls.

- Six ball-type pulverizers with primary air fans.

4.4.1.2.2 Boiler Feediwater System

The arrangenert of the feedwater system is illustrated on Drawing No. 12977-EP-2F located in Appendix B. The steam cycle was designed to provide proccas atcam at the projeatod early-1980 demand level of the four process plants being served.

The hasic equipment contained in this system is:

- Two deaerators, each operating at 45 psia ard $655.733 \mathrm{lb} / \mathrm{hr}$. Deaerating steam is supplied from 45 psia turbine extraction.

- Three ( 2 operating and 1 spare) 50-percent capacity. motor-driven. feedwater pumps arranged in paralle1. Notor drivers are selected to reduce first cost.

- Two strings, one for each boiler, of three closed feedwater heaters arranged in parailel. The second stage heaters are each rated at $475.494 \mathrm{Ib} / \mathrm{hr}$ and operate on extraction steam from the 690 psia header. Ihe two-stage heaters, two per boiler, are rated at $283,681 \mathrm{lb} / \mathrm{hr}$ and operate on extraction steam from the 290 psia header. Heater drains flow to the deaerator.

4.4.1.2.3 Tuxbine Generators

Study was made of four noncondensing steam turbines of double-shell construction with backpressure governor.

A brief description of the turbine generators follows:

- One noncondensing steam turbine with backpressure governor for operation with inlet steam of 2.415 psia and 1,000 degrees FTT. 1,584,724 $\mathrm{lb} / \mathrm{hr}$ throttle flow and

$$
\text { 4-54 }
$$


290 psja exhaust pressure. The turbine is connected to a hydrogen-cowled generator rated at $102.2 \mathrm{MVA}, 0.9 \mathrm{PF}$. $22 \mathrm{kV}$ with static excitation system.

- One noncondensing steam turbine with backpressure governor and 970 psia extraction for operation with inlet steam of 2.415 psia and 1.000 degrees FTT. $1,681.466 \mathrm{1b} / \mathrm{hr}$ throttle flow and 45 psia exhaust pressure. The turbine is connected to a hydrogen-cooled generator rated for $147.7 \mathrm{MVA}$; $0.9 \mathrm{PF}, 22 \mathrm{kV}$ with static excitation system: Extraction flow is $370,0001 \mathrm{~b} / \mathrm{hr}$.

- Two noncondensing stean turbines with backpressure governor for operation with inlet steam of 2,415 psia and 1,000 degrees Fl' $2,985,494 \mathrm{lb} / \mathrm{hr}$ throttle flow and 690 isia exhaust pressure. Each is connected to a hydrogen-cuoled generator rated for $124.3 \mathrm{MVA}, 0.9 \mathrm{PF}$. $22 \mathrm{kV}$ with static excitation system.

\subsection{Fuel Handling System}

This systera contains the equipment required to receive, store, and deliver coal to the boiler house silos. The characteristics of the coals considered in this study are shown in Table 4-5.

Eased on the low heating value. coal consumption for the two units is estimated at 9,928 tons per day for Alabama coal and 15,081 tons per day for Wyoming coal. On a continuous wasis. this amounts to 207 tons per hour per boiler for Alabama coal and 314 tons per hour per boiler for wyoning coal.

coal will be receivea by barge, positioned by barge hauler, and unloaded by barge unloader. A general configuration of the coal harding system is shown on Drawing No. 12977-SK-1B located in ippendix $\mathrm{B}$.

\subsubsection{5 ksh Handling System}

There are basically two ash handling systems: one for bottom ash and one for fly ash removal.

The bottom ash system is hydraulic, using a jet pump to convey ash to a dewatering storage bin for removal by truck to an offsite aisposal area. To conserve water. a closed recirculating water system containing storage and settling tanks is employed. This system permits the particles, which escape from the dewatering bin, to drop out of suspension and be recoverea as sluage. The water is finally drained to a storage tank for reuse in filling ash hoppers and for conveying ash. 
Fly ash is removed from the gas system hoppers pneunatically and conveyed to a silo where it is stured dry. When removed from the silo for tinal disposal. the fly ash is mixed with water and dischargea to a truck for removal to an offsite disposal area.

The system is illustrated on Drawing No. 12977-EP-2C located in Appendix B.

\subsection{Precipitators and scrubbers}

Precipitators: Iwo precïfitators, one per boiler, are included in the cost estinate. Included in the precipitator costs are supporting structures, transformers, controls, and mociel study.

Precipitators were selected to comply with both state and tederal regulations. which limit particulate matter exissions to $0.110 / 10^{\circ}$ Btu heat input.

Scrubbers: 'Iwo scrubbers, one per boiler, are included in the cost estimate. Each scrubbing system consists of supporting steel; demister/absorber; limestone storage and handling equipment: limestone slurry tanks: thickenex: miscellaneous punps, tanks, pîping and duct work: controls: and a sludge handling system.

Scrubbers were selected to colply with proposed regulations, which will soon require 90 percent removal of so2 from the ilue gas. Conplete duplication of all scrubber equipment was eliminated by utilizing some equipment for both scrubbers.

4.4.1.2.7 Watex Ix eatruent systen

The makeup water supply passes through two clarifiers arranged in parallel. each operating at one-quarter of total plant requirements $(50$ percent returns not requiring clarification are anticipated). Underflow from the clarifier is punped to a thickener.

The clarifier effluent flows by gravity to sand gravity filters. Filter backwash is recycled to the clarifier. The filter effluent is pumped through full-flow pressure-type carbon filters to a demineralizing system.

The dissolved solids are removed by demineralizer trains consisting of cation exchangers, vacuum degasifiers, anion exchangers, and mixed-bea exchangers. The denineralizer trains are followed by a battexy of mixed-bed polishing units. Blowdown from the demineralizing system is discharged to the holding basin. 
Condensate returns are put into the system ahead of the carbon filter arter passing through oil removal equipment. The choice of oil removal facilities is dependent upon the form of oil: i.e., dissolved, suspended, or enulsified. The study design includes deep-bea precuat oil removal filters containing anthacite. The filter bed is precoated with an alum-soda ash laix and has a stiall continuous body feed.

A fundamental Hlow diagram of the system is shown on Drawing No. 12977-EP-2A located in Appendix. B.

4.4.1.2.8 Waste Treatument system

In the October 8. $19 \% 4$, Federal Register. EPA reported final eftluent guidelines for the steam electric power generating industry. The wastewater treatment described below will comply with the new source performance standards.

Liguia wastes from the station include water treatment wastes (suspended solidis, acid, caustic, oil). steall plant wastes (floor drainaje, equipment washing wastes, boiler chemical cleaning wastes, boiler blowdown), storm drainage Gara and rool drainage. coal pile runoff). aná sanitary systems.

for coal-fired operation, the bottom ash sluicing is a closed recirculating system incorporating dewatering bins and a claritier with makeup from the wastewater system.

The water treatuent plant clarifier underflow is punped to a thickener and thickener solids are dewatered and sent to a aisposal site. The overtlow is recycled to the clarifier: water from the vacuum filter is returned to the thickener.

fin impervious holding or equalization basin is utilized to collect all other waste flows. These flows include floor drairiage anc intermittent high-flow wastes, the latter of which are high in suspended solids and dissolved metals. coal pile nunofi, equipuent washing wastes, boiler chemical cleaning wastes, and yard and roof drainage being typical examples. The basin is sized to accommodate wastes from equipment washing andi boilex chenical cleaning when heavy rainfall could result in large coal pile runoff and yara drainaye.

Basin effluent flows to a treatnent system consisting of a settling chanuter with chemical feed and neutralization to control pH within the allowable limits for discharge into the river. The effluent is used as makeup to the ash hardiling system, and also may be recirculated back to the water treatment systen clarifier. 
Sludge from the setting chamber is pumpea to the dewatering equipment and the oil is collected and sent to disposal: a bypass systen is provided for abnormal conditions.

Sanitary wastes are treated in a package plant providing secordary biological treatment and chlorination of the treated effluent priox to äischarge.

The sulfur dioxide scrubber wastewater system is a closed syster incorporating couplete recirculation and requiring disposal of solids mily. The three major system components are the scrubber, reaction tank, and thickerier.

A limestone/water slurry passes through the scrubber where it reacts with the 502 laden tlue gas. The reacted solution is dischargea to the reaction tank where completed chemical reactions yield discardable precipitates. Ihese precipitates are settled in a thickener and removed for aisposal. The clarified thickener water is returned to the srrinher alon; with the reusable scrubbing slurry from the reaction tarik.

A fundamental flow diagram of the system is shown on Drawing No. 12977-EP-2A located in Appendix B.

4.4.1.2.9 H1ectrical System

The proposed coal-fired cogeneration facility generates approximately $448.8 \mathrm{MW}$ (grass) of electrical power. zllowing for generator losses and glant auxiliaries, the net electrical output is 352.2 MWe.

Existing substations located at each user's plant will be retained and modified as necessary to allow integration of the cogeneratea electrical power with the present supply from GSU. The distribution system between the cogeneration plant and the users is capable of delivering 100 percent of the electrical requirements to any user. The distribution of power awong the users should be apportioned by a specific formula developed by them.

Distribution voltage is $138 \mathrm{kV}$ according to present user service. Power is transraitted from the plant via overhead lines suppoxted on wood pole-line structures.

AS shown on Drawing No. 12977-EM-1A, located in Appendix B, electrical distribution follows the piping right-of-way to each user. The switchyards of each user serve as tie points for the distribution circuit.

Reliability is achieved by maintaining power availability from GSU in the event of a failure of the plant generator or distribution circuit. 
Power is generated at $22 \mathrm{kV}, 3$ phase, $60 \mathrm{~Hz}$ and connected to a 395-MVA. 22-138-kV step-up, power transformer through isolated-phase bus. The transformer delivers $138 \mathrm{kV}$ to the plant switchyard for distribution to the four users.

F tap fron the isolated-phase bus connects to the plant auxiliary transformer rated $105 \mathrm{MVA}, 22 \mathrm{kV}-4160 \mathrm{~V}$ and supplies all plait electrical equipment.

Power for startup of the plant and reserve supply for auxiliaries is provided by means of a 138-kV tie from Gsu to the plant switchyard and then to a 105-MVA, 22-kV - 4160-V reserve transfordier. This connection will also assure reliability of stean production in the event of a generator or transfonner failure.

Plant electrical auxiliary equipuent consists of:

- 4-kV metal-clad switchgear rated $350 \mathrm{MVA}$.

- 1500-kVA load center unit substations for 480-V loards.

- 480-V wotor control centers with circuit breaker combination starters.

- Wiring system composed of copper conductor. flame-retaraant cable installed in a raceway system of aluminum ladder tray or rigid steel conduit.

- A lighting systera utilizing fluorescent fixtures. incandescent lamps, or high bay lighting as requirea.

- I common grounding system throughout the plant.

- A communications/paging system.

- An emergency dc supply system derived from 125-V station batteries for small, critical loads and switchyear breaker operations.

\subsection{Structural Criteria}

Foundations: Available soil information for the proposed plant indicates that pile foundations may be required for major structures and equipment. The cost estimate includes pile foundations for all plant structures, piperacks, water treatment facilities, and other small buildings. Fuel oil tanks are supported on select compacted backfill. No ringwall foundation is included. 
Yardwork: The cost estimate includes clearing and grubbing the site. local excavation and spoiling of undesirable material, railioad trackwork, permanent plant rcads, and fencing. filso included are the costs for construction of two bridge structures over the New River for roadway and railroad, earth dikes for the fuel oil tanks, a waste holding basin. aud various other hydraulic structures.

Euildings and Other structures: Cost estimates of auxiliary tuildiings are based on a seni-outdoor design. They include two exposea boilers with enclosures over fronts and tops. Snall enclosures are rrovided for each of the force draft fans. Conmon to the boilers is a 275-foot concrete stack erected on a concrete mat supported by piles. The stack is provided with steel liner, ladder. plattorms, and aircraft lights.

The water treatuent plant also will be outdoors, except for a single-story laboratory and control building of steel frame with irisulated fitecal siding constructed on a concrete slab on grade. I simular builaing will provide office anö warehouse space.

The turbine builaing is a steel-frame structure enclosed with uninsulated lietal siuing. metal roof deck with insulated built-up asphalt, and gravel roofing. It has a concrete opelatirly 1 loor and ground floor. Galvanized steel grating supported by steel framing is used in general for other floors, walkways, stair treads, and intermediate landings. The turbine generators are supported on concrete pedestals extencing from operating floor level to below grade. The turbine builaing contains a control room, various switch and cable rooms, and a 50-tion capacity overhead crane to service the turbine generators.

Coal barye Unloadiny Lock: is coal barge unloading dock and associated access structures are included in the cost estimate. It is based un using coffer dam cells filled with granular material. Not included in the estinate are dredging and moáifications to existing revetment systems for bank erosion contiul.

\subsubsection{NUCLEZTK PLANTS - ADVANCED TF.CHNOLOGY ONDER DEVEIOF- MENT}

4.4.2.1 Consolidated Nuclear steam Supply System (CNSS Plant)

The CNSS is a 1200-MWt nuclear steam supply system developed by the Baboock and Wilcox Company (BEW) . BEW has prepared a conceptual design to utilize the CNSS for dual purpose steam/electric power generation.(19) This conceptual design study. done under contract for union Carbide lOak Ridge 
National Laboratoryl and the U.S. Energy Restarch and Development Adninistration, was derived iron nuclear merchant ship propulsion steam systems. It is distinctly different in detail and incorporates steara generators within the reactor pressure vessel. This section reviews the highilghts of the CNSS design. In addition, modifications or additions to the CNSS design which are required for this site are identified and hescribed in sufficient detail to allow the cost estinates developed by $\mathrm{B} \& \mathrm{~W}$ to be appropriately aújustea.

\subsection{Nuclear Steam Supply System (NSSS)}

Whe CNSS is a pressurized water reactor system with both the reactor core and the stean generators located inside the reactor pressure vessel. The reactor consists of 97 tuel assemblies each consisting uf 208 fuel rods, 16 control rod guide trabes, and one instrumentation tube arranged in a $15 \times 15$ array. The fuel is uranium, enriched to about 3.43 wt. $\%$ uzs. The total core loading is 37 ritetric tons of uranium. The core is water cooled and water roderated.

The CNSS utilizes a straight-tube, tube-and-shell. once-through stean yenexatox (OrSG) which, in the referenced stuay, was ar integral part ot the reactor pressure vessel. primary fluia (reactor coolant) flows inside the tubes ana generates steam on the shell sice. At full power the cNss produces $5,290,0001 \mathrm{~b} / \mathrm{hr}$ of saturated steam at 935 usla and $536.5 \mathrm{~F}$. More recent desiyns incorporate ten nodular replacelient units withir the reactor vessel. It is also possible to isolate each unit individually.

Eight reactor coolant puups circulate reactor coolant through the core and the once-through stean generator. The pumps are vertically mounted on penetrations in the reactor pressure vessel head.

Core reactivity is controlled by a conbination of lixed burnable poison. soluble poison (boric acid) in the privary coolant, and movable control rods. $A$ chemical addition and boron recuvery systen is utilized to control the concentration of soluble poison in the primary coolant. ihirty-seven control rod drive mechanisms are used to position control rod assemblies within the reactor core. The control rod drive mecharisms are mounted on penetrations in the reactor pressure vessel head.

A pressurizex is utilized to cuntrol reactor coolant system pressure at about 2.250 psia. The pressurizer is a vertical cylinarical vessel connected to the reactor pressure vessel by four garallel surge lines and one spray line. Electric heater elements in the lower section of the pressurizer along with a water spray nozzle in the upper section 
maintain the water/steam syster at a saturation pressure corresponding to the desired reactor coolant pressure.

4.4.2.1.2 Thermal cycie

The cunceptual design of the CNSS cogeneration plant was basea on two majur assumptions:

1. A reboiler is necessary to reduce the probability of radiadctive stearn being released to the industrial customers.

2. Process steăm must be superheated.

A precedent for using a reboiler to supply process steam using a pressured water reactor (PFR) NSSS has been set at the Midland plant.(20) This plant is a joint venture of the Consuriers Power Company and Dow Chemical Company and will utilize two $B \& W$ pressured water reactors as heat sources. The reboilex is capable of suplying $4 \times 10^{6} \mathrm{lb} / \mathrm{hr}$ of steam for Low Chemical process use. A reboiler is necessary for the cogeneration application to minimize the radioactivity steam release to the industrial users. The reboiler serves as a secona barrier to the radioactive primary coolant. The once-through steari generator is the first barrier. Cogenerating without the reboiler would require either:

1. A sophisticateä process radiation monitoring scheme to terminate stealn to customers in the event of a tube leak in the once-through steam yenerator.

2. In elaborate wonitoring and control system for potentially radioactive steam/condensate throughout the customer's plants.

Alternate 1. would result in low plant reliability because relatively minor once-through steain generator tube leaks woulä result in plant shutaiown. Alternate 2. would be costly. require contiruous mainterance, and be impractical for inaustrial users.

The conceptual ajesign for the cNSS cogeneration plant for the Geismar region includes two 1200 MWt reactors. These reactors will operate at about 60-percent capacity for the design process steam requirements. Either reactor alone can rovide approximately 80 percent of the steam requirements. reducing the need for backup heat sources. There is also antole margin for expansion.

A reboiler and No. 6 fuel oil-fired superheater provide steam at 690 ysia and $750 \mathrm{~F}$. About 74 percent of this is process stean. The remainder is expanded through a single 
autoratic extraction noncondensing turbine supplying process steari at 290 psia and deaerating steam at 45 psia.

At the Geismar site there is a Nonochem requirement oi $370.000 \mathrm{lb} / \mathrm{hr}$ of steall at 970 psia and $850 \mathrm{~F}$. The desigr includes a No. b tuel oil-iired steam generator to provide this requirement. The steam generator is supplied with fecdwater froil the lialin teedwater pumps through booster pumps. Feedwater heating is obtained from the deaerator which receives its heat from the turbine exhaust.

About 80 fercent of the total heat input to the cycle is provided by the nuclear reactors. Gross electric generation is 3.8 percent of the total heat input. These numiers reflect lie Lasic limitations of a PWR system for cogeneration.

4.4.2.1.3 Plant Arrangerwent

The BEW study includes a plot plan and building arrangement drawings for a 400-MWe central generating plant located at a standard hypothetical site. The plot plan would have to be wodified to conform to the specifics of this particular site and to reflect the plant's use for cogeneration rather than central station electric generation.

Modifications. to the plant arrangement would include elimination of the circulating water intake structure and piqing and adcition of oil-fired superheater and boiler. each with a precipitator and common scrubber and stack, fuel oil storage tank, and pumphouse. Reboilers, deaerator, and boiler feed pumps would be located in the turbine building.

The major changes froin the $B \& W$ study are addition of the following:

No. 6 Fuel Oil-Fired Superheater Including Precipitator

Ash Handling System

No. 6 Fuel Oil-Fired Boiler Including Precipitator

Ash Handiling System

Stack - Cormon to superheater and Boiler

Scrubber - Common to Superheater and Boiler

Reboilers

91-NW, Noncondensing. Steam Turbine Generator

Deaerator

Boiler Feed pumps

91-MW substation

Fuel Oil Storage Tank

Fuel Oil pumps and pumphouse

$$
4-63
$$


Deletion of the tollowing:

Two 400-MW, Condensing lurvine Generators

Two Conciensers

'Two Circulating watex systems

Two Circulating Water Intake Structures

Iwo 400-Nih substations

4.4.2. 1.4 Reactor Containment

The Cuss reactur containment, as described in the referenced study, is a tree-stanaing. bottom-supported steel vessel 45 feet in dianetex and 95 feet high. The containnent is further enclosed in a 4-foot thick concrete biological shield with a 57-toot outside diameter. The containment is housed in the reactor service building.

The reactor containment in the referenced study is a pressure-suppression tye which utilizes a pool of water to cordense steam resulting licui a postulated loes of coolant. accident (LOCid). The design basis LOCA for the CNSS is a duuble-erded ruptuxe of ore of the 3.5-inch inside diameter pressurizer surge lines. Hit resulting coolant loss rate is relatively slow conlarea to the design basis LOCA in lwo-type pressuxized water reactors and rakes the use of pressure-suppression containment feasible. Condensing the steam from the postulated LOCF allows the containment to be relatively siall whlle maintairing a reasonable design pressure of afproximately 105 psig. More recent studies by $\mathrm{BEW}$ have found that the LOCA can be handled with a dry containmerit.

The concrete biological suxeld provides radiation shielaing and. In comjunction with the reactor service building ventilation systeri, an aciaitional barrier to uncontrolled release of leakaye frcau the containment.

4.4.2.1.5 Fuel Handiling jystem

The tuel handilng system for the CNSS is similar to that for other pressurized water reactars. Spent fuel is handled under borated watex as it is transferred from the reactor pressure vessel to the spent tuel pool where it is allowed to cool tor approximately 1 year. The spent fuel can thus be loaded, still underwater. into casks for shipnent to offsite storage or to a reprocessing facility.

The BEW study includes a detailed description of the various components of the tuel handling equipment and the associated procedures. A critical path analysis of the refueling procedure is provideà which indicates that the procedure can be completed in 392 hours (16.3 days). For the economic analysis $B E W$ assumed a 50-day refueling outage.

$$
4-64
$$


Two refueling schemes were investigated by B\&w; a 12-nonth and 15-month tuel cycle. The econonic analysis presented by $B G W$ shows a small difference in the fuel cost for the two schenes llevelized cost of 58.5 cents/10 Btu for the 12-inonth cycle and 61.2 cents/106 Btu for the 15 -month cycles - While the dicual cycle chosen depends on many tactors, basically the 15 -month cycle represents higher plant availability but results in refueling during all quarters of the year, while the 12-month cycle permits refueling during a given quarter of the year, year after year. We have basea our evaluation on the 12-nonth cycle because we believe it woulc be more attractive to industrial users. The cost difference between the two refueling schemes is so sluall that going to the 15-month cycle would have negligible allect on the results of the study-

\subsection{Turoine Generator and stean cycle}

urawing No. 12977 LP-2H, located in Appendix B, illustrates the heat cycle and fundanental flow diagram for the cNsis. Basically, the steam from the CNSS is utilized as the heat source for reboilers which generate steam to meet the projected 1985 combined demands of Monochem Inc.. BASF Wyandotte Chemical company, shell Chemical, and vulcan Chemica1. If required. backup steam is provided by existing stean generating lacilities. Stean from the reboiler is sent via an oil-rired superheater to the industrial users and extanded through a steau turbine. The exhaust of the turbine is utilized in a deaerator to preheat condensate which is either returned from the industrial users or supplied as makeup. Steam is extracted at 290 psia for industrial user consunption. Included in this arrangement is a No. 6 tuel oil-1ired boiler rated at $370,0001 \mathrm{~b} / \mathrm{hr}$ of steam at 970 psia and 850 F. Major boiler accessories include feedwater pumps, precipitator, scrubber, and a comulon stack for boiler and superheater.

The nonoundensing stean turinine with backpressure control operates with initet steam of 690 asia and 750 degrees FIT, $1,764.539 \mathrm{lb} / \mathrm{hr}$ throttle flow and 45 psia exhaust pressure. process steam is extracted at 290 psia at a rate of 450.000 $\mathrm{lb} / \mathrm{hr}$. The turbine is connected to a hydrogen-cooled genexator rated at $100 \mathrm{MVA} 0.9 \mathrm{PF}, 22 \mathrm{kV}$ with static excitation system.

A deaerator is included in the heat cycle. It operates at $45 \mathrm{psia}$ and 1,314,539 $\mathrm{ib} / \mathrm{hr}$. Deaerating steam is supplied from the 45 psia turbine extraction.

Three 50-percent capacity, motor-driven boiler feeo pumps arranged in paralled are also included in the heat cycle. 
One No. 6 fuel oil-1ired superheater is included to raise the temperature of $6.784 .539 \mathrm{Lb} / \mathrm{hr}$ of steam from $503.1 \mathrm{~F}$ to 750 F to meet users' requirements.

4.4.2.1.7 Radwaste Systern

The CNSS radwaste systen is actually composed of Iive separate systemis:

- Reactor Coolant (Re) Waste System
- Wiquid Waste System
- Saste Lvaporator System
- Gaseous Waste System

The RC waste systeu contains and collects liquid anö gaseous waste from normal plant letdown, pressurizer relief valve discharge. leakaye, and maintenance drainage. These wastes are routed to the liquid or gaseous waste systeris or recyeled to the pribary system as appropriate.

The liquid radwaste system receives and shares liquid waste from the $R C$ and auxiliary systems. Depending on the activity and chemical content. the wastes are routed to the waste evaporator system or the liquid waste demineralizer. Waste of low enough activity is discharged to the erivilonment through radioactivity monitors. Gases evolved from stored licuids are routed through vent headers to the yaseous waste systerm.

The waste evaporator system separates liquid into distillate and concentrated solutions. The distillate, if pure enough, is stored tor reuse or discharged. If not, it is reprocessed through the waste evaporator. The concentrate is either transferred to concentrated boric acid storage or to the solid waste disposal system depending on analysis results.

The solid waste aisposal system provides for packaging, storage, and offsite shipment of solid and semi-solid radioactive wastes. The solid waste system is used to process low-level wastes such as contaminated rags. papers. filter cartridges, etc.. and high-level wastes such as spent deruineralizer resins and concentrate from the waste evaporator.

The gaseous waste systerus collect waste gases from reactor plant systems in their separate vent headers: low activity. nitxogen-rich, and hydrogen-rich. The low-activity gaseous wastes are vented through filters and the plant stack to the atmosphere. The $\mathrm{H} 2-\mathrm{xich}$ yases are processed through a recombiner to reduce the quantity of $\mathrm{H} 2$. The gases are then 
cumpressed and stored in decay tank for subsequent discharge.

The BEW report includes additional descriptions and flow diagrams for each radioactive waste system.

4.4.2.1.8 Ultimate Heat Sink

Since this site has ready access to Mississippi River water. $B E W$ design was found dequate for decay heat removal and no chariges to the systern were necessary.

4.4.2.1.9 Water Treatment System

Dne to lack of information in the BEW report, il is uut possible to elaborate on the plant water treating systell and equipment.

4.4.2.1.10 Electrical System

The electrical system for the CNSS is basically composed of four major parts; i.e.. satety-related (Class IE), balance of plant, generation, and distribution systems.

Due to lack of information in the $B E W$ report on safetyrelated and balance of plant systems, it is not possible to elaborate on these plant electrical systems and equipment.

The generation equipgent is described in Section 4.4.2.1.6 The following discussion is devoted to the distribution system and the apportionwent of output to sizers.

The proposed CNSS cogeneration facility produces approximately $89 \mathrm{MW}$ of electrical power. A total of $50 \mathrm{MWe}$ will be used for plant auxiliaries leaving 39 MWe net output available to the users.

Wxisting substations located at each user's plant are being retained and modified as necessary to allow integration of the cogenerated electrical power with the present supply from GSU. The distribution system between the cogeneration plant and the users is capable of delivering 100 percent of the electrical requirements to any user. The distribution of power among the users should be apportioned by a specific formula developed by them.

Distribution voltage is $138 \mathrm{kV}$ or according to present user service. Power is transmitted from the plant via overhead lines supported on wood pole-line structures. 
fis shown on Drawing No. 12977-LM-1B, located in appendix B, electrical distribution follows the piping right-of-way to each user. The switchyards of each user serve as tie points for the distribution circuit.

Reliability is achieved by maintaining power availability Iron GSU in the event of a failure of the cogeneration plant generator or ästribution circuit.

Power is gentexated at $\angle 2 \mathrm{kV}, 3$ phase, $60 \mathrm{liz}$ and connected to a 41-MVA, $22-138-k V$ step-up power transtormer through isolated-phase bus. The transformer delivers $138 \mathrm{kV}$ to the plant switchyard for distribution to the four users.

A tap from the isolatea-phase bus connects to the plant nonial station service transformer rated $58 \mathrm{MVK}$. ¿2 kV-4160 V and supplies all plant electrical equipment.

rower for startuy of the plant and reserve supply for aluxiliaries is provined hy means of a $138 \mathrm{kV}$ tie from gsu to the plant switchyard and then to a 58-MVA, 22-kV - 4160-V reserve station service transformer. This connection also assures reliability of steain production in the event of a generator or transformer failure.

4.4.2.1.11 structural Criteria

Due to lack of information in the BEW report. it is not possible to elaborate on plant structural considerations and criterìa.

4.4.2.2 High Temperature Gas-Cooled Reactor Steamer (HTGR stearner)

The HPGR steamer. is a 1200-MN modification of the Fort st. Vrain nuclear steam supply system which was designed and constructed by General Atomic Company.(21) This section presents the highlights of the HIGR steamer design. Three steaniers are reconmended for this site.

4.4.2.2.1 Heat Cycile Optimization

Steam Pressure Determination: The cycles developed by the General Atomic Conpariy for the HTGK steamer at orange were also applicable to the cogeneration plant at Geisinar. As determined in section 4.3.2.2.1. Cycle IV was selected because of the increased power generation resulting from the higher throttle pressure and higher feedwater temperature. The following table compares the various cycles. 
TAble 4-8

COMPARISON OF POUR CYCLES FOR HTGR STEAMLK

\begin{tabular}{|c|c|c|c|c|}
\hline & $\mathrm{IB}$ & $\underline{I I}$ & III & IV \\
\hline $\begin{array}{l}\text { Stean Pressure, psia* } \\
\text { Steam Temperature, A* }\end{array}$ & $\begin{array}{r}1600 \\
940\end{array}$ & $\begin{array}{l}2415 \\
1000\end{array}$ & $\begin{array}{l}2968 \\
1052\end{array}$ & $\begin{array}{l}2968 \\
1052\end{array}$ \\
\hline $\begin{array}{l}\text { Process steam, } 1000 \mathrm{lb} / \mathrm{hr} \\
\text { Gross } \mathrm{khh} / 1000 \mathrm{lb}\end{array}$ & 2809 & 2800 & 2750.5 & 2195 \\
\hline
\end{tabular}

* Leaving the superheaters of the steam generators. * Generation based on $S \varepsilon W$ assumed efficiencies and calculations.

For a giver process stean flow, Cycle II produces 25.5 percent nore power than cycle IB, and cycle III produces 20 percent more power than Cycle II. The levelized net credit for: power over the life of the plant, aiter taking into account the operating costs, is projected to be on the order of $80 \mu i l l s / \mathrm{kWh}$. This yields a capitalized value for $1 \mathrm{~kW}$ of about $\$ 3,900$. (escalated capital costs plus interest during construction) assuming 7.884 hours of operation per year arià a fixed charge rate of 16 percent. It is estimated that the differential capital cost per $\mathrm{kW}$ between the cycles is less than this; hence, cycle III enterges as the most economical choice.

Steam Tuxine selection: Cycle IV was adapted to the process steam requirements at Geismar by adding an extraction at 970 psia and increasing the 640 psia to 690 psia. The three reactors required to meet the projected 1985 stearn dellarid will initially operate at about 74 -percent capacity. The 690 psia steam which constitutes 86 percent of the process requircments will be provided by two straight noncondensing turbines each rated at $94.1 \mathrm{MW}$. The 970 psia stean is providea by a single automatic extraction turbine which exhausts at 290 psia. Separate turbines were considered for these two pressures but were found to be narginal. The feedwater heating steam is provided by a triple uncontrolled extraction turbine which extsausts at 8.42 psia. f throttle pressure of $2.415 \mathrm{psia}$ was used for this unit for a slightly better efficiency and corresponding increase in electric output.

Number of Feedwater Heaters: The final feedwater temperature selected by the General Atomic Company is $435 \mathrm{~F}$. To provide this teraperature, a high-pressure deaerator (100 psia) is utilized in conjunction with two low-pressure heaters operating at 8 psia and 36 psia and a high-pressure heater oferating at $362.2 \mathrm{psia}$. This arrangement generates about $8 \mathrm{MW}$ wore than the fossil-fired arrangement. Closed 
heaters operatiny under vacuuia introduce some complications in a noncondensing cycle, but the additional power produced makes it attractive.

4.4.2.2.2 Nuclear stearn Supply System (NSSS)

The HTGK steamer is a high temperature gas-cooled reactor with the reactor core, steain generator. and helium circulators all located within a prestressed concrete reactor vessel (PCRV). The active core is helium-cooled and contains 1,482 fuel elements in a closely packed hexagonal array. 74 control rod elements, and 37 control rod drives. Fissile U23s and fertile $T^{232}$ fuel particles contained within bonded carbonaceous rods are inserted into the hexagonal graphite iwoderator structures.

The HIGR has unique flexibility because it can utilize both the roliferation-proof low-enriched uranium/thoriun cycle and the previousiy described highly enriched wranium thorium crole. $x$ is important that these cycles be essentially interchangeable, so that the HrGR steamer can start with one cycle and change to another later with little operational penalty and/or nodirication to the reactor plant.

Two independent subsystems control core reactivity - Normal reactor control is accoraplishea by 37 control rod drives mounted in top head penetrations. Each operates a pair of control rods. in independent reserve system utilizing boronated graphite pellets is designed to scram the reactor in the event of normal control system malfunction. pellets are dropped into the core through a guide tube to retard core activity.

Four stean turbine driven helium circulators funp prinary coolant through the core from the top of the steam generator. The circulators are mounted in penetrations on the PCRV in the plenum area under the core.

The HrGR steamer employs four steam generators to froduce superheated steam used to drive the helium circulators and turbine generators. They are also mounted in penetrations on the PCRV in the plenum area under the core. Hot helium flows down over the single helically coiled steam generator bundle counter to the flow of steam and out the bottom of the shroud. Feedwater entering the steam generator flows up through parallel helical coils to the top of the bundle. through a 1800F turnaround, and down the center to the superheater coils. At full power, with $435^{\circ} \mathrm{F}$ feedwater. each HTGR steamer produces $3.910 .820 \mathrm{lb} / \mathrm{hr}$ of primary steam at 2,968 psia and $1,052 \circ$. After expansion of the primary steam in the circulator turbines, it is available at 2,415 psia and $1,000^{\circ} \mathrm{F}$ for process use. 
4.4.2.2.3 Plant Anrangenent

The General Atomic study includes a steamer plant layout which requires modifications to adapt it to the specific site. The reactor containment building houses the reactor, prestressed concrete reactor vessel. steam generators. helium circulators, and auxiliary systems for startup and emergency cooling.

The turbine building contains the turbine generators and other heat cycle equipment. other buildings include facilities for helium storaye, fuel storage, radioactive waste treatuent, diesel generators, and plant controls.

4.4.2.2.4 Reactor Containment

The PCRV serves the dual function of containing the coolant and providing radiological shielding. This protection is provided by walls with a nominal thickness of 9 feet and heads that are norilnally 15 feet thick. The PCRV. which houses the stean generators, circulators, and the core, has an internal diameter of 31 feet and an internal height of 67 feet. Its exterior dimensions are 55 feet diameter and 98.8 feet high. The prestressing system employs a combination of internal vertical tendons and $360 \% \mathrm{~F}$ wirewrapped circunferential tendons that are in molded channels on the outside surface of the PCRV. In the top head are penetrations and wells to house the helium purification systien and neutron chamber as well as the control rod drives. Penetrations in the bottom head include those for the four steam yenerators and the four helium circulators.

\subsection{Fuel Hanaling system}

Refueling of the HTGR steamer is accomplished during shutdown and depressurized conditions while maintaining the gas-tight integrity of the prestressed concrete reactor vessel. Control rod drives are removed in an auxiliary service cask. The tuel handling equipment then removes spent fuel and instails new fuel through the control rod drive penetrations. Approximately one-quarter of the core is replaced each year. The tine required for replacement of about 500 fuel elements is estimated to be 10 days.

4.4.2.2.6 Turbine Generator and Steam Cycle

Drawing No. 12977 EP-2J, located in Appendix B, illustrates the heat cycle and fundamental flow diagram for the HTGR steamer. Basically, stean generated by the three HTGR's is utilized to drive the helium circulators and the four steam turbine generators and to provide the process steam required to meet the 1985 steam demand of Monochem Inc., BASF 
Wyandotte cheraical Company, Shell Chemical, and Vulcan chenical.

The major equipment contained in this plant consists of:

- Four nonconciensing steam turbine generators rated at $3.600 \mathrm{rpm}$ with backpressure governor for operation with inlet steam at 2,415 psia and 1,000 FFY.

Two units each require a throttle flow of $2.510 .000 \mathrm{Ib} / \mathrm{hr}$ exhaust to $690 \mathrm{psia}$ and are connected to hydrogen-cooled generators rated at $104.5 \mathrm{MVA}, 0.9 \mathrm{PF}, 13.8 \mathrm{kV}$ with static excitation.

One unit requires a throttle flow of $820,0001 \mathrm{~b} / \mathrm{hr}$. exhausts to 290 psia and is connected to an air-couled generator rated at $40 \mathrm{MVA}, 0.9 \mathrm{PF}$. $13.8 \mathrm{kV}$ with static excitation systew. Extraction from this turbine provides $370.00016 / \mathrm{hr}$ of 970 psia process steant.

One unit requires a throttle flow of $2.793 .414 \mathrm{lio/nr}$. exhausts to a feedwater heater at $8.42 \mathrm{psia}$, and is connected to a hydrogen-cooled generator rated at $265 \mathrm{MVA}, 0.9 \mathrm{PF}, 22 \mathrm{kV}$ with static excitation. Extractions from this turbine at $3.813 \mathrm{psia}$ and $936,648 \mathrm{lb} / \mathrm{hr}, 105.3 \mathrm{psia}$ and $570.114 \mathrm{Lb} / \mathrm{hr}$, arö 37.9. psia, and $573.544 \mathrm{lb} / \mathrm{hr}$ are utilized for feedwater heating in two shell-and-tule heaters and a dearating.

- One deaerating feedwater heater operating at 100 psia and $570,114 \mathrm{lb} / \mathrm{hr}$.

- Four one-third capacity motor-driven feed pumps.

- One low-pressure heater drains pump.

- One shell-and-tube low-pressure heater operating at 8 psia and a steali flow of $713,108 \mathrm{lb} / \mathrm{hr}$.

- One shell-and-tuke low pressure heater operating at 36 psia and $573,544 \mathrm{lb} / \mathrm{hr}$.

One shell-ard-tube high-pressure heater operating at $362.2 \mathrm{ps} 2 \mathrm{a}$ and $936,648 \mathrm{lb} / \mathrm{Mr}$.

4.4.2.2.7 Electrical system

The proposed HFGR cogeneration facility will produce approximately $462.1 \mathrm{~kW}$ of electrical power. A total of 
$72 \mathrm{MW}$ will be used for plant auxiliaries leaving $391 \mathrm{MW}$ net output available to the users.

The electrical systeri for the HTGR cogeneration facility is composed of four parts; i.e.. safety-related (Class 1E). balance of plant generation, and distribution systens.

Satety-Related (Class IE) Electrical System: The class IE electrical systeu provides a reiiable source of electrical power for sale reactor shutaow under emergency conaitions and/or during loss of offsite power. Major portions of the class IE electrical system are:

- Stanaby power supply consisting of ane or nore diesel generators capable of supplying full power to the 4160-V safety-related buses.

-4160-V satety-related distribution systent
consisting of switcingear, buswork, cable, and associated controls.

- 480-V safety-related distribution system consisting of load center substations, motor control centers, power parels, buswork cable, and associated controls.

- 120/208-V uninterruptible power supply.

- $250 / 125-V$ de systern consisting of station batteries and chargers.

- Raceway systeru.

Balance of Plant ilectrical system: This portion of the plant electrical systen is cesigned to supply reliable and safely controlled power to turbines, reactors, and miscellaneous plarit auxiliaries during all modes of normal plant operation and shutdown conditions. Major portions of this system are:

- 4160-V norwal distribution system consisting of switchgear, tuswork. cable, and associated controls for nonsatety-related loads.

480-V normal distribution system consisting of load center substations, motor control centers, power panels. buswork, cable, and associated controls for nonsafety-related loads.

250/125-V dc systera consisting of station batteries and charger's for supply of $d c$ power to emergency loads of the turbine generator. feedwater. pumps. 
switchgear, control and instrument functions, and lighting.

- 120-V regulateá instrument power system.

- Raceway system.

Plant lighting system.

Intraplant comunications and paging system.

Grounding systen.

Generation Syster: power will be generated by means of four generators rated 104.5, 104.5, 40, and 265 MVA as described earlier. Each generator will be connected to a step-up power transformer by means of isolated-phase bas. The four step-up power transtommers will be rated 76, 76, 39, and 233 MVA, respective $I_{Y}$.

Fuxiliary power for the plant will be provided by three 27-MVA, normal station service transformers connected to three of the four generators through a tap in the isolatedphase bus.

Offsite power for plant startup and reserve will be supplied from the 138-kV switchyard tirough three 27-MVA reserve station service transformers. These transformers will supply the 4160-V buses for each of the three units during startup. shutaown, or emergency operation.

Distribution Systen: ixisting substations located at each user's plant will be retained and modified as necessary to allow integration of the cogenerated electrical power with the present supply from GSU. The distribution system between the cogeneration plant and the users is capable of delivering 100 percent of the electrical requirements of any user. The distribution of power among the users should be apportioned by a specific formula developed by them.

Distribution voltage is $138 \mathrm{kV}$. Power is transmitted from the plant via overhead lines supported on wood pole-line structures.

As shown on Drawing No. 12977-EM1B. 1ocated in Appendix $B$, electrical distribution follows the piping right-of-way to each user. The switchyards of each user also serve as tie points for the distribution circuit.

Reliability is achieved by maintaining power availability from GSU in the event of a failure of the plant generator or distribution circuit. 


\subsection{Raơwaste System}

The radioactive waste system of the HTGR steamer includes liquid and gas waste systems and is designed to preclude the release of activity from the plant in excess of allowable 1imits. Since the HTGK does not produce significant amounls of solid wastes as a result of normal operations, an elaborate handling systeri is not required. Solid wastes that are generated are packaged in drums and shipped offsite for disposal.

Radioactive liquids will not be produced by the HrGR steamer in substantial quantities during normal operation. However. there is a liquid waste syster for handling radioactive liquids generated by infrequent evolutions such as decontamination, anà potential acciaent situations (steam generator tube failure). Low-level liquid waste is collected in a sump and pumped through a filter to a liquid waste receiver for sampling and subsequent discharge through radioactivity monitors. High-level liquid waste such as that producea during decontaxination operations are prefiltered in the decontamination system before transfer to the liquid waste receivers.

Gases generated in the liquid waste receivers are vented to the gaseous waste system. Radioactive gaseous wastes from the heliua purification systen, fuel storage facility purge and exhaust systelius, and the liquid waste receivers are collected and airected to either the low-activity inlet header or the high-activity inlet header for processing. Low-activity gases are filtered to remove particulate matter and iodine before release through the reactor plant exhaust system. High-activity gases are accummlated in storage tanks, isolated, and analyzed for isotopic composition and then released at a controlled rate to the reactor plant exhaust system.

\subsection{Water Treäment System}

The nonsafety-class water treatment system consists of the equipkent. requixed for condensate demineralization. teedwater treatment, and makeup water treatment. The quality of feedwater required is similar to that for a once-through stean generating system.

The nuclear steam system does not have any planned consumption of high purity water. Bearing water drains from the main circulator service system are normally returned to the heat cycle and the quantity so drained is replenished by a makeup stream from the feedwater pump discharge. Leakage from bearing water pump shaft seals and valve stems is expected to be insignificant under normal care and maintenarce. Juring any conditions involving combined 
turbine rip and luss of outside electric power. steam relief to atmosphere fox limated periods would result in a demand on the storage of condensate.

The full-flow deruneralizer system design is based on plant requirements. The system consists of mixed-bed deruineralizers; tull turbine load can be carried while one mixed-bed demineralizer is being regenerated or on standby. Fost-filturc are linvined downstream of the demineralizers to prevent carryover of lines to the steam generators. Condensate, aiter passing through the gland steam condenser. flows through the mixed beas and filters and then on to the low-pressure feeciwater heaters. in full-flow bypass is provided for eluergency operation.

The makeup pretredment and atemineralizer system for the entire two-unit pladut consists of a clarifier with sodium hypochlorite, line, ferrous sulfate, and spare chemical feeders tollowed by two gravity filters and a filtered water clearwell with trassfer pumps. The demineralizer section consists of two trains, each containiay a carbon filter. cation. anion, and nixed-bed unit followed by $a$ denineralized water storage tank with sufficient capacity to regenerate one complete train. Denineralized water transfer punps feed tu the condensers for deaeration and then to the condensate storage tanks of both units.

The regeneratiun system consists of sulfuric acid and sodium ryöroxide storage tanks, automatically controlled metering puwps, and the necessary piping, valves, and controls.

The reyenerant waste disposal system accepts regeneration wastes from both the condensate polishing and makeup denineralizing systems. This system consists of a neutralizing tank, recirculation cump, mixer, and pH control for addition of acid or caustic to neutralize the regenerant wastes. The neutralized wastes are then bled at a controlled rate into the makeup supply or discharged to the river.

The pretreatment waste disposal system accepts blowdown and backwash from the clarifier. gravity filters, and carbon filters. This system consists of a compartmented sludye layoon. The individual compartments can be successively filled and decanted with the decant water drained at a controlled rate into the makeup supply or discharged to the river.

Oily wastes from the turbine room sumps and deluge water are drained into a surge pond followed by an oil/water separator. The separated oil and sludge are transported for offsite disposal and the water is degraded in an oxidation 
pord before disposal at a controlled rate into the makeup supply or aischarged to the river.

4.4 .2 .2 .10 01tiwate Heat sink

To renove decay heat from the reactor on shutdown, a cooling system consisting of iritake structure, vertical cooling water pumps, traveling screens, trash rake, and gantry crane häve been incluảea in plant design. Redundant pumping equipuent has also been included. Cooling water will be taken from the Mississippi River.

4.4.2.2.11 Builaings and Other Structures

This section describes the niajor structuree of a IITGR nuclear power station. Table 4-9 lists the safety classifications of these structures. Safety classes are in contormance with present-day nuclear safety criteria.

Prestressed Concrete Reactor Vessel: The PCRV contains and shielo's the reactor core and the entire primary coolant system. including the stearu yenerators and helium circulators. It tunctions as the primary coolant system pressure boundary. The camplete PCRV is composed of: an internal steel liner acting as a sealing membrane; a thexmal barrier anä cooling system to linit concrete temperatures; 
TABLE 4-9

SAFETY CLASSIFICATION OF STRUCTURES

Structure

Safety* Safety* Safety* No Safety**

Class 1 Class 2 Cláss 3 Class

Reactor Contaimient

Builaing, Ferietra-

tions, and Hatches

$\mathbf{X}$

Keactor Service

Euilding

$\mathrm{X}$

Control Euilaing

$\mathrm{x}$

penetration

Building.

$\mathrm{x}$

fuxiliary Circulator

Power Supply Buildings

$\mathrm{x}$

Diesel Generator

Building

$x$

Turbine Builaing

$\mathbf{x}$

Helium Storage

Building

$x$

ficid and Caustic

storage structure

$\mathrm{X}$

Raw Water Intake

Building

$\mathrm{x}$

Reactor Containment

Building Interior

Structures

$\mathrm{X}$

Substation

Structures

$\mathrm{X}$

Sewage rreatment

Plant

$\mathrm{X}$

Water Treatment

Building

$\mathbf{x}$

Office and Service

Building. 
TABLE 4-9 (Cont)

SAFETY CEASSIFICATION OF STRUCTURES

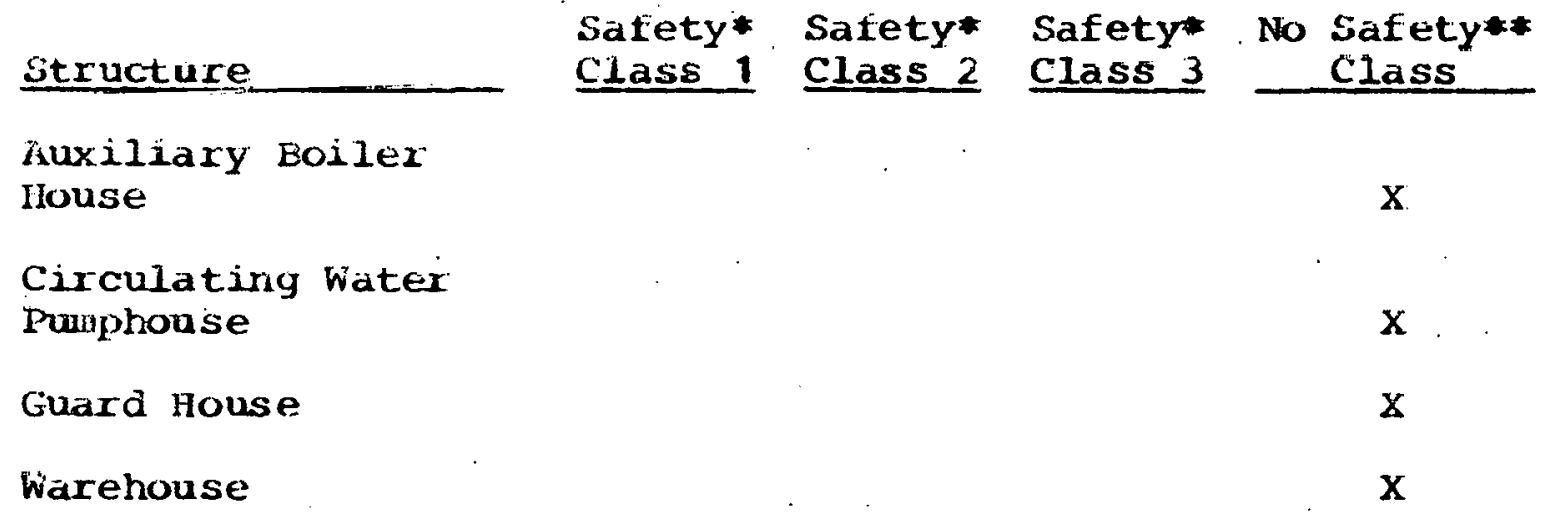

*A. Iso Seisric Category I structures.

* *ilso nonseismic category structures.

penetrations and closures to provide access to the vessel cavities; and high-strength concrete with bonded reinforcing steel and prestressing systems to provide strength. The entire assembly is wounted on a support structure. The liner. concrete, reinforcing steel, and prestressing systems function as a composite structural system.

Reactor Contaimuent blilding: The reactor containment building is a Safety class 2. Seismic Category I structure which provides a leakage barrier against significant fission product release to the atuosphere following an accident. The reactor containment building allows the atrospheric density. in the PCRV to be maintained as required for adequate core cooling following a design basis accident. The concrete structure also provides shielding from fission products which could be airborne within the building under accident conditions.

The reactor containment building is a cylindrical; prestressed concrete structure bearing on sound soil. The foundation mat has conventional steel reinforcing. The cylindrical walls are prestressed with a post-tensioning tendan system in the vertical and horizontal directions. The dame is prestressed utilizing a three-way post-tensioning tencion system: Anchorages for the lower vertical tendon are located in a tendon gallexy. Hoop tendons are anchored to three buttresses. The top vertical tendon anchorage and the dome tendon anchorage are located in the ring girder area. For easy accessibility, the PCRV tendon gallery and the reactor containment building tendon gallery have been cross-connected. 
The inside surface of the reactor containnent building is lined with carbon steel liner plate with stiffeners to ensure a high degree of leak tightness for the containuent. Leak chase channels are provided for the bottom liner plate and for inaccessible areas.

The polar crane, wath main and auxiliary hooks, will be supported from the vertical building walls.

Reactor Service builuing: The safety class 2, Seisraic Category I reactor service building houses new and used fuel storage facilities ana reactor auxiliary systems not located in the reactor contairuent building.

'The primary activity in the reactor service building will be refueling. The reactor will be refueled via the reactor service building through the access door connecting the refueling floor of the reactor containment building to the reactor service builoing. Both new and sipent fuel are haridled through this opening. Refueling equipment is normally stored in the reactor service building and will be transported into the contairuient through the equipment hatch when required.

The fuel storage concrete monolith contains the spent fuel elements. Ihis massive structure comprises the inner core of the reactor service buildirk and is also used for storage of radioactive tools, contiol rods, and other equiprient. The remaining portion of the reactor service building below the refueling floor houses the fuel inspection and sealing facility. equipuent service facility. fuel shipping facility. shipping cask transporter parking and service area, and other auxiliary systems.

A crane mounted on the top of the reactor service building makes all lifts necessary rur storing fuel in the monolith and transferring iuel to the reactor. Also, along with its auxiliary hoist, this crane performs all necessary mainterance lifts. Fuel is transferred to the reactor in a transfer cask.

The reactor service building, a maltistory structure beside the reactor containment building. is structurally independent of the other buildings. The foundation is a reinforced concrete mat on sound soil.

Control Builaing: This is a Safety Class 2. Seismic Category I structure housing the control room. auxiliary electrical equiprent, ventilation equipment, controlled access area, and the reactor plant cooling water system. The following functional areas comprise the control building:

$$
\text { 4-80 }
$$




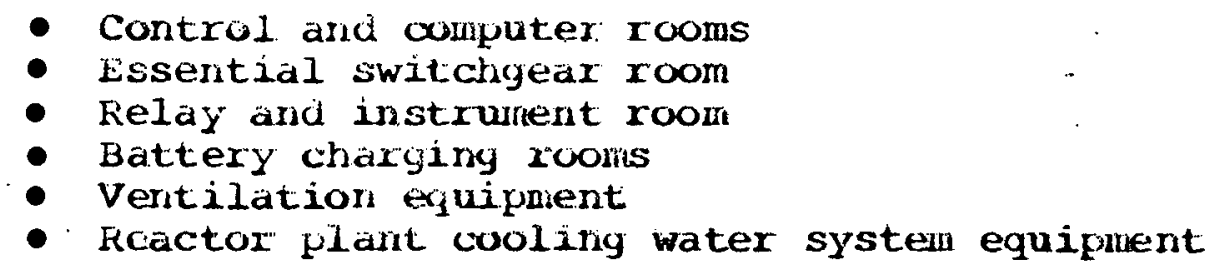

The control building has reinforced concrete floor slabs, walls, and woof. The building is protected from possible raissile damage since it contains safety-related equipment.

Interior walls are reinforced concrete including elevator and stairwell enclosures. thus meeting fire resistance criteria. Walls, floor slab, and ceiling around the control access filters arid emenency charcoal tilters are reinforced concrete for biological shielaing.

Penetration building: The Safety class 2. Seisric Category I penetration builoing protects both safety- and nonsafety-related penterations. The building consists of a turnel housing electrical control and power cables and valve pits housing main steant line stop valves. It is laid out so that it compietely surrounds the reactor containment builaing thereby prutecting tie contairment penetrations at different locations around the perimeter of the containfient structure.

Auxiliary Circulator power supply Building: The safety Class 2. Seismic Category I auxiliary circulator power suply building houses the three auxiliary circulator power supplies. The building is located on the perimeter of the, electrical tunnel. Isuxiliary circulator power supplies are placed 60 degrees apart within the building. Walls, roof, and mat of this structure are designed to withstand the impact of tornado-generated rissiles.

Diesel Generator building: The safety class 2, Seismic Category I diesel yenerator building houses standby power supplies consisting of three diesel generators for each unit.

The diesel generator building is designed to withstand short-term tornado loading including inyact of tornado-generated missiles. Openings are provided with gratings to protect against missiles.

zurbine Building: The turbine building is a nonsafetyclass. nonseisuic-category structure that contains the turbine generator and other equirment related to the conventional portion of the plant.

The turbine builairig is a multistory steel-frane structure with a root of built-uy roofing. rigid insulation, and steel 
deck supported by root purlins and steel frames. The side walls are constructed of insulated metal siding. All floors are of reinforced concrete.

The turbine generator pedestal is a massive reinforced concrete structure designed to supjort the turbine generator with no objectionable deflections. Its natural frequency is above the dynabic vibration irequency of the turbine generator. The turbine generator pedestal is isolated from the turbine bulluing and is supported on adequate subsoil Inateriàl.

A bridge crane is provided to service the turbine building and has access to the laydown area and the railroad access bay.

Helium storaye Builaing: This nonsafety-class, nonseismic categoiy structure houses the primary coolant helium storage bottles. The helium storage building is a pre-engineered stetel ard hetal oiding etructure.

Acid and Caustic storage structure: This nonsafety-class. nonseismic category structure provides storage for acid and caustic reyuired tor plant operation. This building is a lean-to type structure of steel and metal siding.

Raw Water Intake Builciing: This nonsafety-class, nonseismiccategory structure houses equipment required for supply water from a natural source adjacent to the plant. It is a partially subgrade structure. It includes a pumproom house for raw water pumps, a fire-pump pool, and a screening equipment area.

The botton floor slab is a reinforced concrete mat bearing on sound soil. Walls are reinforced concrete. A diesel engine, engine housing, purns, and miscellareous equipment are also supported by a reinforced concrete floor slab.

Miscellaneous Bunldings: The water treatment plant will be outdoors, except for a small laboratory and control building- Also included is a building for office and warehouse space. ithe buildings will be single-story steel-framed structures with insulated metal siding built on a concrete slab on grade.

\subsection{2 uther structural Criteria}

Foundations: Based on available soils information for the propased site, it may be necessary to remove a significant amount of existing soil down to an adequate soil bearing stratum in the area of the main plant. If so, a select compacted backfill will be used to replace the removed soil. All significant structures will be supported on reinforced

$$
\text { 4-82 }
$$


concrete mat foundations. Other structures and equipinent will be supported on reintorced concrete spread footings or pile foundations.

Due to the groundwater level anticipated at the proposed site, extensive dewatering operations will be necessary during construction of the foundations.

Yardwork: The cost estimate includes clearing and grubbing the site, excavation and spoiling of undesirable naterial. railroad trackwork, pemianent plant roads, and fencing. Aso included are costs for the construction of two briage structures over the New River for roadway and railroad.

4.4.3 ADVANCEU FOSSIL FUFT, WGHNOLOGY - FUTURL DEVELOPMEMI

4.4.3.1 Eastern Coal Fluidized-Bed Bailers

Fluidized-bed corribustion of coal in a bed of limestone offers the potential for utilizing our country's vast coal resources in an environmentally acceptable manner for cogeneration as well as electric utility power generation. Fluidized-bed combustion is a process which involves the burning of coal particles in a bed of inert solids fluidized by an evenly äistributea upward flow of air. Heat is transferred from the bed of solids to heat transfer surfaces located in and above the bed. Combustion takes place between 1.500-1.600 F. which is important for two reasons: (1) the terquerature is below the ash fusion point which prevents slagging and related corrosion from low melting sodium-potassium-sulfur compounds, and (2) oxides of nitrogen are minimized by substantialiy reducing the thermal NOx production which occurs at higher temperatures. By using a bed of linestone, sulfur from the coal is captured in the bed so that so2 in the combustion gas is limited to acceptable levels without recourse to flue gas desulfurization systems.

In addition to offering a potentially sound environmental process for burning coal. the process permits the utilization of low grade coals. Fluidized-bed combustion was developed by the British, primarily to utilize low grade coals. The inherent design of the process, involving low combustion temueratures, allows the use of low rank $0 . S$. coals, which to date have been difficult to burn without encountering envirormental and other problems.

A final area of importance is the potential for snaller boiler valumes due to high heat-transfer coefficients for surface located in the bed. These coefficients are in the range of 3-5 times those experienced in convective surfaces of conventional pulverized-coal boilers. This potential 
ofters a possibility of lower capital investment for the boilex.

The tollowing sections compare conventional plant and fluidized-bed boulers.

\subsection{Conventional Cogeneration Plant Boilers}

As shown on Jrawing No. 12977-EP-2F, located in Fppendix B. the total steam generation required for the Geismar cogeneration plant is $9,237,178 \mathrm{lb} / \mathrm{hr}$ at $2,415 \mathrm{psia}$, anc $1,000 \mathrm{~F}$. Hithe steam is supplied by two boilers with boiler efticiencies of 86 pexcent. In contrast to the current typical electric utility boiler, there is no reheat involved.

\subsection{Fluidized-Bed Boiler General Specifications}

The size, number of ivoilers, and the stearn conditions of atwospheric tluidized-bed (AFB) boilers are the same as conventional boilers. AFb boilers are designed to burn high-sulfur eastern or midwestern coals. for which pulverizeä-coal liring requires the use of flue gas desulturization systens to comply with EPA SO2 new source pertormance stanciards. Sulfur dioxide emissions from AFB woilers are controlled by the use of limestone in the bed. In addition, an impo tant economic advantage is realized by using highly coking or slagging coals, which to date have been difficult to burr in conventional boilers. The flexioility of coal parchase possibilities is a very important advantage of hFB tecinnology.

The cogeneration plant is designed to comply with both state and federal regulations. In Louisiana, the federal EPA new source performance standaräs for fossil fuel fired steam electric gererating stations are the limiting regulations. For a coal-fired plant allowable emissions are $0.11 \mathrm{~b} / 10^{6}$ Btu heat input for particulate matter, $1.21 \mathrm{~b} / 10^{6} \mathrm{Btu}$ for SO2. and $0.7 \mathrm{1b} / 10^{\circ} \mathrm{ibtu}$ for NOx. Compliance with particulate enission regulations requires either a hot electrostatic precipitator or a baghouse. Fmission of 502 is controlled by Innestone addition to the bed; Nox would be inherently low $(0.3-0.51 \mathrm{l} / 106 \mathrm{Btu})$ as a result of low combustion teruperatures $(1,500-1,600$ F) .

\subsection{Boiler Equipmient Differences}

There are presently no physical examples of large fluidized-bed boilers of the size required for the present cogeneration study. The largest to date is a $300,000 \mathrm{lb} / \mathrm{hr}$ demonstration unit sponsored by the u.S. Department of Energy at the Rivesvilie station of the Monongahela Electric 
Fower Corquan. However, there exists a more suitable study lor postulating the physical features and relative cost of the atmospheric fluidized-bed boilers in the form of designs developed by tile two major lianufacturers for another application. The study, titiel "Conceptual Design For $h n$ Atrospheric Fluidized-bed birect Combustion fower Generating plant," was undertaken by $S E W$ for the Department of Energy under Contract No. kF-77-c-01-2583.(22) It incluäes Afb boiler designs of the Babcock and Wilcox Company. and Foster Wheeler energy corpolation and is based on their respective interpretation of the present state of the art.

Although the electric utulity application involves reheat. whereas there is nome in the cogeneration case, an analogy can be made on the basis of total fuel heat input to the respective boilers. For the electric utility study application. the total fuel heat input is on the order of 5 $1 / 2$ billion Btu/hr as conpared to slightly nore than 10.5 billion Btw/x fox the cogeneration case. However, the latter would be sibared by two boilers each with an input of about $51 / 4$ billion Btu/hr, or each about 95 percent the size of the exanules displayed in the electric utility woiler study.

lixpressea in tons of coal per hour, the full-load burning rate per boiler for the electric utility application case is about 180, compared to a cogeneration requirenent of 172 per boiler.

The electric utilicy application study examined the aifferences between the conventional coal-fired boiler and the fluidized-bed cases in detail. A general impression is obtained from viewing the following drawings selected from the study:

Base BEW AFI FWAFE

SEw Drawing No. 12977

Site Plan

Side Elevation

General firrargenent plan

Front Elevation

Composite (Front lilevation)

$\begin{array}{ccc}E M-1 G & E M-1 J & E M-1 N \\ E M-1 H & E M-1 K & E M-10 \\ - & E M-1 L & E M-1 P \\ E M-1 I & - & - \\ - & E M-1 M & E M-1 Q\end{array}$

Noting the portion of the site plans marked with elongated circles, a comparison of boiler and associated flue gas systenus is possible. One of the main attractions of fluidized-bed corbustion is that flue gas scrubber (SO2 removal) equipment is omitted. However, the boiler size reduction frequently attributed to the fluidized-bed concept is largely offset $b_{Y}$ the greater size area required for related auxilaary systems. This tradeoff is shown in

$$
4-85
$$


yieater detail or the elevation and plan view drawings 1isted alove. From this comparison the requirements for two such toilers or moverately smaller capacity for cogeneration may be visualized.

Considering the eciuipanent typically included in the scope supplied by the boiler manufacturex, there are many difterences. For this study, it should suffice to point out thice of the most siyniticant: First, the conventional turnace coubustion ione is replacel by a plurality of Lluidizea beds. In the BEW case, they can be seen on the ylan and elevation drawings to include four main beds at each of two elevations and one at a lower elevation, and four carbon burnup beds at one elevation. In the Foster Wheeler case, there are main beds at each of five elevations and a carbon burnup bea at an adjacent lower elevation.

second, there are ro pulverizers or coal burners required For the fluidized-bed boilers. Instead, appropriately sized coal and limestune material is stored in bunkers and fed individually to each of the beds in combination with individually controlled combustion/fluidization aix.

Thiru, in place of a bottom ash removal system, typical for conventional boilers, the fluidized-bed cases require a liaterial letaown systell for roughly 50 percent of the total ash and all of the spent limestone accumulated in the beds. lykically. the bed letown naterial is received continuously in holding tanks froia which it is periodically removed by disposal systens.

\subsection{Balance of Plant Differences}

With the foregoing in wind, a significant balance of plant difference may be seen. The orission of the flue gas desulfurization tacilities (s02 removal equipment) is largely offset in site area by larger particulate collectors. Indsmuch as the flue gas from the AFE boilers is devoid of sulfur oxides, the resistivity of the fly ash with respect to electrostatic precipitation is much higher than for the base case wherein the precipitator precedes the sulfur removal. For this reason, BEW elected to use a hot precipitator and Foster Wheeler elected to use a fabric filter (baghouse), both of which are significantly larger than the base case precipitator.

For the APB cases, notable differences from the conventional systems for preparation and handling of coal and limestane are aptarent tron the drawings of the electric utility power generation study. 'hey result from the AFB need for finer in-the-yard grinding of the coal (to the final size for burning) than is typical for the conventional plant with pulverizers. The resulting addition of a new crusher house 
can be seen on the two site plans. If the cogeneration plant employed fluidized-ued boilers exclusively. although of somewhat greater duty than those required for analogous conventional plants, they would be the only crushers required. Other differdnces in coal and limestone handing are apparent from the arrangement drawings which indicate that more extensive distributed coal and the limestone bunkering is required for the AFB cases than is typical of a corventional coal-iired boiler plant.

Solia wastes trom the AFB boiler cases include dry handling of the fluid bed ash and spent limestone from the bed. These wastes are in contrast to the wet handling of furnace bottom ash ard scrubber sluage in the conventional boiler case. The more important aspect is in the tradeoff between the handling probleras of the wet scrubber sludge and the coniparable quantity of dry sfent limestone renoved with ash from the beds. The relative cost of the two is covered in another section.

For the most part, the substitution of a fluidized-bed boiler in place of a conventional pulverized coal boiler involves differences in the boiler plant only. However. there are two important additional requirements for a tluidized-bed boiler; naniely: (1) the need for a turbine bypass stean system and (2) special capabilities of the electrical auxillary power systems. The first is needed to renove heat from the subnerged tube bundles in the bed in the event of a turbine trip. This requirement is particularly essential to avoid overheating of submerged superheater tube naterial. The second is the need to acconwodate larger horsepower electrical motors than may be typical for a conventional pulverized coal-fired plant. The latter requires a $13.2-\mathrm{kV}$ auxiliary power system in addition to the more typical 4-kv service.

The remainder of the cogeneration plant would be the same as the coa1-fired plant described in section 4.4.1.2.1 and shown on Drawing No. 12977-EP-2F located in Appendix B. The steam output and electric generation would be the same so that water treatment, pumping. feedwater heating. turbine generators. stean, and electrical distribution would be unchanged.

\subsection{Boiler Control Flexibility}

It must be recognized that there are important fundanental differences in the control facilities required for a fluidized-bed boiler as compared to the conventional boiler. The most obvious is the nature of the fluidized bed as a fuel buming device. In contrast to combustion via burners in one comnon furnace of the comventional boiler, the AFB beds are in segments. In the examples of the electric power 
gereration study, the $\mathrm{kEW}$ case contained 20 operating segments divicied between $11 / 2$ tooiler beds and $31 / 2$ superheating beds, whereas the EW case also had 20 seginents. but aiviỏed between two boiling beds, two superheating beds, and one reheating bed. In adaition to the main beds, both designs included carbon burnup cells in which the collected carryuver from the main beds is burned in order to improve overall combustion efficiency. The latter operates at lower fluidization velocity, higher excess air, ard higher temperature than the main beds and does not contain subuerged heat exchange surfaces other than the containiny walls of the bed enclosure. Additional surtaces, including economizers, are included in the rlue yas path following the exits from the beds.

Fuel and air to each bed must be controlled independently in orcier to regulate bed temperature within prescribed limits and be resiconsive to systeit deltands. Load following is accomplished by cutting segments in and out, supplemented by regulat ion nt bas tewyerature within linits. Additionally. the total inventory of material in each bed segment must be continuously regulated by extracting material. This letdown of spent limesture anć ash Irom each segment is controlled as a direct function of the total material inqut to the segment supplemented by automatic correction of departure irum normal bea level.

4.4.3.1.6 Corit bevelowment and Potential

The problems just discussed leave some concern as to whether the challenging aspects of tluidized-bed combustion will be adequately ofiset by its advantages. It must be recognized that $F B$ is not yet a nature commerical entity and that major inprovernents $2 n$ aspects of the designs will evolve in time. with this expectation, the major organizations which are currently supporting $A F B$ developinent frograms associated with electric power generation are: Lepartment of binergy. (DOE). Environuental Protection Agency (EPA), Hlectric Power Research Institute (LPKL). Tennessee Valley Authority (IVA) . and the state of ohjo. $D \mathrm{CE}^{*}$ is the lead organization in the United States for tunding $A F B$ conbustion: it is presently sponsoring two commercial plant conceptual design studies. cofunding with TVH a conceptual design for a 200-MW delionstration $h F E$ plant, and funding the 30-MW Rivesville program. Tabie 4-10 sumarizes the status of these programs.

EPRI is sponsoring several development programs designed to provide basic engineering design data in support of the DOE program. In addition to transport phenomena studies, EPRI is supporting the bin 6-foot $\times$ 6-foot process development facility which recontly started operation. 
TABLE 4-10

DEPARTMENT OF ENERGY

ATMOSPHERIC FLUIDIZED-BED PROJECTS

$\frac{\text { Project }}{\text { Rivesville }}$
Utility Commercial Plant
Conceptual Design
Conceptual Design

Utility Commercial Plant Conceptual Design

Utility Demonstration Plant

\section{Contractor}

Pope, Evans, \& Robbins

Stone \& Webster

Burns \& Roe

TVA

Size
$30 \mathrm{MW}$
$600 \mathrm{MW}$
$600 \mathrm{MW}$
$200 \mathrm{MW}$

\section{Objective}

To demonstrate AFB plant on utility system

To develop a commercial size utility plant design burning high sulfur eastern coal

To develop a commercial size utility plant design burning noncompliance western coal

To demonstrate AFB plant on a commercial scale

\section{Status}

In the testing program

Completed December 1977

Completed March 1978

Phase I AFB boiler concep.

design

phase II

Phase II

to be under-

taken in 1978 
The State of Ohio is supporting four AFB projects as a means of lessening the state's deprendence on gas and oil and pronoting the use of onio high sulfur coal. One of these projects is a $30-M W$ AFB boiler at columbus and southern onio slectric Company, which is scheduled for startup in 1979.

DOE is planning to support one or more 200-MW demonstration plants in the near future: The present timetable for operation of these units is anticipated in 1982 or 1984. IVA also is plaming a $200-\mathrm{W}$ plant in the same tirne frame. Both DCE and IVA anticipate comerical operation of large utility plants $(600-800 \mathrm{MW})$ using $A F B$ boilers by the late $1980^{\circ} \mathrm{s}$ or early $1990^{\circ} \mathrm{s}$.

current literature aplicable to AFB technology. and specificaliy the utility industry, is sumarized below:

- Prelimiriary kvaluation of Atmospheric Pressure Fluidized-Bed Conbustion Applied to Electric Utility Large Stean Generators, February 1976. available Irom EFRI.

- Part IV. Fechirical Notes for the Conceptual Design for an Atmositiexic Fluidized-Bed Direct Conbustion Power Generating plant, Stone $\varepsilon$ Webster Engineering Corporation, to be available through NTIS.

- The Conceptual Design of an AFBC Electric Power Generating flant, December 1977, available from Burns and koe. Incorporated.

- Application of Atmospheric Fluidized-Bed Conbustion for Electric Power Generation. December $19 \%$ availabie lron Babcock ti Wilcox Company.

- Conceptual Design of Foster wheeler Energy Corporation Atmospheric Fluidized-Bed Steam Generator, Deceuber 1977, available from FW.

- Conceptual Desigr of a 570-MW Atmospheric Fluidized-Hed Stean Generator. December 1977. available trom combustion kngineering. Incorporated.

4.4.3.2 Eastern Coal Gasilication

This section defirses and develops three concepts utilizing gasification of eastern coal to provide the energy source for a cogenexation plant. The alternatives outlineo in this section are:

- Burning coal-ảerived fuel gas in conventional boïlers to generate steam. 
- Burning codl-derivea fuel gas in gas turbines to gererate both electricity and steam.

- Utilizing coul-aerivec fuel gas in fuel cells to yenerate both electricity and steam.

is total of six coal gasification schemes were anaiyzed:
1. Aix-blown
convertional
caal gásification
process with
gas-firea boiler.
2. Oxygertulown coal gasitication process with conventional gas-iired boiler.
3. Aix-blow cal gasification process utilizing gas turbines with no ijmit on electrical generation.
4. hir-blowr coal yasification process utilizing gas turbines with a limit on electrical generation.
5. Rir-blown coal gasification process utilizing fuel cells with no linit on electrical generation.
6. Air-julown coal gasification process utilizing fuel cells with a limit on electrical generation.

In all cases, the basic requirement is to provide the steam. to riteet the projected 1985 denand. Electric power generation is the variable and is either left to seek its own level, or limited to approximate the output of the fossil fuel-fired.coyereration plant. Later in this section each coal yasification schelice is economically evaluated to determine the arrangencent nost adaptable to the cogeneration concept.

The main advantage of the coal gasification process is that sultur is converted to hydrogen sulfide gas, which can be removed by combrcially available processes, and ullimately recovered as elemental sulfur. This eliminates the need for precipitators, aria ilue gas desulfurization equipment.

Eecause of its com ruercial availability, the Lurgi coal gasification process was selected as the basis for this study. Althougin it is not the optimun coal gasification process of those listed. the general conclusions arawn by this stuajy would remain the same if one of the other type coal gasifiers were subsituted. Illinois No. 6 coal was utilized as the conwor tuel for all schemes because data for this coal were readily obtainable from various Electric fower Research Institute Reports already published. The properties of Illinois No. 6 coal are shown in Table 4-11. and can be confrared to those of Alabama coal rellected in 
lable 4-5. It was assuned tinat the delivered coal woula be wasled and sized to $11 / 2$ inch $\times 1 / 4$ irch.

TABLE 4-11

COKL CHLRACTERISTICS

111 inois NO. 6

\begin{tabular}{|c|c|}
\hline Proxinate finalysis & Wt $\%$ \\
\hline $\begin{array}{l}\text { Moisture } \\
\text { Asti } \\
\text { Fixea Carbor } \\
\text { Volatile Natter } \\
\text { "orit }\end{array}$ & $\begin{array}{r}4.2 \\
9.6 \\
52.0 \\
34.2 \\
100.0\end{array}$ \\
\hline U1tinate Analysis LAF Coal & Wt $\%$ \\
\hline $\begin{array}{l}\text { Carbon } \\
\text { Hydrugen } \\
\text { oxygen } \\
\text { Nitiogen } \\
\text { Sultux } \\
\text { ron'fis }\end{array}$ & $\begin{array}{r}77.26 \\
5.92 \\
11.14 \\
1.39 \\
4.29 \\
100.00\end{array}$ \\
\hline Weating value (as received) & Btu $\angle 1 b$ \\
\hline $\begin{array}{l}\text { Higher (HHV) } \\
\text { Net (LIVV) } \\
\text { HHV (MAF BasLs) }\end{array}$ & $\begin{array}{l}12,235 \\
11,70.9 \\
14.194\end{array}$ \\
\hline
\end{tabular}

The coal. gasutzers described lezeln repersent existing combercial or neril conmercial technology. current conmercial large-scäle processes are Luryi. Koppers-Totzek. and Winkler. Inuproved processes presently under development include the Eritish Gas Corporation slagging version of the Lurgi yasifier, the shell-krupp koppers pressurized entrained bed gasiiier, the Texaco gasifier, the Foster-Whetlex gasitier, and the Babcock $\&$ Wilcox gasifier. Table 4-12 shows the size, capacity, and performance of various gasifier systeus. The three large-scale processes and the develofinental Texaco process are discussed in the following sections.

Lurgi Process: The conly comnercial pressurized gasifier at the present $t$ ine is the Lurgi unit. None, however, have been installed in the united states. I 170-WW combined-cycle plant using the Lurgi air-blown system was built in Lunen, West Germany, in 1973. 
TABLE 4-12

SIZE, CAPACITY, AND PERFORMANCE OF VARIOUS GASIFIERS

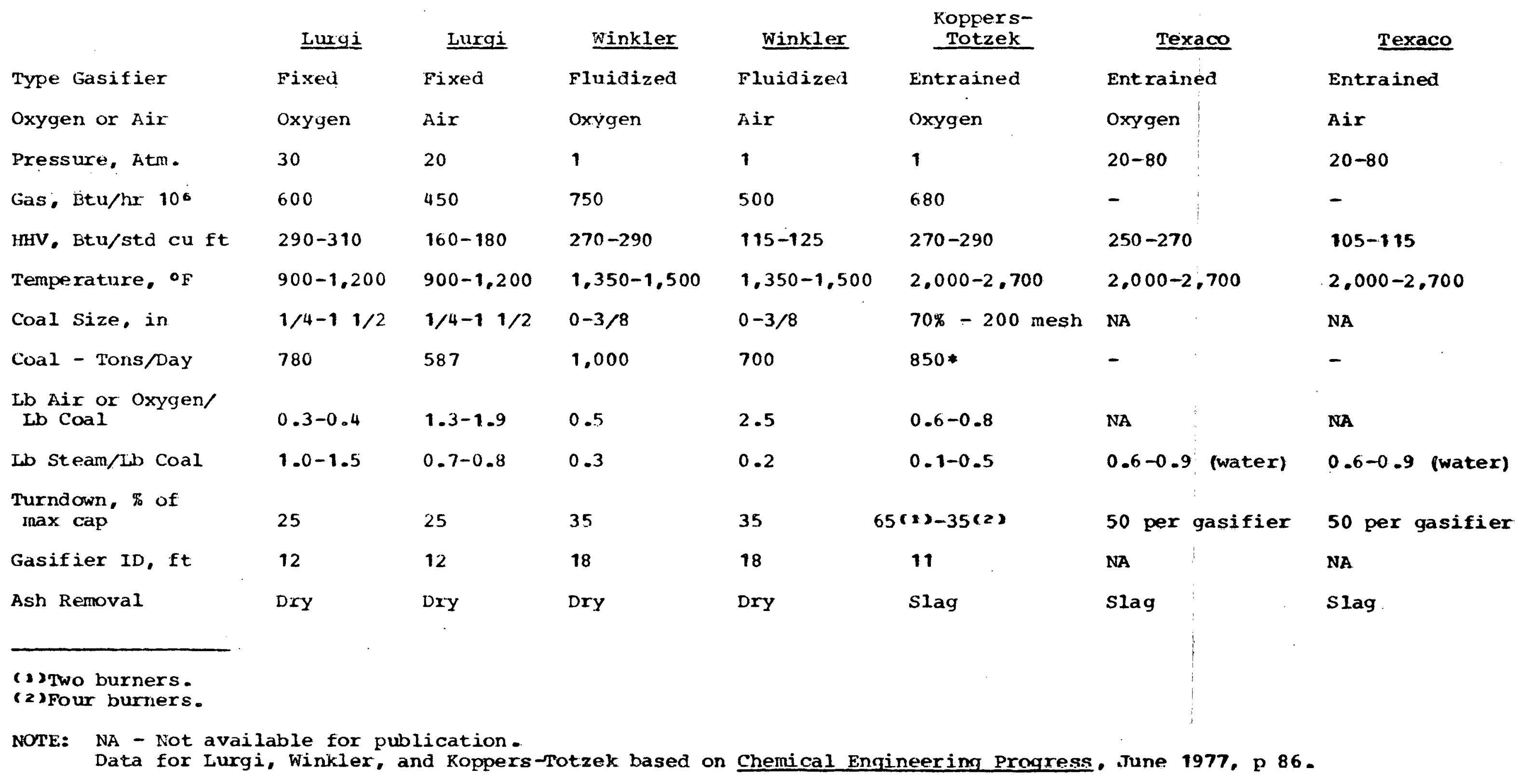


The Lurgi gasitier operates between 350 and 450 psig. requires sized coal (1 1/2 inch $x 1 / 4$ inch), and can utilize either oxygen or air as the oxidant. Noncaking coals are handied nost easily. although tests indicate that caking coals can also be processed. To date there is little contuercial experience with caking coals.

Koppers-Totzek process: This process operates at a pressure slightly above atmospheric uses oxygen as the oxidant and is capable of gasifying all types of coal. Air-blown operation is technically feasible, but thermally inefficient because large volumes of gas are generated at high tempera tures.

For combined-cycle system application, the atmosphericpressure gasification requires that the gas be compressed. A blower could be utilized to boost the effluent gas to the slightly higher pressure required for operating fired boilers or fuel cells.

Winkler Process: The Winkler coal gasification system is a Fluidized-bed atmospheric pressure process. The gasifier has been operated successfully at 1.5 atmospheres and future development calls for testing Onited states coals uv to 15 atmospheres in a proposea 10 ton/day pilot plant. Either air or oxygen can be used as an oxidant.

Winkler units can gasify solid fuels ranging from lignite to monerately caking bituminous coal. It is expected that bituminous coals with free-swelling indices of less than four can be red without pretreatment. Carbon utilization is reduced by 15-30 percent of unconverted carbon contained in the char. It the char is utilized in a coal-fired boiler. the overall efficiericy of the process can be increased.

Texaco Coal Gasification process: The Texaco coal gasifier is high on the list for consideration in advanced technology coal gasification processes and is currently being studied under several goverrmental and industrial contracts. It has been successfully tested on various coals in a 15 ton/day pilot plant at Nicntebello, California. A 160 ton/day pilot plant is scheduled for startup in West Germany during 1978.

The process is based on partial oxidation using a coal/water or coal/oil slurry feed with oxygen or air. It is capable of operating at pressures in excess of 80 atmospheres. The gasifier is the entrained type utilizing a refractory lined vessel similar to those used in commercial oil gasification vessel

Virtually any tyue coal can be gasified in the rexaco gasifier to produce low-or-medium-Btu gas. The slurry feed consisting of ground cod mixed with water or oil is pumped 
into the gasifier, together with air or oxygen. The slurry contains 50-60 percent solids. The slurry and air or oxygen are mixed in a special burner and fed to the gasitier. withir the gasifier, partial oxidation takes place under closely controlled conditions. The gaseous products are first cooled in a waste heat boiler or by direct: water quench and then scrubbea with water to reduce the particulate natter in the gas. Soot from the scrubber is recycled to the gas gererator. The effluent gas then passes thiough a hydrogen sulficie removal system to produce a clean boiler fuel.

The Texaco gasitier has several distinct advantages, namely:

- Simplicity

- Feedstock rlexibility
- No moving parts

- Single stage

- Virtually all U.S. coals

- Coal/water or coal/oil slurxies

- Ahsence of tar by-product reduces clearup and downstrean processing.

- Water slury feed increases safety and reliability. This also serves to minimize aqueous effluent treatment requirements.

- Ability to operate at high pressure.

- Status of development

- Sevexal years pilot plant (15 TPD) operating experience

- operating results on 160 TPD German unit expected in 1978

Accessory Process ëuuipment: Major equipment and processes required to complete the Lurgi coal gasification systerus discussed in this report are:

Acid gas (hydrogen sulfide) removal units. The Alliea Cherical selexol process, which is commercially available. has been selected.

Sulfux recovery unit. The well-established claus process has been selected.

- Process condensate treating to remove phenols and anmoria from the water scrubbing liquor. The lurgi Phenosulvan process removes phenols, and ammonia is recovered by further processing. 
Low-level heat recovery to produce power. A Rankine cycle utilizing isobutare as the working fluia has beer selected.

Gas turbines operating at $1.950 \mathrm{k}$ inlet tenferature. priese turbines are presently available, although further development work is also ir. progress for operation at yet higher teriperatures.

4.4.3.2.1 tasten Coal Gasification with Conventional Boilers

This scheme considers both the air-blown and oxygen-blown moving-bed cual gasification systems in conjunction with a cojerieration plant using coal-derived tuel gas-fired boilers to produce steali. tor consumers. coal-derived fuel yas provides the hed input to the boilers showr on Drawing No. 1297\%-LP-2F iocated in Appendix B. Major changes within the coyeneration purtion of the plant to suit firing of coal-derived tuel gas luclude modllying the boilers and their related accessory equipment, deletion of the precipitators and scrubjers, and increasirg the capacity of the coal handilng tacilities and water treating system. For a description or the cogeneration portion of the plant reter to section 4.4 .1 .2 .

Block-type flow diagrams for these plants are shown on vrawing No. 72977-LP-2R ard $2 S$ in Mrpenaix B. These arawings leflect the various estimated material flows for the ail-blown and oxygen-biown yasifiers, respectively. The reguired boiler leecwatex, cowing water, and wastewater treatmert are provided by licreasing the facilities within the cogeneration plant.

In addition to the electric generation from the cogeneration plant. the coal gasification plant also provides a net output of $122.5 \mathrm{MW}$ ard $124.5 \mathrm{MW}$ for the air and oxygen gasifiers, respectively.

f) coal feed rate of 16,040 and 16,294 tons/day for air-and oxygen-blown gasitiers, respectively. is needed to provide suticient coal ruel yas tor tibe two $4,700,0001 \mathrm{~b} / \mathrm{hr}$ boilers in the cogeneration ulant.

4.4.3.2.2 Eastern Coal Gasification with Combined Cycle Gas Turbines

This section cunsiders the use of a gas turbine combined cycle in the cuyeneration plant. Clean fuel gas generated in a Lurgi coal gasification system provides the fuel for stewn and fower generation. Because the combined cycle is inherently a prifuly producer of electricity rather thar

$$
4-96
$$


steam, two separate scheries were developed and evaluated. In both cases, the prine objective was the generation of stearn to rteet the projected 1985 reguirements. This ierwittea direct congarison with the other types of cogereration plants.

A review of the blectric Power Research Institute's report on coal gas cleaririy indicates that a somewhat higher thermal etficiency is oivained for an air-blown lurgi gasitier than with an oxygen-bllown unit(24). The evaluation of the two scherues proceeded with the air-blown gasifier rather thar the uxyyer-blown based on this information. A surary of thermal efficiencies, not reproduced herein, is shown in Table 4-8A or that LPRI report.

The first scheme, referred to as Alternate $F_{\text {, utilizes the }}$ hot turbine effluent to generate the reguired steall with no 1 ind on the resulting yowex yenerated. The second scheme. Alternate $\mathrm{L}$. linits the net electric generation to $352 \mathrm{MW}$. which in turn linits the flow of turbine effluent and correspondirig waste heat recovery, and necessitates the addition of fuel gas-fired boilers to meet the steam demand. The electrical output was established to approximate the output of the rossil fuel-fired cogeneration plants to permit economic evaluation and comparison.

The arrangenent of ilternate $A$, along with the steam llows. coal requirements, feeawater flow, and power generation, are showr on Drawing 100. 12977-tP-2T located in Appendix B. The clean fuel gas is vuned in a combustor with excess air. The combustion products are quenched with additional air to about $1.950 \mathrm{~F}$ before weing ted into the gas turbines of the corabined cycle coyeneration plant. Each gas turbine drives an air compressor and an electric generator.

Turbine effluent gas at approximately $1.000 \mathrm{~F}$ flows to a waste heat recovery section where steam is generated at three levels: 970 . 690, and 290 psia to meet users. deiaras. In adaztion to users' denands, 690 psia steam is generated to supkly the gasifier steam reyuirements. Adaitional steam at 290 psia is also generated tor deaerator heating. The process side-turbine effluent leaves the waste heat recovery section as stack gas at about 320 F.

Net electrical genelation is $1854 \mathrm{MW}$ based on the summation of the gross output of the sas turbine generaturs plus the tar conbustion generators, less the power required for the gasifier air compressor and all other coal gasification plant and cogenelation plant auxiliary loads.

The $\mathrm{A}$ schene zexuiles a coal feed of $2.276 .569 \mathrm{lb} / \mathrm{Mr}$ $(27,319$ tom/day) to generate the clean coal-derived fuel gas reguirea for the gas turbine cycle. 
Dxawing No. 1<977- $212-20$, located in Appendux B, shows ar uverall block ciagram with flows for liternate $B$ using the same lurgi air-biown gasification system, but with the adaition of coal-derivea fuel yas-tired boilers to generate steam.

Gas turbine eftluent first passes through a heat recovery section where a poition of the required 690 psia superheated steall is gererated. l'his gas stream, which consists of conibustion products as weil as an appreciable anount of oxygen, is cooled trom $1,000 \mathrm{~F}$ to approximately $600 \mathrm{~F}$. The high oxyger content of this steara supplenents the combustion air to the tuel yas-ized boilers.

The stearn generation section consists of gas-tired boilers which generate steara it $3 \%, 690$, and 290 psia. As with ilternate $A$, stean is genelated to meet the expart denands of the users, and the interral requirenents of the gasifiers and the deaeratox.

The electric output of the plant is generated by the gas turbine generators and the tar combustion unit. ifter allowance for auxiliary power, the net generation does not exceed the requirea 352 itw.

6 feed flow of $1,291,487 \mathrm{lb} / \mathrm{hr}(15,498$ ton/day) of coal is required to generate sufficient clean coal-derived fuel gas to operate the contined cycle and provide fuel for the boilers. Boiler tuel has a higher heating value of 2.977 Btu/ $1 \mathrm{~b}(177$ itu/sCF) .

4.4.3.2.3 Fuel Cell with Coal Gasification

Fuel cells combine tuel, usually hydrogen gas and oxygen (supplied either as air or oxygen gas). electrochemically to produce direct current electricity. A simplified diayrain of the basic pxinciple of the fuel cell is shown on Drawing No. 12977-s P-2X lucated in hppendix $B$.

Units of several $\mathrm{kw}$ capacity. operating on hydrogen and oxygen, have been used for military and space applications. Development prograns tor commercialization are in progress. but fuel cells have not yet demonstrated adeguate endurarice and low enough cost for comnercial applications. Factors hindering developmert are the high cost of low temperature cells ana difficulty in obtaining materials suitable for high temperature cells. The types of fuel cells that are being developed and are most likely to be considered for conunercial use are the phosphoric acid cell and the molten carbonate cell. These two types of cells and their application are discussed in the next paragraphs. 
Phojphuric acidu cell: a 1 -w Wirect-current phosphoric acia cell has been operatec using carbon monoxice and hydrogen gas produced by the naphtha steam reforming process. In inverter converts the direct current to alternating current. Investigation of tris cell has been sponsored by various utility companies and by uniteä Technologies corporation (U'C).

Iri 1978, a 4.8-MW phosphorac acia cell is to be deliverea to Con taison in Manhattan for operation on naphtha fuel. The najutha will be steani reformed to produce a gas that will be reacted in a $c O$ converter to reduce the $c O$ content to 1-2 rercent. The object is to obtain a fuel cell feed gas that has a maximura hydrogen concentration since hydrogen is the reactive componerit in the fuel cell.

About 80 percent of the hydrogen in the feed gas is consuned in the fuel cell and the unreacted hydrogen and other gases are purged and used as a fuel in the naphtha reformer. Waste heat is recovered as stean.

The phosphoric acid cell operates in a temperature range of 300-3/5 F. limiting the pressure of the waste heat steam to 15-60 psia. This pressure limitation prohibits its use in a cogeneration plant. whach requires steam at pressures from 290 to 970 psia.

Molten carbonate fuel cell: The molten carbonate fuel cell has been $r$ un on a smail scale in stacked units of 1 and $1 \mathrm{~d} / \mathrm{kW}$. It is expected that demonstration units in megawatt size will probably be available in the early 1980 's. A study by UTC and Eurns $\varepsilon$ Roe evaluated a conceptual design for a molten carbonate fuel cell power plant using gas from a low Btu coal gasifier. The proposed systen comprised:

- U-gas process Iluidized-bed air-blown gasifier (under development by Institute of Gas Technology) to produce fuel yas.

- Iron oxiäe systen (under development by Morgantown Energy Research Center) to remove sulfur from the gas.

- Molten carbonate cell (under development) to produce electric power.

- Steam bottoning cycle to produce electric power.

The overall efficiency of this system (coal pile to busbar) is approximately 49 percent with two-thirds of the gross ac power being generated by the fuel cell and one-third 
supplied by the bottoming cycle. The estinated installed cost for a 635 -iving larit is $\$ 545 / \mathrm{kW}$.

The nolten carboriate cell operates at $1.200 F$ and can generate 2.400 psia steam, making it suitable for the coweneration plunt. Abovt 36 percent of the energy in the coal appears as electricity ard 27 percent as high-quality steall. The hot exhaust gas, similar to high-temperature. high-pressure combusted air is utilized by waste heat recovery. (Molten carbonate fuel cells have not yet been run on gás derived Irom coal.-)

The status and chardcteristics of the phosphoric acid cell and the nolten carbonate cell are outlined in Table 4-13.

\author{
Ti.Bicis 4-13 \\ CHARACTFHISHICS \& STALTS OF \\ PHOSPRUKIC \& MOLILN CALBUNATE FOEL CEILS
}

Phosptoric Acja

rechnology Generation

status

Module Size, NiW

reactant Gas

Heat Rate. Etu/kWh

Operatinc: Teruperature, $F$

Operating Pressure. usia

Projected Installea 250 cost. $\$ / k$ i

Sulfur Tolerance. $\quad 200$

Nuáx. PPM H2S

Cell Enciurance Goail. $\quad 40,000$ Hours
First

Denionstration

4.8

Hydroxyen

9.300

$300-375$

50
Molten Cárioriate

Second

Developmental

Not Developed

Hyärogen \& Carbon

Monoxide

7.500 (Goal)

1,200

$100-150$

$335-465$

Less than 10

40.000

Fuel Cell Buplicatiun: This section covers two schemes for application of the fuel cell in a cogeneration plant. In both cases, clear coal-derived fuel gas from a lurgi coal gasification system is used as the fuel for a cell which generates electricity and provides waste heat for generation of stean. Waste heat in a fuel cell results from the ineificiency of convelting fael heating value to electrical energy. Steam tor the projected 1985 industrial requirements is produced in each case.

The first scheme utilizes fuel cell waste heat to generate the steam with no limitation on the amount of electric power generated. The arrangenient of this system is shown on Drawing No. 12977-ip-2V located in Appendix B. Required

$$
4-100
$$


cual feed to the gasitier is $3.065 .417 \quad 1 \mathrm{~b} / \mathrm{hr} \quad(36.785$ tor/ay).

The secona scheme differs by limiting the net electric gerneration to $352 \mathrm{MW}$, which is the same power output as the tossil fuel-1ileci plart. The steam demand, which cannot be met by available waste heat recovery alone. requires that supplemental coal-cierived fuel gas-fired boilens be installed. I block-type diagram for this plant is shown on Drawing No. 12977-E P- $2 W$ located in Appendix B. Feed rate to the gasifier of 1,251,750 1b/ar (15,021 ton/day) provides the gas for the fuel cell and boilers.

Tábles 4-14 aria 4-15 inaicate projected development dates and cost and performance paraneters for fuel cell systems.

TALId: $4-14$

FORLCASI OF FUEL CELL DEVELOPMELT:

TYFE COMMERCIAL OPERETION

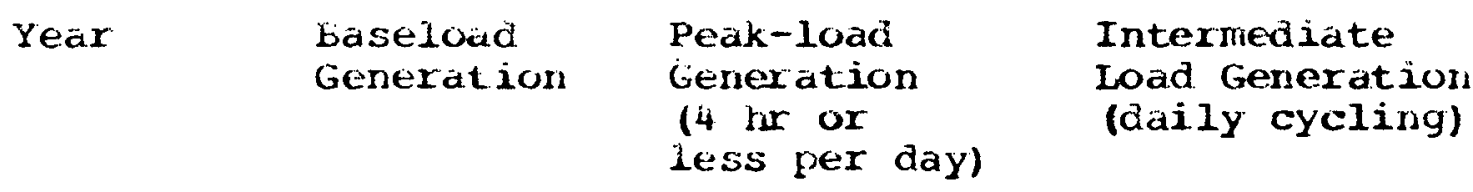

$\begin{array}{cl}\text { 1980-1985 Fuel cell/ } & \text { Fuel Cell- } \\ & \text { Integrated } \\ & \text { Coal Gasi- } \\ & \text { fier }\end{array}$

Hydrocarbon

Fuel Cells

(1st and 2nd

generation)

Suurce: U.s. Energy Kesearch and Development Agency. Comparing Vew Techiologies for the Electrical Utilities. Lrait LkWA-6-141, Necember 1976. 
TABLE $4-15$

\section{PREDICTED COST \& PERFORMANCE PARAMETERS}

FOR FUEL CELL POWER SYSTEM

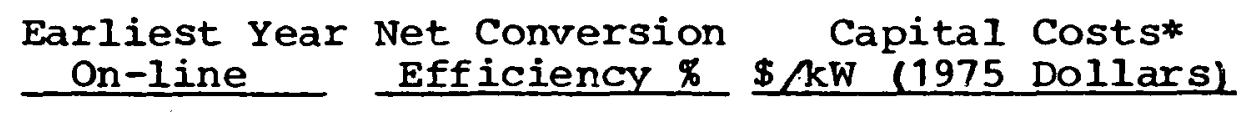

Base-Load

Generation

Molten Carbonate Fuel Cell

1987

1982

Naphtha

Peak-Ioad

Generation Fuel Cell-

Intermediate

Load Generation

Molten Lárboñate

Fuel cell

1987

50

$335-465$

*Capital costs do not include interest during construction or provisions for inflation.

Source: U.S. Energy Research and Development Agency. Comparing New Technologies for the Electrical Utilities. Draft ERDA-6-141, December 1976. 


\section{SECTION 5}

\section{COST EST TMATES}

TABLE OF CONTENTS

Page

5.1 ORANGE SITE

5.1 .1

5.1 .2

Fossil Fuel Plants - Current Technology

Nuclear Plants (Orange) - Advanced Technology Under Development

$5.1 \cdot 2 \cdot 1$

Consolidated Nuclear steam

5.1 .2 .2

High Temperature Gas Reactor Steamer

$5-2$

$5-2$

$5-6$

$5-6$

$5-9$

5.2

GELSMAR SITE:

$5-10$

5.2 .1

Fossil Fuel plants

5.2 .2

Nuclear Plants (Geismar) - Advanced Technology Under Development

$5.2 \cdot 2 \cdot 1$

Consolidated Nuclear Steam System

$5.2 \cdot 2.2$

High Temperature Gas Reactor Steamer

5.2 .3

Advanced Fossil Fuel Technology Cost Estimates Future Development.

$5.2 \cdot 3.1$

Eastern Coal Fluidized-Bed Boiler

$5.2 \cdot 3.2$

Eastern Coal Gasification with Conventional Boiler (Oxygen-Blown and AirElown Gasifiers)

5.2.3.3 Eastern Coal Gasification With Gas Turbines

$5-10$

$5-13$

$5-13$

$5-16$

$5-17$

$5-17$

$5-20$ and Waste Heat Boilers (Unlimited and Limited Power Generation)

5.2.3.4 Eastern coal Gasification with Fuel Cell (Unlimited and Limited Powex Generation)

$5-23$

$5-26$

TABLES

5-1 Cost Estimate for No. 6 Oil-Fired Cogeneration Plant at Orange, Texas 5-3

5-2 Cost Estinate for Alabama Coal-Fired Cogeneration Plant at Orange. Texas

5-3 Cost Estimate for Wyoning Coal-Fired cogeneration plant at Orange. Texas

5-4 Cost Estimate, Part I (B\&W CNSS) Consolidated Nuclear Steam system Plant at Orange. Texas

$5-5$

Cost Estimate, Part II (Escalation and Deductions) Consolidated Nuclear Steam System Plant at Orange, Texas

$5-6$

Cost Estimate, Part III (Summary) for Consolidated Nuclear Steam System plant at Orange. Texas

5-7 Cost Estimate for High Temperature Gas Reactor at Orange, Texas

5-8 Cost Estimate for No. 6 Oil-Fired Cogeneration plant at Geismar. Louisiana 
Page

5-9 Cust Estimate for Alabama Coal-Fired Coyeneration plant at Geismar, Louisiana

5-10 Cost Estimate for Wyoming coal-Fired cogeneration Plant at Geismar, Louisiana 5-12

5-11 Cost Estimate, part I (BEW CNSS) Consolidated Nuclear stean system plant at. Geismax, Louisiana

5-12 Cost kstimate, Part II (Escalation and Deductions) Consolidated Nuclear Steam system Plant at Geismar. Louisiana

5-13 cost istimate, part III (Summary) consolidated ivuclear stean system plant at. Geismár, Louisiana

5-14 Cost Estimate for High Temperature Gas Reactor at Geismar, Louisiana

5-15 Cost Estimate for Atmospheric FluidizedBed Plant Using Bäboock \& Wilcox Boiler at Gciomar, Louisiana

5-16 Cost Estinate for Atrospheric Fluidizedsed Plant Using Foster Weeler Boiler at Gei smar, Louisiana

5-17 Cost Estimate for Eastern Coal Gasification With Conventional Boiler and Oxygen-Blown Gasifiex

5-18 Cost estinate for kastern Coal Gasification With Conventional Boilers and Air-Blown Gäsitier

5-19 Cost Estimate for Eastern Coal Gasification With Gas Turbines and Waste Heat Boilers Unlimited Power Generation

5-20 Cost Estimate for Eastern Coal Gasification With Gas Turbines and Waste Heat Boilers Limitea Power Generation

5-21 Cost Estinate for Eastern Coal Gasification With Fuel Cells - Unlimited Power Generation

$$
5-13
$$$$
5-14
$$

$5-15$

$5-16$

$5-18$

$5-19$

$5-21$

$5-22$

$5-24$

$5-25$

$5-27$

5-22 Cost Estinate for Eastern Coal Gasification With Fuel Cells - Limited Power Generation

$5-28$ 


\section{SECTION 5}

\section{COST ESTIMATES}

This section presents order-of -magnitude cost estimates for each type of cogeneration plant discussed in the previous section. The estimates include the cost for engineering, design, and construction. Fossil fuel plants (Alabama and Wyoming coal and No. 6 oil fired) and nuclear plants (CNSS and HTGR steamer) are costed for both the Orange and Geismar sites. The future advanced technology plants (fluidized-bed boiler and plants utilizing coal gasification) are costed for the Geismar site only.

In addition - to the direct costs, each estimate includes distributables and indirect costs and an allowance for indeterminates. These are defined as follows:

- Indirects: Those costs, including salaries, expenses, overhead, payroll taxes, and fee, associated with the architectural-engineer's (AEs) engineering and desigr. activities including all support services.

- Distributables: Those field costs associated with the operation of construction management field offices and support of direct construction activities. This includes both "temporary services," manual labor, and field-supervisory nonmanual labor with associated benefits, payroll taxes, insurance, expenses, and premium pay. Also included are materials and equipment associated with the construction facilities, such as utilities.

- Allowance For Indeterminates: This is a contingency figure provided for unknowns and is affected by the type of estimate and engineering information available.

For conceptual estimates, the amount allowed for each of these items is usually a percentage established from previous projects of similar nature.

The estimates were prepared and are presented according to accounts established by the Federal Power Commission.

The estimates for the cogeneration plants do not include items which each user must provide to permit receipt of electric power and steam and the return of condensate to the cogeneration plant. Depending on existing facilities at each user's plant, these items may include the following:

- Condensate return pumps

- Condensate storage tank 
- Steam and condensate piping, including valves, insulation, pipe supports, and pipe-supporting structures from the plant property line

- Pressure reducing stations

- Step-down transformers with associated switching and protective equipment

- Subdistribution within the user"s plant

- Steam and electric metering

- Instrumentation.

Also excluded from any of the cogeneration plant cost estimates are:

- Cogeneration plant land costs, including rights-of-way

- Iand costs for steam and electric distribution systems

- Escalation duxing construction (accounted for in plant evaluation)

- Licensing effort

- Environmental iminäct statement preparation

- Public presentations

- Relocation of existing underground services

- Relocation of existing railroad spurs

- Relocation of existing above-ground structures

- Spare parts

- Dismantling of the cogeneration plant at the end of its useful life.

\subsection{ORANGE SITE}

5.1.1 FOSSIL FUEL PLANTS - CURRENT TECHNOLOGY

Order-of-magnitude cost estimates for No. 6 fuel oil-, Alabama coal-, and Wyoming coal-fired plants were developed by obtaining current market prices for major equipment and systems and utilizing existing cost data for the remainder of the plant. These estimates are shown in Tables 5-1 through 5-3. 
TABLE 5-1

COST ESTIMATE FOR

NO. 6 OII-FIRED COGENERATION PLANT

AT ORANGE, TEXAS

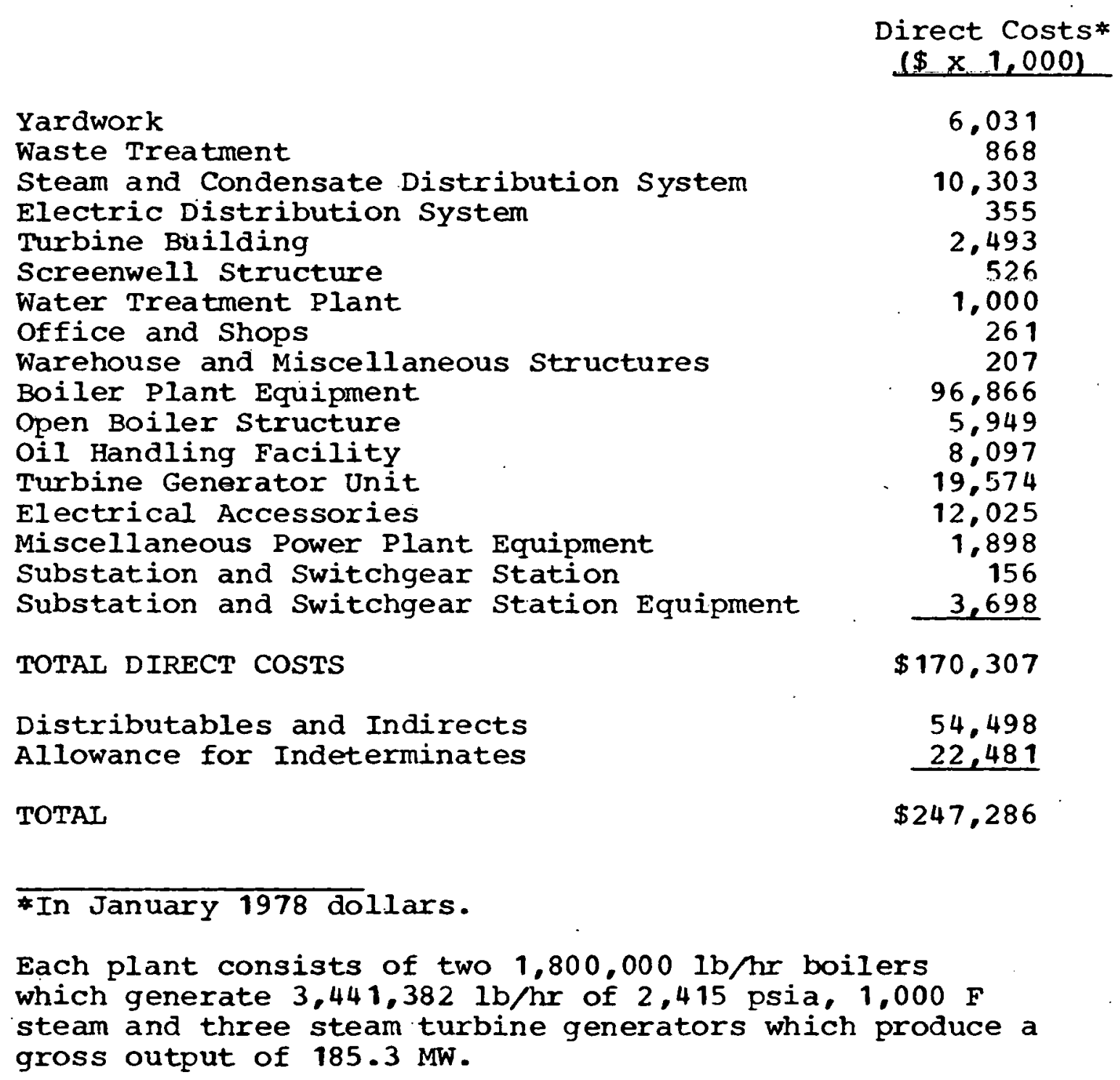




\section{TABLE 5-2}

COST ESTIMATE FOR

ALABAMA COAL-FIRED COGENERATION PLANT

AT ORANGE, TEXAS

Yardwork

Waste Treatment

Steam and Condensate Distribution System

Electric Distribution System

Turbine Building

Screenwell Structure

Water Treatment Plant

office and shops

Warehouse and Miscellaneous Structures

Boiler Plant Equipment

Open Boiler Structure

Coal Handling Pacility

Turbine Generator Unit

Electrical Accessories

Miscellaneous Power Plant Equipment

Substation and Switchgear Station

Substation and Switchgear Station Equipment

Direct Costs*
$(\$ \times 1,000)$

TOTAL DIRECT COSTS

$\$ 201,530$

Distributables and Indirects

64,490

Allowance for Indeterminates

26,600

TOTAL

$\$ 292,620$

* In January 1978 dollars. 


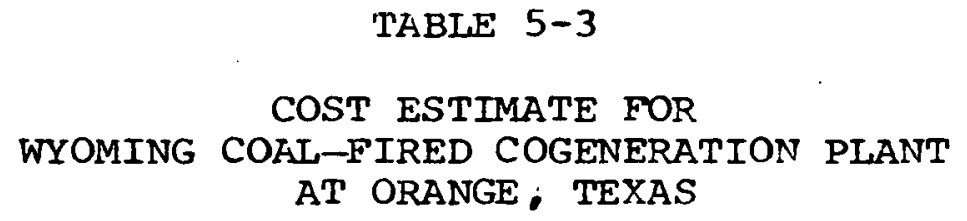

COST ESTIMATE FOR

WYOMING COAL-FIRED COGENERATION PLANT

AT ORANGE; TEXAS

Yardwork

Waste Treatment

Steam and Condensate Distribution System

Electric Distribution System

Turbine Building

Screenwell Structure

Water Treatment plant

office and Shops

Direct Costs*

Warehouse and Miscellaneous Structures

$(\$ \times 1,000)$

Boiler Plant Equipment

Open Boiler Structure

7,184

868

10.303

355

2,493

526

1,000

261

207

114,389

5,949

Coal Handling Facility

22,277

19,574

12,025

Electrical Accessories

1,898

156

Substation and Switchgear station

3,698

TOTAL DIRECT COSTS

$\$ 203,163$

Distributables and Indirects

65,012

Allowance for Indeterminates

26,818

TOTAL

$\$ 294.993$

* In January 1978 dollars. 


\subsubsection{NUCLEAR PLANTS (ORANGE) - ADVANCED TECHNOLOGY UNDER DEVELOPMENT}

\subsubsection{Consolidated Nuclear Steam System}

This order-of-magnitude estimate was prepared assuming an nth-of-a-kind unit using the cost estimate contained in Babcock \& Wilcox's report (see Table 5-4). (19) Equipment and systems were deleted to adapt the electric generating plant proposed by $B \& W$ to a cogenerating plant (see Table 5-5) . Costs were escalated to raise the september 1976 cost level to January 1978. Equipment and systems were added to convert the plant to cogeneration (see Table 5-6).

\section{TABLE 5-4}

COST ESTIMATE, PART I (BEW CNSS)

CONSOLIDATED NUCLEAR STEAM SYSTEM PIANT

AT ORANGE, TEXAS

Difect Costst
$(\$ \times 1,000)$

Land anc Land Rights

Special Material

Structural and Site Facilities

$---$

Reactor Plant Equipment

Turbine Plant Equipment

48,967

Electric Plant Equipment

64,121

48,300

13,220

4,536

Miscellaneous Plant Equipment

Construction Facilities and Equipment

11,533

Engineering Services

other Costs

SUBTOTAL

$\$ \quad 231,377$

Contingency (10\%)

23,138

SUBTOTAL

$\$ \quad 254,515$

Indirect Costs

TOTAL

$\$ \quad 307,861$

*In September 1976 dollars. 
TABLE 5-5

COST ESTIMATE, PART II (ESCALATION AND DEDUCTIONS)

CONSOLIDATED NUCLEAR STEAM SYSTEM PLANT

AT ORANGE, TEXAS

Direct Costs*

$(\$ \times 1,000)$

Cost Estimate, Part I (Table 5-4)

307,861

\section{Deductions*}

Land and Land Rights

Construction Facilities and

Equiphient

Engineering Services

11,533

31,035

Other Costs

9,285

Contingency $\cdot(10 \%)$

23,138

Indirect Costs

53,346

TOTAL DEDUCTIONS*

$\$ 128,717$

TOTAI COST*

$\$ 179,144$

Escalated Cost $(9 \%) * *$

195,267

Deductions * *

Condenser Equipment

Circulating Water System

Circulating water Equipment

400-MW Turbine Generator

400-MW Substation

2,500

2,050

450

25,900

3,950

TOTAL DEDUCTIONS* *

$\$ \quad 34,050$

TOTAL (Modified CNSS - 1 Unit)**

$\$ 161,217$ 
TABLE 5-6

COST ESTIMATE, PART III (SUMMARY)

FOR CONSOLIDATED NUCLEAR STEAM SYSTEM PLANT

AT ORANGE, TEXAS

CNSS Modified (Table 5-5)

Yardwork

Waste Treatment

Direct Costs*

$(\$ \times 1,000)$

Steam and Condensate Distribution System

Electrical and Distribution system

Turbine. Building

Screenwell

Water Treatment

Offices and Shops

161,217

3,297

10,303

355

$-\cdots$

$--$

$--$

$--$

Warehouses

188

Reactor Structure

Reaclor Plant

Turbine Generator Unit

$+--$

Electrical Accessories

4.500

Miscellaneous Power Plant Equipment

2,316

Substation Equipment

1,044

Guard House

775

Reboiler

Superheater

Fuel Oil system

Cooling Towers

4.444

17.285

1,336

4,454

TOTAL DIRECT COSTS

$\$ 211,514$

Indirects

57,400

Distributables

QA/QC

Allowance for Indeterminates

69,300

8,000

34,586

TOTAL

$\$ 380,800$

* In January 1978 dollars. 


\subsubsection{High Temperature Gas Reactor Steamer}

The order-of-magnitude estimate for the high temperature gas reactor was prepared assuming an nth-of-a-kind unit. Costs were developed utilizing existing in-house data and information obtained from General A.tomic Company. (21)

The cost estimate is shown on Table $5-7$.

$$
\text { TABIE 5-7 }
$$

COST ESTIMATE FOR HIGH TEMPERATURE GAS-COOLED REACTOR AT ORANGE, TEXAS

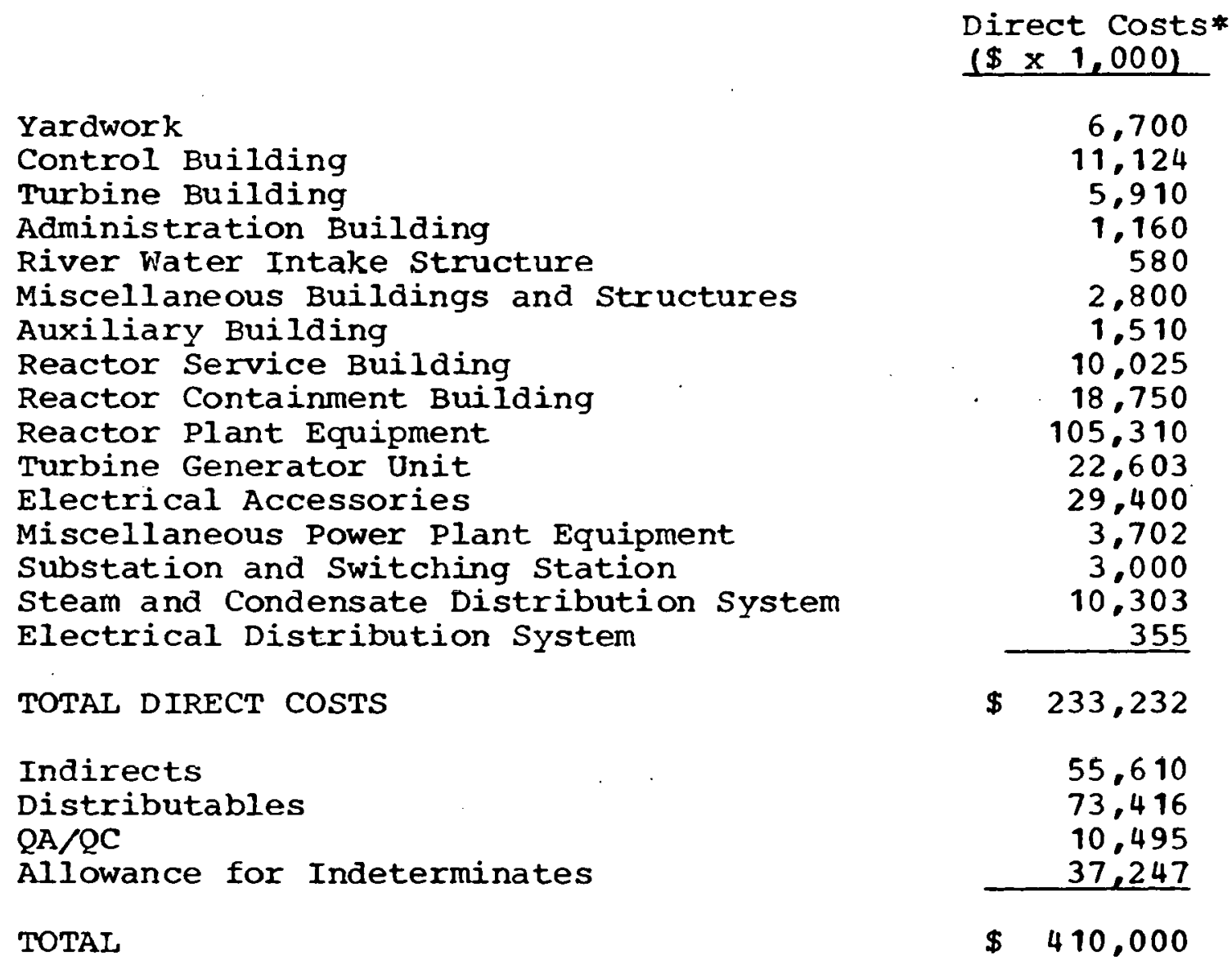

*In January 1978 dollars. 


\subsection{GEISMAR SITE}

\subsubsection{FOSSIL FUEL PLANTS}

Cost estimates for No. 6 fuel oil-, Alabama coal-, and Wyoming coal-fired plants were developed by obtaining current market prices for major equipment and systems and utilizing existing cost data for the remainder of the plant. These estimates are shown on Tables 5-8 through 5-10.

$$
\text { TABLE 5-8 }
$$

COST ESTIMATE FOR

NO. 6 OIL-FIRED COGENERATION PLANT AT GEISMAR, LOUTSIANA

Yardwork

waste 'l'reatment

Steam and Condensate Distribution System

Electric Distribution System

Turbine Building

Screenwell Structure

Water Treatment Plant

Direct Costs*

$(\$ \times 1,000)$

Office and Shops

8,406

1,325

84,091

2,535

3,530

1,237

324

256

Warehouse and Miscellaneous Structures

Boiler Plant Equipment

217,812

Open Boiler Structure

20,392

Oil Hancling Facility

16,366

Turbine Generator Unit

47,707

Electrical Accessories

23,827

Miscellaneous Power Plant Equipment

4,181

195

Substation and Switchgear Station Equipment

TOTAL DIRECT COSTS

$\$ 438,135$

Distributables and Indirects

140,203

Allowance for Indeterminates

TOTAI

$\$ 636,172$

*In January 1978 dollars.

Each plant consists of two $4,700,000 \mathrm{Ib} / \mathrm{hr}$ boilers which generate $9,237,178 \mathrm{lb} / \mathrm{hr}$ of 2,415 psia, 1,000 F steam and four steam turbine generators which produce a gross output of $448.8 \mathrm{MW}$. 
TABLE 5-9

\section{COST ESTIMATE FOR \\ ALABAMA COAL-FIRED COGENERATION PLANT \\ AT GEISMAR, LOUISIANA}

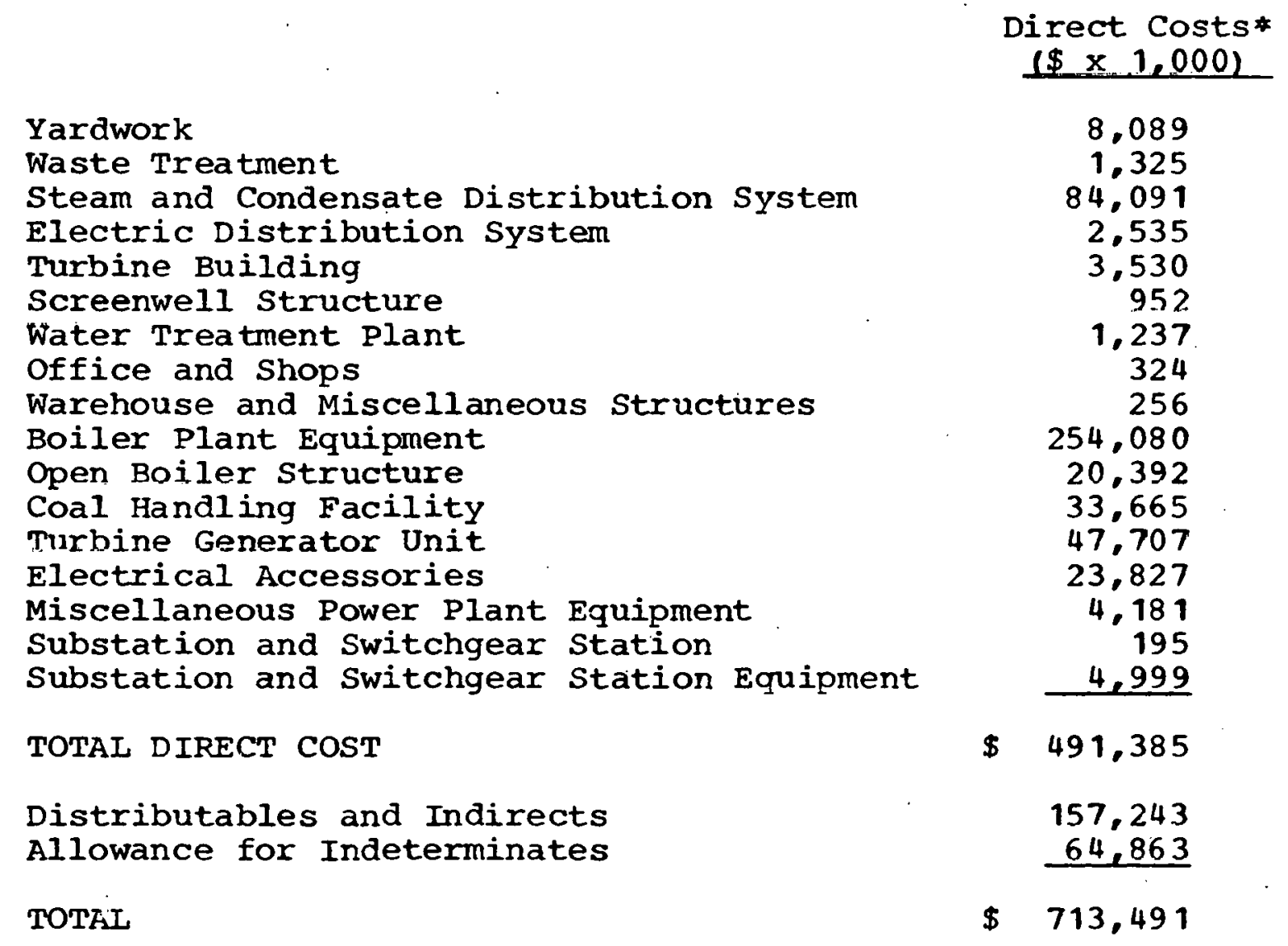

* In January 1978 dollars. 


$$
\begin{gathered}
\text { TABLE } 5-10 \\
\text { COST ESTIMATE FOR } \\
\text { WYOMING COAI-FIRED COGENERATION PLANT } \\
\text { AT GEISMAR, IOUISIANA }
\end{gathered}
$$

Direct Costs*

$(\$ \times 1,000)$

Yardwork

Waste Treatment

Steam and Condensate Distribution System

Electric Distribution System

Turbine Building

8,089

1,325

84.091

2,535

3,530

95.2

screenwell structure

1,237

324

256

Warehouse and Miscellaneous Structures

256,850

Boiler Plant Equipment

Open Boiler Structure

20,392

coal Handiny Facility

33,665

Turbine Generator Unit

47.707

Electrical Accessories

23,827

Miscellaneous Power Plant Equipment

4,181

195

Substation and Switchgear Station Equipment

4,999

TOTAL DIRECT COSTS

$\$ 494.155$

Distributables and Indirects

Aliowance for Indeterminates

158,130

$\underline{65,229}$

TOTAL

$\$ \quad 717,514$

* In January 1978 dollars. 
5.2.2 NUCLEAR PLANTS (GEISMAR) - ADVANCED TECHNOLOGY UNDER DEVELOPMENT

\subsubsection{Consolidated Nuclear Steam System}

This order-of-magnitude estimate was prepared assuming an nth-of-a find unit using the cost estimate contained in Babcock \& Wilcox's report (see Table 5-11).(19) Equipment and systems were deleted to adapt the electric generating plant proposed by $B \& W$ to a cogenerating plant (see Table 5-12). Costs were escalated to raise the September 1976 cost level to January 1978. Equipment and systems were added to convert the plant to cogeneration (see Table 5-13).

\section{TABLE: 5-11}

COST ESTIMATE, PART I (BEW CNSS) CONSOLIDATED NUCLEAR STEAM SYSTEM PLANT AT GEISMAR, LOUISIANA

Land and Land Rights Direct Costs* $(\$ \times 1,000)$

Special Material

Structural and site Facilities

Reactor Plant Equipment

Turbine Plant Equipment Electric Plant Equipment Miscellaneous Plant Equipment

Construction Facilities and Equipment

Engineering Services

Other Costs

SUBTOTAL

$\$ 231,377$

Contingency (10\%)

SUBTOTAL

$\$ 254,515$

Indirect Costs

TOTAL

$\$ 307,861$

* In September 1976 dollars. 
COST ESTIMATE, PART II (ESCAIATION AND DEDUCTIONS) CONSOLIDATED NUCLEAR STEAM SYSTEM PLANT. AT GEISMAR, LOUISIANA

Cost Estimate, Part I (Table 5-11)

$$
\frac{\begin{array}{c}
\text { Direct Costs* } \\
(\$ \times 1,000)
\end{array}}{307,861}
$$

\section{Deductions*}

Land and Land Rights

Construction Facilities and Equipment

Engineering Services

Other Costs

Contingency $(10 \%)$

Indirect costs

11,533

31,035

9,285

23,138

53,346

TOTAL DEDUCTIONS*

$\$ 128,717$

TOTAL COST*

$\$ 179,144$

Escalated cost (9\%) **

195,267

\section{Deductions *}

Condenser Equipment

Circulating Water System

Circulating Water Equipment

400-MW Turbine Generator

400-MW Substation

2,500

2,050

450

25,900

3,150

TOTAI DEDUCTIONS**

$\$ \quad 34,050$

TOTAL (MOdified CNSS - 1 Unit)* *

$\$ 161,217$

TOTAL (Modified CNSS - 2 Units) * *

$\$ 322,434$ 
COST ESTIMATE, PART III (SUMMARY)

CONSOLIDATED INUCLEAR STEAM SYSTEM PIANT AT GEISMAR, LOUISIANA

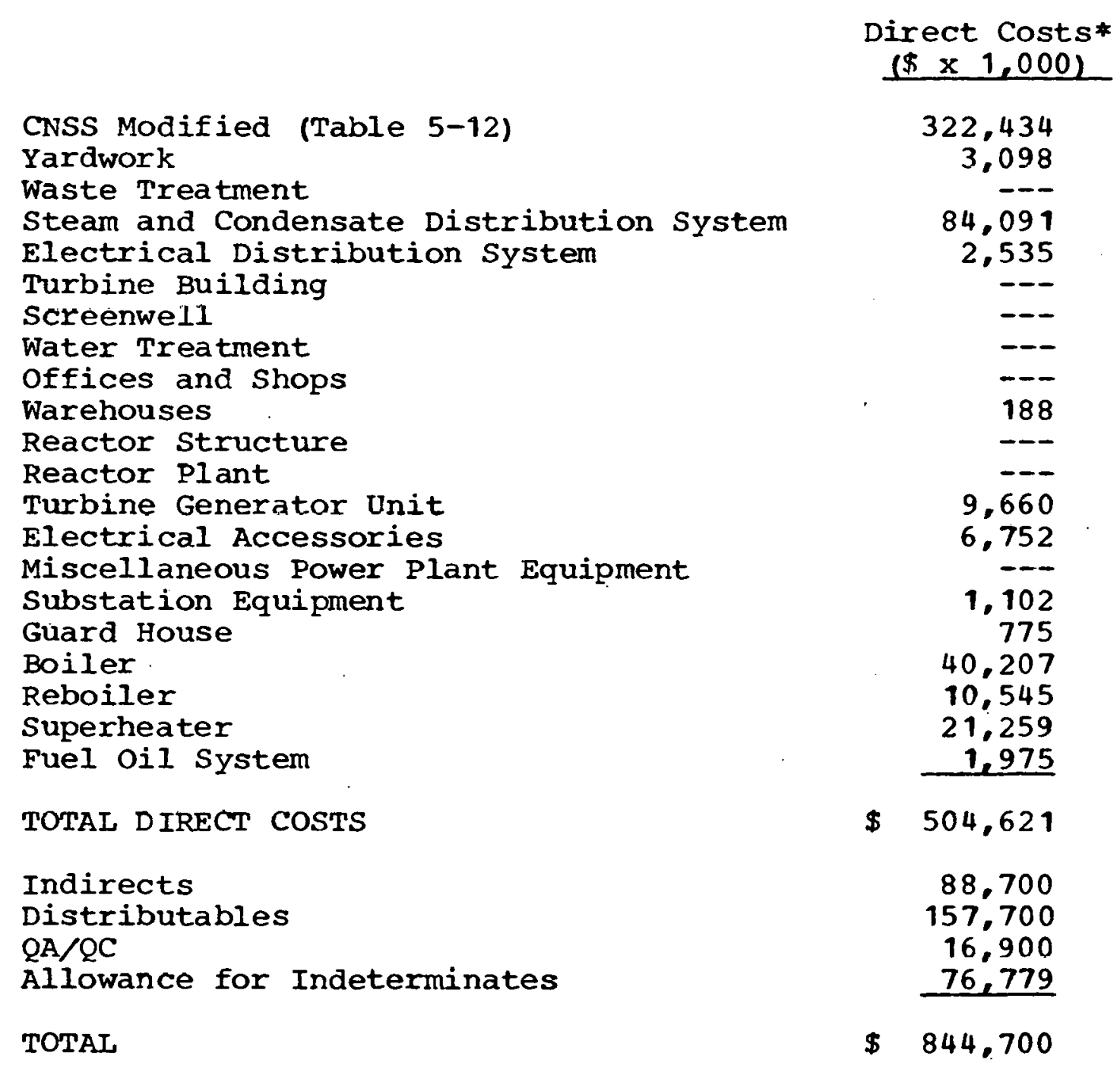

*In January 1978 dollars. 


\subsubsection{High Temperature Gas Reactor Steamer}

The order-of-magnitude estimate for the high temperature gas reactor was prepared assuming an nth-of-a-kind unit. Costs were developed utilizing existing in-house data and information obtained from General Atomic Company.(21) The cost estimate is shown on Table 5-14.

$$
\begin{gathered}
\text { TABLE 5-14 } \\
\text { COST ESTIMATE FOR } \\
\text { HIGH TEMPERATURE GAS REACTOR } \\
\text { AT GEISMAR, LOUISIANA }
\end{gathered}
$$

Yardwork

Control Buildings

Turbine Building

Administration Bullaing

River Water Intake Structures

Miscellaneous Buildings and Structures

Auxiliary Buildings

Reactor Service Builaings

Reactor Containment Buildings

Reactor Plant Equipment

Turbine Generator Unit

Electrical Accessories

Miscellaneous Power Plant Equipment

Substation and Switching Station

Steam \& Condensate Distribution System

Electrical Distribution

Direct Costs*

$(\$ \times 1,000)$

TOTAL DIRECT COSTS

20,100

33,372

6,000

1,200

1,740

8,400

4,530

30,075

56,250

315,930

41,603

88,200

11,106

4,400

84,091

2,535

$\$ 709,532$

Indirects

Distributables

87,728

QA $/ Q C$

Allowance for Indeterminates

198,768

28,602

102,370

TOTAL

$\$ 1,127,000$

*In January 1978 dollars. 


\subsubsection{ADVANCED FOSSIL FUEL TECHNOLOGY COST ESTIMATES}

FUTURE DEVELOPMENT

\subsubsection{Eastern Coal Fluidized-Bed Boiler}

The order-of-magnitude estimate for the atmospheric fluidiced-bed (AFB) steam generating plant was developed utilizing data contained in the report prepared by Stone 8 Webster Fur the U.S. Nepartment of Energy under Contract No. EF-77-C-01-2583.(22) It compares the economics of an AFB combustion power plant with a conventional pulverized coal-fired plant. Foster wheeler Energy Corporation and Babcock \& Wilcox, under contract with Stone $\varepsilon$ webster. provided the AFB boiler design data and cost information.

Differences in plant design developed in the report were costed and system (block) multipliers calculated and applied to the eastern coal-fired plant at Geismar to arrive at estimated costs. Tables 5-15 and 5-16 provide these cost estimates for $A F B$ plants at Geismar using $B E W$ and $F W$ boilers. 
TABIE 5-15

COST ESTIMATE FOR ATMOSPHERIC FLUIDIZED-BED PLANT

USING BABCOCK \& WILCOX BOILER AT GEISMAR, LOUISIANA

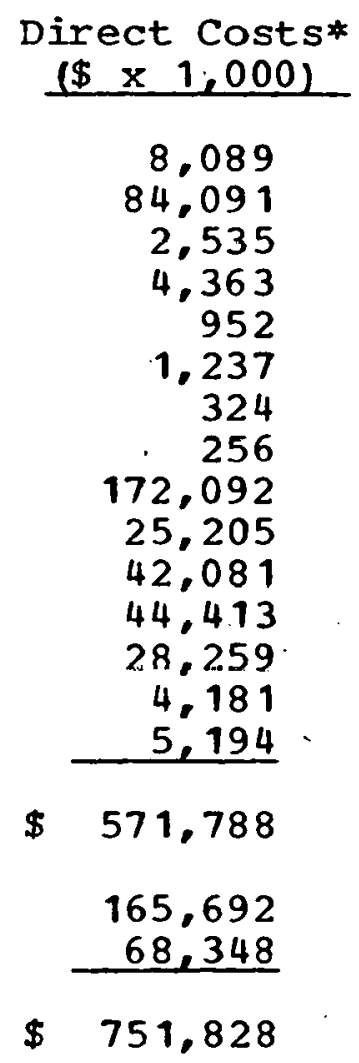

165,692

$\$ \quad 751,828$

Yardwork

Steam and Condensate Distribution System

Electrical Distribution System

Turbine Building

Screenwell

Water Treatment Plant

Offices and Shops

Warehouses and Miscellaneous

Boiler Plant Equipment

Open Boiler structure

Coal Handling

Turbine Generator Unit

Electrical Accessories

Miscellaneous Power Plant Equipment

Substation and Switchyard

TOTAL DIRECT COSTS

Distributables and Indirects

Allowance for Indeterminates

TOTAL

*In January 1978 dollars. 
COST ESTIMATE FOR ATMOSPHERIC FLUIDIZED-BED PLANT USING FOSTER WHEELER BOIIER AT GEISMAR, LOUISIANA

\begin{tabular}{c} 
Direct Costs* \\
$(\$ \times 1,000)$ \\
\hline 8,089 \\
84,091 \\
2,535 \\
2,898 \\
952 \\
1,237 \\
324 \\
256 \\
104,679 \\
16,742 \\
42,081 \\
44,413 \\
27,783 \\
4,181 \\
5,194 \\
\hline 431,269 \\
138,006 \\
56,927 \\
\hline 626,202 \\
\hline 1
\end{tabular}

Yardwork

Steam and Condensate Distribution System Electrical Distribution System

Turbine Building

Screenwe1l

Water Treatment Plant

Offices and Shops

Warehouses and Miscellaneous

Boiler Plant Equipment

Open Boiler Structure

Coal Handling

Turbine Generator Unit

Electrical Accessories

Miscellaneous Power Plant Equipment

Substation and Switchyard

$\$ 626,202$
TOTAL DIRECT COSTS

Distributables and Indirects

Allowance for Indeterminates

TOTAL
Direct Costs*

8,089

84,091

2,535

898

237

324

256

16,742

42,081

44,413

7,783

4,181

5,194

$\$ 431,269$

138,006

56,927

*In January 1978 dollars. 
5.2.3.2 Eastern Coal Gasification With Conventional Boiler (Oxygen-Blown and Air-Blown Gasifiers)

Order-of-magnitude estimates for this cogeneration plant arrangement using oxygen-blown and air-blown gasifiers are shown in Tables 5-17 and 5-18. The estimates are comprised of the cost of the coal gasification plant and the cost of the eastern coal-fired cogeneration plant (see Table 5-9) modified to account for larger coal handling facilities, coal gas-fired boilers, larger water treatment facilities, deletion of the precipitators and scrubbers, modifications to the waste treatment facilities, and other related items. See Section 4.4.1.2 for a description of the plant. The costs for the coal gasification process were prorated and escalated from the Electric Power Research Institute Report entitled Economics of Current and Advanced Gasification Processes for Fuel Gas Production.(23) 


\author{
TABLE 5-17 \\ COST ESTTMATE FOR \\ EASTERN COAL GASIFICATION WITH \\ CONVENTIONAL BOILER AND OXYGEN-BLOWN GASIFIER
}

Direct Costs*

$(\$ \times 1,000)$

Coal Handling Facilities

39,400

Oxidant Feed System

Gasification and Ash Handling

Gas Cooling

Acid Gas Removal

Process Condensate Treating

Power Recovery

Utility and offsite Facilities

Initial Chemical and Catalyst Charge

Yardwork

Waste Treatment

Steam and Condensate Distribution System

Electrical Distribution System

Turbine Building

100,116

108,561

82,068

50,455

125,690

39,895

114,400

2,960

8,500

700

84,091

2,535

3,530

952

Screenwell structure

1,000

324

Office and Shops

256

Warehouse and Miscellaneous

136,930

Boiler Plant Equipment

Open Boiler Structure

16,855

Turbine Generator Unit

47,707

Electrical Accessories

23,327

4,181

195

Substation \& Switchyard Station

4,999

TOTAL DIRECT COSTS

$\$ \quad 999,627$

Distributables and Indirects

319,883

131,950

Allowance for Indeterminates

21,979

TOTAL

$\$ 1,473,439$

*In January 1978 dollars. 


\author{
TABLE 5-18 \\ COST ESTIMATE FOR \\ EASTERN COFL GASIFICATION WITH \\ CONVENTIONAL BOILERS AND AIR-BLOWN GASIFIER
}

Coal Handling Facilities

Direct Costs*
$(\$ \times 1,000)$

Oxidant Feed System

Gasification and Ash Handling

Gas Cooling

Acid Gas Removal

Process Condensate Treating

Power Recovery

Utility and Offsite Facilities

Initial Chemical and Catalyst Charge

Yardwork

Waste Treatment

Steam and Condensate Distribution system

Electrical Distribution System

Turbine Building

Screenwell structure

Water Treatment Plant

Office and Shops

39,000

42.682

107,540

50,307

66,174

100,202

45,602

89,000

4,385

8,500

700

84.091

2,535

3,530

952

1,000

324

256

Warehouse and Miscellaneous

136,930

Boiler Plant Equipment

Open Boiler Structure

Turbine Generator Unit

16,855

Electrical lccessories

47.707

Miscellaneous Power Plant Equipment

23,327

Substation $\varepsilon$ Switchyard Station

4,181

195

Substation \& Switchyard Equipment

4,999

TOTAL DIRECT COSTS

$\$ 880,974$

Distributables and Indirects

Allowance for Indeterminates

Royalties (Paid)

281,926

116,300

17,886

TOTAL

$\$ 1,297,086$

* In January 1978 dollars. 


\subsubsection{Eastern Coal Gasification With Gas Turbines and Waste Heat Boilers Unlimited and Limited Power Generation)}

The order-of-magnitude estimates for this cogeneration plant arrangement using unlimited and limited power are shown in Tables 5-19 and 5-20. The estimates were developed trom data contained in the Electric Power Research Institute report entitled Comparative Evaluation of High and Low Temperature Gas Cleaning for Coal Gasification - Combined Cycle Power systems.(24) This report was prepared by Stone \& Webster for EPRI, under Research Project 243-2, to evaluate the incentives for developing hot-gas purification technology for application to coal gasification combine-cycle power generating systems.

The cost information from this report was prorated on the basis of coal gas output to develop the cost of the coal gasification plant. The balance of plant cost was developed by obtaining current market prices for major equipment and systems and utilizing existing in-house cost data. 
TABLE 5-19

COST ESTIMATE FOR

EASTERN COAI GASIFICATION WITH GAS TURBINES AND WASTE

HEAT BOILERS - UNLIMITED POWER GENERATION

Direct Costs*
$(\$ \times 1,000)$

Coal Handling Facilities

Gasification

Gas Cooling/Heating

Air Compression

Water Treatment

Cold Purification

Combined Cycle

offsites

Tar-Fired Power Unit

Initial Charge for Catalyst and Chemicals

Yardwork

Waste Treatment Plant

Steam and Condensate Distribution system

Electrical Distribution System

Screenwell Structure

Water Treatment (Feedwater $\varepsilon$ Condensate)

Office and Shops

Warehouse and Miscellaneous Structures

Boiler Plant Equipment

Electrical Accessories

Miscellaneous Power Plant Equipment

Substation and Switchyard Station

Substation and Switchyard Station Equipment

TOTAL DIRECT COSTS

60,000

185,539

96,177

79,532

211,806

132,832

499,887

273,278

306,894

10,690

3.235

800

84,091

2,535

1,200

1,500

150

100

34,220

8,050

1,000

700

17.020

Distributables and Indirects

$\$ 2,011,236$

Allowance for Indeterminates

645,317

266,000

SUBTOTAL PROJECT COST

$\$ 2,922,553$

Royalties (Paid)

53.447

TOTAL

$\$ 2,976,000$

*In January 1978 dollars. 
COST ESTTMATE FOR

EASTERN COAL GASIFICATION WITH GAS TURBINES AND WASTE HEAT BOILERS - LIMITED POWER GENERATION

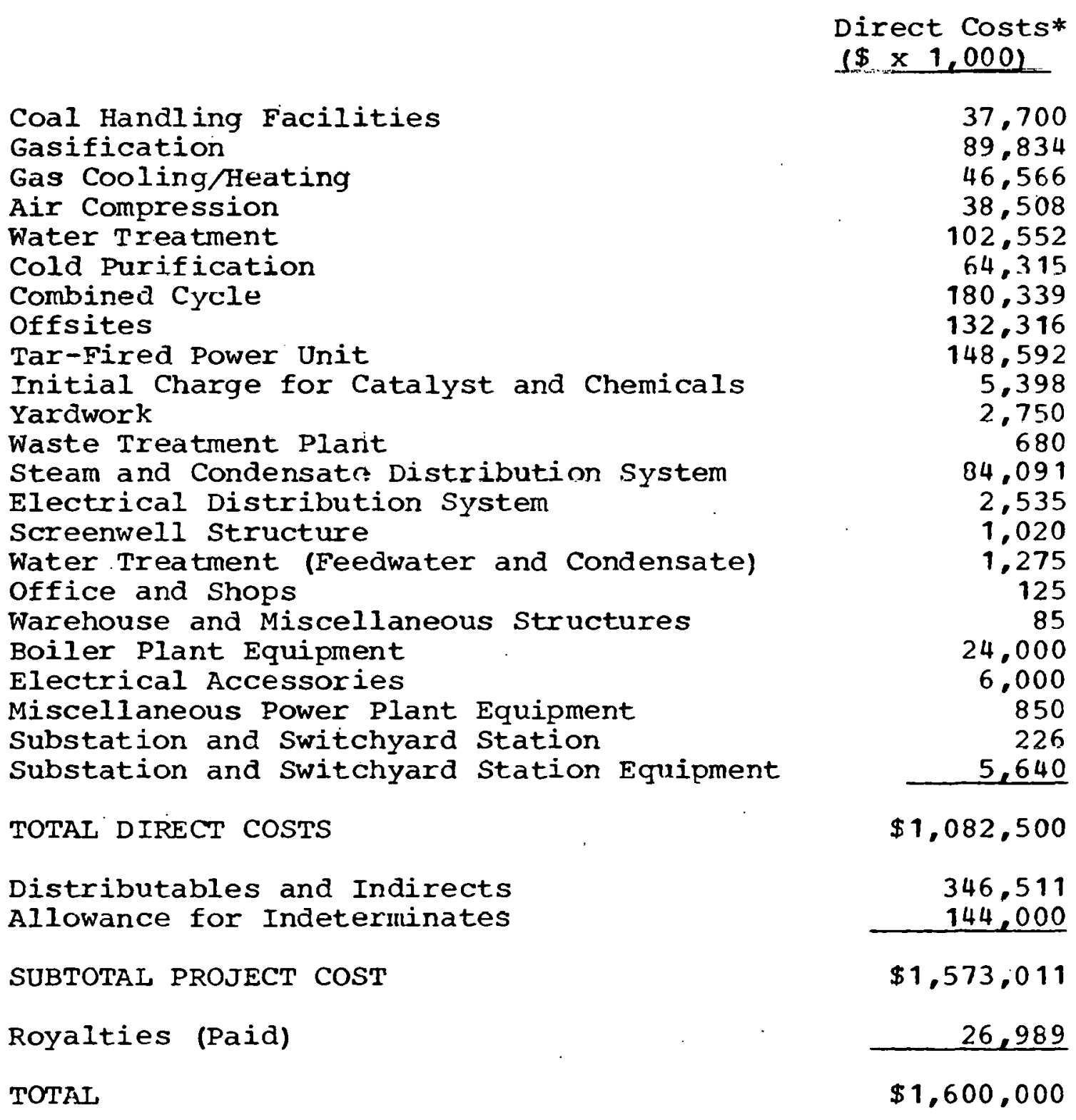

*In January 1978 dollars. 
5.2.3.4 Eastern Coal Gasification With Fuel Cell (UnIimited and Limited Power Generation)

This schene assumes thät clean coal gas can be used directly in a molten carbonate fuel cell. The gasification system portion is a Lurgi air-blown system. Tables 5-21 and 5-22 show the estimates for unlimited and limited power generation.

The fuel cell costs were assumed to be $\$ 350 / \mathrm{kw}$, based on an upper range for predicted cost given in a report prepared for ERDA by United Technologies.(25) 


\section{TABLE 5-21}

COST ESTIMATE FOR

EASTERN COAL GASIFICATION WITH

FUEL CELLS - UNLIMITED POWER GENERATION

Direct Costs*

$(\$ \times 1,000)$

Coal Handling Facilities

$69,3.00$

Oxidant Feed System

Gasification and Ash Handling

Gas Cooling

Acid Gas Removal

Process Condensate Treating

Power Recovery

Utilities and offsites

Fuel Cells

Initial Chemical and Catalyst Charge

Steam and Curdensate Distribution System

Electrical nistribution system

82,980

208,010

97,800

128,650

187,040

88,650

205,945

897,934

11,125

84,091

2,535

TOTAL DIRECT COSTS

$\$ 2,064,060$

Distributables and Indirects

Allowance for Indeterminates

660,500

27,250

SUBTOTAL PROJECT COST

$\$ 2,751,810$

Royalties (Paid)

45,420

TOTAL

$\$ 2,797,230$

* In January 1978 dollars. 
TABLE 5-22

COST ESTIMATE FOR

EASTERN COAL GASIFICATION WTTH

FUEL CELLS - LIMITED POWER GENERATION

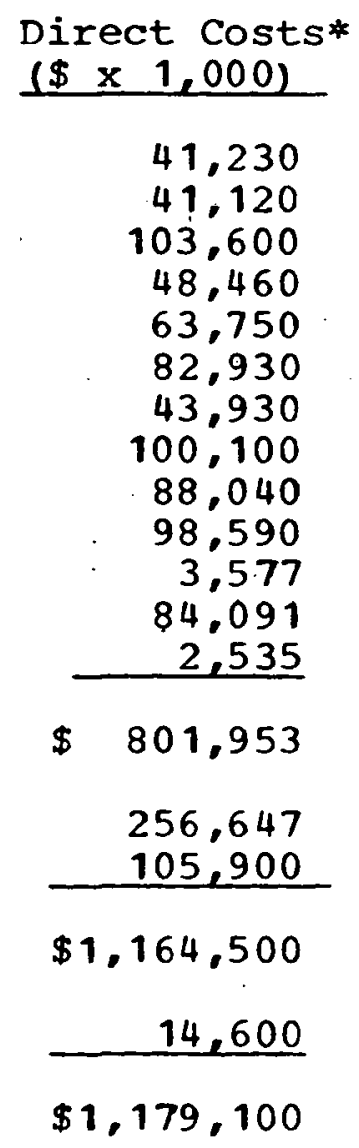

$\$ 1,179,100$

Coal Handling Facilities

Oxidant Feed System

Gasification and Ash Handling system

Gas Cooling

Acid Gas Removal

Process Condensate Treating

Power Recovery

Utilities and offsites

Fuel Cells

Fuel' Fired Boiler system

Initial Chemical and Catalyst Charge

iteam and Condensate Distribution system

Electrical Distribution System

TOTAL DIRECT COSTS

Distributables and Indirects

Allowance for Indeterminates

SUBTOTAL PROJECT COST

Royalties (Paid)

TOTAL

*In January 1978 dollars. 
(1)

(3) 


\section{SECTION 6}

ECONOMIC ANALYSIS

TABLE OF CONTENTS

Page

6.1 LCONOMIC ASSUMPTIONS AND TABULATIONS 6-1

6.2 ECONOMIC COMPARISONS 6-13

6.2.1 Coal-Fired plants (Eastern Coal vs Western coall at Orange and Geismar 6-13

6.2.2 Eastern Coal-Fired vs Oil-Fired. Plants at Orange and Geismar

6.2.3 Consolidated Nuclear Steam System vs High Temperature Gas-Cooled. Reactor at orange and Geismar

6.2.4 Eastern Coal and High Temperature

Gas-Cooled Reactor at Orange and Geismar 6-15

6.2.5 Coal Gasification Alternatives Generating Limited Power

6.2.6 Coal Gasitication Considering Gas Turbines and Fuel Cells With No Iimit on Electric Power Generation

6.2.7 Fuel Cells without Limitation of Electric Power and Air-Blown Gasification with Conventional Boilers

6.2.8 Atmospheric Fluidized-Bed Boiler vs Fuel cell with Unlimited Electric Generation

$6-14$

$6-14$

$6-16$

$6-17$

$6-17$

$6-18$

6.2.9 High Temperature Gas-Cooled Reactor anö Atmospheric Fluidized-Bed Boiler at Geismar

$6-18$

RELIABBLITY - FOSSIL FUEL AND NUCLEAR PLANT'S - ORANGE AND GEISMAR

$6-18$

ECONOMICS CONSIDERING ADVANCED TECHNOLOGY CONDENSING CAPABILITIES (HTGR AND CNSS)

$6-24$

6.5 SEQUENTIAL INSTALLATION OF THE HIGH TEMPERATURE GAS-COOLED REACTOR AND CONSOLIDATED NUCLEAR SITEAM SYSTEM

DISCOUNTED CASH FLOW ANALYSIS

$6-33$

6.7

PRESENT VALUE STEAM COST

$6-39$

TABLES 


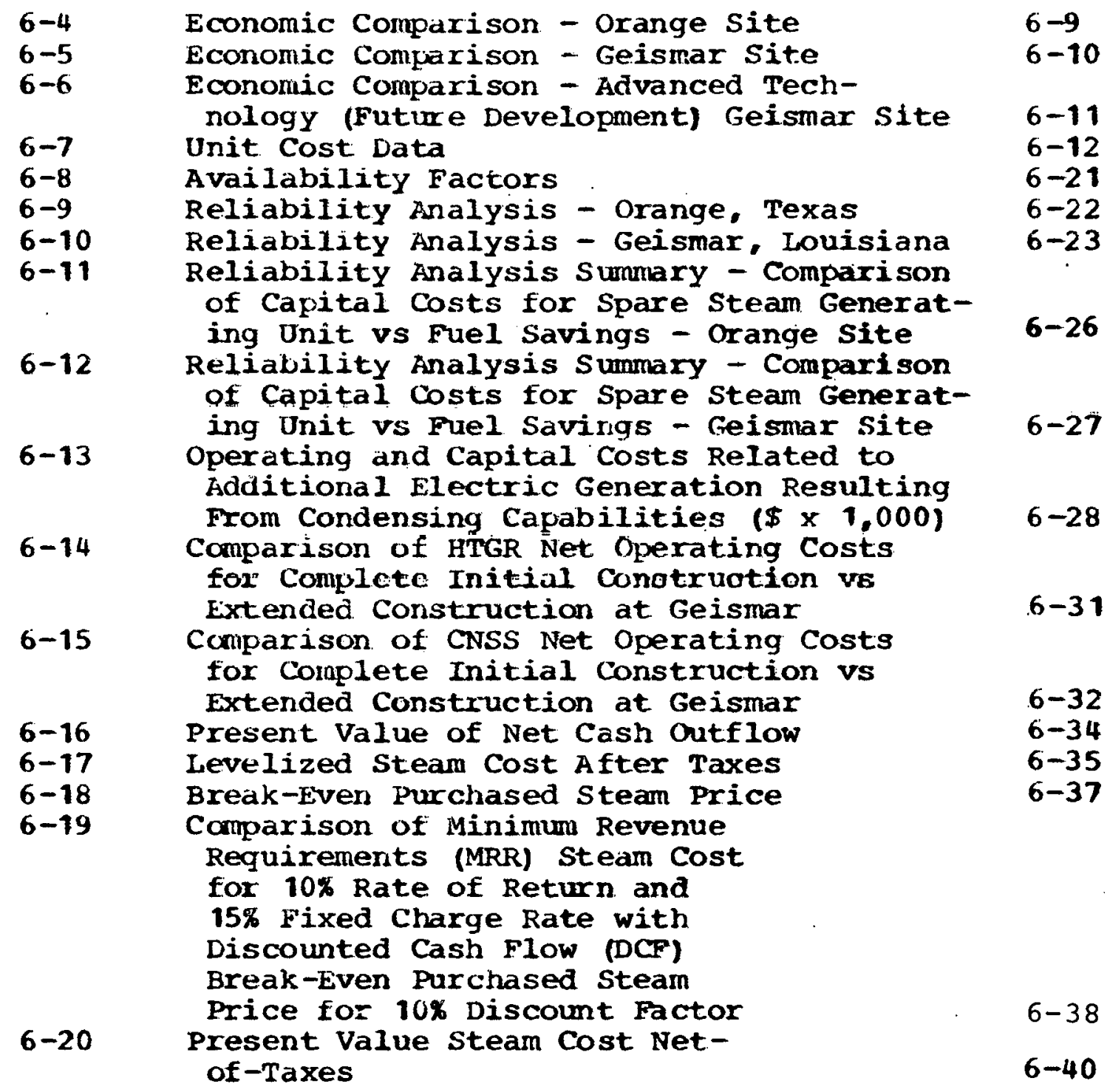

\section{FIGURES}

6-1 Diagram of Economic Comparisons of Cogeneration Plants at Geismar and Orange

6-2 Net Present Value vs Discount Rate at Orange with $90 \%$ Fuel Cost

6-3 Net Present Value vs Discount Rate at Orange with $100 \%$ Fuel Cost

6-4 Net Present Value vs Discourt Rate at Orange with 150\% Fuel Cost

6-5 Net Present Value vs Discount Rate at Orange with $200 \%$ Fuel Cost

6-6 Net Present Value vs Discount Rate at Geismar with 90\% Fuel Cost

6-7. Net Present Value vs Discount Rate 
at Geismax with 100\% Fuel Cost

Net Present Value vs Discount Rate

at Geismar with 150\% Fuel Cost

6-9 Net Present Value vs Discount Rate at Geismar with 200\% Fuel Cost

6-10 Ratio of Levelized Steam Costs to Net Present Value of Steam vs Discount Rate for Various Escalation Rates

6-11 Ratios of NPV (and Steam Costs)

for Alternatives to NPV (and Stean Cost) for Eastern Coal at Gei smar

6-12 Ratio of Levelized Steam Costs to Net Present Value of steam vs Discount Rate for Various Escalation Rates 


\section{SECTION 6}

\section{ECONOMIC ANALYSIS}

This section presents the basic assumptions and data necessary to make an economic comparison of plant cogeneration alternatives. The basic assumptions and economic data are included in section 6.1. Analyses of these data are discussed in Section 6.2, Economic Comparisons.

Other factors impacting the design and economics of the cogeneration plant are developed in section 6.3, which discusses the reliability of steam generating equipment: Section 6.4, which describes the economics of condensing capabilities using a consolidated nuclear steam system (CNSS) and a high temperature gas-cooled reactor (HTGR) steamer: and section 6.5, which investigates sequential installation.

\subsection{ECONOMIC ASSUMPTIONS AND TABULATIONS}

This section contains the basic assumptions and economic tabulations developed to permit economic comparison of the various cogeneration plant concepts at each site. The basic assumptions and econonic factors are listed in Table 6-1. Sample calculations depicting the method used to determine the total capital costs and annual operating costs for Taules 6-4 and 6-5 axe shown in Tables 6-2 and 6-3. respectively.

Tables 6-4 and 6-5, for Orange and Geismar, respectively, sumarize the operating conditions, capital costs, operating costs, and process steam costs for both current technology and advanced technology presently being developed. Because of the potential utilization of inherent excess stean generating capacity in the CNSS plant, data are included for plants with and without condensing capabilities. For comparison purposes, process steam costs are also shown for the users' facilities assuming that they would continue operating using No. 2 fuel oil. These costs include only fuel and operating and maintenance costs with no allowance for capital costs, which are unknown but assuredly would be necessary.

The cost data for rables $6-4$ and 6-5 were calculated using assumptions from Table 6-1 and the capital cost estimates in Section 5.

Since the different alternatives have unequal economic lives, comparison has been made on the basis of uniform annual costs to the users. These are based on the minimum revenue requirements of the cogeneration entity necessary to 
realize a rate of return of 10 percent, which is a return that is appropriate for a utility. The higher rates typically required by unregulated industries would increase users: steam costs.

The fixed charges are the components of the revenue requirements, which are a function of the invested capital. These include return, depreciation, income tax, other taxes, and insurance. The fixed charge rate is the sum of ali these components expressed as a percentage of the investment capital. The higher fixed charge rate for the nuclear alternatives results from a higher percentage for income tax calculated for a longer construction period and operating life.

The levelized fuel and operating and maintenance charges are the uniform annual costs which have the same present value in the first year of operation as the predicted costs. The total of these operating costs and the fixed charges represents revenue which must be realized from the users. However, for this they receive electric power which is shown as a credit based on the levelized utility rate. I'he net annual operating cost represents the users * levelized before-income-tax cash flow chargeable to process steam. The net-of-taxes cash flow would be reduced by the users* effective income tax rate.

The bottom line shows the average levelized cost per thousand pounds of process steam assuming that the cogeneration plant is able to supply steam equivalent to full load capacity for 7884 hours per year. This equates to a load factor of 90 percent which is based on users. requirements, not plant availability. (Plant reliability is treated separately in section 6.3.) Cogeneration plant outages would increase the unit steain cost and entail backup expenses as shown in Figure 7-t. No attempt has been made to develop the sale price of steam at the various pressures which would be affected by heat input, electric power generated, and the quantity and condition of returned condensate.

The advanced technology costs which were investigated only for Geismar are shown in Table 6-6.

Table 6-7 provides various unit cost economic data for reference and general information. It must be emphasized that these data are site specific and therefore are correct only for Geismar and Orange and their projected steam requirements. 
TABLEE 6-1

ASSUMPTIONS USED IN ECONOMIC ANALYSES

Fuel oil Coal Gasifi- Fuel Comb.

1. Construction period (yrs)

2. Operating date

3. Basis for capital costs

4. Escalation of capital costs ( $\mathrm{x}$ per year) (1)

5. Interest during construction ( $x$ per year) (2)

6. Operating life of unit (yrs)

7. Rate of return (x)

8. Annual fixed charge rate (x) (26)

9. Load factor (\$)

10. Fuel cost (1977 $\$$ per $10^{\circ}$ Btu)

11. Escalation of fuel cost ( $x$ per year)

12. Limestone cost ( 1977

\begin{tabular}{|c|c|c|c|c|c|c|c|c|c|}
\hline 5 & - & 6 & 6 & 7 & 7 & 6 & 6 & 6 & 6 \\
\hline 1984 & - & 1985 & 1985 & 1986 & 1986 & 1985 & 1985 & 1985 & 1985 \\
\hline $1 / 78$ & - & $1 / 78$ & $1 / 78$ & $1 / 78$ & $1 / 78$ & $1 / 78$ & $1 / 78$ & $1 / 78$ & $1 / 78$ \\
\hline 7 & - & 7 & 7 & $7(6)$ & 7 & 7 & 7 & 7 & 7 \\
\hline 9 & 9 & 9 & 9 & 9 & 9 & 9 & 9 & 9 & 9 \\
\hline 30 & - & $30(5)$ & $30(5)$ & $35(2)$ & 35 & 30 & 30 & 30 & 30 \\
\hline 10 & - & $10(5)$ & $10(5)$ & $10(5)$ & 10 & 10 & 10 & 10 & 10 \\
\hline 15 & - & $15(5)$ & $15(5)$ & 16 & 16 & 15 & 15 & 15 & 15 \\
\hline 90 & 90 & 90 & 90 & 90 & 90 & 90 & 90 & 90 & 90 \\
\hline $1.98(3)$ & $2.55(3)$ & 1.11 & $1.22(4)$ & $0.72(8)$ & 0.63 & 1.11 & 1.116320 & 1.11 & 1.11 \\
\hline $7(4)$ & 7 & 6 & 6 & $(80)$ & $(10)$ & 6 & 6 & 6 & 6 \\
\hline 13 & - & 13 & 13 & - & - & - & 13 & - & - \\
\hline
\end{tabular}


TABLE 6-1 (Cont)

No. $\frac{\text { Fuel Oil }}{6}$ No. 2 Eastern Western $\quad$ CNSS HTGR cation AFB $\begin{aligned} & \text { Coal } \\ & \text { casifi- Fuel Cells Cycle }\end{aligned}$

13. Escalation of limestone ( $\%$ per year)

14. O\&M costs $(1977$

15. Escalation for $O \& M$ costs ( $*$ per year)

16. GSU electric power rates (1977 mills/kwh)

0.

6

6

0.23

0.14

$\begin{array}{ll}0.29 & 0.27\end{array}$

0.18

0.16

(13)

0.26

(14)

(15)

6

$6(9)$

$6(9)$

$6(9)$

6

6

6

66

16.5

16.5

$16.5 \quad 16.5$

16.5

$16.5 \quad 16.5$

16.5

$16.5 \quad 16.5$

17. Escalation for electric power ( $x$ per year) :

$$
\text { To } 1985
$$

18. Sulfur (\$ per ton)

19. Escalation for sulfur

$$
\text { ( } x \text { per year) }
$$

20. Aqueous anmonia (\$ per ton)

21. Escalation for aqueous ammonia. (\% per year)

22. Anhydrous anmonia (\$ per ton)

23. Escalation for anhydrous ammonia ( $x$ per year) 
NOTES

Unless noted otherwise, economic factors are best estimates by Stone $\varepsilon$ Webster Engineering Corporation.

(1) Escalation compounded through $60 \%$ of the construction period.

Simple interest (not compounded) during last $40 \%$ of construction period.

From Reference (c) for No. 6 and No. 2 fuel oil.

From Reference (c).

From Reference (a) Section 5.9

From Reference (b) page 4-18.

From Reference (b) page 4-15, assuming same life of CNSG and CNSS.

From Reference (d) page $B-4$ excluding plutonium credit and escalated one year.

From Reference (e) page 28.

(10). Yellowcake escalation (1/3) is estimated at $6 \%$ per year. Conversion, enrichment, shipping, and fabrication escalation $(2 / 3)$ is estimated at $4 \%$ per year.

(11) Scrubbers included for fossil units except for No. 2 oil.

(12) Comparison made on basis of eastern coal.

(13) 0.52 for air-blown OGM. 0.54 for oxygen-blown.

(14) 0.61 for unlimited power. 0.54 for 1 imited power.

(15) 0.63 for unlimited power, 0.57 for limited power.

(16) Includes taxes, insurance, and debt service.

\section{RUFERENCES}

(a) Steam Supply Study in Geismar Area for Gulf States Utilities.

prepared by Stone \& Webster Engineering.Corporation, Cherry Hill, N.J. (July 1975) -

(b) Nuclear Power plant Sitiny Study, prepared for Department of the Army by United Engineers and Constructors. Inc. (June 1976)

(c) R. G. Chapman, Gulf States Utilities Company, to R. B. Steiner Stone \& Webster Engineering Corporation, comunication dated July 22, 1977.

(d) 400-MWe Consolidated Nuclear Steam System (CNSS) - 1200 Mwe/Conceptual Design. prepared by Babcock $\&$ Wilcox Company for Oak Ridge National Laboratory. ORNL/Sub-4390/4 (June 1977) .

(e) Evaluation of Geismar Steam - Electric Project, prepared for Gulf States Utilities Company by Arthux D. Little, Inc. (December 12, 1975) • 
SAMPLE CALCULATIONS FOR ECONOMIC COMPARISON CAPITAL COSTS

Capital costs

Example is for Geismar coal-fired plant using eastern coal:

$$
\text { 6-Year Construction Period }
$$

1985 Service Date

Estimated capital cost (in January 1978 dollars).

Escalation based on $7 \%$ per year

compounded through $60 \%$ of construction

period.

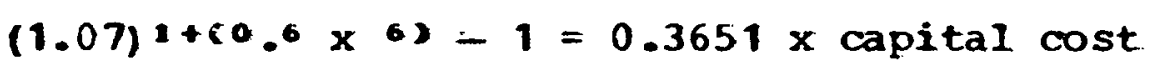

SUBTOTAL (Escalated capital cost)

260,496

Interest during construction at $9 \%$

per year simple interest during last $40 \%$

of construction period.

$(0.09) \times(6$ yrs $\times 0.4)=0.216 \times$ escalated capital cost

$\$ \quad 973,987$

TOTAL CAPITAL COSTS

$\$ 1,184,368$ 
Example is for Geismar coal-fired plant using

eastern coal:

Assumptions

30-Year Operating Life

Rate of Return - 10\%

Boiler Efficiency - $86 \%$

Availability - 90\%

1. Fixea charges at $15 \%$ of total capital

cost for insurance, taxes,

and debt service.

$\$ 177.655$

2. Fuel costs $\left(\$ 1.11 /(10)^{6} \mathrm{btu}\right)$

escalated at $6 \%$ and levelized.

$\$ 1.11 \times 1.59385 \times \frac{16.771225}{9.426914}=\$ 3.15 /(10)^{6}$ Btu

$2630.958 \mathrm{Mh}$ ' $\times 3413(10)^{3} \times 3.15 \times 7.884 \mathrm{hr} / \mathrm{yr}$ $0.86 \times(10)^{6}$

$\$ 259,304$

3. O\&M costs $\left(\$ 0.29 /(10)^{\circ}\right.$ Etu

escalated at $6 \%$ and levelized.

$\$ 0.29 \times 1.59385 \times \frac{16.771225}{9.426914}=\$ 0.82 /(10)^{6} \mathrm{Btu}$ 9.426914

2630.958 MWt $\times 3413(10)^{3} \times 0.82 \times 7.884 \mathrm{hr} / \mathrm{yr}$ $0.86 \times(10)^{6}$

$\$ 67,501$

SUBTOTAL (Armual operäting Cost)

$\$ 504.460$

4. Credit for power $(16.5 \mathrm{mills} / \mathrm{kWh})$

escalated at $11 \%$ to 1985 and $7 \%$

thereatter and levelized.

$16: 5 \times 2.30454 \times \frac{18.79176}{9.426914}=75.7 \mathrm{mi} 11 \mathrm{~s} / \mathrm{kWh}$

352.2 MWe $\times 7.884$ hrs $\times 0.0757(10)^{3}$

$\$ 210.200$

NET ANNOAL OPERATING COST

$\$ 294.260$

5. Stean cost/1000 1b process steam

$\$ 294,260 \quad(10)^{3}$

$5.8401 \mathrm{~b} \times(10)^{3 / \mathrm{hr}} \times 7.884 \mathrm{hr} / \mathrm{yr}$

$\$ \quad 6.39$ 
TABLE 6-3

SAMPLE CALCULATIONS FOR ECONOMIC COMPARISON

OPERATING COSTS

Annua 1

Operating Costs

Example is for Geismar coal-fired plant using

$(\$ \times 1,000)$ eastern coal:

\section{Assumptions}

30-Year Operating Life

Rate of Return - $10 \%$

Boiler Efficiency - 86\%

Availability - 90\%

1. Fixed charges at $15 \%$ of total capital

cost for insurance, taxes,

and debt service.

$\$ 177.655$

2. Fuel costs $\left(\$ 1.11 /(10)^{6} \mathrm{Btu}\right)$

escalated at $6 \%$ and levelized. $\$ 1.11 \times 1.59385 \times \frac{16.771225}{9.426914}=\$ 3.15 /(10)^{6} \mathrm{Btu}$

$\frac{2630.958 \text { HWt } \times 3413(10)^{3}}{0.86 \times(10)^{6}} \times 3.15 \times 7,884 \mathrm{hr} / \mathrm{Yr}$

$\$ 259,304$

3. OEM costs $\left(\$ 0.29 /(10)^{6}\right.$ Btu

escalated at $6 \%$ and levelized.

$\$ 0.29 \times 1.59385 \times \frac{16.771225}{9.426914}=\$ 0.82 /(10)^{6}$ Btu

$\frac{2630.958 \text { MWt } \times 3413(10)^{3}}{0.86 \times(10)^{6}} \times 0.82 \times 7.884 \mathrm{hr} / \mathrm{yr}$

$\$ 67,501$

SUBTOTAL (Annual Operating Cost)

$\$ 504,460$

4. Credit for power (16.5 mills/(kWh)

escalated at $11 \%$ to 1985 and $7 \%$

thereafter and levelized.

$16.5 \times 2.30454 \times \frac{18.79176}{9.426914}=75.7 \mathrm{mills} / \mathrm{kWh}$

352.2. MNe $\times 7.884$ hrs $\times 0.0757(10)^{3}$

$\$ 210,200$

NET ANUUAL OPERATING COST

$\$ 294,260$

5. Steam cost/1000 ib process steam

$\$ 294,260(10)^{3}$

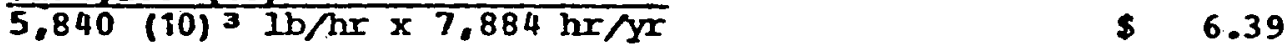


TABLE $6-4$

ECONOMIC COMPARISON - ORANGE SITE

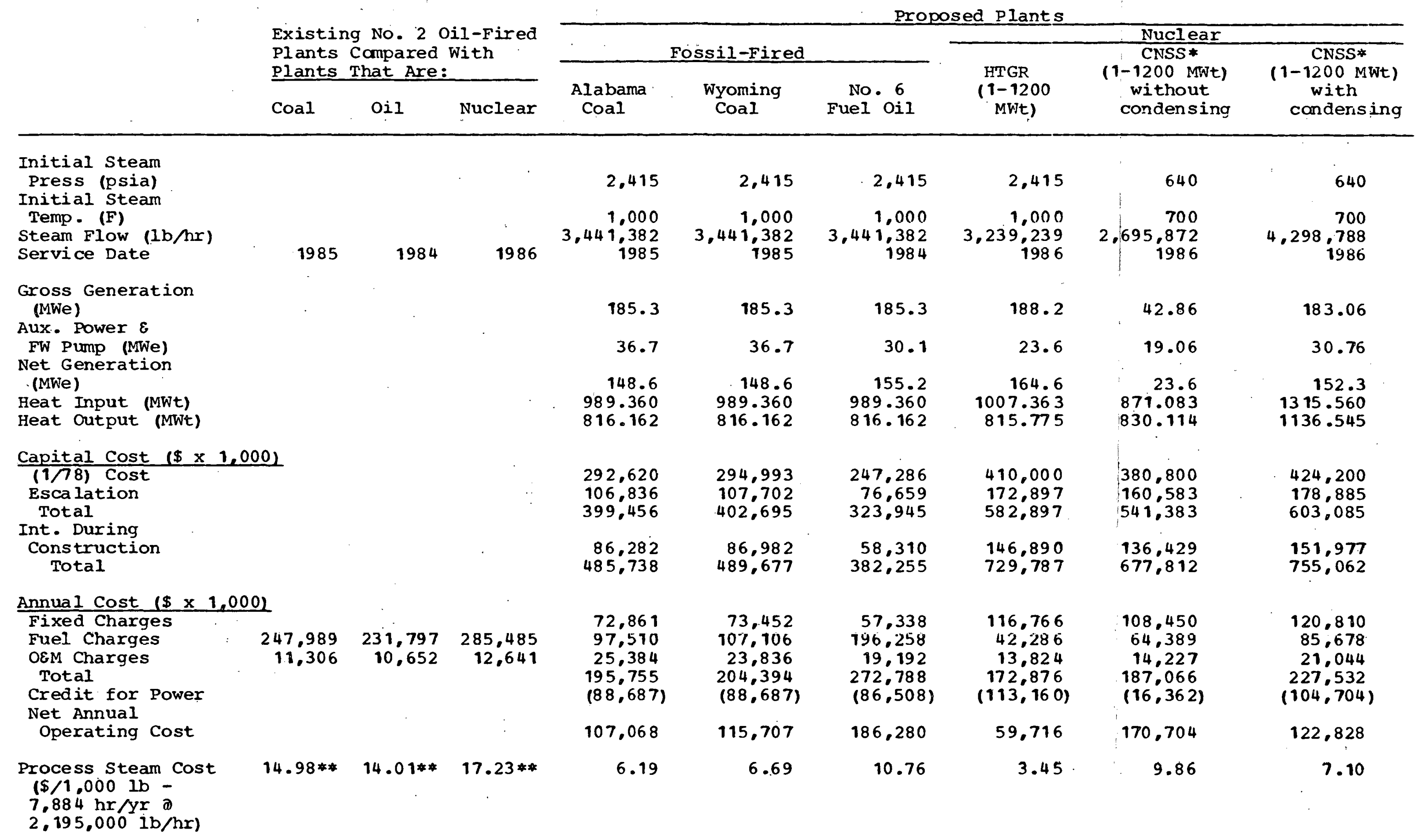

* Plus oil-fired superheater.

* * Process steam cost based on operating costs only.

No allowance for capital cost (fixed charges). 
TABLE 6-5

ECONOMIC COMPARISON - GEISMAR SITE

Existing No. 2 Oil-Fired Plants Compared with Plants That Are:

Coal oil Nuclear

$\begin{array}{cc} & \text { Fossil-Fired } \\ \text { Alabama } \quad \text { Wyoming }\end{array}$

Coal Coal Fuel oil
Proposed Plants

\begin{tabular}{ccc} 
& Nuclear & \\
\hline CNSS* & CNSS* \\
HTGR & $(2-1200$ MWt $)$ & $(2-1200 \mathrm{MWt})$ \\
$(3-1200$ & without & with \\
MWt $)$ & condensing & condensing
\end{tabular}

\section{Initial steam} Press (psia) Initial Steam Temp. (F)
Steam Flow $(1 \mathrm{~b} / \mathrm{hr})$

Service Date

1985

1984

1986

2,415

Gross Generation

(MWe)

Aux. Power \&

FW Pump (MWe)

Net Generation

(MWe)

Heat Input (MWt)

Heat Output (MWt)

Capital Cost $(\$ \times 1,000)$

(1/8) Cost
Escalation

Escalat
Total

Int. During

Construction

Total

\section{Annual Cost $(\$ \times 1,000)$}

Fixed Charges

oqM Charges

Total

$\begin{array}{rrr}685,749 & 640,975 & 789,436 \\ 31,263 & 29,456 & 34,955\end{array}$

Credit for Power

Net Annual

$31,263 \quad 29,456 \quad 34,955$

Operating cost

Process Steam Cost

$7,1,0001 \mathrm{~b}-$

$5,840.000 \mathrm{lb} / \mathrm{hr})$

$15.57 * 14.56 * 17.90 *$
2,415

1,000
$9,237,178$
1985

2,415
1,000
$9,237,178$
1984

2,415
1,000
$8.633,414$
1986

690
750

$6,784,539$

1986

$8,591,312$

90.8

62.1

52.4

79.1

62.1

38.4

2684.800

2213.709

2371.290

2286.277

2214.604

2630.958

2214.604

2214.604

713,491

260,496

717,514

261,964

979,478

636,172

197,213

833,385

$1,127,000$

475,256

844,700

$211,567 \quad 15 n, 0 n 9$

$2.10,381$

$1,191,045$

983,394

403,769

844,700
356,210

356,210
$1,200,910$

$2.006,025$

302,629
$1,503,539$

320.964

112,702

36,845

$\begin{array}{rr}177.655 & 178.657 \\ 259.304 & 284.823 \\ 67.501 & 63.385\end{array}$

63,385
526,865

504,460

$(210,200)$

$(210,200)$

294,260

316,665

521,900

51,038

720,447

$(206,070)$

$(274,994)$

514,377

195,517

11.17

4.25

$240,5.56$

206.219

39,914
486,699

$(26,399)$

460,300

10.00

6.88

*Plus oil-fired boiler and superheater.

* Process steam cost based on operating costs only.

Nothing included for capital costs (fixed charges). 
TABLE 6-6

ECONOMIC COMPARISON - ADVANCED TECHNOLOGY (FUTURE DEVELORMENT) - GEISMAR SITE

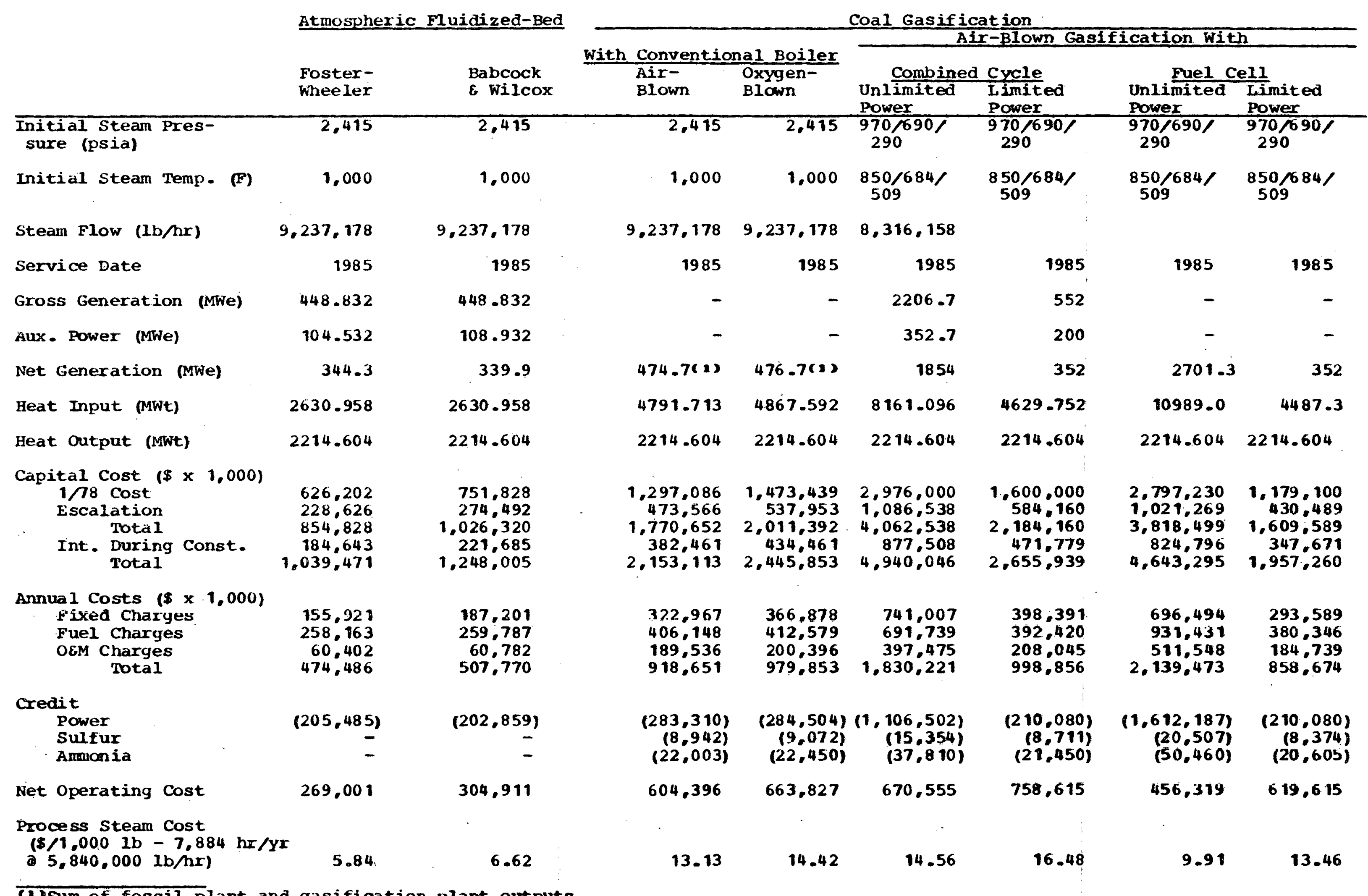


TABLE $\quad 6-7$

UNIT COST DATA

Net Operating Cost $\$ \angle 1,000$ ib Process Steam

Net $k W h$

per 1.000

Lb Process

Steam

\section{(erore}

for Power
Capital Cost Per $1,00010 / \mathrm{hr}$ Process Steam

After

Credit

\section{January}

1978

Dollars
Including

Escalation

and I.D.C.
Capital Cost $/ \mathrm{kW}$

January Including

1978 Escalation

Dollars and I.D.C.

\section{Geismar}

\section{Eastern Coal}

western coal

No. 6 Fuel Oil

HTGR

CNSS

AFB

Faster-wheelex

Babcock \& Wilcox

Coal Gasification

Air-Blown w/Boilers 81 .

Oxygen-Blown w/Boilers 81.6

w/Comb. Cycle-Unlimited Power 317.5

w/Comb. Cycle-Linited Power 60.3

w/Fuel Cell-Unlimited Power

462.6

w/Fuel Cell-Liraited Power

60.3

10.96

11.44

6.39

6.88

122,173

122,862

11.17

4.25

108,934

192.979

10.00

144.640

5.84

6.62

107.226

10.31
11.03

19.95

21.28

39.75

21.69

46.47

18.65

\subsection{42}

14.42

16.48

9.91

13.46

222.104

252,301

509.589

273,973

478,978

201,901

11.31

Eastern coal

67.7

67.7

11.81

6.19

133,312

6.69

134,393

70.7

15.76

75.0

9.99

10.76

112,659

3.45

186,788

10.81

9.86

173,485

crss (without Condensing)
10.8
3,363

3,382

2.660

5.015

39. 155

3,019

3,672

4.536

5,131
2,665

2,665

1.719

5.560

1.036
3.350

3.350
.036

3,269

3,295

2.463

4.434

$\begin{array}{ll}221.293 & 1.969 \\ 223.087 & 1.985 \\ 174.148 & 1.593 \\ 332.477 & 2.491 \\ 308.798 & 16.000\end{array}$

28.479 


\subsection{ECONOMIC COMPARISONS}

The objective is to compare cost data for the various alternatives for each site and arrive at the most economical plant arrangement based on net steam costs. It should be emphasized that the following are economic comparisons for nth-of-a-kind plants providing the required process steam. The nuclear plants use standard designs, which result in a mismatch of steam generating capacity and higher capital costs. Condensing capability utilizing inherent excess steam generating capacity to generate additional electric power is not included in the basic plant arrangement used in the comparisons, but it is treated separately.

Pairs of plants were compared in a logical sequence. For example, the two coal-fired plants were first compared to establish which was best economically: the choice was then compared to the reference oil-fired plant. This method was used for both current and advanced technologies and then between. thuse technologies. Figure 6-1 shows the step-by-step procedure, the combinations compared, and the resulting conclusions. Similar cost data allowed conclusions applicable at both sites.

Final plant selection, considering all major factors, is developed in Section 7 of this report.

6.2.1 COAL-FIRED PLANIS (EASTERN COAL VS WESTERN COAL) AT ORANGE AND GEISMAR

Review and comparison of the economic evaluation data (Tables 6-4 and 6-5) for the eastern and western coal-fired plants at Orange and Geismar indicate that the high-sulfur eastern (Alabama) coal is the better choice of fuel for the coal-fired cogeneration plant.

The cost estimates and economic evaluations show that the capital costs for western coal-fired plants are only slightly higher than eastern coal, principally because of the higher cost of the boilers, their accessories, and the precipitators. Net annual operating costs favor eastern coal by 7.6 percent at Geismar and 8 percent at orange. This amounts to an annual savings of $\$ 22,405,000$ and $\$ 8,639,000$, respectively. On the basis of dollars per thousand pounis of process steam, eastern coal is approximately $\$ 0.49$ less than western coal $(\$ 6.88$ and $\$ 6.39$ at Geismar. \$6.69 and $\$ 6.19$ at Orange).

Although the delivered price of western coal for the regions considered is less than for eastern coal. the higher Btu value of eastern coal results in a 9 percent fuel savings. This savings exceeds the 6.5 percent higher operating and maintenance cost created by the high sulfur content of the

$$
6-13
$$


coal. For eastern coal to have the same operating cost as western coal. fuel cost per million Btu would have to increase from $\$ 1.11$ to $\$ 1.207$, or about 8.64 percent. Limestone cost would have to more than double to equalize net operating costs.

\subsubsection{EASTERN COAL-FIRED VS OIL-FIRED PLANTS AT ORANGE AND GEISNAR}

The total capital cost is about 17 percent less for an oil-fired plant: however, as shown below, the coal-fired plant burning eastern coal is the better choice economically.

The annual costs for fixed charges and operating and maintenance are 19 percent less at Geismar and 22 percent less at orange for the oil-fired steam generating plant: i.e.. \$46,609,000 and $\$ 21,715,000$, respectively. However. the levelized cost difference for the two fuels is $\$ 3.19$ per million Btu, making the coal-fired plant fuel favorable by $\$ 262,596,000$ per year at Geismar. Fuel savings at Orange amount to $\$ 98,748,000$ per year.

When a credit for electric power generation is included, the cost per thousand pounds of process steam is $\$ 6.31$ for the coal-fired plant compared to $\$ 11.17$ for the oil-fired plant at Geismar. The costs at orange are $\$ 6.19$ for coal and $\$ 10.76$ for oil. Eastern coal is about 43 percent less per thousand pounás of process steam at both sites.

Historically. mainterance outages for coal-fired plants have been higher than for oil-fired plants. The above analysis. which is based on 7.884 hours per year for both plants, tends to favor the coal-tired plant. However, this factor does not greatly impact the overall results. Assuming that users facilities are operated during a boiler outage, the difference in fuel cost and credit for power reduces the difference in net operating cost. To equal the cost differences shown on Tables $6-4$ and 6-5, one coal-fired boiler would have to be out of service at least 6.500 hours per year more than the oil-fired unit. Based on reliability data. downtime of this magnitude is not expected.

\subsubsection{CONSOLIDATED NUCLEAR STEAM SYSTEM VS HIGH TEMPERATURE} GAS - COOLED REACTOR AT ORANGE AND GEISMAR

The HTGR energes, by far, as the better economic choice for a nuclear-powered cogeneration plant when compared with the CNSS for the conditions encountered at orange and Geismar.

Capital cost of the HTGR is approximately 8 percent higher than the CNSS at Orange. At Geismar, the HTGR is approximately 33 percent higher due to the fact that three

$$
\text { 6-14 }
$$


1200-MW units must be used to provide the 2631-MW heat input required. This results in excess steam generating capacity. A third CNSS unit is not required because steam users. projected needs can be met with two cNSS units, a superheater, and an oil-fired steam generator.

The annual operating costs for the CNSS are slightly higher than the HTGR $(3.4$ percent at Geismar and 8 percent at Orange) before credit is taken for power generated and exported. The net power generation after deducting requirements for auxiliaries at Geismar is $400 \mathrm{MW}$ for the HTGR versus only $38.4 \mathrm{MW}$ for the CNSS. At Orange, net generated power is $164.6 \mathrm{MW}$ for the HTGR versus $23.8 \mathrm{MW}$ for the CNSS. The annual value of these differences is $\$ 248,595,000$ and $\$ 96,798,000$, respectively. making the net annual operating cost less for the HTGR by 57 percent at Geismar and 65 percent at Orange. In terms of dollars per thousand pounds of process steam, steam cost using the HTGR at Geismar is $\$ 4.25$ compared to $\$ 10.00$ for the CNSS. At Orange, steam costs are $\$ 3.45$ versus $\$ 9.86$.

\subsubsection{EASTERN COAL AND HIGH TEMPERATURE GAS-COOLED REACTOR AT ORANGE AND GEISMAR}

Economically, the HTGR is the better choice of steam generator when compared to an eastern coal-fired boiler. This results frota a fuel cost which is only one-half that of an eastern coal-fired boiler on an escalated and levelized basis. Also, the net available electrical output for export is 12 percent higher because of lower auxiliary power requirements for the HTGR plant. The maintenance costs for the HTGR are also estinated to be considerably less. These factors result in a net cost of $\$ 4.25$ per thousand pounds of process steam for the HTGR plant, which represents approximately 67 percent of the cost for the eastern coal-fired plant at Geismar. At Orange, the estimated net cost of $\$ 3.45$ per thousand pounds of process steam represents approximately 56 percent of the eastern coal-fired plant steam cost. At the projected 1985 steam demand level, this amounts to annual savings of $\$ 98,743,000$ and $\$ 47,352,000$ for Geismar and Orange, respectively.

Initial total capital costs are considerably higher for the HTGR: 69 percent at Gesimar and 50 percent at orange. The Geismar plant is somewhat more because the HTGR units are not operating at 100 percent capacity. Two HTGR units are insufficient to meet the users' demands and a third unit would have to be added, creating excess capacity. The excess steam generating capacity could be available initially to generate additional power or to provide process steam for future needs. 
Methods of utilizing the excess capacity are dependent on ownership of the cogeneration plant and the owners specific needs. The basic arrangement and cost estimate does not consider methods of utilizing the excess steam generating capacity, since the original concept of the study is to provide a cogeneration plant capable of meeting the users * projected steam requirements, not to meet users" electric power needs.

Section 6.2.10 aiscusses the merits of utilizing the excess steam capacity in a condensing steam turbine.

\subsubsection{COAL GASIFICATIUN ALTERNATIVES GENERATING LIMITED POWER}

This section considers oxygen- and air-blown gasifiers with conventional boilers, gas turbines, and fuel cells used in a limited power generation mode. A cogeneration plant that uses air-blown coal gasification in combination with conventional coal gas-fired bojlers produces the lowest net operating cost when compared to arrangements using either fuel celis or the gas turbine combined cycle.

To allow comparison on an equivalent basis, three coal gasification arrangenents were developed to produce the required process steam while limiting the net electrical output to $352 \mathrm{MW}$. This output corresponds to the power developed by fossil fuel fired cogeneration plants.

In the first alternative studied, the coal gasification plant provides coal gas to conventional boilers in a cogeneration plant. Both air-blown and oxygen-blown gasification plants were considered. The results indicate the air-blown gasifier to be the more economical choice. This particular arrangement provides more than $352 \mathrm{MW}$ of electric power due to the electrical generation which is available from the gasification plant.

Although either air-blown or oxygen-blown Lurgi gasifiers are suitable to produce coal gas, the arrangements utilizing yasification with the gas turbine combine cycle and the fuel cell are based on air-blown gasifiers, which provide higher therral efficiency.

The air-blown gasifier has lower net operating costs than the oxygen-blown system when combined with conventional boilers. Net costs are $\$ 59,431,000$ less per year, with the cost per thousand pounds of process steam being $\$ 13.13$ compared to $\$ 14.42$, or approximately 9 percent less than the oxygen-blown arrangement. This combination also results in the lowest operating costs of the three cases studied. 
The cost of $\$ 13.13$ per thousand pounds of process steam is only slightly less (2 $1 / 2$ percent) than the $\$ 13.46$ for the coal gasification arrangement with fuel cells, waste heat recovery, and gas-fired boilers and yields an annual savings of $\$ 15,219,000$. It is about 20 percent lower than the combined cycle arrangement which amounts to an annual savings of $\$ 154,219,000$. The lower cost is attributable mainly to the higher credits for electric power and byproduct chemicals.

\subsubsection{COAL GASIFICATION CONSIDERING GAS TURBINES AND FUEL CEIIS WITH NO IIMIT ON ELECTRIC POWER GENERATION}

For the required process steam to be generated by waste heat alone, both the gas turbine combined cycle and the fuel cell system generate considerably more electric power than is required by the industrial users. With no limit specified for electric power, the fuel cell in combination with coal gasification provides the process steam at a lower net operating cost than the combined cycle.

Although the fuel cell total annual operating cost is about 17 percent higher than the combined cycle, the net operating cost is considerably less after credit is taken for electric power, sulfur, and ammonia. On an economic basis, the fuel cell is the better choice with the cost per thousand pounds of process steam at $\$ 9.91$, versus $\$ 14.56$ for the gas turbine system. This amount represents a 32 percent savings, or $\$ 214,236,000$ per year. due primarily to the $847 \mathrm{MW}$ of additional power generated.

\subsubsection{FUEL CELLS WITHOUT IIMITATION OF ELECTRIC POWER AND AIR-BLOWN GASIFICATION WITH CONVENTIONAL BOILERS}

Based solely on economics, with no consideration for plant ownership and ultimate use of the electric power generated, the coal gasification/fuel cell cogeneration plant utilizing only waste heat to generate process steam with no limit on electric power generated provides a net operating cost 25 percent lower than a gasification/conventional boiler arrangenent having limited electric power output. The savings in operating costs results primarily from the large quantity of electric power generated.

After credit for power and byproduct sulfur and ammonia, the cost per thousand pounds of process steam is $\$ 9.91$ compared to . $\$ 13.13$ for a plant that has an electric power output of 474.7 MW.

Although the total annual operating costs are almost three times.as much, the net electric power output of $2786 \mathrm{MW}$ provides a sufficient credit to reduce the cost of steam to 
make the fuel cell scheme with no limit on electrical generation the more economical.

\subsubsection{ATMOSPHERIC FLUIDIZED-BED BOILER VS FUEL CELL WITH UNL IMITED ELECTRIC GENERATION}

A cogeneration plant employing the AFB to generate process and feedwater heating steam has a lower net operating cost than a coal gasification/fuel cell plant which has been sized to generate the required export steam using only waste heat with no limitation on electric power output.

Although the fuel cell arrangement generates considerably more electric power, the overali net operating cost (\$9.91 per thousand pounds of process steam) is 59 percent higher than the $\$ 6.23$ average cost of the two AFB plants studied. This represents an annual savings of $\$ 169,363,000$. The use of the average cost of the $B \& W$ and $F W$ AFB boilers was considered justified because of the present state of the art and the differences in design philosophies of the two manufacturers.

The higher costs for the fuel cell are attributed to the high initial capital costs and its higher operating costs. Fuel input requirements for the fuel cell are approxinately four times that of the AFB.

6.2.9 HIGH-TEMPERITURE GAS-COOLED REACTOR AND ATMOSPHERIC FLUIDIZED-BED BOILER AT GEISMAR

When compared with the AFB, the HTGR cogeneration plant provides a considerably lower net cost per thousand pounds of process steain. This result is similar to the results obtained when comparing the HIGR plant with the eastern coal plant.

The HTGR cost of $\$ 4.25$ per thousand pounds of steam is 32 percent less than the $\$ 6.23$ average cost for the AFB plant. This savings anounts to approximately $\$ 91,439,000$ per year, assuming 7.884 operating hours.

Cost differences are attributable to lower fuel costs, lower operating and maintenance costs, and lower auxiliary power usage, which results in higher net electric output and credit.

$6.3 \frac{\text { RELIABICITY - FOSSIL FUEL AND NUCLEAR PLANTS - ORANGE }}{\text { AND GEISMAR }}$

This section examines fossil and nuclear fuel systems in an effort to ascertain the economics of adding a spare steam generating unit. 
The basis of this evaluation consists of:

- Establishing operating availability for the steam generating equipment.

- Determining capital investment necessary to add a spare steam generator.

- Calculating the annual fixed charges.

- Comparing fuel costs and electric power credits

for the cogeneration plant operating with and without a spare boiler and utilizing the users" existing steam generators.

Availability of the steam generators for the various arrangements was calculated using factors obtained from the Edison Electric Institute's (EEI) Report on Equipment Availability for the 'Ten Year Period - 1966 to' 1975.(26) Operating availability (cumulative percent) and hours of planned outages were extracted on the basis of equivalent MWe rating of the cogeneration plant. These data are shown in Table $6-8$.

The cogeneration plants were developed to generate the projected 1985 steam demand with backup provided by the existing facilities within users plants. Utilizing data frow the EEI report, an analysis was made to determine and compare the expected combined fuel costs and the electric power credit with and without a spare steam generating unit at the cogeneration plant. The steam flows, fuel rates, credit for power, operating hours, and costs are shown in Tables 6-9 and 6-10 for Orange and Geismar, respectively.

These tables also indicate the savings in yearly fuel costs which can he nsed to justify installation of a spare steam generator.

Tables 6-11 and 6-12 show the estimated capital costs for installation of the spare units and the resulting annual fixed charges at orange and Geismar. Comparison of the fixed charge to tuel savings provides a means of evaluating the economics of spare steam yenerating facilities.

The reboilers within the CNSE plant are an integral part of the systera and have been accounted for in the reliability analysis.. Contemplated redundancy for the superheaters required in the CNSS cycle should achieve an availability of +99 percent. For this reason, they were not considered in the steam reliability analysis. 
The following assumptions were used in the analysis:

Fuels - Levelized Cost Per (10) 6 Btu

Date of Plant Startup:

1984

1985

1986

Western Coal

Eastern Coal

No. 6 Fuel oil

No. 2 Fuel Oil

Nuclear - HTGR

$\begin{array}{ccr}- & \$ 3.46 & - \\ - & \$ 3.15 & - \\ \$ 6.34 & - & \$ 7.80 \\ \$ 8.15 & \$ 8.73 & \$ 10.05 \\ - & - & \$ 1.56 \\ - & - & \$ 1.78\end{array}$

Credit for Electric Power

Mills/kWh (Levelized)

70.7

75.7

87.2

Boiler Efficiencies

Cogeneration Plants

Users* Plants

$86 \%$

$78 \%$

Reactor Eificiencies

- Nuclear fuel costs were adjusted to account for reactor efficiency.

\section{Miscellaneous}

- Operating and maintenance costs were assumed to remaln cunstanl with and without spare steam. generating capacity.

- Costs were escalated to the plant service date and levelized for the projected plant life.

- Steam distribution to the users w1th unt cogeneration steam generator out of service was made to achieve the least total net cost (fuel cost less power generation credit).

- A condensate return temperature of $68^{\circ} \mathrm{F}$ was assumed to calculate fuel consumption of users" boilers.

- Users* boiler fuel costs were based on No. 2 fuel oil. 
TABLE 6-8

AVRILABILITY FACTORS

Planned Outages
$\begin{gathered}\text { Operating } \\ \text { Availability }\end{gathered}$ $\begin{gathered}\text { Operating } \\ \text { Availability } \\ \text { (Adjusted } \%)\end{gathered}$

Geismar

$\begin{array}{llll}\text { Fossil } & 604.31 & 84.3 & 90.5 \\ \text { Nuclear } & 773.78 & 81.1 & 89.0\end{array}$

Orange

$\begin{array}{llll}\text { Fossil } & 464.15 & 89.7 & 94.7\end{array}$

$\begin{array}{llll}\text { Nuclear } & 773.78 & 81.1 & 89.0\end{array}$

*Ajusted operating availability when not on planned outage $=\frac{\text { operating Availability } \times(8,760 \mathrm{hr} / \mathrm{yr})}{8.760}$

$8.760 \mathrm{hr} / \mathrm{Yr}^{\mathrm{r}}$ - Planned Outage

NOTE: An availability factor of 98 percent for the reboilers in the CNSS plant was obtained from Reliability Estimation for Multiunit Nuclear and Fossil-Fired Industrial Energy Systems, Oak Ridge National Laboratory, ORNL/TM-5837. August 1977 . 
TABLE 6-9

RELIAEILITY ANALYSIS

OFANGE, TEXAS

\begin{tabular}{|c|c|c|c|c|c|c|c|c|c|c|c|c|c|c|c|}
\hline \multicolumn{8}{|c|}{ Cogeneration Plart } & \multirow{2}{*}{\multicolumn{2}{|c|}{$\frac{\text { Steam Users P1ant }}{\text { Fuel }}$}} & \multirow{3}{*}{\begin{tabular}{|l||} 
Total \\
Net Cost \\
Fuel Cost \\
Less \\
Elec- \\
tric \\
Cred1t \\
$(\$ /$ hr $)$
\end{tabular}} & \multicolumn{4}{|c|}{ Total Yearly Fuel Costs (Levelized) } & \multirow{3}{*}{ 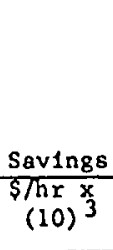 } \\
\hline & \multirow[b]{2}{*}{$\mid \begin{array}{l}\text { Units } \\
\text { Opera- } \\
\text { ting }\end{array}$} & \multicolumn{2}{|c|}{ Steam Flow (1.h/lir) } & \multicolumn{2}{|c|}{ Fuel } & & & & & $\begin{array}{l}\text { Without S } \\
\text { Steam Gene }\end{array}$ & $\begin{array}{l}\text { Spare } \\
\text { erator }\end{array}$ & $\begin{array}{l}\text { With Spe } \\
\text { Steam Gent }\end{array}$ & are & \\
\hline Pue1 & & $\begin{array}{l}\text { Total } \\
\text { Generated }\end{array}$ & $\int_{\substack{\text { To } \\
\text { Users }}}$ & $\left(\begin{array}{c}10^{6} \mathrm{Btu} \\
\mathrm{hr})\end{array}\right.$ & $\begin{array}{c}\text { Cost } \\
(\$ / \mathrm{hr})\end{array}$ & $\begin{array}{c}\text { Exported. } \\
(\text { Mhk') }\end{array}$ & $\begin{array}{l}\text { Cred } \\
(\$ / \mathrm{hr})\end{array}$ & $\left|\begin{array}{c}\left(10^{6} \text { Btul }\right. \\
h r)\end{array}\right|$ & $\mid \begin{array}{c}\text { Cost } \\
(\$ / \mathrm{hr})\end{array}$ & & $\begin{array}{c}\text { Operatione } \\
(\mathrm{hr} / \mathrm{yr})\end{array}$ & $\begin{array}{r}\$ / h r \\
(10)^{3}\end{array}$ & \begin{tabular}{|l|} 
Operation \\
(hr/yr)
\end{tabular} & $\begin{array}{c}\$ / h \times x \\
(10)^{3}\end{array}$ & \\
\hline \multirow[t]{2}{*}{$\begin{array}{c}\text { Western } \\
\text { Coal }\end{array}$} & \multirow[t]{2}{*}{$\begin{array}{l}2 \\
1 \\
0\end{array}$} & \multirow[t]{2}{*}{$\begin{array}{r}3,441,382 \\
1,720,000 \\
0\end{array}$} & \multirow[t]{2}{*}{$\begin{array}{r}2,195,000 \\
1,395,584 \\
0\end{array}$} & \multirow[t]{2}{*}{$\begin{array}{r}3926.4 \\
2411.6 \\
0\end{array}$} & \multirow[t]{2}{*}{$\begin{array}{r}13,585 \\
8,344 \\
0\end{array}$} & \multirow[t]{2}{*}{$\begin{array}{r}148.6 \\
77.6 \\
0\end{array}$} & \multirow[t]{2}{*}{$\begin{array}{r}11,249 \\
5,874 \\
0\end{array}$} & \multirow[t]{2}{*}{$\begin{array}{r}0 \\
1322.7 \\
3571.2\end{array}$} & \multirow[t]{2}{*}{$\begin{array}{r}0 \\
11,547 \\
31,177\end{array}$} & $\begin{array}{r}2,336 \\
14,017 \\
31,177\end{array}$ & $\mid \begin{array}{c}7023.54 \\
1665.26 \\
71.2\end{array}$ & $\begin{array}{r}16,407 \\
23,342 \\
2,220\end{array}$ & $\begin{array}{r}8556.4 \\
198.6 \\
5.0\end{array}$ & $\begin{array}{r}19,988 \\
2,784 \\
156\end{array}$ & \\
\hline & & & & & & & & & & Totals & $\mid 8760$ & 41,969 & 8760 & 22,928 & 19,041 \\
\hline \multirow[t]{2}{*}{$\begin{array}{c}\text { Eastern } \\
\text { Coa1 }\end{array}$} & \multirow[t]{2}{*}{$\begin{array}{l}2 \\
1 \\
0\end{array}$} & \multirow[t]{2}{*}{$\begin{array}{r}3,441,382 \\
1,720,000 \\
0\end{array}$} & \multirow[t]{2}{*}{$\mid \begin{array}{r}2,195,000 \\
1,395,584 \\
0\end{array}$} & \multirow[t]{2}{*}{$\begin{array}{r}3926.4 \\
2411.6 \\
0\end{array}$} & \multirow[t]{2}{*}{$\begin{array}{r}12,368 \\
7,597 \\
0\end{array}$} & \multirow[t]{2}{*}{$\begin{array}{r}148.6 \\
77.6 \\
0\end{array}$} & \multirow[t]{2}{*}{$\begin{array}{r}11,249 \\
5,874 \\
0\end{array}$} & \multirow[t]{2}{*}{$\begin{array}{r}0 \\
1332.7 \\
.3571 .2\end{array}$} & \multirow[t]{2}{*}{$\begin{array}{r}0 \\
11,547 \\
31,177\end{array}$} & $\begin{array}{r}1,119 \\
13,270 \\
31,177\end{array}$ & $\begin{array}{c}7023.54 \\
1665.26 \\
71.2\end{array}$ & $\begin{array}{r}7,859 \\
22,098 \\
2,220\end{array}$ & $\begin{array}{r}8556.4 \\
198 .: \\
5.0\end{array}$ & $\begin{array}{r}9,575 \\
2,635 \\
156\end{array}$ & \\
\hline & & & & & & & & & & Totals & 8760 & $32 ; 177$ & 8760 & 12,366 & 19,811 \\
\hline \multirow[t]{2}{*}{$\begin{array}{l}\text { No. }{ }^{6} \\
011\end{array}$} & \multirow[t]{2}{*}{$\begin{array}{l}2 \\
1 \\
0\end{array}$} & \multirow[t]{2}{*}{$\begin{array}{r}8,441,382 \\
1,720,000 \\
0\end{array}$} & \multirow[t]{2}{*}{$\begin{array}{r}2,195,000 \\
1,395,584 \\
0\end{array}$} & \multirow[t]{2}{*}{$\begin{array}{r}3926.4 \\
2411.5 \\
0\end{array}$} & \multirow[t]{2}{*}{$\begin{array}{r}24,893 \\
15,290 \\
0\end{array}$} & $\begin{array}{r}155.2 \\
77.6 \\
0\end{array}$ & $\begin{array}{r}10,973 \\
5,486 \\
0\end{array}$ & $\begin{array}{r}0 \\
1322.7 \\
3571.2\end{array}$ & $\begin{array}{r}0 \\
10,793 \\
29,141\end{array}$ & $\begin{array}{l}13,920 \\
20,597 \\
29,141\end{array}$ & $\mid \begin{array}{c}7023.54 \\
1665.26 \\
71.2\end{array}$ & $\begin{array}{r}97,768 \\
34,299 \\
2,075 \\
\end{array}$ & $\begin{array}{r}8556.4 \\
198.6 \\
5.0\end{array}$ & $\begin{array}{r}119,105 \\
4,091 \\
146 \\
\end{array}$ & \\
\hline & & & & & & & & & & Totals & 8760 & 134,142 & 8760 & 123,342 & 10,800 \\
\hline HTGR & 1 & $\begin{array}{r}3,239,239 \\
0\end{array}$ & $\begin{array}{r}2,195,000 \\
0\end{array}$ & $\begin{array}{r}3438.1 \\
0\end{array}$ & $\begin{array}{r}5,363 \\
0\end{array}$ & $\begin{array}{r}164.6 \\
0\end{array}$ & $\begin{array}{r}14,353 \\
0\end{array}$ & $\begin{array}{r}0 \\
3571.2\end{array}$ & $\begin{array}{r}0 \\
35,891\end{array}$ & $\begin{array}{l}(8,990) \\
35,891\end{array}$ & 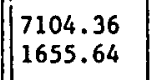 & $\begin{array}{c}(63,868) \\
59,423\end{array}$ & $\begin{array}{r}8332.451 \\
427.549\end{array}$ & $\begin{array}{c}(74,908) \\
15,384\end{array}$ & \\
\hline & & & & & & & & & & Totals & 8760 & $(4,445)$ & 8760 & $(59,524)$ & 55,079 \\
\hline cass & $\begin{array}{l}1 \\
0\end{array}$ & $\begin{array}{r}2,695,872 \\
0\end{array}$ & $\begin{array}{r}2,195,000 \\
0\end{array}$ & $\begin{array}{r}3037.2 \\
0\end{array}$ & $\begin{array}{r}8,167 \\
0\end{array}$ & $\begin{array}{r}23.8 \\
0\end{array}$ & $\begin{array}{r}2,075 \\
0\end{array}$ & $\begin{array}{r}0 \\
3632.3\end{array}$ & $\begin{array}{r}0 \\
36,505\end{array}$ & $\begin{array}{r}6,092 \\
36,505\end{array}$ & $\mid \begin{array}{l}6965.58 \\
1794.42\end{array}$ & $\begin{array}{l}42,434 \\
65,505\end{array}$ & $\begin{array}{r}8332.451 \\
427.549\end{array}$ & $\begin{array}{l}50,761 \\
15,608\end{array}$ & \\
\hline & & & & & & & & & & Tota1s & 8760 & 107,939 & 8760 & 66,369 & 41,079 \\
\hline
\end{tabular}


TABLE $\quad 6-10$

RELIABILITY ANALYSIS

GEISMAR, LOUISIANA

\begin{tabular}{|c|c|c|c|c|c|c|c|c|c|c|c|c|c|c|c|}
\hline \multirow[b]{3}{*}{ Fuel. } & \multirow{3}{*}{$\begin{array}{l}\text { Untts } \\
\text { Opera- } \\
\text { ting }\end{array}$} & \multicolumn{4}{|c|}{ Cogeneration Plant } & & & \multicolumn{2}{|c|}{$\frac{\text { Steam Users Plant }}{\text { Fuel }}$} & \multirow{3}{*}{\begin{tabular}{|l|} 
Total \\
Net Cost \\
Fuel Cost \\
Less \\
Elec- \\
tric \\
Credit \\
$(\$ / \mathrm{hr})$ \\
\end{tabular}} & \multirow{2}{*}{\multicolumn{4}{|c|}{\begin{tabular}{|c|c} 
Total Yearly Fuel & Costs (Levelized) \\
W1thout Spare & W1th Spare \\
Steam Geaerator & Steam Generator
\end{tabular}}} & \multirow{3}{*}{$\begin{array}{l}\text { Sav1ngs } \\
\$ \$ / \text { hr } x \\
(10)^{3}\end{array}$} \\
\hline & & \multirow{2}{*}{\multicolumn{2}{|c|}{$\frac{\text { Stean Flow }(1 \mathrm{~b} / \mathrm{hr})}{\text { Total }}$}} & \multirow{2}{*}{$\begin{array}{l}\text { Input } \\
\left(10^{6} \mathrm{Btu}\right. \\
\mathrm{hr})\end{array}$} & \multirow[b]{2}{*}{$\begin{array}{c}\text { Cost } \\
(\$ / h r)\end{array}$} & \multicolumn{2}{|c|}{ Eiectric Power } & \multirow{2}{*}{$\begin{array}{c}\text { Input } \\
\left(10^{6} \mathrm{Btu} /\right. \\
\mathrm{hr})\end{array}$} & \multirow[b]{2}{*}{$\begin{array}{c}\text { Cost } \\
(\$ / \mathrm{hr})\end{array}$} & & & & & & \\
\hline & & & & & & $\begin{array}{c}\text { Exported } \\
\text { (MW) }\end{array}$ & $\begin{array}{l}\text { Credlt } \\
(\$ / h r)\end{array}$ & & & & $\mid \begin{array}{c}\text { Operation } \\
(\mathrm{hr} / \mathrm{yr})\end{array}$ & $\begin{array}{r}\frac{\text { racor }}{\$ / h r} \mathbf{x} \\
(10)^{3}\end{array}$ & $\begin{array}{c}\text { Operation } \\
\text { (hr/yr) }\end{array}$ & $\begin{array}{r}\$ / \mathrm{hr} x \\
(10)^{3}\end{array}$ & \\
\hline \multirow[t]{2}{*}{$\begin{array}{c}\text { Western } \\
\text { Caal }\end{array}$} & \multirow{2}{*}{$\begin{array}{c}2 \\
1 \\
0 \\
\end{array}$} & \multirow[t]{2}{*}{$\begin{array}{r}9,237,178 \\
4,520,000 \\
0\end{array}$} & \multirow[t]{2}{*}{$\begin{array}{r}5,840,000 \\
3,752,390 \\
0\end{array}$} & \multirow[t]{2}{*}{$\begin{array}{r}10441.2 \\
6477.7 \\
0\end{array}$} & \multirow[t]{2}{*}{$\begin{array}{r}36,127 \\
22,413 \\
0\end{array}$} & \multirow[t]{2}{*}{$\begin{array}{r}352.2 \\
163.3 \\
0\end{array}$} & \multirow[t]{2}{*}{$\begin{array}{r}26,662 \\
12,362 \\
0\end{array}$} & \multirow[t]{2}{*}{$\begin{array}{l}0 \\
3449.4 \\
9690\end{array}$} & \multirow[t]{2}{*}{$\left|\begin{array}{r}0 \\
30,113 \\
84,594\end{array}\right|$} & $\begin{array}{r}9,465 \\
40,164 \\
84,594\end{array}$ & $\begin{array}{r}6184.77 \\
2392.26 \\
182.97\end{array}$ & $\begin{array}{l}58,539 \\
96,083 \\
15,478\end{array}$ & $\begin{array}{r}8255.71 \\
481.98 \\
22.31\end{array}$ & $\begin{array}{r}78,140 \\
19,358 \\
1,887\end{array}$ & \\
\hline & & & & & & & & & & Tota1s & 8760 & 170,100 & 8760 & 99,385 & 70,715 \\
\hline \multirow[t]{2}{*}{$\begin{array}{c}\text { Eastern } \\
\text { Conl }\end{array}$} & \multirow[t]{2}{*}{$\begin{array}{l}2 \\
1 \\
0\end{array}$} & \multirow[t]{2}{*}{$\begin{array}{r}9,237,178 \\
4,520,000 \\
0\end{array}$} & \multirow[t]{2}{*}{$\begin{array}{r}5,840,000 \\
3,752,390 \\
0\end{array}$} & \multirow[t]{2}{*}{$\begin{array}{r}10441.2 \\
6477.7 \\
0\end{array}$} & \multirow[t]{2}{*}{$\begin{array}{r}32,890 \\
20,405 \\
0\end{array}$} & \multirow[t]{2}{*}{$\begin{array}{r}352.2 \\
163.3 \\
0\end{array}$} & \multirow[t]{2}{*}{$\begin{array}{r}26,662 \\
12,362 \\
0\end{array}$} & $\begin{array}{l}0 \\
3449.4 \\
9690\end{array}$ & $\left|\begin{array}{r}0 \\
30,113 \\
84,594\end{array}\right|$ & $\begin{array}{r}6,228 \\
38,156 \\
84,594\end{array}$ & $\begin{array}{r}6184.77 \\
2392.26 \\
182.97\end{array}$ & $\begin{array}{l}38,519 \\
91,279 \\
15,478\end{array}$ & $\begin{array}{r}8255.71 \\
481.98 \\
22.31\end{array}$ & $\begin{array}{r}51,417 \\
18,390 \\
1,887\end{array}$ & \\
\hline & & & & & & & & & & Totals & 8760 & 145,276 & 8760 & 71,694 & 73,582 \\
\hline No. 6 & $\begin{array}{l}2 \\
1 \\
0\end{array}$ & $\begin{array}{r}9,237,178 \\
4,620,000 \\
0\end{array}$ & $\begin{array}{r}5,840,000 \\
3,752,390 \\
0\end{array}$ & $\begin{array}{r}10441.2 \\
6477.7 \\
0\end{array}$ & $\begin{array}{r}66,197 \\
41,069 \\
0\end{array}$ & $\begin{array}{r}369.7 \\
163.3 \\
0\end{array}$ & $\begin{array}{r}26,138 \\
11,545 \\
0\end{array}$ & $\begin{array}{l}\quad 0 \\
3449.4 \\
9690\end{array}$ & $\begin{array}{r}0 \\
28,147 \\
79,070\end{array}$ & $\begin{array}{l}40,059 \\
57,671 \\
79,070\end{array}$ & $\mid \begin{array}{r}6184.77 \\
2392.26 \\
182.97\end{array}$ & $\begin{array}{r}247,755 \\
137,964 \\
14,467\end{array}$ & $\begin{array}{r}8255.71 \\
481.98 \\
22.31\end{array}$ & $\begin{array}{r}330,715 \\
27,796 \\
1,764\end{array}$ & \\
\hline & & & & & & & & & & Totals & 8760 & 400,186 & 8760 & 360,275 & 39,911 \\
\hline HTGR & $\begin{array}{l}3 \\
2 \\
1 \\
0\end{array}$ & $\begin{array}{r}8,633,414 \\
7,821,640 \\
3,910,820 \\
0\end{array}$ & $\begin{array}{r}5,840,000 \\
5,290,882 \\
2,645,441 \\
0\end{array}$ & $\begin{array}{r}9163.3 \\
8301.9 \\
4151.0 \\
0\end{array}$ & $\begin{array}{r}14,295 \\
12,951 \\
6,476 \\
0\end{array}$ & $\begin{array}{l}400 \\
366 \\
216.3 \\
0\end{array}$ & $\begin{array}{r}34,880 \\
31,915 \\
18,861 \\
0\end{array}$ & $\begin{array}{r}0 \\
923.7 \\
5330.9 \\
9690\end{array}$ & $\begin{array}{r}0 \\
9,283 \\
53,576 \\
97,385\end{array}$ & $\left(\begin{array}{l}20,585) \\
(9,681) \\
41,191 \\
97,385\end{array}\right.$ & $\begin{array}{r}4539.056 \\
3521.754 \\
662.532 \\
36.659\end{array}$ & $\begin{array}{c}(93,436) \\
(34,094) \\
27,290 \\
3,570\end{array}$ & $\begin{array}{r}7493.401 \\
1134.813 \\
126.837 \\
4.949\end{array}$ & $\begin{array}{c}(154,252) \\
(10,986) \\
5,225 \\
482\end{array}$ & \\
\hline & & & & & & & & & & Totals & 8760 & $(96,670)$ & 8760 & $(159,531)$ & 62,861 \\
\hline giss & $\begin{array}{c}1 \\
\text { Bo1ler* } \\
0 \\
\text { Bo1ler }\end{array}$ & $\begin{array}{r}453,284 \\
0\end{array}$ & $\begin{array}{r}370,000 \\
0\end{array}$ & 520 & $\begin{array}{r}4,056 \\
0\end{array}$ & $\begin{array}{r}\text { Neg. } \\
0\end{array}$ & $\begin{array}{r}\text { Neg. } \\
0\end{array}$ & $\begin{array}{r}0 \\
656.8\end{array}$ & $\begin{array}{r}0 \\
6,601\end{array}$ & $\begin{array}{l}4,056 \\
6,601\end{array}$ & $\mid \begin{array}{r}8142.849 \\
617.151\end{array}$ & $\begin{array}{r}33,027 \\
4,074\end{array}$ & $\begin{array}{r}8730.856 \\
29.144\end{array}$ & $\begin{array}{r}35,412 \\
192\end{array}$ & \\
\hline & & & & & & & & & & Totals & 8760 & 37,101 & 8760 & 35,604 & 1,497 \\
\hline coss & $\begin{array}{l}2 \\
1 \\
0\end{array}$ & $\begin{array}{r}6,784,539 \\
4,287,240 \\
0\end{array}$ & $\begin{array}{r}5,470,000 \\
3,499,524 \\
0\end{array}$ & $\begin{array}{r}7852.4 \\
4962 \\
0\end{array}$ & $\begin{array}{r}22,232 \\
14,048 \\
0\end{array}$ & $\begin{array}{r}38.4 \\
27.4 \\
0\end{array}$ & $\begin{array}{r}3,348 \\
2,389 \\
0\end{array}$ & $\begin{array}{r}3382.7 \\
9347.1\end{array}$ & \begin{tabular}{|r|}
0 \\
33,996 \\
93,938
\end{tabular} & $\begin{array}{l}18,884 \\
45,655 \\
93,938\end{array}$ & $\begin{array}{r}5598.717 \\
2733.734 \\
427.549\end{array}$ & $\begin{array}{r}105,726 \\
124,809 \\
40,163\end{array}$ & $\begin{array}{r}7899.598 \\
649.281 \\
211.121\end{array}$ & $\begin{array}{r}149,176 \\
29,643 \\
19,832\end{array}$ & \\
\hline & & & & & & & & & & Totals & 8760 & 270,698 & 8760 & 198,651 & 72,047 \\
\hline
\end{tabular}

Wis. 6 o11-fired bo1ler for 970 pala steam demand. 
6.4 ECONOMICS CONSIDERING ADVANCED TECHNOLOGY CONDENSING CAPABIIITIES (HTGR AND CNSS)

It was initially established that condensing capabilities were not to be considered in the design of the cogeneration plant. The basic concept was to provide the required process steam with electric power generation as a by-product. The fossil fuel fired plants are readily sized to meet the specific steam conditions, but both the HTGR and CNSS plants have excess steam generating capacity due to the standard size of available designs. However, a cursory investigation was made to determine the benefits of utilizing this excess capacity in a condensing turbine generator. In addition, the study was extended to evaluate the operating costs with the addition of a third half-size boiler in the eastern coal plants. The resulting data are shown in Table 6-13.

The basic approach taken in this analysis was to develop the differential annual operating costs attributable to the operation of the condensing facilities for each of the three types of plants. The net annual costs, which result in a savings, are the summation of the additional fuel and operating and maintenance costs and the credit for the additional net electric power generated. All of these costs are based on the projected yearly operating hours developed for the reliability analysis and shown in Tables 6-9 and $6-10$.

The net annual savings were then equated to the annual fixed charges which would provide the required return un investment. Applying the appropriate fixed charge rates. escalation rates and interest during construction yielded the break-even capital costs, in January 1978 dollars, to provide the equipment necessary to utilize the condensing feature. Any cost up to this amount is economically justified.

From the results in Table 6-13, it appears that the addition of condensing facilities to use inherent excess steam capacity could be easily justified by virtue of the revenue from the additional electric power generated and lower costs for installation of the condensing facilities. On the same basis, installation and use of a spare boiler in a condensing cycle may be justified.

looking at each type of plant separately. the CNSS cogeneration plant has a great potential for utilizing condensing because the excess steam generating capacity. which involves high capital investment, already exists due to the size of available equipment used in the basic plant design. At both Geismar and orange, the large amount of additional power which would be generated yields a savings 
more than adequate to pay for the required equipment. Generally, condensing could be utilized by the addition of a condensing turbine-generator, a condenser, condensate pumps. deaerator, feedwater heater. feedwater pumps, additional piping, a cooling water recirculating system including the cooling tower, and the related additional electrical equipment.

The order-of-magnitude cost estimates for adding condensing capabilities amount to $\$ 44,200,000$ at Geismar and $\$ 43.400 .000$ at Orange and are much lower than the corresponding justified costs of $\$ 169,224,000$ and $\$ 186.868 .000$ for the CNSS. Since the CNSS is a viable option, data for plants with condensing capabilities were included in the ecomomic comparisons in Tables 6-4 and 6-5 which show results in levelized costs per thousand pounds of process steam based on 90 percent load factor Utilizing condensing reduces cNSS process steam costs by 12 percent at Geismar and 28 percent at orange Geismar and 28 percent at Orange. Although not less than the coal-fired plants, the steam costs are lower than an the existing oil-fired facilites.

The capital costs justified by the HTGR are also adequate to pay for the condensing equipment which would be similar to the CNSS; but since the HTGR is not considered a viable option based on its present development status, it has not been included in the economic comparison tables.

The coal-fired plants may also justify addition of condensing facilities. However, the capital costs would be condensing facilities hivher because ho excess steam generating capacity is available and a third boiler nust be

If and when the cogeneration plant becomes an actuality, whether it be nuclear or fossil fuel, it is recommended that the ecunonics of adding condensing capabilities be revaluated using applicable economic factors, current equipment costs, and considering institutional implications. 
TABLE 6-11

RELIABILITY ANALYSIS SUMMARY - COMPFRISON OF CAPITAL COSTS FOR SPARE STEAM GENERATING UNTT VS FUEL SAVINGS - ORANGE SITE

$$
(\$ \times 1,000)
$$

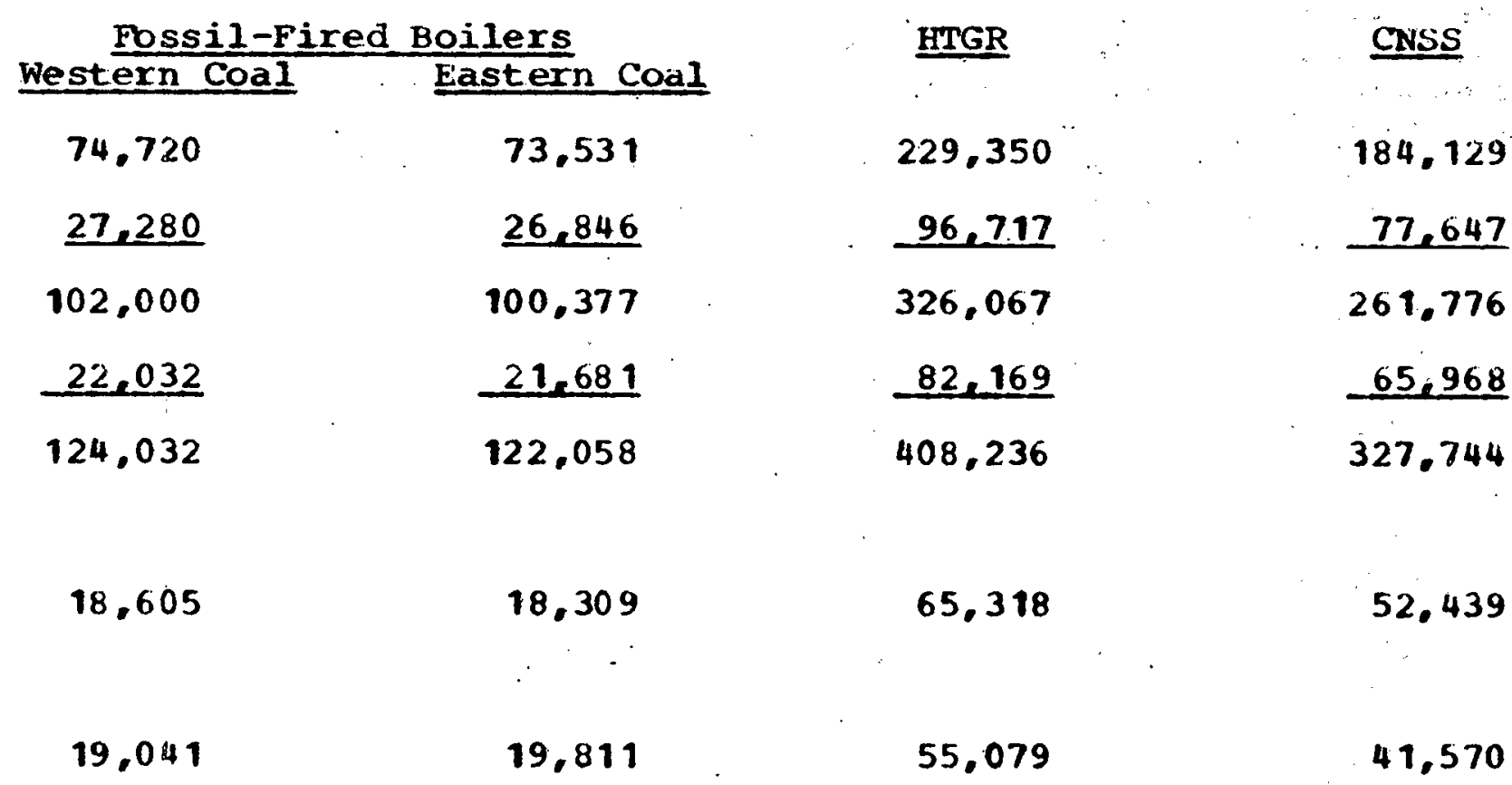

Annual Fuel Savings with Spare Stean Generating Unit (Levelized) 
TABLE $\quad$ 6-12

REIIABIIITY ANALYSIS SUMMARY - COMPARISON OF CAPTTAL COSTS FOR SPARE STEAM GENERATING UNIT VS FUEL SAVINGS - GEISMAR SITE

$(\$ \times 1,000)$

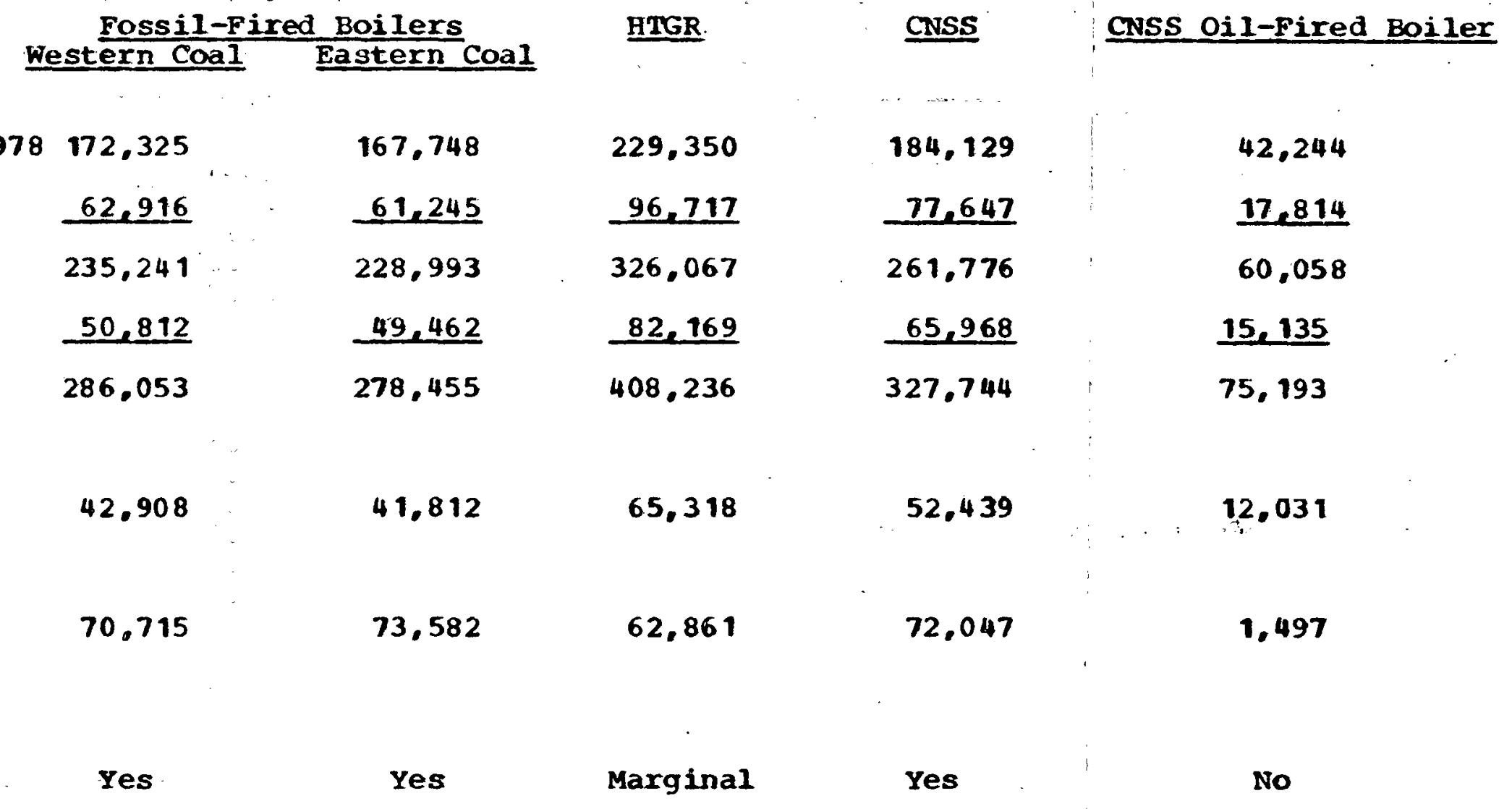


TABLE $6-13$

OPERATING AND CAPITAL COSTS RELATED

TO F.DDITIONAL ELECTRIC GENERATION RESULTING FROM CONDENSING CAPABILITIES

$(\$ \times 1,000)$

\begin{tabular}{|c|c|c|c|c|c|c|}
\hline & \multicolumn{3}{|c|}{ Geismax } & \multicolumn{3}{|c|}{ Orange } \\
\hline & HTGR & CNSS & Eastern Coal & RTGR & CNSS & Eastern Coal \\
\hline $\begin{array}{l}\text { Condensing Capacity Availability } \\
\left(\mathrm{h} x / \mathrm{yx}^{\prime}\right)\end{array}$ & 4.539 .06 & 5.598 .7 .1 & 5.149 .27 & 5.712 .97 & $6,965.58$ & 6.257 .1 \\
\hline $\begin{array}{l}\text { Additional Net Electric Puwer (WWe) } \\
\text { credit for Add. Power }(\$ / Y r) *\end{array}$ & $\begin{array}{r}355.6 \\
(740.749)\end{array}$ & $\begin{array}{r}144.8 \\
(70.692)\end{array}$ & $\begin{array}{r}465 \\
(181.257)\end{array}$ & $\begin{array}{r}76.8 \\
(38,260)\end{array}$ & $\begin{array}{r}128.5 \\
(78.051)\end{array}$ & $\begin{array}{r}174 \\
(82.417)\end{array}$ \\
\hline $\begin{array}{l}\text { Increase Annual Operating costs } \\
\text { Fuel }(\$ / Y I) \\
\text { O\&M }(\Phi / Y I)\end{array}$ & $\begin{array}{r}23,288 \\
7.614\end{array}$ & $\begin{array}{l}1.704 .1 \\
5.457\end{array}$ & $\begin{array}{l}82,431 \\
21,458\end{array}$ & $\begin{array}{l}6,316 \\
2,065\end{array}$ & $\begin{array}{r}18.809 \\
6,023\end{array}$ & $\begin{array}{r}37.573 \\
9.781\end{array}$ \\
\hline Net Annual Oper. Costs $(\$ / y r)$ & $(109.847)$ & $(48.194)$ & $(77,368)$ & $(29,879)$ & $(53 ; 219)$ & $(35,063)$ \\
\hline $\begin{array}{l}\text { Capital Costs Assuming Increaseã } \\
\text { Revenue for Power is Equal to } \\
\text { Fixeä Charges (\$) }\end{array}$ & 686.544 & 301,213 & 515.787 & 186,743 & 332,619 & 233.753 \\
\hline Int. During Construction (\$) & 138,186 & 60.627 & 91.620 & 37.587 & 66.949 & 41,522 \\
\hline Escalation (\$) & 162,652 & 71,362 & 113,445 & 44,242 & 78.802 & 51.413 \\
\hline $\begin{array}{l}\text { Capital cost Justified by } \\
\text { Added power (January } 1978 \$ \text { ) }\end{array}$ & 385,706 & 169.224 & 310.722 & 104.914 & 186.868 & 140,818 \\
\hline
\end{tabular}

* Based on availability of stean generators from Tables 6-9 and 6-10. 


\subsection{SEQUENTIAL INSTALIATION OF THE HIGH TEMPERATURE GAS-COOLED REACTOR AND CONSOLIDATED NUCLEAR STEAM SYSTYM}

Sequential installation of steam generators was investigated for the HTGR and CNSS at Geismar only, because the systell planned at that site contains the greater number of units. indicating what could be expected for any of the other schernes considered in this study.

Options of installing only two HTGRs or three HTGRs on an extended construction schedule at Geismar were analyzed.

Under the base option, all three steam generators would be placed in service in 1986. The first alternative provides for installation of two units initially and for operation in 1986. In this case, the third unit would not be installed and the steam load not produced in the cogeneration plant would be provided by the users facilities. (Two units provide alnost 90 percent of the required heat input.)

The second alternative provides for two units to operate in 1986. with the third unit 5 years later. The third alternative considess one HTGR initially for operation in 1986, and the other two following at 5-year intervals in 1991 and 1996.

Because there axe only two units involved in the CNSS plant, there was only one alternative to the base case wilich provides for two units initially with startup in 1986. As an alternative, one unit would hegin operating in 1986 and one in 1991.

Tables 6-14 and 6-15 reflect a comparison of the operating costs of each alternate for the HTGR and CNSS, respectively. The operating coots include the annual fixed charges based on the escalateú capital costs. Fuel costs and operating and maintenance costs for both the cogeneration plant and the users facilities were combined, since sequential installation requires both the existing and cogeneration plant to provide the required $5.840 .000 \mathrm{lb} / \mathrm{hr}$ of process steam. Appropriate credit was given for the net electric power generated under each option.

As shown in Table 6-14, which covers 16 years of operation. of the options which call for the installation of all three HTGRS, Alternate II has a better operating cost up until the third unit is added. At that time, the higher fixed charges that result from the construction delay cause the annual costs to exceed the base case. Alternate III spreads the capital cost over 16 years (1979 to 1996). which results in much higher operating custs due to related escalation and the higher user's fuel cost for an extended period. Based

$$
6-29
$$


on present worth, in 1986 dollars, the base option provides the least net operating cost when considering a three-unit plant.

The figures in Table 6-14 al so show that Alternate II has lower annual operating costs until 1995 and that the total present worth is lower for the 16-year study period. After 1995, the difference in operating costs continually increases each year with the base case having the advantage. By the year 2009, the present worth of the operating costs for both plants would be equal.

The initial advantage of Alternate II is the much lower capital costs caused by the omission of the third steam generator. As the years progress, this is eventually overcome by the higher fuel costs for No. 2 oil in the users* plants and the increasing credit for the higher electric output. The initial fuel oil price is more than three times the cost of the nuclear fuel and escalates at a higher rate.

An analysis inaicates that installation of two CNSS steam generators for operation in 1986 is the more economical choice. Table 6-15 shows that operating costs are always lower than for an installation on a delayed schedule. This is a result of higher cost of users fuel oil, the low amount of net electric power generation, and the increase in fixed charges due to escalated capital cost resulting from the delay.

The data reflenter nn Tables 6-14 and 6-15 indicate clearly that for the conditions and economic factors associated with the study, the lezst present worth dollars over the life of the plant can be achieved by installing all units simultaneously - Reasons for this result are:

- Capital cost and resulting fixed charges are lower due to less escalation.

- Cogeneration fuel costs are lower.

- More credit is derived for electric power since the users plants du nut contain electric generating capabilities.

The economics of sequential installation for all the schemes and sites associated with this study may vary, but the conclusions would be the same. It should be noted, however, that these analyses are site specific and apply only under the conditions set forth in this report. Each cogeneration plant must be investigated for the specific conditions associated with its installation and operation. The addition of condensing capabilities would not affect the results since it would improve the economics of the preferred option more than the others. Sequential installations also require continued use of oil which is not in accordance with the national energy policy. 
TABLE $6-14$

COMPARISON OF HTGR NET OPERATING COSTS FOR COMPLETE INITIAL CONSTRUCTION VS EXTENDED CONSTRUCTION AT GEISMAR( 1$)$

(Current $\$ \times 1,000$ )

Base Option ( 2 )

1986

1987

1988

1989

1990

1991

1992

1993

1994

1995

1996

1997

1998

1999

2000

2001
281.111

276.556

271,629

266.265

260.435

254.106

247.240

239,792

231.719

222.974

213,501

203,250

192,150

180,137

167,151

153,111
Alternate I (3)

248,673

246.988

245,114

243.034

240.729

295.535

288,669

281,221

273,148

264.403

254,930

244.679

233.579

221.566

208.580

194,540

\section{Alternate II (4)}

356,839

368.480

380,902

394,157

408.176

279.479

276,654

273,519

270.067

266,275

341,478

331.227

320,127

308,114

295,128

281,088

Present Worth

in Dollars

as of $1 / 86 \quad \$ 1,914,184$

$\$ 1,979.309$

$\$ 2,613,055$

(1)Costs are based on escalated values and operating at full capacity for 7,884 hours per year.

(2)Three 1200-MW HTGRs installed for operation in 1986.

(3)Two HTGR installed for operation in 1986, the third for operation in 1991.

(4) Sone HTGR installed for operation in 1986, 1991, and 1996, respectively. 
TABLE 6-15

COMPARISON OF CNSS NET OPERATING COSTS FOR

COMPLETE INITTAL CONSTRUCTION VS EXTENDED CONSTRUCTION AT GEISMAR (Current $\$ 1,000$ )

\section{Base Option (1) Alternate I (2)}

1986

1987

1988

1989

1990

1991

1992

1993

1994

1995

1996

1997

1998

1999

2000

2001

Present Worth in

Dollars as of $1 / 86$
311.763

288,126

266,486

246,632

228.417

211.720

196.379

182.263

169,312

157,383

146.446

136,347

127,089

118,503

110.634

103,341

$\$ 3,000,841$
432.433

409.361

387.877

367,904

349,289

240.189

222.261

205,790

190,701

176,825

164.123

152.415

141,700

131,782

122.708

114,315

$\$ 3.806 .673$

(1)Two 1200-MW CNSS units installed for operation in 1986.

(2)First unit installed for operation in 1986, second unit for operation in 1991. 
The economic comparisons contained in sections 6.1 and 6.2 were based on the revenue requirements which must be realized from the sale of steam in order to produce the minimum acceptable rate of return, taken as 10 percent. . An "expense center" analysis has also been made to determine. for each fossil-fired and muclear alternative, the net present value of the cash flow both during the construction present and for 30 the cash flow both during thion period and for start of construction for the fossil-fired alternatives has been delayed so that all al initial operation, 1986.

Tabulations of the net present value for four different fuel costs and three discount rates are shown on Table 6-16 for existing plants (fuel, operation and maintenance, working capital only), eastern coal, western coal, No. 6 fuel oil, the HrGR, and the CNSS at both Orange and Geismar. These results are compared graphically on Figures 6-2 through 6-9. Annual fuel costs were taken as 90, 100, 150, and 200 percent of the 1986 costs used in the minimum revenue requirements study. The net. present worth has been determined for each fuel cost at discount rates of 10,15 and 20 percent. Cash flow computer printouts for four and 20 percent. Cash flow computer printouts for four a description of the method and input used for the calculations.

Utilities industrial rates are affected by fuel cost passthrough charges. A sensitivity analysis of the GSU electric power rates used to calculate the credit for power was not included in the scope of this study. All of the computer printouts have been included to permit interested users printouts have been included to permit interested users of this report to perform additional sensi

The ratios of the net present value of each alternative to the net present value for the eastern coal-fired plants axe shown in Figures 6-10 and 6-11 for a fuel cost of 100 percent. The range of the discount rate has been extended to 25 percent. These curves clearly show the discount rates where the HTGR, eastern coal, and existing plants are the economic choice. The ratios are valid for steam costs, which are a linear function of the net present value.

Table 6-17 shows levelized steam costs (LSC) calculated from the following equation:

$$
\text { LSC }=\frac{(1+i)^{7}(\mathrm{NPV})}{\frac{1}{i}\left[1-\left(\frac{1}{1+i}\right)^{30}\right](S)}
$$


TABLE 6-16

PRESENT VALUE OF NET CASH OUTFLOW

$(1979 \$ \times 103)$

\begin{tabular}{|c|c|c|c|c|c|c|c|c|c|}
\hline Site & $\begin{array}{c}\text { Fuel cost } \\
(\%)\end{array}$ & $\begin{array}{l}\text { Discount Rate } \\
(\mathbb{x})\end{array}$ & $\begin{array}{c}\text { Existing } \\
\text { Plants }\end{array}$ & $\begin{array}{l}\text { Eastern } \\
\text { Coal }\end{array}$ & $\begin{array}{l}\text { Western } \\
\text { Coal }\end{array}$ & $\begin{array}{c}\text { No. } 6 \\
\text { Fuel oil }\end{array}$ & HTGR & CNSS & \\
\hline \multirow[t]{4}{*}{ Orange } & $\begin{array}{l}90 \\
90 \\
90\end{array}$ & $\begin{array}{l}10 \\
15 \\
20\end{array}$ & $\begin{array}{l}675.068 \\
296.124 \\
150.455\end{array}$ & $\begin{array}{l}276,386 \\
199,534 \\
151,510\end{array}$ & $\begin{array}{l}297,952 \\
209,852 \\
157,246\end{array}$ & $\begin{array}{l}513,997 \\
290,062 \\
189,525\end{array}$ & $\begin{array}{l}160.794 \\
201.241 \\
194.847\end{array}$ & $\begin{array}{l}414.206 \\
289.093 \\
220.155\end{array}$ & \\
\hline & $\begin{array}{l}100 \\
100 \\
100\end{array}$ & $\begin{array}{l}10 \\
15 \\
20\end{array}$ & $\begin{array}{l}744.412 \\
326.035 \\
165.398\end{array}$ & $\begin{array}{l}303,356 \\
211,487 \\
157,600\end{array}$ & $\begin{array}{l}327,592 \\
222,991 \\
163,949\end{array}$ & $\begin{array}{l}572,676 \\
315,369 \\
202,164\end{array}$ & $\begin{array}{l}171,451 \\
206,102 \\
197,377\end{array}$ & $\begin{array}{l}430.185 \\
296.213 \\
223.803\end{array}$ & \\
\hline & $\begin{array}{l}150 \\
150 \\
150\end{array}$ & $\begin{array}{l}10 \\
15 \\
20\end{array}$ & $\begin{array}{r}1,091.144 \\
475,572 \\
240.111\end{array}$ & $\begin{array}{l}438,205 \\
271,257 \\
188,082\end{array}$ & $\begin{array}{l}475.769 \\
288.668 \\
197.436\end{array}$ & $\begin{array}{l}866.051 \\
441.895 \\
265,385\end{array}$ & $\begin{array}{l}224,739 \\
230,418 \\
210,044\end{array}$ & $\begin{array}{l}510,072 \\
331,813 \\
242,026\end{array}$ & \\
\hline & $\begin{array}{l}200 \\
200 \\
200\end{array}$ & $\begin{array}{l}10 \\
15 \\
20\end{array}$ & $\begin{array}{r}1.437 .868 \\
625.109 \\
314.826\end{array}$ & $\begin{array}{l}573,052 \\
331,033 \\
218,563\end{array}$ & $\begin{array}{l}623,947 \\
354,348 \\
230,927\end{array}$ & $\begin{array}{r}1.159 .423 \\
568.425 \\
328.601\end{array}$ & $\begin{array}{l}278.027 \\
254.727 \\
222.704\end{array}$ & $\begin{array}{l}589.974 \\
367.414 \\
260.252\end{array}$ & \\
\hline \multirow[t]{4}{*}{ Geiomúr } & $\begin{array}{l}90 \\
90 \\
90\end{array}$ & $\begin{array}{l}10 \\
15 \\
20\end{array}$ & $\begin{array}{r}1.786 .205 \\
784.100 \\
398.675\end{array}$ & $\begin{array}{l}690,414 \\
481,969 \\
361,008\end{array}$ & $\begin{array}{l}743,527 \\
506,926 \\
374,604\end{array}$ & $\begin{array}{r}1.326 .839 \\
736.940 \\
477,065\end{array}$ & $\begin{array}{l}429.173 \\
523,303 \\
507,040\end{array}$ & $\begin{array}{r}1.011 .718 \\
666.772 \\
493,246\end{array}$ & \\
\hline & $\begin{array}{l}100 \\
100 \\
100\end{array}$ & $\begin{array}{l}10 \\
15 \\
20\end{array}$ & $\begin{array}{r}1.969 .440 \\
863.126 \\
438.158\end{array}$ & $\begin{array}{l}758.953 \\
512.351 \\
376,501\end{array}$ & $\begin{array}{l}818,832 \\
540,309 \\
391,625\end{array}$ & $\begin{array}{r}1.475 .937 \\
801.246 \\
509.194\end{array}$ & $\begin{array}{l}456,317 \\
535,690 \\
513,488\end{array}$ & $\begin{array}{r}1.059,805 \\
688.321 \\
504.222\end{array}$ & \\
\hline & $\begin{array}{l}150 \\
150 \\
150\end{array}$ & $\begin{array}{l}10 \\
15 \\
20\end{array}$ & $\begin{array}{r}2.885 .617 \\
1.258 .261 \\
635.581\end{array}$ & $\begin{array}{r}1,101,670 \\
664,259 \\
453,960\end{array}$ & $\begin{array}{r}1.195,362 \\
707.205 \\
476,730\end{array}$ & $\begin{array}{r}2.221 .418 \\
1.122 .758 \\
669.835\end{array}$ & $\begin{array}{l}592,029 \\
597,612 \\
545,739\end{array}$ & $\begin{array}{r}1.303 .206 \\
796.033 \\
559.097\end{array}$ & \\
\hline & $\begin{array}{l}200 \\
200 \\
200\end{array}$ & $\begin{array}{l}10 \\
15 \\
20\end{array}$ & $\begin{array}{r}3.801,788 \\
1.653,393 \\
832,997\end{array}$ & $\begin{array}{r}1,444,390 \\
816,175 \\
531,424\end{array}$ & $\begin{array}{r}1.571 .892 \\
874.100 \\
561.833\end{array}$ & $\begin{array}{r}2.966 .903 \\
1.444 .276 \\
830.472\end{array}$ & $\begin{array}{l}727,736 \\
659,536 \\
57, .989\end{array}$ & $\begin{array}{r}1.546 .619 \\
903,755 \\
613,975\end{array}$ & \\
\hline
\end{tabular}


TABLE 6-17

LEVELIZED STEAM COST AFTER TAXES

BASED ON THE DCF ANALYSIS

$(\$ / 1000$ LB)

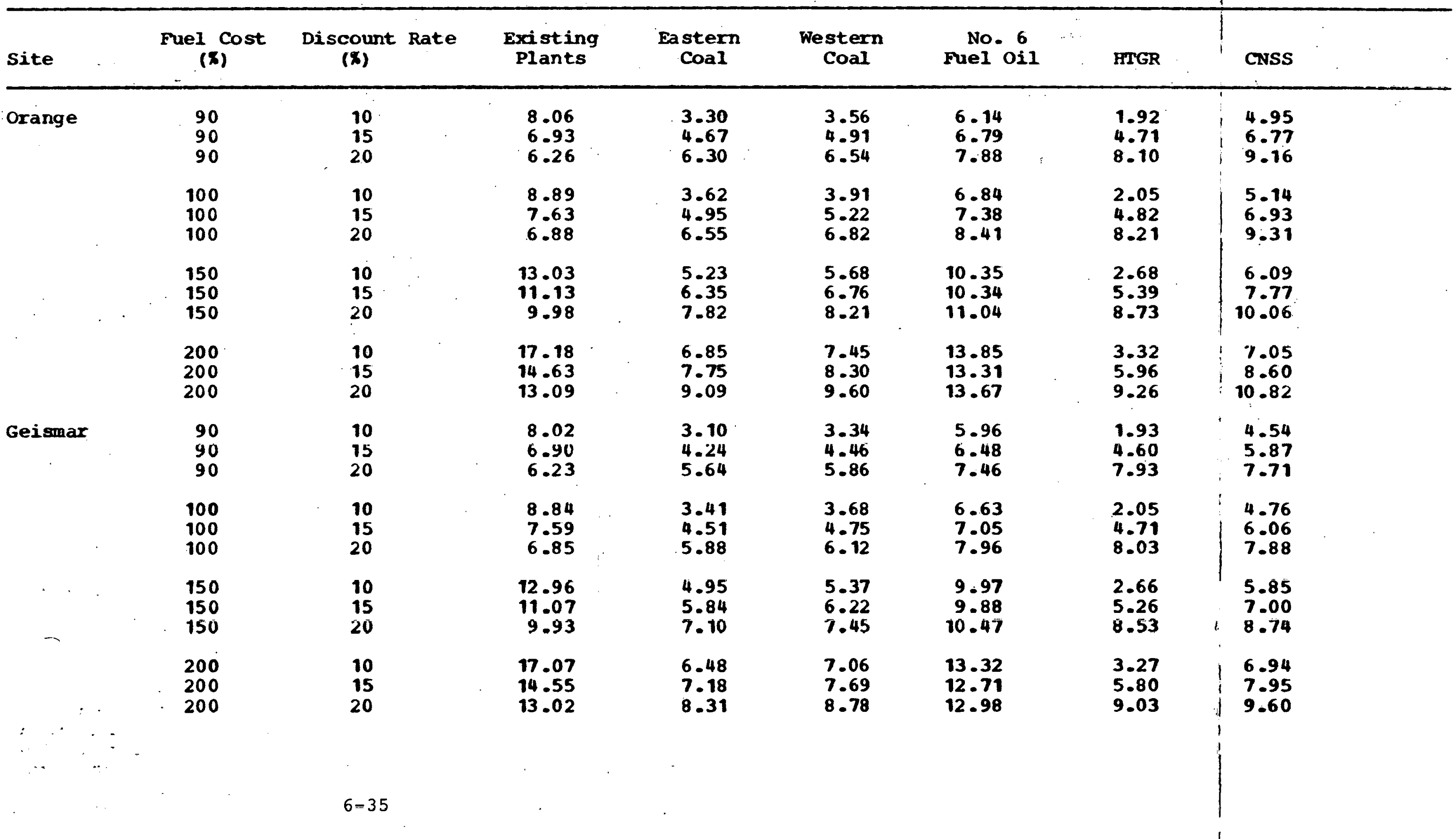

1.20 1.22

1.25 1.26
1.27

1.31

1.32

1.33

1.37

1.38

1.39

1.43

1.44
1.45

1.49

1.50
1.51

1.55

1.56
1.57

2.3

2.4

2.5
2.7 
Where LSC $=$ steam cost levelized over the 30 years of operation, $1986 \$ / 10^{3} 1 \mathrm{~b}$

$i=$ discount rate

NPV = net present value, 1979 dollars from DCF analysis

$S=$ annual process steam sendout, $10^{3} \mathrm{lb}$

These levelized steam costs are after taxes. The break-even price of purchased steam to give the same levelized aftertax costs are shown in Table 6-18. These prices are not tax costs are comparable to the levelized steam costs in Tables $6-4$ and $6-5$ since the fossil-fired plants tabulated there begin operation earlier, and the nuclear plant costs there begin operation earlier.
are levelized over 35 years.

Table 6-19 shows the figures from Tables 6-4 and 6-5 adjusted to a starting date of 1986 and 30 years of operation. For comparison, the before tax break-even purchased steam prices are shown for 100 percent fuel cost and 10 percent discount factor. The numbers are very close. showing that if industrial owners were willing to accept a 10 percent rate of return, it would make little difference economically whether they owned the cogeneration plant. or bought steam from a plant owned by others.

The fixed charge rate of 15 percent is a typical value for a utility with roughly equal debt and equity financing, a minimum acceptable rate of return of 10 percent, and a
30-year plant operating life. The site-specific fixed charge rate would be on the order of 1 percent higher at Orange than at Geismar because of the effect of taxes. This wnld accmint for the slightly aifferent ratios at the two sites.

If the hurdle rate of return were 15 or 20 percent, there would be a definite economic advantage to purchasing steam from an entity whose rate of return was limited by regulation. If this is not possible, the economic choice at a hurdle rate of return of 15 percent is between the HTGR and the coal-fired plants. Eastern coal produces the lowest cost steam at a fuel cust of 90 percent, but the HTGR has the advantage at fuel costs of 150 and 200 percent. At a fuel cost of 100 percent, the two are competitive. The cNsS with a fuel cost of 90 percent would become conpetitive with eastern coal plants having a fuel cost at about 150 percent.

At a hurdle rate of return of 20 percent the HTGR is not competitive with coal-fired plants except at a fuel cost above 200 percent. The cNSS with a fuel cost of 90 percent becomes cormetitive with coal plants with fuel costs of about 200 percent. Fuel, operating and maintenance, and working capital costs for existing oil/gas plants fall below the coal fired plant costs at a fuel cost of 100 percent for discount rates above 20 percent existing boilers will affect this comparison, and it is 37 years is a viable option. 6-36 
TABLE $6-18(1)$

BREAK-EVEN PURCHASED STEAM PRICE

$(1986 \$ / 1000$ LB)

\begin{tabular}{|c|c|c|c|c|c|c|c|c|}
\hline site & $\begin{array}{c}\text { Fuel cost } \\
(x)\end{array}$ & $\begin{array}{l}\text { Discount Rate } \\
\text { (\%) }\end{array}$ & $\begin{array}{l}\text { Existing } \\
\text { Plants }\end{array}$ & $\begin{array}{l}\text { Eastern } \\
\text { Coal }\end{array}$ & $\begin{array}{l}\text { Western } \\
\text { Coal }\end{array}$ & $\begin{array}{c}\text { No } \\
\text { Fuel } \\
6 \\
\text { oil }\end{array}$ & HTGR & CNSS \\
\hline \multirow[t]{4}{*}{ Orange } & $\begin{array}{l}90 \\
90 \\
90\end{array}$ & $\begin{array}{l}10 \\
15 \\
20\end{array}$ & $\begin{array}{l}14.93 \\
12.83 \\
11.59\end{array}$ & $\begin{array}{r}6.11 \\
8.65 \\
11.67\end{array}$ & $\begin{array}{r}6.59 \\
9.09 \\
12.11\end{array}$ & $\begin{array}{l}11.37 \\
12.57 \\
14.59\end{array}$ & $\begin{array}{r}3.56 \\
8.72 \\
15.00\end{array}$ & $\begin{array}{r}9.17 \\
12.54 \\
16.96\end{array}$ \\
\hline & $\begin{array}{l}100 \\
100 \\
100\end{array}$ & $\begin{array}{l}10 \\
15 \\
20\end{array}$ & $\begin{array}{l}16.46 \\
14.13 \\
12.74\end{array}$ & $\begin{array}{r}6.70 \\
9.17 \\
12.13\end{array}$ & $\begin{array}{r}7.24 \\
9.67 \\
12.63\end{array}$ & $\begin{array}{l}12.67 \\
13.67 \\
15.57\end{array}$ & $\begin{array}{r}3.80 \\
8.93 \\
15.20\end{array}$ & $\begin{array}{r}9.51 \\
12.83 \\
17.24\end{array}$ \\
\hline & $\begin{array}{l}150 \\
150 \\
150\end{array}$ & $\begin{array}{l}10 \\
15 \\
20\end{array}$ & $\begin{array}{l}24.13 \\
20.61 \\
18.48\end{array}$ & $\begin{array}{r}9.69 \\
11.76 \\
14.48\end{array}$ & $\begin{array}{l}10.52 \\
12.52 \\
15.20\end{array}$ & $\begin{array}{l}19.17 \\
19.15 \\
20.44\end{array}$ & $\begin{array}{r}4.96 \\
9.98 \\
16.17\end{array}$ & $\begin{array}{r}11.28 \\
14.39 \\
18.63\end{array}$ \\
\hline & $\begin{array}{l}200 \\
200 \\
200\end{array}$ & $\begin{array}{l}10 \\
15 \\
20\end{array}$ & $\begin{array}{l}31.81 \\
27.09 \\
24.24\end{array}$ & $\begin{array}{l}12.69 \\
14.35 \\
16.83\end{array}$ & $\begin{array}{l}13.80 \\
15.37 \\
17.78\end{array}$ & $\begin{array}{l}25.65 \\
24.65 \\
25.31\end{array}$ & $\begin{array}{r}6.15 \\
11.04 \\
17.15\end{array}$ & $\begin{array}{r}13.06 \\
15.93 \\
20.04\end{array}$ \\
\hline \multirow[t]{4}{*}{ Geismar } & $\begin{array}{l}90 \\
90 \\
90\end{array}$ & $\begin{array}{l}10 \\
15 \\
20\end{array}$ & $\begin{array}{l}15.42 \\
13.27 \\
11.98\end{array}$ & $\begin{array}{r}5.96 \\
8.15 \\
10.85\end{array}$ & $\begin{array}{r}6.42 \\
8.58 \\
11.27\end{array}$ & $\begin{array}{l}11.46 \\
12.46 \\
14.35\end{array}$ & $\begin{array}{r}3.71 \\
8.85 \\
15.25\end{array}$ & $\begin{array}{r}8.73 \\
11.29 \\
14.83\end{array}$ \\
\hline & $\begin{array}{l}100 \\
100 \\
100\end{array}$ & $\begin{array}{l}10 \\
15 \\
20\end{array}$ & $\begin{array}{l}17.00 \\
14.60 \\
13.17\end{array}$ & $\begin{array}{r}6.56 \\
8.67 \\
11.31\end{array}$ & $\begin{array}{r}7.08 \\
9.13 \\
11.77\end{array}$ & $\begin{array}{l}12.75 \\
13.56 \\
15.31\end{array}$ & $\begin{array}{r}3.94 \\
9.06 \\
15.44\end{array}$ & $\begin{array}{r}9.15 \\
11.66 \\
15.13\end{array}$ \\
\hline & $\begin{array}{l}150 \\
150 \\
150\end{array}$ & $\begin{array}{l}10 \\
15 \\
20\end{array}$ & $\begin{array}{l}24.92 \\
21.29 \\
19.10\end{array}$ & $\begin{array}{r}9.52 \\
11.23 \\
13.65\end{array}$ & $\begin{array}{l}10.33 \\
11.96 \\
14.33\end{array}$ & $\begin{array}{l}19.17 \\
19.00 \\
20.13\end{array}$ & $\begin{array}{r}5.12 \\
10.12 \\
16.40\end{array}$ & $\begin{array}{r}11.25 \\
13.46 \\
16.81\end{array}$ \\
\hline & $\begin{array}{l}200 \\
200 \\
200\end{array}$ & $\begin{array}{l}10 \\
15 \\
20\end{array}$ & $\begin{array}{l}32.83 \\
27.98 \\
25.04\end{array}$ & $\begin{array}{l}12.46 \\
13.81 \\
15.98\end{array}$ & $\begin{array}{l}13.58 \\
14.79 \\
16.88\end{array}$ & $\begin{array}{l}25.62 \\
24.44 \\
24.96\end{array}$ & $\begin{array}{r}6.29 \\
11.15 \\
17.37\end{array}$ & $\begin{array}{l}13.35 \\
15.29 \\
18.46\end{array}$ \\
\hline
\end{tabular}

(1)Based on nominal income tax rate of 46 percent at Orange and 48 percent at Geismar (See Appendix C). 
TABLE $\quad 6-19$

COMPARISON OF WINIMUN REVENUE REQUIREMENTS (MRR) STEAM COST FOR 10\% RATE OF RETURN AND 15\% FIXED CIYARE RATE WITH DISCOUNTED CASH FLOW (DCF) BREAR-EVEN PURCHASED STEAM PRICE FOR 10\% DISCOUNT FACTCK

\begin{tabular}{|c|c|c|c|}
\hline Orange Site & $\begin{array}{l}\text { WRR } \\
\text { Steam cost } \\
\left(\$ / 10^{3} 1 \mathrm{~b}\right)\end{array}$ & $\begin{array}{c}\text { DCF } \\
\text { Break-Even Price(1) } \\
\left(\$ / 10^{3} 1 \mathrm{~b}\right)\end{array}$ & $\begin{array}{c}\text { Ratio } \\
\text { MRR/DCF }\end{array}$ \\
\hline $\begin{array}{l}\text { Lastern coal } \\
\text { Western coal } \\
\text { No. } 6 \text { fuel oil } \\
\text { HTGR } \\
\text { CNSS }\end{array}$ & $\begin{array}{r}6.55 \\
7.06 \\
12.28 \\
3.33 \\
9.29\end{array}$ & $\begin{array}{r}6.70 \\
7.24 \\
12.67 \\
3.80 \\
9.51\end{array}$ & $\begin{array}{l}0.978 \\
0.975 \\
0.969 \\
0.876 \\
0.977\end{array}$ \\
\hline \multicolumn{4}{|l|}{ Geismar site } \\
\hline $\begin{array}{l}\text { Eastern coal } \\
\text { Western coal } \\
\text { No. } 6 \text { fuel oil } \\
\text { HTGR } \\
\text { CNSS }\end{array}$ & $\begin{array}{r}6.76 \\
7.27 \\
12.75 \\
4.07 \\
9.40\end{array}$ & $\begin{array}{r}6.56 \\
7.08 \\
12.75 \\
3.94 \\
9.15\end{array}$ & $\begin{array}{l}1.030 \\
1.027 \\
1.000 \\
1.033 \\
1.027\end{array}$ \\
\hline
\end{tabular}

NOIE: $\bar{H}_{11}$ figures are levelized over a 30-year period for plants beginning operation in 1986 .

(1) Based on nominal incone tax rate of 46 percent at Orange and 48 percent at Geismar. 


\subsection{PRESENT VALUE STEAM COST}

Steam costs levelized over a 30-year period beginning in 1986 are good for comparison of alternatives, but are difficult to compare with present steam costs. A present value steam cost (PVSC) may be calculated from the net present value (NPV) using the following equation:

$$
\operatorname{PVSC}=\frac{(1+i)^{7}(\mathrm{NPV})}{(1+e)^{7}\left(\frac{1}{i-e}\left[1-\left(\frac{1+e}{1+i}\right)^{30}\right]\right)(\mathrm{S})}
$$

Where PVSC $=$ present value steam cost, $\$ / 103$ Ib

NPV $=$ net present value in 1979

$i$ = rate of return

$e=$ rate of steam cost escalation

$s=$ process steam sendout, $10^{3} 1 \mathrm{~b}$.

The present value steam cost calculated from this equation is the cost which, if escalated year-by-year for 37 years. would yield the given NPV for steam use during the 30-year period beginning in 1986. The curves in Figure 6-12 show the ratio of levelized steam cost to present value steam cost for discount rates from 10 to 20 percent and escalation rates from 5 to 9 percent. The present value steam cost is quite sensitive to the assumed rate of escalation. Table 6-20 shows the present value steam costs for the five alternative plants at orange and Geismar for 100 percent fuel cost, 6 and 7 percent escalation, and discount rates of 10. 15, and 20 percent. For comparison, fuel and operation and maintenance costs only are shown for the existing plants net-of-taxes. At discount rates of 10 and 15 percert the coal-fired plants and the HTGR show a clearcut economic advantage over continued operation of existing plants with No. 2 fuel oil. The cNSS plant has an advantge over existing plants and new, No. 6 fuel oil plants at discount rates of 10 and 15 percent, except for one case at orange. 
TABLE 6-20

PRESENT VALUE STEAM COST NET-OF-TAXES

$(1979 \$ / 1000 \mathrm{LB})$

\begin{tabular}{|c|c|c|c|c|c|c|c|c|}
\hline Site & $\begin{array}{c}\text { Escalation Rate } \\
(\%)\end{array}$ & $\begin{array}{c}\text { Discount Rate } \\
\text { (\%) }\end{array}$ & $\begin{array}{l}\text { Existing } \\
\text { Plants }\end{array}$ & $\begin{array}{l}\text { Eastern } \\
\text { Coal }\end{array}$ & $\begin{array}{l}\text { Western } \\
\text { Coal }\end{array}$ & $\begin{array}{c}\text { No. } 6 \\
\text { Fuel oil }\end{array}$ & HTGR & CNSS \\
\hline \multirow[t]{2}{*}{ Orange } & $\begin{array}{l}6 \\
6 \\
6\end{array}$ & $\begin{array}{l}10 \\
15 \\
20\end{array}$ & $\begin{array}{l}2.73 \\
2.73 \\
2.73\end{array}$ & $\begin{array}{l}1.35 \\
2.13 \\
3.11\end{array}$ & $\begin{array}{l}1.46 \\
2.25 \\
3.24\end{array}$ & $\begin{array}{l}2.56 \\
3.18 \\
3.99\end{array}$ & $\begin{array}{l}0.77 \\
2.08 \\
3.90\end{array}$ & $\begin{array}{l}1.92 \\
2.98 \\
4.42\end{array}$ \\
\hline & $\begin{array}{l}7 \\
7 \\
7\end{array}$ & $\begin{array}{l}10 \\
15 \\
20\end{array}$ & $\begin{array}{l}2.73 \\
2.73 \\
2.73\end{array}$ & $\begin{array}{l}1.13 \\
1.83 \\
2.73\end{array}$ & $\begin{array}{l}1.22 \\
1.93 \\
2.84\end{array}$ & $\begin{array}{l}2.14 \\
2.73 \\
3.50\end{array}$ & $\begin{array}{l}0.64 \\
1.78 \\
3.42\end{array}$ & $\begin{array}{l}1.61 \\
2.56 \\
3.88\end{array}$ \\
\hline \multirow[t]{2}{*}{ Geismar } & $\begin{array}{l}6 \\
6 \\
6\end{array}$ & $\begin{array}{l}10 \\
15 \\
20\end{array}$ & $\begin{array}{l}2.73 \\
2.73 \\
.2 .73\end{array}$ & $\begin{array}{l}1.27 \\
1.94 \\
2.80\end{array}$ & $\begin{array}{l}1.37 \\
2.05 \\
2.91\end{array}$ & $\begin{array}{l}2.48 \\
3.03 \\
3.78\end{array}$ & $\begin{array}{l}0.77 \\
2.03 \\
3.81\end{array}$ & $\begin{array}{l}1.78 \\
2.61 \\
3.74\end{array}$ \\
\hline & $\begin{array}{l}7 \\
7 \\
7\end{array}$ & $\begin{array}{l}10 \\
15 \\
20\end{array}$ & $\begin{array}{l}2.73 \\
2.73 \\
2.73\end{array}$ & $\begin{array}{l}1.06 \\
1.67 \\
2.45\end{array}$ & $\begin{array}{l}1.15 \\
1.76 \\
2.55\end{array}$ & $\begin{array}{l}3.07 \\
2.51 \\
3.31\end{array}$ & $\begin{array}{l}0.64 \\
1.74 \\
3.34\end{array}$ & $\begin{array}{l}1.49 \\
2.24 \\
3.28\end{array}$ \\
\hline
\end{tabular}

*1979 Fuel, Operation and Maintenance Costs Only, Net-of-Taxes (not derived from NPV) 


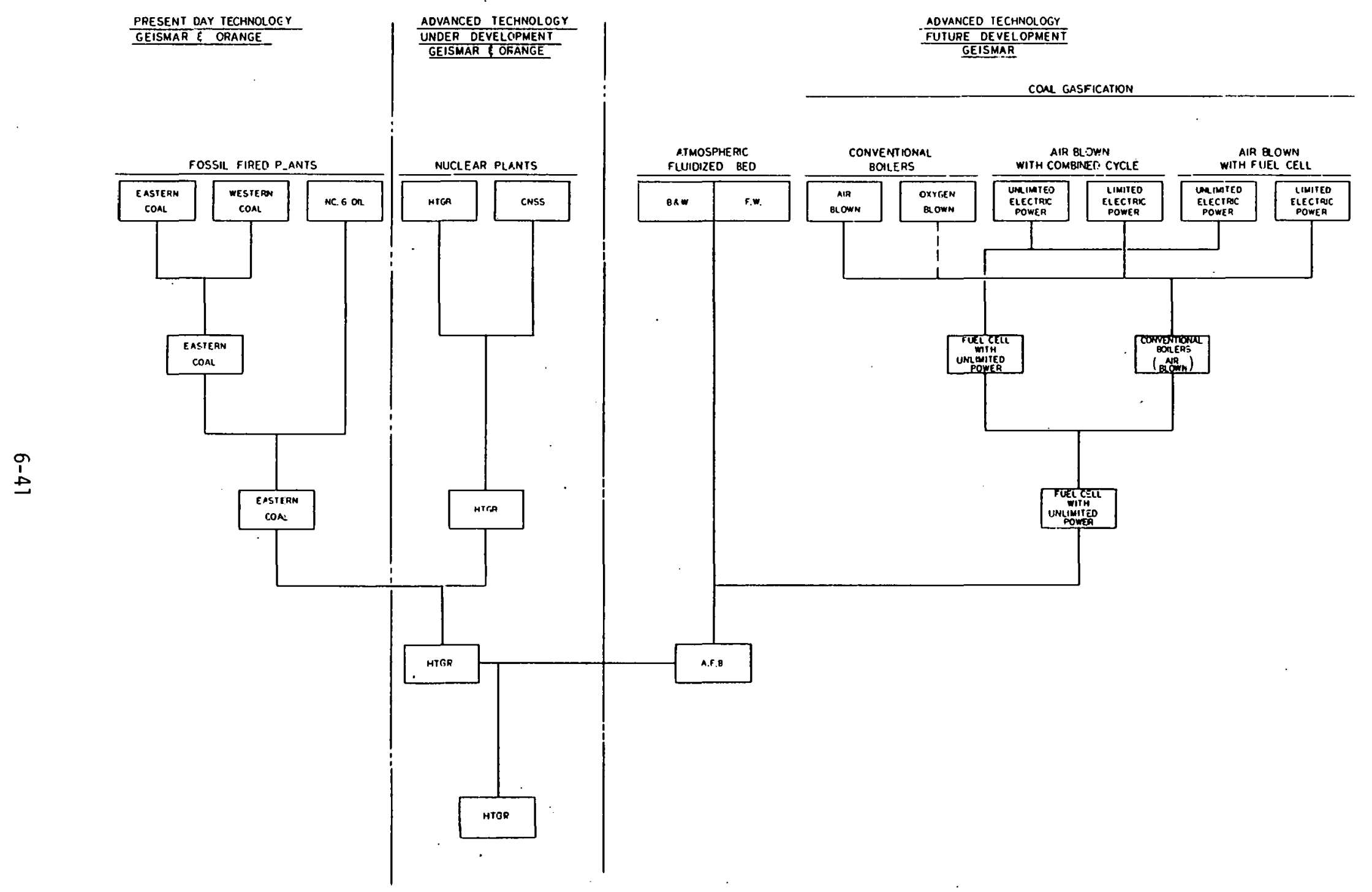

FIGURE 6-1. DIAGRAM OF ECONOMIC COMPARISONS OF COGENERATION PLANTS AT GEISMAR AND ORANGE 


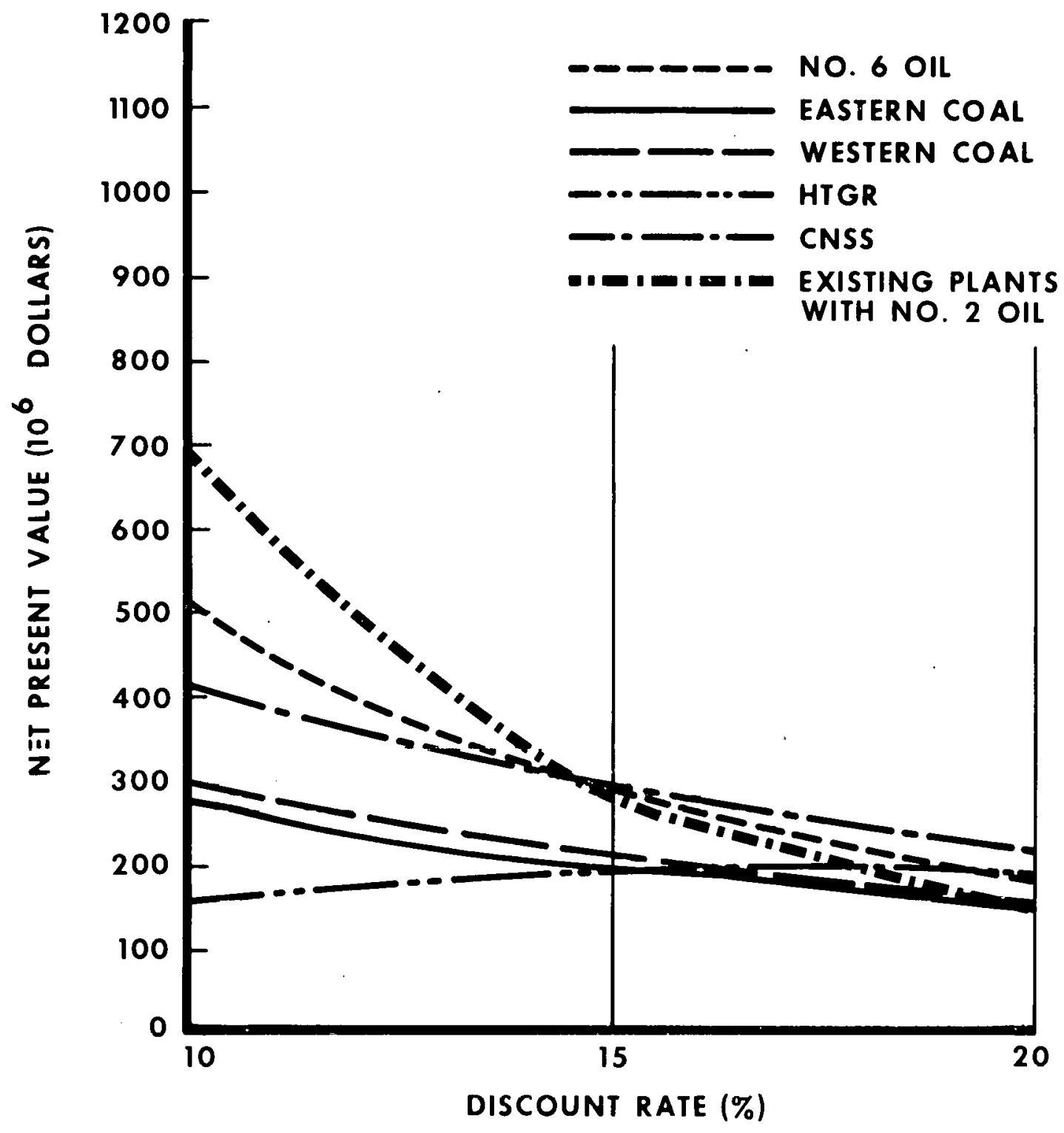

FIGURE 6-2. NET PRESENT VALUE VS DISCOUNT RATE AT ORANGE WITH $90 \%$ FUEL COST 


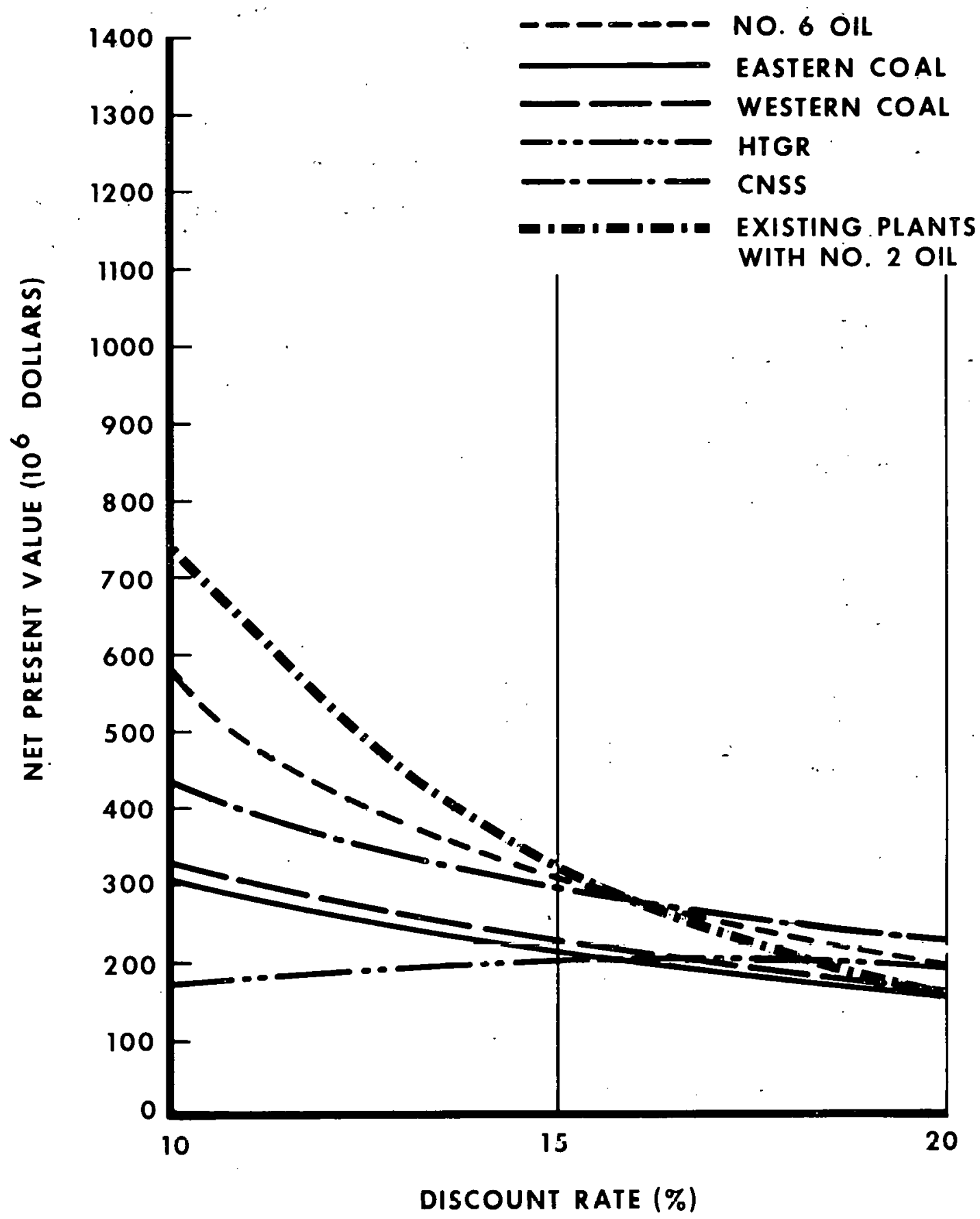

FIGURE 6-3. NET PRESENT VALUE VS DISCOUNT RATE AT ORANGE WITH 100\% FUEL COST 


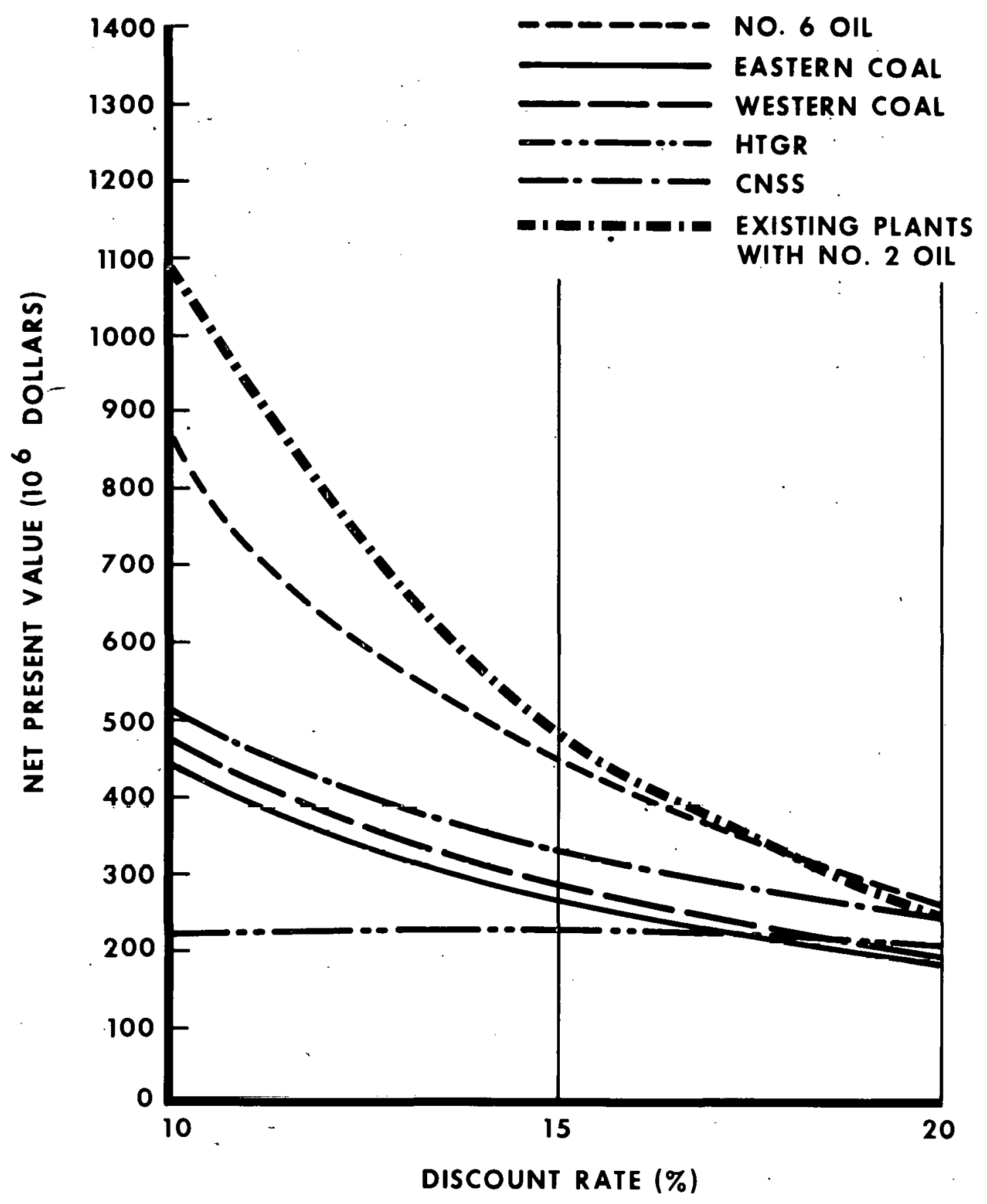

FIGURE 6-4. NET PRESENT VALUE VS DISCOUNT RATE AT ORANGE WITH 150\% FUEL COST 


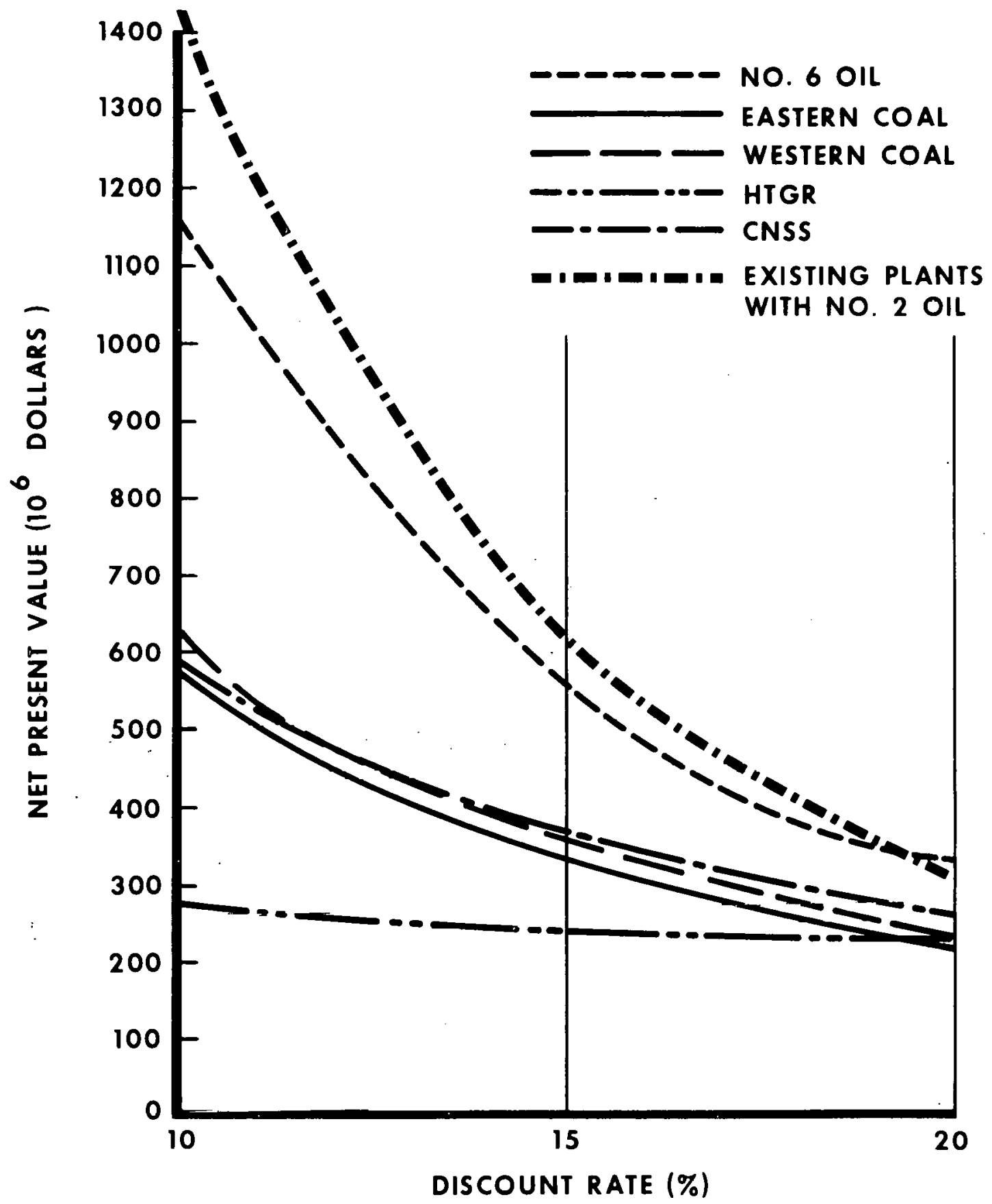

FIGURE 6-5. NET PRESENT VALUE VS DISCOUNT RATE AT ORANGE WITH 200\% FUEL COST 


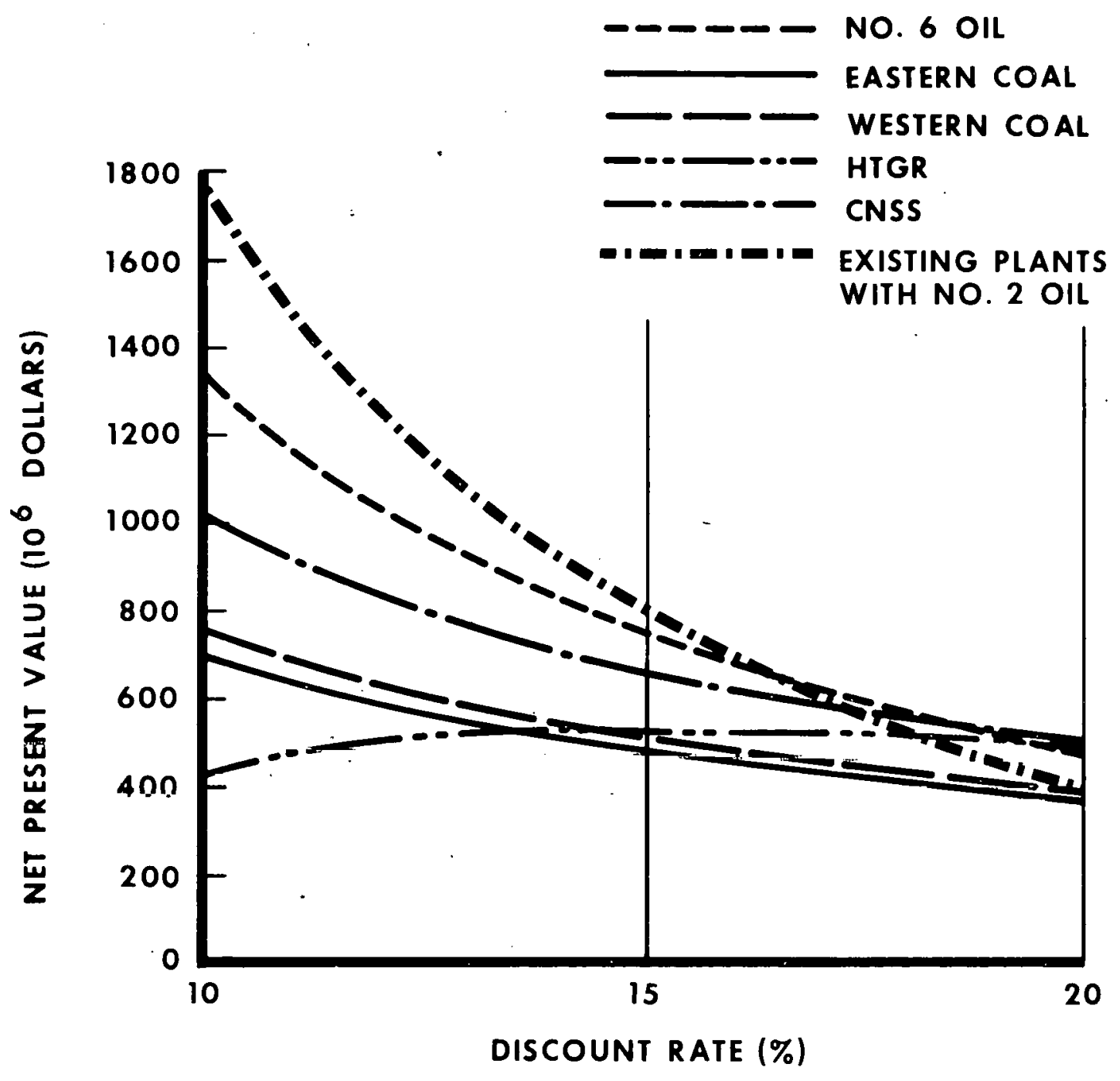

FIGURE 6-6. NET PRESENT VALUE VS DISCOUNT RATE AT GEISMAR WITH 90\% FUEL COST 


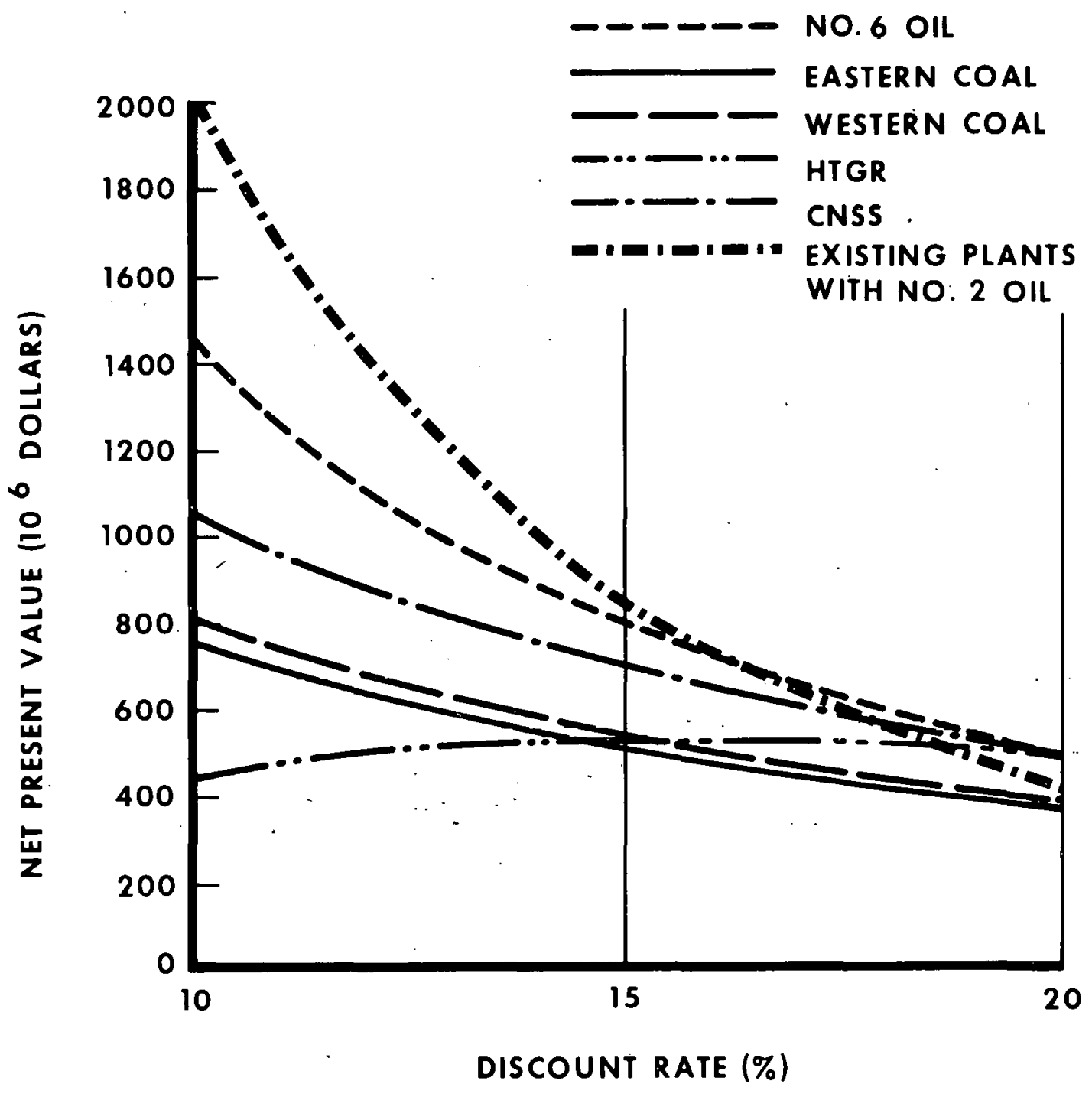

FIGUTRE 6-7. NET PRESENT VALUE VS DISCOUNT RATE AT GEISMAR WITII 1003 FUEL COST 


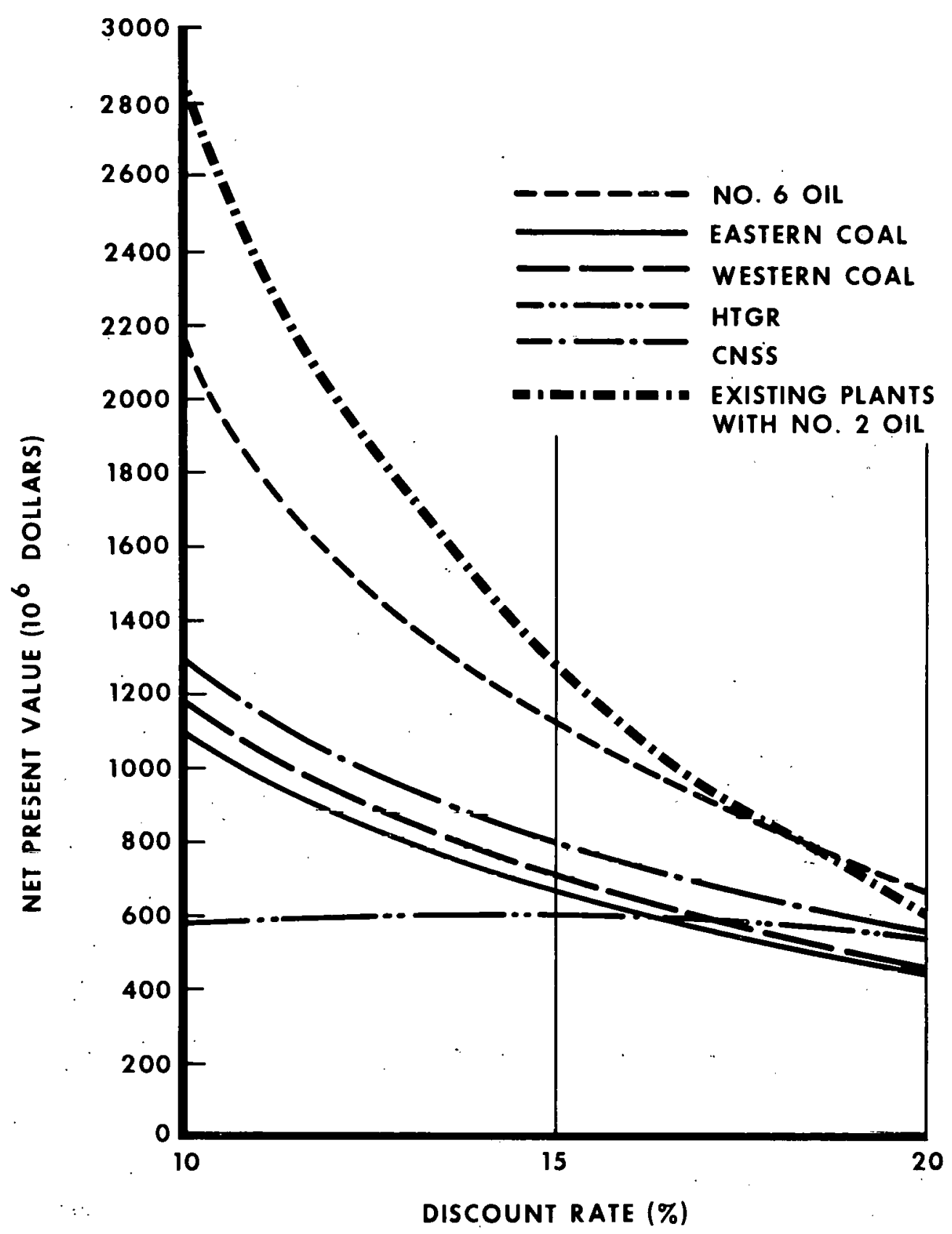

FIGURE 6-8. NET PRESENT VALUE VS DISCOUNT RATE AT GEISMAR WITH 150\% FUEL COST 


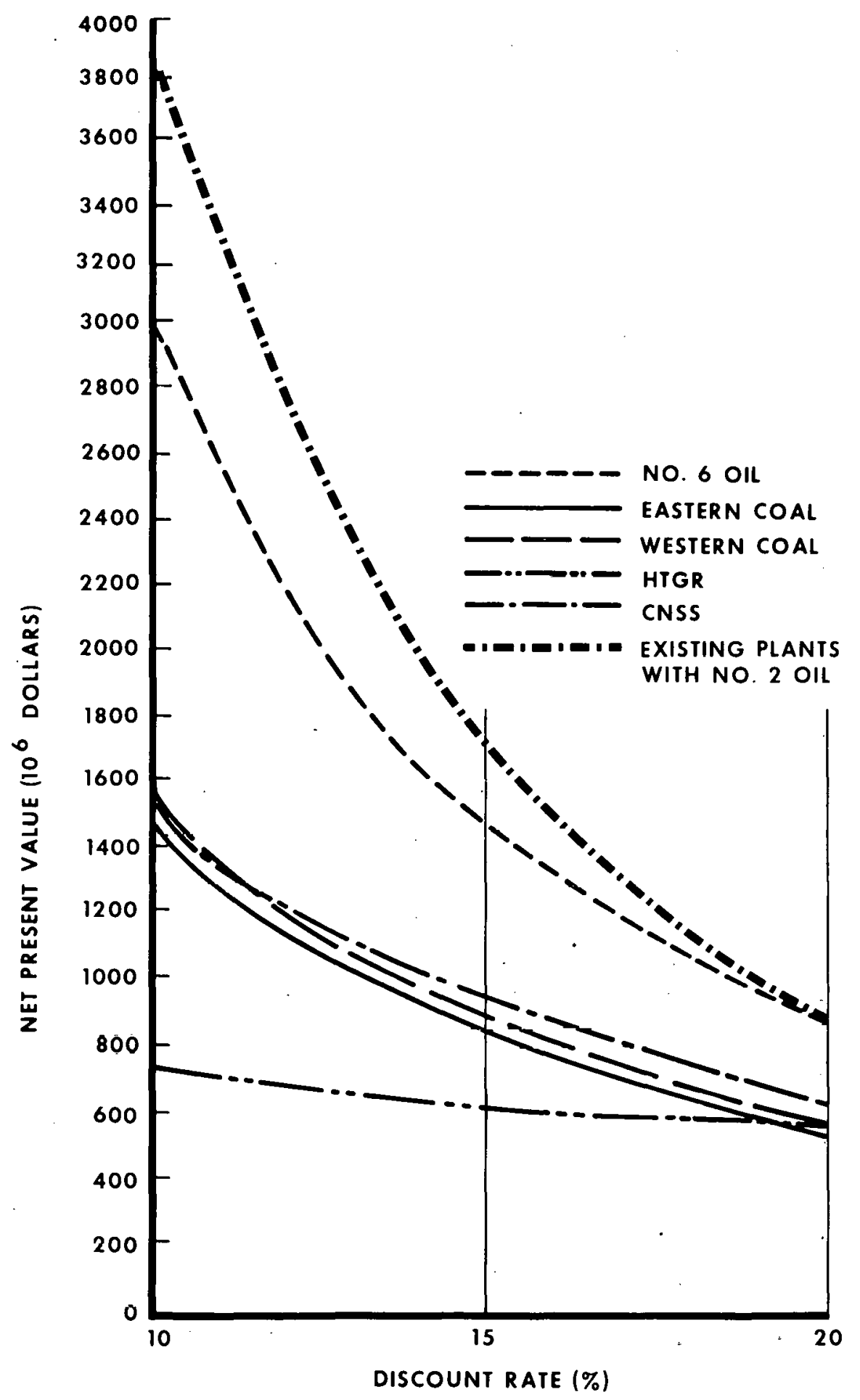

FIGURE 6-9. NET PRESENT VALUE VS DISCOUNT RATE AT GEISMAR WITH $200 \%$ FUEL COST 


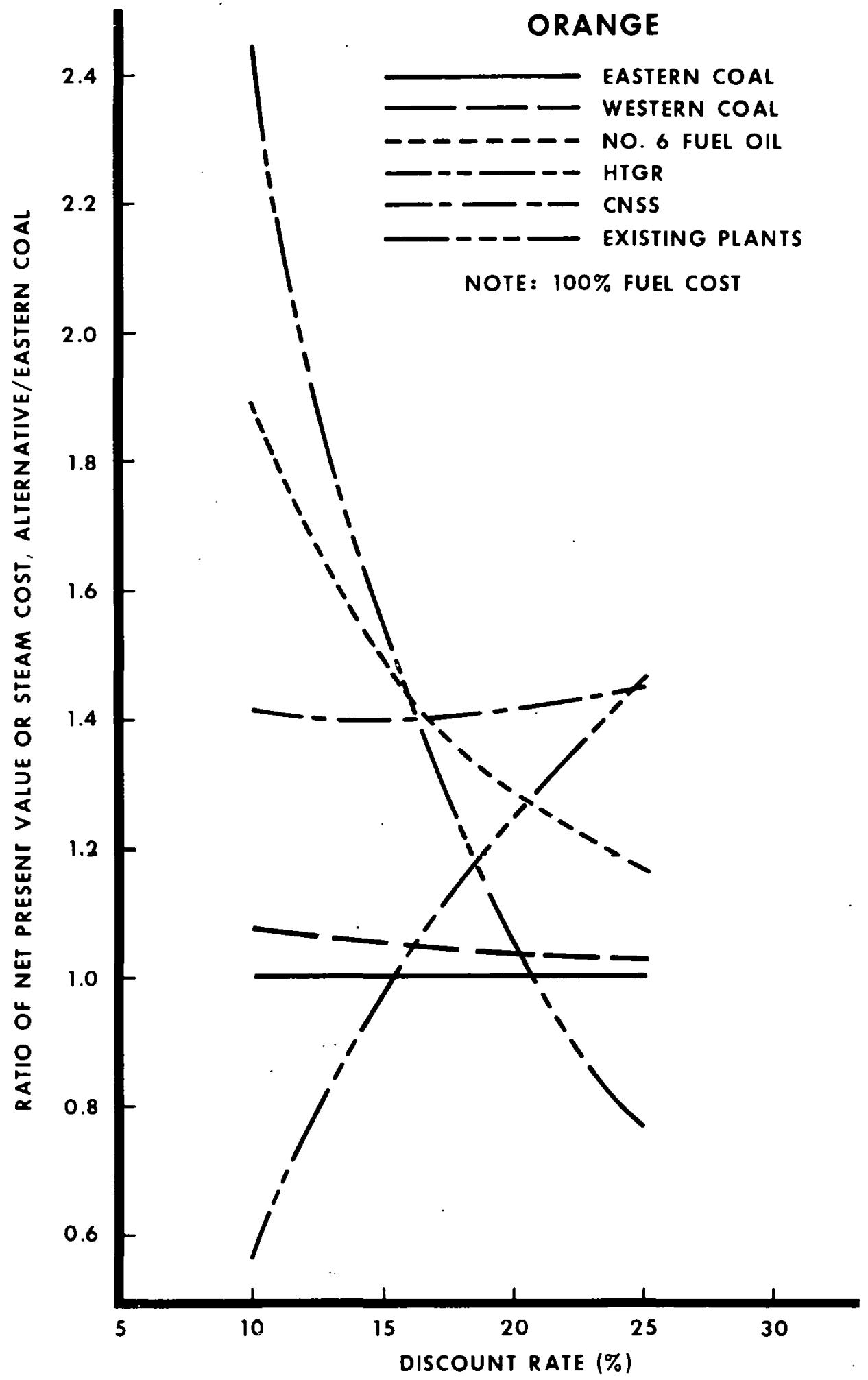

FIGURE 6-10. RATIOS OF NPV (AND STEAM COSTS) FOR ALTERNATIVES TO THE NPV (AND STEAM COST) FOR EASTERN COAL AT ORANGE 


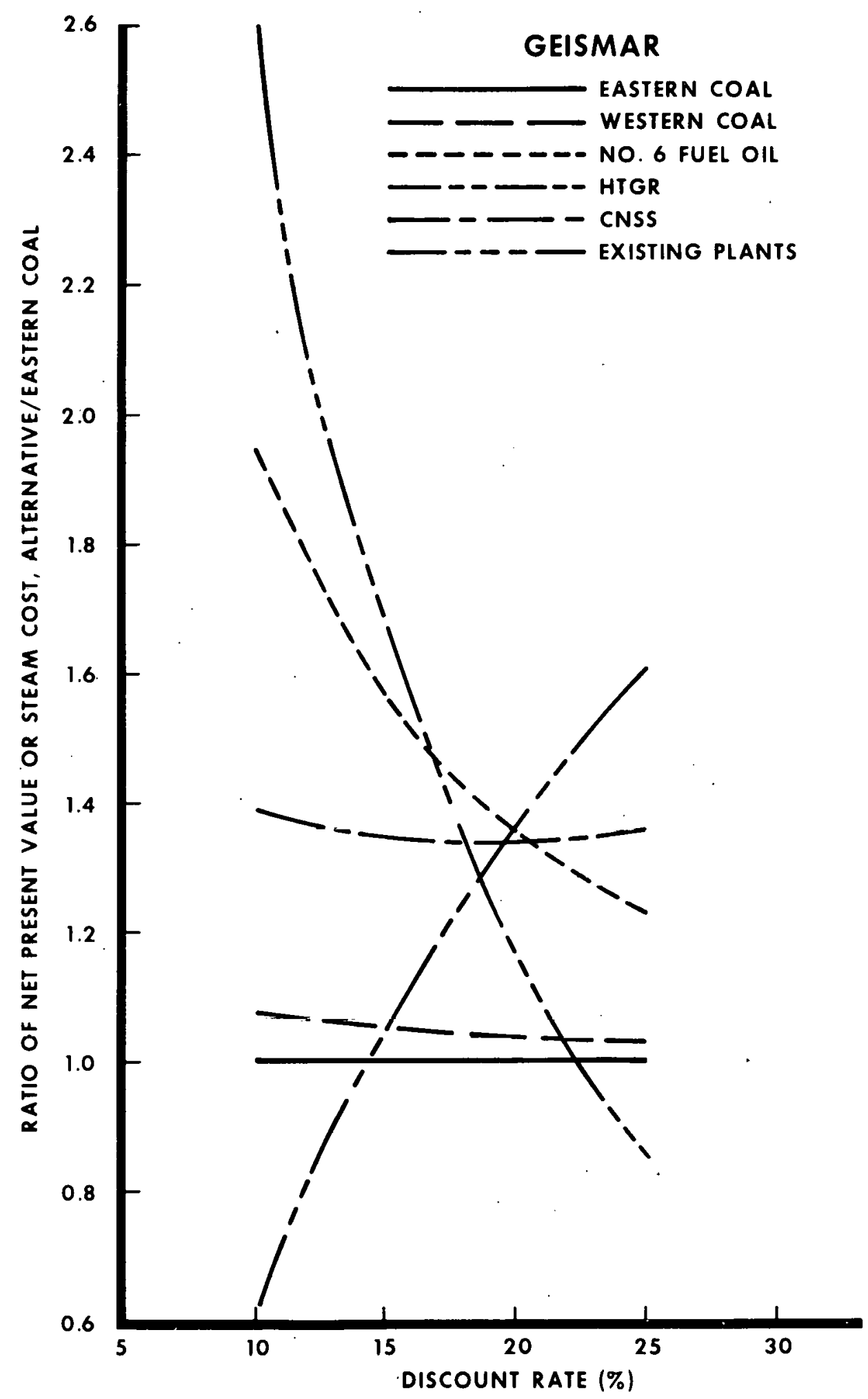

FIGURE 6-11. RATIOS OF NPV (AND STEAM COSTS) FOR ALTERNATIVES TO THE NPV (AND STEAM COST). FOR EASTERN COAL AT GEISMAR 


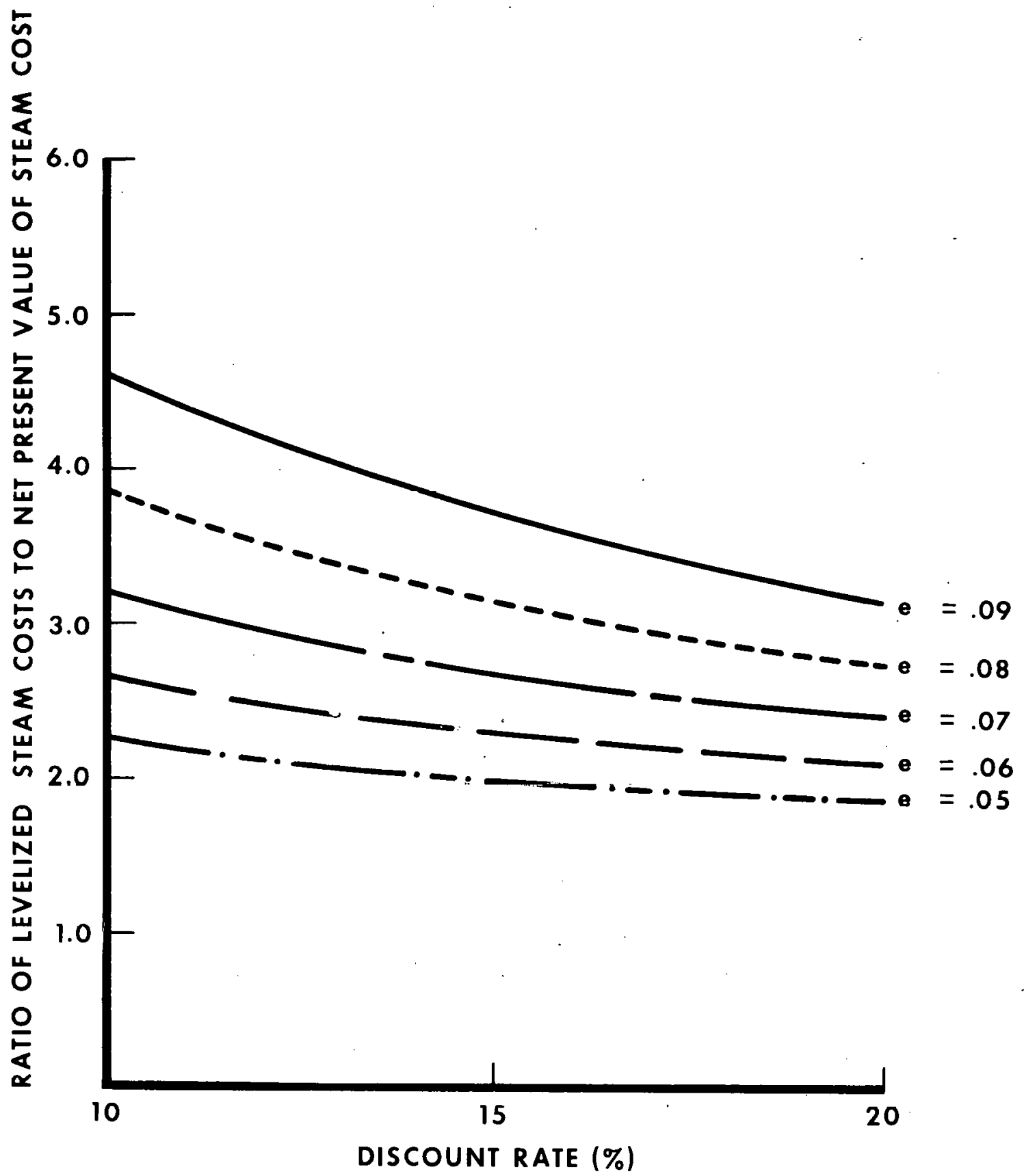

FIGURE 6-12. RATIO OF LEVELIZED STEAM COSTS TO NET PRESENT VALUE OF STEAM VS DISCOUNT RATE FOR VARIOUS ESCALATION RATES 


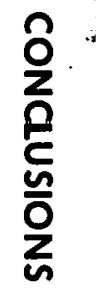




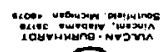

(3) 


\section{SECTION 7}

\section{CONCLUSIONS}

This section discusses the conclusions reached from the study, specifically addressing the following areas:

1. Site selection

2. Heat Cycle optimization

3. Current Techrology

4. Advanced Technology - Under Development

5. Advanced Technology - Future Development

6. Plant size and Stean Conditions

7. Plant Reliability

8. Condensing Capabilities

9. Sequential Construction - High Temperature Gas-Cooled Reactor (HTGR) and Consolidated Nuclear Steam System (CNSS)

10. Comparison With Existing Plants

11. Sensitivity

12. Energy Savings

13. Discounted Cash Flow Analysis

The conclusions reflect the assumption that all plants represent the $n$th of a kind. In reality, it is impossible to apply sone of the concepts considered at this time. This is especially true for the CNSS; HTGR, AFB, and the coal gasification plants. However, the report attempts to define the role each might have relative to those which are available.

Further, this report does not address itself to future availability of the various fuels involved. It is assumed that all fuels will be availabie at a price commensurate with the anticipated normal rate of inflation.

Although two coal gasification concepts were developed with no restriction on electric power generation, the basic criterion was to provide the process steam required by the industrial users and develop electricity as a byproduct. ultimate uwnership and operation of the cogeneration plant 
litay have an influence on the final plant selection - the utility riay be interested in maximum electric power generation and the industrial users may desire to limit it.

\section{7 . SI'L SELECTION}

In in-depth investigation of the four regions designated by DOE/GSU as having the best potential for the cogeneration concept resulted in the selection of sites at Geismar. Louisiana, and Orange, Texas. Ten sites stucied within the four regions resulted in Geismar site $B$ and Orange site $B$ being ranked best according to the sumnation of the numerical values assigned to various siting factors. Since the variations in the total siting scores for other candidate sites are not siynificantly less than the selected sites, a cogeneration plant would be suitable at other sites anö may be considerec for future expansion planning.

It is reconmended that the siting factor approach be used to determine site auequacy and suitability in connection with any coyereration plants contemplated for the future.

\subsection{HEFI CYCLE OI'IMIZATION}

fnalyses show that the higher steam turbine inlet pressures reauce the net operating cost due to the increased credit for electric power yeneration that results from the expansion of the steara through the tuxbines. The 2,400 psig selected as the optiram operating pressure is consistent with today's trend and technology and affords adequate operating experience.

Ideally, maximurn work is obtained using an infinite number of stages of feedwater heating with a given initial and final feedwater terqerature. The number of feedwater heaters used in a inal plant design is deternined by the incremental return on investment for the additional equipment and installation costs. The three stages of feedwater heating selected for fossil-fired plants in this study produce about 70 percent of the infinite-stage work. The four stages of feedwater heating selected for the HTGR plant produce about 80 percent of the infinite-stage work.

\subsection{CURRENT TECHNOLOGY}

A coal-fired cogeneration plant is recommended to meet the inrmediate needs of industrial users. This conclusion is based on the alternatives studied, the steam costs developed, and the present state of technology. A coal-fired cogeneration plant can be built with confidence because the technology is known and performance can be predicted with a high degree of accuracy. In addition, the 


\section{SECTION 7}

CONCLUS IONSS

TALLE OF CONTENTS

\section{Page}

7.1 SITE SELECTION

$7-2$

7.

HEAT CYCLE OPTIMIZTIION

$7-2$

7.3

CURKENT TECHNOLOGY

$7-2$

7.4 ADVANCED TECHNOLOGY UNDER DEVELOPMENT HIGH TEMPLRATURE GFS-COOLED REACTOR AND CONSOLIDATED NUCLEAR STEAM SYSTEM

$7-4$

7.5

ADVANCED 'RCHNOLOGY - FUTURF DEVET OFMENT'
AtתOSpleric Fluidized-Bed BOilers

$7-4$

7.5 .1

$7-4$

7.5.2 Coal Gasitication

$7-5$

7.6

PLANT SIZE AND STEAM CONDITIONS

$7-8$

7.7

PLANT RELIABTLITY

$7-8$

7.8

CONDENSING CAPABILITIES

$7-9$

7.9. SEQUENTIAL CONSTRUCTION OF TMT. HIGH TEMPERATUKE GAS-COOLED REACTOR AND CONSOLIDATED NUCLEAR STEAM SYSTEM

7.10 COMPARISON WITH EXISTING PLANTS

7.11 SENSITIVITY

7.12 ENERGY SHVINGS

7.13 DISCOUNTED CASH FLOW ANALYSIS

TAELES

7-1 Comparisun of Coal Consumption - Advanced Technology (Future Development) vs Eastern Pulverized Coal-Fired cogeneration Plant

7-2 Energy Saved by Cogeneration - Btu $x$ 106 hour

FIGURES

7-1 Arnual Fuel cost to Generate steam in Users' Plants at Oranye and reismar sites 
7-2 Effect of Changes in Load Factor at Orange and Geismar Sites

7-3 Effect of Changes in Estimates for Capital Costs, Fuel Cost, and OEM for HTGR and Eastern coal at Geismar

7-4 Effect of Chanyes in Estimates for Capital costs, fuel costs, and OGM for the HTTiR and Eastern Coal at orange

7-5 Eifect of Changes in Escalation Rate for Electric power at Geismar and orange 
use of coal as a fuel agrees favorably with the present energy program directed towand utilization of coal reserves.

Based on the economic considerations shown in Table 6-1, the eastern coal-fired plants are marginally nore economical than western coal-fired plants at both orange and Geismar. Should a coal-fired cogeneration plant be contemplated. we strungly reconwiend a thorough investigation and establistment of prevailing economic factors. Because the choice of eastern coal over western coal is marginal, the selection of econonic factors is critical to the final economic choice.

The inclusion of scrubiers in the fossil-fired cogeneration plant acids appreciably to both the capital costs and the operatiny costs. Whe following indicates the high investment required to rewove the $\mathrm{SO}_{2}$ from the fiue gas:

Cust for $\mathrm{SO}_{2}$ scrubbers Expressed as a percent of the Total Estimated Capital cost

Geismax

$15 x$

$13 \%$

$16 \%$
Orange

$14 \%$

$13 x$

$16 \%$

No. 6 Oil

The operating and maintenance costs for the scrubbers amount to about 25 percent of the total for western coal and about 40 percent for the oil-tired plant and eastern coal.

Maximum flexibility shuuld be incorporated in the design of a coal-fired coyeneration plant in order to accomnodate both eastern and western cuals. For example, flue gas scrubbers should be sized tor ligh-sulfur eastern coal, while the boilers, coal handling, and ash handling systems should be sized to handle the lower-Btu western coals. The increased capital cost to achieve this flexibility appears to be justified to ensure against uncertainties in fuel supply.

In castern cual-fired cogeneration plant requires 39 percent less coal storage area than a western coal-fired plant because of eastern cuals ' higher Btu value. This advantage could be a prime consideration because most cogeneration plants will be located in established industrial areas. 
7.4 ADVANCED TECHNUIUGY UNDER DEVELOPMENT - HIGL TEMPERA TURE GAS-COOLED REFCTOR AND CONSOLIDATED NUCLEAR STEAM $\underline{\text { SYSTEM }}$

The CNSS was not suitable for either cogeneration plant because of the relationship of steam pressure and temperature linitations to users" steam requirements at orange and Geismar. The addition of reboilers and oil-firea superheaters at buth sites and an auxiliary oil-fired boiler at Geismar to generate the 970 psia, $850 \circ \mathrm{F}$ steam adds to the capital cost and complexity of the plants. In addition. electric power yeneration is minimal, which results in less credit for power and, consequently, a significantly higher net operating cost.

Use of the HTGR in the cogeneration plants at both Geismar and orange would result in lower steam cost. The lower net operating costs (a result of the lower fuel cost, assuming the uranium/thorium reprocessing fuel cycle) make the HIGR very attractive. At present, however, the HTGR concept is under development asul cannot be considered as an inmediate candidate plant because:

- There has been minimal operating experience and limited success in the united states.

- Projected schedules and startup date are very optinistic considering present state of the art anà historical licensing schedules. Long lead time is not practical for industrial expansion.

- The HTGR as a reliable source for process steam generation has not been denunstiated to incustrial users.

- Technical problems within the HTGR require resolution to increase reliability.

- Fuel reprocessing is currently unauthorized.

The attractiveness of the lower steam cost suggests that problems associated with the HTGK be defined and solutions developed to increase its reliability for possible future inplementation.

7.5 ADVENCED TECHNOLOGY - FUTURE DEVELOPMENT

\subsubsection{ATMOSPHERIC FLUIDIZED-BED BOILERS}

The cost estimate for the atmospheric fluidized-bed boilers was based on the designs of Babcock $\&$ wilcox and Foster-Wheeler. Due to the state of the art and the magnitude of the difference in cost estimates of the two AFB 
boilers, their costs were averaged for the purpose of comparison with the other alternatives. Estimated capital and operating costs were found to be very similar to those of the basic pulverized coal-fired cogeneration plants, with the cost per thousand pounds of process steam in the sane general range.

The coal and linestone feeding systeins and the boiler auxiliaries require slightly more electric power than the conventional pulverized coal-fired boiler so that the net electric power output is somewhat less. The lower power creait in turn increases the net operating cost. Thernal efficiencies were found to be similar to that of conventional pulverized coal-fired boilers.

Until sufficient experience has been accumulated on large-scale installations, application of the AFB boiler to cogeneration plants should not be contemplated. is major problem requiring further study and resolution involves the method of feeaing coal and limestone to the boiler. Experience to date with systems that utilize numerous injection points for the coal and limestone mixture indicates the need for further work.

Present ongoing development anticipates commercial operation of large-scale utility plants before the end of the century. Since the fluidized-bed combustion of coal in a bed of limestone offers the potential for utilizing our vast low-grade coal resources in an environmentally acceptable manner, developnent of fluidized-bed combustion should be continued and encouraged.

\subsubsection{COAL GASIFICATION}

Only advanced concepts that generate the required process steam and a limited anount of electric power should be considered when comparing coal gasification plants on an equivalent basis. Utilization of the waste heat to generate required steam results in a plant which produces an abundance of electric power. This creates nore or less a special case beyond the linits of the basic concept of the cogeneration plants studied. The following conclusions are therefore derived from considering plants with the same general capacities as the eastern pulverized coal-fired coyeneration plant.

It should first be noted that in all cases, the use of coal gasification requires considerably more fuel input than the basic coal-fired boiler plant. Table 7-1 lists the three comparable coal gasification concepts and compares fuel input with the basic coal-fired plant. The atmospheric fluidizeulbed boller plant, which is considered as an advanced technology, is also included in the table. 


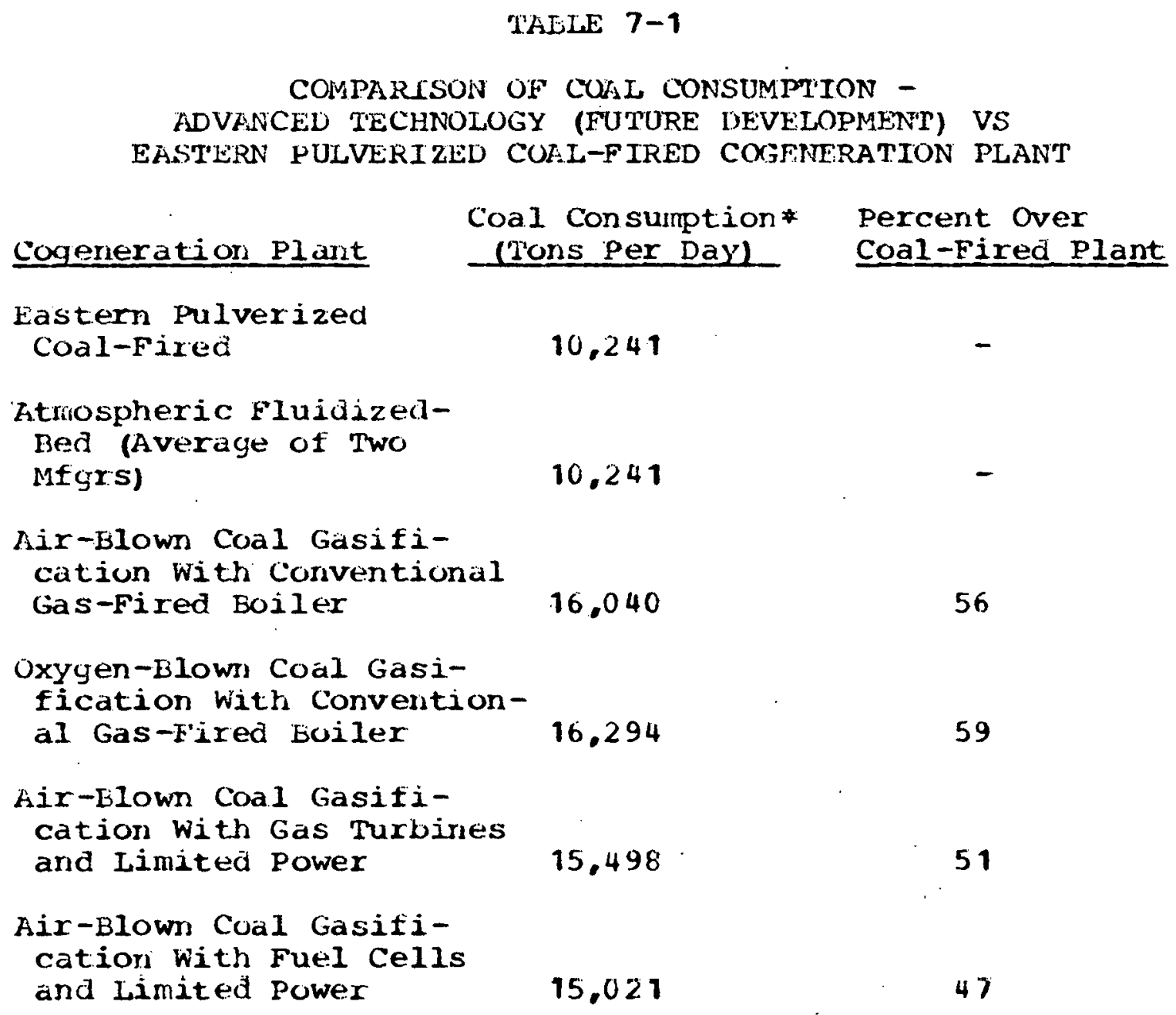

* Based on $12,235 \mathrm{Bt} u / 1 \mathrm{~b}$. 
As shown by econailic comparison of the gasification alternatives, the lowest estimated cost for process steam results from a cogeneration plant utilizing coal gasification and employing an advanced type of fuel cell. Lat the present tine, forecasted development of fuel cells indicates that cournercial application will not be feasible for at least 25 to 30 years. Fuel cells suitable for direct use of gasified coal axe presently in the development stage. and associated cost estimates should be viewed with that in nind.

The largest tuel cell considered available in the near future is rated at 26 MWe. is this rating 10 to 12 cells would le required tor a plant producing limited prower. A plant providing urlimited power would require over 100 cells of this size. Another factor to consider when developing the overall plant arrangenent is that fuel cells have not yet been operated on gas derived from coal. It has been assumed that this operation will be possible after further development.

While the coal gasifiers selected for this study represent commercial or near-comaicial technology, development work presentily in progress should result in improved processes withir the next 5 to 10 years. The main disadvantage of coal gasification is the loss of heating value in converting coal to a clean gas. For the generation of electricity. conversion of coal to a clean yas is attractive because gas turbine combined cycles appear to be more efficient than the conventional condensing steam turbine cycle.

The use of a coal gasitication system in conjunction with a gas turbine cycle is not suitable for cogeneration if the basic criteria require that most of the export energy be in the form of steam. Limitation of power while generating the necessary process stean reguires the addition of convertional coal gas-tired boilers firing fuel gas derived from coal. In either case, with limited or unlimited power output, the cost of process steam is considerably higher than a conventional coal-fired plant.

At present, the use of clean coal gas from a yasification plant in a conventional gas-fired boiler is not yet competitive with pulverized coal firing and limestone flue gas scrubbing.

Iny type of coal gasification, whether it be in conjunction with gas-fired boilers, gas turbines, or fuel cells, adds a considerable amount of operdting equipment to a cogeneration plant causing increased operating and maintenance costs and reduced overall plant reliability. 
In sumuary, use of the coal gasification process with gas turbines or fuel cells produces wost of the product energy as electric power and is not suitable for cogeneration plants with process steall as the principal commodity. operating costs for all yasification alternatives were found to be higher than the current coal technologies investiyated. Fuel cells cannot be considered for any near-term, large cogeneration apolication because considerable development effort is required to use coal-äerived yas.

\subsection{PLANT SIZE ANU STEAM CONOITIONS}

A review of the economic comparisons for Geismar and orange indicates that plant size does not impact the end results. The same relationshils exist arlong each of the coyeneration plants studied for the two locations with process steam flows of $5,840,000 \mathrm{ll} / \mathrm{hr}$ and $2,195,000 \mathrm{lb} / \mathrm{hr}$. respectively. Comparison of the net operating costs per thousand pounds of process steam results in the same economic choices for each site. Ir:e differences at the sites are very slight when expressed as percentages.

Opurating cost per thousand pounds of process steam, before credit for electric power, is generally lower at Geismar. the larger of the two plants. However, the net operating costs on the same basis are slightly higher because of the credit for the electric power generated by the steam. Steam at orange is expanded through the turbines from $2,415 \mathrm{psia}$ to 290 and 640 psia and at Geismar from 2.415 psia to 290 . 690. and 970 peia. Because the steam expansion is greater at Oxange, more work is done and therefore more electric power is generated. The increased power credit decreases the unit cost per thousind pounds of process steam.

\subsection{PLANT RELIABIIIIY}

A review of the reliability data for pulverized coal-fired plants indicates that the availability factor airectly aftects the operating costs and the justification for spare or backup units. At Geismar, a spare boiler is clearly warranted, while at orange a spare boiler is only marginally justified.

A thorough economic analysis should be made to determine the number and size of boilers that would provide the optium reliability prior to cogeneration plant design. The use of multiple boilers improves availability but increases capital costs making reliability evaluations a delicate balance. sensitive to prevailing economic factors.

At Geismar, where there are three HTGR units each operating at about 70 percent capacity, a spare umit appears to be 
marginally justified. The increase in availability does not increase the fuel savings sufficiently to oftset the increase in anrual fixed charges related to the higher capital costs for installation of a spare unit. At orange. with the lower stean demand and the same capital costs, a spare HTGR steani generator could not be justified.

Although not a canciidate plant, a spare steam generator for the CNSS plant can be justifiex at Geismar because of the increase in fuel savings. I spare CNSs unit at orange does not yield the required return on investrient and therefore cannot be justified.

\subsection{CONUENSING CAPABTIIITES}

Providing steam turbine condensing equipment to generate additional electric power by utilizing excess steam capacity is justified by the revenue derived from the additional power if the increase in plant capital cost does not exceed the values shown in Table 6-13. This is true for the HrGR and CNSS coyeneration plants, both of which have excess capacity. at orange and Geismar. Similarly, a third half-size boiler with steam turbine condensing equipment may be economically justified for the fossil-fired plants. provided the increased electric power output can be used or sold.

In both the nuclear and fossil fuel cases, the addition of steam turbine condensing capability provides additional electric power output. The addition of steam generation for use in condensing facilities in a fossil fuel cogeneration plant offers further benefits by creating a backup steain source and contributing toward improved plant reliability. Availability of stean for process is, however, contingent upon the electrical load being interruptible.

A detailed study of condensing using the excess steam generating capacity in the CNSS plants confirmed that the added capital and operating custs are more than justified by the credit received for the resulting increase in power generation. Applying this net gain to costs, however, does not reduce the steam costs sufficiently to compete with the coal-fired plants. It does make it more attractive when comparing costs witli an oil-fired cogeneration plant or continued operations of the present facilities.

At Orange, use of the condensing concept reduces steam cost from $\$ 9.86$ to $\$ 7.10$ per thousand pounds, or 28 percent. Use of condensing in the CNSS plant at Geismar would reduce costs only 12 percent, from $\$ 10.00$ to $\$ 8.80$.

Generally speaking, utilization of condensing equipment is appropriate for a cogeneration plant owned and operated by 
parties having a need or market for electric power. Industrial users are usually interested in generation of process stearn. Installation of condensing equipunent shoula be evaluated for a particular plant site, taking into account the specific steam and power requirements arid ownership.

\subsection{SEOUENIIA CONSTKUCTION OF THE HIGH TEMPERATURE GAS- COULED REICTOR AND CONSULIDATED NUCLEAR STEAM SYSTEM}

Extending the construction period of the nuclear plants at Geismar by installing the reactors at 5 -year intervals was studied, and it was concluded that the accumulated operating cost over the life of the plant is higher than with simultaneous installation. Higher operating costs result for cvery year by installing one HrGR at a tine. Installing two HTGKs initially yields lower costs for the first 5 years but after the third unit is added, the costs reverse. Using present worth, the lotal is higher than simultaneous installation of three units.

Another option studied considers installation of only two HTGRs initially and totally onitting the third. Compared to the base case, this alternate has lower annual operating costs until 1995. Aiter that time. the cost difference continually increases in favor of the three-unit plant, and, by the year 2009, the total present worth of the operating costs for both plants would be equal. Over the full life of the plant, the base case would still have the lower total present worth. The alternate also has the disadvantage of using fuel oil to make up the steam deficiency of the cogeneration plant.

The addition of condensing capabilities would not affect the conclusions for sexuential installations. It would make the Lase case an even better option since additional credit for power would occur at the initial startup. fiddition of condensing would improve the position of the three HTGRs when compared with unly two.

Installation of one CNSS unit at a time is of no advantage because annual savings in operating costs of a plant with two units initially exceeds the fixed charges incurred for the second cNSS. Irstallation of two CNSSs initially results in lower operating costs for each year over the life of the plant. 


\subsection{COMPRRISON WITH EXISTING PLANTS}

Tables $6-4$ and $0-5$ include steam costs for the existing plants based on estimated fuel, operating, and maintenance costs. These costs assune burning No. 2 fuel oil in existing boilers and generation of steari at current conditions. No scrubber costs or fixed charges are included, and credit for power is not applicable.

Even without scruber operating costs ard the fixed charges for existing equipment or nodifications for conversion to allow tor oil firing, the net cost of process steanl is yenerally higher for the existing plants than for the cogeneration plants with a 10 percent rate of return. The following comparisons of the cost per thousand pounds of process steam inäicate that coyeneration plants can provide steam at a cost much lower than the existing plants using No. 2 oil:

Comparison of the Cost of Steam $(\$ / 1000$ 1b)

\begin{tabular}{|c|c|c|c|}
\hline \multicolumn{2}{|c|}{ ORANGE } & \multicolumn{2}{|c|}{ GEISNAR } \\
\hline $\begin{array}{l}\text { Existing } \\
\text { Plants }\end{array}$ & $\begin{array}{l}\text { Cogenera- } \\
\text { tion plant }\end{array}$ & $\begin{array}{l}\text { Existing } \\
\text { plants }\end{array}$ & $\begin{array}{l}\text { Cogenera- } \\
\text { tion Plant }\end{array}$ \\
\hline
\end{tabular}

$\begin{array}{lcccc}\text { Lastern Coal } & \$ 13.90 & \$ 6.19 & \$ 11.83 & \$ 6.39 \\ \text { Western Coal } & \$ 13.90 & \$ 6.69 & \$ 11.83 & \$ 6.88 \\ \begin{array}{l}\text { No. } 6 \text { Fuel oil } \\ \text { HIGR }\end{array} & \$ 12.99 & \$ 10.76 & \$ 11.06 & \$ 11.17 \\ \text { H158 } & \$ 3.45 & \$ 13.60 & \$ 4.25 \\ \begin{array}{l}\text { CNSS without } \\ \text { Condensing }\end{array} & \$ 15.98 & \$ 9.86 & \$ 13.60 & \$ 10.00 \\ \begin{array}{l}\text { CNSS with } \\ \text { Conderising }\end{array} & \$ 15.98 & \$ 7.10 & \$ 13.60 & \$ 8.80\end{array}$

\subsection{SENSITIVITY}

The results shown in Tables $6-4$ and $6-5$ and other sections of this report involve specific economic assumptions. Sorne of these assumptions, such as load factor and escalation rates. have been forecast on the basis of historical data and/or best available information. Additionally, estimated costs are of the order of magnituäe type.

Figures 7-1 through 7-5 were developen to indicate the effect of certain variables on the net cost of steam. Figure 7-1 reflects users fuel costs when generating process steam at Geismar and orange facilities burning №. 2 fuel oil. 
Figure 7-2 shows how the cost of steam increases for the CNSS. HTGR, and eastern codl at orange and Geismar when the load factor is assumed lower than 90 percent (equivalent to 7.884 hours per year). For example, HTGR steam costs at orange increase fxon $\$ 3.45$ to $\$ 6.82$, or almost 100 percent, using a 60 percent load factor. Steam cost of an eastern coal-fired cogeneration plant at orange increases from $\$ 6.19$ to $\$ 8.29$, reflecting a 34 percent increase.

Figures $7-3$ and $7-4$ reflect the changes in cost caused by deviations from the base figures for capital, operating and maintenarice, and luel costs for Geismar and orange, respectively. These curves show the ef fect for the CNSS, HTGR, and eastern coal. It can be seen that changes ir fuel. operating, and maintenance costs of an HTGK at Geismar have little impact on steam costs. Capital costs of the HTGR must increase nore than 30 percent before net stearn costs equal those of eastern coal. Changes in cost of fuel have more effect than changes in capital cost in an eastern coal plant. Changes for each of the items can be noted from the graphs and the total effect on steam cost determined by summing the changes in cost.

Figure $7-5$ shows the effect on changes in the escalation rate of credited electric fower when determining net steam costs. At both Geismar and orange, the cost per kWh was escalated at a rate of 11 percent to 1985 and 7 percent from 1985 over the life of the plant, based on present economic assumptions. Again. figures represent the economically more attractive HTGR and eastem coal and the CNSS with and without condensing capabilities.

Avother variable that would have a substantial effect on stean cost is the rate of escalation assumed for fuel. As an example, the following shows how steam costs would change for the eastern coal plant for escalation rates of 2 to 16 percent with the rate of return held at 10 percent. A rate of 6 percent was used in the base calculations for Tables $6-4$ and $6-5$. 
Effect of Fuel Escalation Rates on steam Costs For
Eastern Coal-Fired plarts

Escalation Rate

(\%)

\begin{tabular}{cc} 
Steam Cost $-\$ / 1000$ & 10 \\
\hline Geismax & Orange \\
\hline 4.51 & 4.31 \\
5.32 & 5.12 \\
6.39 & 6.19 \\
7.87 & 7.68 \\
9.91 & 9.72 \\
12.79 & 12.60 \\
16.87 & 16.68 \\
22.69 & 22.51
\end{tabular}

although there is an interrelationship between coal prices and power costs, the above analysis holds power cost at a constant price. In reality, the cost of rower would have to be similarly escalated to determine net steam costs.

It is apparent that the basic assumptions have a great impact on the results. is change in the escalation rate from 6 to 10 percent causes a 55 percent increase in the cost of steam. For a range of escalation rates from 2 to 16 percent, the fuel costs are 40 to 80 percent of the total operating costs before credit for power.

\subsection{ENERGY SAVINGS}

All of the fossil-fired cogeneration plants, categorized as current technology, provide a global saving in energy at both sites when compared to maintaining the present steam generating facilities and continuing to purchase all electric power. Similarly, the muclear plants also yield a reduction in total energy input. Energy savings result from higher operating efficiencies and the lower heat chargeable to cogenerated electric power.

Only the AFB provides an energy saving among the cogeneration plants considered as advanced technology. future development.

Table 7-2 shows the expected energy savings, or 1oss, expressed in Btu $x 10 \% /$ hour for each of the alternative plarts with limited electric power output.

At Orange, the fuel oil input for steam generation by the existing industrial facilities amounts to $25.000 \mathrm{gph}$ based on a heating value of 142,000 Etu/gallon. At Geismar, the required fuel oil input is $70,000 \mathrm{gph}$. This amount of oil would be replaced if either a coal-fired or HTGR plant were implemented. Because oil is used as the fuel for the superheaters and boilers required in the cNSS plants, oil 
TIBSLE 7-2

ENERGY SAVED BY COGENERATION - Btu $\times 10 \% /$ hour

Energy Input For Existing Operations

By Gisu to Input

Generate Cogen\begin{tabular}{llll} 
For Steam & Electric & Total & eration \\
Generation & Power* & Plant \\
\hline
\end{tabular}

Energy Savings (Loss)

Cogeneration Plant

Percent

\section{Orange}

kastern and western Coal-Fired

3603.1

1587.5
1658.0

5190.6

3926.4

Ftu $\times 10^{\circ} / \mathrm{Mr}$

No. 6 Fuel oil-Fired

HTGR

CNSS

1758.4

5260.5

3926.4

1264.2

24.4

254.3

5361.5

3438.1

1334.7

25.4

Geismar.

Easterm and western Coal-Firea

$\begin{array}{rrrrrr}9963.3 & 3762.6 & 13.725 .8 & 10.441 .2 & 3284.6 & 23.9 \\ 9963.3 & 3949.5 & 13.912 .8 & 10.441 .2 & 3471.6 & 25.0 \\ 9963.3 & 4273.2 & 14.236 .5 & 9.163 .5 & 5073.0 & 35.6 \\ 9963.3 & 410.2 & 10.373 .5 & 3372.4 & 2001.1 & 19.3 \\ 9963.3 & 3678.2 & 13.641 .5 & 10.395 .3 & 3246.2 & 23.8 \\ 9963.3 & 3631.2 & 13.594 .5 & 10.460 .7 & 3133.8 & 23.0\end{array}$

No. 6 Fuel Oil-Fired

HTGK

CNSS

Foster-wheeler $\mathrm{AF}$

rabcock \& Wilcox AFE

coal Gasification with

Conventional Boiler ( $(4$ is-blown)

9963.3

5071.2

15.034 .5

16.354 .1

$(8.8)$

Conventional Boiler (Oxygen-Blown)

9963.3

5092.6

$15,055.9$

$16,613.1$

$(10.3)$

Conbined cycle (Limited Electric)

9963.3

3760.4

$13,723.7$

15.801 .3

(15.1)

Fuel cell (Limited Electric)

9963.3

3760.4

13.723 .7

$15,315.2$

(11.6)

* Energy input required to generate the same net output as cogeneration plant. Based on GSU average of 10,683 Btu/kw as reported in Electric Light and Fower, sugust 1978. 
savings would be reduced by $3,200 \mathrm{gph}$ at orange and 9.800 gph at Geismar.

If it is assumea that the cugenerated electrical power from coal replaces the output from an oil-fired utility power station, then an auditional savings of fuel oil would result. At Orange this would anount to about 11,000 gph: while at Geismar it would be around $26,000 \mathrm{gph}$.

7.13. DISCOUNTED CASH FLOW ANALYSIS

All of the foregoing cormparisons and conclusions are based on levelized steam costs that were developed using a fixed charge rate of 15 or 16 percent. which provides for a 10 percent rate of return. This is basically the mininum revenue requirements methods common to utility-type economic evaluations. The analyses sumarized in Tables $6-4$ and 6-5 also use a specific year for starting all construction. which means that the initial operating dates are different for the various options because of varying construction periods.

Because the owner of a cogeneration plant could be other than a utility, an expense center analysis has been made to determine stean costs with rates of return of 10,15 , and 20 percent. For simplicity, the start of construction for each option was timed so that initial operation begins in the same year. Also, a 30-year period of plant operation was used in all cases. For further evaluations, the effects of varying the fuel costs was determined. All net present worth values generated are in 1979 dollars.

From the resulting data presented in Figures 6-2 through 6-12 and tabulated in Tables 6-16 through 6-20. the reader can make evaluations based on his own selected rate of return and projected fuel costs. The effect of varying the escalation rate is illustrated in Figure 6-13. Some conclusions made apparent by the developed cost data are as follows :

1. The levelized steam costs developed by the minimum requirenents method, when adjusted for the same startup date anä operating life, are comparable to the results of the DCF analysis at a discount rate of 10 percent when allowances are made for applicable taxes. The conclusions in sections 7.3 and 7.4 apply.

2. At a discount rate of 15 percent, the comparison between the various cogeneration options remains the same as of 10 percent based on steam costs for fuel costs at 150 and 200 percent. For fuel costs at 90 and 100 percent, the HTGR loses most or all 
of its advantage over eastern coal. with this exception, the HTGR provides the lowest steam cost. After that, the order is eastern coal, western coal, the cNiss, and No. 6 fuel oil.

3. At a 20 percent discount rate, eastern coal and western coal steam costs are the lowest. The other plants change order with the various fuel costs.

4. The net present value of fuel, operation and rnaintenarce, and working capital costs for the existiny jlants using No. 2 fuel oil fall below eastern anà western coal-fired cogeneration plants at fuel costs of 90 ard 100 percent as the discount rate exceeás 20 percent. Inclusion of capital custs for new oll/gas fired boilers for expansion and replacenient would move the break-even discount rate to righer values. However, since industry historically requires hurdle or threshold rates of return as high as 25 to 30 percent, the arialysis presented here explains why there is little action in the field of industrially-owned coal-fireo cogeneration plants at this time.

5. There is a definite econonic advantage for an industrial user to purchase steam from an entity having a rate of return limited by regulation. 


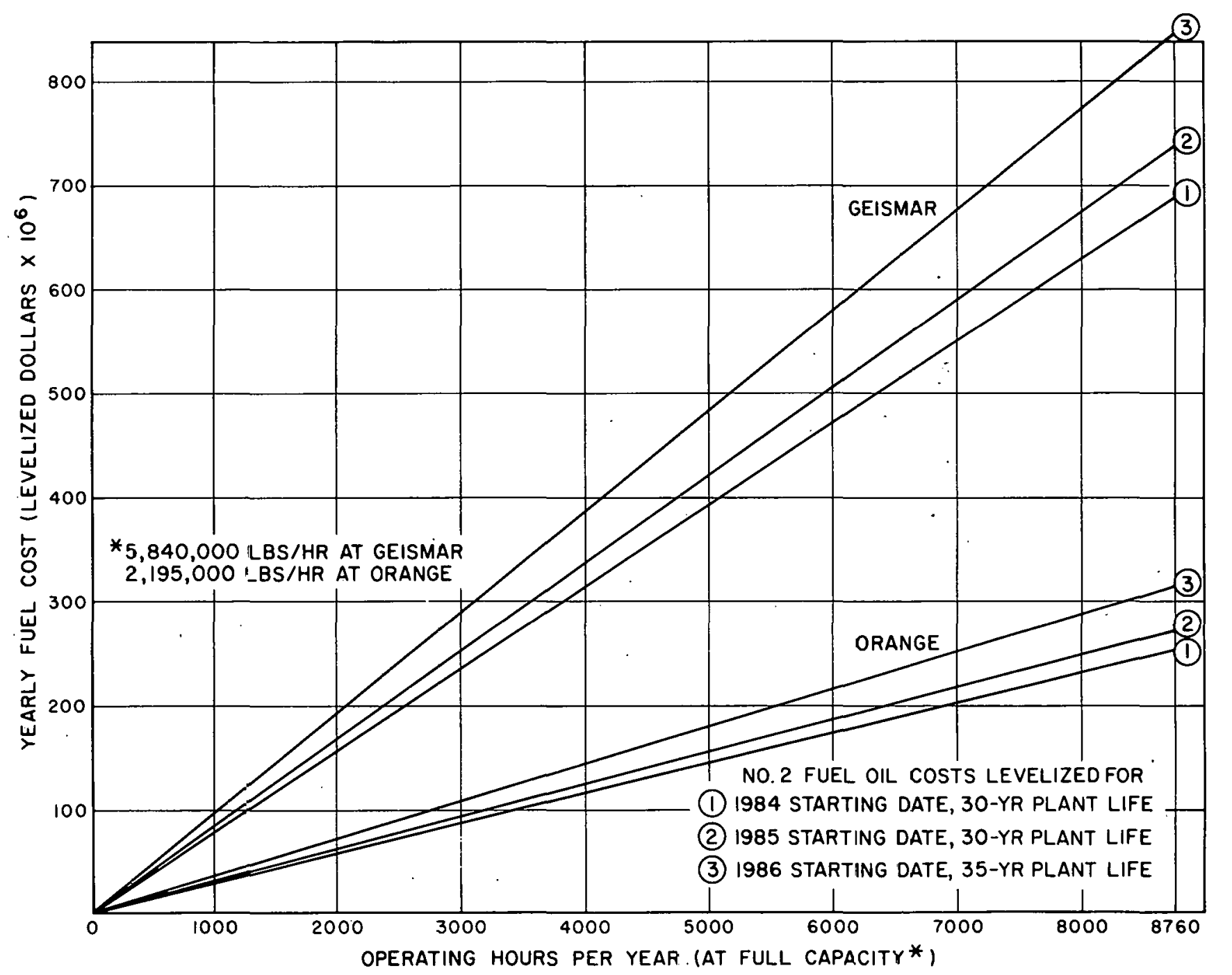

FIGURE 7-1. ANNUAL FUEL COST TO GENERATE STEAM IN USERS' PLANTS AT ORANGE AND GEISMAR SITES 


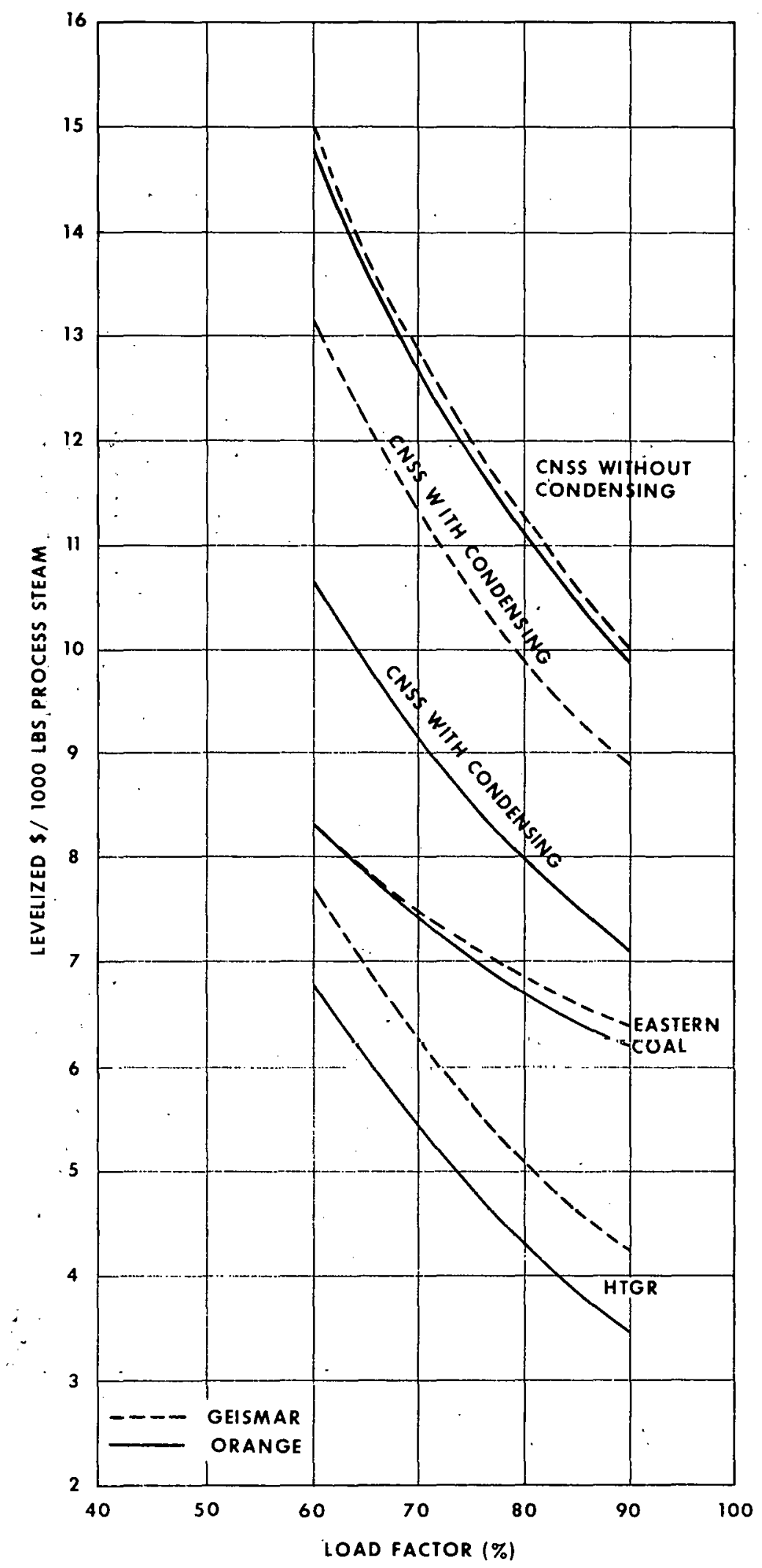

FIGURE 7-2. EFFECT OF CHANGES IN LOAD FACTORS AT ORANGE AND GEISMAR SITES 


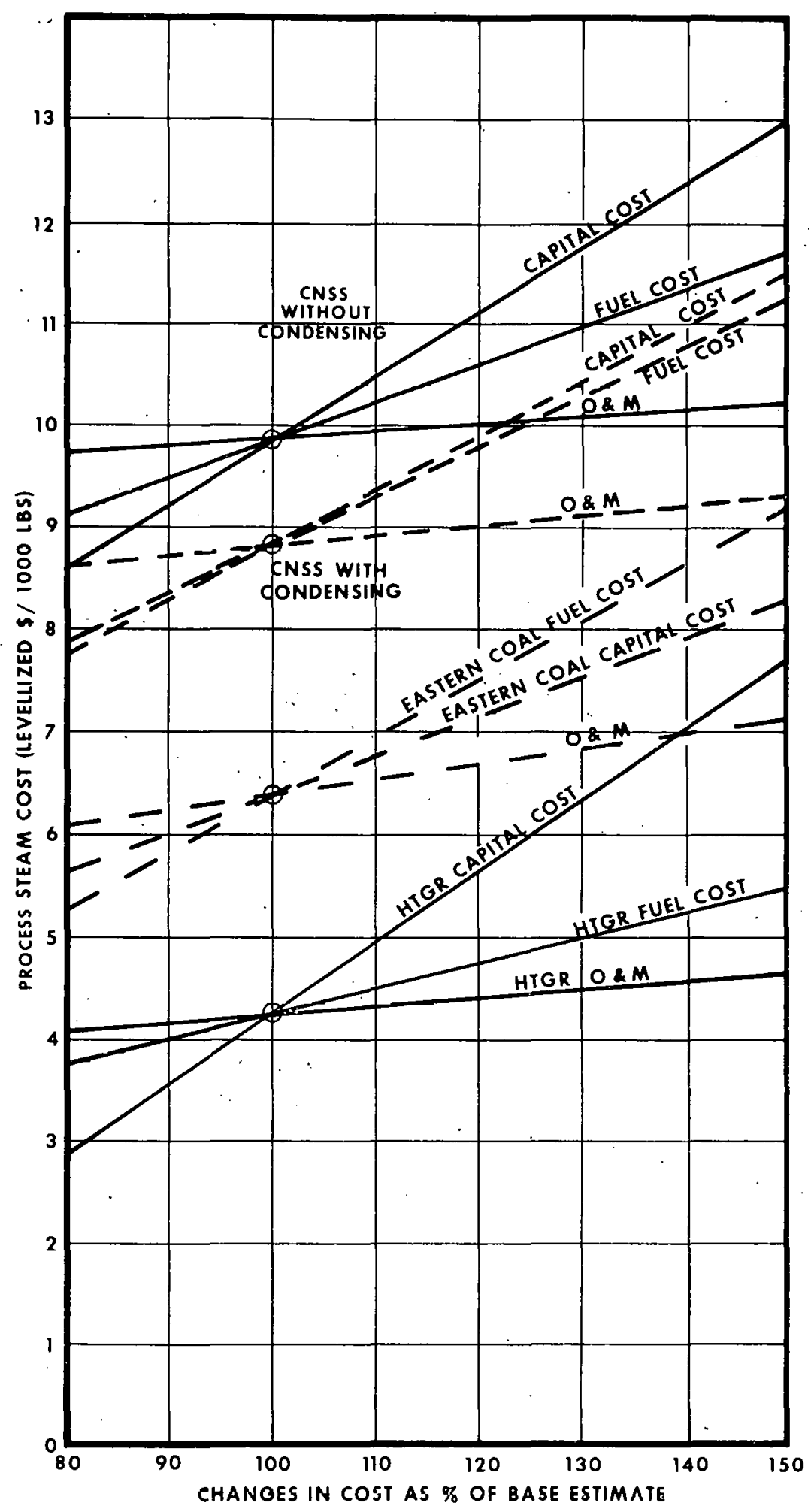

FIGURE 7-3: EFFECT OF CHANGES IN ESTIMATES FOR CAPITAL COSTS, FUEL COST AND O\&M FOR HTGR, CNSS AND EAS'IERN COAL AT GEISMAR 


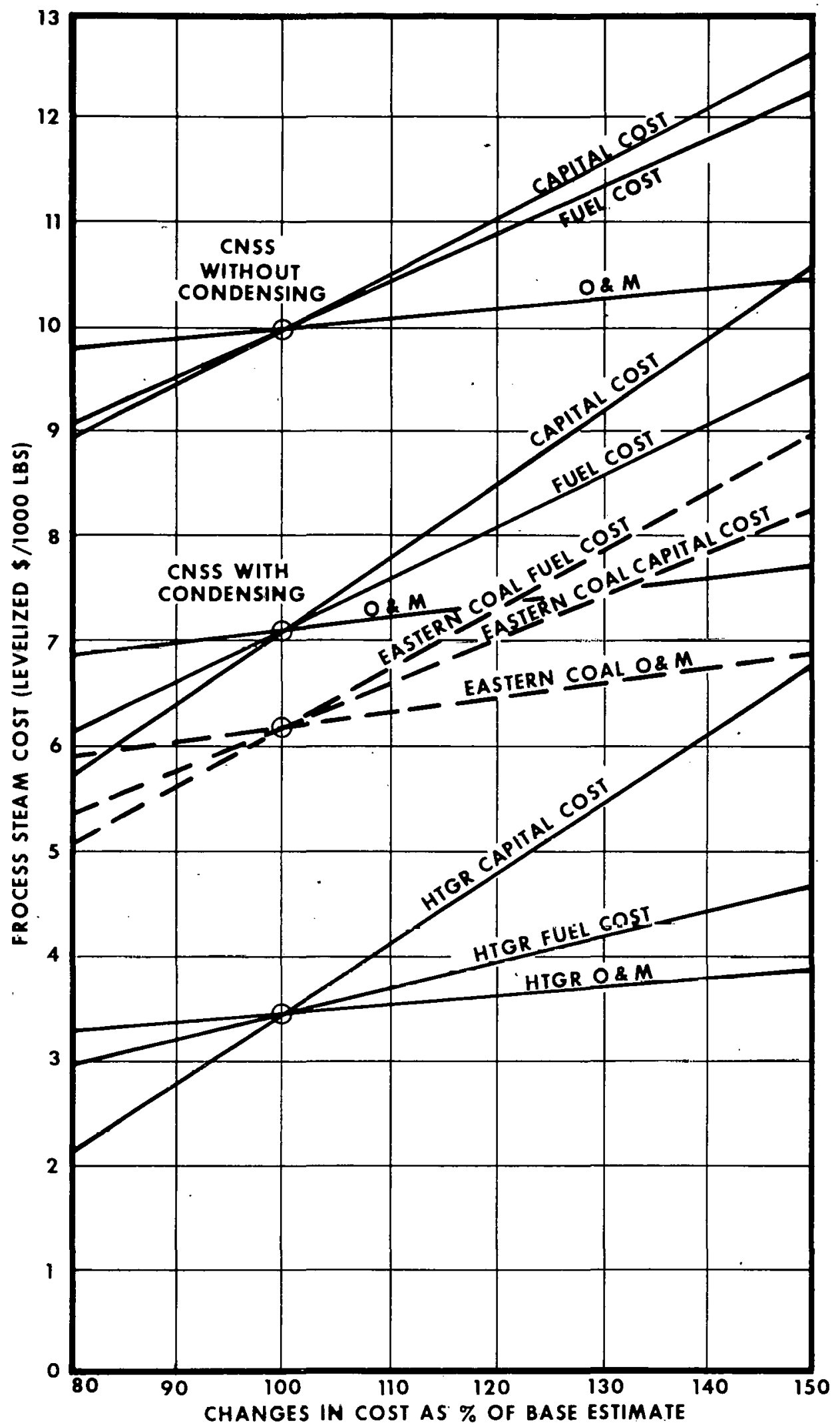

FIGURE 7-4. EFFECT OF CHANGES IN ESTIMATES FOR CAPITAL COSTS, FUEL COSTS AND O\&M FOR THE HTGR, CNSS AND EASTERN COAL AT ORANGE 


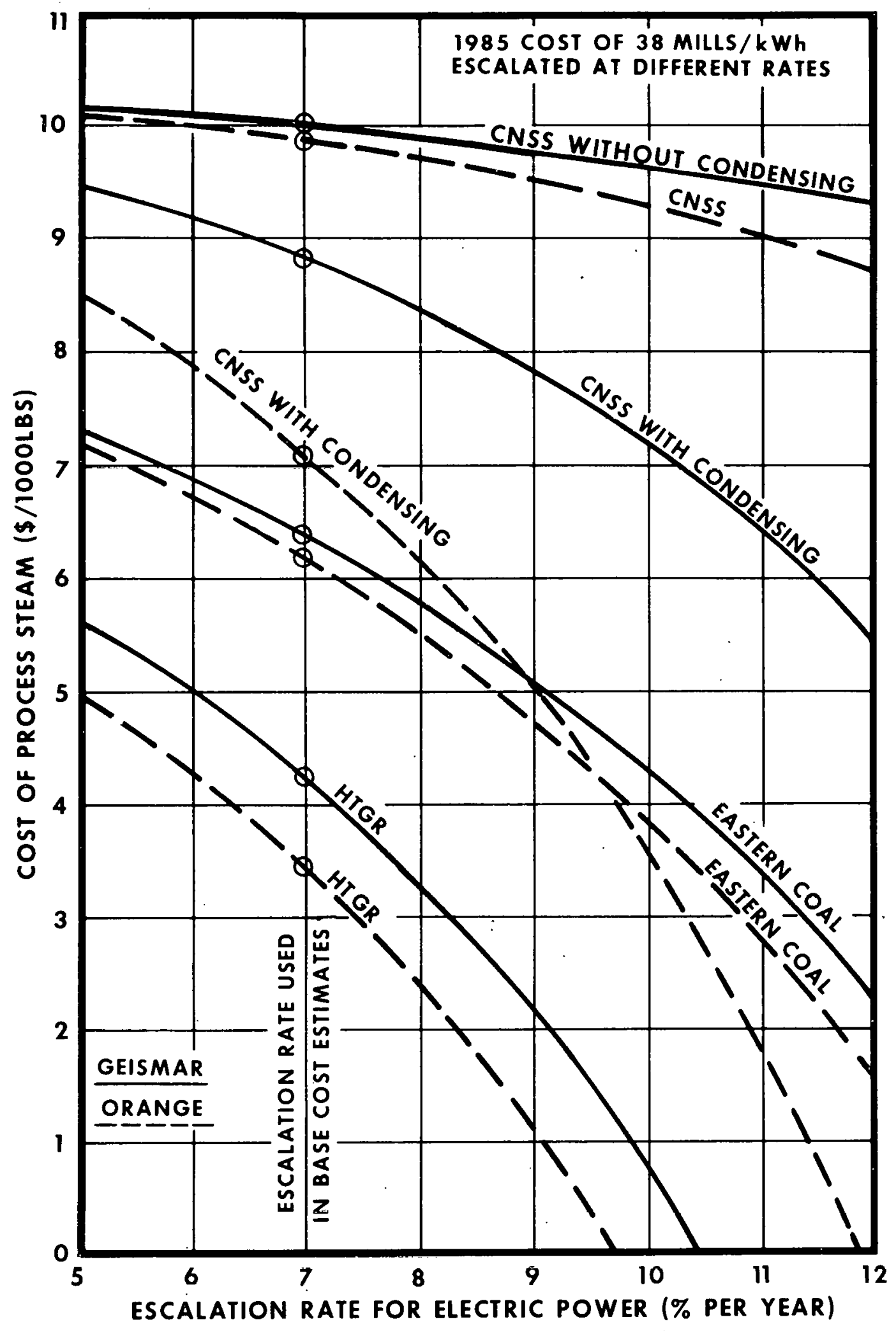

FIGURE 7-5. EFFECT OF CHANGES IN ESCALATION RATE FOR ELECTRIC POWER AT GEISMAR AND ORANGE 
SECTION 8

PLANT SCFEDULE AND IMPLENENTATION

TABLE OF CONTENTS

Page

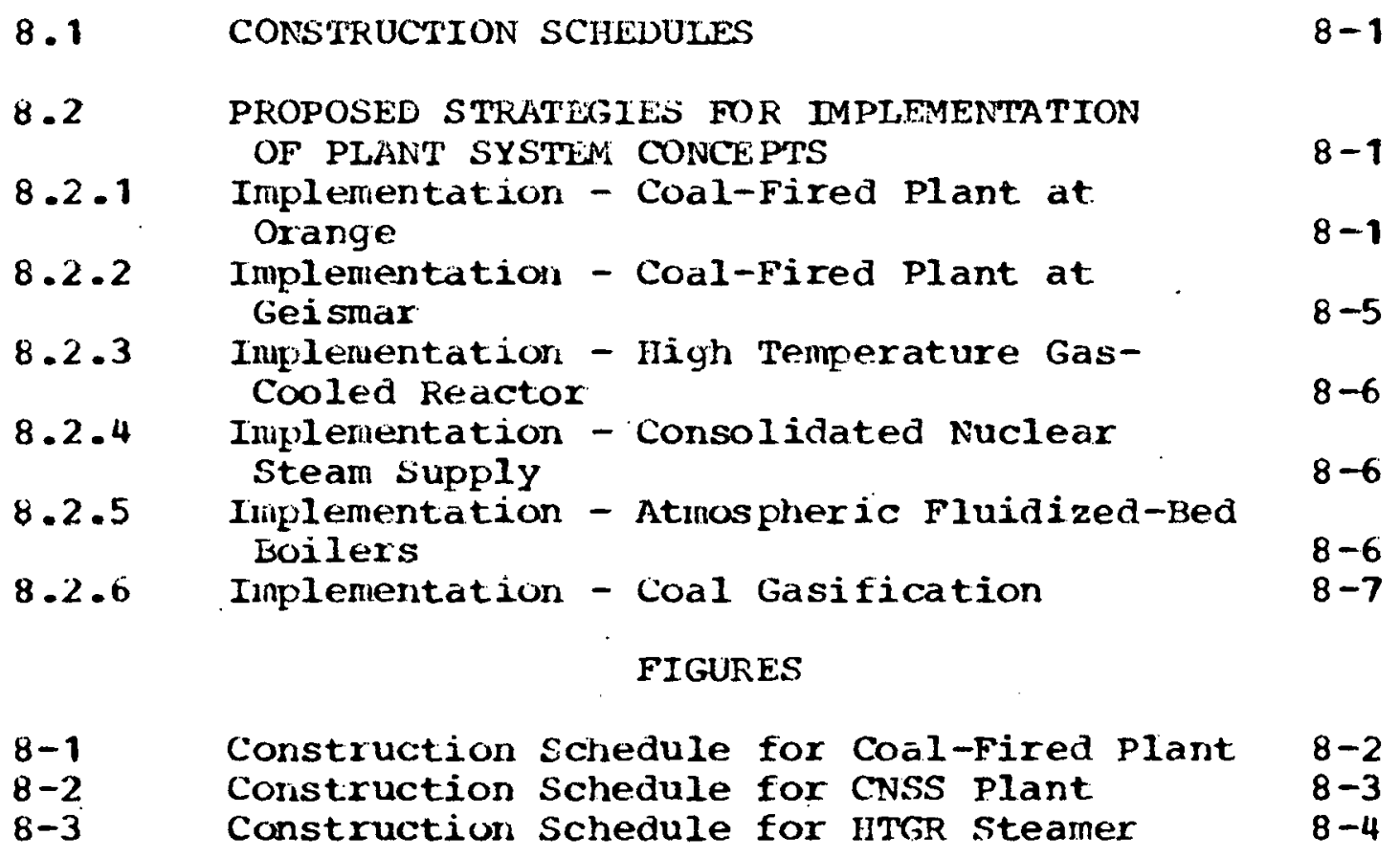




\section{PLÄNT SCHEDULE AND IMPLEMENTATION}

\subsection{CONSTKUCTION SCHEDULES}

This section contains the construction schedules for the cojeneration plants from the conceptual engineering phase to comnercial operation. The sciedules, which are divided into quarterly increments, show a total elapsed time of 6 years for the coal-fired plants and 7 years for the nuclear plants. Schedules reflecting both the orange and Geismar sites are as follows:

\begin{tabular}{|c|c|}
\hline Drawing No. & Cogeneration Plant \\
\hline $12977-\mathrm{PSN}-1$ & Coal-Fired \\
\hline 12977-PSN-2 & $\begin{array}{l}\text { Consolidated Nuclear steam supply } \\
\text { (CNSS) }\end{array}$ \\
\hline $12977-\mathrm{PSN}-3$ & $\begin{array}{l}\text { High Temperature Gas-Cooled Reactor } \\
\text { (HTGR) }\end{array}$ \\
\hline
\end{tabular}

These drawings are included in this section as Figures 8-1 to $8-3$.

The coal-fired plant schedule was developed from in-house data. Babcock \& Wilcox and General Atomic Company supplied the basic data from which the construction schedule was developed for the CNSS and HTGR, respectively.

\subsection{PROPOSEL STRATEGIES FOR IMPLEMENTATION OF PLANT SYSTEM CONCEPTS}

\subsubsection{IMPLEMENTATION - COAL-FIRED PLANT AT ORANGE}

Construction of the coal-fired plant is feasible without. technical constraints and could start immediately.

The projected steam flows indicate a minimum industrial expansion from 1985 to 1990. It was assumed that the users: present steam generating facilities contain adequate capacity to serve as backup after completion of a cogeneration plant. During the construction period of the plant. their facilities must be operated and maintained on the premise that the boilers are to be available for future intermittent use. Where necessary, the users boilers must be modified for firing No. 2 fuel oil, unless continued use of natural gas is permitted for standby service. These changes should be made after startup of the cogeneration plant. 


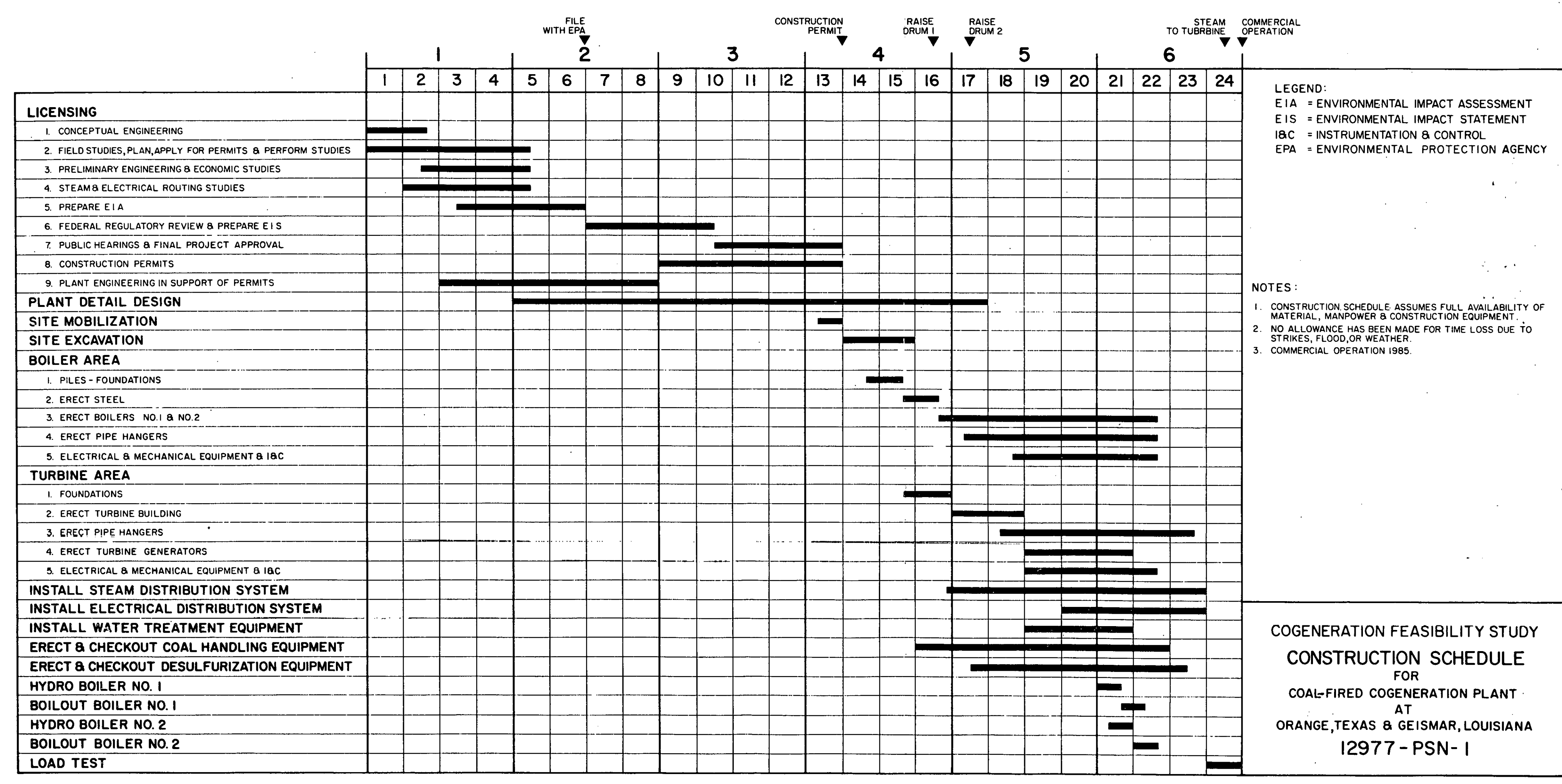

FIGURE 8-1

CONSTRUCTION SCHEDULE 


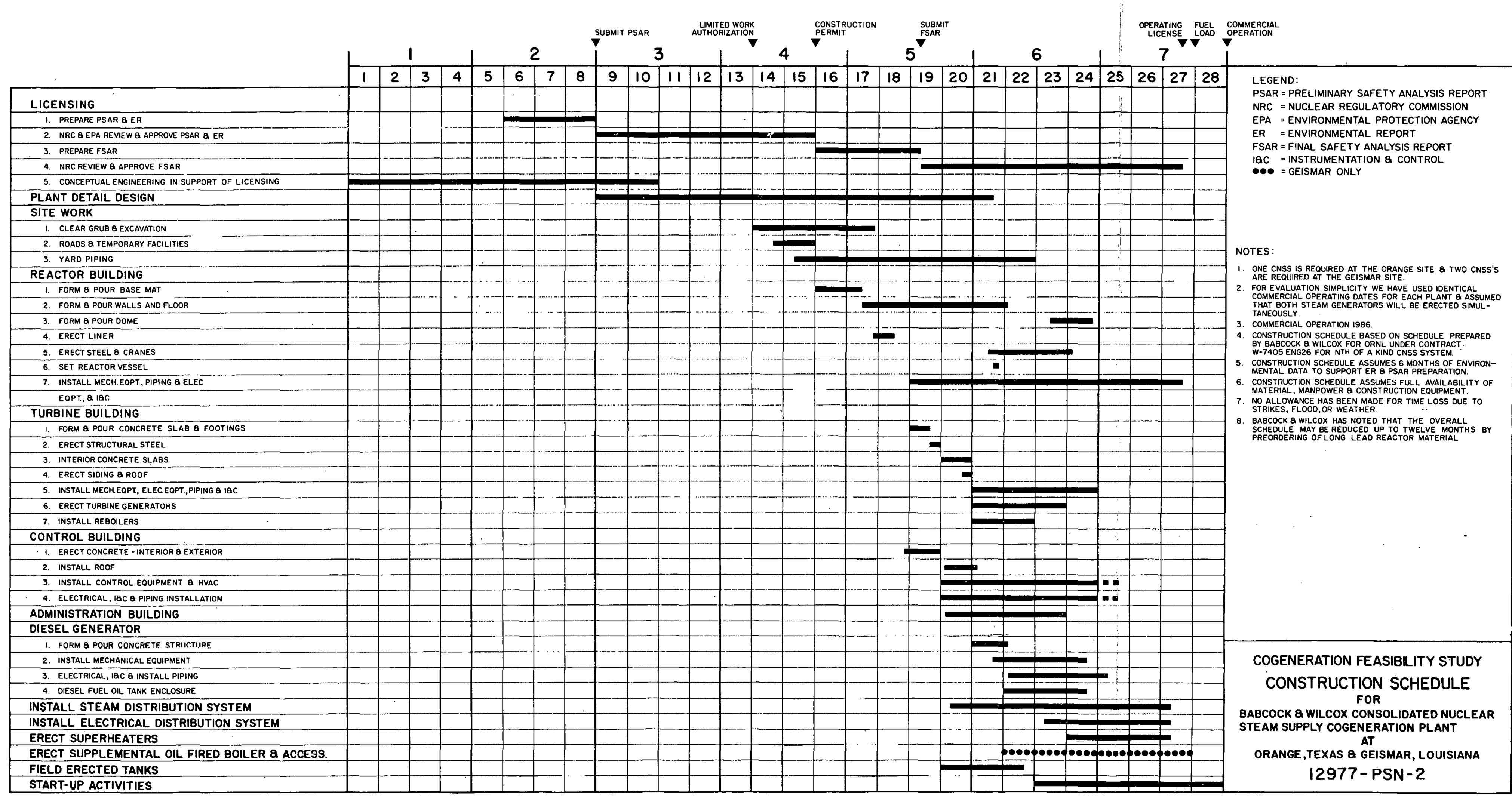

FIELD ERECTED TANKS
START-UP ACTIVITIES

FIGURE 8-2

CONSTRUCTION SCHEDULE FOR CNSS PLANT 


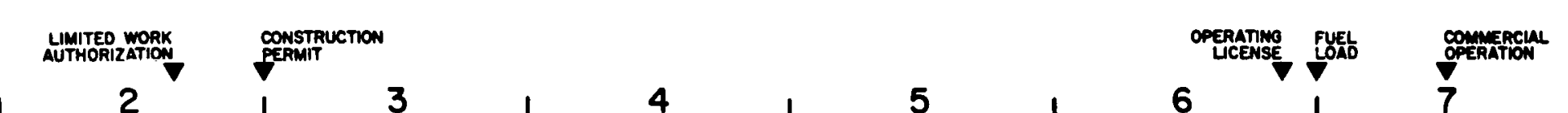

\begin{tabular}{|c|c|c|c|c|c|c|c|c|c|c|c|c|c|c|c|c|c|c|c|c|c|c|c|c|c|c|}
\hline & & 1 & & & & & & & 3 & & & & 4 & & & & 5 & & & & 6 & & & 7 & & \\
\hline & 1 & 2 & & 4 & 5 & \begin{tabular}{l|l}
6 & 1 \\
\end{tabular} & \begin{tabular}{l|l}
7 & 8 \\
\end{tabular} & \begin{tabular}{l|l}
8 & 9 \\
\end{tabular} & 10 & 11 & 12 & 13 & 14 & 15 & 16 & 17 & 18 & 19 & 20 & & & \begin{tabular}{|l|l}
324 \\
\end{tabular} & 25 & & 28 & LEGENO: \\
\hline LICENSING & & & & & & & & & & & & & & & & & & - & & & & & & & - & \\
\hline 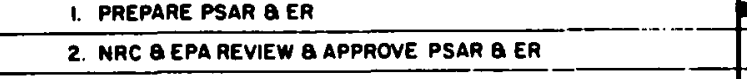 & & & & & & & & & & & & & & & & - & & 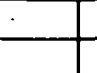 & & - & & & & & - & 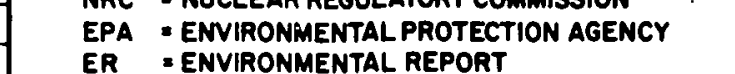 \\
\hline 3. PREPARE F FAR & & & & & & & & & & & & & & & & $=$ & & & & & & & & & & 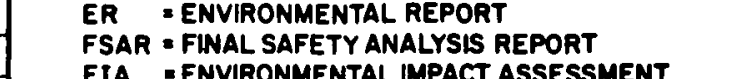 \\
\hline 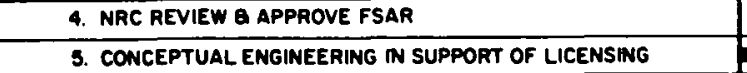 & & & & & & & & & & & & & & & & & & & & & & & & & & $\begin{array}{l}\text { EIA } \\
\text { EIS }\end{array}$ \\
\hline 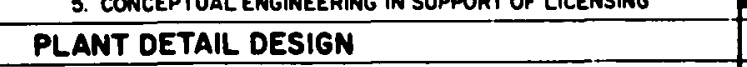 & & & & & & & & & $=$ & & & & & & & $=$ & & & & & & & & & - & 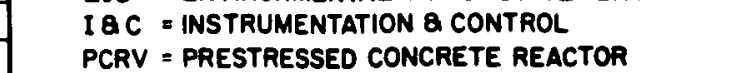 \\
\hline SITE WORK & & & & & & & & & & & & & & & & & & & & & & & & & & \\
\hline $\begin{array}{l}\text { 1. CLEAA GRUB a E } \\
\text { 2. ACCESS ROAOS } \\
\end{array}$ & & & & & & & & 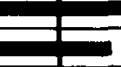 & & & & & & & & & & $\square$ & & & & & - & & - & \\
\hline 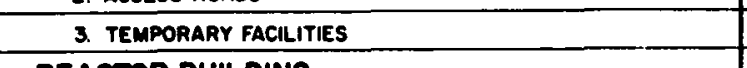 & & & & & & & & & & & & & & & & & & E & & & & & & & - & \\
\hline 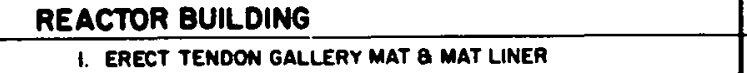 & & & & & & & & & & & $=$ & & & & & & & & & & & & & & 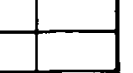 & \\
\hline 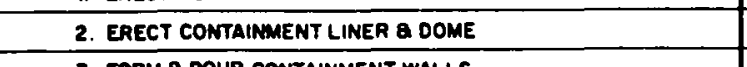 & & & & & & & & & & & & & & $E$ & E & - & & $E$ & & & & & & & E & \\
\hline 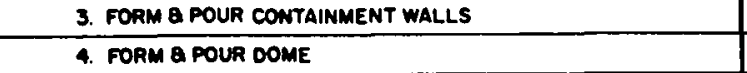 & & & & & & & & & & & & & & & & & & $\because$ & & E & & & & & - & 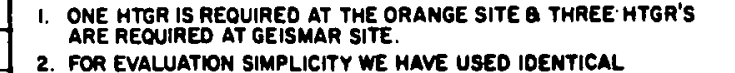 \\
\hline 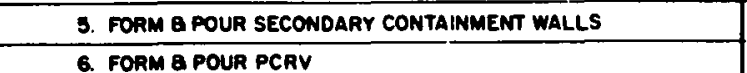 & & & & & & & & & & & & & & E & & $=$ & & & & & & & & & 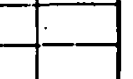 & 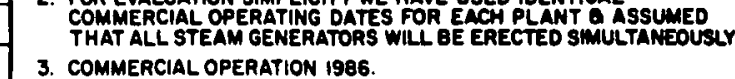 \\
\hline T. WRE WRAP PCRV Q IEENSION TENOONS & & & & & & & & & & & & & & & & & E & $\underline{E}$ & & & & & & & E & 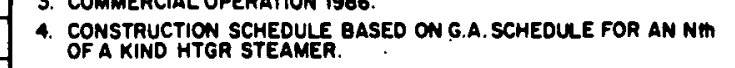 \\
\hline 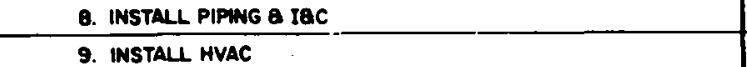 & & & & & & & & & & & & & & & & & & $=$ & & E & & & & & - & 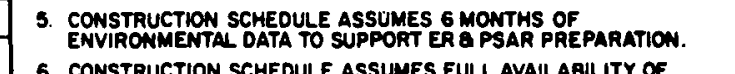 \\
\hline 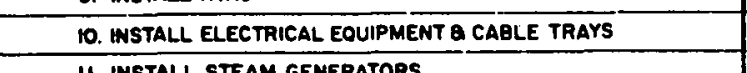 & & & & & & & & & & & & & & & & & & & & E & & & & & & 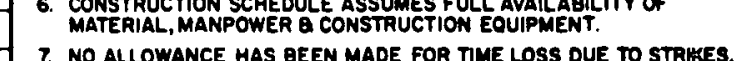 \\
\hline $\begin{array}{l}\text { 11. WSSTAL STEM } \\
\text { FUEL BUILDING }\end{array}$ & & - & & - & & & & & & & & & & & & & & $\boldsymbol{F}$ & & & & & & & & 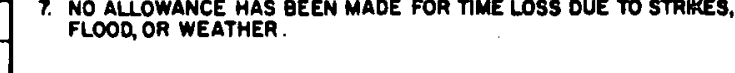 \\
\hline . Fone & & & & & & & & & & & ב & & & & & & & & & & & & & & & \\
\hline 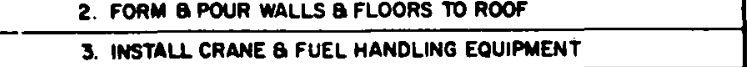 & & & & & & & & & & & & & & & & 1 & & & & & & & & & - & \\
\hline 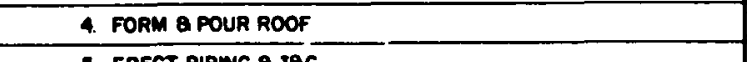 & & & & & & & & & & & & & & & & & & $=$ & & & & & & & & \\
\hline 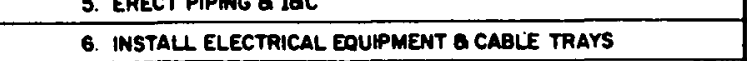 & & & & & & & & & & & - & 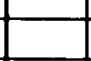 & - & $\bar{E}$ & 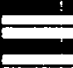 & $=$ & $\Longrightarrow$ & & & 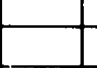 & & 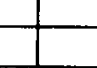 & - & - & 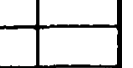 & \\
\hline CONTROL BUILDING & & & & & & & & & & & - & & & & & & & & & & & & & & E & \\
\hline 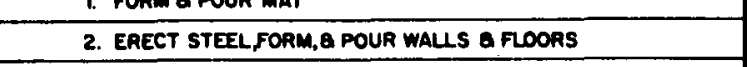 & & & & & & & & & & & & & & & $=$ & & & $\square$ & & $L_{-}$ & & - & - & E & + & \\
\hline 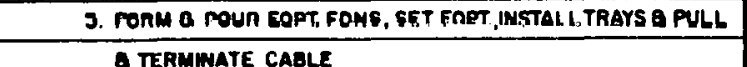 & & & & & & & & & & & & & & & & & & & & $=$ & & & & & & \\
\hline $4 \mathrm{me}$ & & & & & & & & & & & & & & & & & & $\underline{E}$ & & & & & & & & \\
\hline TUREAINE BUILDING & & & & & & & & & & & & & - & - & & & & ב & & 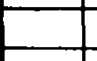 & & - & - & - & E & . \\
\hline 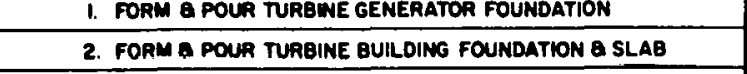 & & & & & & & & & & & & & & & & & & & & & & & & & & \\
\hline 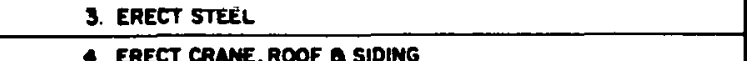 & & & & & & & & & & & & & & & & & & & & & & - & - & - & -1 & FIGURE 8-3 \\
\hline 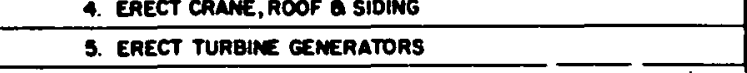 & & & & & & & & & & & & & & & & & & $E$ & & $\underline{E}$ & & -5 & - & & + & NN SCHEDULE \\
\hline 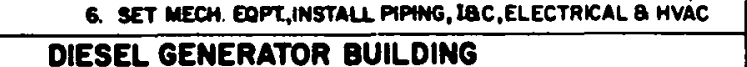 & & & & & & & & & & & & & & & & & & & & & & & & & & FOR HTGR STEAMER \\
\hline 1. rom & & & & & & & & & & & & & & & & & & & & & & & & & & \\
\hline 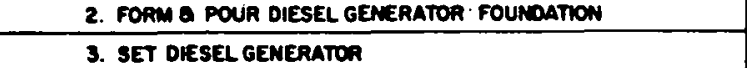 & & & & & & & & & & & & & & & & & & & & & & & & & - & \\
\hline 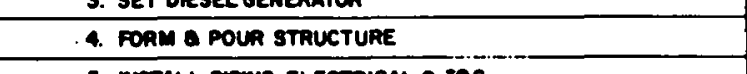 & & & & & & & & & & & 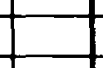 & & & & 드 & $=$ & 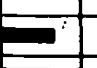 & & & & & $t$ & - & $1--$ & $\square$ & COGENEPATION EF \\
\hline $\begin{array}{l}\text { Dat } \\
\text { IUM FACLLITIES }\end{array}$ & & & & & & & & & & & - & & & & & & E & & & - & & & - & I. & -1 & CONSTRUCTION SCHEDULE \\
\hline $\begin{array}{l}\text { SYTSEM } \\
\text { STION SYSTEM }\end{array}$ & & & & & & & & & & & & & & & & & & & & & & & & & & GENERAL ATOMICHT \\
\hline 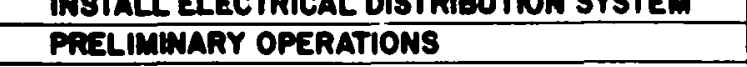 & & & & & & & & & & & & & & & & & & & & & & & & & -5 & COGENERATO \\
\hline 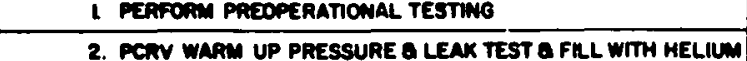 & & & & & & & & & & & & & & & & & & & & & & & 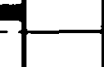 & & - & ORANGE, TEXAS \& G̈EISMAR, LOUISIANA \\
\hline 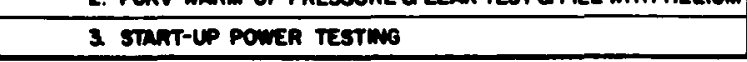 & & & & & & & & 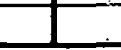 & & & & & & & & 1 & & & & & & & $=$ & & 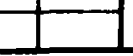 & 12977 - PSN-3 \\
\hline
\end{tabular}


The reliability analysis shows that a spare 50-percent capacity boiler can only be marginally justified. However. it is recommended that a review be made during the initial design phase to consider three or more boilers to provide the capacity required. Multiple, small boilers improve the overall reliability and permit smaller increments of expansions in the future either to meet additional steam requirements or to provide spare capacity.

The inclusion of condensing capabilities and related adaitional steam generating equipment is only applicable if cogeneration plant ownership or legal agreements allow utilization of the excess electric power.

\subsubsection{IMPLEMENTATION - COAL-FIRED PLANT AT GEISMAR}

Current technology perinits design and construction of a coal-fired cogeneration plant to begin immediately with steam generation available in 6 years after start of construction.

The process steam capacity of the cogeneration plant at this location was established to equal the projected 1985 stean deruand. This means that when construction is completed, the plant will operate at full capacity with no excess for standby or expansion. Steam consumption between 1985. and 1990 is projected to increase 18.5 percent.

During the cogeneration plant construction period, the projected stean requirements indicate that certain users must add to their facilities to meet increasing demands. The users would therefore have 100-percent backup available when the cogeneration plant yoes into operation.

On the basis of the reliability study it was detemined that a spare 50 -percent capacity boiler could be justified. It is therefore recommencied that an investigation be made during the initial design stage of the cogeneration plant to optimize the number and size of the boilers. For a further inuruvenent in reliability, more than three boilers should be considered. The eccromic analysis should consider potential expansions and spare capacity requirements.

Other areas that should be investigated during the initial design phase are:

Size of turbine generators, considering peak loads, mininum flows, and anticipated expansion.

Condensing capabilities, if additional electric power can be utilized.

- Feedwater heating equiprnent size, number of heaters, need for spares and reliability. 


\subsubsection{IMPLEMENTATION - HIGH TEMPRRATURE: GAS-COOLED RFACTOR}

Since the HTGF coyeneration plant can provide process steam at the required pressures and temperatures and tuel costs are low, it is economically very attractive. However, based on experience to date within the united States, the liTGR las not progressed technically to a point to be considered as a viable option for a cogeneration plant in an industrial complex. Although classified here as advanced technology under development, the HTGR should be considered more as future technology coinparable to the status of the atniospheric fluidized-bed concept.

An IITGR system, whether it be a steam cycle or a gas turbine or combined cycle, may not be technically acceptable for another 10 to 20 years. Development of the HTGR for utility use may ultimately produce a system that has applicability for cogeneration.

\subsubsection{IMPLEMENIATION - CONSOLIDATED NUCIEAR STEAM SUPPLY}

The specific steam requirements at orange and Geismar diluted the attractiveness of the CNSS for the cogeneration plants in this study. The need for oil-fired auxiliary equiproent increased capital and operating costs, and credit for electric power was minimal due to its imitation on stean pressure.

It should not be assumed from this that the CNSS is not suitable for other potential cugeneration applications. The operating conditions, which penalize it in this study, may be acceptable where superheated or higher pressure steam is not required. Cogeneration plants can be considered for providing heating steam tor hospltals, resilueves, and comnercial areas. Some industrial complexes may also have needs within the capabilities of the CNSS. The cNSS is further aơvanced than the HTGR in the United states and its use should be evaluated for application at specific sites.

\subsubsection{IMPLEMENTATION - ATMOSPHERIC FLUIDIZED-BED BOILERS}

Fluidized-bed combustion of coal in a bed of limestone offers the potential for utilizing our vast coal resources in an environmentally acceptable manner for cogeneration as well as electric utility power generation. The operating efficiencies are sinilar to that of pulverized coal-fired boilers: in addition, the AFB boiler has the capability of using low-ranked coals. 
As mentioned in section 4.4.3.1.6, several development programs are presently in progress. Considering the potential benefits of the AFI, it appears that present efforts are justified and they should be continued to develop large-scale installations in the near future.

\subsubsection{IMPLEMLNTATION - COAL GASIFICATION}

The coai gasification processes developed and discussed in this study are not suited to meet the specific requirements of the subject cogeneration plants. Therefore, further development of these processes cannot be justified by this stuộy.

There are ongoing studies to improve the coal gasification process and to develup both the combined cycle and fuel ce11. so that advancements in these areas may warrant future review and consideration. Specific steam and electric requirements have a great influence on the adaptibility of the combined cycle and tuel cell concepts which have the capability of producing large amounts of electric power. 


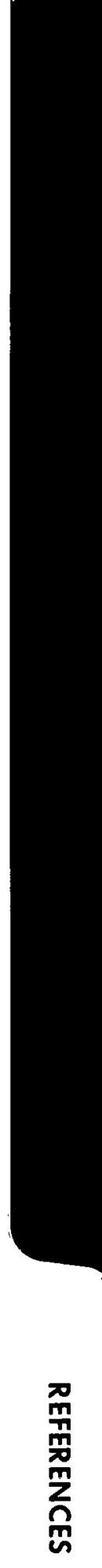




\section{SECTION 9}

\section{RLFERENCES}

1. U.S. Nuclear Regulatury Comuission. Preparation of Envirormental Reforts for Nuclear Power stations. Nuclear Regulatory Guide 4.2, Rev 2, Chapter 4, p 2-5. July 1976.

2. U.S. Nuclear Regulatory Commission. Ultimate Reat Sink for Nuclear power flants. Nuclear Regulatory Guide 1.27, Rev 2, January 1976.

3. Personal Conumication, U.S. Amy Corps of Engineers, New Orleans District, New Orleans, Louisiana, september 1977.

4. Federal Register. Seismic and Geologic Siting Criteria for Nuclear Power plants. Code of Federal Regulations, Title 10. Appendix A, part 100. Goverment Printing Office. Washington. D.C., 1977, p 409-419.

5. U.S. Nuclear Reyulatory Commission. Standard Format and content of Safety frnalysis Reports for Nuclear Power Plants. Nuclear Regulatory Guide 1.70, Rev 2. washingtun. D.C.. September 1975.

6. Gulf States Utilities. Preliminary Safety Analysis Report. River Beria Station Urits 1 and 2. June 1973.

7. Federal Reyister. Executive Order 11988 - Floodplain Management, Vol 42, Nu. 101, Part VI. Office of the Federal Register, Washington, D.C.. May 1977, p 26951.

8. U.S. Nuclear Regulatory Commission. Design Basis for Nuclear Power Plants. Nuclear Regulatory Guide 1.59. Rev 1, Washington, D.C.. April 1976.

9. Federal keglster, Executive Order 11990 - Protection of Wetlands, Vol 42, No. 101, Part VI, office of the Federal Reyister. Washington, D.C.. May 1977. p 26961.

10. 16 U.S. Congress. The Endangered Species Act of 1973. Public Law 93-205, 1531-43, 87 Stat. 884.

11. 16 U.S. Congress. The National Wildife Refuge system Administration of 1966. Public Law 93-205. Stat. 668 dd.

12. Federal Register. Air guality standards - Interpretive Ruling, Vol 41, No. 246, Title 40, Part 51, Chapter I, Subchapter C, December 1976, p 55524-55560. 
13. U.S. Nuclear keyulatory Conmission. General Site Suitability Criteria for Nuclear power Stations. Nuclear Regulatory Guide 4.7, Rev 1, Washington, D.C.. Novenber 1975.

14. Federal Register. Determination of Exclusion Area, Low Population Zune, and Population Center Distance. Code of Federal kegulations, Title 10, Part 100.11, Appendix A, Government Printing office, washington. D.C.. 1977, p 411.

15. Louisiana Powex and Light Company, New Orleans, Louisiana. Environmental Report. Waterford Steam Electric Station, Units 3 and 4, January 1971.

16. Barnard and surk, Incorporated, Baton Rouge, Louisiana. Elvironmental Statement for Sabine River Diversion Channel and Distribution system to Lake Charles Industrial lirea.

17. Personal Conmunication with Messrs. D. Brown and H. Sprinkle of Raynond International. Incorporated. Metairie, Louisiana, and Houston, Texas, respectively.

18. U.S. Nuclear Regulatory Commission. General Site Suitability Criteria for Nuclear power Stations. Nuclear Regulatory Guide 4.7, Rev 1, Washington, D.C.. Novenber 1975 .

19. Babcock E Wilcox, Lynchburg, V1rginia. 400 wiwe Consolidated Huclear steam System CNSS - 1200 MWT Conceptual Design, BAW-1445, ORNL/sub. 43904, June 1977.

20. Kessler, W. E. and Burroughs, J. R., The Midland Process Steamblectric Project. Proceedings of the first National Topical Meeting on Nuclear Process Heat Applications, Los Alamos Scientific Laboratory. octobex 1-3, 1974.

21. General Atornic Company, San Diego, California. Small HTGR Steamer for Index Trial process Applications, GA-A13888, April 1976.

22. Stone $\varepsilon$ Webster Engineering Corporation, Boston, Massachusetts. Conceptual Design for an Atmospheric Fluidized-Bed Direct Cormbustion Power Generating Plant. December 1977.

23. Electric Power Research Institute, Palo Alto, California. Economics of Current and Advanced Gasification Processes for Fuel Gas Production. EPRIAF-244, Project 239. July 1976. 
24. Stone \& Webster kngineering Corporation, New York, New York for lilectric Power Research Institute. Evaluation of High and Low Temperature Gas cleaning for Coal Gasifications - Combined Cycle power system. EPRIAF-416. April 1977.

25. Onited riechnologies Corporation, Power Systems Division, Farmington, Connecticut. ERDA 76-54, UC-93, National Benefits Associated with Commercial Application of Fuel Cell Power Plants. Prepared for the Energy. Research and Developrnent Aduinistration, February 1976.

26. Edison Electric Institute, New York, New York. Report on Equipment Availability for the Ten-Year Period - 1966-1975. No. 76-85. Decernber 1976. Publication NO. EEI-76-85.

27. Power Systems knyineering, Inc. Feasibility study Comparison of Coal-and Nuclear-fueled Alternatives for Process Steam and Byproduct Electrical power Generation for the E. I. dupont de Nenours $\&$ Company. Incorporated. Plant Site - Victoria, Texas. ORNL/Sub-7257/7. July 1978.

28. Power systems Engineering, Inc. Feasibility study Comparison of Coal-and Nuclear-fueled Alternatives for Process Stean and Byproduct Electrical Power Generation for the PPG Industries. Incorporated, Plant site - Lake Charles, Louisiana. ORNL/Sub-7257/8, JuIY 1978 . 


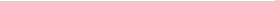


APPENDIX A

APPICATION OF SITING CONSIDERATIONS TO CANDIDATE SITES

TABLE OF CONTENTS

page

1

1.1

1.1.1

1.1 .2

1.1.3

1.1 .4

1.1 .5

1.1.6

1.1 .7

1.1 .8

1.2

1.2 .1

1.2 .2

1.2 .3

1.2 .4

1.2 .5

1.2 .6

1.2 .7

1.2 .8

1.2 .9

1.2 .10

1.2 .11

1.2 .12

1.2 .13

1.2 .14

1.3

1.3 .1

1.3 .2

1.3 .3

1.3 .4

1.3 .5

2

2.1

2.1 .1

2.1 .2

2.1 .3

2.1 .4

2.1 .5

2.1 .6

2.1 .7

2.1 .8

2.2

2.2 .1
NORTH BATON ROUGE - SITE $A / B$

Technical/Engineering Considerations

Site preparation

Proximity to Load Demand

water Availability

Highway, Rail, and Water Access

Foundations

Water Supply systems

Land Costs

Steam Supply/Denand Match

Physical and Environmental/Licensing

Considerations

Wastewater Impact

Cooling water Impact (Nuclear)

Land Use

Land Requirements

Geology

Hydrology

Seismology

Meteorology

Ecology and Croplands

Air quality (Fossil)

Radiological Considerations (Nuclear)

Denography (Iuclear)

Noise Irrpact

Proximity to Hazardous Facilities (Nuclear)

Socioeconomic Considerations

Transportation

Community Impact

Archaeoloyical and Historical Impact

Visual Iupdct

Transmission/Steam Line Impact

LAKE CHARLES - SITE A

Technical/Engineering Considerations

Site Preparation

Proximity to Load Demand

Water Availability

Highway, Rail, and Water Access

Foundations

Water Supply systerns

Land Costs

Steanı Supply/Nemand Match

Physical and Environmentąl/Licensing

Considerations

Wastewater Impact
K-1

$A-1$

$A-1$

A -2

$A-2$

$A-2$

A -3

$A-4$

A -4

A -4

A -4

A -4

A -4

A -5

A -5

A -5

$A-6$

A -6

$A-9$

A -9

A. -10

I -10

$A-11$

$A-11$

$A-11$

A. -11

$A-11$

$\mathrm{A}-12$

$A-12$

$A-12$

A -12

A -13

$A-13$

$A-13$

A -13

$A-13$

$A-13$

A -14

$A-14$

$A-14$

$A-15$

$A-15$

$A-15$ 


\begin{tabular}{|c|c|}
\hline $\begin{array}{l}2.2 .2 \\
2.2 .3 \\
2.2 .4 \\
2.2 .5 \\
2.2 .6 \\
2.2 .7 \\
2.2 .8 \\
2.2 .9 \\
2.2 .10 \\
2.2 .11 \\
2.2 .12 \\
2.2 .13 \\
2.2 .14 \\
2.3 \\
2.3 .1\end{array}$ & $\begin{array}{l}\text { Cooling Water Impact (Nuclear) } \\
\text { Land Use } \\
\text { Land Requirements } \\
\text { Geology } \\
\text { Hydrology } \\
\text { Seismology } \\
\text { Meteorology } \\
\text { Ecology and Croplands } \\
\text { Air Quality (Fossil) } \\
\text { Radiological Considerations (Nuclear) } \\
\text { Derugraphy (Nuclear) } \\
\text { Noise Impact } \\
\text { Proximity to Hazardous Facilities (Nuclear) } \\
\text { Socioeconomic Considerations } \\
\text { Transportation } \\
\text { Community Impact } \\
\text { Archaeological and Historical Impact } \\
\text { Visual Impact } \\
\text { Transmission/Steam Line Impact }\end{array}$ \\
\hline
\end{tabular}

\section{3 \\ 3.1 \\ 3.1. 1 \\ 3.1. 2 \\ 3. 1.3 \\ 3.1. 4 \\ 3.1 .5 \\ 3.1.6 \\ 3.1 .7 \\ 3.1 .8 \\ 3.2}

3.2 .1

3.2 .2

3.2 .3

3.2 .4

3.2 .5

3.2 .6

3.2 .7

3.2 .8

3.2 .9

3.2 .10

3.2 .11

3.2. 12

$3.2 \cdot 13$

3.2 .14

3.3

3.3. 1

3.3.2

3.3 .3

3.3 .4

3.3 .5

LAKE CHARLES - SITE B

$A-15$

$A-15$

$A-15$

$A-16$

$A-16$

$A-17$

$A-17$

$A-17$

A. -17

$A-17$

$A-17$

$A-18$

$A-18$

$A-18$

$A-18$

$A-18$

$A-18$

$A-19$

A -19

$A-20$

Technical/Engineering Considerations

$A-20$

Site Preparation

Proximity to Load Demand

$A-20$

$A-20$

Water Availability

Highway, Rail, ana Water Access A-20

Foundations

Water Supply systems

Land Costs

Steam Supply/Demand Match

Fhysical and Environmental M.irensing

Considerations

Wastewater Inqaat

Cooling Water Impact (Nuclear) A-21

Land Use

Land Requirements

A -20

$A-20$

$A-20$

$A-20$

$A-21$

$A-21$

$A-21$

Geology

Hydrology

$A-21$

$A-21$

$A-21$

Seisnology

$A-21$

Meteorology

Ecology and Croplands

$A-21$

$A-21$

Air Quality (Fossil) A-22

Radiological Considerations (Nuclear) A-22

Demography (Nuclear)

$A-22$

Noise Impact

$A-22$

Proximity to Hazardous Facilities (Nuclear) A-22

Socioeconomic Considerations

A -22

Transportation

$A-22$

Community Impact

Archaeological and Historical Impact

$A-22$

$A-23$

Visual Impact

$A-23$

Transmission/Steam Iine Impact

A -23 
Page

4 LAKE CHARLES - SITE C A-24

4.1 Technical/Engineering Considerations A-24

4.1.1 Site Preparation A-24

4.1.2 Proximity to Load Demand A-24

4.1.3 Water Availability A A-24

4.1.4 Highway, Rail, and Water Access A-24

4.1.5 Foundations A-24

4.1.6 Water Supply Systems A-24

4.1.7 Land Costs h-25

4.1.8 Steam Supply/Demand Match A-25

4.2 Physical and Environmental/Licensing

Considerations

4.2.1 Wastewater Impact

4.2 .2

4.2 .3

4.2 .4

4.2 .5

4.2 .6

4.2 .7

4.2 .8

4.2 .9

$4.2 \cdot 10$

4.2 .11

4.2 .12

4.2 .13

$4 \cdot 2 \cdot 14$

4.3

4.3 .1

4.3 .2

4.3 .3

$4 \cdot 3 \cdot 4$

4.3 .5

Cooling Water Impact (Nuclear)

Land Use

$A-25$

Land Requirements

$A-25$

$A-25$

A -25

Geology

$A-25$

Hydrology

$A-25$

Seismology

Meteorology

Ecology and Croplands

Air Quality (Fossil)

Radiological Considerations (Nuclear)

A -25

A -26

A -26

A -26

$A-26$

Demography (Nuclear)

A-26

Noise Impact

Proximity to Hazardous Facilities (Nuclear)

Socioeconomic Considerations

$A-26$

$A-26$

$A-26$

Transportation

$A-27$

Community Impact

Archaeological and Historical Impact.

A -27

$A-27$

Visual Impact

$A-27$

Transmission/Steam Iine Impact

$A-27$

$\mathrm{A}-27$

5

ORANGE COUNTY - SITE A

5.1

5.1 .1

5.1 .2

5.1 .3

5.1 .4

5.1 .5

5.1 .6

5.1 .7

5.1 .8

5.2

Technical/Engineering Considerations

$A-28$

$A-28$

Site Preparation

Proximity to Load Demand

$A-28$

Water Availability

Foundations

$A-28$

$A-28$

$A-29$

Water Supply Systems $\quad A-29$

Land Costs

$A-29$

Steam Supply/Demand Match

Physical and Environmental/Licensing

$A-30$

Considerations

$A-30$

5.2 .1

5.2 .2

Wastewater Impact

$A-30$

Cooling Water Inpact (Nuclear)

$A-30$

5.2 .3

Land ose

A -30

5.2 .4

Land Requirements

$A-30$

5.2 .5

Geology

$A-31$

5.2 .6

5.2 .7

Hydrology

$A=31$

Seismology

$A-32$ 
5.2 .8

5.2 .9

5.2 .10

5.2 .11

5.2 .12

5.2 .13

5.2 .14

5.3

5.3. 1

5.3 .2

5.3 .3

5.3 .4

5.3 .5

6

6.1

6.1 .1

6.1 .2

6.1 .3

6.1 .4

6.1 .5

6.1 .6

6.1 .7

6.1 .8

6.2

6.2 .1

6.2 .2

$6 \cdot 2 \cdot 3$

6.2 .4

6.2 .5

6.2 .6

6.2 .7

6.2 .8

6.2 .9

$6.2 \cdot 10$

6.2 .11

6.2 .12

$6.2 \cdot 13$

6.2 .14

6.3

6.3 .1

6.3 .2

6.3 .3

6.3 .4

6.3 .5

7

7.1

7.1. 1

7.1 .2

7.1 .3
Meteorology

Ecology anà croplands

Air Quality (Fossil)

Radiological Considerations (Nuclear)

Demography (Nuclear)

Noise Impact

Proximity to Hazardous Facilities (Nuclear)

Socioeconomic Conditions

Transportation

Community Impact

Archaeological and Historical Impact

Visual Inpact

Transmission/Steam Line Impact

$A-32$

$A-32$

$A-32$

$A-33$

$A-33$

$A-33$

$A-33$

$A-33$

$A-33$

$A-33$

$A-34$

$A-34$

$A-34$

ORANGE COUNTY - SITE B

Technical/Engineering Considerations

Site Pxeparation

Proximity to Load Demand

Water Availability

Highway, Rail, and Water Access

Foundations

Water Supply Systerus

Land Costs

Steaul Supply/Demand Match

Physical and Environmental/Licensing

Considerations

Wastewater Impact

Cooling Water Impact (Nuclear)

Land Use

Land Requirements

Geology

Hydrology

Seismology

Meteorology

Eoology anà Croplands

Air Quality (Fossil)

Radiological Considerations (Nuclear)

Demography (Nuclear)

Noise Impact

Proximity to Hazardous Facilities (Nuclear)

Socioeconomic Considerations

Transportation

Community Inpact

Archaeological and Historical Impact

Visual Impact

Transmission/Steam Line Impact

$A-35$

$A-35$

$A-35$

$A-35$

A -35

$A-35$

$A-35$

$A-35$

A -35

A -35

A -36

A -36

A -36

A -36

A -36

A -36

A -36

A -36

A -36

A -36

A. -36

A -36

A -37

A -37

A -37

A -37

A -37

A-37

A -37

A -37

A -37

GEISMAR REGION - SITE A

Technical/Engineering Considerations

$A-38$

$A-38$

$A-38$

$A-38$

Proximity to Ioad Demand

Water Availability

$A-38$ 
7.1 .4

7.1 .5

7.1 .6

7.1 .7

7.1 .8

7.2

7.2 .1

7.2 .2

7.2 .3

7.2 .4

7.2 .5

7.2 .6

7.2 .7

7.2 .8

7.2 .9

$7.2 \cdot 10$

7.2 .11

7.2 .12

7.2 .13

7.2 .14

7.3

7.3 .1

7.3 .2

7.3 .3

7.3 .4

7.3 .6

8

8.1

8.1.1

8.1. 2

8.1 .3

8.1 .4

8.1 .5

8.1 .6

8.1.7

8.1. 8

8.2

8.2 .1

8.2.2

8.2 .3

8.2 .4

8.2.5

8.2 .6

8.2 .7

8.2 .8

8.2 .9

8.2 .10

8.2.11

$8.2 \cdot 12$

Highway, Rail, and Water Access

A -39

Foundations

$A-39$

water supply systems

Land Costs

Steau Supply/Demand Match

Physical and Environmental/Licensing Considerations

Wastewater Inpact

Cooling Water Impact (Nuclear)

Land Use

Land Requirements

$A-40$

$A-40$

$A-40$

Geoloyy

Hydrology

Seismology

Meteorology

Ecology and Croplands

$A-40$

$A-40$

A. -40

$A-41$

$A-41$

$A-41$

$A-42$

$A-42$

$A-43$

hir quality (Fossil)

$A-43$

Radiological Considerations (Nuclear)

$A-43$

Demography (Nuclear)

$A-45$

Noise Impact

$A-45$

$A-45$

Proximity to Hazardous Facilities (Nuclear) A-45

Socioeconomic Considerations

$A-45$

Transportation

Comuunity Impact

Archaeological and Historical Impact

Visual Impact

Transmission/Steam line Impact

$\mathrm{A}-45$

$A-46$

$A-46$

$A-46$

$A-46$

GEISMAR REGION - SITE B

Technical/Engineering Considerations

$A-47$

$A-47$

Site Preparation

Proximity to Load Demand

A -47

Water Availability

Highway, Rail, and Water Access

$A-47$

$A-47$

$A-47$

Foundations

Water Supply Systems

$A-47$

A -47

Land Costs

$A-47$

Steam Supply/Demand Match

Physical and Environmental/Licensing Considerations

Vastewater Inpact

Cooling Water Inpact (Nuclear)

Land Use

Land Requirements

$A-47$

Geology

Hydrology

Seismology

Meteorology

Ecology and Croplands

$A-48$

$A-48$

$A-48$

$A-48$

$A-48$

$A-48$

$A-48$

$A-48$

$A-48$

A -48

Air Quality (Fossil)

Radiological Considerations (Nuclear)

$A-48$

$A-48$

Demography (Nuclear)

$A-48$ 
Page

$\begin{array}{ll}\text { 8.2.13 } & \text { Noise Iraact } \\ 8.2 .14 & \text { Proximity to Hazardous Facilities (Nuclear) } \\ 8.3 & \text { Socioeconomic Considerations } \\ 8.3 .1 & \text { Transportation } \\ 8.3 .2 & \text { Community Impact } \\ 8.3 .3 & \text { Archaeological and Historical Impact } \\ 8.3 .4 & \text { Visual Impact } \\ 8.3 .5 & \text { Transmission/Stean Line Impact }\end{array}$

$\begin{array}{ll}9 & \text { GEISMAR REGION - SITE C } \\ 9.1 & \text { Technical/Engineering Considerations } \\ 9.1 .1 & \text { Site Preparation }\end{array}$

9.1 .1

9.1.3 Water Availability

9.1 .4

9.1 .5

$9 \cdot 1 \cdot 6$

9.1 .7

9.1 .8

9.2

Highway, Rail, and Water Access

Foundations

Water Supply Systerns

Land costs

Steam Supply/Demand Match

Physical and Enviromental/Licensing Considerations

9.2 .1

Wastewater Iupact

9.2 .2

Cooling Water Impact (Nuclear)

$A-49$

A -49

$A-49$

$A-49$

$A-49$

$A-49$

$A-49$

$A-49$

$A-50$

$A-50$

$A-50$

$A-50$

$A-50$

A. -50

$A-50$

$A-50$

$A-50$

$A-50$

$A-50$

$A-50$

$A-50$

Land Use

$A-50$

$A-51$

9.2 .4

Land Requirenents

$A-51$

Geology

Hydrology

$A-51$

9.2 .6

9.2 .7

Seismoloyy

$A-51$

9.2 .8

Meteurology

9.2 .9

Ecology and Croplands

$A-51$

$A-51$

Air quality (Fossil)

9.2 .11

Radiological Considerations (Nucleax)

$A=51$

$A-51$

Dernography (Nuclear)

$A-51$

Noise Impact

$A-51$

9.2 .13

Proxinity to llazardous Facilities (Nuclear)

$A-51$

Socioeconomic considerations

$A-52$

Transportation

$A-52$

Community Impact

$A-52$

Archaeological and Historical Impact A-52

$9 \cdot 3 \cdot 3$

Visual Impact

$A-52$

$9 \cdot 3.4$

Transmission/Steam tine Impact

$A-52$

$\begin{array}{llr}\text { 10 } & \text { GEISMAR REGION - SITE D } & \text { A-53 } \\ 10.1 & \text { Technical/Engineering Considerations } & A-53 \\ 10.1 .1 & \text { Site Preparation } & A-53 \\ 10.1 .2 & \text { Proximity to Ioad Demand } & A-53 \\ 10.1 .3 & \text { Water Availability } & A-53 \\ 10.1 .4 & \text { Highway, Rail, and water Access } & A-53 \\ 10.1 .5 & \text { Founáations } & A-53 \\ 10.1 .6 & \text { Water Supply Systems } & A-53 \\ 10.1 .7 & \text { Land Costs } & A-53 \\ 10.1 .8 & \text { Steam Supply/Demand Match } & A-53\end{array}$


10.2 Physical and Environmental/Licensing

10.2 .1

10.2 .2

$10.2 \cdot 3$

10.2 .4

10.2 .5

10.2 .6

10.2 .7

10.2 .8

10.2 .9

$10.2 \cdot 10$

10.2 .11

10.2 .12

$10.2 \cdot 13$

$10.2 \cdot 14$

10.3

$10.3 \cdot 1$

10.3 .2

10.3 .3

10.3 .4

10.3 .5

11

$A-2$

A -3

\section{Considerations}

Wastewater Inpact

Cooling Water Impact (Nuclear)

Land Use

Land Requirements

Geology

Hydrology

Seismology

Meteorology

Ecology and Croplands

Air Quality (Fossil)

Radiological Considerations (Nuclear)

Demography (Nuclear)

Noise Impact

Proximity to Hazardous Facilities (Nuclear)

Socioeconomic Considerations

Transportation

Community Impact

Archaeological and Historical Impact

Visual Impact

Transmission Steam Iine Impact

REFERENCES

TABLES

Ambient Air quality Standards

Annual Mean Precipitation and Temperature Orange Region

Geismar Area Ground-Level Concentration of Contaminants Compared to National Air Quality Standards
$A-10$

$A-32$

A -53

A -53

$A-53$

$A-54$

$A-54$

$A-54$

$A-54$

$A-54$

A -54

A -54

A -54

A -54

A -54

A -54

A -55

$A-55$

A -55

$A-55$

A -55

$A-55$

A -55

A -56

$A-44$ 


\section{APPENDIX A}

APPLICATION OF SITING CONSIDERATIONS TO CANDIDATE SITES

1 NORTH BATON ROUGE - SITE A/B

\subsection{TECHNICAL/ENGINEER ING CONSIDERATIONS}

\subsubsection{Site Preparation}

Site $A$ at North Baton Rouge is a flat area containing heavily wooded sections and low vegetation. Near the center of site $A$ is an abandoned setting basin previously used by Kaiser Chernical Company. Prior to 1973, effluent from their plant operations was pumped to this basin. A treatment plant has been installed and the settling basin has reportedly not been used since 1973. It is probable that subsurface soil conditions in the immediate vicinity of the abandoned settling basin have been affected by chemical constituents of previous effluent seepage. Such contaminated soils, if they exist. would likely cause wide variations in shear strength and settlement characteristics. Because of concern for the bearing capacity and settlement of any facilities constructed in the vicinity of the abandoned settling basin, a large excavation is probable at Site $A$, even if it were to be used only for coal storage.

Site B, which lies between the existing Louisiana station and the Mississippi River, is covered by low scrub vegetation. Its topography is believed to denote previous construction activities.

Groundwater levels at both sites will be influenced by Mississippi River levels. Thus, seasonal fluctuations in river levels would cause corresponding changes in groundwater levels at site A/B. Groundwater levels within several feet of existing ground surface are quite comon and, accordingly. excavations at either site would require dewatering. pump tests are required to properly design temporary dewatering systems for construction. Concern for falling groundwater levels in the Baton Rouge area initiated the formation of the Capital Area Groundwater Conservation Commission (CAGCC) to regulate groundwater witharawal in that area. Although dewatering of any excavation would only be temporary. the CAGCC would undoubtedly want to assess the impact of any dewatering system on existing wells in the vicinity of Site $A / B \cdot(1,2)$

Excavated material from either site could be used for grading and/or construction of retaining dikes around any oil tanks or to control runoff from coal storage piles. The depth to firm bearing strata at the North Baton Rouge sites would be significantly smaller than the Geismar sites. It 
appears that approxiniately 50 feet of excavation might be required in the North Baton Rouge region for a nuclear plant. whereas in the Geismar region, the depth of excavation to suitable firm bearing soil might be as great as 90 feet.

Matrix ratings of 7 and 8 were assigned to nuclear and fossil plants, respectively. These values reflect the difficulty of dewatering and problems associated with the suspected presence of chemical effluents in the former settling basin vicinity.

\subsubsection{Proxinity to Load Demand}

The proposed site is centrally located and was given the maximum rating of 25 for both types of plants.

\subsubsection{Water Availability}

The Mississippi River is the potential source of water. The low-water flow of the Mississippi near Baton Rouge is approximately 100,000 cfs. The average flow is about 419,000 cfs with a maximum historical flow of $1,248,000$ cfs. As indicated in section 3.2.2.1.3, the river has ample water available for the needs of a power plant. In light of this information. we have assigned a matrix rating of 20 to nuclear and fossil plants.

\subsubsection{Highway, Rail, and Water Access}

Interstate Highways 10 and 12 are the principal arteries of the region's highway system. Interstate 10 connects the cities of New Orleans, Baton Rouge, and Lafayette: Interstate 12 trends in ain east-west direction from Baton Rouge to Alabama. Locally, the principal routes are $\mathrm{U} . \mathrm{S}$. Highway 61, and Interstates 110 and 190. U.S.61 extends from Baton Rouge to St. Francisville and north to Natchez, Mississippi. U.S. 190 extends in an east-west direction across the state and passes through Baton Rouge. State and county roads serve the remainder of the region.

The Illinois Central, Texas and Pacific, Iouisiana and Arkansas, and South Shore Railroads serve the Mississippi region with Baton Rouge as the major rail center. The main line of the Illinois Central Railroad borders the eastern edge of the site.

The Mississippi River qualifies as a navigable waterway and handles considerable annual tonnage of barge traffic. Also, ocean freighters cone as far north as the Raton Rouge Port. The proximity of this candidate site to a bend in the river and the resulting potential hazards to river navigation raise questions as to whether the site could utilize barge 
unloading of fuel. Further detailed studies would be required to affirm the suitability of the site for barge unloading. A matrix rating of 5 was assigned to nuclear plant siting: a matrix rating of 20 was given to fossil plant siting due to the uncertainty of fuel unloading by barge.

\subsubsection{Foundations}

As indicated in site preparation, the depths to firm bearing strata are important to determine the depth of excavation for nuclear plants or the required length of piles for fossil power plants. Existing soils to depths of about 50 feet at Sites $A$ and $B$ are not capable of satisfactorily supporting the relatively heavy structure loads typical of either fossil or nuclear power plants. In the case of nuclear power plants, the near-surface soil strata in the North Baton Rouge area are cohesive silts and clays.(1,3) These soils are not susceptible to liquefaction during seismic events; however, long-term compressibility precludes such soils being left in place. In fossil power plants, these softer silts and clays must be excavated or bypassed in the form of piles or caissons to carry the heavy structural loads down to firm bearing strata.

If it were desirable to situate a nuclear plant at an elevation higher than the required hottom of excavation, compacted granular backfill could be placed between the excavation grade and required foundation grade. Granular backfill suitable for this purpose would have to be obtained offsite. The excavated silts and clays could theoretically be replaced and compacted to a sufficiently high density. However, the logistics of excavating and stockpiling the cohesive silts and clays until they could be replaced in the excavation would probably be nore expensive than utilizing offsite granular borrow sources.

Foundation design loads of 50 to 60 tons for 50-foot long step taper or precast concrete piles are typical for the Baton Rouge vicinity.(3) Alternately. drilled caissons might prove to be more economical; the cohesive nature of the foundation soils in the North Baton Rouge region and the relatively shallow depths to firm bearing strata permit the economic competitiveness between pile and caisson type foundations. This situation is in contrast to Geismar, for example, where pile foundations are more feasible and cheaper than caissons.

Matrix ratings of 12 and 10 for nuclear and fossil plants. respectively, were assigned primarily due to the relatively shallow depths to firm bearing strata. 


\subsubsection{Water Supply Systems}

The topography of the site suggests that special or unusual construction features would not be required for the water supply systems. The site is bordered on the west by the Mississippi River. Plant-river distance would be approximately 600 feet. A maximum matrix rating of 10 has been assigned for both nuclear and fossil plants.

\subsubsection{Land Costs}

The adjacent areas are well developed industrially. commercially, and residentially; thus, high land costs would prevail. For these reasons a matrix rating of 2 was assigned to both nuclear and fossil plants.

\subsubsection{Steani Supply/Demanä Match}

In comun with all sites. Site $A / B$ was rated 10 for steam Supply/Demand Watch for a fossil plant. The steam demand lies between what could be supplied by a commercial IWR and an interwediate-size LWR, so the site was rated 10 for a nuclear plant.

\subsection{PHYSICAL AND ENVIRONMENTAL/LICENSING CONSIDERATIONS}

\subsubsection{Wastewater Impact}

The wastewaters from the power plant will have no adverse effect on water quality. A National Pollutant Discharge Elimination statement (NPDES) will be filed and required limits complied with for the steam Electric Power Generating Point Source Category.(t) The wastes will also meet Louisiana water quality criteria. Since the Mississippi River has a large volume of water, water consumption will not be adverse even during the low-water flow in the river (see Cooling Water Inpact). Matrix ratings of 5 and 10 were assigned for nuclear and fossil plants, respectively.

\subsubsection{Cooling Water Impact (Nuclear)}

Due to the high flow of the Mississippi River, cooling water requirements would produce a negligible effect on the river. if emergency cooling were required.

The low water flow of the Misisissippi is approximately $100,000 \mathrm{cfs}$ (Section 1.1.3). With once-through emergency core cooling requiring a flow of approximately $120 \mathrm{cfs}$, the net temperature rise of the river would be an imperceptible 0.012 F. A matrix rating of 5 was assigned. 


\subsubsection{Land Use}

The site area is commercially and industrially zoned. A potential land use problem may exist since the site is contiguous on one side with a college campus. However, because of earlier industrial land use, the potential problem is expected to be minimal. A matrix rating of 6 was assigned for both plants.

\subsubsection{Land Requirements}

The North Baton Rouye site consists of two parcels of land. Subsite A, the northern parcel, contains 220 acres and Subsite $B$, the southern parcel, contains 30 acres. They are separated by a distance of approximately 8.400 feet. The $A / B$ site was evaluated collectively in this category providing a matrix rating of 6 for fossil and 20 for nuclear plants.

\section{2 .5 Geology}

A slump fault passes under Glen Oaks High School several miles due east of proposed site A.(2) The general trend of the slump fault is east-west. Although there is no onsite evidence that this fault extends west from the Gien Oaks High School vicinity to site $A$, it is probable that the NRC would postulate the extension of the fault below site $A$. Extensive onsite and offsite geologic investigations would be required to address this question.

The slump fault is insignificant from a seismologic standpoint since slump faults are not determined to be "capable" sources of generating earthquakes. (5) However, any postulation of the existence of the slump fault would concern plant design (fossil or nuclear) as it relates to differential settlements. Should the slump fault extend below site $A$, particular attention must be focused on designing for possible differential displacements and/or tilting of adjacent foundations.

Large-scale withdrawal of groundwater as a supply source in the Baton Rouge area implicates subsidence as a major concern at both sites $A$ and B. (2,5) Predictions of 4 to 8 feet of subsidence in the general Baton Rouge area during the period 1970 to 1990 are cormon. Subsidence caused by extraction of 011 and water typically results in relatively widespread settlements so that future subsidence at sites $A$ and $B$ would be fairly uniform at each site. Thus. differential settlements between adjacent facilities would not be significant; however. protecting the sites against Mississippi River floods and plant system hydraulics may be adversely affected by a uniform settlement of the plant sites by several feet. 
stratified deposits of silty clays and clayey silts with occasional lenses of silty fine sands are likely to underlie both sites. This geologic profile is typical of petrochemical plant sites bordering the Mississippi River in the North Batun Rouge area.(3) of significance in the area is the absence of typical soft clay (Pleistocene) layers that occur at many southern Mississippi River sites. Accordingly, depths to firm bearing strata are shallower than the Geismar sites. for exanple, requiring shorter pile or caisson lengths for a fossil plant or shallower excavation for a nuclear plant.

In accordance with the above reasons, matrix ratings of 20 and 10 were assigned for nuclear and fossil plants. respectively, at the North Baton Rouge site.

\subsubsection{Hyarology}

When flooding duration is limited, the construction of impervious dikes higher than flood level might be acceptable to the NRC for a nuclear plant located on the floodplain of the Mississippi River. The only adequate protection against extended flooding would be a grade elevation higher than the level of the dikes or extensive flood protection in plant design in order to comply with strict NRC siting criteria. Fossil-fueled plant flood design criteria are less severe. Matrix ratings of 20 and 15 were assigned for nuclear and fossil plants, respectively.

\section{2 .7 Seismology}

All four proposed regions 1 ie within the seismo-tectonic province knowm as the Gulf coastal Plain (GCP). Since the GCP is a low seismicity area, nuclear power plant seismic design is governed by the minimum acceleration values permitted by the NRC, rather than by the actual historical earthquake events felt in the four regions. Accordingly, most of the discussion for the North Baton Rouge sites is applicable to all of the regions under consideration.

In determining the safe shutdown earthquake (SSE) or the operating basis earthquake (OBE) for the four regions under consideration. attention must be focused on both local and distant earthquakes. Both the waterford and River Bend Nuclear Power plants (which lie south and north of the Daton Rouge and Geismar regions, respectively) have the Donaldsonville, Louisiana, earthquake of 1930 as the controlling local seismic event with an epicentral intensity of VI MM (Modified Mercalli). (5,6) Seismology for the Blue Hills Nuclear Power Plant is influenced by the Hemphill earthquakes of 1964.(7) Like the Donaldsonville event, the intensities of the Hemphill earthquakes have been estimated to be as high as VI MM. 
The New Madrid, Missouri, earthquakes of 1811-1812 were the largest histuric earthquakes affecting nuclear plant siting in the Central United States. However, because the epicentral locations of these events were hundreats of miles north of the proposed site regions, the resulting ground motion at the Waterford and River Bend sites was no greater than the ground motion caused by the Donaldsonville earthquake. Even when the New Madrid earthquakes are hypothesized to recur at the southermost boundary of the seismo-tectonic province in which the New Madrid events occurred, the attenuation with distance results in predicted ground motions at the four proposed regions no greater than that which would be caused by a postulated repeat of the Donaldsonville or Hemphill earthquakes directly beneath any of the four proposed regions. Thus, in terms of identifying the SSE for any of the four regions, the controlling earthquakes would be a local Intensity VI MM event.

The next step in the determination of the seismic design bases for nuclear power plants is to correlate MM intensities with horizontal ground accelerations. Thus, having determined that the onsite ground motion at any of the four regions can be characterized as Intensity VI MM for the SSE, the ground acceleration corresponding to this level of seismic motion must be estimated. Mumerous correlations have been developed over the years between $M M$ intensity and acceleration. Historically, it appears that the NRC has used the most conservative of the correlations postulated at any given tinte. The Gutenberg-Richter relationship was used extensively in early nuclear plant licensing.(8) Since the early $1970^{\circ} \mathrm{s}$, utility applicants for nuclear plant permits have most often used the Neumann, (9) Trifunac and Brady, (10) or Coulter-waldron-Devine (is) relationships, although the last appears to have fallen into some disfavor recently, $(3,4,12)$

Using any of the above correlations, the SSE accelerations at any of the four sites would be $0.07 \mathrm{~g}$ based on the aforementioned corresponding intensity. Since this value is lower than the currently mandated minimum value of $0.10 \mathrm{~g}$ for the SSE, the acceleration of $0.10 \mathrm{~g}$ is recommended for conceptual and feasibility purposes.

The OBE earthquakes governing the design of nuclear plants at the four regions would be controlled by the same "local earthquakes: $i . e .$, the Donaldsonville affecting the North Baton Rouge and Geismar regions and the Hemphill affecting the Lake Charles and Orange regions. In all cases, the intensity of gruund motion observed at the four regions during the aforenentioned earthquakes was less than the equivalent minimum required by the NRC for OBE design, as subsequently discussed. Thus, intensities observed at the four regions during the Donaldsonville or Hemphill events 
are estimated to have been in the range III-IV MM. These intensities result in ground acceleration lower than the mininum value of $0.05 \mathrm{~g}$ which is currently required by the NRC for OBE seismic design.

It should be pointed out that in other regions of the United states, the NRC appears to be mandating higher minimum values of $O B E$ and SSE accelerations. This is being accomplisheà by assuming nore conservative boundaries for seismo-tectonic provinces. This results in the governing "distant" earthquakes being artificially postulated to recur closer to the proposed sites. For example, in the Northeast Dnited states the end result of this position by the NRC is that the current "unofficial" minimum value of SSE acceleration has been raised to $0.20 \mathrm{~g}$. It is emphasized that the minimum acceleration values which can be licensed for nuclear plants seem to be increasing. Values recormended for any of the four regions (i.e.., $0.05 \mathrm{~g}$ and $0.10 \mathrm{~g}$ ) are based on current seismo-tectonic boundaries for the New Madrid earthquakes of 1811-1812. The current southern limit of the seismo-tectonic province for the New Madrid earthquakes results in the postulation that the New Madrid events cannot be assumed to recur any closer to the four evaluated regions than Memphis, Tennessee. Very detailed "vibroseis" data across the Mississippi Embayment north and south of Memphis have been used to define geologic structure and thereby proviae the geologic evidence for the southern limit of the New Madrid seismic zone. This evidence is considered to be definitive and it is unlikely that the New Madrid events could be postulated to recur any farther south than Meruphis. Tennessee.

The consequences of increasing the design acceleration values are primarily in increased costs for pipe supports and seismic qualitication of electrical and mechanical equipinent.

For fossil power plants, the Southern or Uniform Building Codes provide recomendations for the seismic design. The seismic risk map contained in these building codes delineate the four proposed regions within zone 1, which is the lowest permissible seismic design basis for continental united States. Typically for zone 1, seismic design is not the governing criterion; other design parameters such as wind. thermal, or equipment loads result in higher stresses.

Matrix rating values of 20 and 10 for nuclear and fossil plants. respectively, were assigned to all the evaluated regions except Orange. For muclear plant siting. Orange was downgraded to a matrix rating of 17 in recognition of the existing SSE acceleration value of $0.13 \mathrm{~g}$ that was docketed for the Blue Hills Nuclear Plant. (r) 


\subsubsection{Meteorology}

The climate of the site is generally described as humid subtropical. Prevailing southeasterly winds combined with the moisture supply and warm waters of the Gulf of Mexico provide mild but rather humid weather throughout most of the year. Air from the continental interior occasionally brings drier and usually cooler weather, but air of continental origin influences the region very little during the summer and partly during other seasons.

The sumner clinate is warm and humid. Daily mean and maximum tenperatures average about $82 \mathrm{~F}$ and $92 \mathrm{~F}$. respectively. Precipitation averages about 5 inches per month. Afternoon thumdershowers, which account for much of the rainfall, occur about one day in three during the summer months.

The winter climate is pleasant, due to mild temperatures and only moderate precipitation. Daily mean and maximum temperatuxes average $54 \mathrm{~F}$ and $64 \mathrm{~F}$, respectively; and freezing temperatures occur on an average of one night in four.

Cold air, accompanied by brisk winds, occasionally moves southward causing rapia temperature drops of considerable magnitude: however, prolonged cold spells are unusual. winter precipitation, which averages nearly 5 inches per month, occurs partiy from steady rains caused by tornadoes and partly from showers accompanying the arrival of cold air from the north. Snow or freezing rain is rare.

Spring comes early and is the season of most frequent tornado occurrence. Based on a study of tornado occurrences during the period 1955 through 1967, mean tornado frequency in a 1 degree (latitude-longitude) square was determined to be about 1.7 per year.(13) The probability of a tornado striking a point on a given site is estimated at once every 855 years.

Tropical sturm frequency is highest in early autumn. The most pleasant month is usually october, which has moderate temperatures and the least precipitation and cloudiness of any month. A matrix rating of 11 was assigned to both nuclear and fossil plants.

\section{$1.2 .9 \cdot$ Ecology and Croplands}

The site is located in an industrial area with no significant ecological features. There are no croplands in the site vicinity. The Mississippi River at that location does not have any fishing activity. A matrix rating of 10 
was assignea to both nuclear and fossil plant considerations.

\subsubsection{Air Quality (Fossil)}

Iouisiana state ambient air quality standards became effective January 30, 1972. The ambient air standards established for suspended particulates, sulfur oxides, and nitrogen oxides are essentially equivalent to existing national primary standards, referenced in Table A-1. A matrix $x$ ating of 16 was assigned to a fossil-fuel plant at this site.

TABLE $A-1$

\section{A. LOUISIANA AMEIENT AIR QUALITY STANDARDS}

\section{POLLUTANT}

Suspended

Particulates

Sulfur Dioxide

Nitrogen Oxides
PERIOD

Annual Geometric Mean. Maximum 24-hr Average*

Annual Axithmetic Mean Maximum 24-hr Average*

Arurual Arithmetic Mean $\underline{\mathrm{ug}} / \mathrm{m}^{3} \quad \mathrm{ppm}$

$\begin{aligned} 75 & - \\ 260 & -\end{aligned}$

$80 \quad 0.03$

$365 \quad 0.14$

$100 \quad 0.05$

B. NATIONAL AMBIEN' AIR QUALITY STANDARDS

POLLUTANT

Particulate

Sulfur Oxides

Nitrogen Oxides
AVERAGING TIME

Annual Geonelíic Meari

$24 \cdot \mathrm{hr} *$

Annual

$24 h r^{*}$

$3 \mathrm{hr} *$

Annual
PRIMARY STD. $\underline{\mathrm{ug} / \mathrm{m}^{3}} \quad \mathrm{ppm}$

SECONDARY STD. $\underline{\mathrm{ug} / 3}$

LPM

$\begin{array}{rlrl}75 & - & 60 & - \\ 260 & - & 150 & - \\ 80 & 0.03 & 60 & 0.03 \\ 365 & 0.14 & 260 & 0.1 \\ - & - & 1.300 & 0.5 \\ 100 & 0.05 & 100 & 0.05\end{array}$

* Not to be exceeded more than once per year.

\subsubsection{Radiological Considerations (Nuclear)}

Although the North Baton Rouge site has an acceptable exclusion area boundary (EAB), the low population zone (LPZ) must be coincident with the EAB or it will far exceed the NRC guide of approximately 4,000 persons in the LPZ. This means, of course, that immediately surrounding the $E A B$, the population density is extremely high (far in excess of 500

$$
A-10
$$


persons per square mile). This site is least suitable for a nuclear plant. Consequently, it received a matrix rating of 5.

\section{2 .12 Demography (Nuclear)}

The North Eaton Rouge region is located about 3 miles from downtown Baton Rouge. The site is actually located within the city limits of Baton Rouge, which has a current population of about 209,000. The population within a $30-\mathrm{mile}$ radius is approximately 487,600 , reflecting a population density of 172 persons per square mile. The population within a 2 -mile radius of the plant is greater than 40,000, which translates to a population density exceeding 3,000 persons per square mile. For this reason, a matrix rating of 0 was assigned to nuclear plants at this site. (Demography is not a licensing consideration in connection with fossil fuel plants.)

\subsubsection{Noise Iimuact}

It is expected that no significant noise will be generated by a nuclear power plant.

Significant noise impact is anticipated during the operation of a fossil plant due to noise generated by outside equipment and the proximity to the university and residential conmunities. Sound barriers and other antinoise features would add to the cost of facility construction. A matrix rating of 4 was assigned to nuclear and 5 to fossil plants.

\subsubsection{Proximity to Hazardous Facilities (Nuclear)}

North Baton Rouge site $A / B$ is located approximately 1,000 feet from a facility/activity with potentially hazardous materials. A matrix rating of 2 was assigned to nuclear plants.

\subsection{SOCIOECONOMIC CONSIDERATIONS}

\subsubsection{Transportation}

As. stated earlier in Section 1.1.3, the site has access to rail, highway, and water as possible modes of transportation. Assuming the site can accept fuel by barge, the impact on the river corridor will be minimal. If fuel is received by train, the impact on the rail corridor will also be minimal. Transportation of wastes by barge or rail will have little effect on the systems, but it is likely that solid wastes will be removed from the site by highway and some adverse traffic conditions may result. The traffic pattern must be studied closely and shipments properly

$$
A-11
$$


scheduled to minimize the impact on the highway corridors. A matrix rating of 5 was assigned to nuclear plants, 15 to fossil plants.

\subsubsection{Community Impact}

The North Baton Rouge site is located within the political boundaries of Baton Rouge. It is probable that there will be some undesirable impacts on the surrounding community due to the movement of men, material, and machines. Impact to community infrastructures is expected to be minimal, even when assuming that the total work force resides in the Baton Rouge area. The estimated average construction work force for a nuclear plant is 1,200, slightly less for a fossil plant. Therefore, the total population addition (construction workers plus their fanilies) would be approximately 3,200 persons, a 1.5 percent increase over several years. This is substantially less than the average annual population growth of the Baton Rouge area. Matrix ratings of 6 and 8 for nuclear and fossil plants were assigned, respectively.

\subsubsection{Archaeological and Historical Impact}

There are no known archaeological or historical areas within the site vicinity and no adverse effect is anticipated. Therefore, a matrix rating of 5 was assigned each plant.

\subsubsection{Visual Impact}

The candidate site is on the fringe of an industrial complex and acts as a buffer zone between the industrial area and the campus of Southern University. A low profile, such as a nuclear plant without cooling towers, would have ntyligible aesthetic impact: however, a fossil plant with its prominent stack will have an effect, since even a low-profile stack and boiler will be visible over a considerable distance. Of all the candidate sites, this site would have the greatest visual impact on the area. Matrix ratings of 5 and 4 were assigned to nuclear and fossil plants, respectively.

\subsubsection{Transmission/Steam Line Impact}

All sites in all regions were given a matrix rating of 5 since ecology and community impact were assessed to be the same. 


\subsection{TECHNICAL/ENGINEERING CONS IDERATIONS}

\subsubsection{Site Preparation}

Subsurface conditions in the Lake Charles region are extremely heterogeneous. Without specific information at the proposed sites, it is imprudent to suggest probable excavation depths or pile lengths and capacities for nuclear or fossil plants, respectively. For example, design loads for pile foundations in the lake Charles region vary from 20 tons at a length of 56 feet to 50 tons at 50 to 85 feet. to 75 tons at 75 feet.(3) On a qualitative basis, it appears that depths to firm bearing strata are greater in the Lake Charles region compared to the orange region.

Because of relatively flat terrain adjacent to the Calcasieu River, flood protection will probably require construction of impervious dikes around the proposed Sites $A$ and $B$ rated 7 on the matrices. Site $C$ is far enough removed from the flood potential inuediately adjacent to the Calcasieu Rivex to be given a rating of 10 for both plants.

\subsubsection{Proximity to Load Demand}

The steam customers in the Lake Charles region are widely dispersed.. A preliminary calculation of the installed cost of the steam distribution system was made for sites $A$ and $B$. The distance from Site $A$ to the steam users varies from 5,000 to 15,000 feet. Site $A$ was the better of the two and was rated 20 for both plants.

\subsubsection{Water Availability}

The Calcasieu River and its tributaries are the principal sources of surface waters in the area. The average flow of the Calcasieu River is $2.470 \mathrm{cts}$, with a minimum measured daily flow of $136 \mathrm{cfs}$ and a maximum daily floodflow of 182,000 cfs. Since the power plant will replace the process needs of consumers by supplying steam, it is expected not to have a net effect on the total consumption of water for the industrial complex. The maximum plant water requirement of 30 cfs would equal about 1.2 percent of the average river flow and 22 percent of the minimum river flow. Due to lower volumetric flow of the Calcasieu River as compared to the Mississippi River, a matrix rating of 10 was assigned both plants. 


\subsubsection{Highway, Rail, and Water Access}

The region is served by three railroad companies, one interstate highway, and one waterway. The Kansas City and Southern, the Missouri Pacific, and the Southern Pacific and Texas Railway companies serve the city of Lake Charles ana vicinity. Interstate 10 connects the city of Lake Charles with points east and west, while U.S. Highways 171 and 165 link this region with areas to the north. These are supplemented by Interstate 210 and nurnerous state and parish roads located throughout the Lake Charles region. The Gulf Intracoastal Waterway, crossing the southern portion of the Lake Charles region, connects Sabine Lake at the TexasLouisiana border with New Orleans and the Mississippi River. Since the site is 10cated approximately 10,000 feet from the ship channel (river), economic penalties would be incurred if barge fuel unloading was installed. The construction costs for a new channel to serve the site would be expensive. An additional unloading site on the channel would be required with overland conveyers to the site, which again would result in relatively high costs. A matrix rating of 5 was assigned to nuclear and 20 to fossil plants.

\subsubsection{Foundations}

Because of the flood potential referred to in the section on Site Pxeparation. Sites $A$ and $B$ were rated 8 and site $C 12$ for nuclear plants: fossil-fuel plants mere rated 7 at Sites $A$ and $B$, and 8 at site $C$.

\subsubsection{Water Supply Systems}

The construction requirements for water supply systems, such as makeup and service water systems. do not pose any unusual problems. If placed on Bayo d'Inde, the water intake structure may provide water of better quality than the Calcasieu ship Clannel, which has high dissolved solids content: however, the unknown flows of Bayo d'Inde must be evaluated. The distance to either water source is approximately 10,000 feet. A matrix rating of 6 was assigned to both nuclear and fossil considerations.

\subsubsection{Land Costs}

The land costs at Lake Charles are slightly lower than the North Baton Rouge site, but still quite high because of its proximity to an industrial complex and developed areas. The proximity of this site to the railroad, the interstate highway, and Maplewood, and its higher elevation would be conducive to light manufacturing with resulting high land costs. A matrix rating of 3 was assigned for nuclear and fossil considerations. 


\subsubsection{Steam Supply/Demand Match}

The steam demand in the Lake charles region is similar to North Baton Rouge. All the sites were rated 10 for nuclear and fossil plants.

\subsection{PHYSICAL AND ENVIRONMENTAL/LICENSING CONSIDERATIONS}

\subsubsection{Wastewater Impact}

Wastewaters from the power plant will not have an adverse effect on water quality. Any water discharged to the river will be fully treated so that requirements of all regulatory agencies will be met. A National pollutant Discharge Elimination statement (NPDES) will be filed and limits required for the steam Electric Power Generating Point Source Category will be met.(4) Every effort, including complete recycle, will be considered to close the wastewater cycle within economic limits. Matrix ratings of 3 and 6 were assigned for nuclear and fossil plants, respectively.

\section{2 .2 Cooling Watex Impact (Nuclearl}

The normal water flow through the Calcasieu Ship Channel should be adequate for emergency cooling: however, reservoirs or ponds may be required to ensure an adequate supply during dry periods or under certain tidal conditions. The peak emergency core cooling load is estimated at 270 million Btu/hr. On the basis of evaporative cooling, a makeup flow of approximately 40 cfs is required. This flow represents about 29 percent of the minimum measured daily flow and 16 percent of the average flow. A matrix rating of 3 was assigned.

\section{2 .3 Land Use}

Since the site is located near the industrial users, has good transportation mrridor access and relatively high elevation, ard is close to residential Maplewood, it may be suitable for inaustrial development. Industrial use would not conflict with current zoning (industrial-commercial) or present land use. A matrix rating of 8 was assigned to both nuclear and fossil plants.

\subsubsection{Iand Requirements}

Site A, the suallest of the three sites at lake Charles, contains approximately 400 acres sufficient for either a fossil or a nuclear plant. Consequently. matrix ratings of 22 and 20 were assigned for fossil and nuclear plant siting. respectively. 


\section{2 .5 Geology}

The Lake Charles region is geologically dominated by the Lockport salt dome with its associated oil and gas fields.(7) The two southern sites in the Lake Charles region are in the inmediate vicinity of the Lockport dome; the third site is farther removed but, nonetheless, influenced by it.

The Lockport salt dome is seated deeper than those in the Geismar area, and ground subsidence, due to oil and gas withdrawal, is not regarded as a significant problem in contrast to the Geismar and North Baton Rouge reyions.

The Tepetate-Baton Rouge fault zone is located about 10 miles north of Lake Charles. The Lake Arthur fault zone passes approximately 5 miles south of Lake Charles, and the Iowa fault zone strikes east-northwest across the lockport salt dome. The proximity of these fault zones to the proposed Lake Charles sites may require considerable onsite and offsite geologic investigations for nuclear plant siting.

The generalized soil profiles at the proposed sites consist of interbedded silty sands, sandy clayey silts, and silty clays.(3) Depths to firm bearing strata vary considerably throughout the Lake Charles area. Accordingly, pile capacities are highly site dependent, as are the probable depths of excavation for nuclear plant siting. Without detailed subsurface information at the specific proposed sites. pile capacities and lengths of piles cannot be estimated realistically. The depositional environment in the Lake Charles region has resulted in extreme variability in soil conaltions.

Near-surface groundwater in the Lake Charles region contains dissolved methane gas which is generated from organic debris within the freshwater aquifers or from oil and gas sands underlying the aquifers.c15 This could present considerable safety concerns if dewatering is required for construction. In addition, encroachment of salt water into freshwater aquifers is a concern in this area. Again, any construction dewatering, if required, might result in environmental impacts. Matrix ratings of 15 and 14 were assigned to nuclear and fossil plants, respectively, for sites $A$ and $B$.

\section{2 .6 Hyarology}

Lake Charles reyion has no record of severe flooding and, hence, it is not anticipated that more than minimal flood protection is required. Matrix ratings of 20 and 15 were assigned for nuclear and fossil plants, respectively.

$$
A-16
$$




\subsubsection{Seismology}

Refer to this heading under the North Baton Rouge description, Section 1.2.7.

\subsubsection{Meteorology}

The climate of the site is essentially the same as the forth Baton Rouge site described in section 1.2.7. A matrix rating of 9 was assigned to both nucleax and fossil plants.

\subsubsection{Ecology and Croplands}

The site and its surroundings are largely industrial and residential with an absence of croplands. There are no known wildilife preserves or endangered species in the area. Thus, impacts would be minimal. A matrix rating of 10 was assigned to both nuclear and fossil plants.

\subsubsection{Air Quality (Fossil)}

Same as North Baton Rouge (Section 1.2.10).

\subsubsection{Radiological Considerations (Nuclear).}

Having a 2.0-mile LPZ, Lake charles site A is not within the LPZ guidelines of 3.0 miles. Furthermore, the population center boundary distance of 2.8 miles is barely adequate to meet the $11 / 3 \mathrm{LPZ}$ distance requirement. A matrix rating of 10 was assigned.

\subsubsection{Demoryaphy (Nuclear)}

lake Charles site A. located in the southwest corner of Louisiana, is in an area of gently rolling prairie and marshland. The population in 1970 was 137.779. Today (1977) there are about 149,000 persons, and it is expected that approximately 206,000 persons will be living in this ared by 2020. Calcasleu parish, in which the proposed site is located, had a 1976 population of 150,520 and is growing at about 0.98 percent per year. There are approximately 257,000 persons within a $30-$ mile radius of the site. reflecting a population density of 91 persons per square mile. Population projections indicate a population of about 365,000 by 2020 , which reflects a population density of 129 persons per square mile.

The city of Lake Charles, located about 5 miles east of the candidate site, has a population of approximately 84,000 . Other population concentrations include: Hollywood, located 1.5 miles west, with a population of 2,500: Sulphur, located 3.5 miles northwest, with a population of 14,600; and Westlake, located 3 miles northeast, with a population of 
4.400. Therefore, the total population in a 5-mile radius of the site is approximately 105,000, a population density of 1,340 persons per square mile. A matrix rating of 19 was assigned.

\section{2 .13 Noise Impact}

Because of the proximity of residential sections Maplewood and Hollywood (approximately 2 miles distant), noise is a problem with a fossil plant and antinoise design and construction cost factors in the overall cost of the station. Therefore, a matxix rating of 5 was assigned for fossil and 4 for nuclear plants.

\subsubsection{Proximity to Hazardous Facilities (Nuclear)}

Lake Charles Site $A$ is located approximately 6,000 feet from a facility that contains potentially hazardous materials. A matrix rating of 15 was assigned.

\subsection{SOCIOECONOMIC CONSIDERATIONS}

\subsubsection{Transportation}

The site has access to rail, highway, and water transportation. The transportation of fuel to the plant by rail and of wastes from the plant by rail or highway would not have adverse effects on transportation systems. Nuclear and fossil plants received full-value matrix ratings of 5 and 15 , respectively.

\subsubsection{Compunity Impact}

Lake Charles Site $A$ is located approximately 5 miles from the City of Lake Charles and includes a population of about 84.000. Also within the 5-mile radius are three towns with a total population of 22,000. The movement of men. material, and machines should have little impact on surrounding communities. As indicated in section 1.3.2, the estimated construction work force plus families would add a maximun of about 3,200 persons to surrounding conmunities. This represents a 3 percent population increase, which should have little impact on the infrastructure of these comunities. Matrix ratings of 8 and 9 were assigned to nuclear and tossil plants, respectively.

\subsubsection{Archaeological And Historical Impact}

There are no known archaeological sites in the site vicinity. There is a significant historical and recreation area in the Calcasieu Parish about 8 miles distant: the Imperial Calcasieu Historical Museum and Sam Houston state

$$
A-18
$$


Park. However, no adverse impact is expected on these installations if a power plant were built. We assigned a matrix rating of 5 to both plants.

\section{3 .4 Visual Impact}

A power plant on this site may create visual impact problems affecting nearby residential communities. The proposed power plant presents a significant profile because it will stand alone on the site which is located near Interstate 210. A matrix rating of 8 was applied to a fossil plant and 5 to a nuclear plant.

\subsubsection{Transmission/Steam Line Impact}

Same as North Baton Rouge, Section 1.3.5. 


\subsection{TECHNICAL/ENGINEFRING CONS IDERATIONS}

\subsubsection{Site Preparation}

Refer to Site Preparation, Lake Charles Site A. Section 2.1.1.

\subsubsection{Proximity to Load Demand}

The distances from site $B$ to the steam users vary from 6,000 to 21,000 feet. Based on the analysis described in 2.1.2. Site B was rated 15 for Proximity to Load Demand.

\subsubsection{Water Availability}

The availability of water is essentially the same as Irake Charles Site A.

\subsubsection{Highway, Rail, and Water Access}

Highway and rail access is essentially the same as for Lake Charles Site $A$, and favorable access to the Calcasieu Ship Channel should allow barge transportation of coal for a fossil plant. Special dock unloading facilities will be required due to the narrow channel. A matrix rating of 5 was assigned for nuclear and 20 for fossil plants.

\subsubsection{Foundations}

Refer to Foundations. Lake Charles Site A, Section 2.1.5.

3.1.6 Water Supply Systems

The water supply systems would be the same as Lake Charles Site A.

\subsubsection{Land Costs}

Iand costs are expected to be high and similar to Lake Charles Site $A$. Direct access to the ship channel increases its value as does its proximity to the industrial complex. Offsetting these advantages is the lower elevation compared to Site $A$. A matrix rating of 3 was assigned for nuclear and fossil plant considerations.

3.1.8 Steam Supply/Demand Match

See Lake Charles Site A. Section 2.1.8. 
3.2 PHYSICAL AND ENVIRONMENTAL/LICENSING CONSIDERATIONS

\subsubsection{Wastewater Impact}

Same as Lake Charles Site A. See Section 2.2.1.

3.2.2 Cooling Water Impact (Nuclear)

Same as Lake Charles Site A. See Section 2.2.2.

\subsubsection{Land Use}

The site, zoned industrial-commercial, is located adjacent to an industrial complex. A process plant appears to be the main competition for this site. Serious conflicts regarding land use are not expected. Matrix ratings are the same as for Lake Charles Site A.

\subsubsection{Land Requirements}

Site B contains approximately 600 acres and sufficient area to support either plant. Consequently, matrix ratings of 25 and 20 were assigned for fossil and nuclear plant siting. respect ively.

\section{2 .5 Geology}

Refer to Lake Charles Site A, Section 2.2.5.

\section{2 .6 Hydrology}

Similar to Lake Charles site A, except the elevation is lower (see Section 2.2.6). Same minor flood protection may be required. A matrix rating of 16 was assigned to the nuclear plant; a rating of 13 was assigned to the fossil plant.

\subsubsection{Seismology}

Refer to North Baton Rouge Sites A/B, Section 1.2.7.

\subsubsection{Meteorology}

Similar to Lake Charles site A except for a favorable location of the plant relative to prevailing winds (Section 2.2.8). A matrix rating of 11 was assigned to both nuclear and fossil sites.

\subsubsection{Ecology and Croplands}

Same as Lake Charles Site A. See Section 2.2.9. 


\subsubsection{Air Quality (Fossil)}

Same as North Baton Rouge, Section 1.2.10.

\subsubsection{Radiological Considerations (Nuclear)}

Lake Charles Site B distances are slightly less to the LPZ outer boundary and population center boundary 11.8 miles and 2.5 miles, respectively) than Lake Charles Site A. It is not a favorable nuclear site. Consistent with the Lake Charles Site A, a matrix rating of 10 was given.

\subsubsection{Demography (Nuclear)}

Refer to Demography, Lake Charles Site A, Section 2.2.1.2.

The city of Lake Charles is located about 5 miles east of the candidate site and has a population of approximately 84,100. Other population concentrations include: Hollywood, located 2 miles north, with a population of 2,500: Sulphur, located 3.5 miles northwest, with a population of 14,600; and Westlake, located $4.5 \mathrm{miles}$ northeast. with a population of 4,400 . A matrix rating of 14 was assigned.

\subsubsection{Noise Impact}

The potential impact of noise is similar to Lake Charles Site $A$, except that this site is further from the residential communities of Hollywood and Maplewood; the distance is approximately $2 \mathrm{mil}$ es. Noise proofing would not be as extensive for this site. A matrix rating of 8 was assigned for fossil and 4 for nuclear plants.

\subsubsection{Proxinity to Hazardous Facilities (Nuclear)}

Lake Charles Site $B$ is located approximately 5,300 feet from a facility that contains potentially hazardous materials. A matrix rating of 15 was assigned.

\subsection{SOCIOECONOMIC CONSIDERATIONS}

\subsubsection{Transportation}

Same as Lake Charles Site A, Section 2.3.1.

\subsubsection{Community Impact}

Sarne as Lake Charles Site A, Section 2.3.2. 


\subsubsection{Archaeological and Historical Impact}

Satue as Lake Charles Site A, Section 2.3.3.

3.3.4. Visual Impact

Lake Charles site $B$ 's proximity to the industrial complex and its remoteness from residential commuties and highways should not impact significantly. Matrix ratings of 9 and 5 have been assigned to fosil and nuclear plants, respectively.

3.3.5 Transmission/Steam Line Impact

Same as North Baton Rouge, Section 1.3.5. 
4.1 TECHNICAL/ENGINEER ING CONSIUERATIONS

4.1.1 Site Preparation

Refer to Site Preparation, Lake Charles Site A, Section 2.1.1.

\subsubsection{Proximity to Laad Demand}

A matrix rating of 0 was assigned to site $c$ because it requires steam distribution pipes longer than 5 miles.

\subsubsection{Water Availability}

The Houston River appears to be the best source of water for this site. The Sabine River diversion channel, which is presently under construction, could provide an alternate source but is limited by its design capacity to an ultimate flow capability of $446 \mathrm{cfs}$. The Houston River, while with water of better quality than the Calcasieu Ship Channel, has an average flow availability of less than 2.000 cfs; thus. this site would be less desirable than the other two Lake Charles sites from a water availability standpoint. Therefore, a matrix rating of 7 was assigned for nuclear and fossil plants.

\subsubsection{Highway, Rail, and Water Access}

Kansas City southern Railroad runs near the site and provides an excellent corridor for train delivery of coal. Barge unloading is not economically feaslble fur this site due to excessive distance to the Calcasieu ship Channel. Highway access is also poor, since the site is served by secondary roads. A matrix rating of 15 for fossil and 5 for nuclear plants has been assigned.

\subsubsection{Foundations}

Refer to Lake Charles Site A. Section 2.1.5.

\subsubsection{Water Supply Systems}

Construction requirements for water supply systems are more expensive for Lake Charles site $c$ due to its greater distance $(7,000 \mathrm{ft})$ from the Houston River. Treatment costs, however, are less, since the water is of better quality. A matrix rating of 7 was assigned for both nuclear and fossil considerations. 


\subsubsection{Land Costs}

The land costs for this site are expected to be low since it is in a remote location. There is no present use of land adjacent to the site other than Gulf states vtilities Corapany's Nelson station located nearby. The higher elevation tends to offset the remoteness of the site. A matrix rating of 5 was assigned for nuclear and fossil plants.

\subsubsection{Steain Supply/Demand Match}

Refer to Steam Supply/Demand Match, Lake Charles Site $A$, Section 2.1.8.

4.2 PHYSICAI AND ENVIRONMENTAI,/LICENSING CONSIDERATIONS

\subsubsection{Wastewater Impact}

Same as Lake Charles site A. See Section 2.2.1.

4.2.2 Cooling Water Inpact (Nuclearl

Same as Lake Charles Site A, Section 2.2.2.

\subsubsection{Land Use}

This site, zoned inaustrial commercial, is remotely located from industrial and residential communities and is close to an existing electric generating plant: therefore, no conflicts are expected from land use. Matrix ratings of 10 were assigned.

\subsubsection{Land Requirements}

This landlocked site contains approximately 700 acres, sufficient to support either a fossil or a nuclear plant. Consequently, matrix ratings of 25 and 20 were assigned for fossil and nuclear plant siting, respectively.

\subsubsection{Geology}

Refer to Lake Charles Site A. Section 2.2.5. Matrix ratings of 17 and 15 were assigned to nuclear and fossil plants. respectively.

\subsubsection{Hydrology}

Similar to site A, Site C has a higher elevation than Lake Charles site $B$ and is desirable from a hydrological standpoint. Therefore, matrix ratings of 20 and 15 were assigned for nuclear and fossil plants, respectively. 
4.2.7 Seismology

Refex to North Baton Rouge, Section 1.2.7.

4.2.8 Meteorolosy

Same as Lake Charles Site A. See Section 2.2.8.

4.2.9 Ecology and Croplands

Same as Lake Charles Site A. See Section 2.2.9.

4.2.10 Air Quality (Fossil)

Same as North Baton Rouge, Section 1.2.10.

4.2.11 Radiological Considerations (Muclear)

Lake Charles site $C$ meets the LPZ and population center boundary distance guidelines with $a$ distance of 3.0 and 4.0 miles, respectively. It is therefore adequate for a nuclear site. Because these distances are adequate, but do not exceed guidelines by a significant margin, a matrix rating of 20 was assigned.

\subsubsection{Demography (Nuclear)}

Refer to Demography, Lake Charles Site A, Section 2.2.12.

The city of Lake Charles, located 5 miles east of the candidate site, has a population of approximately 84,000. Other population concentrations include: Hollywood, located 3.5 miles southwest, with a population of 2.500: Sulphur, located 5 miles west northwest, with a population of 14,600; and Westlake, located 2.2 miles northeast, with a population of 4.400. A matrix rating of 14 was assigned.

\section{2 .13 Noise Impact}

Sinilar to Lake Charles site $B$. The nearest residential coramurity of Westlake is approximately $2 \mathrm{miles}$ distant. Matrix ratings are 4 for nuclear and 8 for fossil plants, as in Site $B$.

\subsubsection{Proximity to Hazardous Facilities (Nuclear)}

Lake Charles Site $C$ is located approximateiy 12,000 feet from a facility that contains potentially hazardous materials. A matrix rating of 20 was assigned. 


\subsection{SOCIOECONOMIC CONSIDERATIONS}

\subsubsection{Transportation}

The site has access to rail and secondary highway systerns. The transportation of fuel to the plant and of wastes from the plant by rail would have little impact on rail transportation corridors. The transportation of ash wastes from the plant by highway may present problems depending upon the location of the disposal site and onsite waste áisposal must be seriously considered. Accordingly, a matrix rating of 5 has been assigned to nuclear plants and 12 to fossil plants.

\subsubsection{Community Impact}

Same as Lake Charles $A$, Section 2.3.2.

4.3.3 Archaeolonical and Historical Impact

Same as the other Lake Charles sites.

4.3.4 Visual Inivact

Visual impact is not expected because of the remote location of this site. The full-value matrix ratings of 5 and 10 were assigned to both the nuclear and fossil plants, respectively.

\subsubsection{Transuission/Steam Line Impact}

Same as North Baton Rouge, Section 1.3.5. 


\subsection{TECHNICAL/ENGINEER ING CONS IDERATIONS}

\subsubsection{Site Preparation}

As previously indicated, soil stratification appears to be somewhat more uniform in the Orange region than in the Lake Charles area.(3) Nearby chemical plants are typically founded on piles ranging in length from 50 to 70 feet, with pile design Load capacities from 40 to 60 tons. Piles are usually founded in a medium-dense fine sand at these depths. Irmediately overlying this sandy bearing stratum is a silty clay ranging in consistency from firm to very stiff. Depending on the magritude of foundation-bearing pressures, large mat foundations inight conceivably be founded on this higher silty clay layer, depending on design criteria for gross and differential building settlements. The silty clay stratum is not a problem in terms of liquefaction. Thus, depth of excavation for a nuclear plant, or length of piles for a fossil plant, apyear to be less at orange than at lake Charles.

Salt water encroachment in the groundwater aquifers is a concern in the Orange area. Therefore, any construction dewatering that may be required will necessitate a thorough evaluation to assess its impact on existing groundwater wells in the region.

The proposed sites are adjacent to swampy terrain bordering the Sabine River. protection in the form of impervious earth dikes appear necessary to preclude flooding at the proposed sites. Considering these factors, Matrix values of 7 were assigned to sites $A$ and $B$ for both types of plants.

\subsubsection{Proximity to Load Demand}

The steam custorners in the Orange region are clustered in a reasonably small area. The distance from site $A$ to the users varies from 5,000 to 10,000 feet. By observation, Site A was rated 20 for Proximity to Load Demand.

\subsubsection{Water Fuailability}

The Sabine River is the principal source of surface water. The average flow at BonWier, Texas, several miles upstream of the site, is 6,528 cfs with a minimum measured daily flow of 134 cfs and a maximum daily flow of 115,000 cfs. A power plant would not increase the total consumption of water. since steam supplied by the plant replaces existing customer supplies. In this way. the plant does not create new demands but reduces overall consumption through more

$$
A-28
$$


flexible and efficient operation. Maximum plant water use equals 0.46 percent of the average river flow and 22 percent of the minimum flow. A matrix rating of 15 was assigned for nuclear and tossil plants.

\subsubsection{Righway, Rail, and Water Access}

This region is served by two major railway lines, the Missouri Pacific Railroad and the Southern Pacific Railroad. These lines provide rail connections to the southwestern. far western, and central states. The Kansas City Southern Railroad is located $14 \mathrm{miles}$ north of Orange and provides excellent interchange with the Missouri Pacific Railroad. The Sabine River and Northern Railroad, a short line of 30 miles, connects with four major railroads including the Missouri Pacific, Southern Pacific, Kansas City Southern, and Santa Fe. Interstate 10 is a major highway connecting with points to the east and west. The Gulf Intracoastal Waterway intercepts the Sabine and Neches Rivers south of Orange and links Orange to area water transportation. Orange is served by a deep channel link to the Gulf via the Sabine River and the Intracoastal Waterway. Barge unloading of fuel does not appear economical. Matrix ratings of 5 and 20 were assigned to nuclear and fossil plants, respectively.

\subsubsection{Foundations}

See the section Site Preparation, above. In accordance with the conditions indicated, values of 11 were assigned both sites for each type of plant.

\subsubsection{Water Supply Systems}

The construction requirements of water supply systerns, such as makeup and service water. should not pose unusual problems. An intake structure placed on a branch of Cow Bayou may provide water of better quality than the sabine River. However, because of the unknown flows of Cow Bayou, the site must also be evaluated based on the use of the Sabine River as the water source. Matrix ratings of 8 were assigned to both nuclear and fossil plants.

\subsubsection{Land Costs}

Land costs are expected to be high because of the proximate location to the industrial complex and the Sabine River. offsetting the advantages is the relatively low elevation of the site. Therefore, a matrix rating of 3 was assigned to both nuclear and fossil. 


\subsubsection{Steam Supply/Demand Match}

The steam demand in the orange region can be supplied from an intermediate-size IWR, and both sites in this region were given the maximun matrix rating of 15 for steam Supply/Demand Match for nuclear plants; both sites were rated 10 in the fossil consideration.

\subsection{PHYSICAL AND ENVIRONMENTAL/LICENSING CONSIDERATIONS}

\subsubsection{Wastewater Impact}

The wastewaters from the power plant will have no adverse effect on water quality since all applicable restrictions and regulations will be net. Matrix ratings of 4 for nuclear and 9 for fossil were assigned.

\subsubsection{Cooling Water Impact (Nuclear)}

The normal flow through the Sabine River should be adequate for emergency cooling: however, reservoirs or ponds may be reruired to ensure adequate ooling water supply during dry periods or under varying tidal conditions. The peak emergency core cooling load is estimated at 270 miliion Btu/hr. On the basis of evaporative cooling, a makeup flow of approximately $40 \mathrm{cfs}$ is required. This flow represents about 30 percent of the minimum measured daily flow and 0.6 percent of the average flow. A matrix rating of 4 was assigned.

\section{2 .3 Land Use}

Since: the sile is zuned industrial and lucated near the steam users and some distance from any residential community, it is unlikely to have conmercial or residential value. The relatively low elevation of the site and its remoteness make it likely to be used for industrial purposes. A matrix rating of 10 was assigned for both nuclear and fossil plants.

\section{2 .4 Land Requirements}

Site $A$ is snaller than Orange site B, totaling approximately 300 acres. This acreage is adequate to support either a fossil or a nuclear plant. Consequently, matrix ratings of 20 and 15 were assigned for nuclear and fossil sites. respectively. 


\section{2 .5 Geology}

The Orange salt dome is located several miles north of the proposed site.(7) The oil field adjacent to the site does not appear to be associated with the Orange salt domes, but is associated with sone minor faulting mapped in the region. This faulting uay be an extension for the lowa fault zone described in the Geology section for the lake charles region.

The nearby faults nay require considerable offsite and onsite geologic investigations for nuclear plant siting.

Subsidence is not a significant problem in the proposed region.

Subsurface stratigraphy consists of interbedded fine sands and silty clays.(3) Individual soil layers appear to be appreciably thicker than at Lake Charles; $i . e .$. deposits are less heterogeneous. Accordingly, variations in depth to firm bearing strata and resulting lengths of piles are less than in the Lake Charles region.

The geological considerations lead to the assignment of 15 and 12 to nuclear and fossil plant sites, respectively.

\section{2 .6 Hydrology}

The Orange site is a part of the flat Texas Coastal plain that extends along the Gulf coast. It is located on the Sabine River about $15 \mathrm{miles}$ northeast of Port Arthur. The elevation of the site area ranges from 12 to 20 feet above mean sea level. The average discharge rate of the Sabine River in the Orange site area is 6,000 to 8,000 cfs. This flow is partially regulated by the Toledo Bend Reservoir (completed in 1966) located 90 miles upstream. The peak discharge within the last 90 years, which occurred on May 22, 1953, was 121,000 cfs. This discharge resulted in a water level of approximately 29 feet above mean sea level at Ruiloff. Texas. Since the Orange site is located on a wider floodplain about $18 \mathrm{miles}$ downstream, the area to disperse the floodwaters is larger. Therefore, the flood elevation would be lower. It is estimated that a 20-foot flood level at Ruiloff would translate to about a 15-foot flood level above mean sea level at the orange site area. This estimate is subject to further hydrologic investigation. Therefore. it appears that the degree of plant flood protection or hardening would be miniulal. Maximum matrix ratings of 20 and 15 were assigned to nuclear and fossil plants. respectively. 


\section{2 .7 Seismology}

Refer to section 1.2.7 under the North Baton Rouge description. As indicated therein, the precedent licensing of the Blue Hills Nuclear plant with $0.13 \mathrm{~g}$ acceleration has caused a slight downgrading of the Orange sites to matrix values of 17 .

\section{2 .8 Meteorology}

The climate is humid subtropical and essentially the same as the North Baton Rouge site. Temperatures below freezing occur on the average of 11 days per year. The precipitation and mean temperature are shown on Table A-2. Maximum matrix ratings of 15 were assigned to both nuclear and fossil plants.

TABLE A-2

\section{ANMUAL MEAN PRECIPITATION AND TEMPERATURE} ORANGE REGION

\begin{tabular}{ccc} 
Year & $\begin{array}{c}\text { Annual Mean } \\
\text { Precipitation (In.) }\end{array}$ & $\begin{array}{c}\text { Annua } \\
\text { Temperatu }\end{array}$ \\
\cline { 3 - 4 } 1969 & 47.31 & 66.9 \\
1970 & 51.63 & 69.4 \\
1971 & 45.42 & 69.2 \\
1072 & 58.96 & 68.9 \\
1973 & 78.90 & 67.4 \\
1974 & 63.24 & 68.6 \\
1975 & 86.15 & 68.2
\end{tabular}

5.2.9 Eoology and Croplands

As mentioned. Orange county is part of the flat Texas Coastal plain. The southern portion of the county is prairie land. whereas the northern portion is timberland. There are no known endangered species or croplands in the vicinity of the site and there should be little or no impact on the ecology. A matrix rating of 10 was assigned to both nuclear and fossil plants.

5.2.10 Air Quality (Fossil)

Same as the North Baton Rouge site: see Section 1.2.10. 


\subsubsection{Radiological Considerations (Nuclear)}

Orange Site A's LPZ distance is $1.7 \mathrm{miles}$. The population center boundary distance is 2.2 miles. This location is not favorable for a nuclear site. Consequently, it was assigned a matrix rating of 10 .

\subsubsection{Demography (Nuclear)}

As mentioned, Orange Site A is located about 15 miles northeast of Port Arthur. The population of the area known as Greater Orange is about 48,000. The population of Orange County is about 88,000 and is expected to reach 199,000 by 2020. The city of orange is the closest population center. located 3 miles north, with a current population of about 29,000. Currently, there are approximately 760,000 persons living within a 30 mile radius of the candidate region. This reflects a population density of 269 persons per square mile and a matrix rating of 20 .

\subsubsection{Noise Impact}

The nearest residential comnunity, West Orange, is almost 2 miles away. Serious impact problens are not anticipated; however. some noise prevention may be required in the design of a fossil plant. We have appointed a matrix rating of 10 for fossil and 5 for nuclear plants.

5.2 .14 Proximity to Hazardous Facilities (Nuclear)

Orange Site $A$ is located approximately 4.000 feet from a facility that contains potentially hazardous materials. A matrix rating of 12 was assigned.

\subsection{SOCIOECONOMIC CONDITIONS}

\subsubsection{Transportation}

The site has access to rail and highway systems. The transportation of fuel to the plant would have no major adverse effects on the transportation corridors. Waste transportation by highway may present problems depending upon the location of the disposal sites. The nuclear matrix rating is 5 , the fossil rating 13 .

\subsubsection{Community Impact}

Orange Site $A$ is located about 15 miles from Port Arthur. which has a population of over 40,000, and 4 miles from the city of Orange, described in Section 5.2.12. As indicated in section 1.3.2, the addition of construction workers plus their families (about 3,200 persons) should have little

$$
\text { A }-33
$$


impact on the infrastructures of this area. Also, the relatively longer distance to the surrounding communities indicates that the movement of men, material, and machines during plant construction should not have major impact on the conmunities. A matrix rating of 10 was assigned to both nuclear and tossil plants.

\subsubsection{Erchaeological and Historical Impact}

There are no known archaeological or historical sites within the vicinity of the site. Therefore, matrix ratings of 5 were assigned.

\section{3 .4 Visual Impact}

The location of the site poses no visual problems, since the area is located in an existing industrial commity. Matrix ratings of 5 and 9 have been assigned to nuclear and fossil plants, respectively.

\subsubsection{Transmission/Steam Line Impact}

Same as North Baton Rouge, Section 1.3.5. 


\subsection{TECINICAL/ERTGINEER ING CONS IDERATIONS}

\subsubsection{Site Preparation}

Refer to Site Preparation, Orange Site A, Section 5.1.1.

\section{1 .2 Proximity to Load Demand}

All steam users are located within a distance of 8,000 feet from Site B, which was given the maximum rating of 25 .

\section{1 .3 Water Availability}

This site is landlocked and would require piping water from the Sabine River or Cow Bayou, thus incurring greater cost than site A. A matrix rating of 15 was assigned for both nuclear and fossil plants.

\subsubsection{Higlrway, Rail, and Water Access}

Site B is similar to Orange site A except there is no access to water transportation. Matrix rating is 5 for a nuclear plant, 20 for a fossil plant.

\subsubsection{Foundations}

Refer to Orange Site A, Section 5.1.5.

6.1.6 Water Supply Systems

This site is similar to Orange site A; however, supply lines from the Sabine River or from Cow Bayou would be longer (approximately 12,000 feet) and more expensive. The assigned matrix rating is 7 for both plants.

\subsubsection{Tand Cost.s}

Land costs of Site $B$ are similar to Orange site A. While land elevation is higher than site $A$, it lacks water transportation. In accordance with this. costs can be expected to be lower than Site A. A matrix rating of 5 was assigned to both muclear and fossil plants.

6.1.8 Steam Supply/Demand Match

Refer to Steam Supply/Demand Match, Orange Site A, Section 5.1.8. 
6.2 PHYSICAL AND ENVIRONMENTAL/LICENSING CONSIDERATIONS

6.2.1 Wastewater Impact

Same as Orange Site A, Section 5.2.1.

6.2.2 Cooling Water Impact (Muclear)

Same as Orange Site $A$, Section 5.2.2.

6.2 .3 Land Use

Same as Orange Site A, Section 5.2.3.

6.2 .4 Land Requirements

Site $B$ contains approximately 580 acres and is adequate to support either a nuclear or fosisil plant. Matrix ratings of 25 and 20 were assigned for fossil and nuclear plants. respectively.

6.2 .5 Geology

Same as Orange Site A, Section 5.2.5.

6.2 .6 Hydrology

Same as Orange Site A. Section 5.2.6.

6.2 .7 Seismology

See North Baton Rouge, Section 1.2.7, and Orange Site A, Section 5.2.7.

6.2 .8 Meteorology

Same as Section 5.2.8.

6.2 .9 Ecology and Croplands

Same as Section 5.2.9.

6.2 .10 Air Quality (Fossil)

Same as the North Baton Rouge site; see Section 1.2.10.

6.2.11 Radiological Considerations (Nuclear)

Orange Site B has an LPZ distance of 1.5 miles and a population center boundary distance of 3.4 miles. This is not favorable for a nuclear site; consistent with orange Site $A$, a matrix rating of 10 was assigned. 
6.2.12 Demography (Nuclear)

Refer to Demography, Orange site A, Section 5.2.12. The city of Orange is the closest population center to orange Site B. located 3.4 miles northeast. There are about 760.000 persons living within a $30-\mathrm{mile}$ radius of the candidate site. This reflects a population density of 269 persons per square mile and a matrix rating of 20 .

6.2.13 Noise Impact

Noise impact at this site is the same as orange Site $A$, except that the distance to residential west orange is slightly less. The matrix ratings are 5 for nuclear and 10 for fossil plants.

\subsubsection{Proximity to Hazardous Facilities (Nuclear)}

Orange Site $B$ is located approximately 4.500 feet from a facility which contains potentially hazardous materials. A matrix rating of 12 was assigned.

6.3 SOCIOECONOMIC CONSIDERATIONS

6.3.1 Iransportation

Same as Orange Site A, Section 5.3.1.

6.3.2 Community Impact

Same as Orange Site $\mathrm{A}$, Section 5.3.2.

6.3.3 Archaeological and Historical Impact

Same as Section 5.3.3.

6.3 .4 Visual impact

Same as Section 5.3.4.

6.3.5 Transmission/Steam Iine Impact

Same as North Baton Rouge. Section 1.3.5. 
7.1 TECHNICAL/ENGINEERING CONSIDERATIONS

\subsubsection{Site Preparation}

All four Geismar reyion sites are relatively flat with a slight dip in ground surface elevation away from the Mississippi River. Sites $A, B$, and $D$ have varying amounts of heavily wooded and cattle grazing lands. Site $C$ is almost entirely without heavy tree stands.

Nuclear plant requirements necessitate that poor bearing capacity soils be excavated to almost 100 feet and replaced by well-compacted backfill at all four Geismar sites. This massive excavation is further complicated by a need to dewater the excavation until building foundations and walls are poured up to grade. The groundwater level at the four Geismar sites fluctuates seasonally with the Mississippi River.(1) Much of the year the groundwater level is probabiy near the ground surface. Thus, construction dewatering must start at the beginning of excavation and operate for several years until plant construction reaches at least existing ground surface elevation. This would require an extremely large dewatering system, and the impact of construction dewatering operations on neighboring wells in the Geismar area must be thoroughly evaluated.

Pile foundations would be required in a fossil plant to bypass the soft clays and transfer structure loads to the dense alluvial sand.

The potential impact on the construction schedule due to required deep excavation or installation of very long piles for both nuclear or fossil plants leads to low matrix ratings at all four Geismar sites. Matrix ratings of 5 and 8 points were assigned for nuclear and fossil plants, respectively.

\subsubsection{Proximity to Load Demand}

This site is located at the north end of all steam customers and was rated 10 for Proximity to Load Demand. The distances from Site A to the steam users vary from 10,000 to 25,000 feet.

\subsubsection{Water Availability}

The Mississippi River is the potentlal source of water. The low-water flow of the Mississippi near Baton Rouge is approximately $100,000 \mathrm{cfs}$. The average flow of the 
Mississippi is about 419,000 cfs with a maximum recorded flood flow of $2,280,000$ cfs.

Ample water is available for the needs of the power plant. The maximum water consumption requirement of the plant is about 0.0007 percent of the average river flow. Therefore, a matrix rating of 20 was assigned to nuclear and fossil plants.

\subsubsection{Highway, Rail, and Water Access}

Baton Rouge is the major rail center. The Illinois Central Railroad traverses the site and the Illinois Central, Texas and Pacific. Louisiana and Arkansas, and South Shore Railroads serve the Mississippi region.

Interstate Highways 10 and 12 are the principal highways of this region. Interstate 10 connects New orleans, Baton Rouge, and Lafayette: Interstate 12 runs in an east-west direction from Baton Rouge to Alabama. There are secondary routes linking Geismar to the Baton Rouge area.

The Mississippi River qualifies as a navigable waterway and in this region handles considerable annual tonnage of barge and ocean freighter traffic. The proximity of this site to a bend in the river creates potential hazards to river navigation and raises the question of feasible barge unloading of fuel. Detailed studies are required to affirm the suitability of the site for barge unloading. Prelininary review indicates matrix ratings of 5 for nuclear and 10 for fossil plants.

\subsubsection{Foundations}

Overexcavation and replacement with well-compacted backfill. required at all Geismar sites, minimize the concern for total and differential settlements, assure adequate static and dynamic bearing capacity, and preclude liquefaction during the design earthquakes for nuclear plants.

In order to construct a fossil plant at any Geismar site, pile foundations at least 100 feet long, with their tips at the top of the alluvial sand. would provide design capacities of about 50 to 60 tons. By ariving the piles 10 to 20 feet into the alluvial sand, significantly higher pile capacities of up to 150 tons could be obtained. if required. However, handling and installing 110-to 120-foot long piles is expensive. Caiseone are not ecorunically competitive with pile foundations because of the high groundwater table. soft soil conditions, and large depth of penetration required.(3) 
On the other hand, installation of a pile foundation for a fossil plant, in contrast to the required overexcavation and backfill required for a nuclear plant, is advantageous in that it does not require the installation and operation of a construction dewatering system.

Weighing these considerations, matrix ratings of 8 and 7 were assigned for nuclear and fossil plants, respectively. at all four Geisuar sites.

\subsubsection{Water Supply Systems}

Along the river bank is a revetment and levee at this site. No special or unusual construction features are required for water systems other than routing the piping over the levee. The distance to the river is approximately 5,000 ft. Water supply systems for all Geismar sites were given a matrix rating of 8 for both plants.

\subsubsection{Land costs}

The site is located next to an existing industrial comunity and land costs are expected to be less than North Baton Rouge but more than Orange. Because Site A is located on the river bend and is less conducive to barge loading and unloading, it would be less expensive than the other sites at Geismar. A natrix rating of 4 was assigned.

\subsubsection{Steam Supply/Demand Match}

The steam demand in the Geismar region is about 30 percent more than can be supplied by an intermediate-size LWR. AII sites for nuclear plants in the region were rated 12 . As stated in section 1.1.8, all fossil plants were given the maxinum matrix rating of 10 .

\subsection{PHYSICAL AND ENVIRONMENTAL/LICENSING CONSIDERATIONS}

\subsubsection{Wastewater Impact}

Same as the North Baton Rouge site (see Section 1.2.1). All Geismar sites were assigned maximun matrix ratings of 5 for nuclear and 10 for fossil plants, respectively.

\subsubsection{Cooling Water Impact (Nuclear)}

The high flow availability of the Mississippi River causes the impact from cooling water to produce a negligible effect on the river should emergency cooling be required. See Cooling water Impact. Section 1.2.2. A matrix of 5 was assigned. 


\section{2 .3 Land Use}

Since Geismar Site $A$ is zoned industrial and located adjacent to an industrial complex, the use of the site for a power plant is compatible with the surrounding area. Therefore, a matrix rating of 9 was assigned for both nuclear and fossil plants.

\subsubsection{Land Reguirements}

Site $A$ is the smallest of the Geismar sites (approximately 64 acres) and cannot support either a nuclear or fossil plant. Consequently, matrix ratings of 1 and 0 were assigned to nuclear and fossil plant land requirements. respectively.

other siting factors are considered because the site may serve as reserve for developing future energy production alternatives.

\section{2 .5 Geology}

The Geismar region, containing sites A, B, C, and D, is dominated by its proximity to the Darrow salt dome located south of the proposed sites, and the st. Gabriel salt dome and oil and gas fields located to the north.(5,6) Oil, gas, and brine are being extracted from the Darrow salt dome vicinity. The combined withdrawal of fluids north and south of the Geismar region sites is leading to widespread subsidence in this area.(1,2) The four proposed Geismar sites are on the Mississippi River floodplain, and U.S. Army Corps of Engineers levees have been constructed to protect the area from flooding. Future widespread subsidence of several feet may necessitate increasing the height of the levees to ensure an adequate level of protection against floods.

The Lake Arthur fault zone is believed to be buried about 5 miles south of Geismax, trending in an east-west direction. The significance of this buried fault in nuclear plant licensing is likely to necessitate considerable offsite geological investigations.

The combination of nearby salt domes and a buried fault are indicators of possible development of slump faults in the Geismar area.

The subsurface stratigraphy in the Geismar region consists of soft pleistocene clays and silts to a depth of approximately 100 feet, overlying dense alluvial sand deposits.(3) There are thin sand lenses and layers within the Pleistocene deposits. The alluvial sand deposit is typically about 50 feet thick and provides an excellent 
bearing stratum for deep foundations. Conversely, the 100-foot thick Pleistocene clay deposits are so soft that they would have to be excavated for a nuclear plant or bypassed with piles for a fossil plant. The presence of soft deposits below any coal storage yard may result in very stringent operating procedures on the storage of coal: i.e.. the maximum height and rate at which the coal could be stacked may have to be carefully controlled so as to preclude a massive bearing capacity failure of the underlying soft clays. Alternatively, some of the soft clays could be excavated below any proposed coal storage pile and replaced with well-compacted backfill.

Liquefaction is not a licensing concern, assuming the soft Pleistocene clays were removed and replaced by a well-compacted backfill between excavation grade and the desired foundation grade.

As a result of the above review, matrix rating values of 15 and 12 were assigned for nuclear and fossil plants, respectively, at all Geismar sites.

\section{2 .6 Hydrology}

As mentioned earlier, the Geismar site slopes slightly downward away froli the Mississippi River levee. Immediately adjacent to the river, the elevation is about 25 feet above mean sea level. The elevation of the area ranges from about 16 to 20 feet above raean sea level. The levee in the area is about 15 feet hiqher than the adjacent land which provides a protective height of about 40 feet above mean sea level. The peak historical flow, occurring May 13, 1975, was $1,248,000 \mathrm{cfs}$, approximately three times the averaqe annual flow rate. (i) The peak gage height occurred April 14. 1973. and reached a height of 35.8 feet above mean sea level.(1) Since the land elevation decreases with distance from the river, a nuclear plant would require protection against flooding either through elevating the grade. "hardening" any openings below elevation 35.8 fect, or both. The matrix rating of 16 was designated for muclear plants and 12 for fossil plants.

\subsubsection{Sei smology}

Refer to this topic under the North Baton Rouge region. Note that the epicenter of the "local" design earthquakes governing the $O B E$ ana $S S E$ for Geismar was located at Donaldsonville, Louisiana, which is approximately 7 miles from the Geismar sites. Since the epicenter of the Donaldsonville earthquake is not precisely known. considerable investigation is anticipated to satisfactorily document this seismic event. 
As previously indicated, matrix rating values of 20 and 10 were assigned to nuclear and fossil plants, respectively. for all four Geismar sites.

\section{2 .8 Meteorology}

The meteorology is similar to North Baton Rouge (see Section 1.2 .8 ). A matrix rating of 12 was assigned.

\subsubsection{Ecology and Croplands}

Generally, Geismar is surrounded by cultivated croplands and pasturelands. Major crops include corn, sweet potatoes, Irish potatoes, sugar cane, and soybeans. Natural flora include tupelo gum, bald cypress, hackberry, ash, box elder. and sycamore. There are no known endangered species in this area and no impact is expected since all discharges will meet applicable standards and will not threaten croplands or the ecology. A matrix rating of 8 was assigned to both nuclear and fossil plants.

\section{2 .10 Air Quality (Fossil)}

The Gei smar area ground-level concentrations with associated background levels and federal air quality standaras are shown in Table A-3.(14) Other studies performed for this area indicate that the air quality in this area will not impact the licensability of this site. The matrix rating assigned is 18 . 
TABLE A-3

GEISMAR AREA GROUND-LEVEL CONCENTRATION OF CONTAMINANTS COMPARED TO NATIONAL AIR QUALITY STANDARDS

\begin{tabular}{lll} 
Concentration & Primary & Secondary \\
Background & Air Quality & Air Quality \\
Levels & Standard & Standard \\
\hline
\end{tabular}

Particulates, ug/m3

$\begin{array}{llll}\text { Annual average conc. } & 36 * & 75 & 60 \\ \text { Maximum 24-hr conc. } & - & 260 & 150\end{array}$

Sulfur Dioxide, ppm

$\begin{array}{llll}\text { Annual average conc. } & 0.001 * & 0.03 & 0.02 \\ \text { Maximum 24-hr conc. } & - & 0.14 & 0.10 \\ \text { Maximum 3-hr conc. } & - & - & 0.50\end{array}$

Nitrogen Oxides, ppm
Annual average conc. $0.032 *$
0.05
0.05

* Data supplied by Gulf states Utilities taken at three sites in the St. Gabriel area for 1975. 


\subsubsection{Radiological Considerations (Nuclear)}

Geismar Sites A, B, C, and D have a population center boundary distance of 18 miles. The population density (approximately 110 persons per square mile) within any reasonable LPZ makes the Geismar sites favorable for a nuclear plant location. Therefore, the Geismar sites received a high matrix rating of 25 .

\subsubsection{Demography (Nuclear)}

Geismar Site A, located in south-central Louisiana, is 16 miles south-southeast of Baton Rouge. The current population within a 30 -mile radius of the candidate site is about 313,000 , reflecting a population density of 110 persons per square mile. It is estimated that this region will contain a population of about 709,000 by 2020 . The town of Gonzales, located $\dot{b}$ miles east-northeast, is the closest population concentration and has a current population of approximately 6,250. Other population concentrations include Donaldsonville, located 7 miles south-southeast, with a current population of about 10,200, and Baton Rouge, located 16 miles north-northwest, with a current population of about 209,000. A matrix rating of 25 was assigned. The above demographic information is also applicable to Geismar Sites B, C, and D.

\subsubsection{Noise Impact}

The nearest residential conumity is Gonzales, located more than 4 miles away. Since the plant is situated in an industrial complex with relatively high ambient noise levels, no additional impact would be expected on the distant residential community. In accordance with this information, a matrix rating of 10 has been assigned to fossil plants, a rating of 5 to nuclear plants.

\subsubsection{Proximity to Hazardous Facilities (Nuclear)}

Geismar Site A is located approximately 3,000 feet from a facility that contains potentially hazardous materials. A matrix rating of 8 was assigned.

\subsection{SOCIOECONOMIC CONSIDERATIONS}

\subsubsection{Transportation}

The area has access to rail, highway, and water transportation, but as indicated in section 7.1.4, use of the Mississippi River as a transportation corridor is in doubt. However, the impact on river traffic may be significant if fuel is unloaded by barge. There would be 
little, if any, impact on rail or highway systems if fuel is delivered by rail and wastes are trucked away. $A l 1$ the Geismar sites have been assigned full-value transportation matrix ratings of 5 for fossil and 15 for nuclear plants.

\subsubsection{Community Impact}

As mentioned, Geismar Site A is located 16 miles from Baton Rouge (population approximately 209.000). Within 10 miles of the site are several towns with a total population of 17.000. Therefore, as stated in Section 1.3.2, the addition of construction workers plus their families (about 3.200 persons) should have little impact to the area's infrastructure. The transportation of men and equipment during plant construction should not affect the surrounding communities because of their distance from the site. A matrix rating of 10 was assigned for both nuclear and fossil plants.

\subsubsection{Archaeological and Historical Impact}

There are no known archaeological sites in the vicinity of Site $A$. The Belle Helene Plantation, a historic landmark, would not be affected because of its distance from the site. A matrix rating of 5 was assigned.

\subsubsection{Visual Impact}

The nearest residential community, Gonzales, is 6 miles from the site. The surrounding area is largely industrial, so the plant would not create any visual impact problems. Matrix ratings of 5 and 9 were applied to nuclear and fossil plants, respectively.

\subsubsection{Transmission/Steam Line Inpact}

Same as North Baton Rouge. Section 1.3.5. 


\subsection{TECHNICAL/ENGINEERING CONS IDERATIONS}

\subsubsection{Site Preparation}

Refer to Site Preparation, Geismar Site A, Section 7.1.1.

\subsubsection{Proximity to Load Demand}

Site B lies north of the complex. The distance to steam users varies from 5,000 to 22,000 feet. Proximity to Load Demand was rated 20 for nuclear and 22 for fossil plants.

\subsubsection{Water Availability}

The site has the same excellent water availability as Geismar Site A, Section 7.1.3. The same matrix rating, 20 , was assigned to both types of plants.

8.1.4 Highway, Rail, and Water Access

The site has access to highway, rail, and water transportation as mentioned in the discussion of Geismar Site A. Concerning water transportation, the site is better than Geismar Site $A$ because it is farther from the river bend. It may be possible to utilize existing docking facilities of neighboring shell and Wyandotte industrial complexes. The nuclear matrix rating remains the same as Site A; however, due to better water access, the matrix rating for fossil fuel is 23 .

\subsubsection{Foundations}

Refer to Foundations, Geismar Site A, Section 7.1.5.

\subsubsection{Water Supply Systems}

Same as Geismar Site A.

\subsubsection{Lana Costs}

Similar to Geismar site $A$, but probably more expensive since barge unloading is feasible and, therefore, the property is more valuable. Matrix ratings of 3 were assigned.

\subsubsection{Steam Supply/Demand Match}

Refer to Steam Supply/Nemand Match, Geismar Site A. Section 7.1 .8 . 
8.2 PHYSICAL AND ENVIRONMENTAL/LICENSING CONSIDERATIONS

8.2.1 Wastewater Impact

Same as Geismar Site $\mathrm{A}$, Section 7.2.1.

8.2.2 Cooling Water Impact (Nuclear)

Same as Geisuar Site A, Section 7.2.2.

8.2.3 Lana Use

Same as Geismar Site A, Section 7.2.3.

8.2.4 Land Requirements

Site $B$ is the largest Geismar site, comprising approximately 600 acres, an ample area to support a nuclear or fossil plant. Consequently, matrix ratings of 25 and 20 were assigned for fossil and nuclear plants, respectively.

8.2 .5 Geology

Same as Geisnar Site A, Section 7.2.5.

8.2.6 Eydrology

Same as Geismar Site A, Section 7.2.6.

8.2.7 Seismology

Refer to Section 1.2.7 and Geismar Site A, Section 7.2.7.

8.2.0 Meteorology

Same as Geismar site A, Section 7.2.8.

8.2.9 Ecology and Croplands

Same as Geismar Site A, Section 7.2.9.

8.2.10 Air Quality (Fossil)

Same as Geismar Site A, Section 7.2.10.

8.2.11 Radiological Considerations (Nuclear)

See Section 7.2.11, Radiological Considerations.

8.2.12 Demography (Nuclear)

The demographic information contained in Section 7.2.12, Geismar Site A, is applicable. 
8.2.13 Noise Impact

Same as Geismar Site A, Section 7.2.13.

8.2. 14 Proximity to Hazardous Facilities (Nuclear)

Geismar Site $B$ is located approximately 4,000 feet from a facility that contains potentially hazardous materials. A matrix rating of 12 was assigned.

\subsection{SOCIOECONOMIC CONSIDERATIONS}

\subsubsection{Transportation}

Assuming fuel is delivered by barge or rail, no significant impact is expected on any of the transportation corridors. Accordingly, full-value matrix ratings of 5 and 15 were assigned, respectively. to nuclear and fossil plants.

8.3.2 Community Impact

Same as Geismar Site A, Section 7.3.2.

8.3.3 Archaeological and Historical Impact

Same as Geisuar Site A, Section 7.3.3.

8.3.4 Visual Impact

Same as Geismar Site A, Section 7.3.4.

8.3.5 Transmission/Steam Line Impact

Same as North Baton Rouge, Section 1.3.5. 


$$
9 \text { GEISMAR REGION - SITE C }
$$

9. 1 TECHNICAL/ENGINEERING CONSIDERATIONS

\subsubsection{Site preparation}

Refer to Geismar Site A. Section 7.1.1.

9.1.2 Proximity to Load Demand

This site is centrally located (all steam users lie within a distance of 10,000 feet) and was given the maximum rating of 25.

\subsubsection{Water Availability}

Same as Geismax site A.

9.1.4 Highway, Rail, and Water Access

Sane as Geismar site B:

9.1.5 Foundations

Refer to Geismar Site A, Section 7.1.5.

9.1.6 Water Supply Systems

Same as Geismar sites $A$ and $B$.

\subsubsection{Land Costs}

Same as Geismar site B.

9.1.8 Steam Supply/Demand Match

Refer to Geismar Site A, Section 7.1.8.

9.2 PHYSICAL AND ENVIRONMENTAL/LICENSING CONSIDERATIONS

\subsubsection{Wastewater Impact}

Same as Geismar Site A, Section 7.2.1.

\subsubsection{Cooling Water Impact (Muclearl}

Same as Geismar Site F, Section 7.2.2.

9.2.3 Iand Use

Same as Geismar Site A, Section 7.2.3.

$$
\text { A }-50
$$




\subsubsection{Land Requirements}

Site C contains approximately 500 acres and is able to support a nuclear or fossil plant. Consequently, natrix ratings of 25 and 20 were assigned for fossil and nuclear plant considerations, respectively.

9.2.5 Geology

Same as Geismax Site A, Section 7.2.5.

9.2.6 Hydrology

Same as Geismar Site A, Section 7.2.6.

9.2.7 Seismology

Refer to section 1.2.7 and Geismar site A, Section 7.2.7.

9.2.8 Meteorology

Same as Geismar Site A, Section 7.2.8.

9.2.9 Ecology and Croplands

Same as Geismár Site A, Section 7.2.9.

9.2.10 Air Quality (Fossil)

Same as Geismar Site A, Section 7.2.10.

9.2.11 Radiological Considerations (Nuclear)

Same as Geismar site A, Section 7.2.11.

9.2.12 Demography (Nuclear)

The demographic information continued in section 7.2.12, Geisual site A, is applicable.

9.2.13 Noise Impact

Same as Geismar Site A, Section 7.2.13.

9.2. 14 Proximity to Hazardous Facilities (Nuclear)

Geismar Site $C$ is located approximately 2,100 feet fxom a facility that contains potentially hazardous materials. A matrix rating of 5 was assigned. 
9.3 SOCIOECONOMIC CONSIDERATIONS

\subsubsection{Transportation}

Same as Geismar Site B, Section 8.3.1.

9.3.2 Community Impact

Same as Geismar Site A, Section 7.3.2.

9.3.3 Archaeological and Historical Impact

There are no known archaeological sites in this area. The proximity of the Belle Helene plantation (less than 1 mile) to this site may present a historical siting impact. Although there is a buffer zone, a matrix rating of 4 was assigneä.

\subsubsection{Visual Impact}

The site is quite far from any significant residential community (e.g... Gonzales is 6 miles distant). Due to plant visual impact of the Belle Helene plantation, matrix ratings of 4 and 6 have been assigned to nuclear and fossil plants, respectively.

\subsection{Transmission/Steam Line Impact}

Same as North Baton Rouge, Section 1.3.5. 
10 GEISMAR REGION - SITE D

10.1 TECHNICAL/ENGINEERING CONSIDERATIONS

10.1.1 Site Preparation

Refer to Geismar Site A, Section 7.1.1.

10.1.2 Proximity to Load Demand

Site $D$ is south of all of the steam customers, and distances to them vary from 8,000 to 18,000 feet. The site was rated 10.

10.1.3 Water Availability

Same as other Geismar sites.

10.1.4 Highway, Rail, and Water Access

Same as Geismar Sites $B$ and $C$.

10.1.5 Foundations

Refer to Geismar Site A, Section 7.1.5.

10.1.6 Water Supply Systems

Same as other Geismar sites.

10.1.7 Land Costs

The land costs and matrix rating would be similar to that for Geismar Sites $B$ and $C$.

10.1.8 Steam Supply/Demand Match

Refer to Geismar Site A, Section 7.1.8.

10.2 PHYS ICAL AND ENVIRONMENTAL/LICENSING CONSIDERATIONS

10.2.1 Wastewater Impact

Same as Section 7.2.1.

10.2.2 Cooling Water Impact (Nuclear)

Same as Section 7.2.2. 


\section{2 .3 Land Use}

The proximity of the Belle Helene plantation, a historical landmark, to Geismar D may present siting problems. Matrix ratings of 6 and 5 were assigned for nuclear and fossil plants, respectively.

\subsubsection{Land Requirements}

Site $D$ has a narrow configuration that limits its use for a nuclear plant site, and it has inadequate acreage (100 acres) for a fossil plant site. Consequently, matrix ratings of 2 and 0 were assigned for siting a nuclear and fossil plant, respectively. other siting factors are considered, however, since the site may serve as reserve for developing future energy production alternatives.

\section{2 .5 Geology}

Same as Section 7.2 .5 .

10.2.6 Bydrology

Same as section 7.2 .6 .

10.2.7 Seismology

Same as section 7.2.7.

10.2.8 Meteorology

Sane as Section 7.2.8.

10.2.9 Ecology and Croplands

Same as Section 7.2.9.

10.2.10 Air Quality (Fossil)

Same as section 7.2.10.

10.2.11 Radiological Considerations (Nuclear)

Same as Geismar Site A, Section 7.2.11.

10.2.12 Demography (Nuclear)

The demographic information contained in section 7.2.12, Geismar Site A, is applicable.

10.2. 13 Noise Impact

Same as section 7.2 .13 . 
10.2.14 Proximity to Hazardous Facilities (Nuclear)

Geismar Site $D$ is located approximately 3.500 feet from a facility that has potentially hazardous materials. It was assigned a matrix rating of 10 .

\subsection{SOCIOECONOMIC CONSIDERATIONS}

\subsubsection{Transportation}

As mentioned in Section 7.3 .1 on Geismar Site A, this site has adequate access to rail, water, and highway transportation. Therefore, there should be no impact of fuel or waste transportation on nearby communities. We have assigned a matrix rating of $S$ to a nuclear plant, 15 to a fossil plant.

\subsubsection{Community Impact}

Same as Geismar Site A, Section 7.3.2.

\subsubsection{Archaeological and Historical Impact}

There are no known archaeological sites in the region. However. the Belle Helene plantation. located on the adjacent property. may present siting problems. Consequently, a matrix rating of 2 has been assigned for nuclear and fossil plants.

\subsubsection{Visual Impact}

The site is sufficiently distant from the residential community of Gonzales to exclude any visual impact. The plant may visually impact the Belle Helene Plantation. Matrix ratings of 3 for nuclear plants and 4 for fossil plants were applied.

\subsubsection{Transmission/Steam Line Impact}

Same as North Baton Rouge. Section 1.3.5. 


\section{REFERENCES}

1. Personal communication with Messrs. M. McGrath and K. Dugas of Stamm Scheele, Incorporated, Rayne, Louisiana. July 1977.

2. Personal communication with Dr. C. Durham of Durham \& Associates, Baton Rouge, Louisiana, July 1977.

3. Personal communication with Messrs. D. Brown and H. Sprinkle of kaymond International, Incorporated, Metairie, Louisiana and Houston. Texas, July 1977.

4. Federal Register, Vol 39, No. 196, October 8, 1974.

5. Gulf States Utilities. Preliminary Safety Analysis Report, River Bend Nuclear Station - Units 1 and 2. Beaumont, Texas, September 1976.

6. Louisiana Power and Light Company- Preliminary Safety Analysis Report, Waterford Steam Electric Station. New Orleans, Louisiana, January 1971.

7. Gulf States Utilities. Preliminary Safety Analysis Report. Blue Hills Station. Beaumont. Texas. September 1976.

8. Gutenberg, B. and Richter, C. F. Earthquake Magnitude, Intensity, Fnergy and Acceleration. Bulletin of the Seismologic Society of America, Vol 46, No. 2, 1956.

9. Neumann, F. Earthquake Intensity and Related Ground Motion. University of washington Press, Seattle, Waslisigutun. 1954.

10. Trifunac, M. D. and Brady, A. G. On the Correlation of Seismic Intensity Scales with the Peaks of Recorded Strong Ground Motion. Bulletin of the Seismological Society of Anerica, Vol 65, No. 1, 1975.

11. Coulter, H. W.. Devine, J. F.. and Waldron, H. H. Seismic and Geologic siting Considerations for Nuclear Power Facilities. Fifth World Conference on Earthquake Engineering, Rome. Italy, 1973.

12. Environmental Statement for Sabine River Diversion Channel and Distribution System to Lake Charles Industrial Area. Barnard and Burk, Incorporated, Baton Rouge, Louisiana, Pebruary 1972.

13. Severe Local Storm Occurrences, 1955-1967. Technical Mernorandum WBTM FCST 12, Weather Bureau, U.S. Department of Commerce, 1969. 
14. Stone $\varepsilon$ Webster Engineering Corporation. Report on Air quality Control for Geismar station for Gulf States Utilities. Cherry Hill, New Jersey, March 1976. 
D
竞
$\frac{\mathrm{m}}{\mathbf{x}}$
$\mathbf{0}$

I 
제

(3)

(4) 
APPENDIX B

LIST OF DRAWINGS

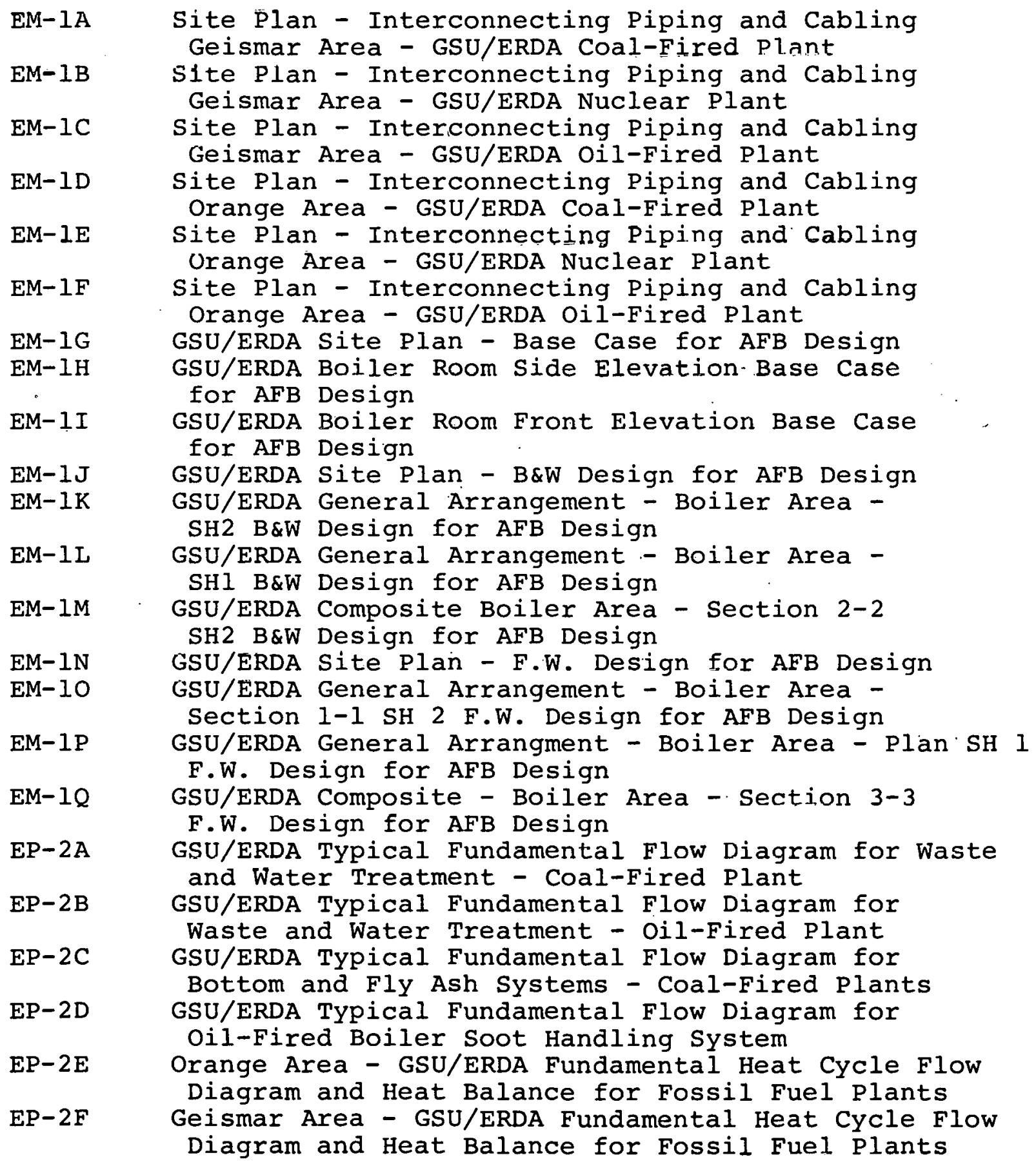




\begin{tabular}{|c|c|}
\hline$E P-2 G$ & $\begin{array}{l}\text { Orange Area - GSU/ERDA Fundamental Heat Cycle Flow } \\
\text { Diagram and Heat Balance for Consolidated } \\
\text { Nuclear Steam Supply }\end{array}$ \\
\hline $\mathrm{P}-2 \mathrm{H}$ & $\begin{array}{l}\text { Geismar Area - GSU/ERDA Fundamental Heat Cycle Flow } \\
\text { Diagram and Heat Balance for Consolidated } \\
\text { Nuclear Steam Supply }\end{array}$ \\
\hline$E P-2 I$ & $\begin{array}{l}\text { Geismar Area - GSU/ERDA Fundamental Heat Cycle Flow } \\
\text { Diagram and Heat Balance for High Temperature Gas- } \\
\text { Cooled Reactor Plant (HTGR Steamer). }\end{array}$ \\
\hline$E P-2 J$ & $\begin{array}{l}\text { Orange Area - GSU/ERDA Fundamental Heat Cycle Flow } \\
\text { Diagram and Heat Balance for High Temperature Gas- } \\
\text { Cooled Reactor Plant (HTGR Steamer) }\end{array}$ \\
\hline$P-2 R$ & $\begin{array}{l}\text { GSU/ERDA - Geismar Area Moving Bed Coal Gasification } \\
\text { Air Blown Block Flow Diagram }\end{array}$ \\
\hline$E P-2 S$ & $\begin{array}{l}\text { GSU/ERDA - Geismar Area Moving Bed Coal Gasification } \\
\text { Oxygen Blown Block Flow Diagram }\end{array}$ \\
\hline$E P-2 T$ & $\begin{array}{l}\text { GSU/ERDA - Geismar Area Lurgi Air Blown Gasifier } \\
\text { with Cold Purification, Gas Turbines, and Waste } \\
\text { Heat Recovery Boiler (Unlimited Power Output) }\end{array}$ \\
\hline$P-2 U$ & $\begin{array}{l}\text { GSU/ERDA - Geismar Area Lurgi A1r Blown Gasifier } \\
\text { with Cold Purification, Gas Turbine, Waste Heat } \\
\text { Recovery Boiler, and Steam Generator (Limited } \\
\text { Power Output) }\end{array}$ \\
\hline $\mathrm{EP}-2 \mathrm{~V}$ & $\begin{array}{l}\text { GSU/ERDA - Geismar Area Lurgi Air Blown Gasifier } \\
\text { with Cold Purification, Fuel Cell, and Waste Heat } \\
\text { Recovery Boiler (Unlimited Power Output) }\end{array}$ \\
\hline$P-2 W$ & $\begin{array}{l}\text { GSU/ERDA - Geismar Area Lurgi Air Blown Gasifier with } \\
\text { Cold Purification, Fuel Cells, Waste Heat Recovery } \\
\text { Boiler, and steam Generator (Limited Power Output) }\end{array}$ \\
\hline$F-2 \Lambda$ & Schematic Diagram of Phosphoric Acid Fuel Cell \\
\hline$K-1 A$ & $\begin{array}{l}\text { Orange Area - GSU/ERDA Fundamental Diagram of } \\
\text { Coal Handling System }\end{array}$ \\
\hline SK-IB & $\begin{array}{l}\text { Geismar Area - GSU/ERDA Fundamental Diagram of } \\
\text { Coal Handling System }\end{array}$ \\
\hline
\end{tabular}




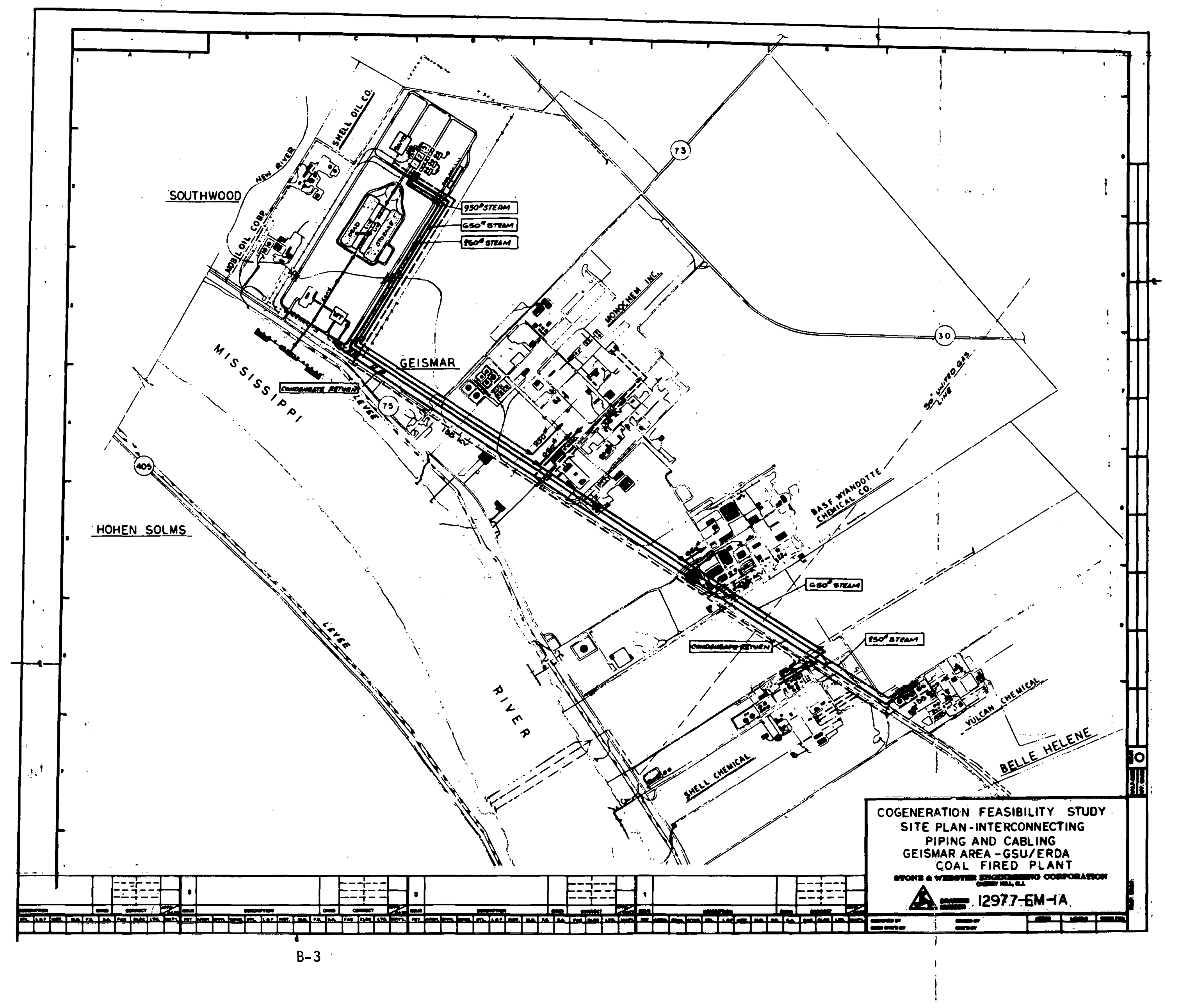




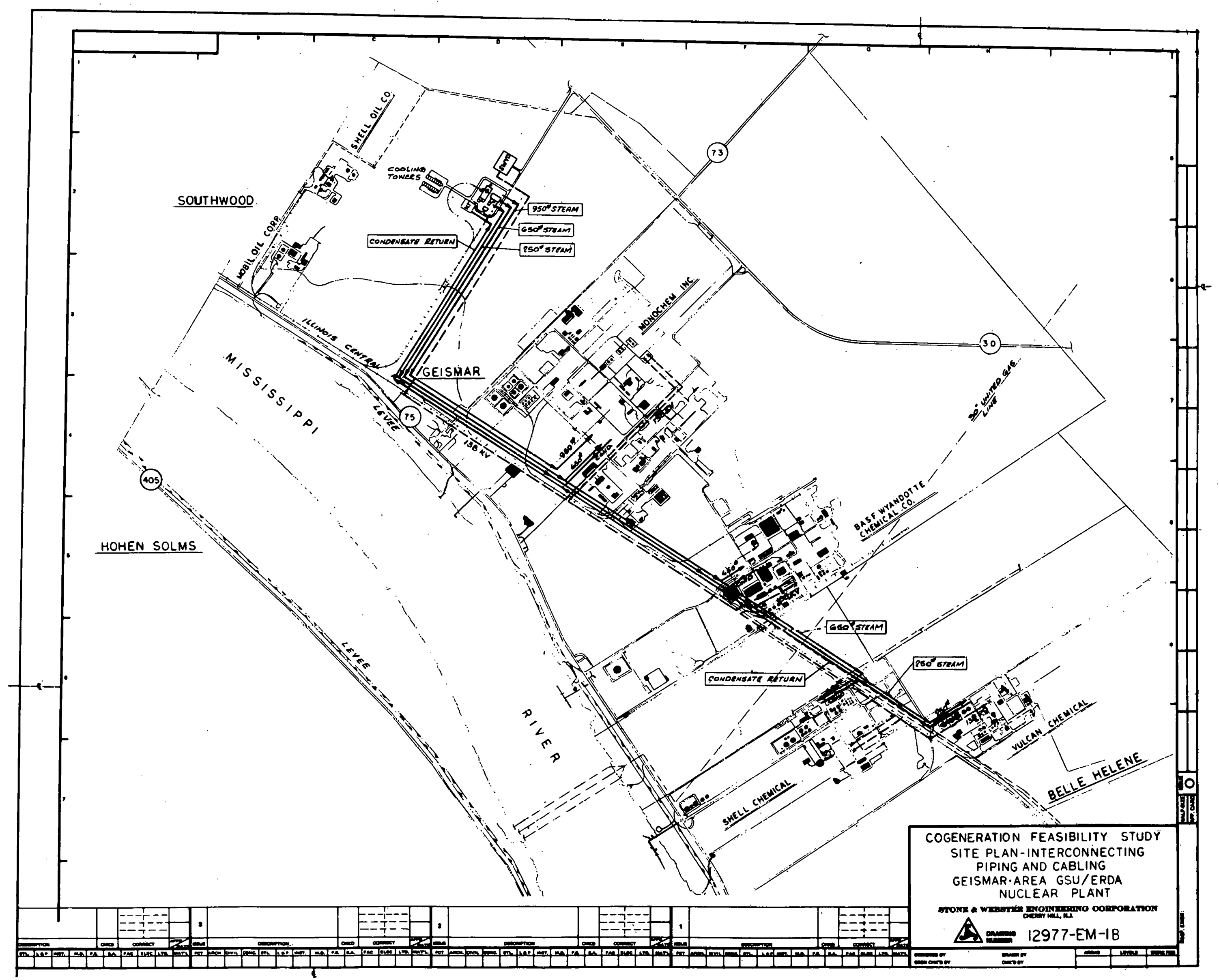




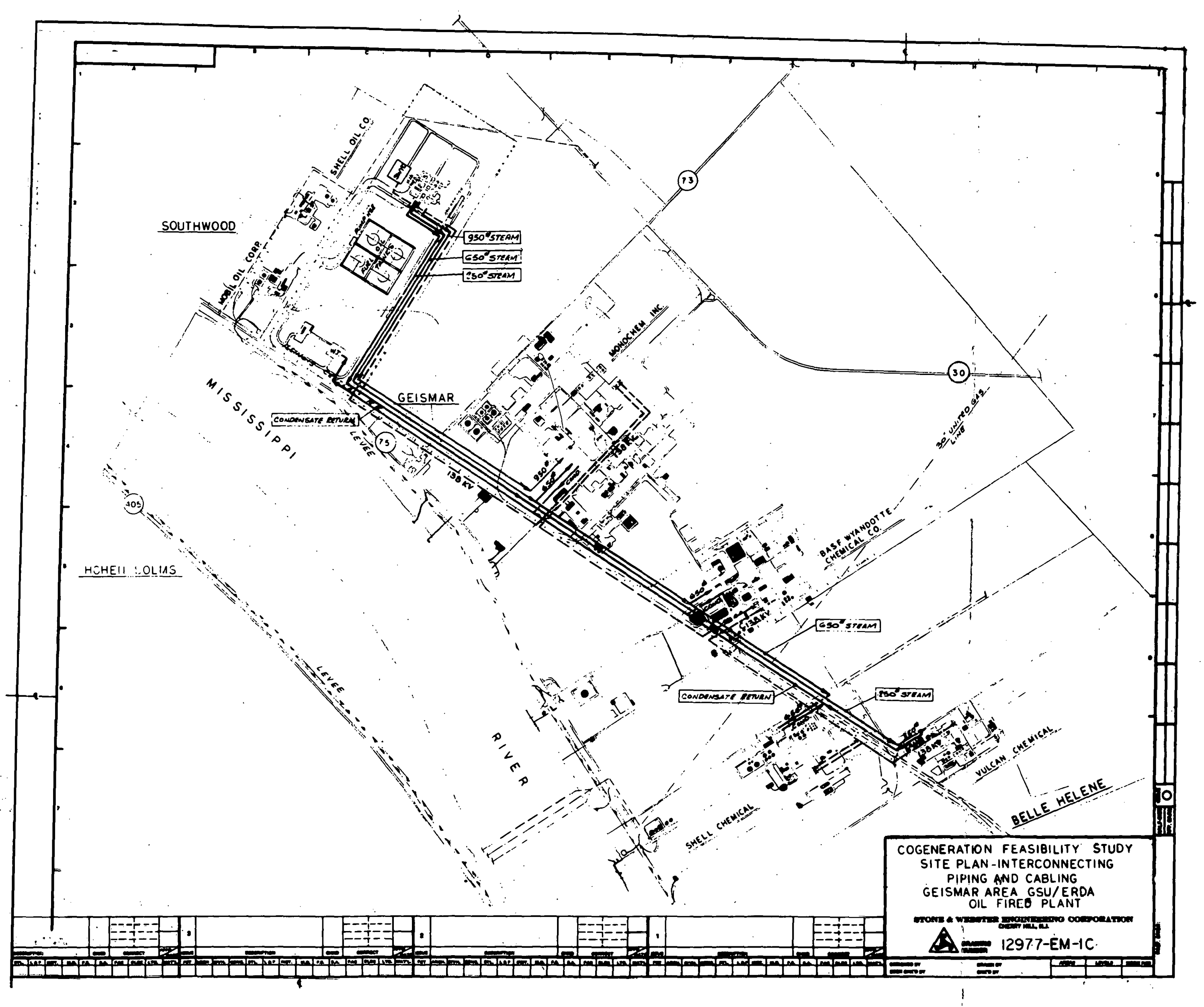




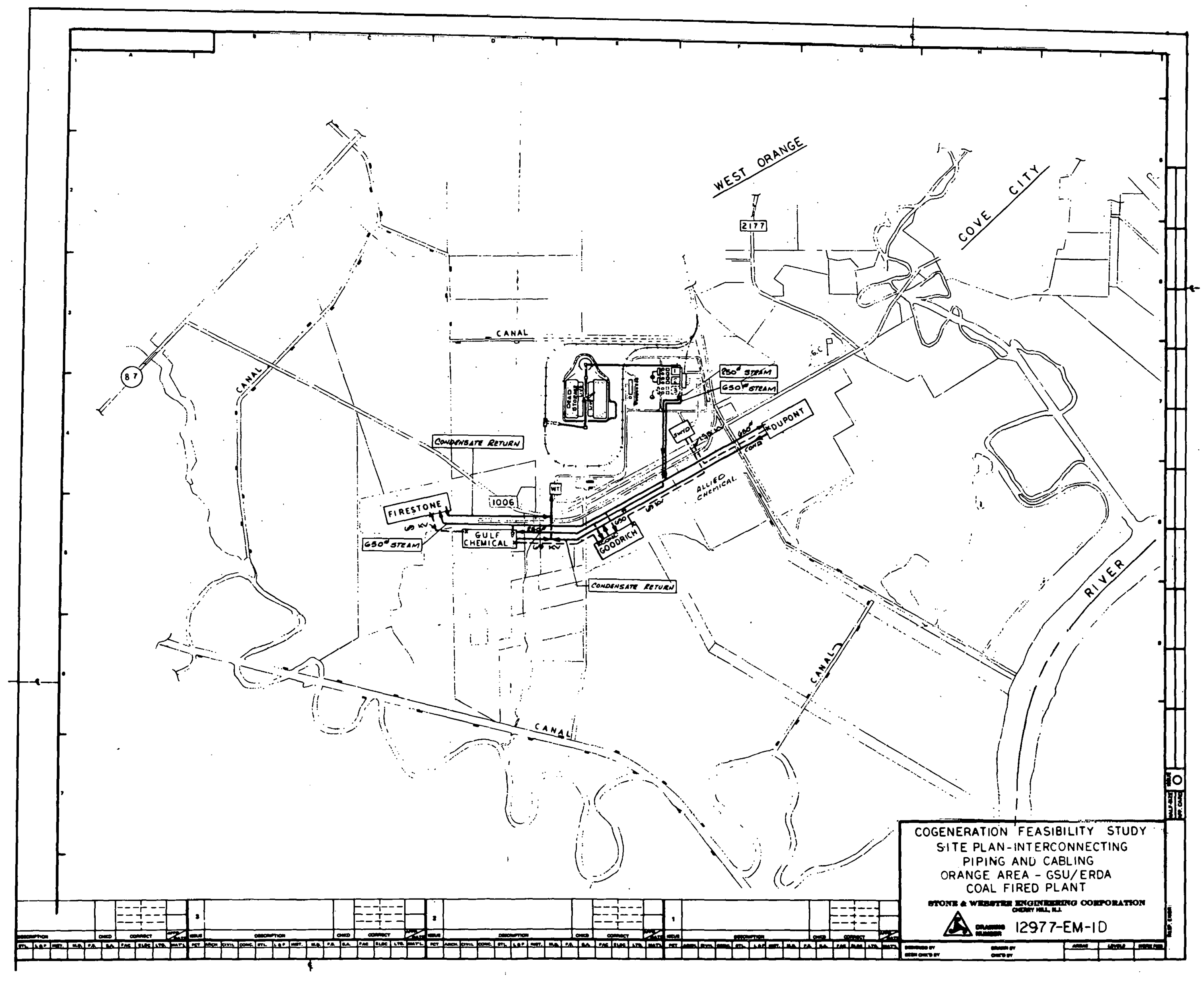




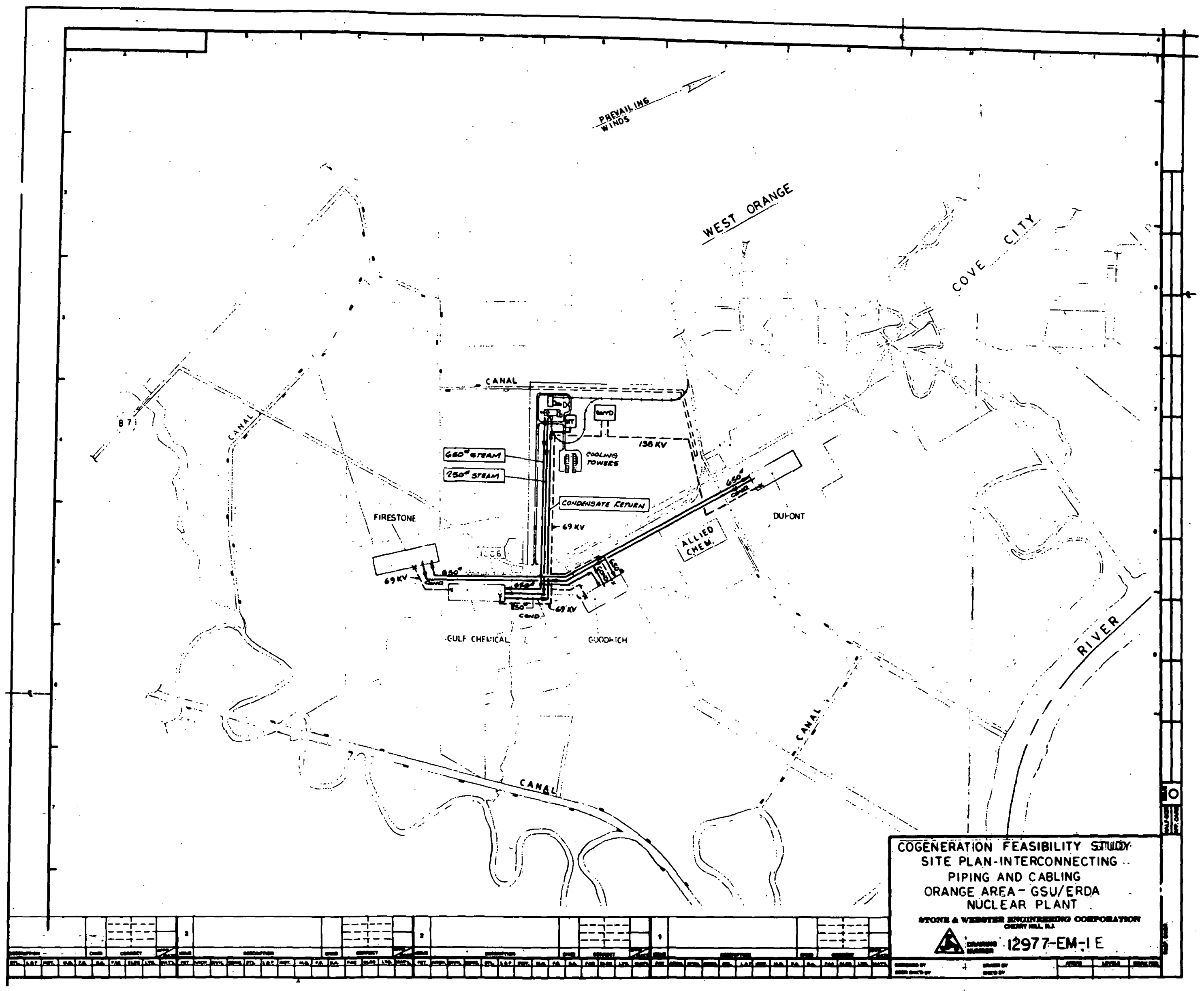




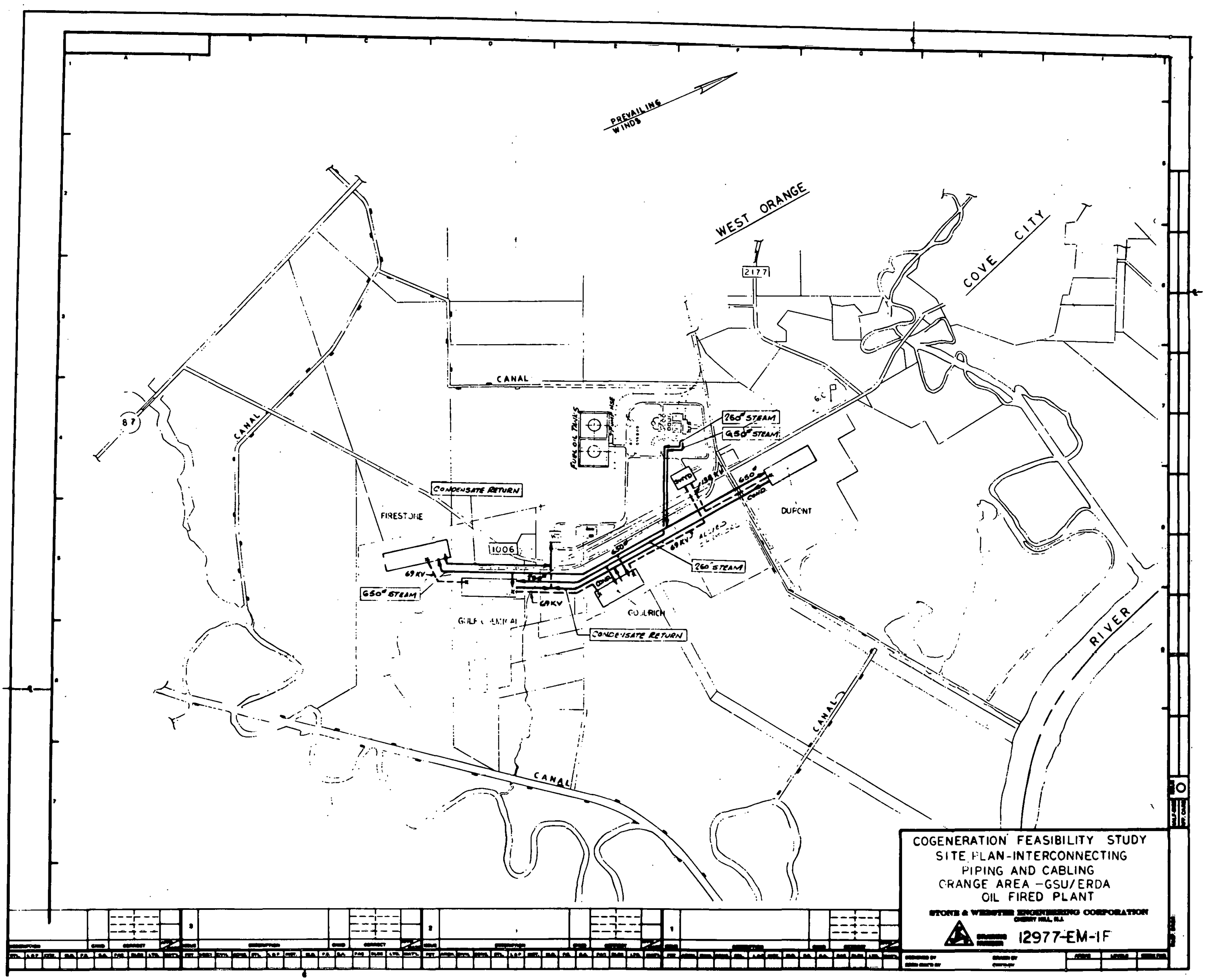




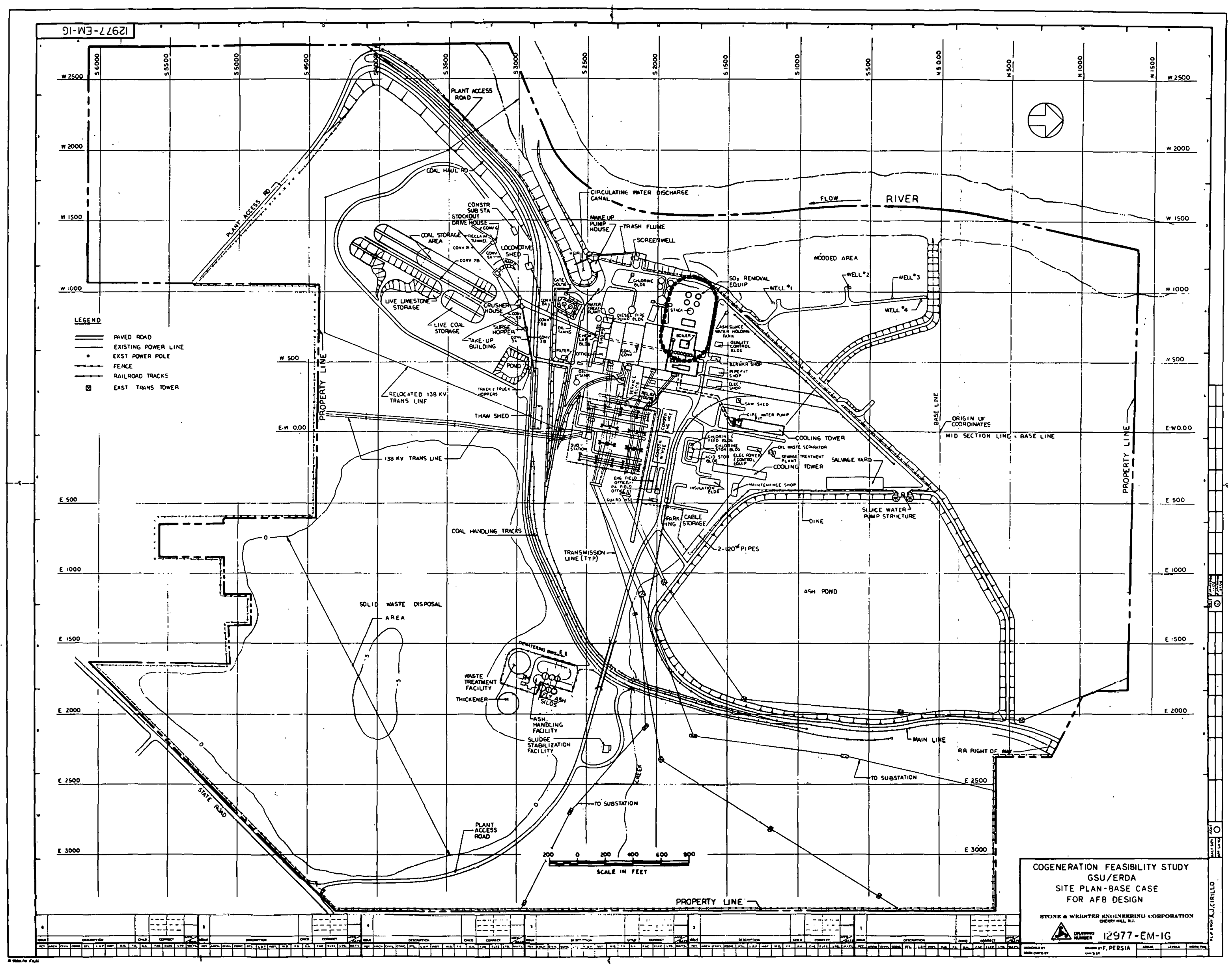




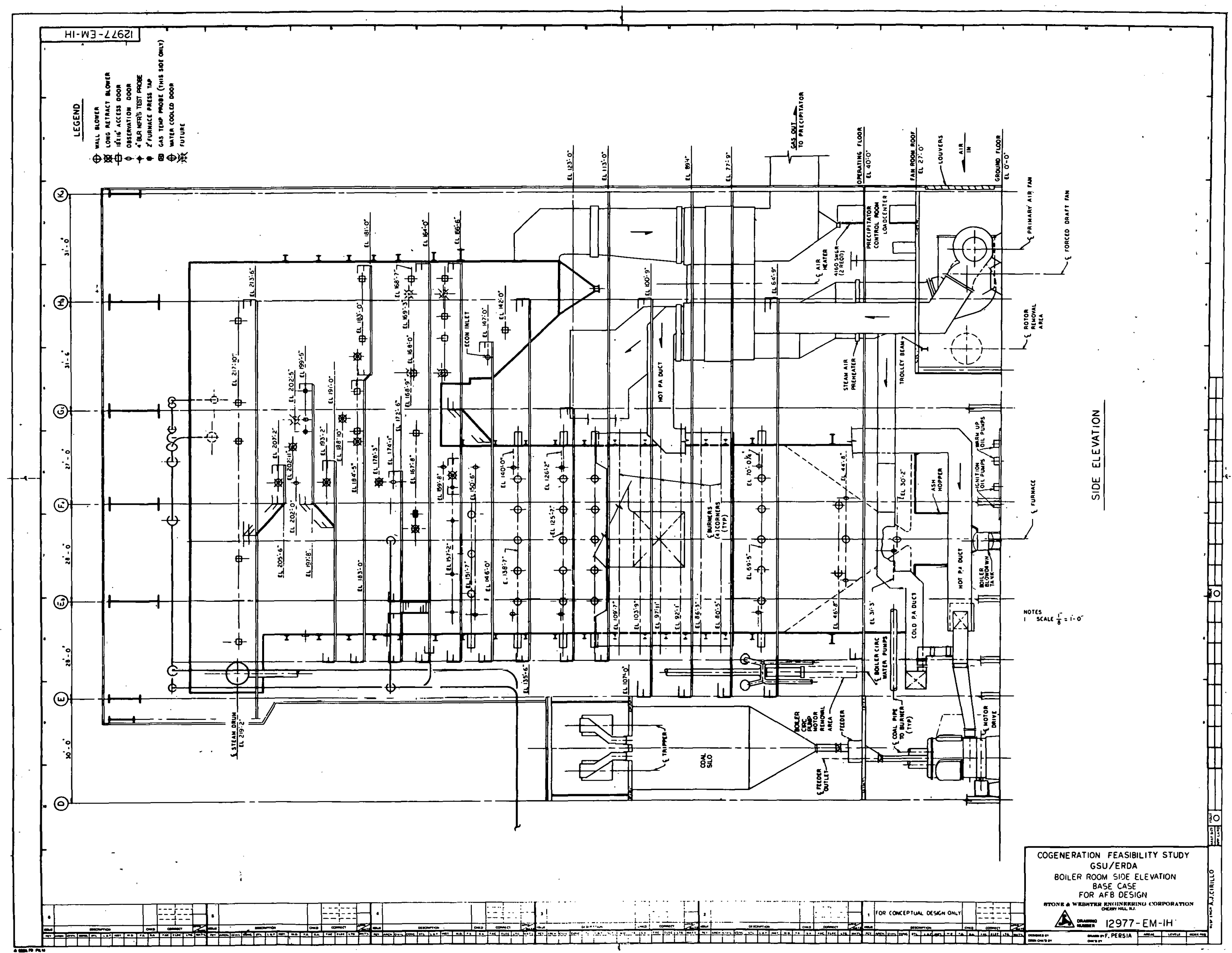




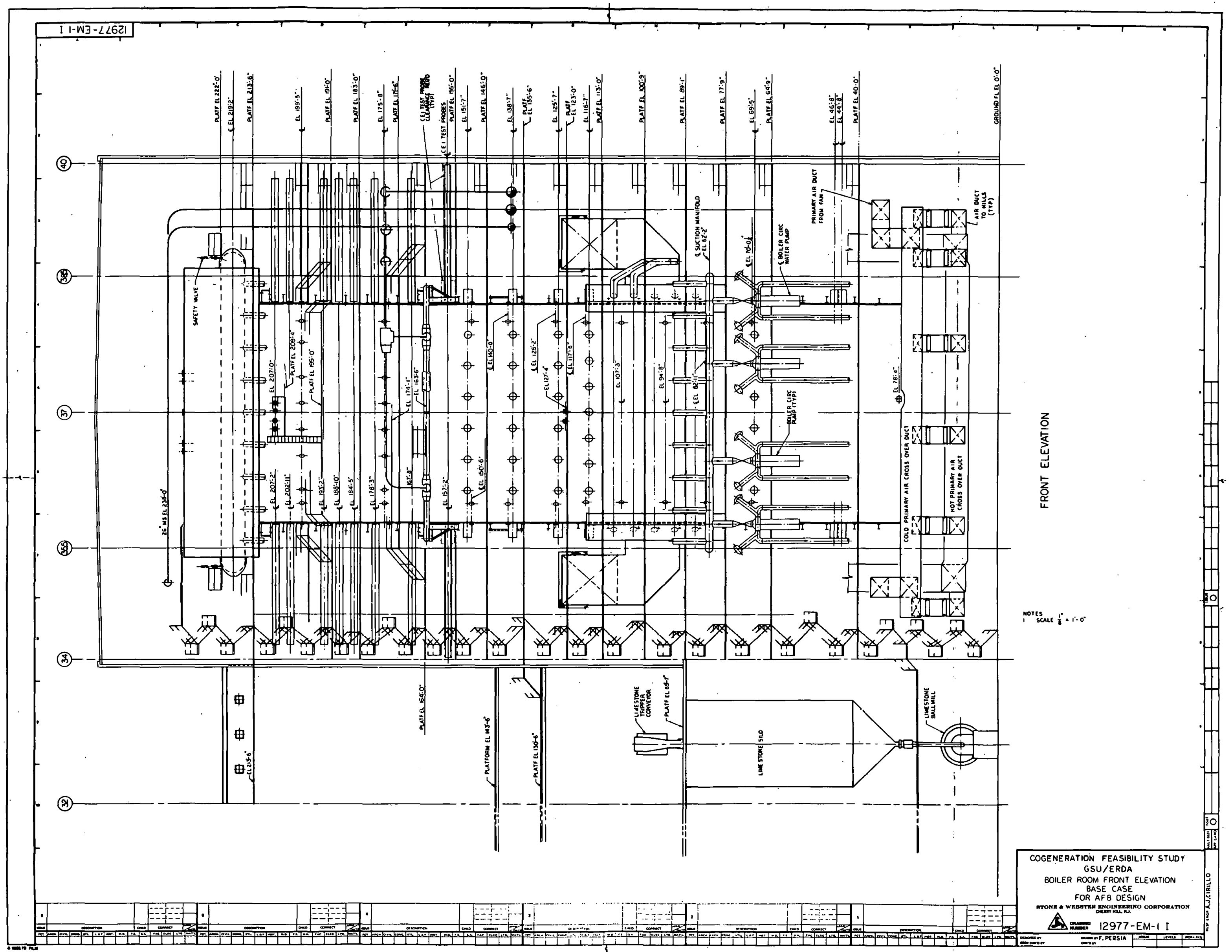




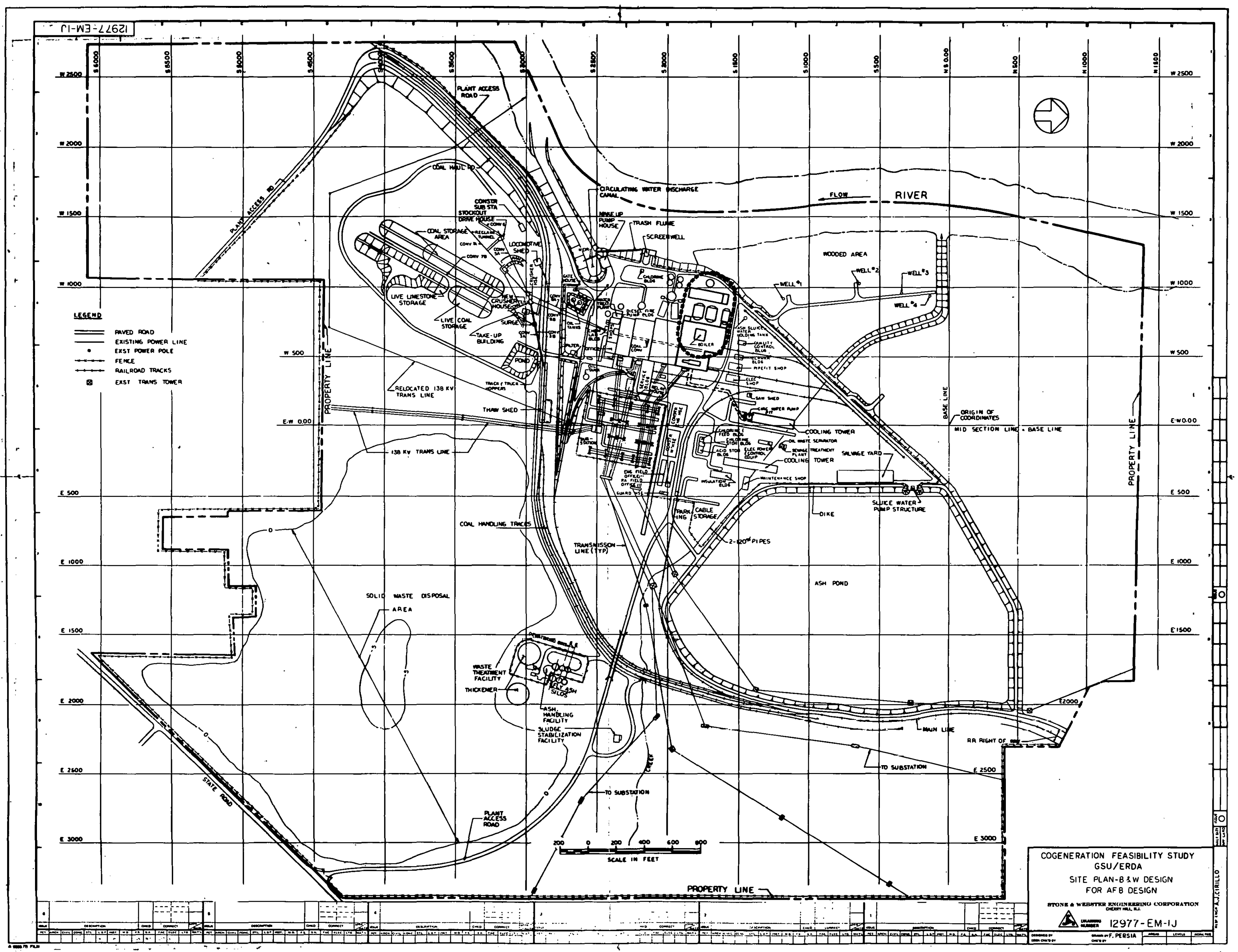




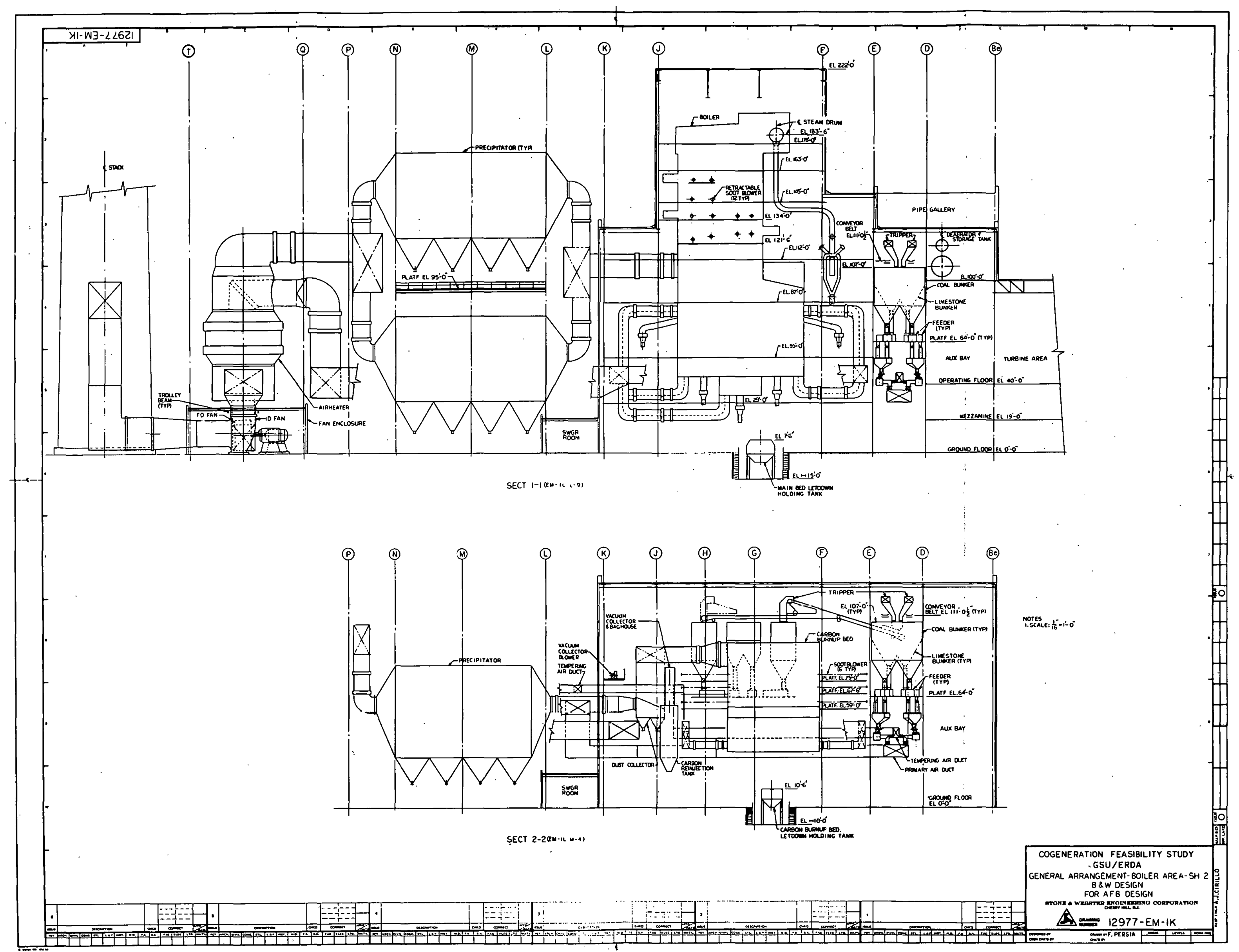




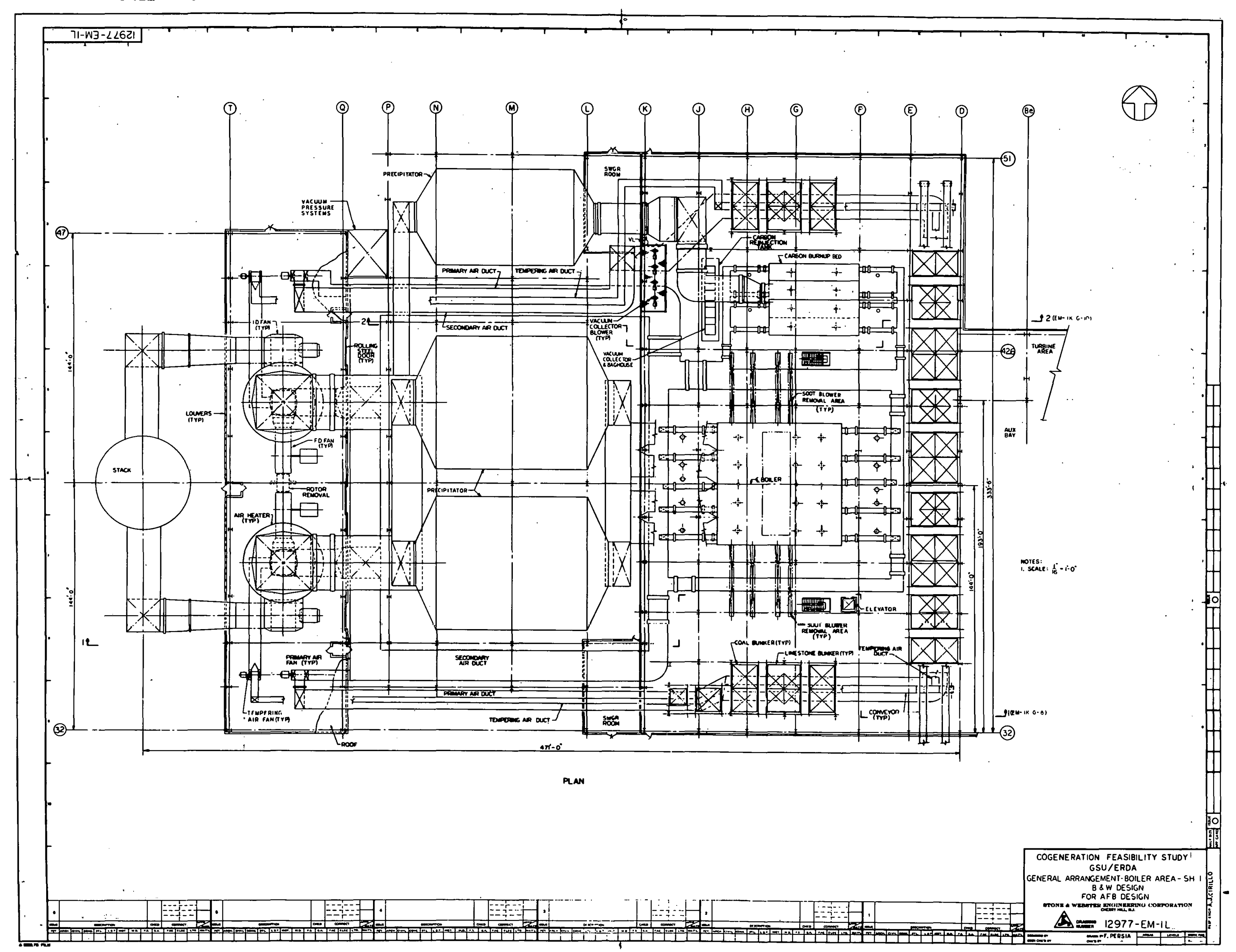




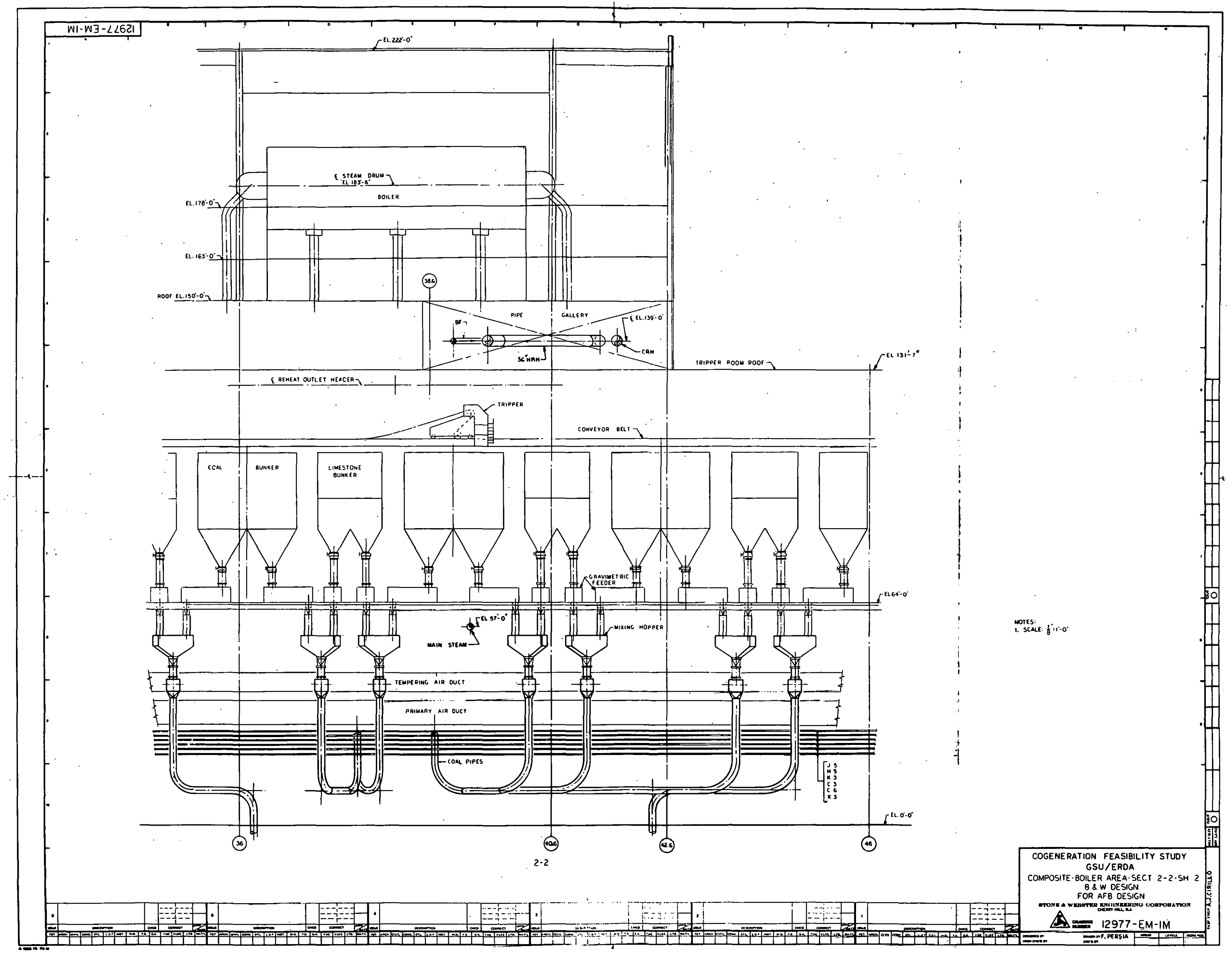




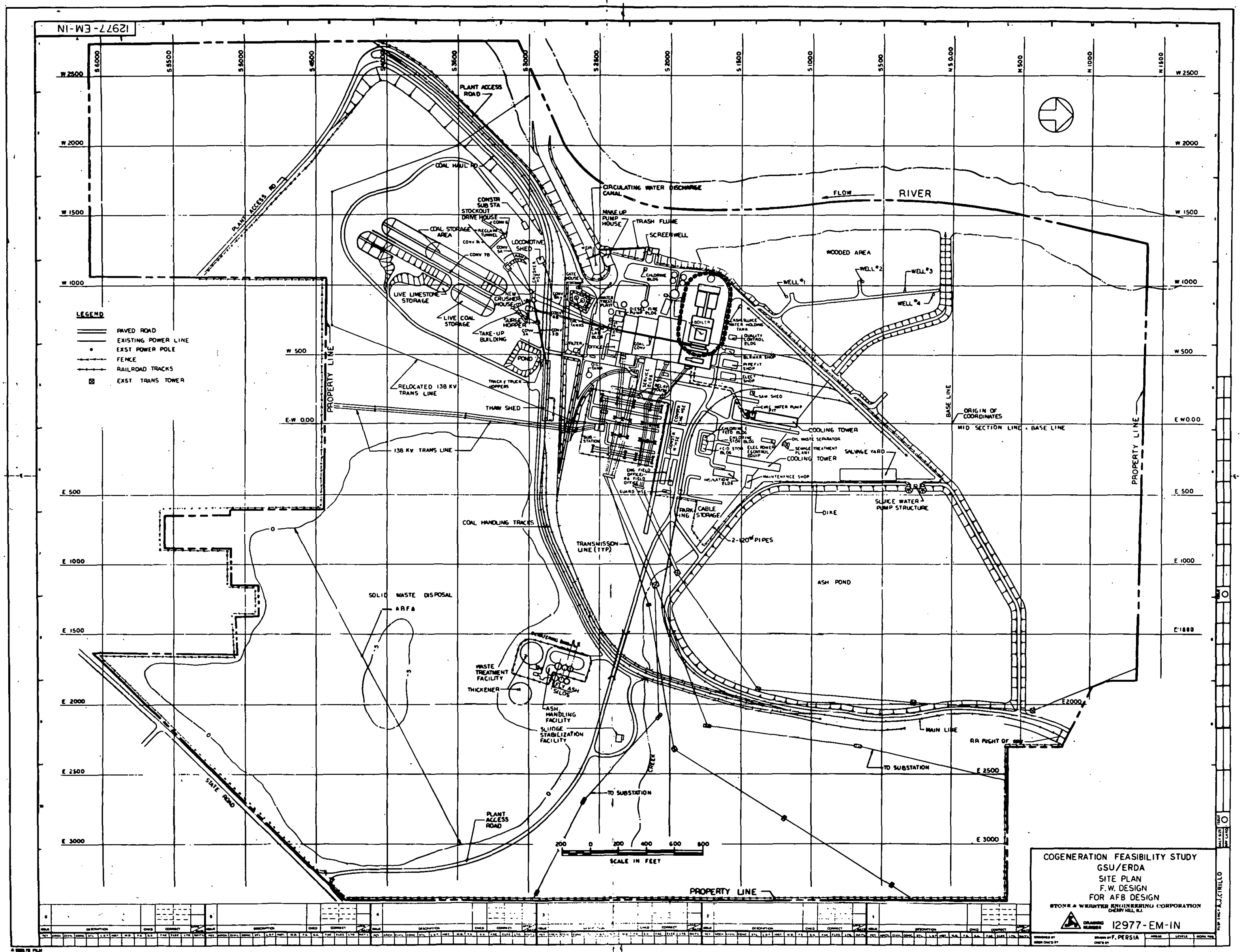




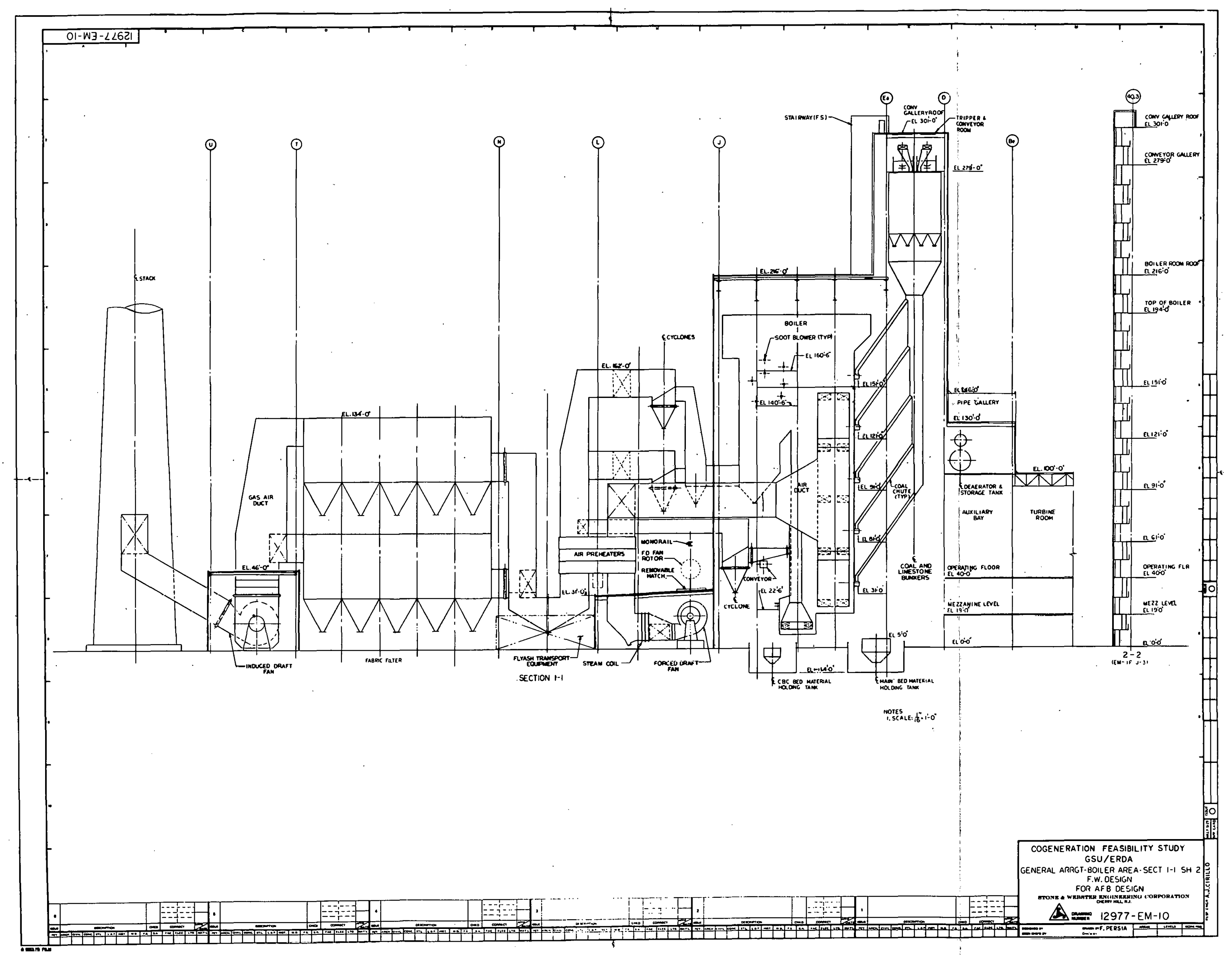




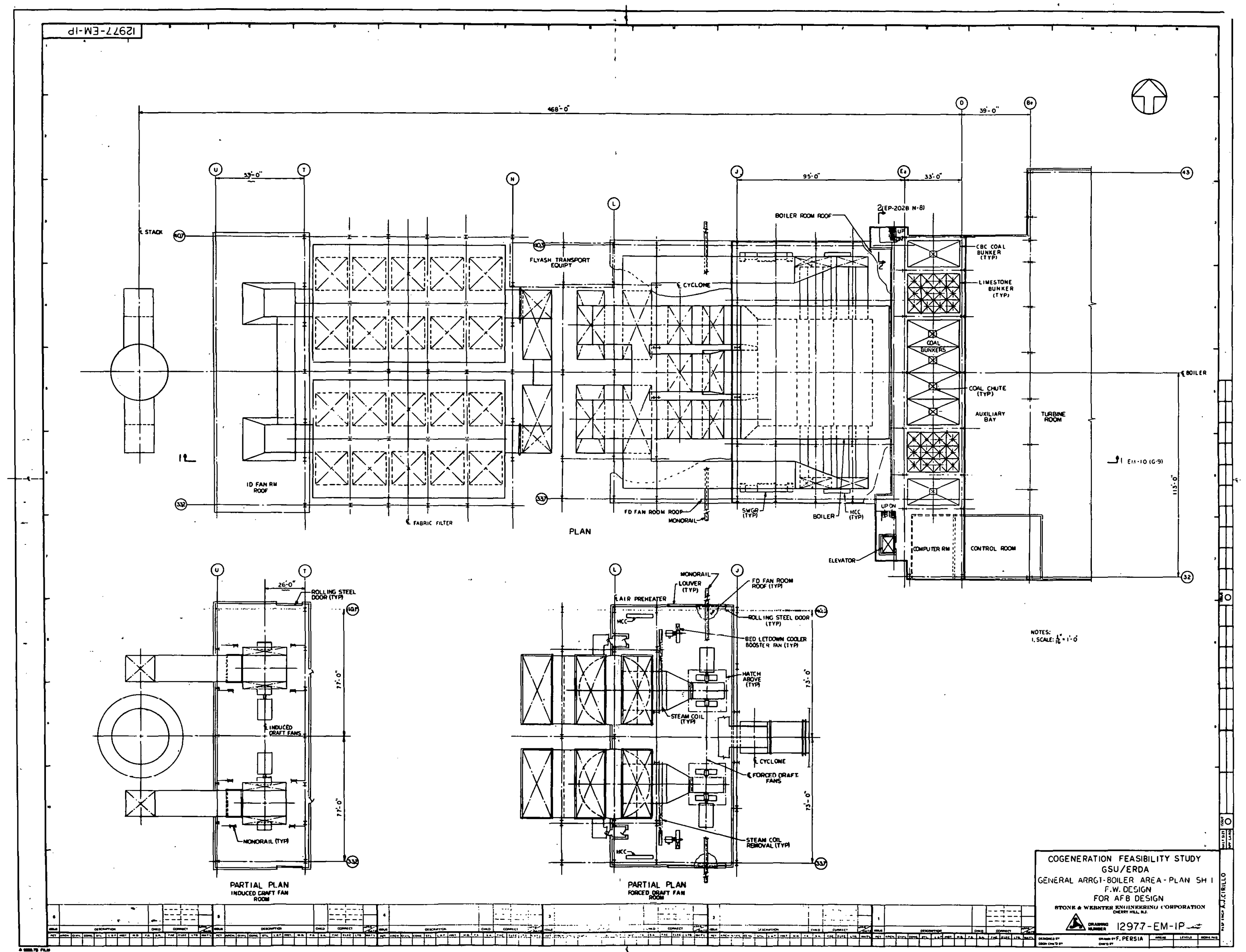




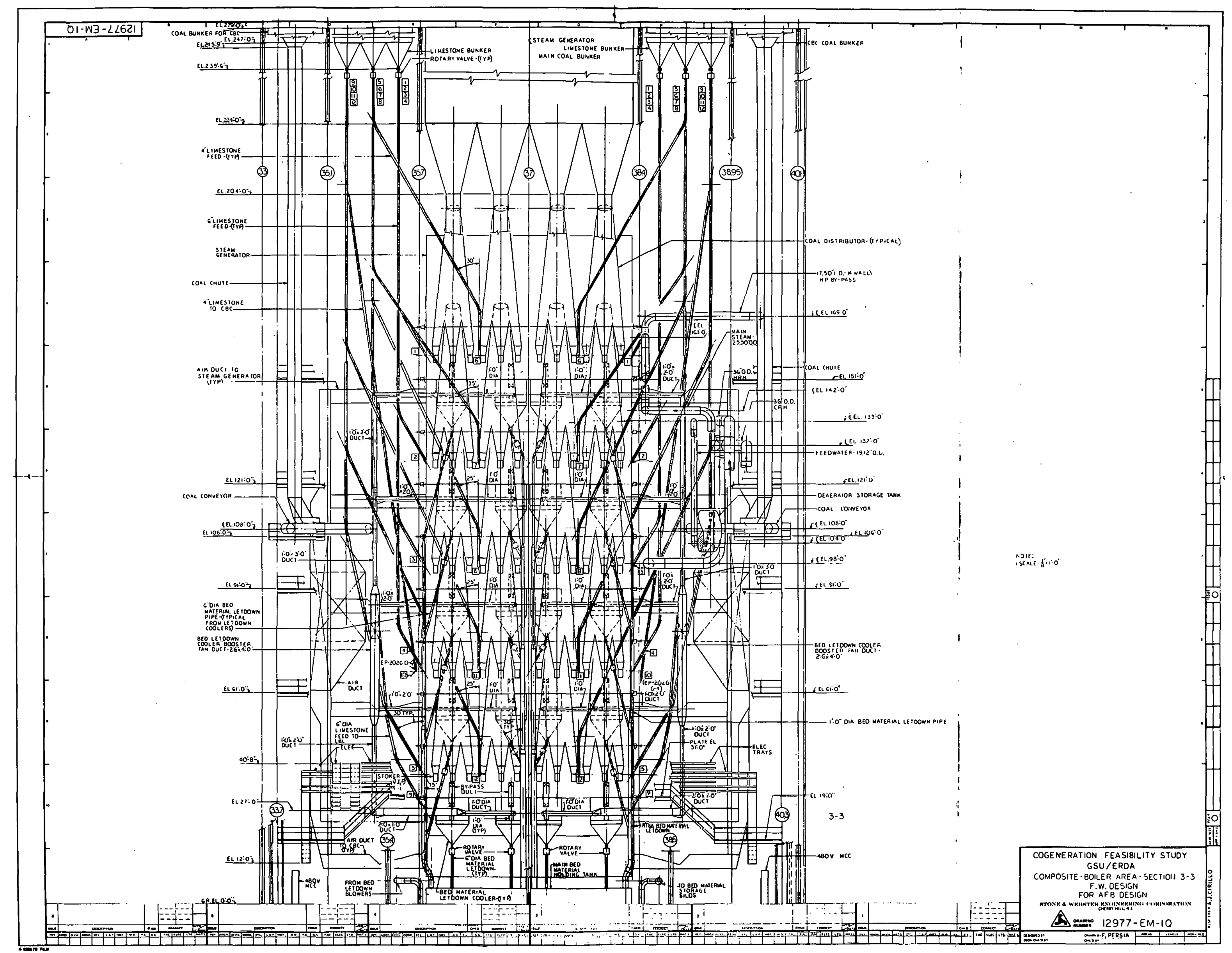




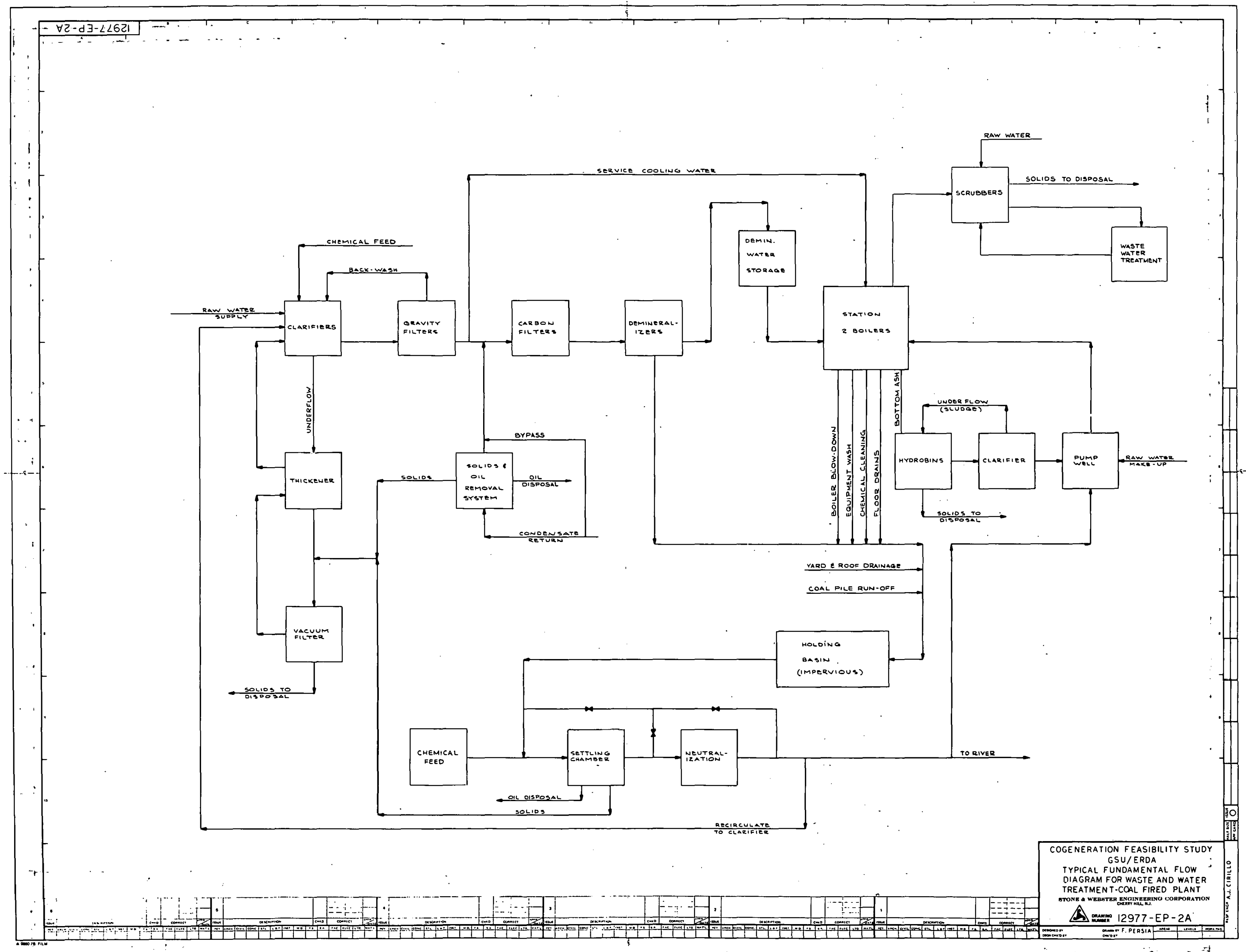




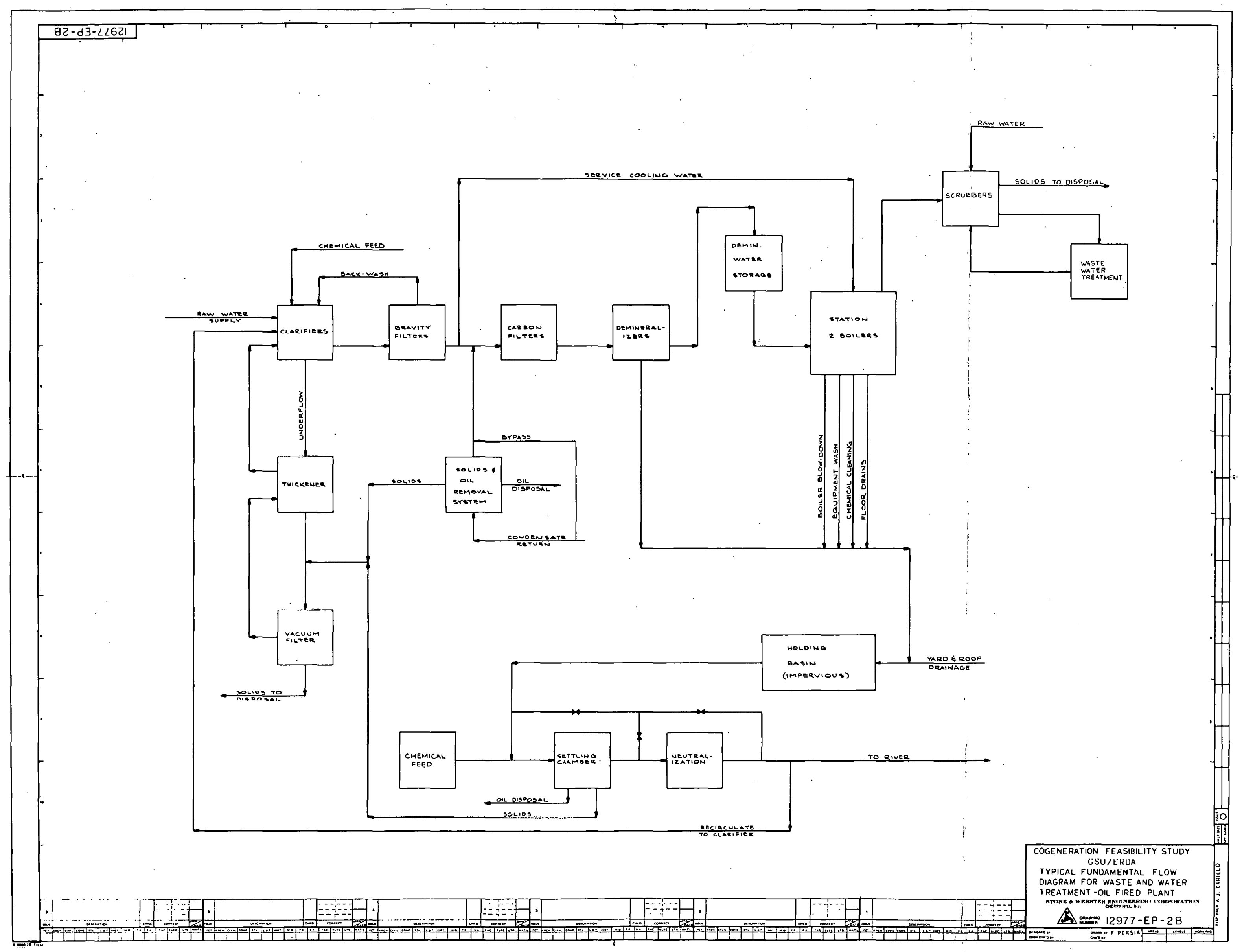




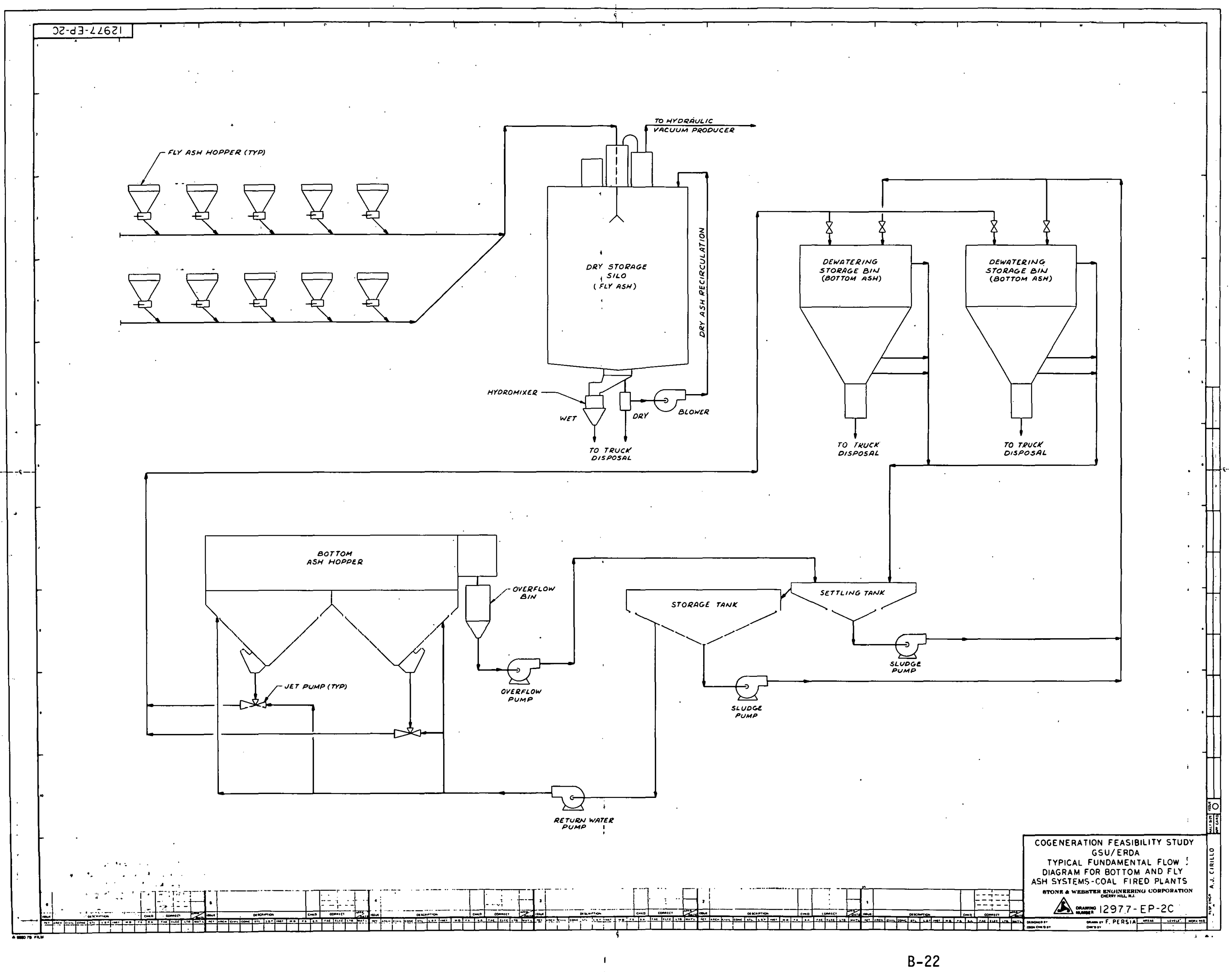




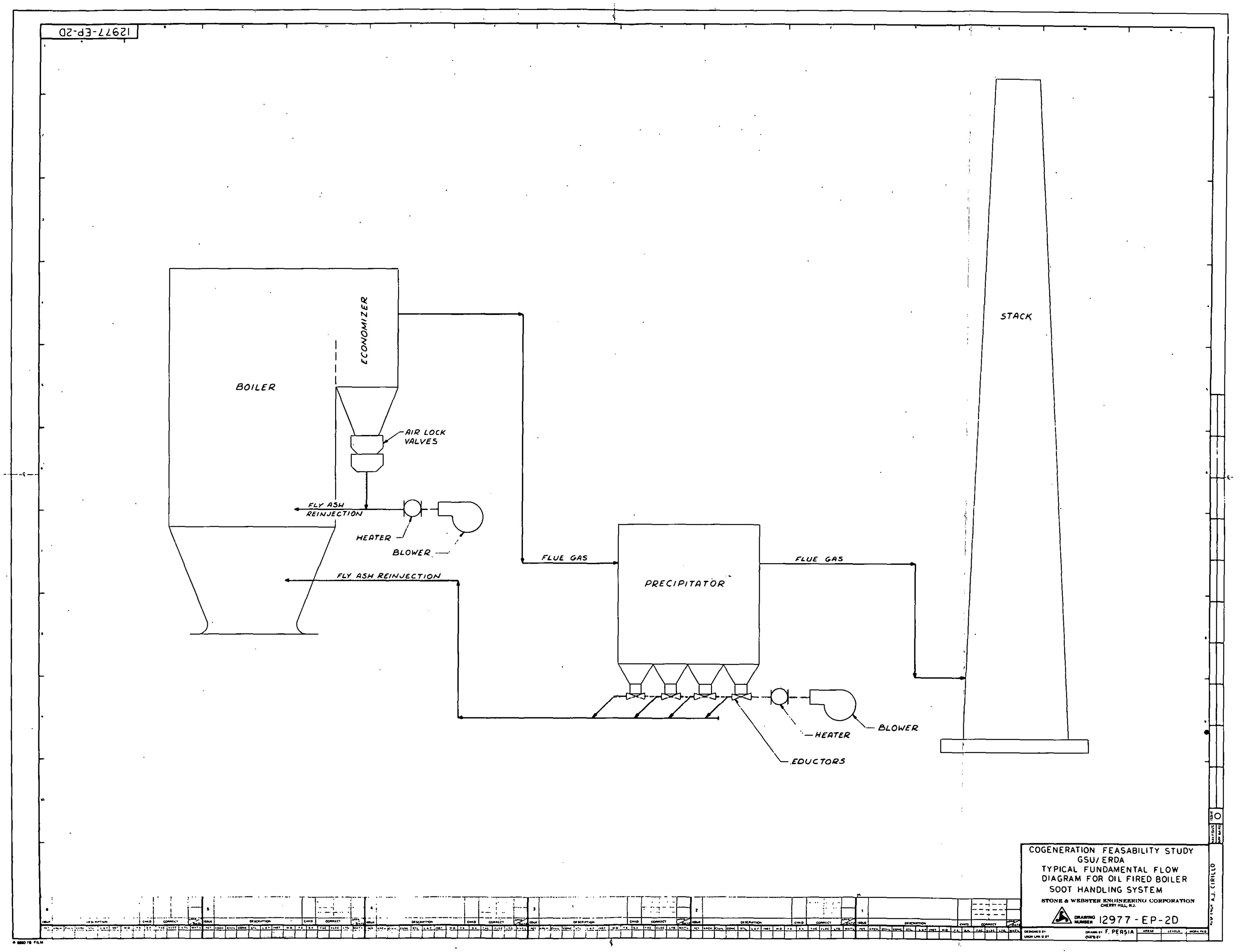




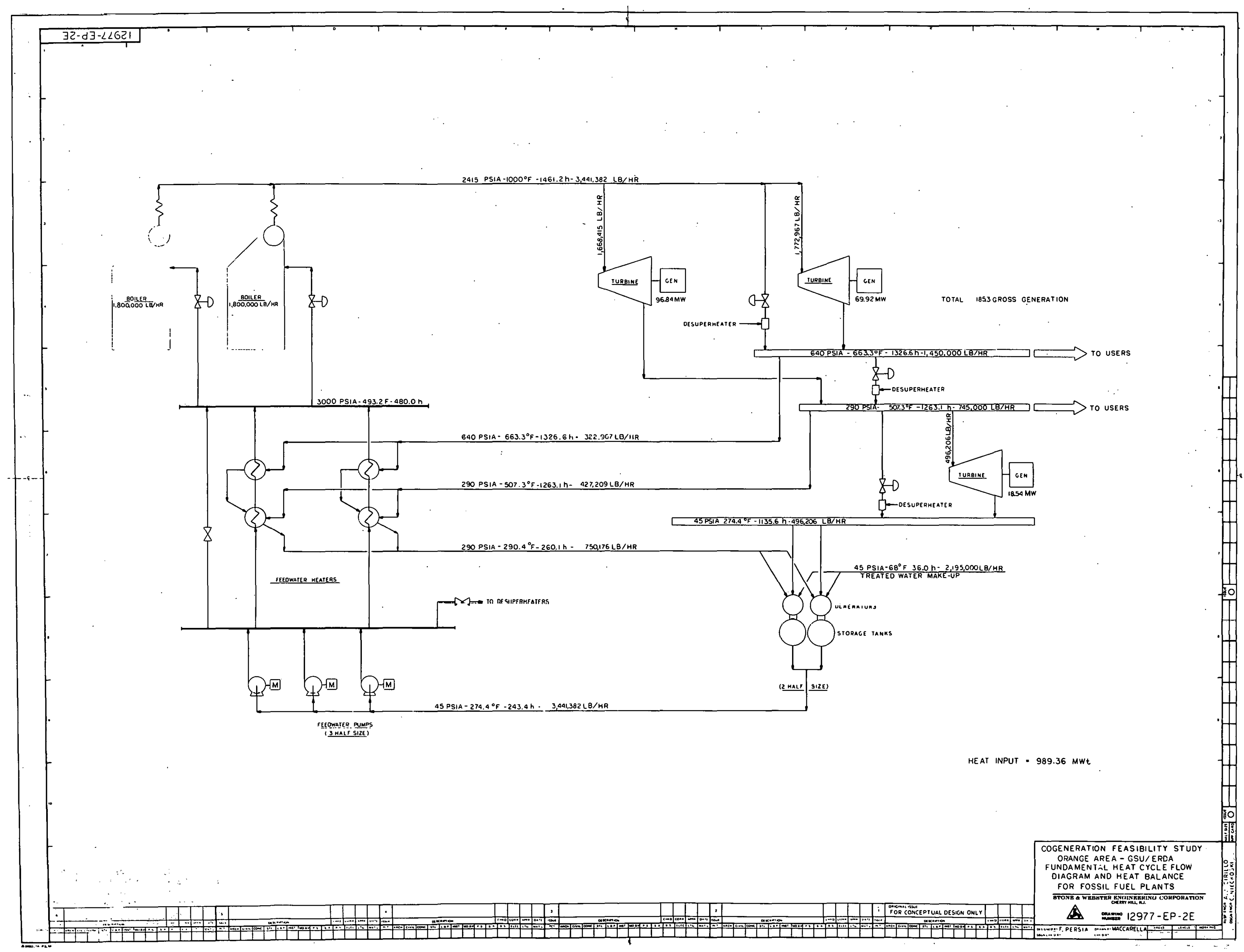




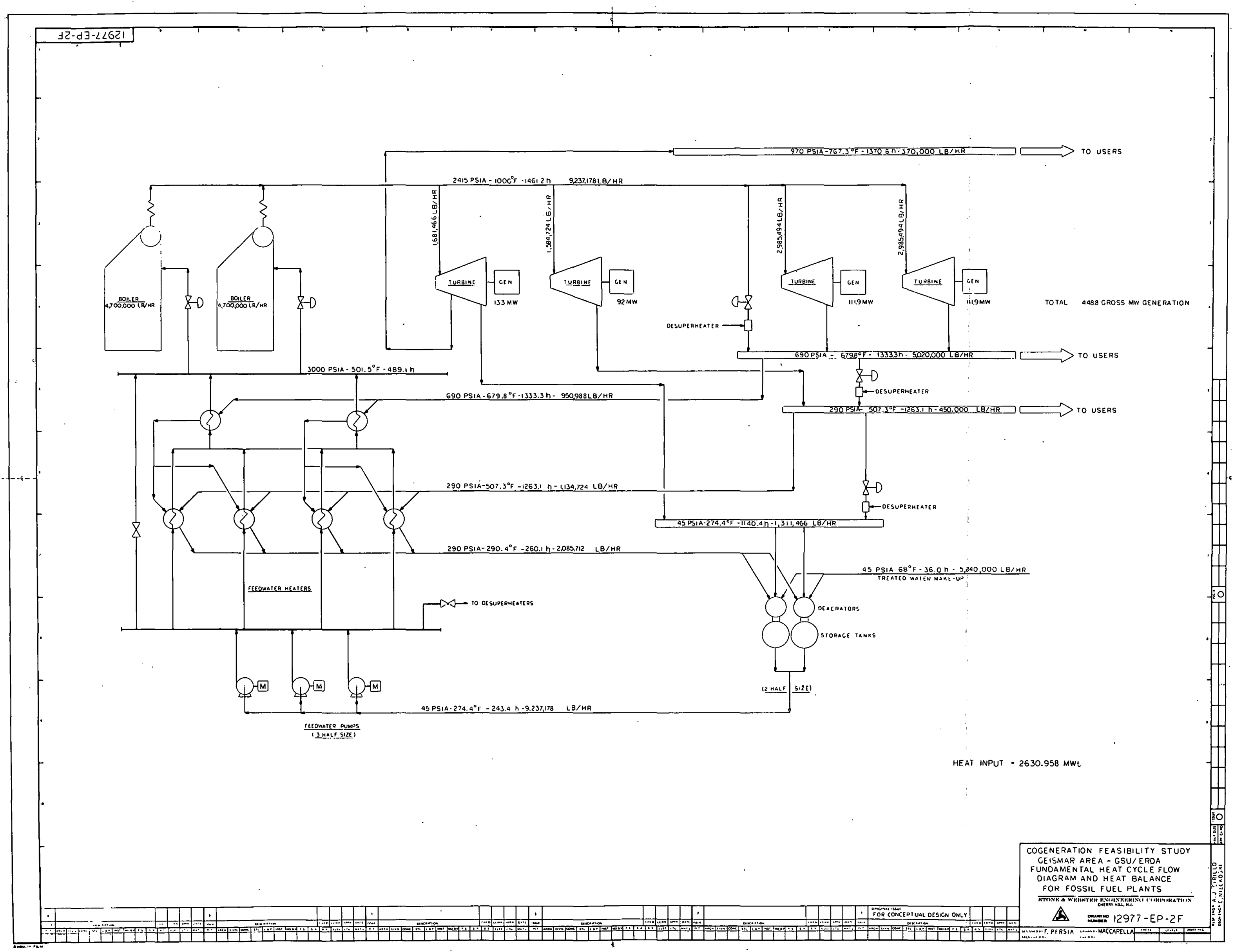




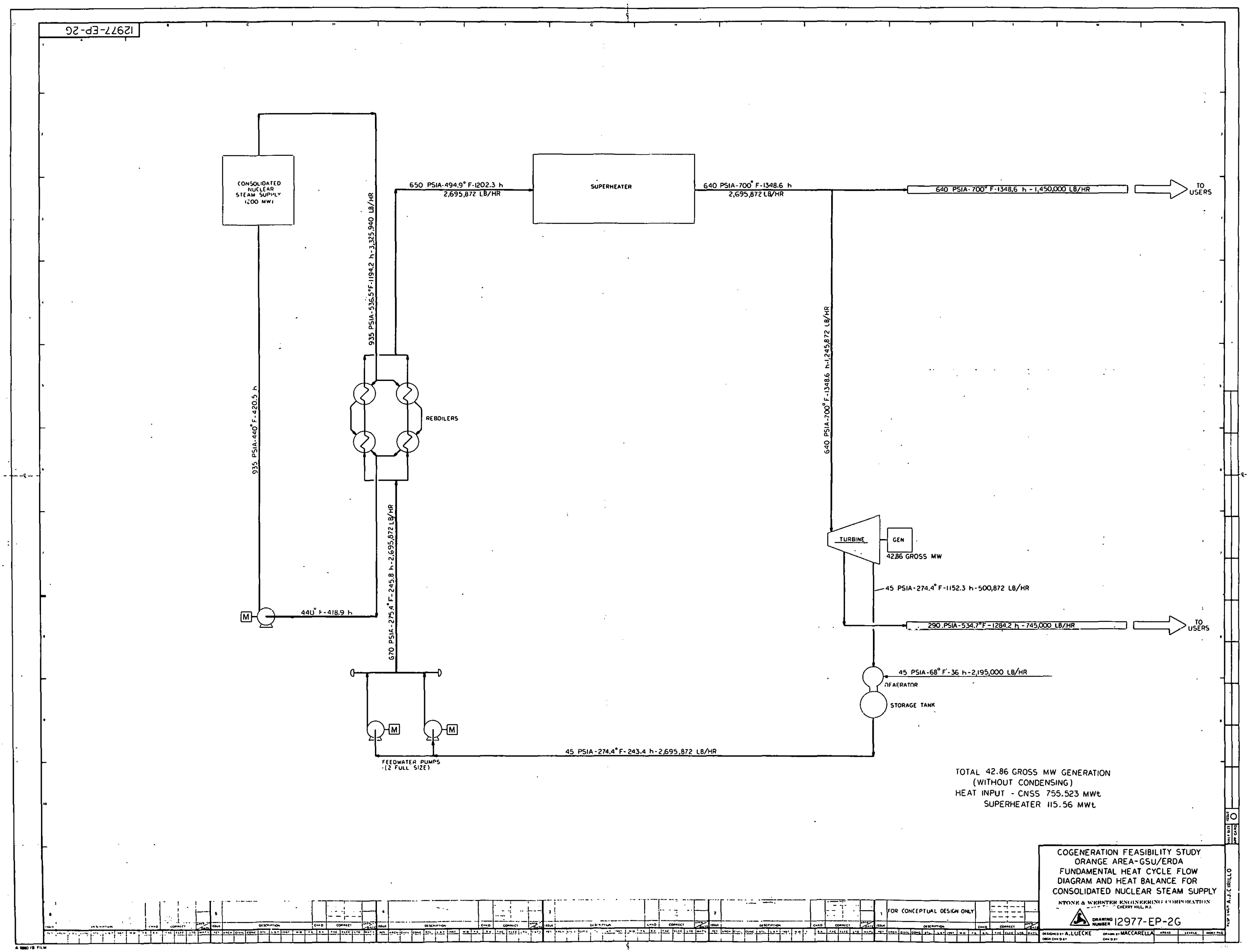




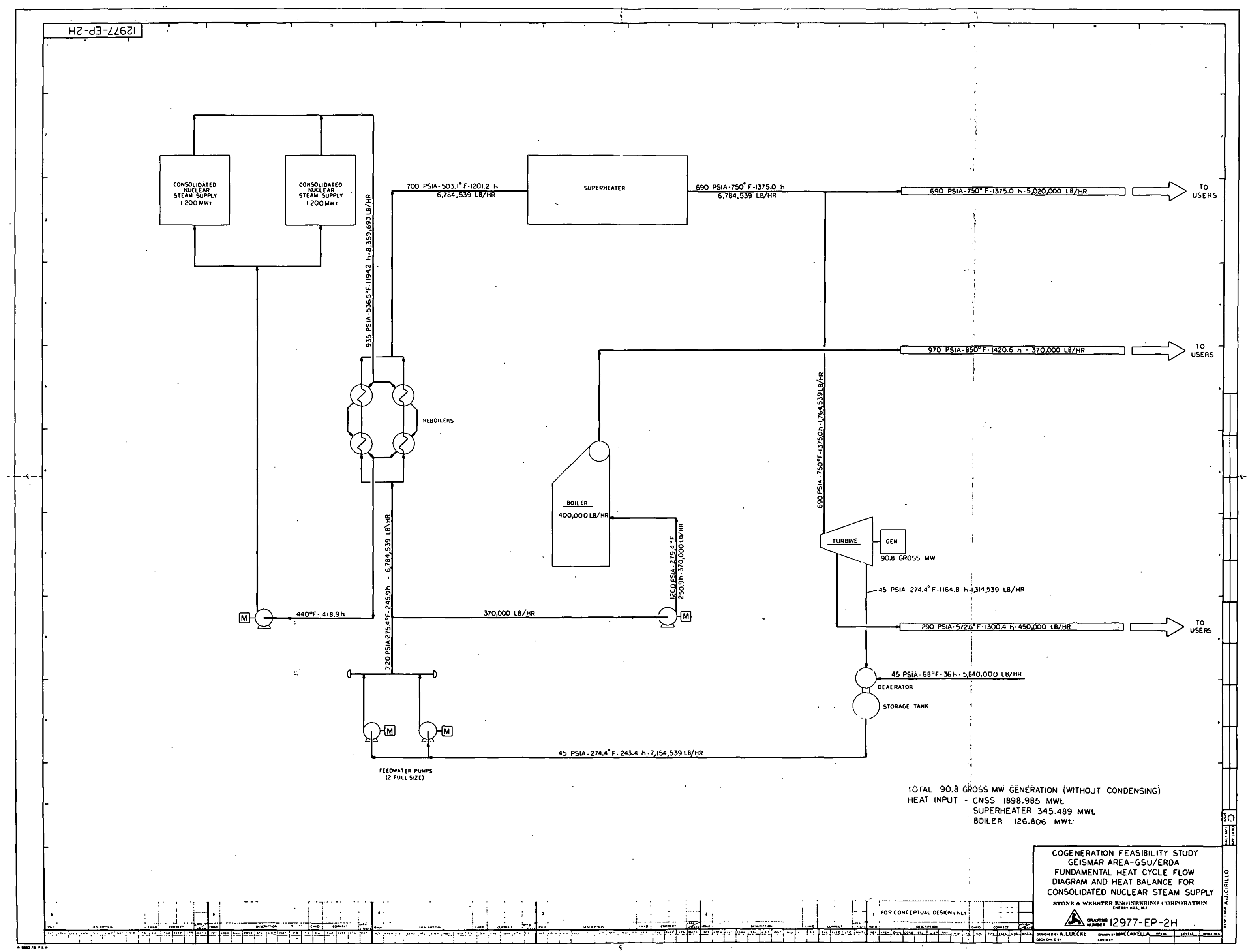




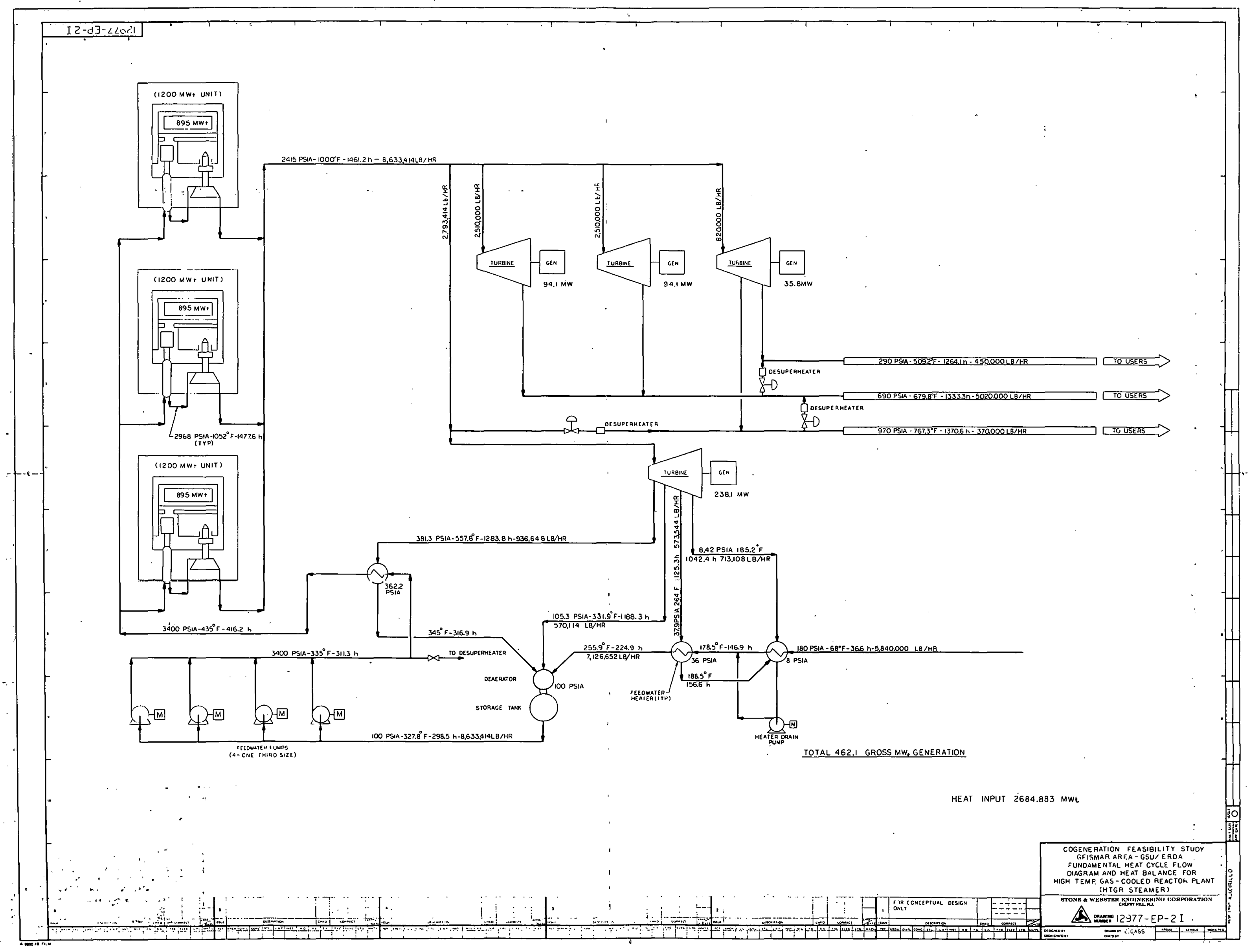




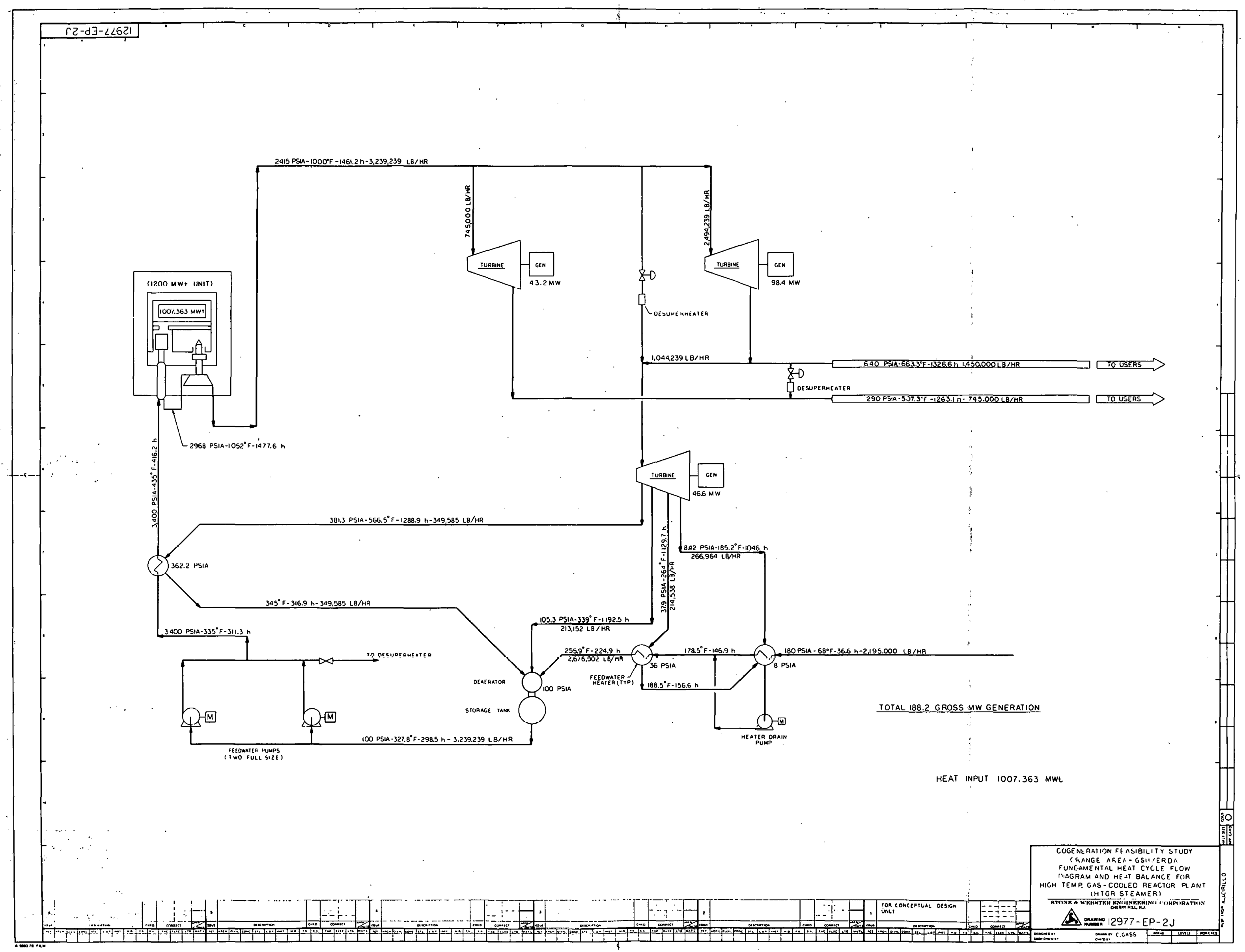




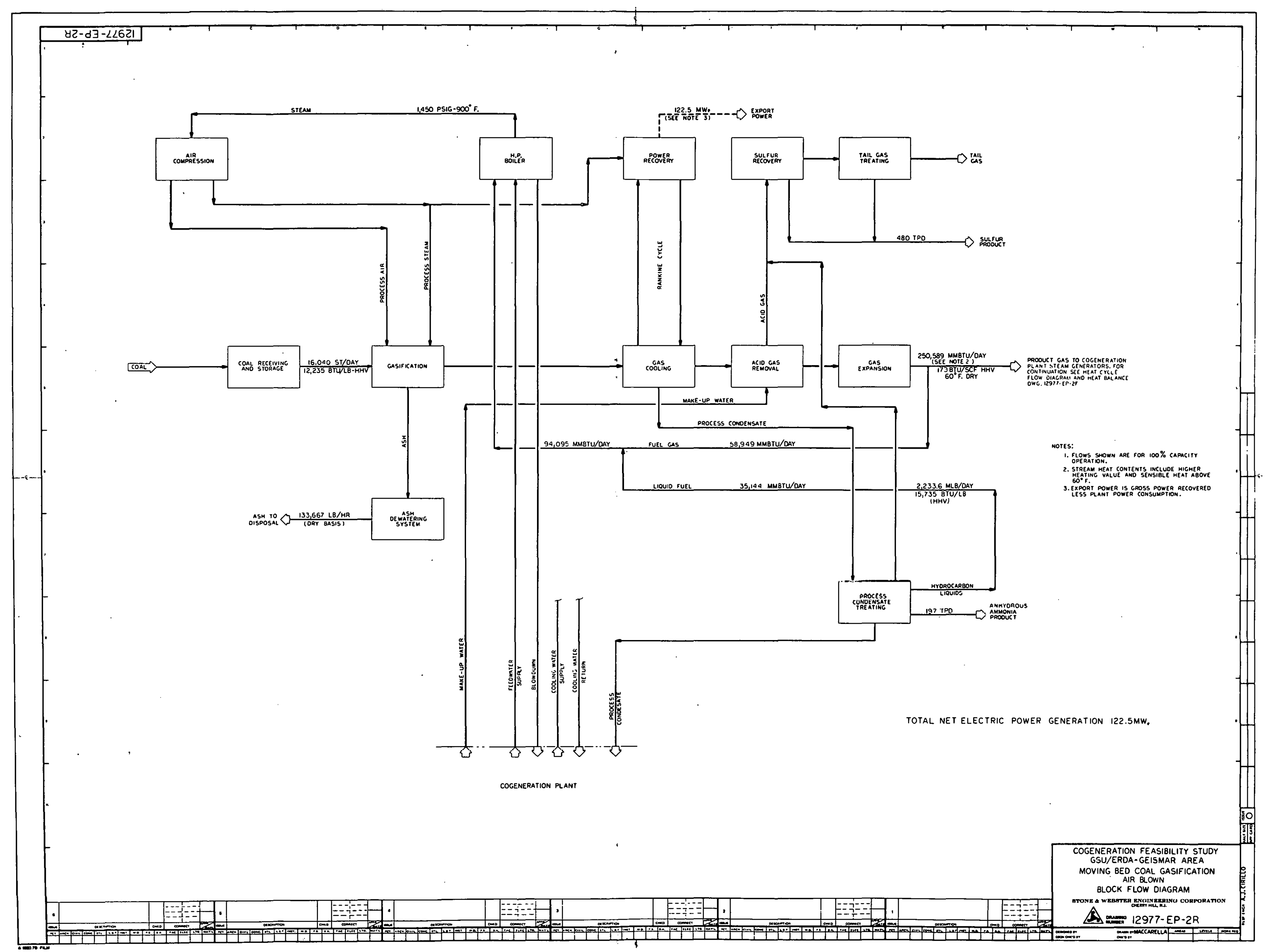




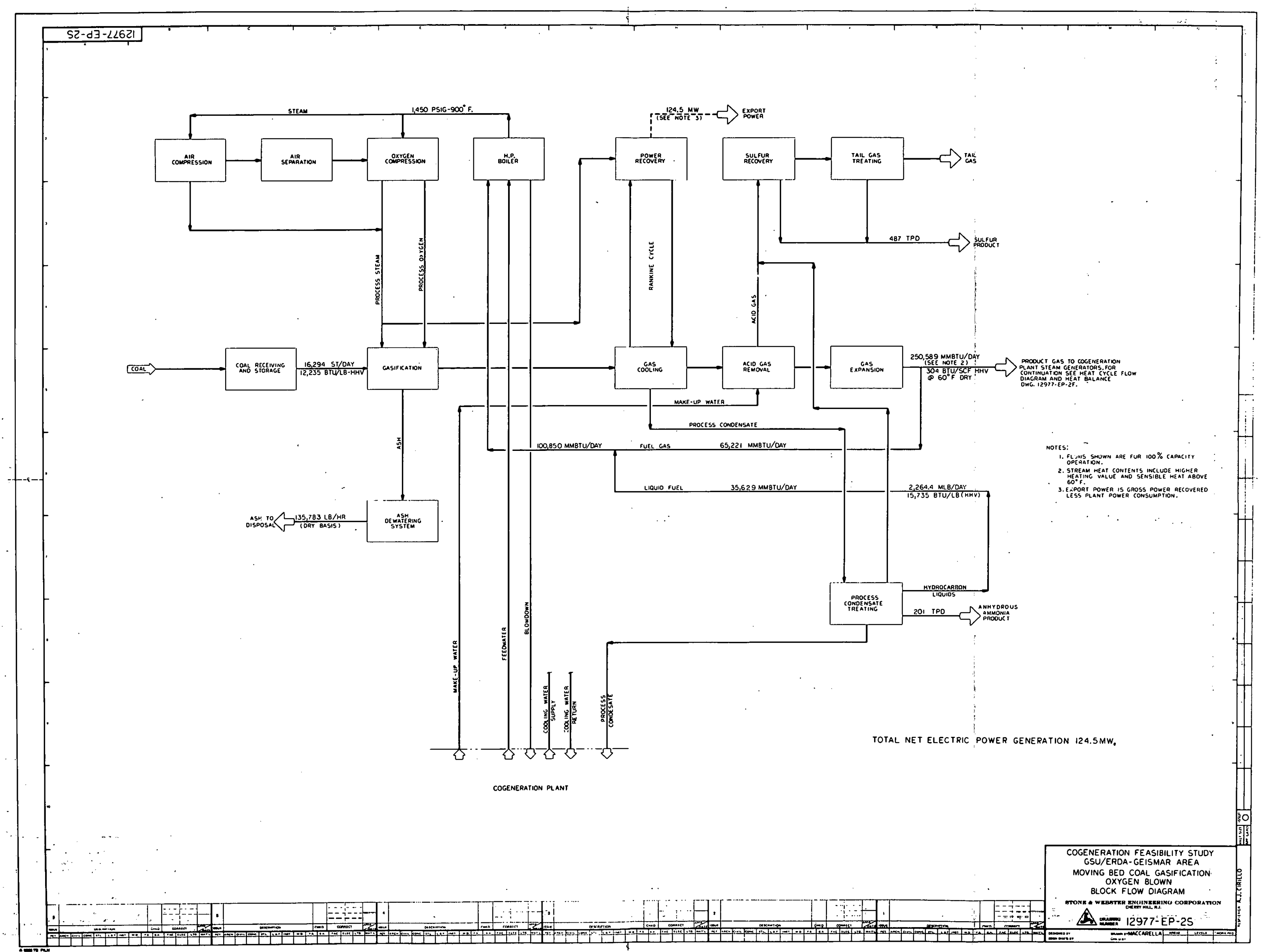




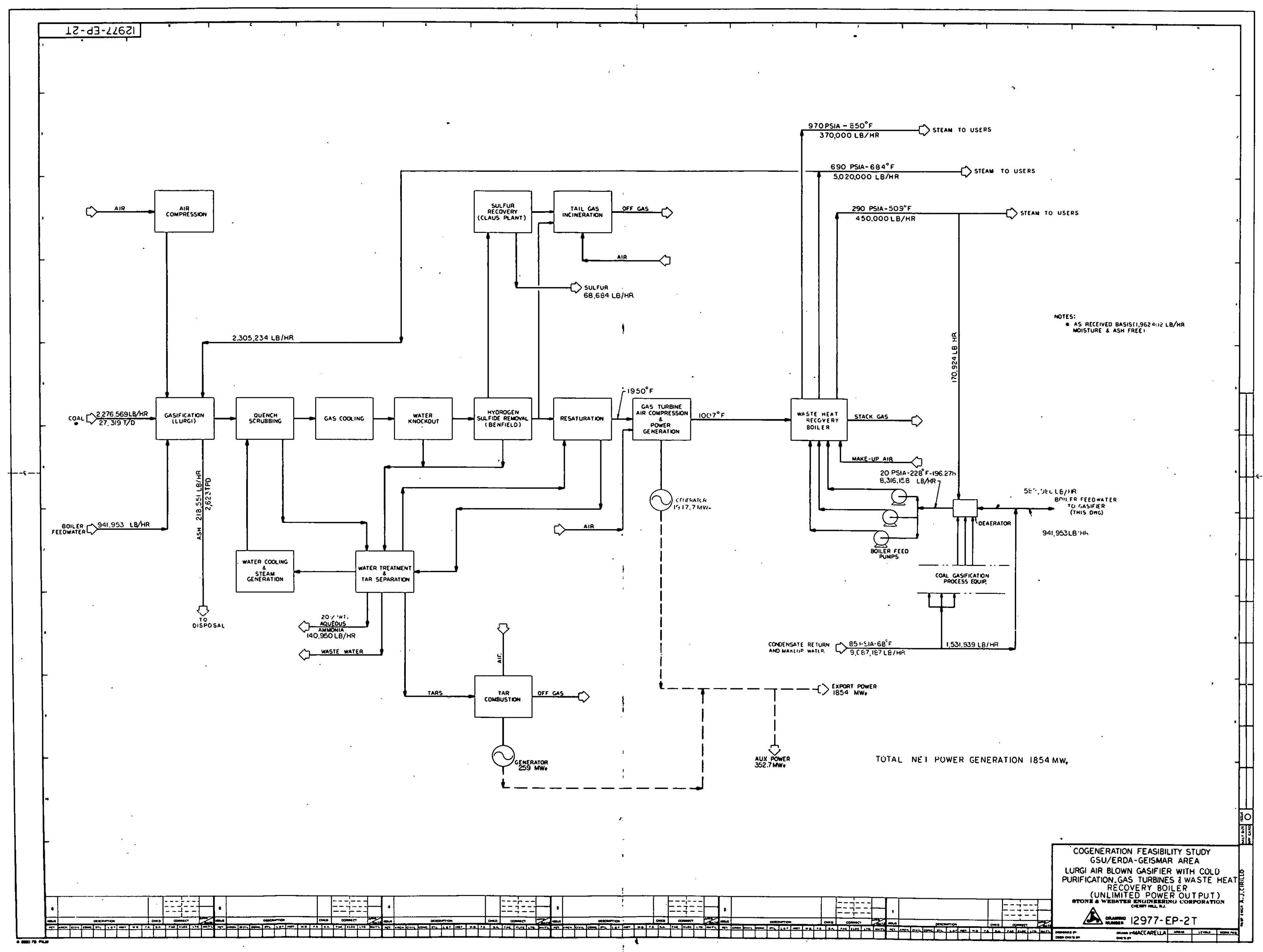




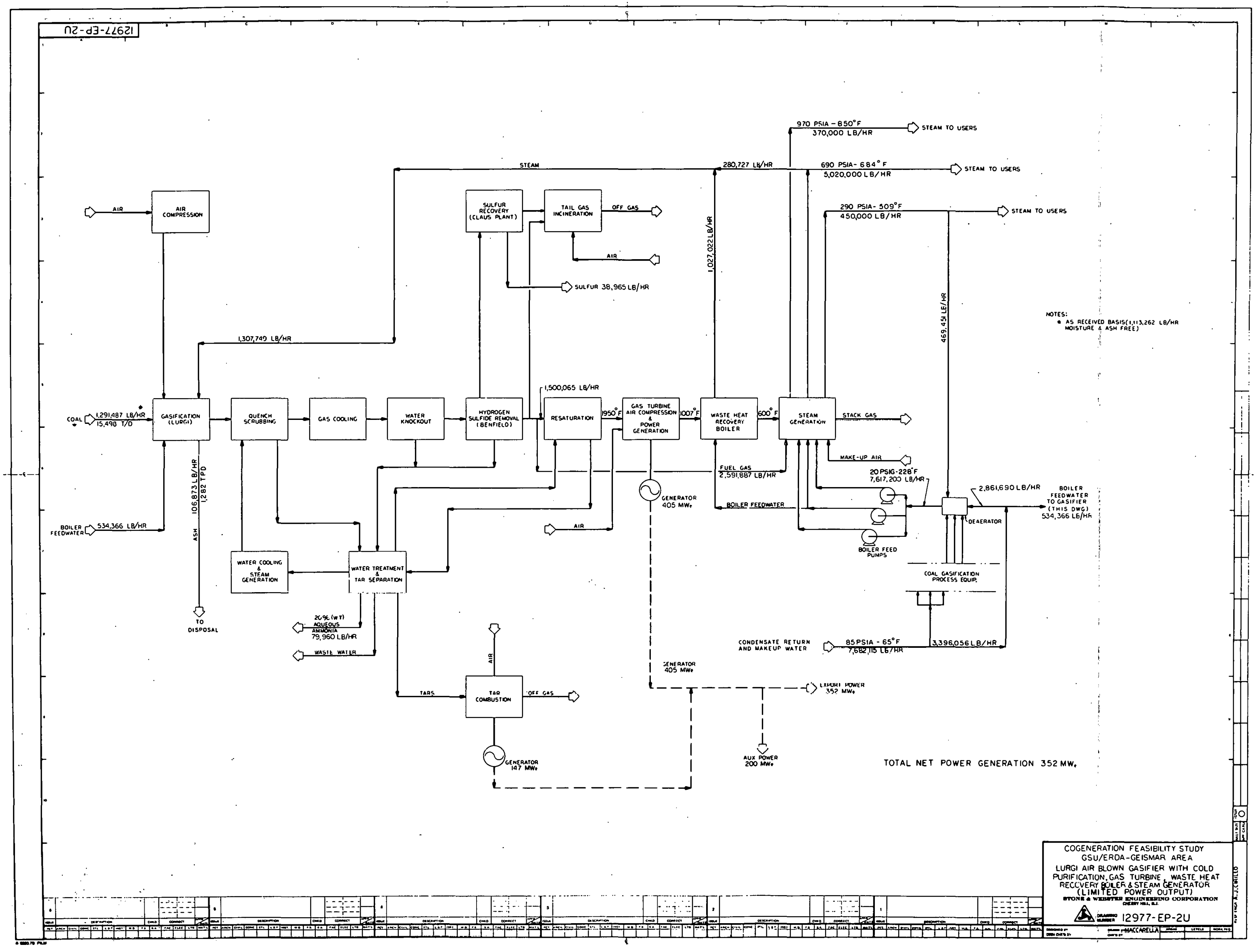




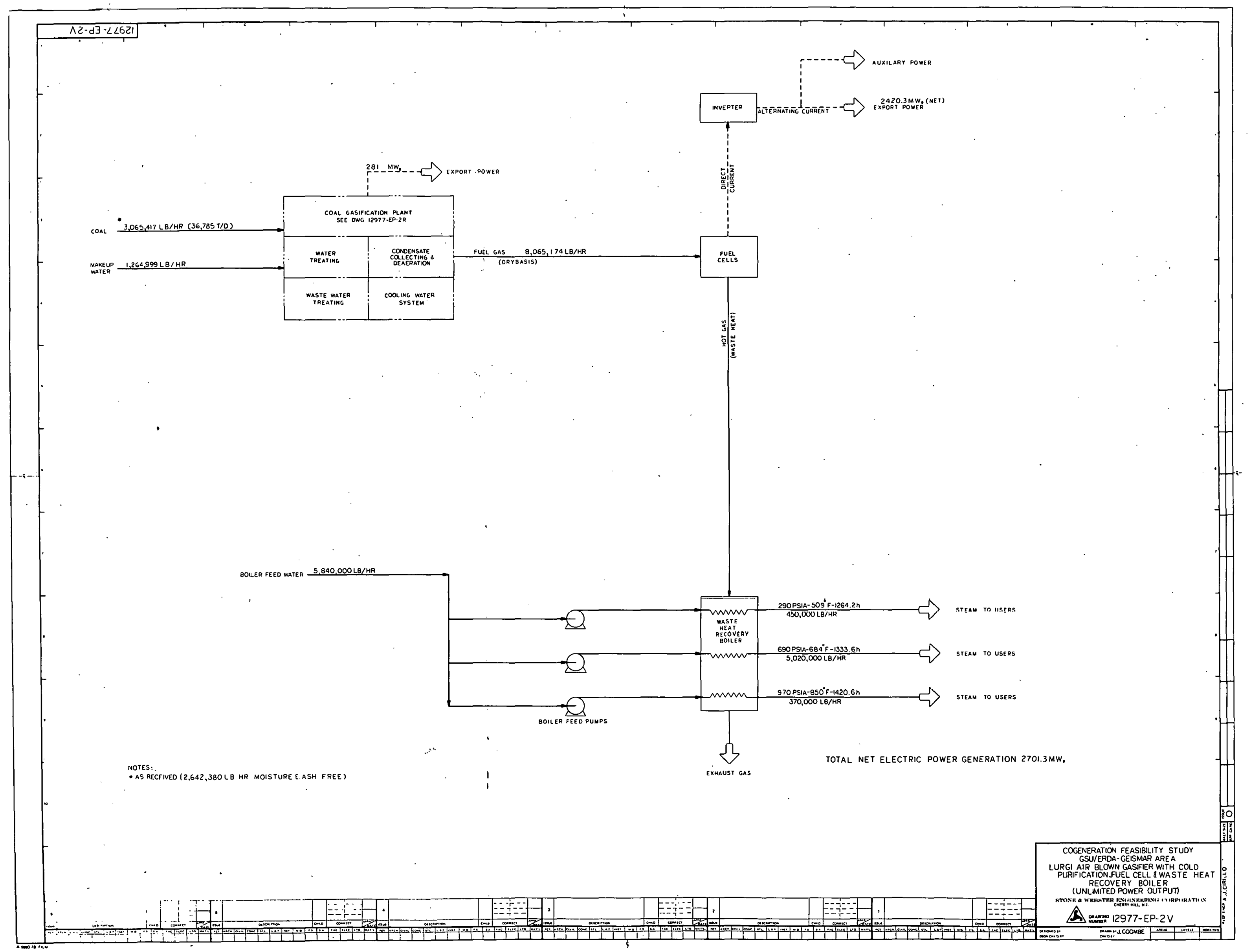




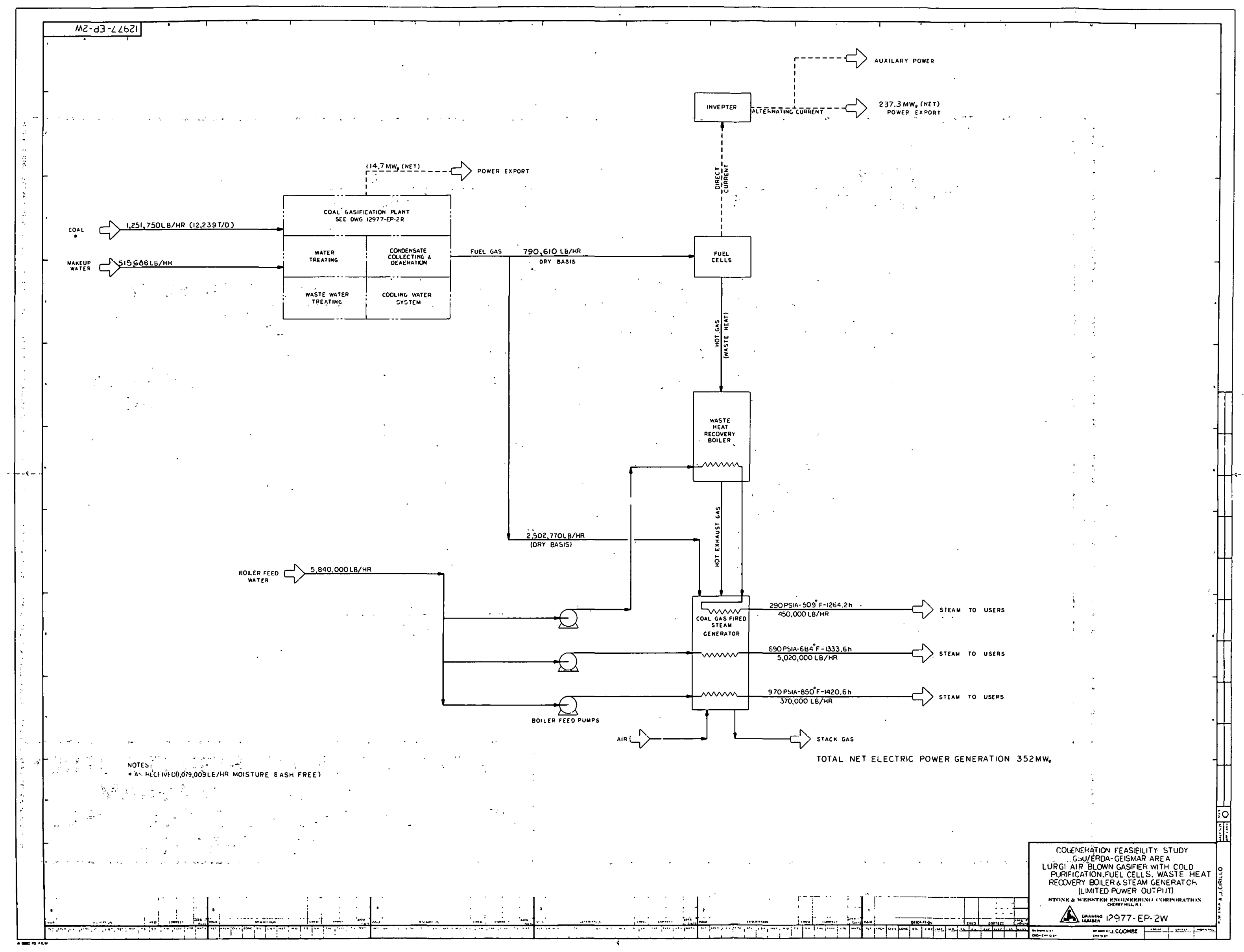




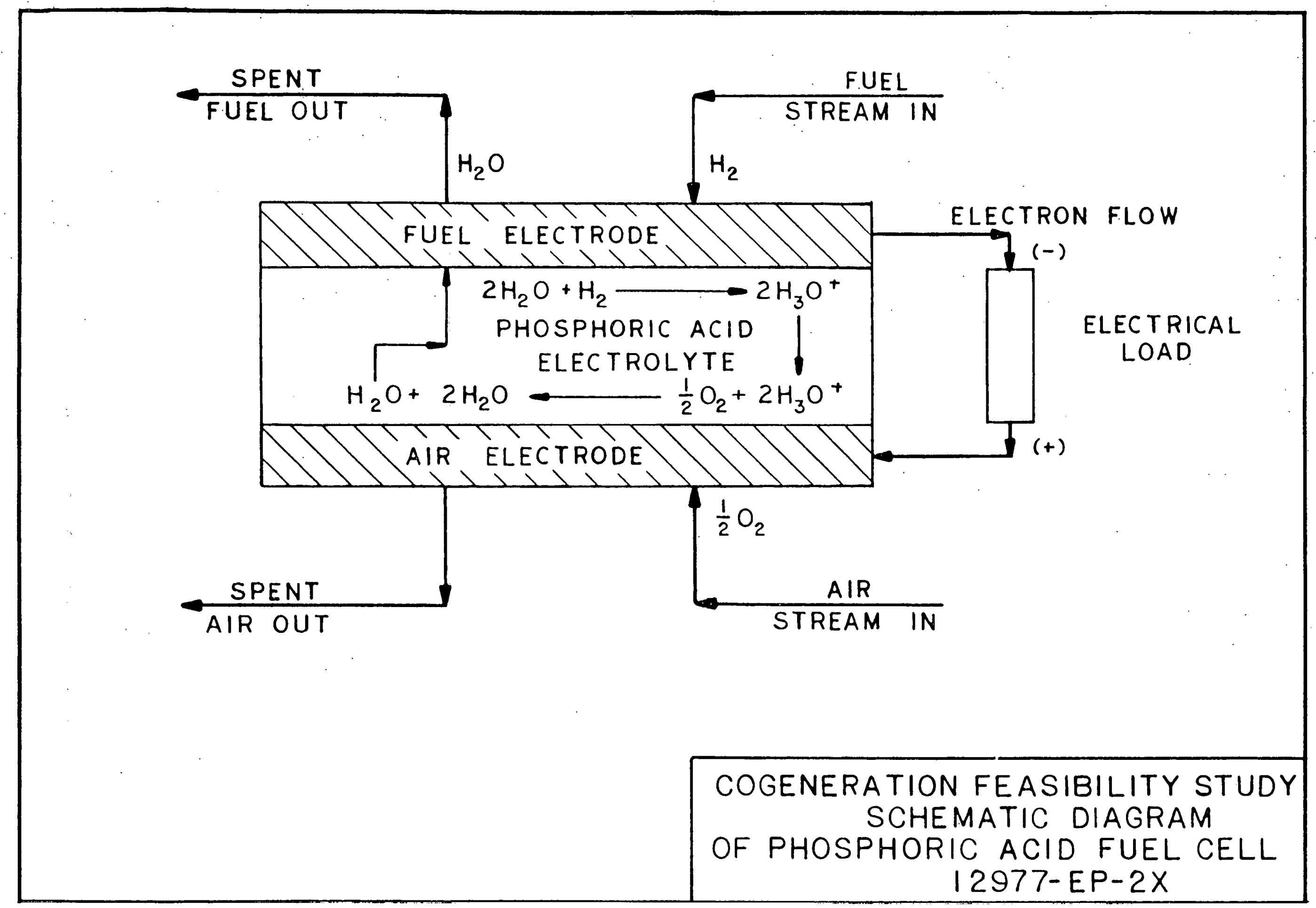




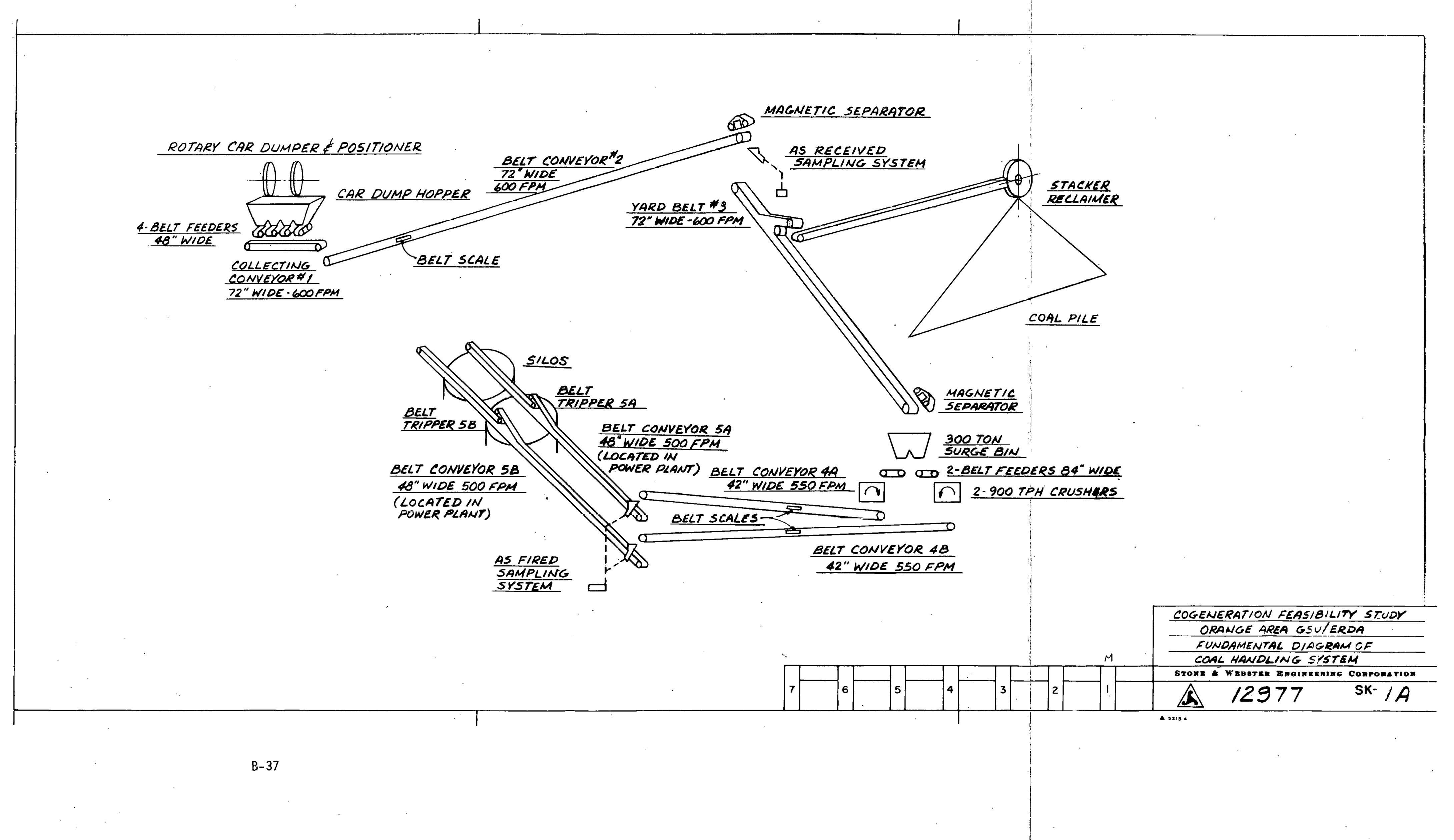



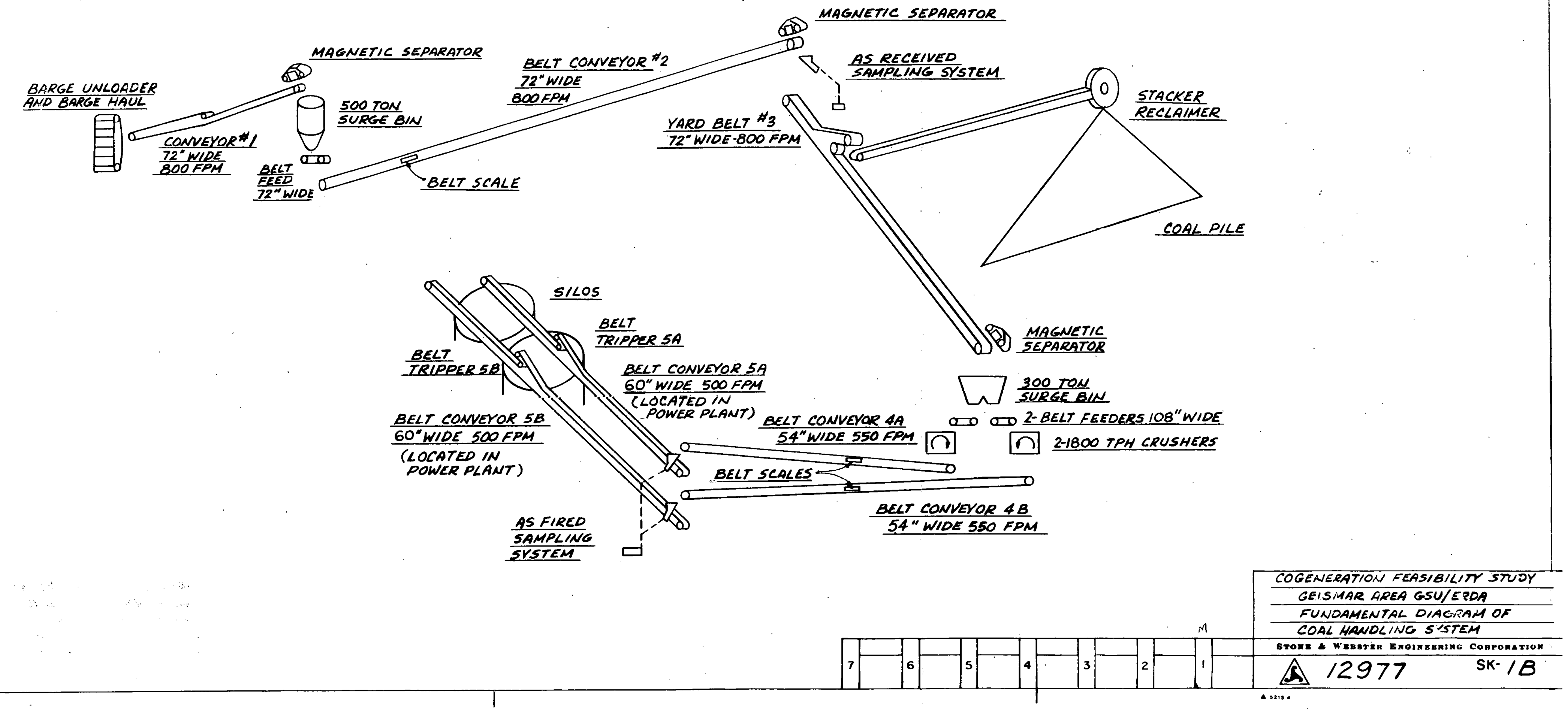


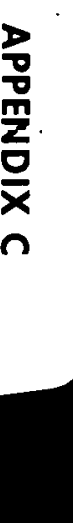




\section{APPENDIX C \\ DISCOUNTED CASH FLOW ANALYSIS}

Cash flow summary statements for 90, 100, 150, and 200 percent of the estimated fuel costs are included in this appendix. The analysis was adapted with minor changes from the method described in Section 4 of References 27 and 28 . All cash flows are reported in current end-of-year dollars. In the following paragraphs, the entries in each column are defined.

Column (1) - Capital Expense

Capital expense cash flow is detennined from the estimated total capital investruent and schedule of expenditures. Construction of the fossil-fired plants is delayed so that the first year of opexation of all plants is 1986. The estimates in January 1978 dollars have been apportioned to the appropriate year and escalated at an annual rate of 7 percent. Lard expense is included in the first year of construction and returned in 2015 at its escalated value.

Column (2) - Backup Expenses

Backup operating expense is assumed to be the current cost (net-of-taxes) of No. 2 fuel oil burned in existing facilities to compensate for study plant unavailability or differences in operating life. These costs have been excluded in this study in order to arrive at comparative costs solely for the alternative stean sources. For the CNSS, this column was useä for the cost of No. 6 fuel oil. net-of-taxes.

Column (3) - Working Capital

Working capital has been estinated for a 60-day inventory of fossil fuel. An allowance for capital charges has been included in the cost of nuclear fuel, and is excluded here.

The escalated estimate is entered in the year prior to operation. The net change in subsequent years is the escalation to maintain constant value in current dollars. Total working capital is returned in the last year of operation. 
Column (4) - Investment Cash Flow

Investment cash flow is the sum of columns (1). (2), and (3): Capital expense, backup expenses, and working capital.

Colurn (5) - Fuel Expenses

The cost of primary fuel in current dollars is entered in this column. Escalation rates are 6 percent for coal and 7 percent per year for oil. Nuclear fuel costs have been escalated at a composite rate of 4.9 percent based on $1 / 3$ escalating at 6 percent and $2 / 3$ escalating at 4 percent. Colum (2) was used for the No. 6 fuel oil consumed for superheating and making high pressure steam in the CNSS plants because it escalates at a rate different from nuclear fuel. Entries in Colurn (5) are before taxes; those in Column (2) are net-of-taxes.

Column (6) Other Operating Expenses

Entries in column (6) are estimates of the wages and material costs for operating the plant exclusive of fuel. Auxiliary power is provided by the plant and does not represent a cash flow. It does reduce the credit for power generated shown in Column (9).

Column (7) - Taxes Other Ihan Income

At Geismar, taxes other than income tax are calculated at 2.0 percent of total capital cost, beginning in the eleventh year after first operation. At orange, taxes begin in the first year and have been calculated as 1 percent of the current year's capital cash flow plus 2 percent of total prïor expenditures.

Colum (8) - Tax Depreciation

Capital expenditures exclusive of land costs are depreciated over a 22.5-year tax life. The first two years are depreciated by the double declining balance method and the remaining 20.5 years by the sum-of-the year's digits method.

Column (9) - Credit for power

The net power generated is multiplied by the cost of power for large industrial users in the Gulf States Utilities area and entered in the column. After 1986. escalation is estinnated to be at an ànual rate of 7 percent. 
Column (10) - Total Expenses Before Tax

Column (10) is the sum of columns (5), (6), (7), (8), and (9) -

Colum (11) - Total Expenses Before Tax

Column (11) is Column. (10) brought forward.

Column (12) - Income Tax

Column (12) is computed as column (11) times the income tax rate. The federal income tax rate is 46.0 percent. At Geismar, there is also a Louisiana state income tax of 8.0 percent. Because these taxes are mutually deductible, the effective income tax rate at Geismar is 48.4 percent.

Column (13) - Total Expenses After Tax

Colum (13) is the sum of Columns (11) and (12).

Column (14) - Tax Depreciation

The tax depreciation shown in column (8) as an expense for tax purposes is entered here as a cash in-flow.

Column (15) - Investment Tax Credit

The investment tax credit is calculated as 10 percent of the amount in Column (1) exclusive of land costs.

Columr (16) - Operating Cash Flow

Column (16) is the sum of columins (13), (14), and (15) - It is the total expense charged to operations reduced by income tax credits.

Colum (17) - Net Cash Flow

Column (17) is the sum of investment cash flow, Coluinn (4), and operating cash flow, Column (16).

Columns (18), (19), (20) - Present Worth-Net Cash Flow (NCF)

These columns are the net present worth of the cash flows in Column (17) discounted at 10, 15, and 20 percent. respectively. 
APPENDIX C

ORNJECT COST ANALYSIS

BASED ON PRESENT WORTH

Geismar

PROJECT: GEISMAR COGENERATION

CASE I EASTENN COAL QOX FUEL COST

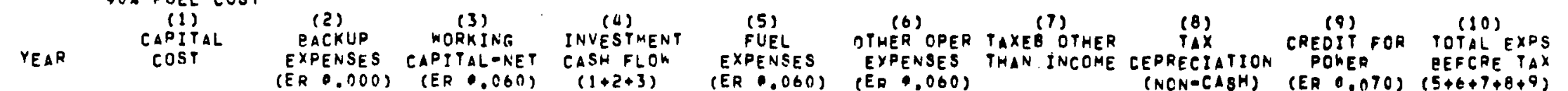

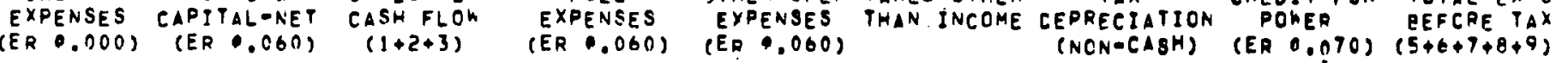

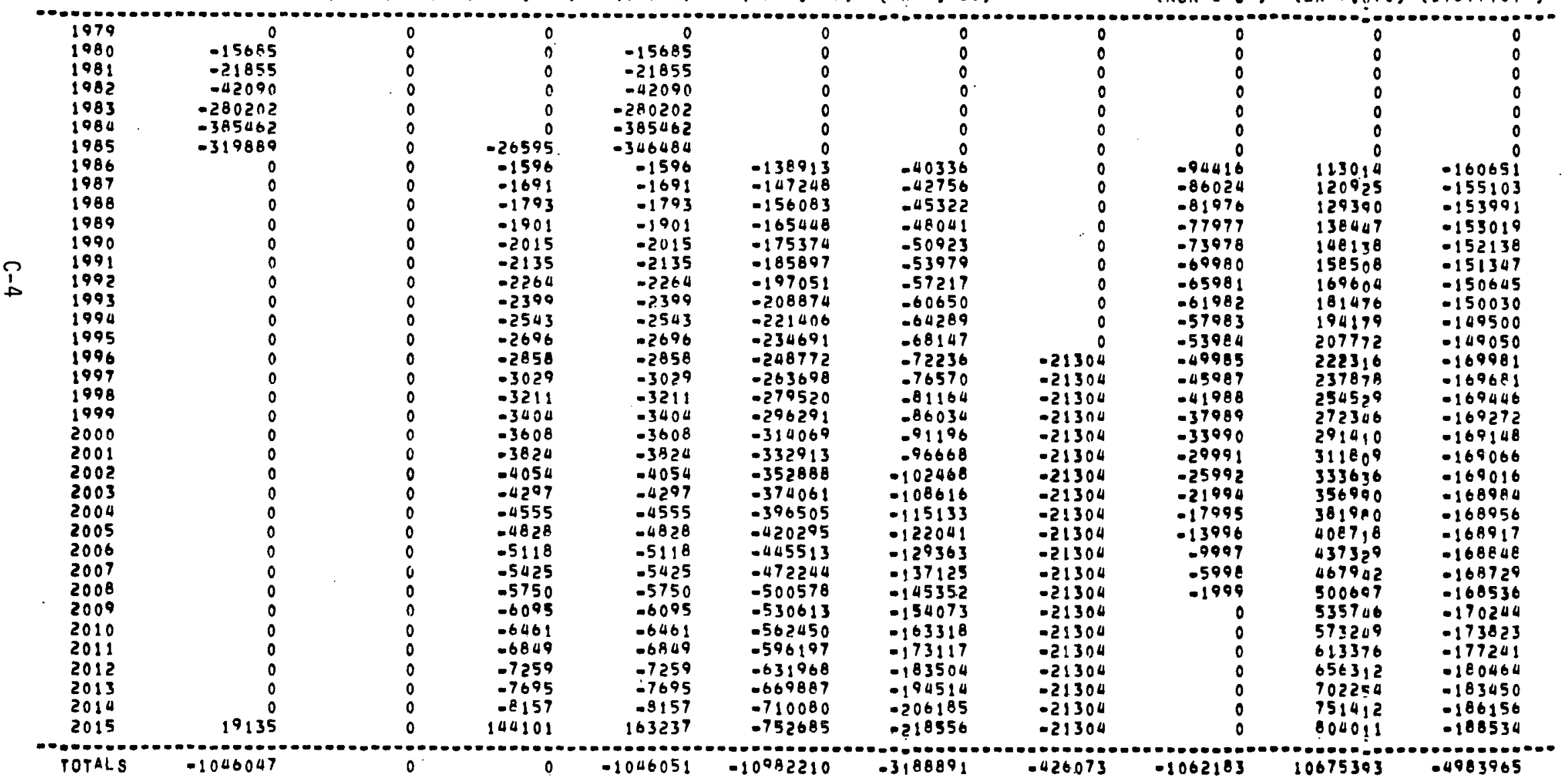


PROJECT COST ANALYSIS

BASED ON PRESENT WORTH
OF ANNUAL CASH REOUIREMENTS

PAGE 2 OF 2

PROJECT: GEISNAR COGENERATION

CASE : EASTERN COAL

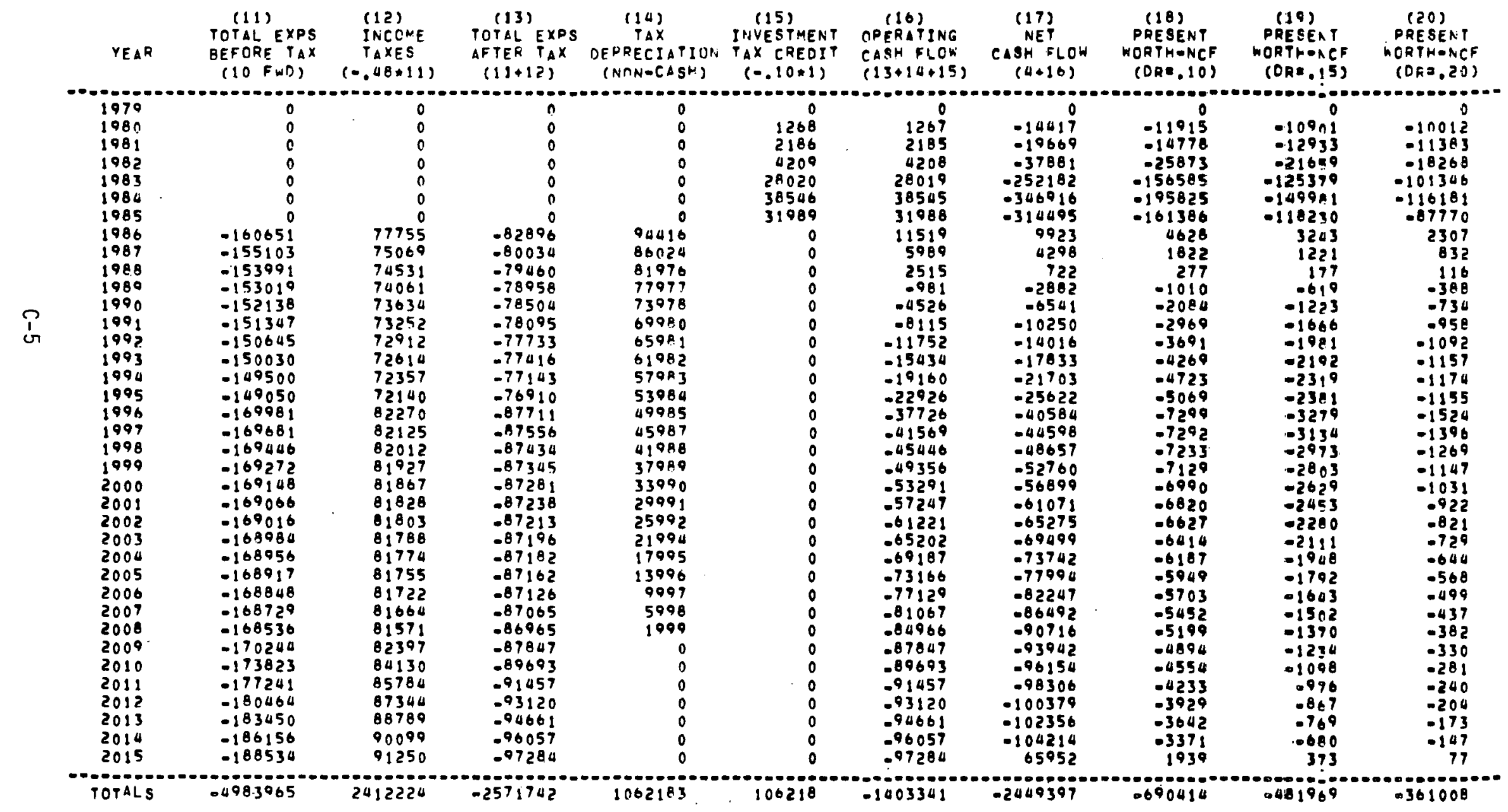


PROJECT COST ANALYSIS

page 1 of 2

OF ANAUAL CASH REOUIFEMEATE

PROJECT, GEISMAR COGENEPATIOA

$\begin{aligned} \text { CASE : EASTERN COAL } & \text { IOOX FUEL COST }\end{aligned}$

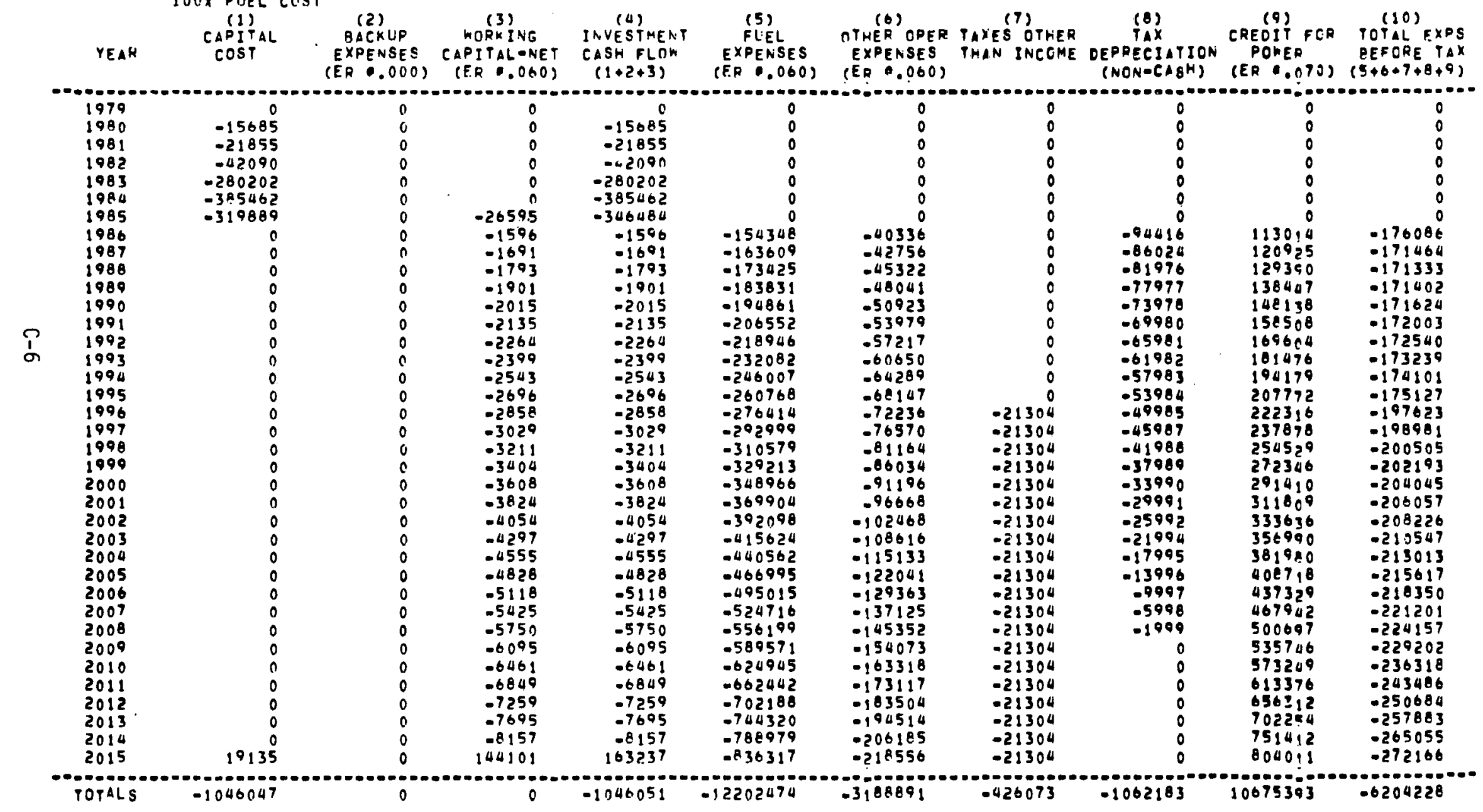


PRCIJECT COST ANALYSIS

OF ANNUAL CASH REQUIREMEATS

PROJECT: GEISMAR COGENERATION

CASE I EASTERN COAL

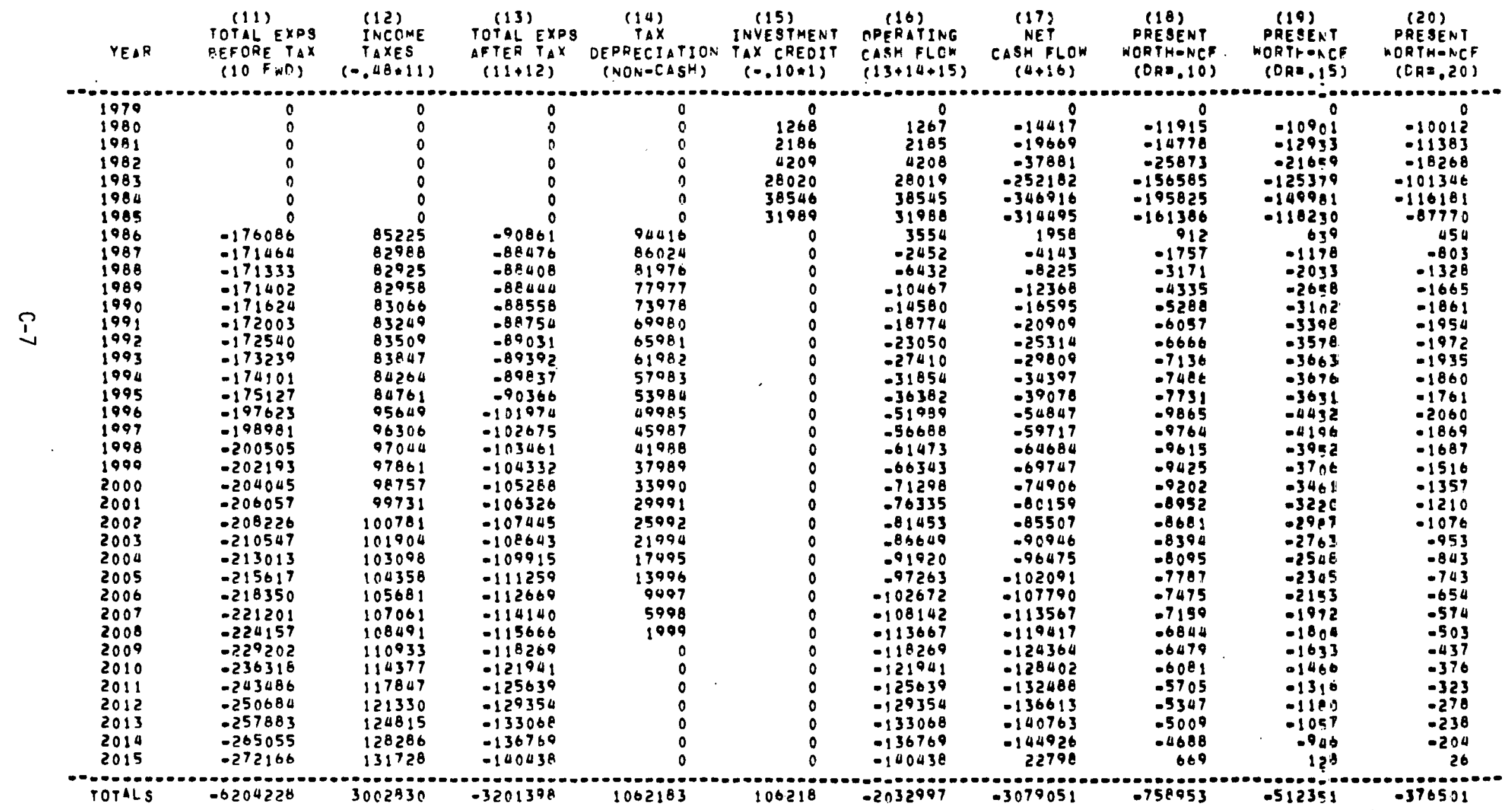


PROJECT COST ANALYSIS

PAGE \& OF 2

UF ANVUAL CASH REQUIREMERTS

PROJECT: GEISMAR COGENERATIDN

CASE EASTERAI COAL

$150 \times$ FIEEL COST
(1)

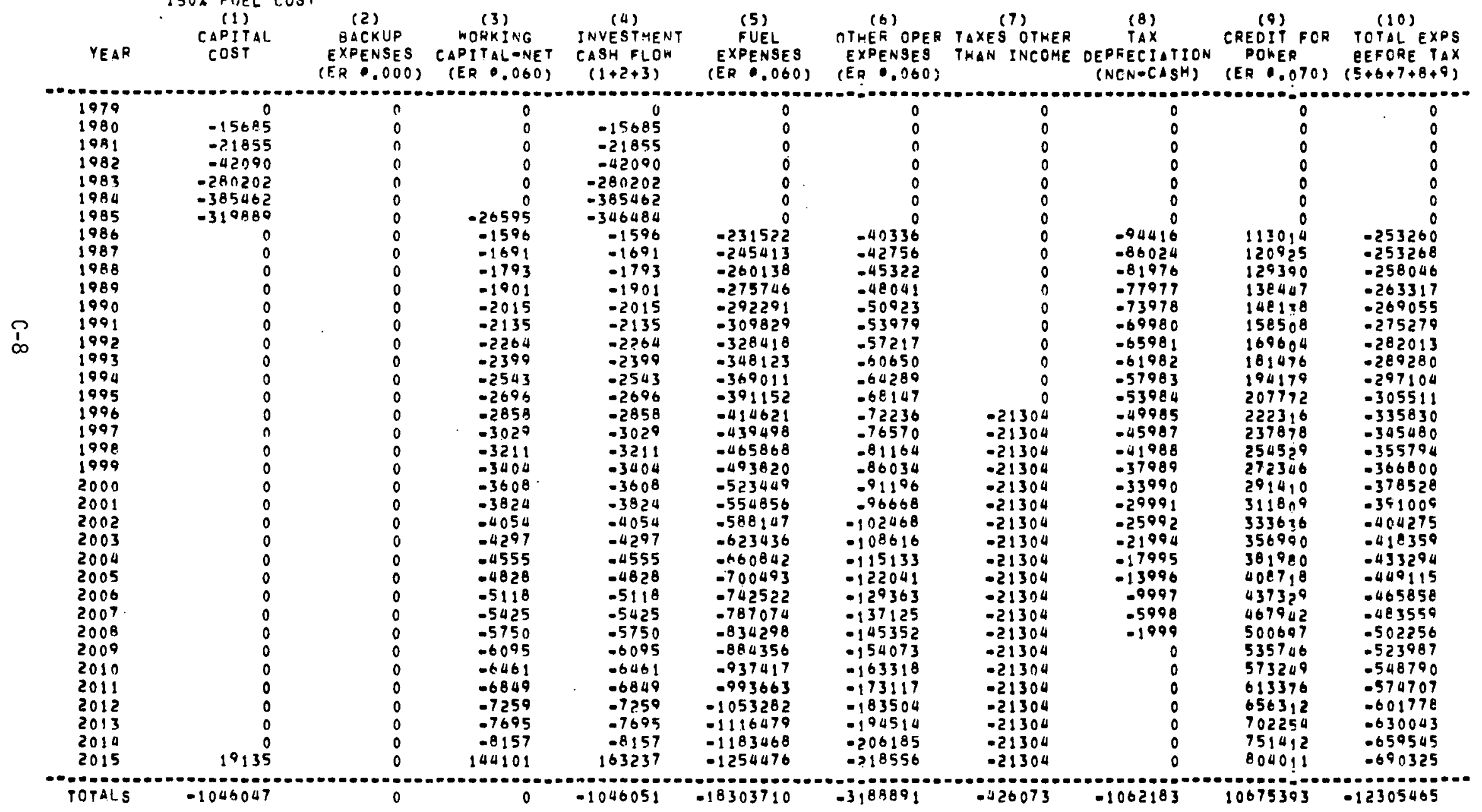


PROJECT COST ANALYSIS

DF ANNUAL CASH REQUIRFMENTS

PROJECTI GEISMAR COGENERATION

CASE I EASTEHN COAL

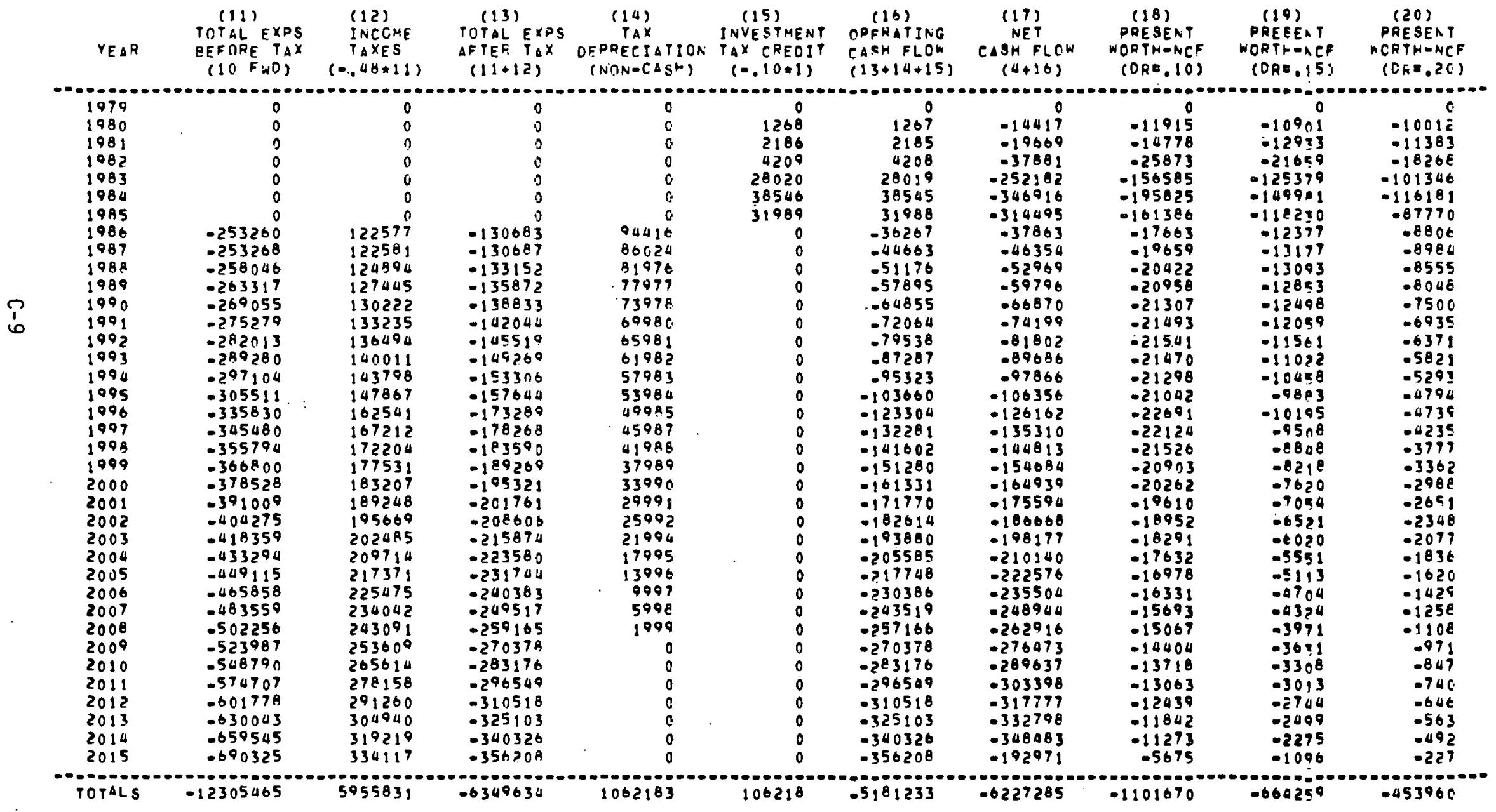


PROJECT COST ANALYSIS

PAGE 1 OF 2

OF ANNUIL CASH REOUIRFMENTS

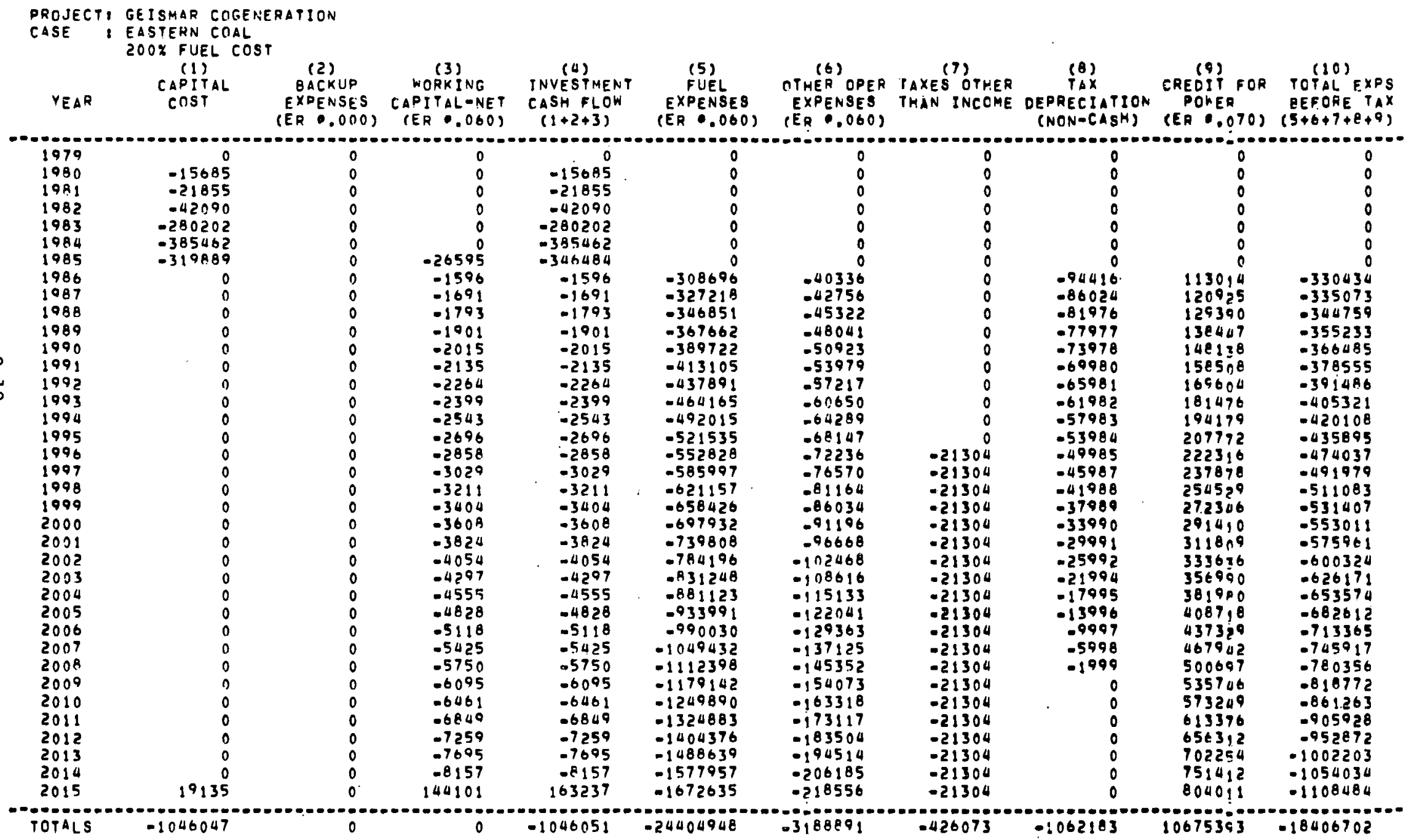


FRCIJECT COST ANALYSIS

PROJECT: GEISMAR COGENERATION

CASE. E EASTERN COAL

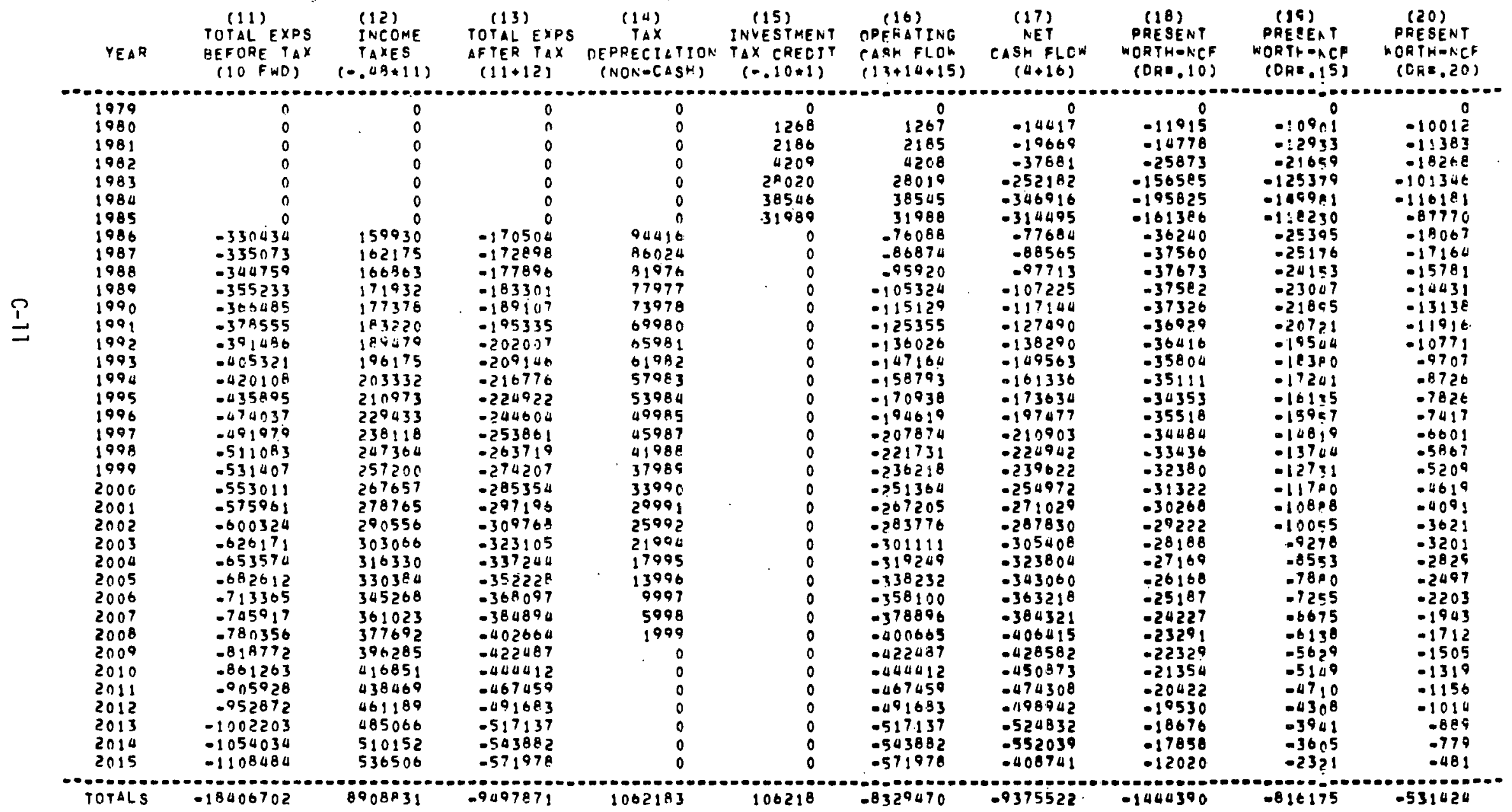


PROJECT COST ANALYSIS

BASED ON PRESENT WORTH

page \& of 2

PROJECT: GEISMAR COGENERATICN

CASE : WESTERN COAL
OOY FUEL COST

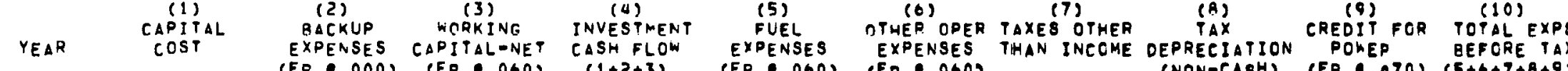

BACKUP (3)

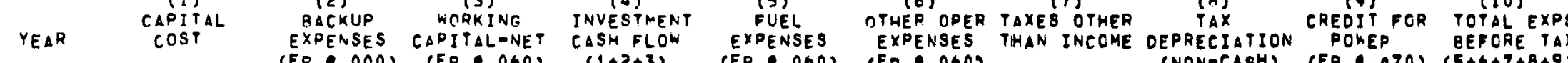

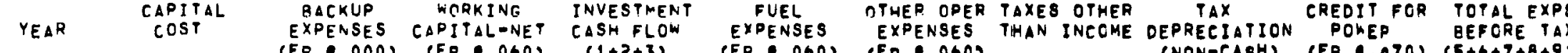

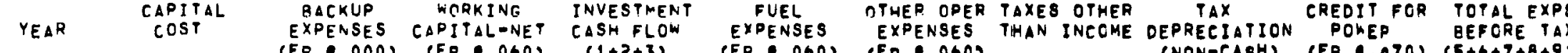

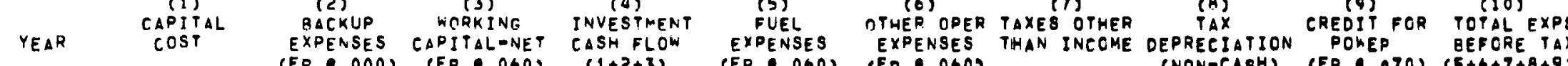

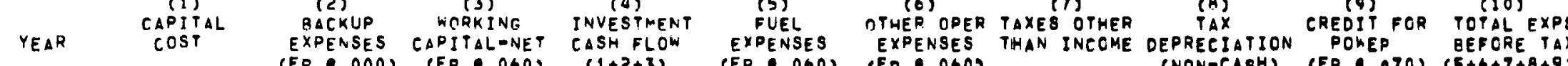

TAX

CREDTT FOR TOPDL

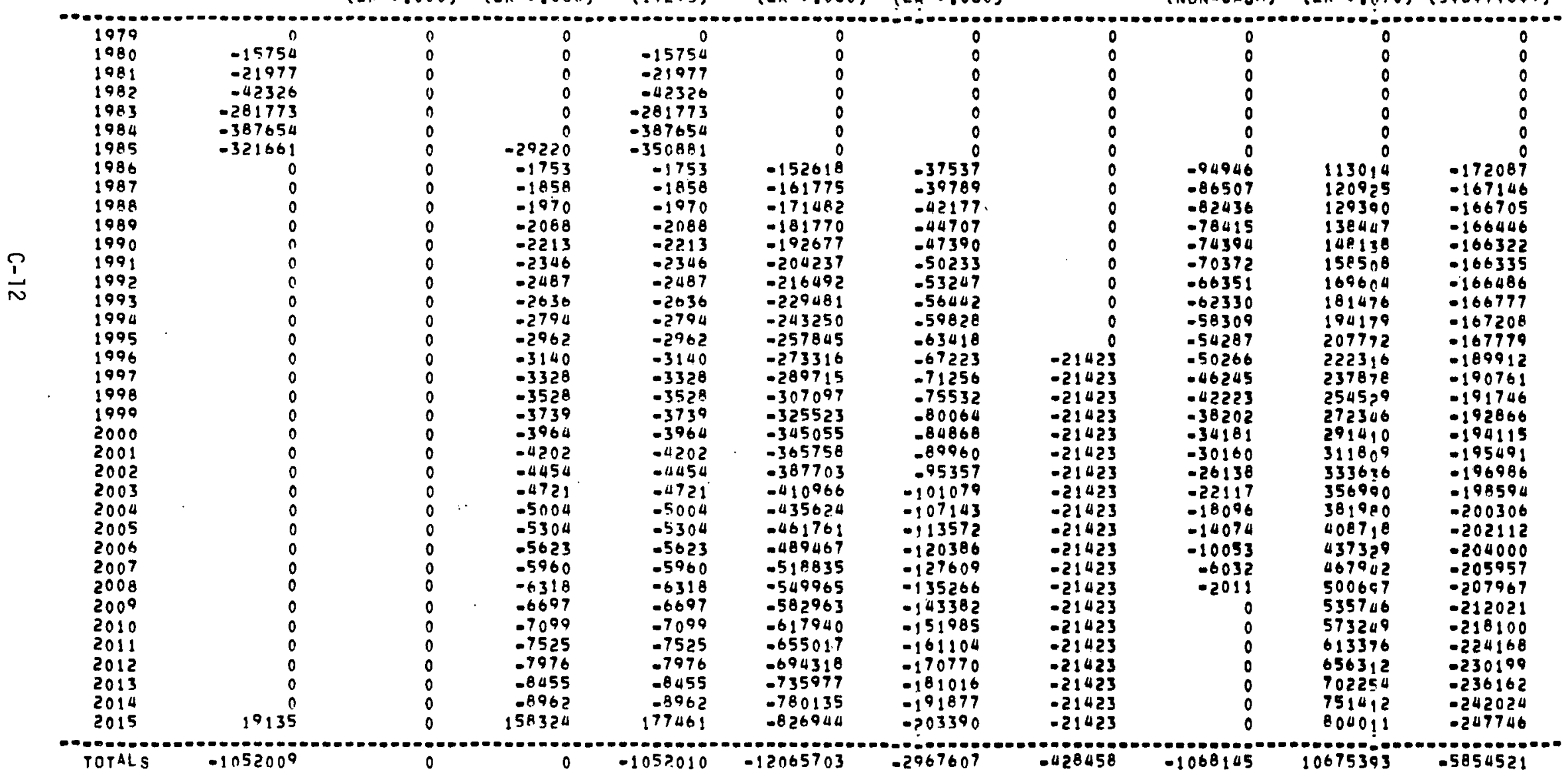


PROJFCT: GEISMAR COGENEHATION CASE TESTERN COAL
QOY FUEL COST

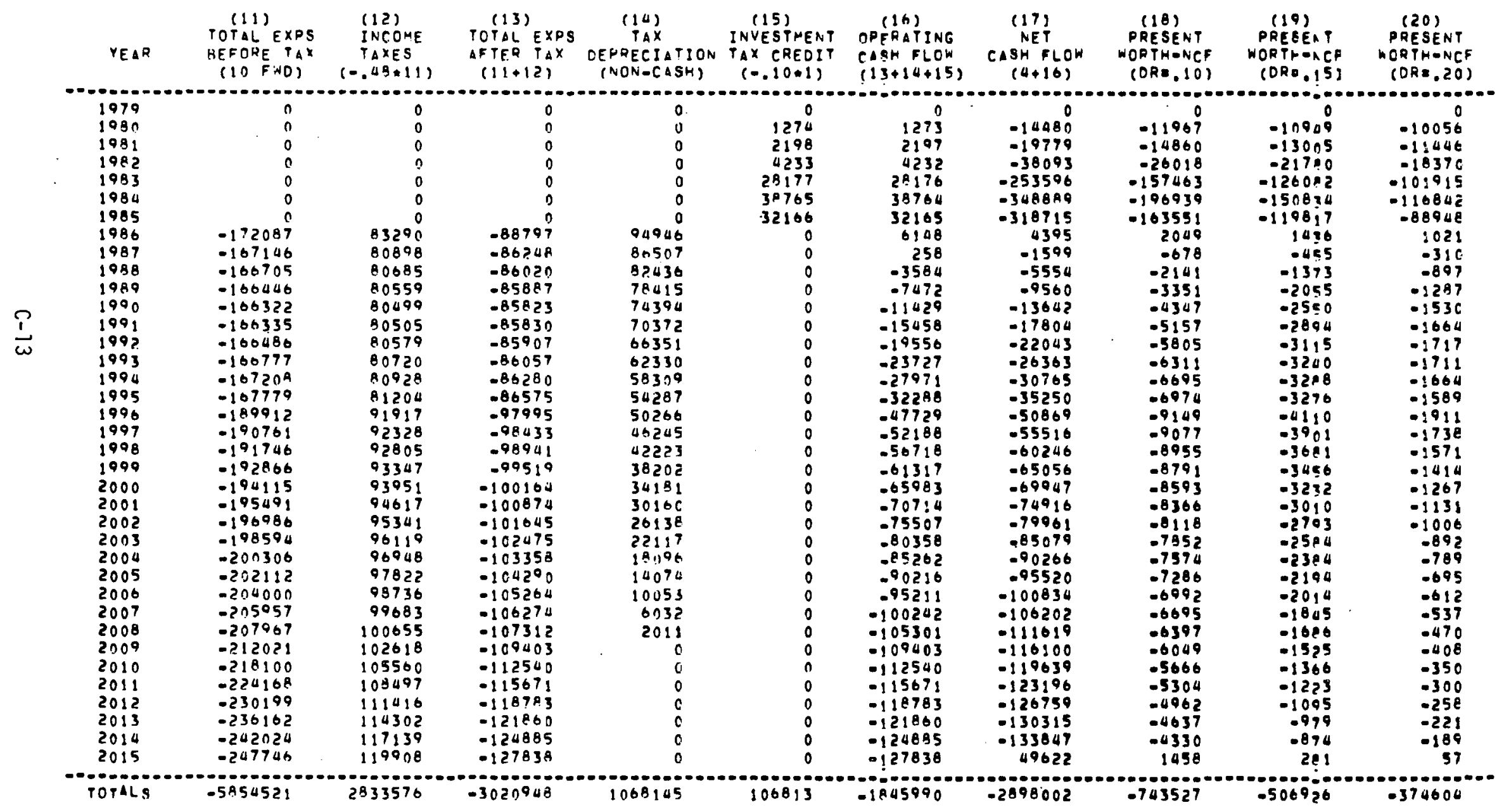


PROJECT COST ANALYSIS

OF ANNUAL CASH REOUIREMFNTS

DROJECT: GEISMAR COGENERATION

CASE THETERA CRAL
DOT FUEL COST (1)

(2)

WORKING INVESTMENT

(4) (ER 0.000$)$ (ER -.060$)(1+2+3)$ (ER-.060) (ER 0.060$)$ (ER 0.000$)$ (ER -.060$)(1+2+3)$ (ER-.060) (ER 0.060$)$

(5)

EXPENSES

(6)

(7)

ATHER OPER TIXES OTMER TAX TAX CREOTT FOR TOTAL EXPS
EXPENSES TAAN INCOME OEPRECIATION POMEP

(NON-CAGH) (ER .070$)(5+6+7+B+9)$

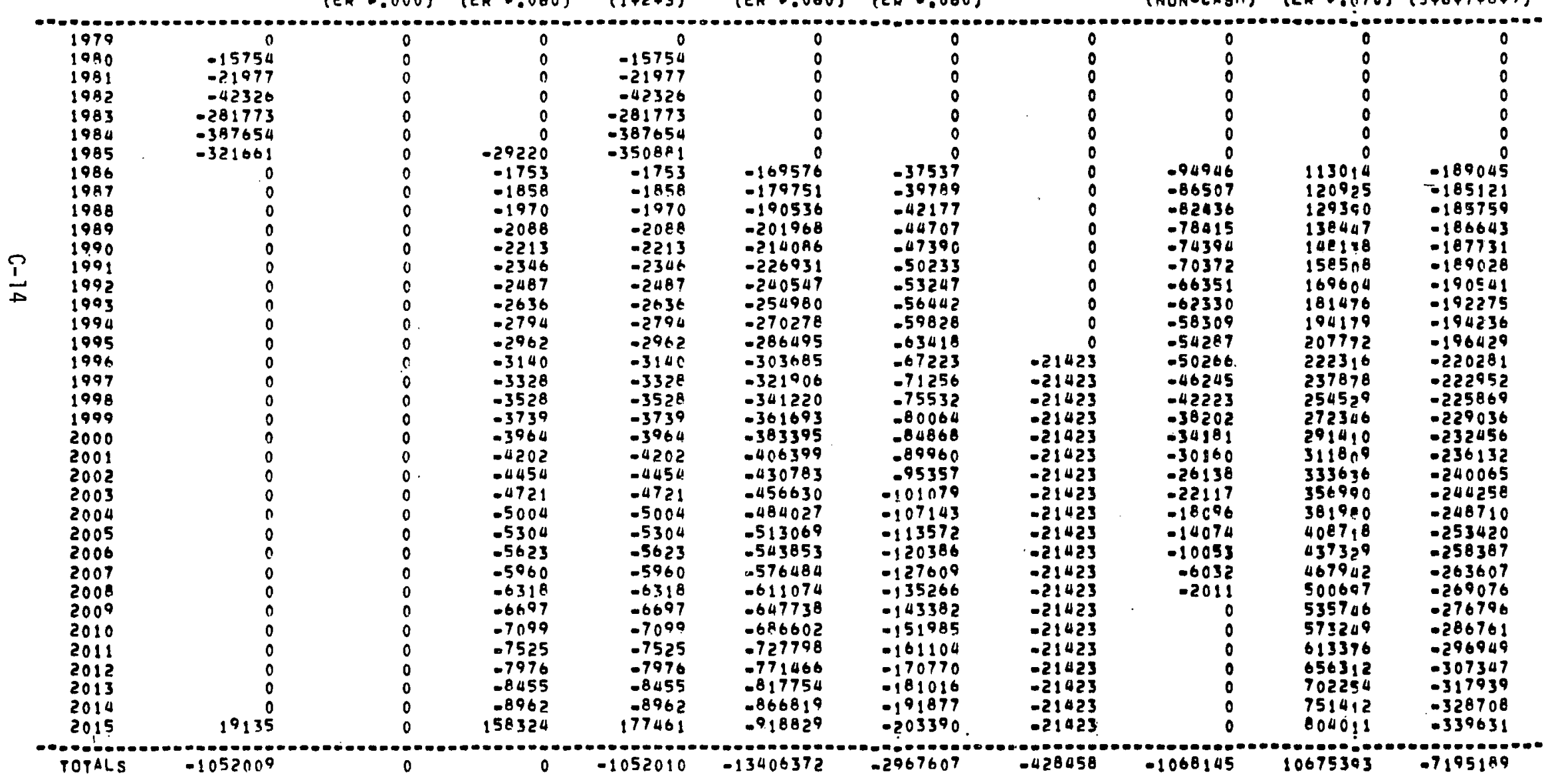


PROJECTI GEISMAR COGENERATICN

CASE I LESTERN COAL
IOOX FUEL COST

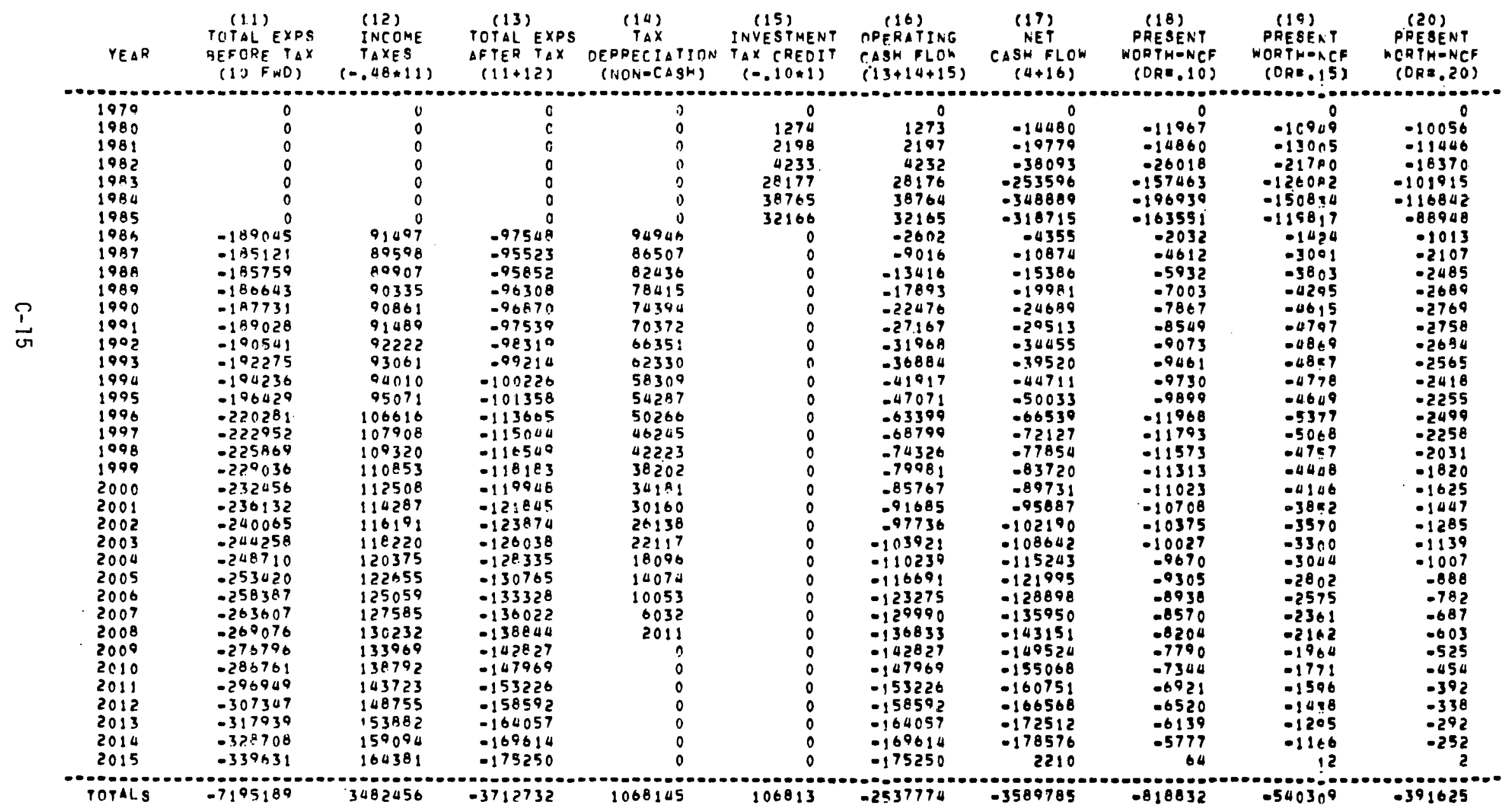


PROJECT: GEISMAR COGENERATION (9) (10)

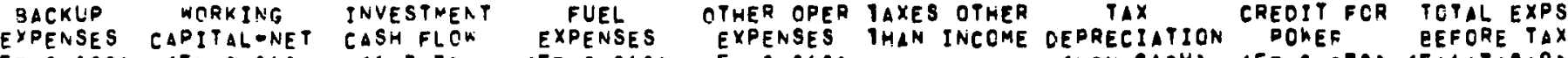
(ER .000$)$ (ER $(.060)(1+2+3)$ (ER $(.060)$ (ER (NON-CABH) (ER .070$)(5+6+7+6+9)$

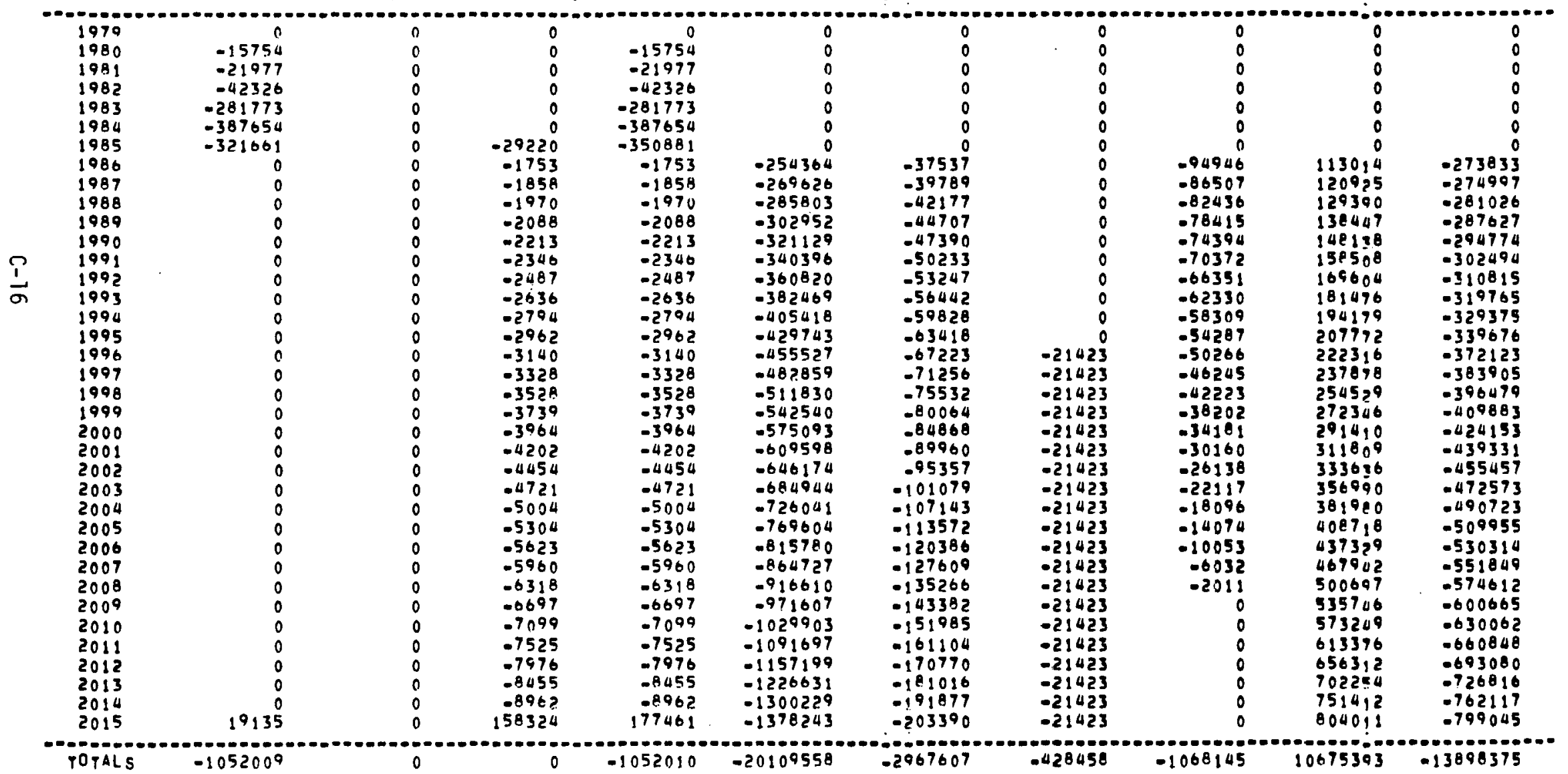


PROJECT COST ANALYSIS

PAGE 2 OF 2

OF AMNUAL CASH REQUIREMENTS

PROJECT: REISMAR COGENEPATION

CASE WESTERN COAL

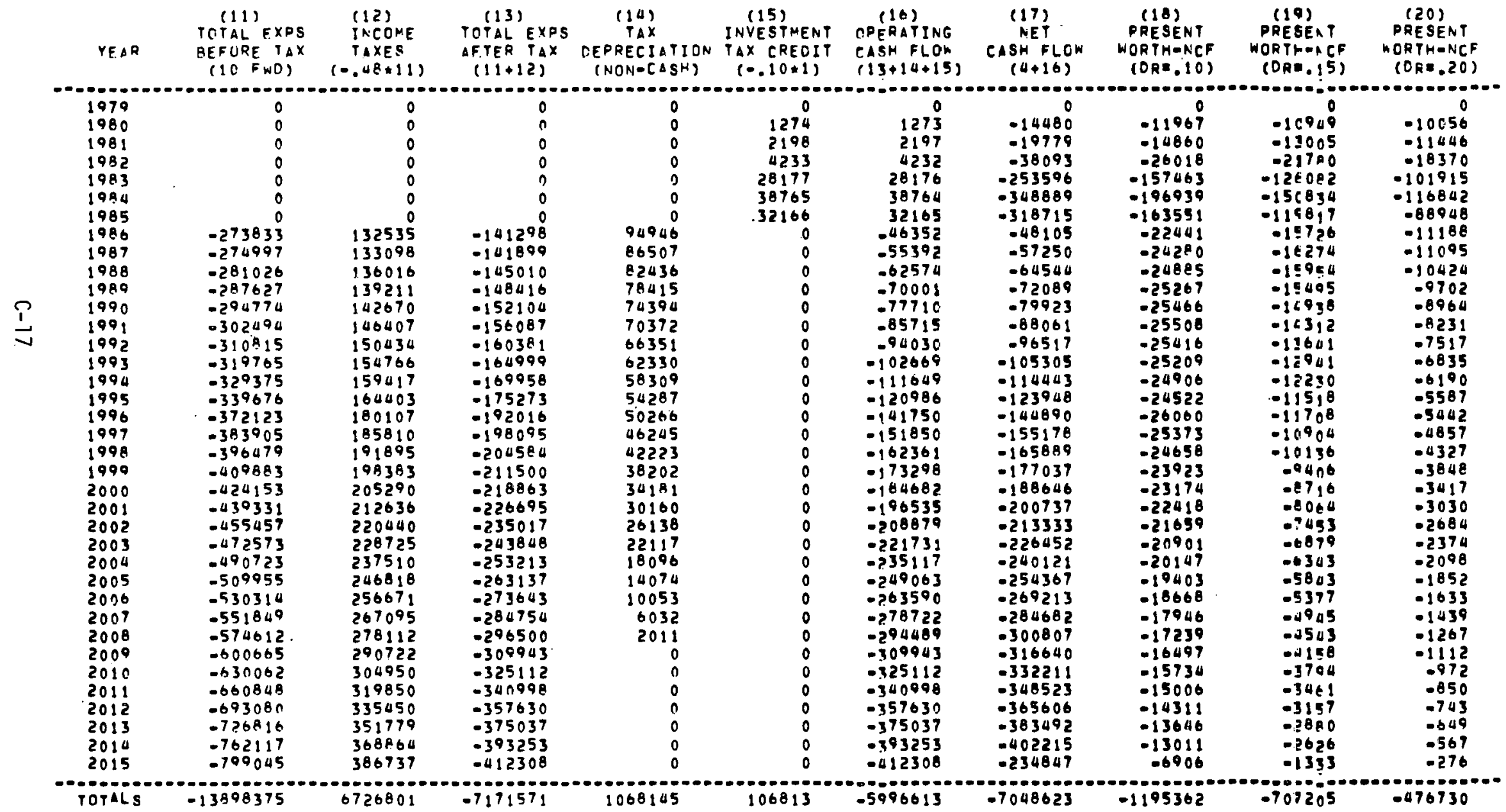


PROJECTI GEISMAR COGENERATION CASE WESTERN COAL

WESTERN COAL

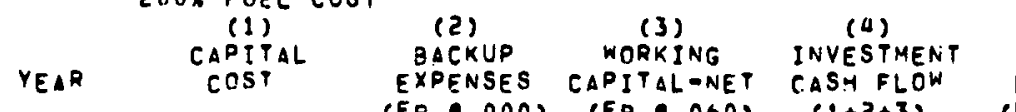

(5) (b) (6) (7) (B) EXP

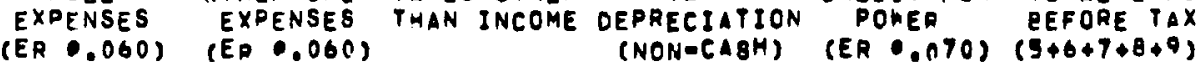
GTHER OPER TAXES OTHER CREDIT FOR TOTAL EXPS

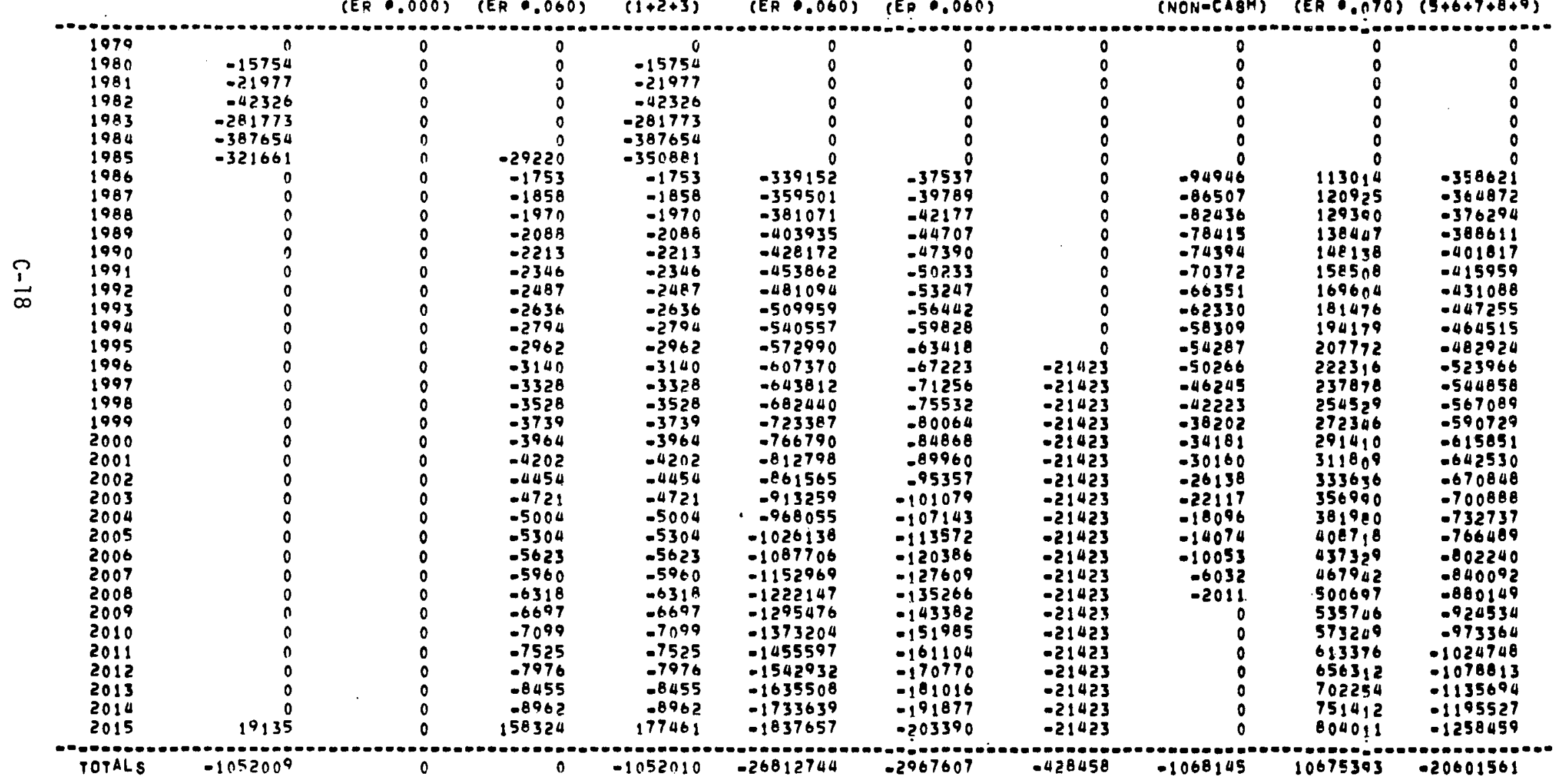


PREJECT COST ANALYSIS

PAGE 2 OF 2

DF ANNUAL CASH REQUIREMENTS

PROJECT: GEISMAR COGENERATION

CASE I WESTERH COAL

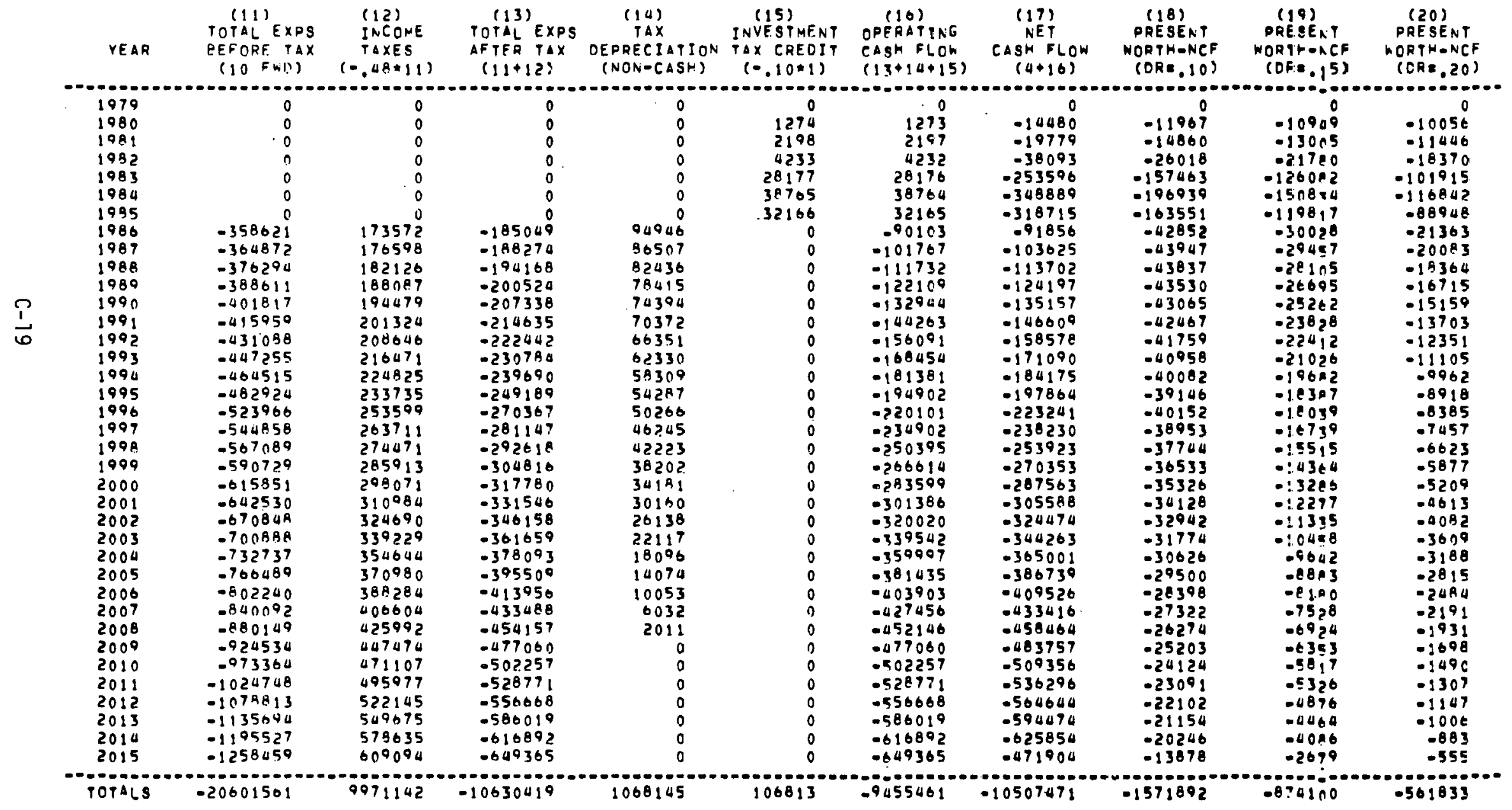


PROJECT: GEISMAR COGENERATIOA

CASE MOQ G FUEL OIL
QOX FUEL COST

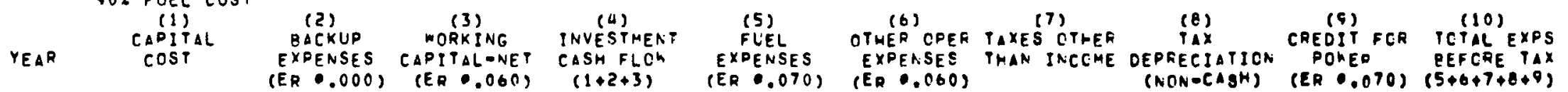

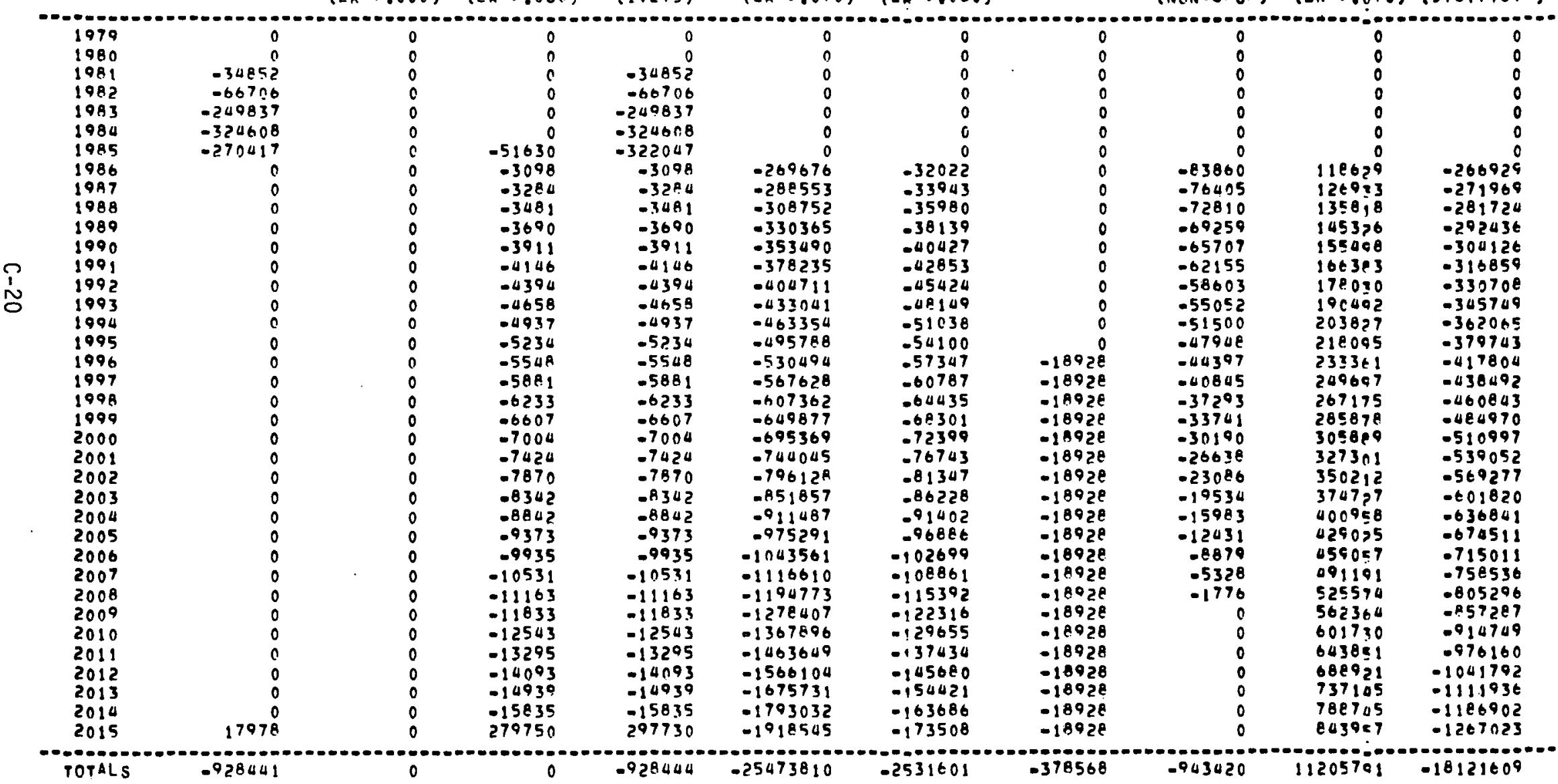


PROJECT COST ANALYSIS

PROJECT: GEISMAR CUGENERATION

CASE I NO. G FUEL OIL

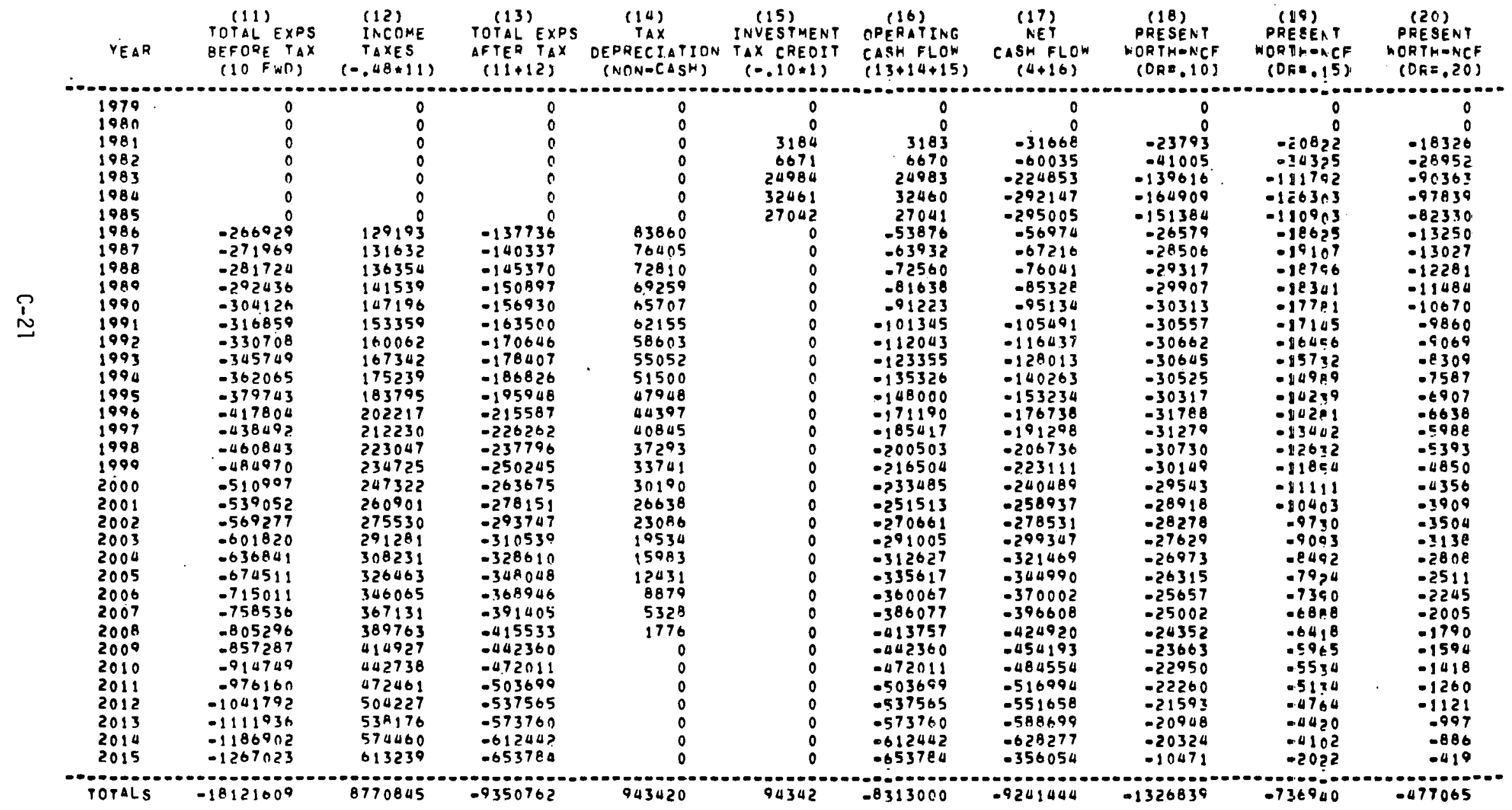


PROJECT COST ANALYSIS

OF ANNUIAL CASH REQUIRFMENTS

PROJECT: GEISMAR COGENERATION

CASE \& NO O FUEL OIL

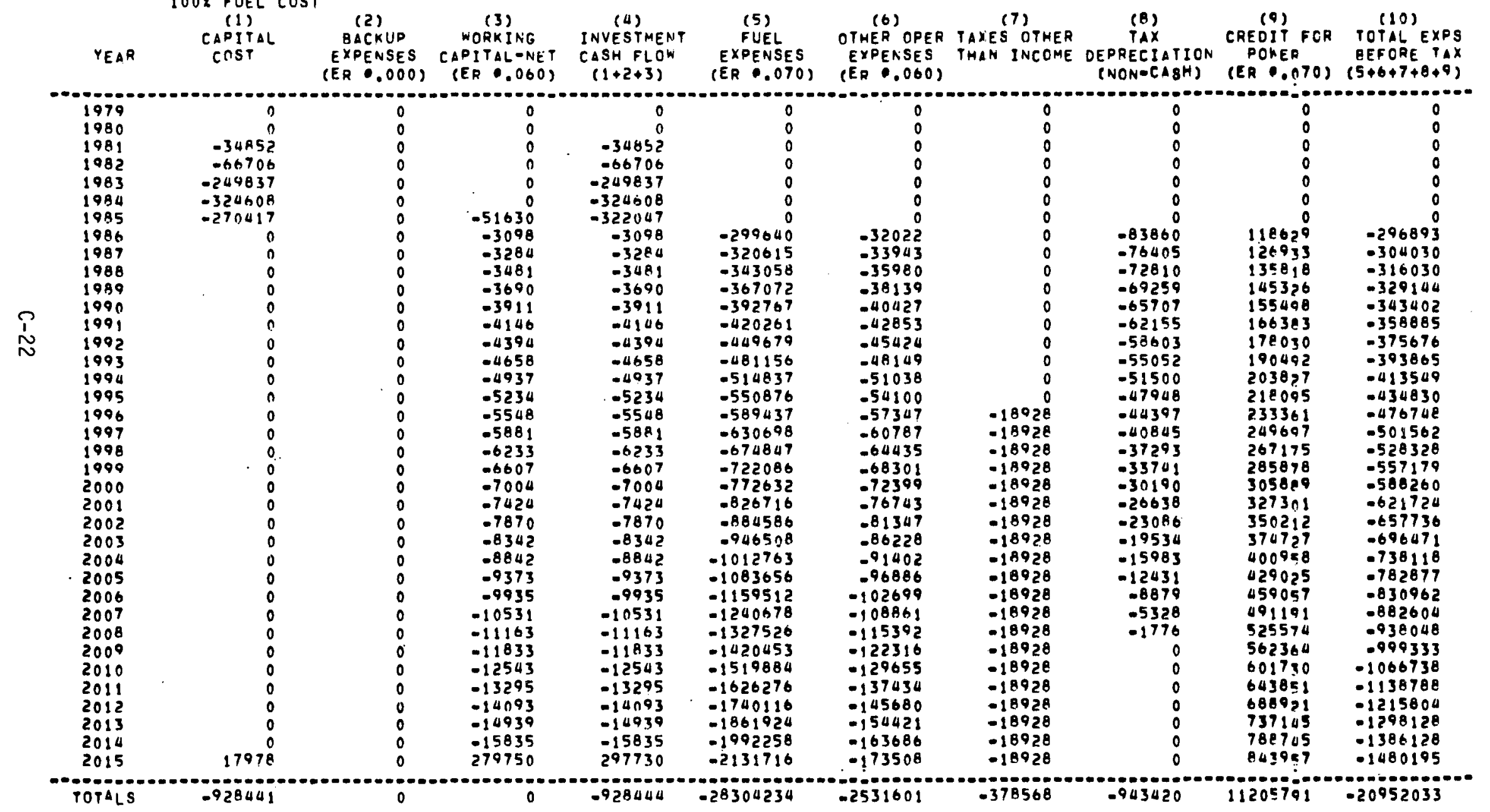


PRCJECT COST ANALYSIS

OF ANNUAL CASH PEQUIREMENTS

PROJECT: GEISMAQ COGENERATION

CASE I NO. G FUEL OIL

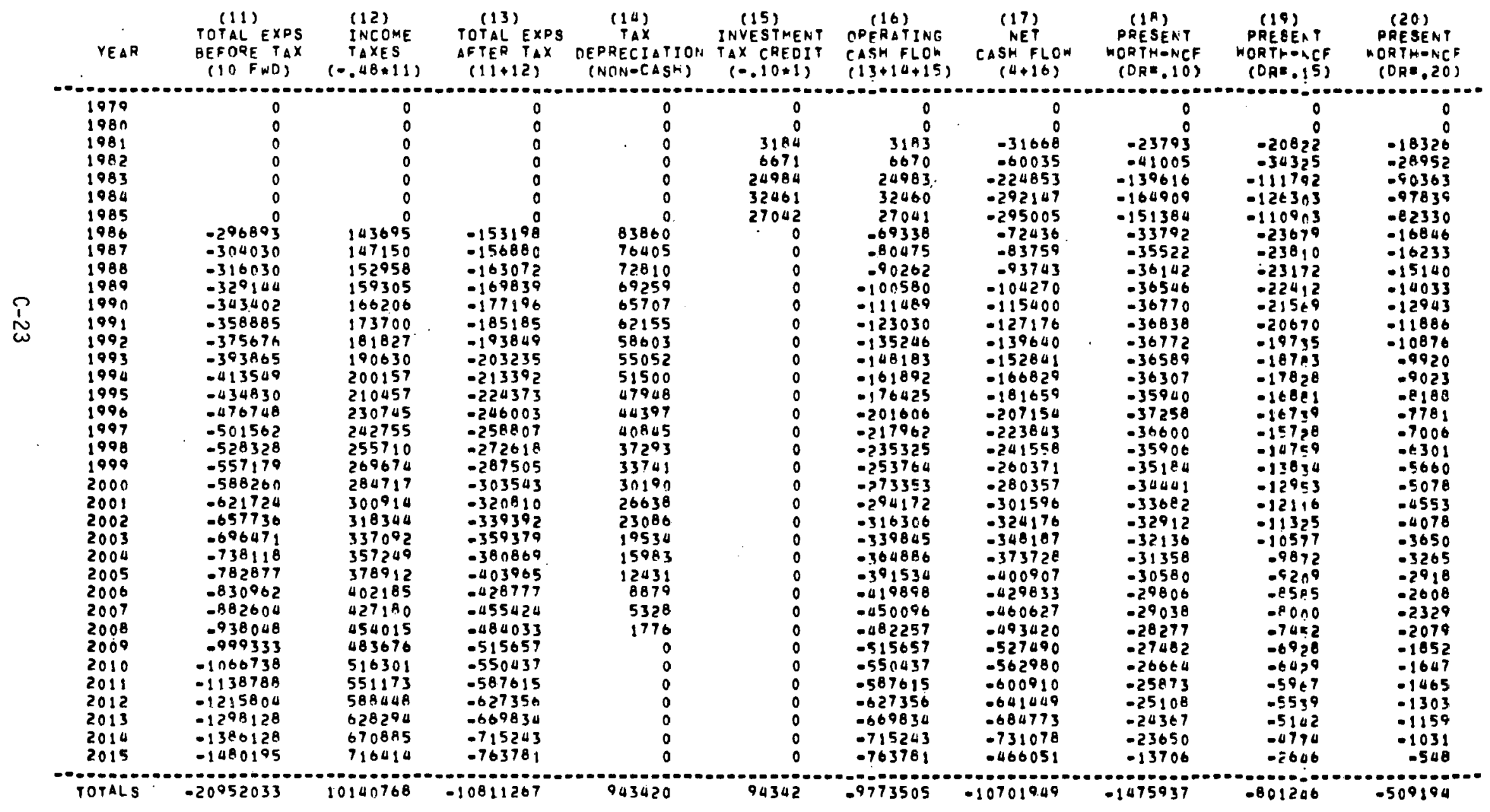


PROJECT: GEISMAR COGENERATION

$\begin{aligned} \text { CASE I NO. O FUEL OIL } & \text { 150\% FUEL COST }\end{aligned}$

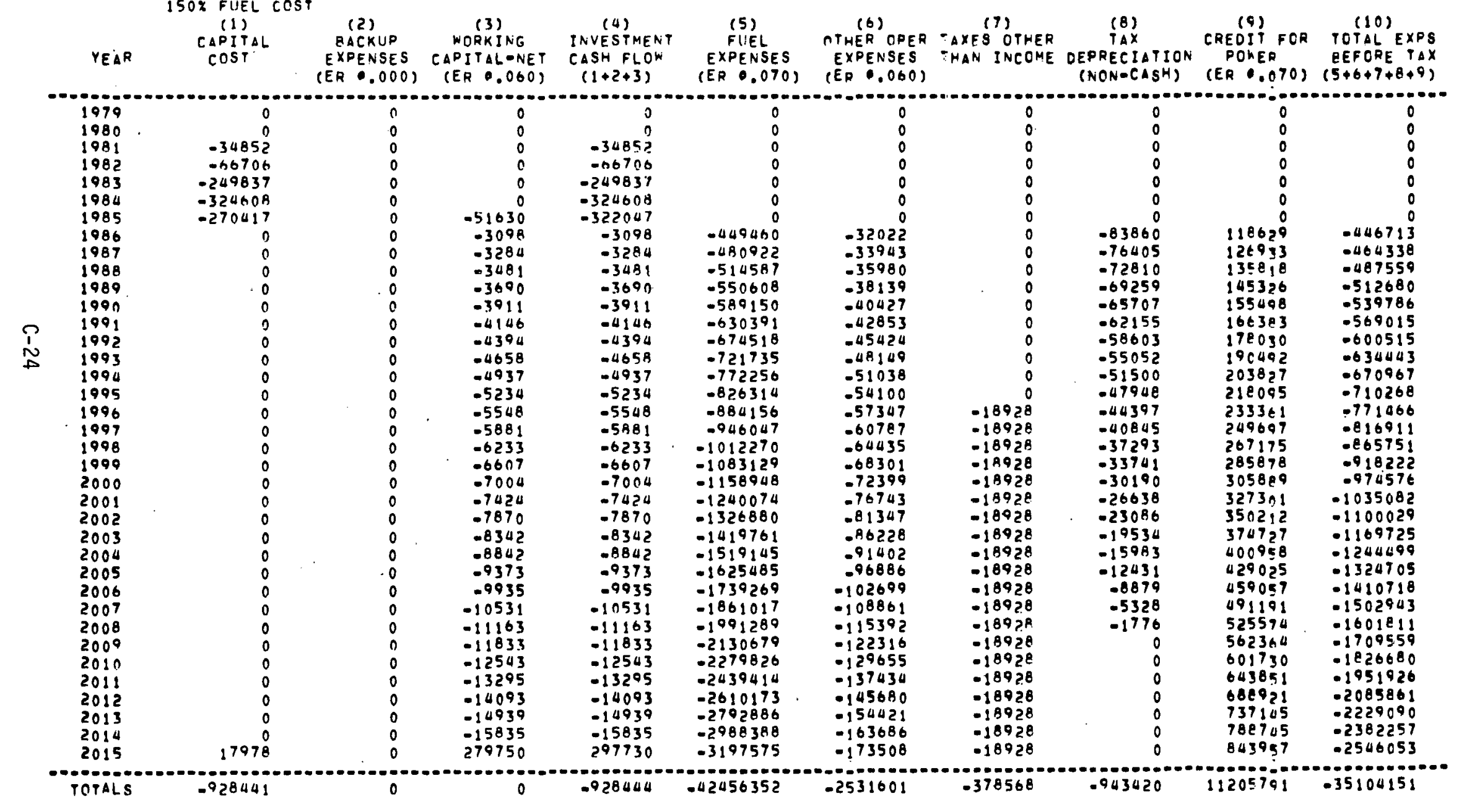


PROJECT: GEISMAR COGENERATION

CASE INO. 6 FUEL OIL

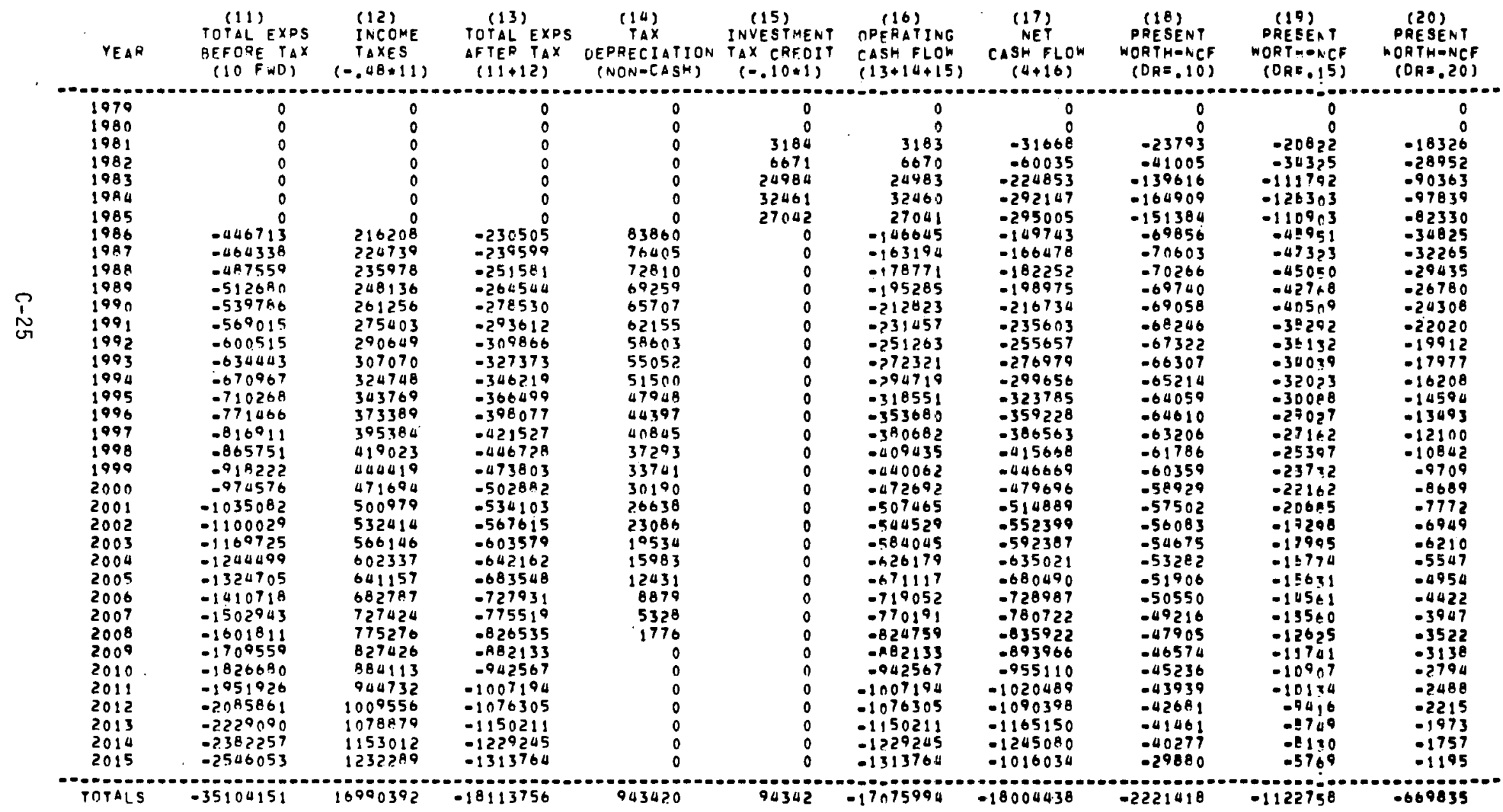


PROJECT, GEISMAR COGENERATION

$$
\begin{array}{ll}
\text { CASE IOD FUEL OIL } \\
\text { 2OOX FUEL COST }
\end{array}
$$

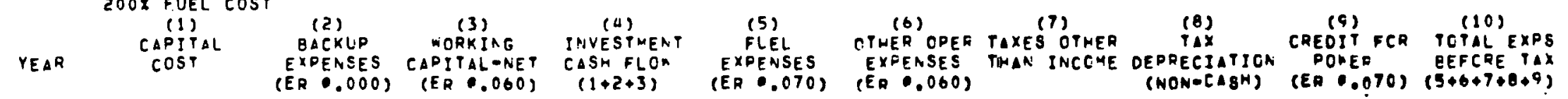

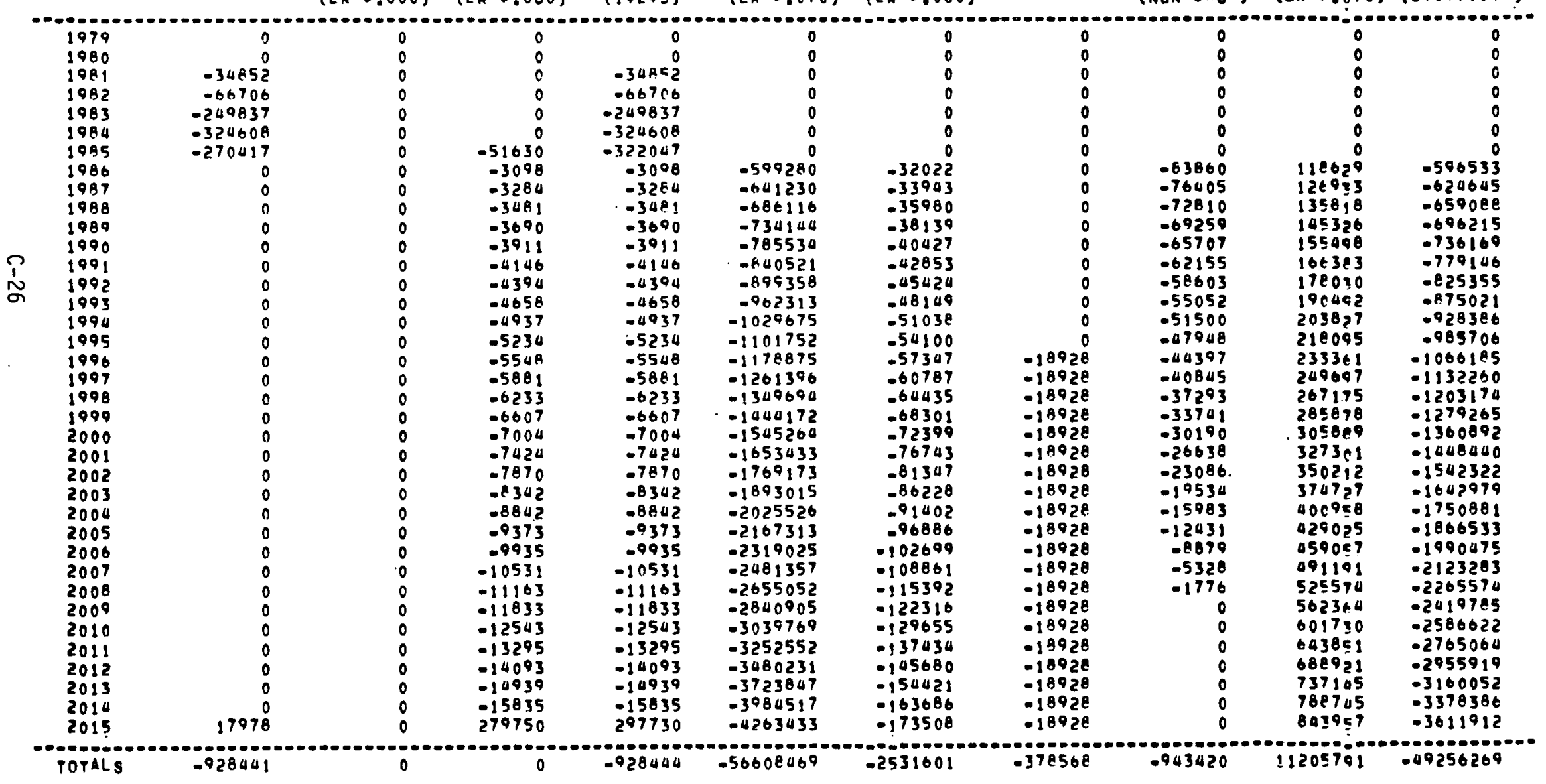


PROJECTI GEISMAR COGENEMATION

CASE NO. 6 FUEL OIL

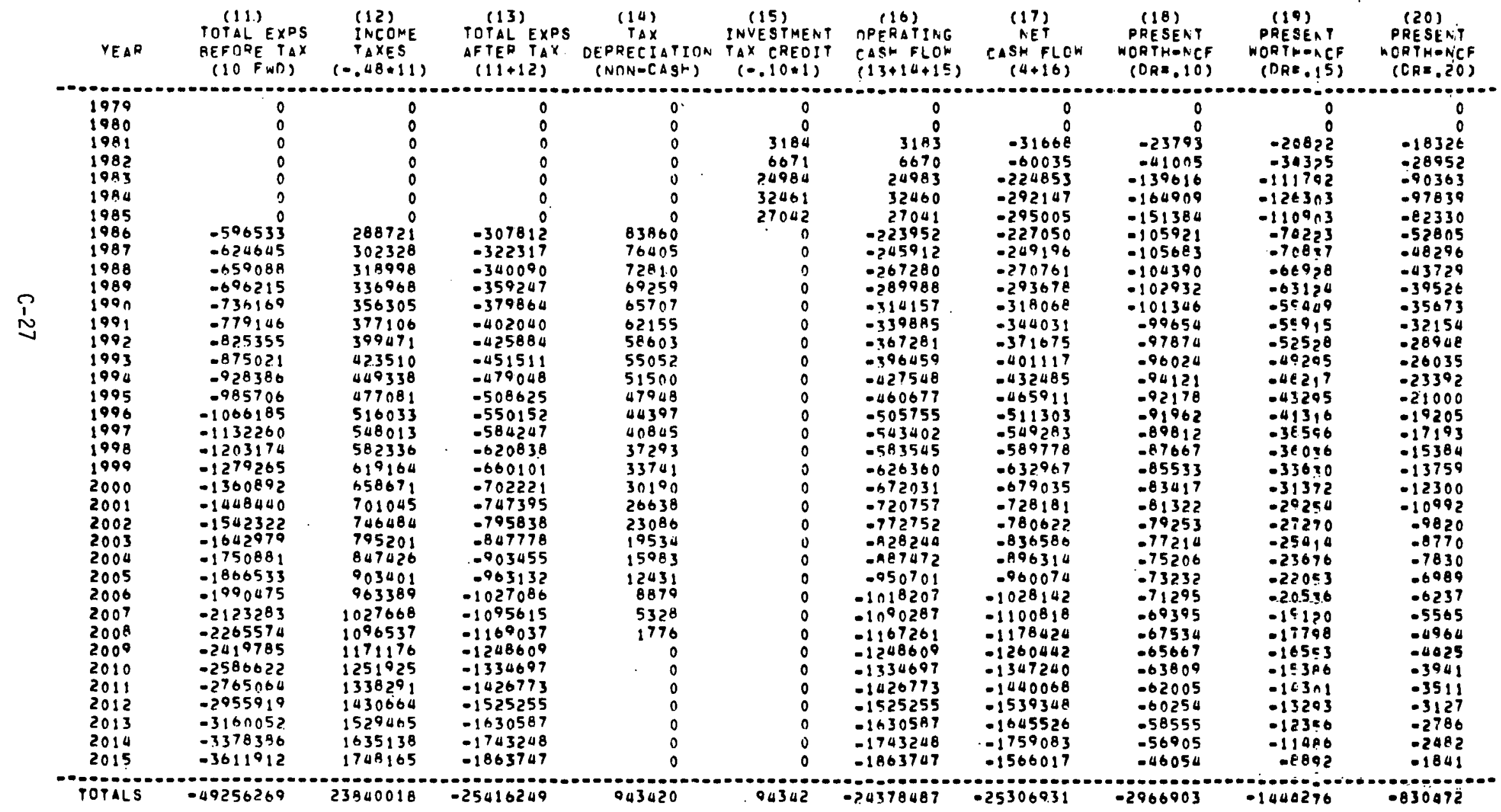


PROJECT: GEISMAR COTEEHERATION CASE : MTG

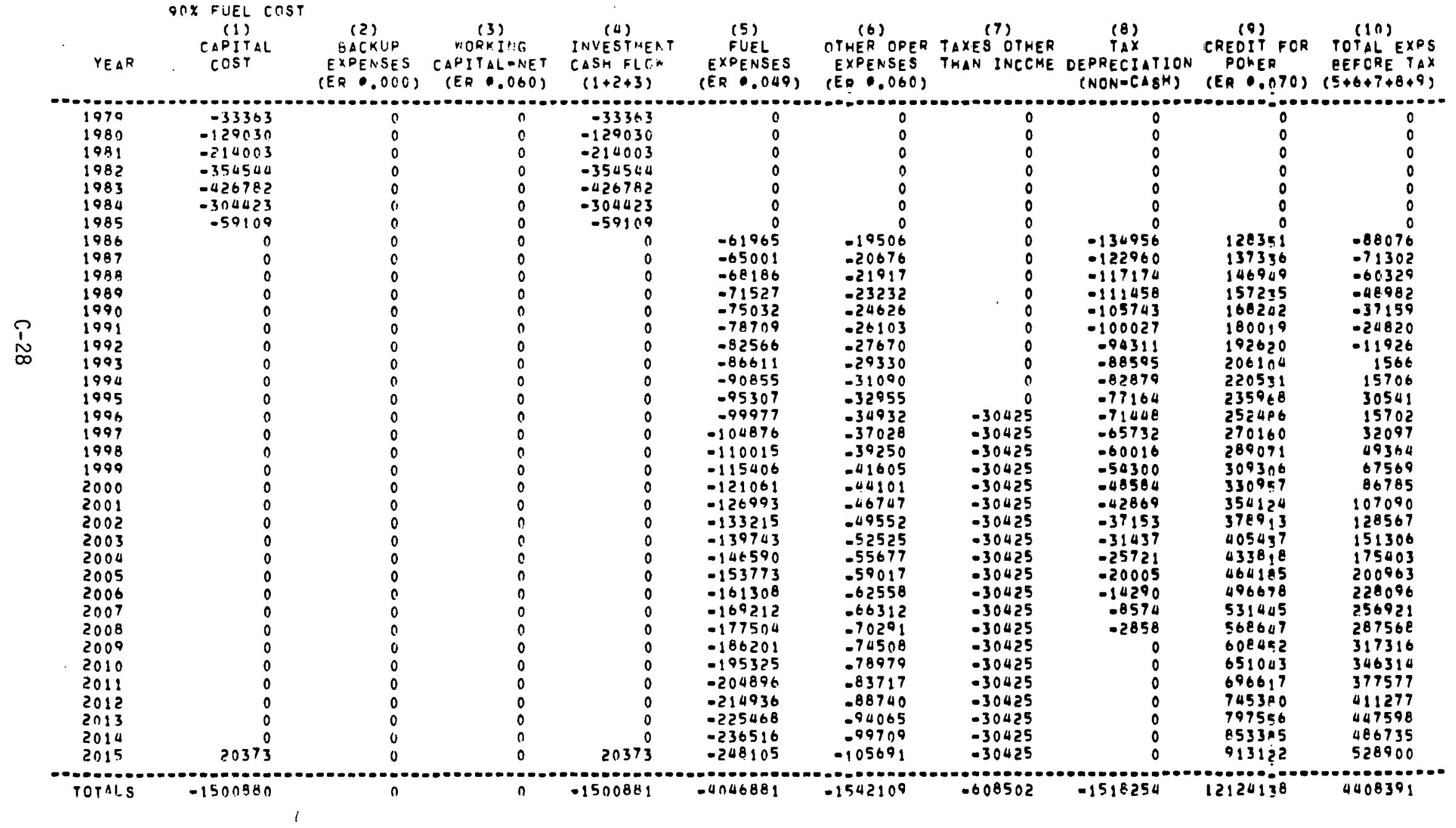


PRUUECT COST ANALYSIS

OF ANNUAL CAST REQUIREMENTS

PROJECT: GEISTAAR COGEIVERTION

CASE : MTGF

- MTER FUF COST
GOX FU

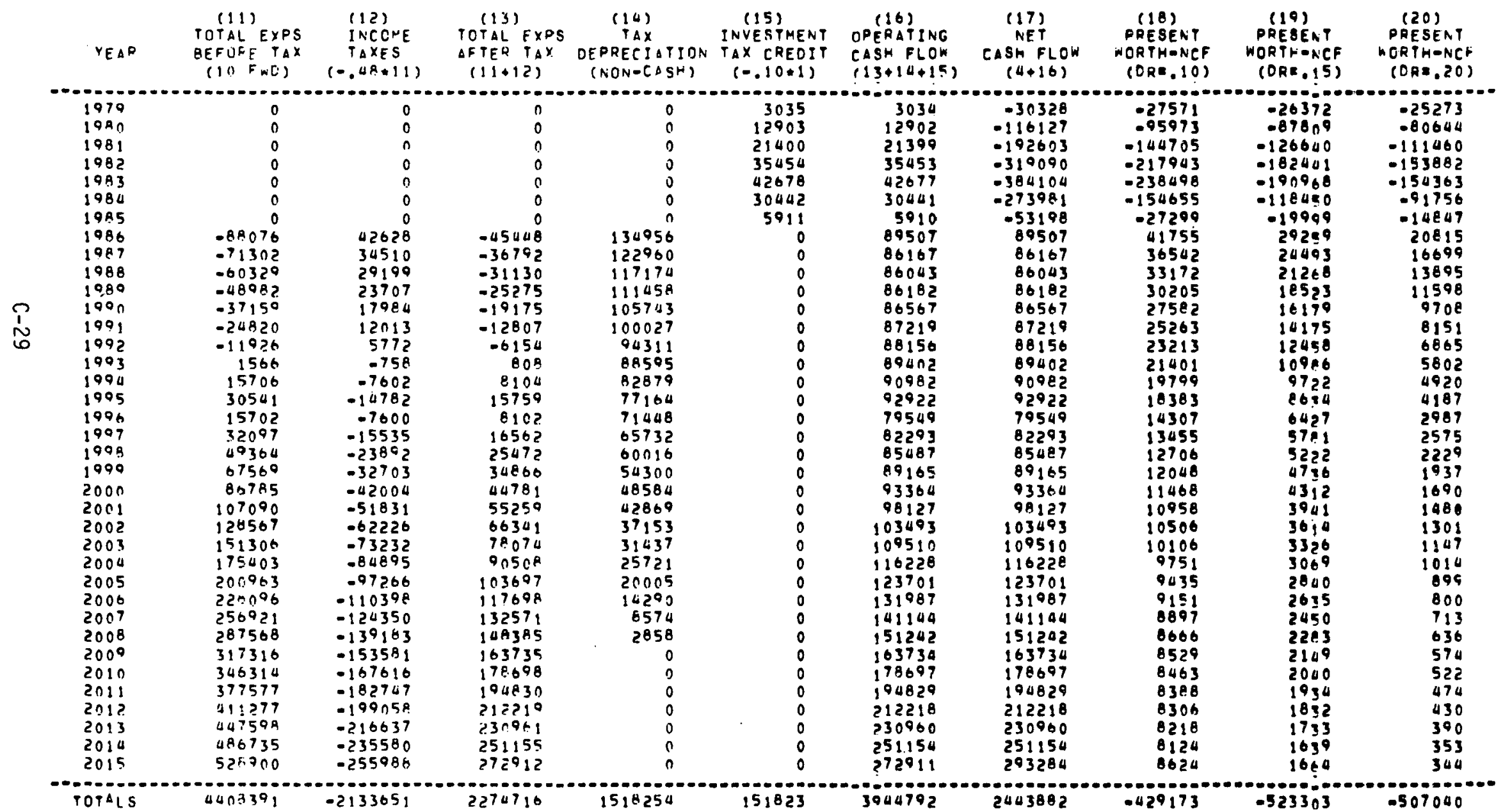


PROJECT COST AHALYSIS

PAGE I OF 2

OF ANNIJAL CASH REQUIAEMENTS

PROJECT: GEISMAP COGENERATILIN

CASE : HTGR

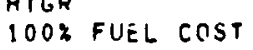

1002 FUEL COST (1) RAPITL (2)

(5) (3)
RACKUP WDRKING

(4)

NVESTMENT

(5)

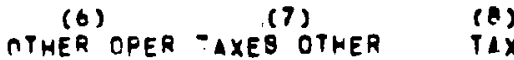

(a)

(9) (10) EXPENSES CAPITAL-NET CASH FL

EXPENSES

EXPENSES - MAN INCOME

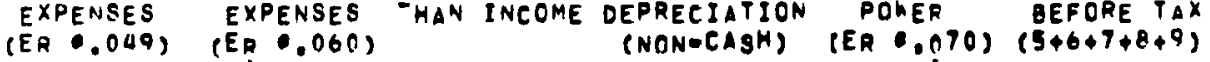

PONER TOTAL EXPS

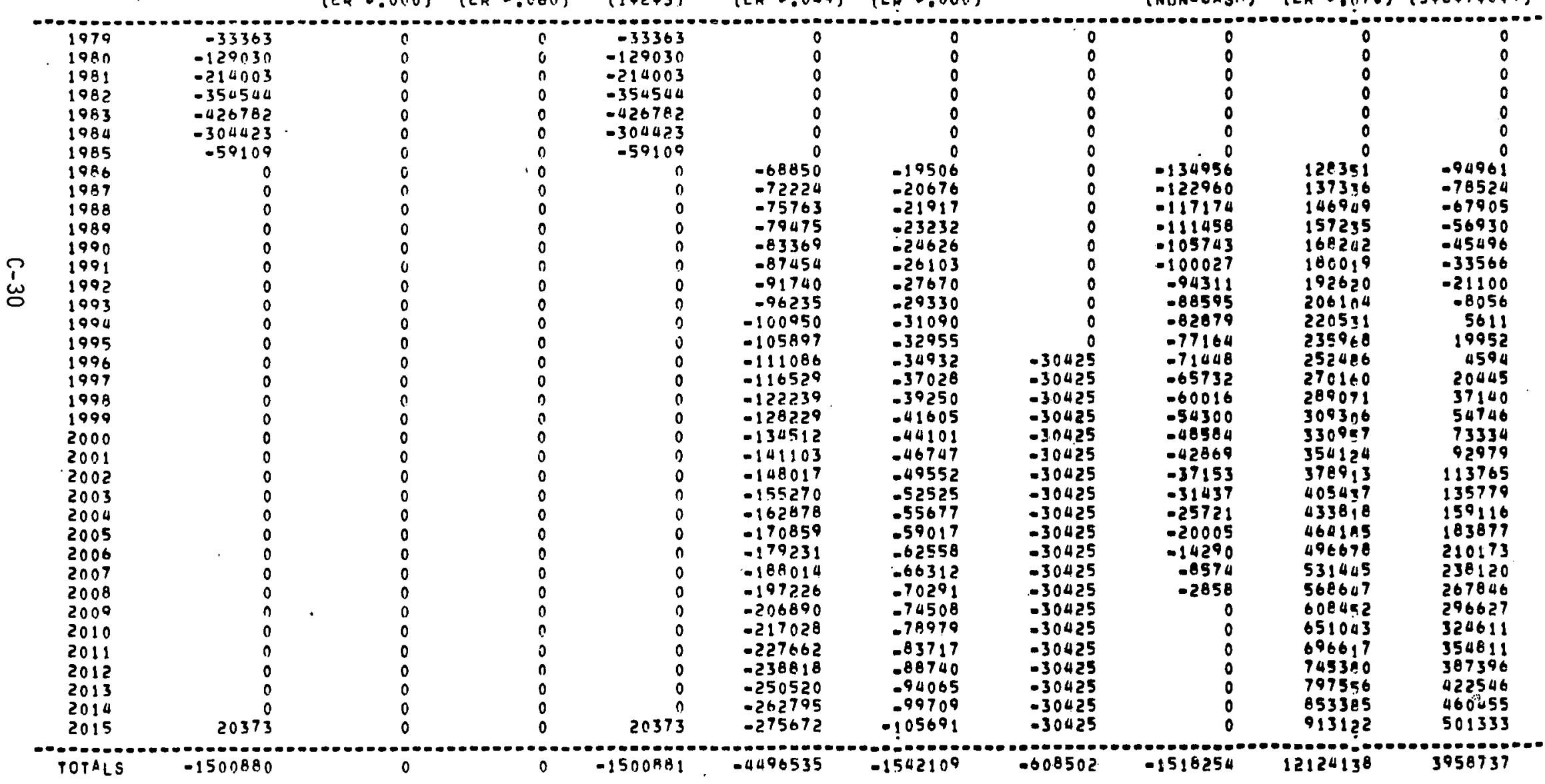


OROJECT COST ANALYSIS

PAGE 2 OF 2

OF ANPUAL CASH REQUIFEMFATS

PROJECT: GEISHAK CGGENERATION

CASE I WTGR

$$
\text { IOOX FUEL COST }
$$

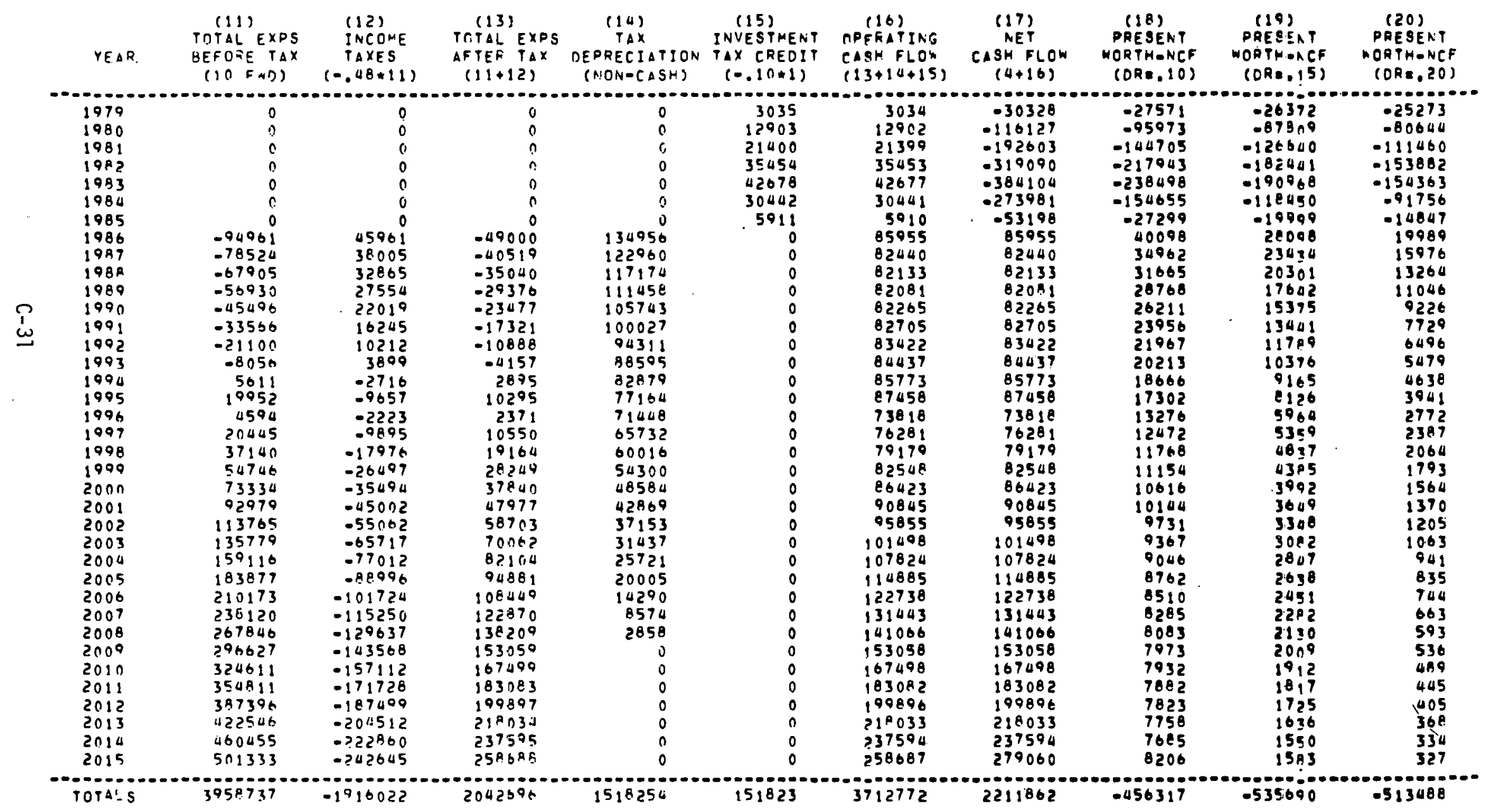


PROJECT: GEISMAE: COGENERATICN

CASE : HTGR

$$
\text { ISOX FUEL COST }
$$

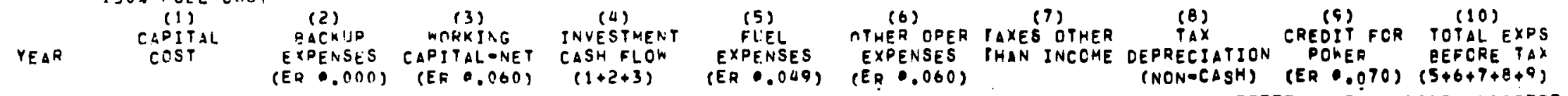

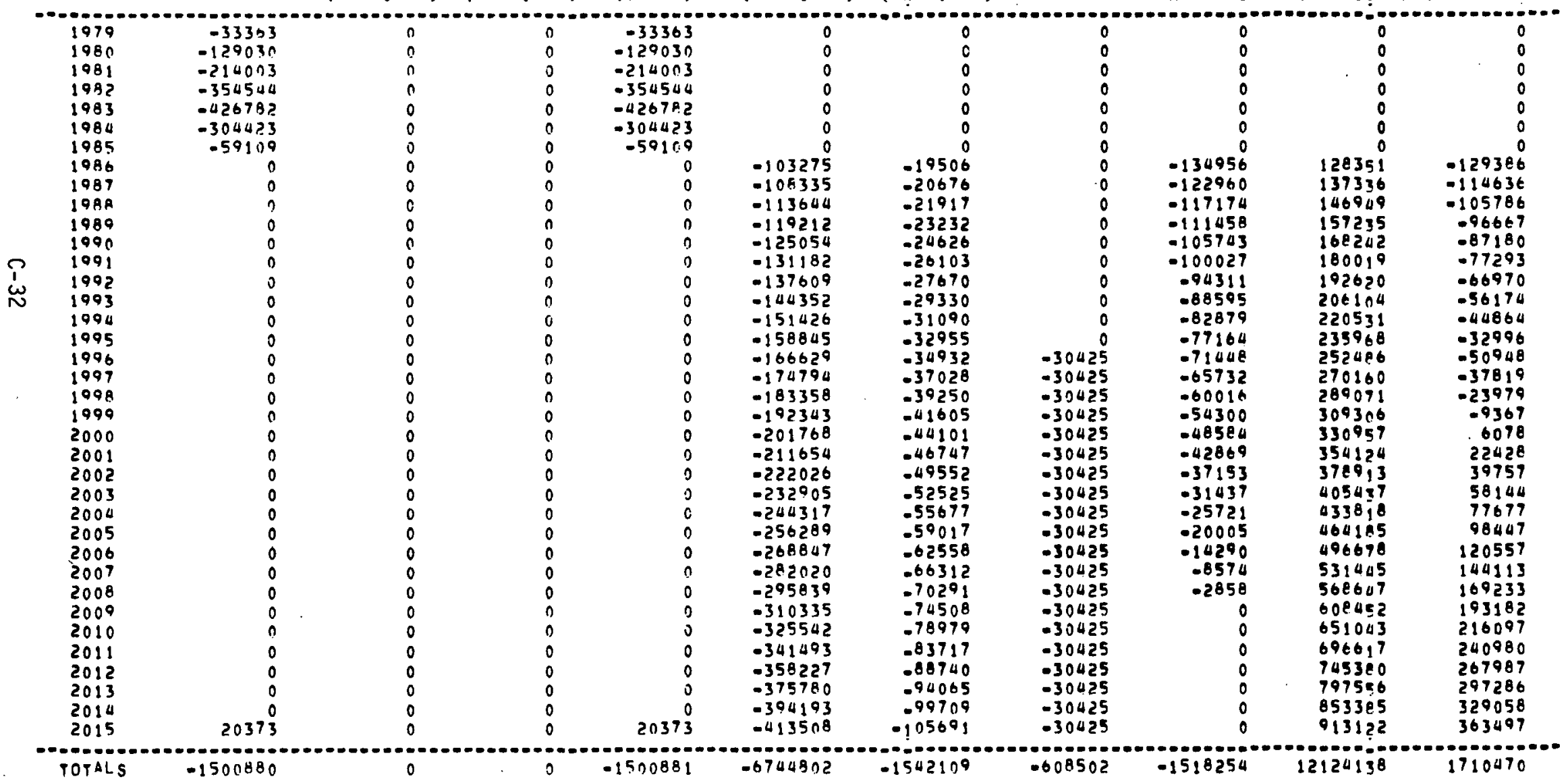


PPOJECT COST ANQLYSIS

PAGE 2 OF 2

OF ANFUAL CLSH REDUIRFMENTS

PROJFCT: GEISMAR COGEMEPATIOA

CASE : HTGR

ISUY FIIEL COST

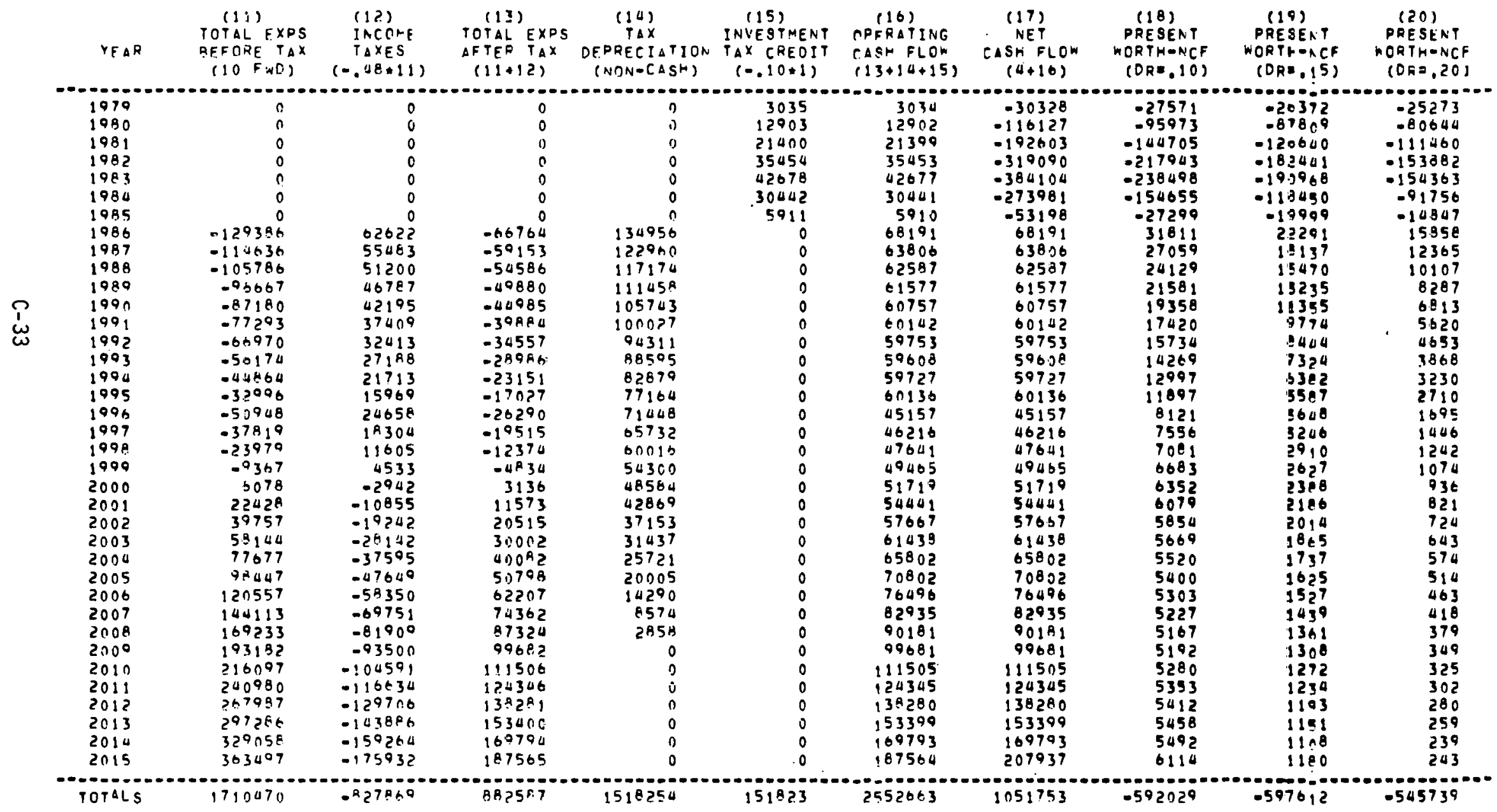


FHNJECT COST ANALYSIS

PAGE I OF 2

OF AUIUSL CAST REOUIFEMFNTS

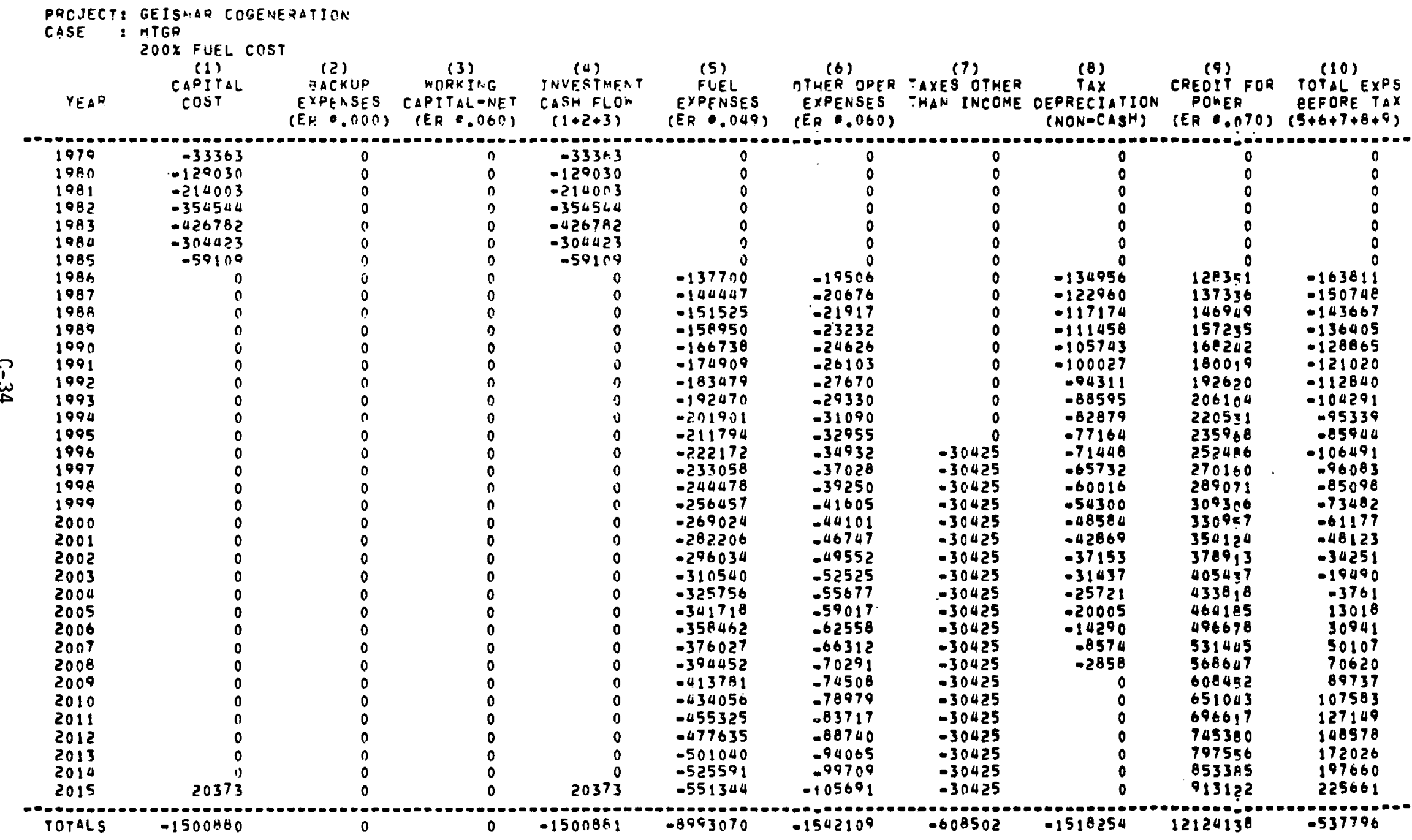


PROJECT: GEISHAR COEENF.PATIOA

CASE I MTGR

ZTOX FUEL COST

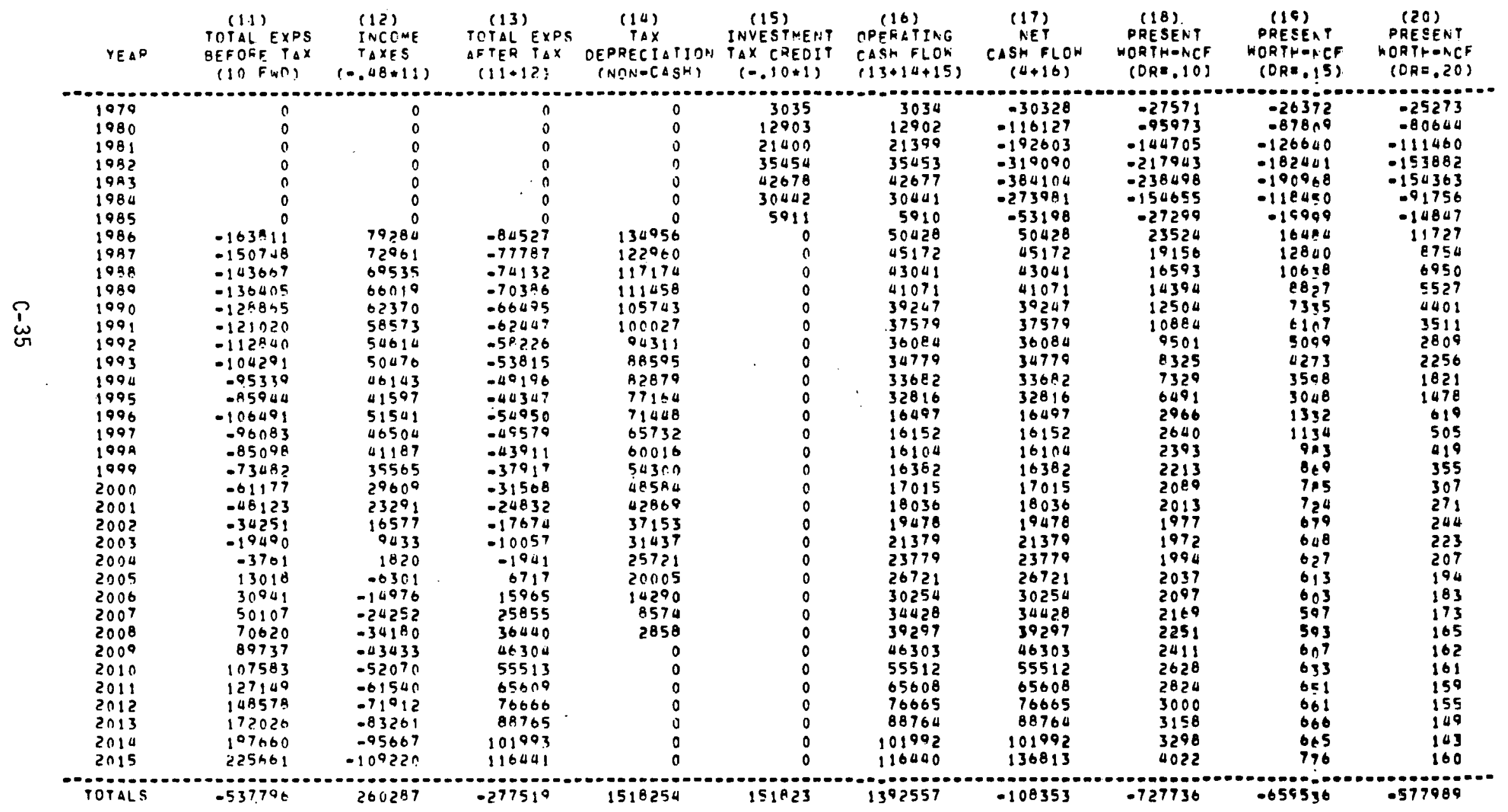


PROJECT: TOEISYGR COGENERATIOA

CASE I CNSS

$$
\text { QNX FUEL COST }
$$

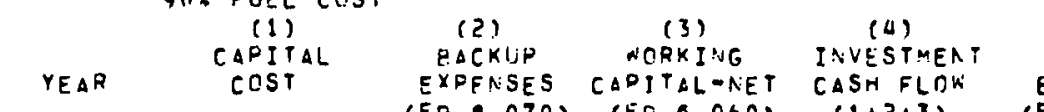

$\begin{array}{ll}\text { IER } \\ 1979 & -21232 \\ 1980 & -38696 \\ 1981 & -32738 \\ 1982 & -166978 \\ 1983 & -296191 \\ 1984 & -418329 \\ 1985 & -131148 \\ 1986 & 0\end{array}$
(ER 0.070 ) (ER 0.060$)$ FLEL TTHER OPER IAXES OTHER (ER 0.040$)$ (ER .060$)$

THAN INCCME DEPRECIATION (9) $(10)$ 0

\begin{tabular}{|c|c|c|}
\hline & 1987 & 0 \\
\hline & 1988 & 0 \\
\hline & 1989 & 0 \\
\hline & $\begin{array}{l}1990 \\
1990\end{array}$ & $\begin{array}{l}0 \\
0\end{array}$ \\
\hline & 1902 & 0 \\
\hline & 1003 & 0 \\
\hline
\end{tabular}

0

0
0
0

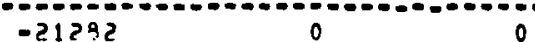
(NON-CASH) ER 0.070$) \quad(5+6+7+6+9)$

1903

1995

1990

1907

1998

1999
2000

2001

2002

2003

2004

2005
2006

2007

200 A

5009

2011

2012

2014

2015

0
0
0

0
0
-24980

-24980
-26729

$-58600$

-30602
-32744

$-35036$

- 37488

-40112
-42920

$-05925$

-49130
-52570

-52570
-56260

$-5620198$

-64412
-68921

.68921
.73745

-73745
.78907

$-84431$

$-90341$

$-96665$

$-103431$

$-110671$

-118418
-126708

$-135577$

$-105068$

$-38606$

-857 a

$-166078$

$-296191$

$\begin{array}{rr}-0269 & -418329 \\ -190417\end{array}$

$\begin{array}{ll}-556 & -25536 \\ -590 & -27318\end{array}$

$-590$

-27318
-29224

$-625$

-662
-702

$-31264$

$-33446$

-744
-789

$-3578$

$\begin{array}{ll}-836 & -38277 \\ -8096 & -40909\end{array}$

-836
-940

$-43807$

-996
-1056

-1056
-1119

$-46864$

$-50135$

-53635
-57370

$-1186$

$-1257$

-1333
-1413

$-57379$

.61384

$-65669$

$-70 \geq 53$

$-1498 \quad-80405$

$-1587$

$-1683$

-80405
-86018

.8601
.9202

1784

$-1891$

$-2000$

$-98448$

$-105322$

.112676

$-120543$

$-3252$

$-2367$

$-2367$

$-160088$

$-137960$

$-160088$

$-2843$

-147598
-157904

TOTALS

20373

$-2359631$

-168931
-107117

$-1184128$

0

$-3543759$

$\begin{array}{ll}0 & 0 \\ 0 & 0 \\ 0 & 0 \\ 0 & 0\end{array}$

$\begin{array}{ll}0 & 0 \\ 0 & 0\end{array}$

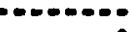

$\begin{array}{ll}0 & 0 \\ 0 & 0 \\ 0 & 0\end{array}$

$\begin{array}{rr}0 & 0 \\ 0 & 0\end{array}$

$-50036 \quad-21282$

$\begin{aligned}-55060 & -22559 \\ -570750 & -2391\end{aligned}$

$.57758 \quad-25347$

$-60588 \quad-26868$

$-63557 \quad-28480$

$\begin{array}{ll}-66671 & -30189 \\ -69938 & -32000\end{array}$

$-73365 \quad-33020$

$-76959 \quad-35955$

$-80730 \quad-38113$

$\begin{array}{ll}-84686 & -40400 \\ -88836 & .42826\end{array}$

$-88836$

$-45393$

$-97755 \quad-49117$

$.107570 \quad-5100$

$-112841 \quad-57308$

$-118370 \quad-60746$

$.-130254 \quad-6439$

$-136637 \quad-72350$

$.143332 \quad-76600$

$-150355 \quad-81292$

$-157723$

-165451
-173558

$-182063$

$-190984$

$-200342$

.3267809

$-1682516$

$-1201502$

11630460506962 
PROJECT: GEISMAR CCGENERATION CASE, CNSS OOY FUEL COST

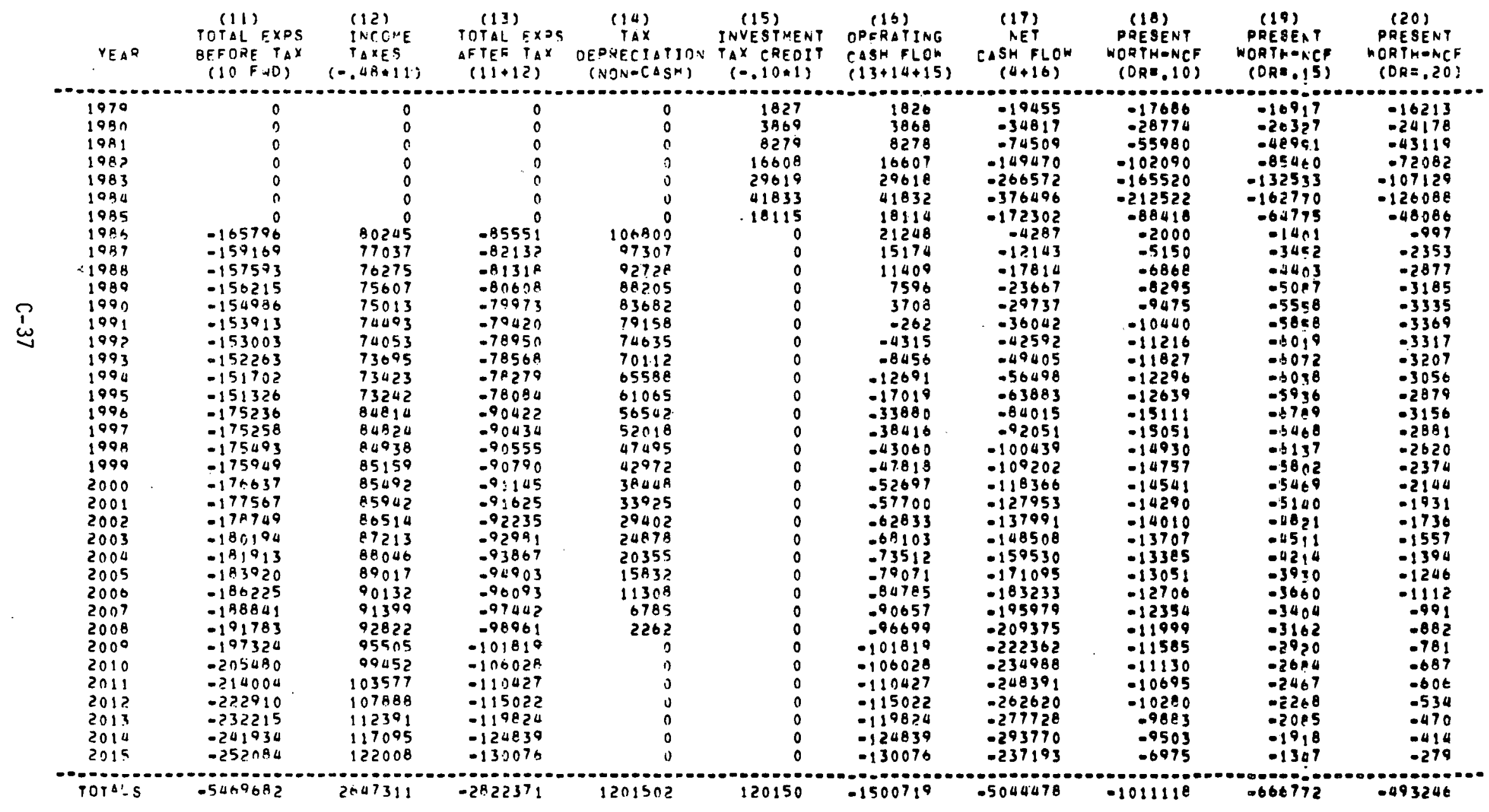


PROJECT: GEISMAR COGENEPATION CASE CNSS

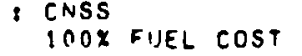
(I) (?)
CAPITAL SACKUP

(3)
WDRKING, (a)

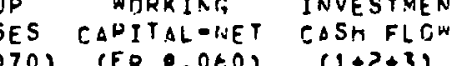
FUEL

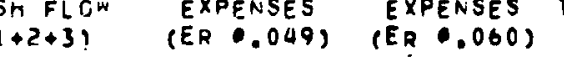
(6) (6)
TTHER OPER TAXES OTHER (B) TAX
TAXTION PEFORE TAX $049)$ (ER 1.060$)$

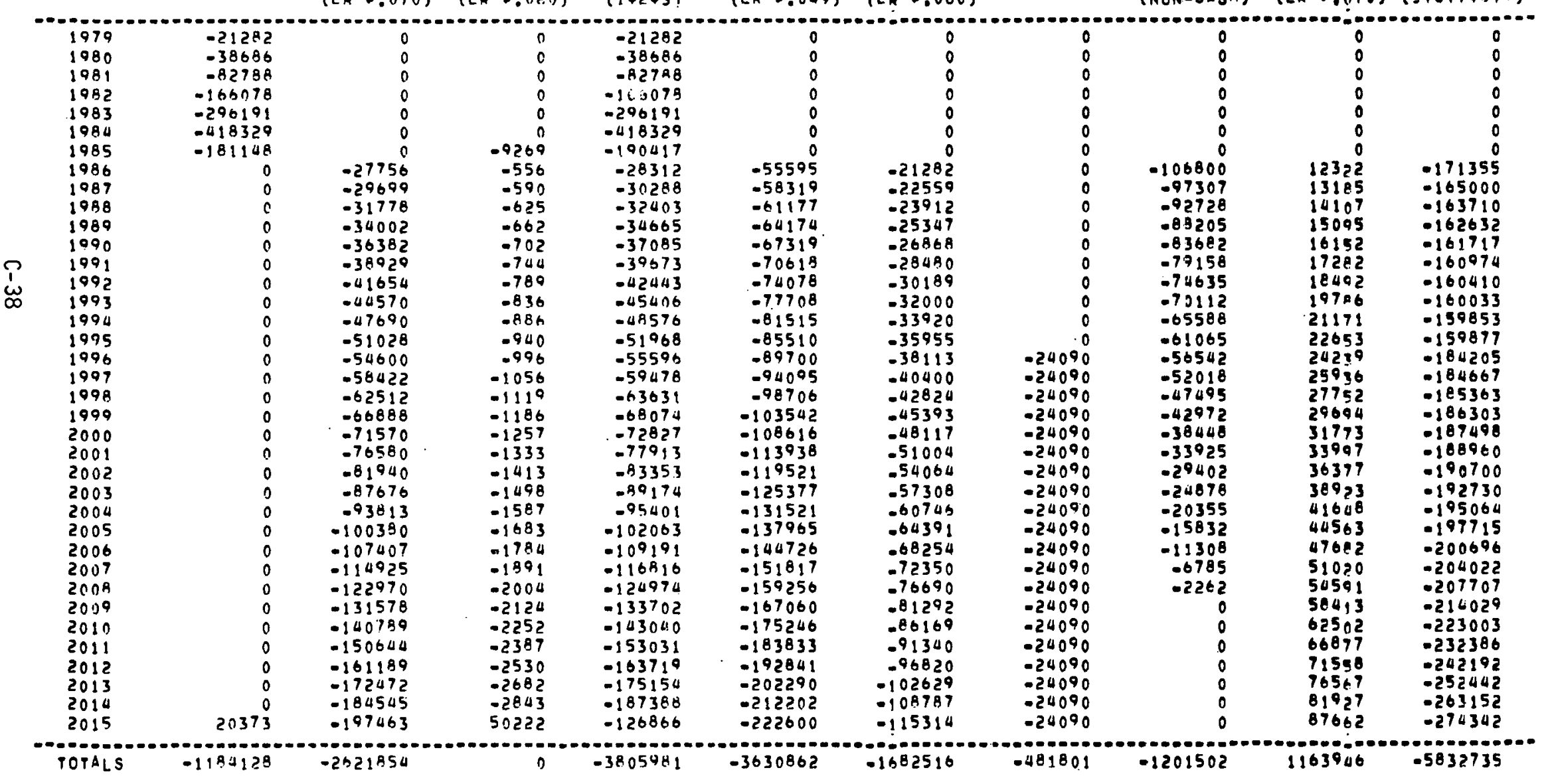


PROJECT COST ANALLYSIS

PAGE 2 OF 2

OF ANVUAL CASH REQUIREMENTS

PROJECT: GEISMAR COGENEZATIOA

CASE : CNSS IOOX FUEL COST

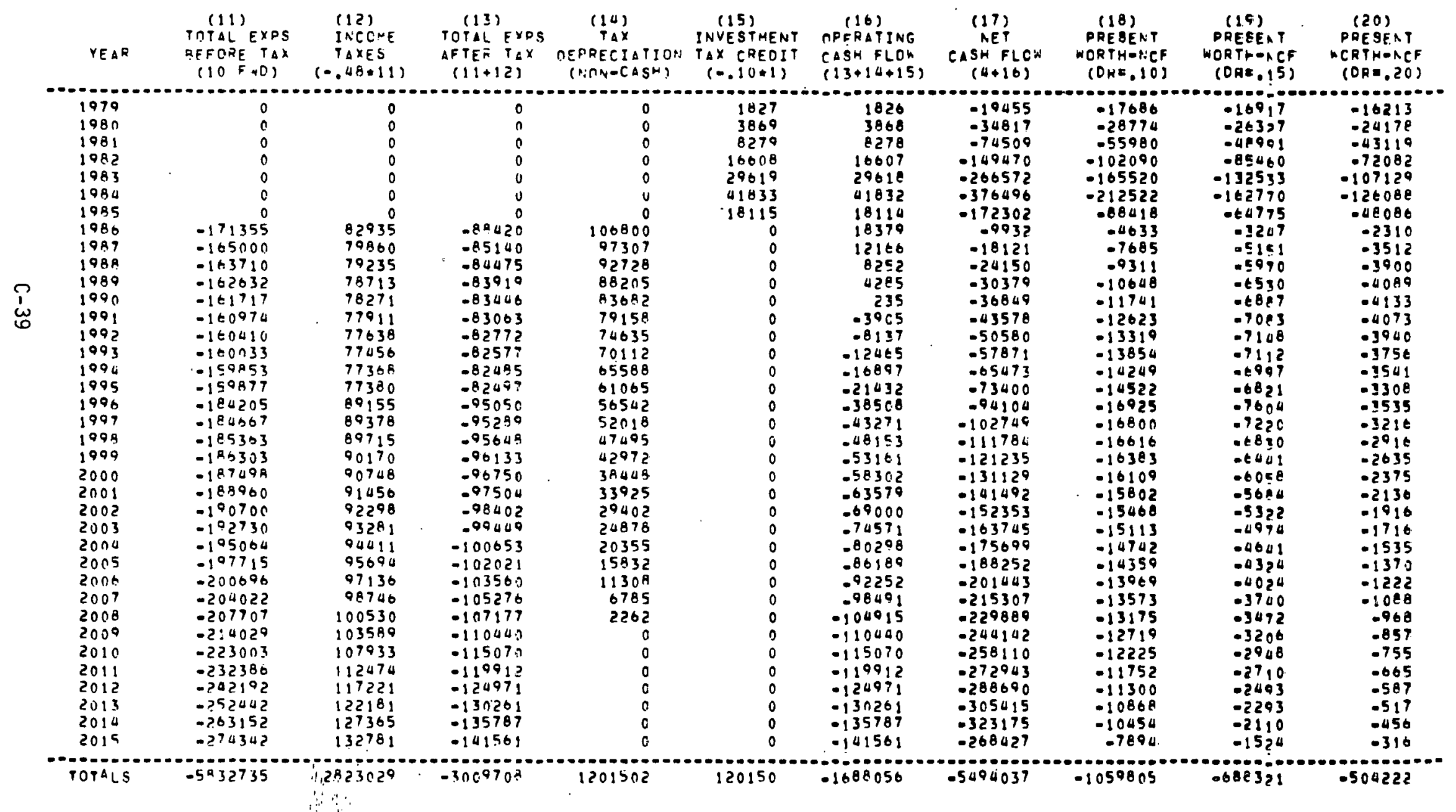


PRO.JFCT: GEISIADQ COGENERATION CASE : CNSS

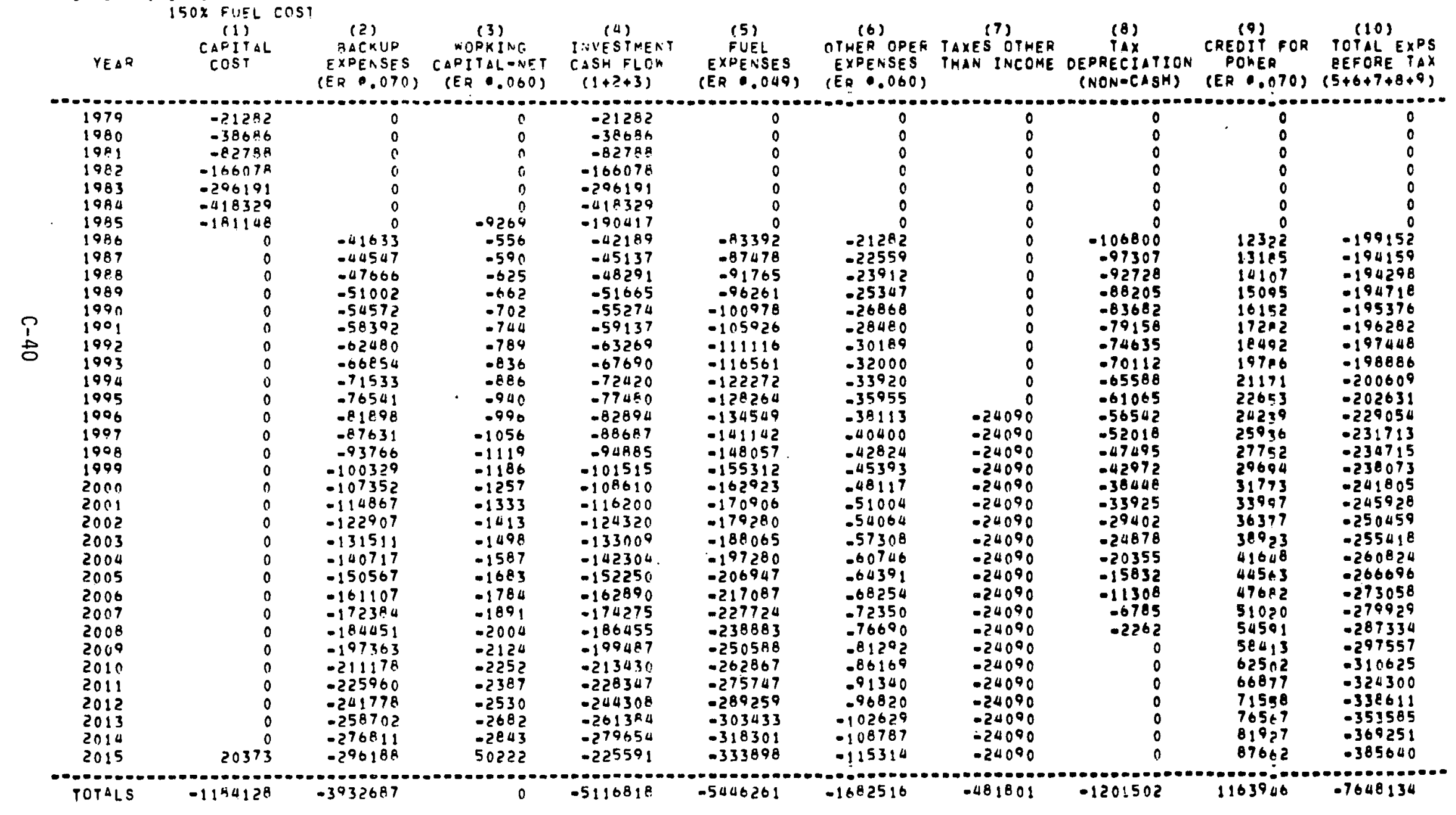


PROJECT: GEISHAO CCGENEZATION

CASE : CNSS

? 1502 FUEL COST

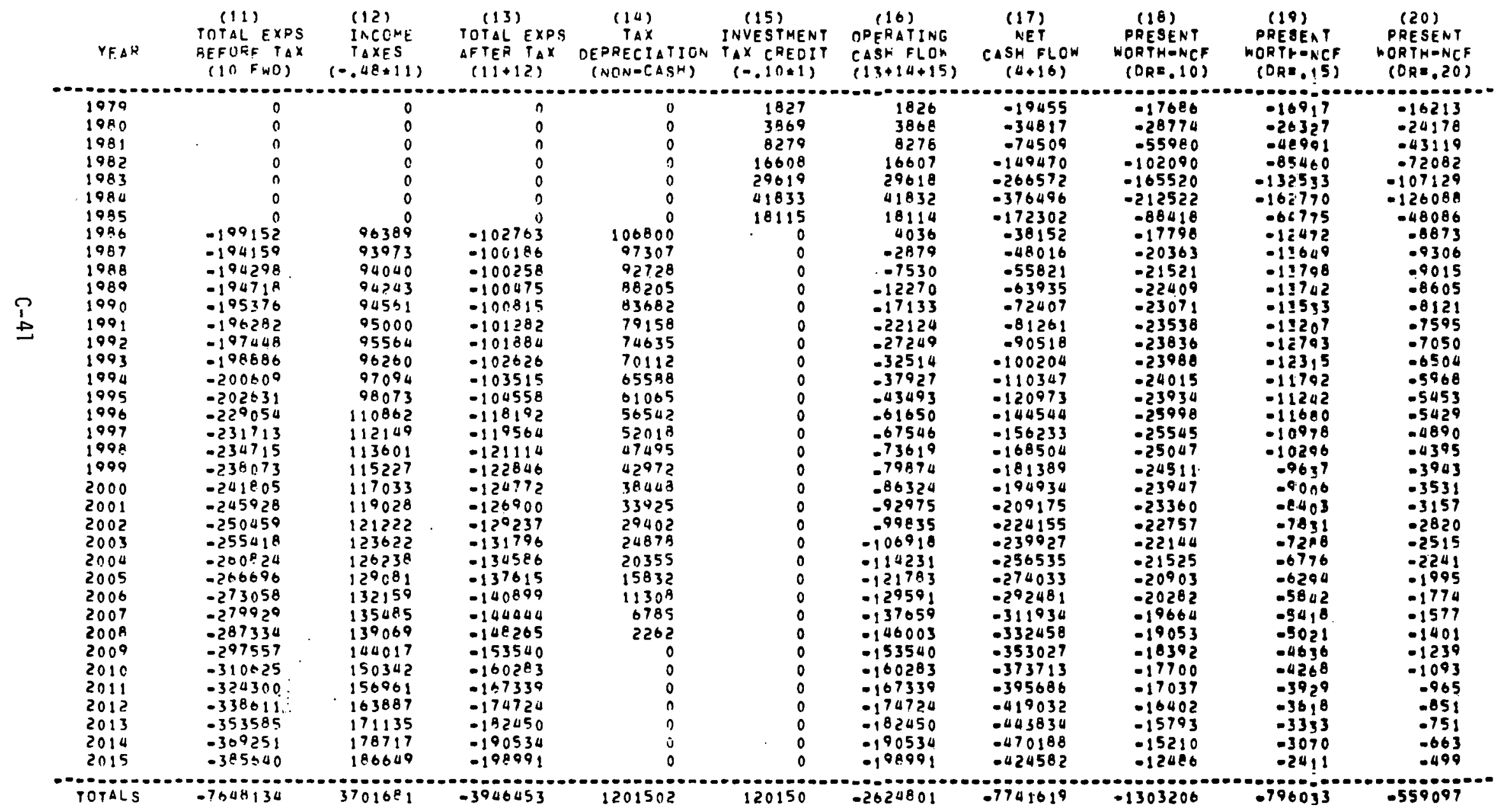


PREJJECT COST AMALLSIS

CF ANIJAL CAST CEGLIREFEATS

PROJECT: GEISMAO COGEIERATISO

CASE : C:SS

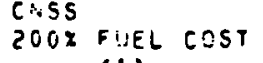

(3)

(4)
(4) CATHEST

(5)

EXNEASES CEDITALOAET CASHFLEN EXPEISES CASH FLC

EXPEVSES
(ED 0.009 )

(6) (T)

OTUEE OPES TAXES OTHE P YAX

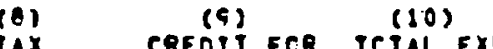
EXPEASES THAA INCCHE CEPFECIATICA POHER REFCPE TAX

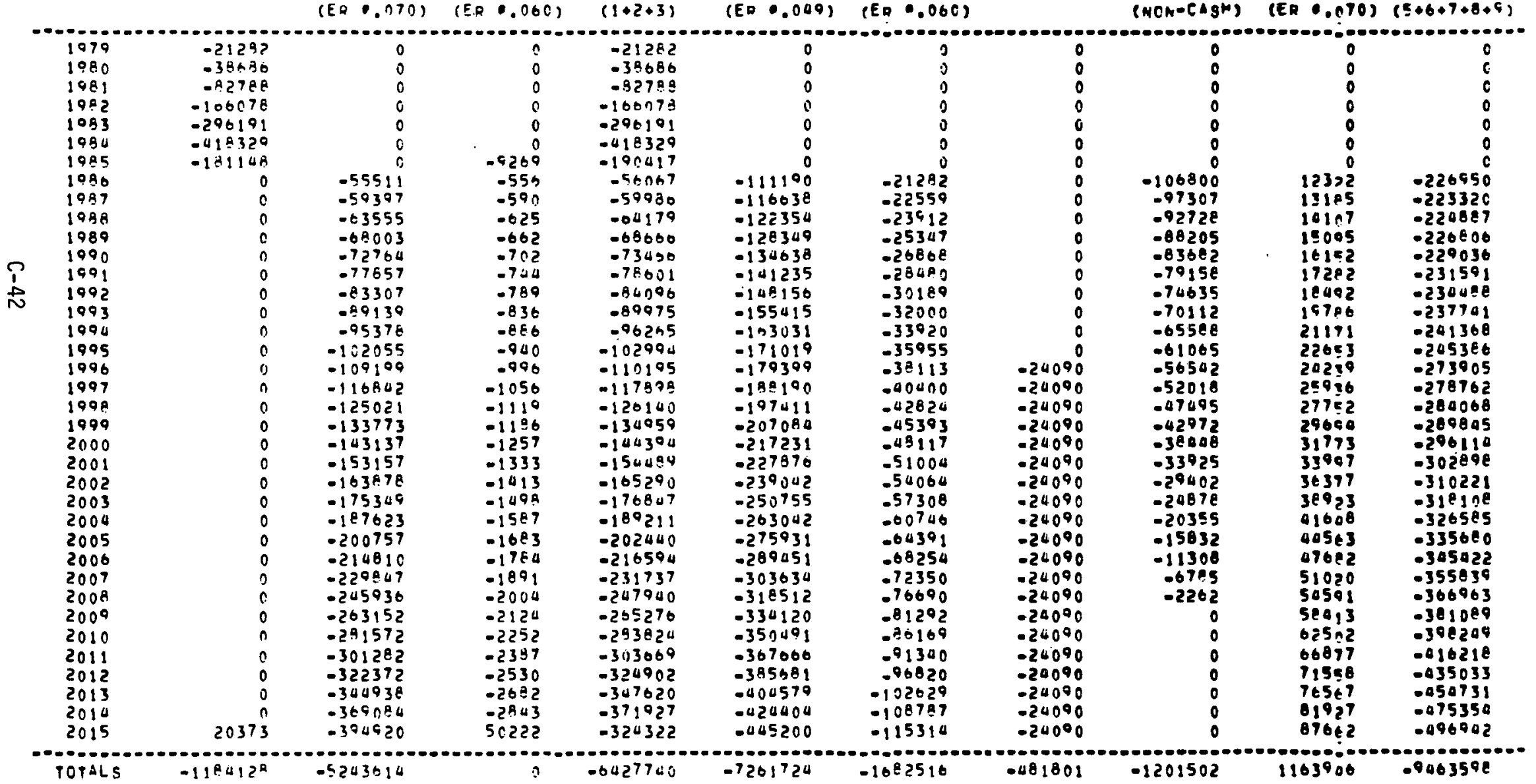


PROJECT COST ANALYSIS

PAGE 2 OF 2

DF ATANIIAL CASH REDUIREMEATS

PROJECT G GEISMAD COGENERATICA

CASE : CNSS

2OOK FUFL COST

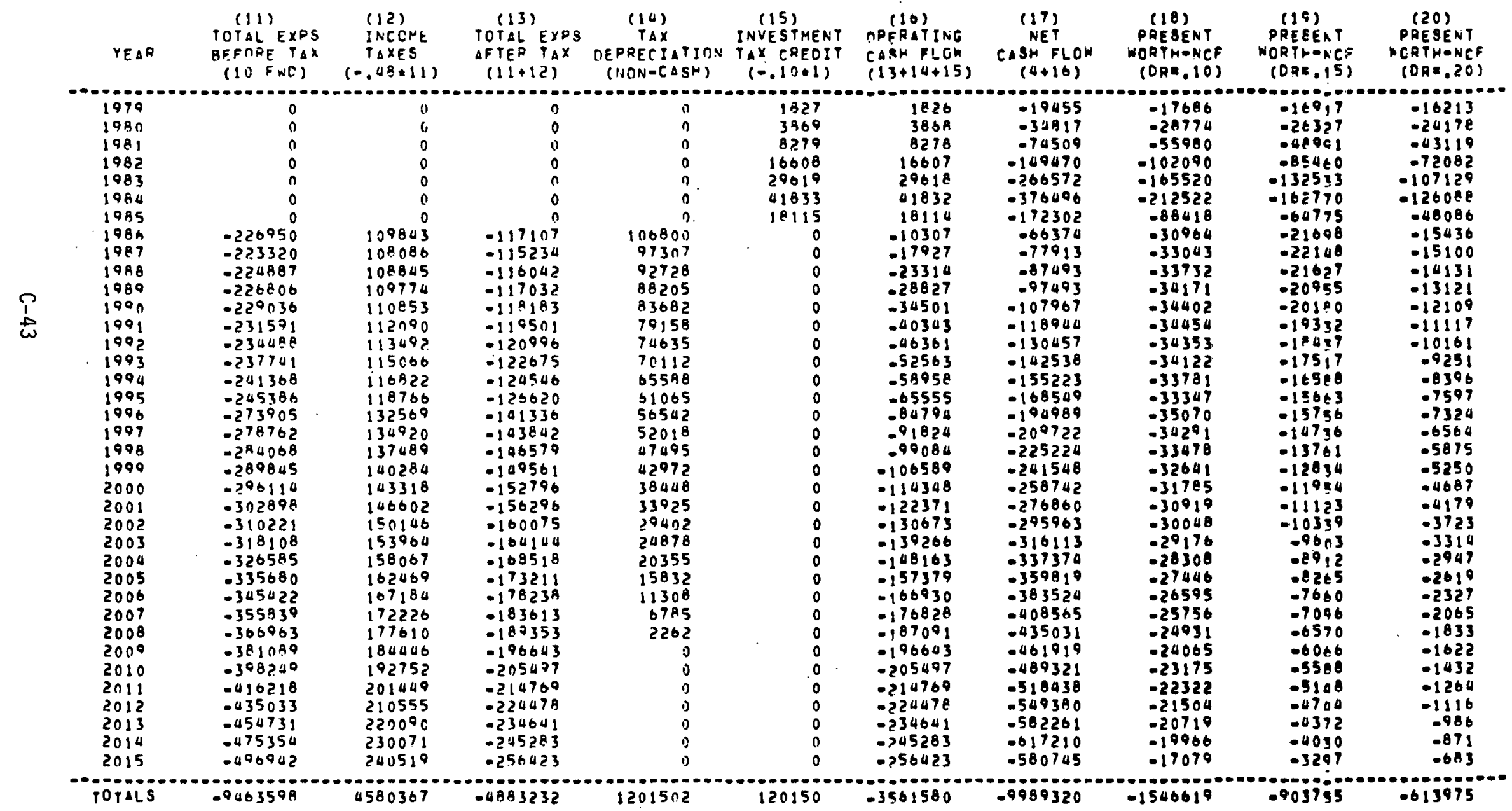


PROJECI: GEISMAF COTEENERATIOA

CASE IEXIST. PLAPTS
FCZ FIJEL COST CAPITAL (1) (Z)

HACKUF

(3) EXPENSES CAFITALOAET INVESTMENT (ER 0.000 ) (EH 0.060$)$ (ESH FLO

(5)

FTHER OPER TAXES OTHE

TAX (9)

(9)

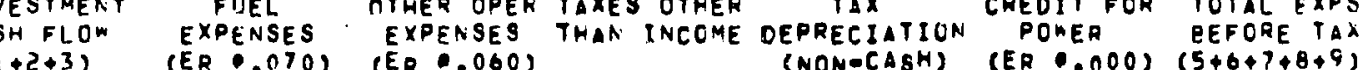

(10)

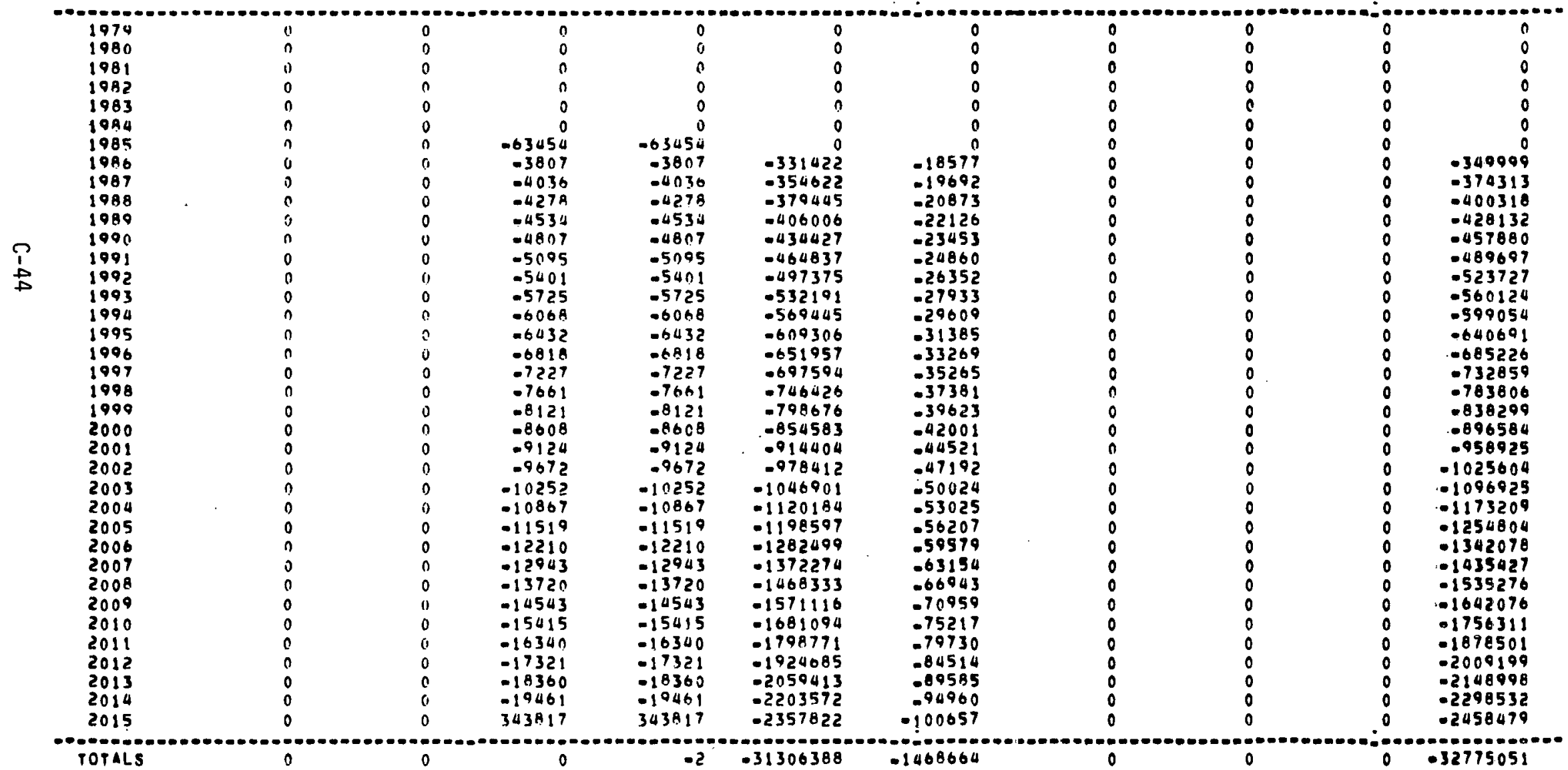


PROJECT COST ANALYSIS

PAGE 2 OF 2

OF ARNUALL CASH REUUIREMENTS

PRIJECT: GETSMAR CONGEDERATIOT

CASE : EXIST. PLANTS

anX FIUEL COST

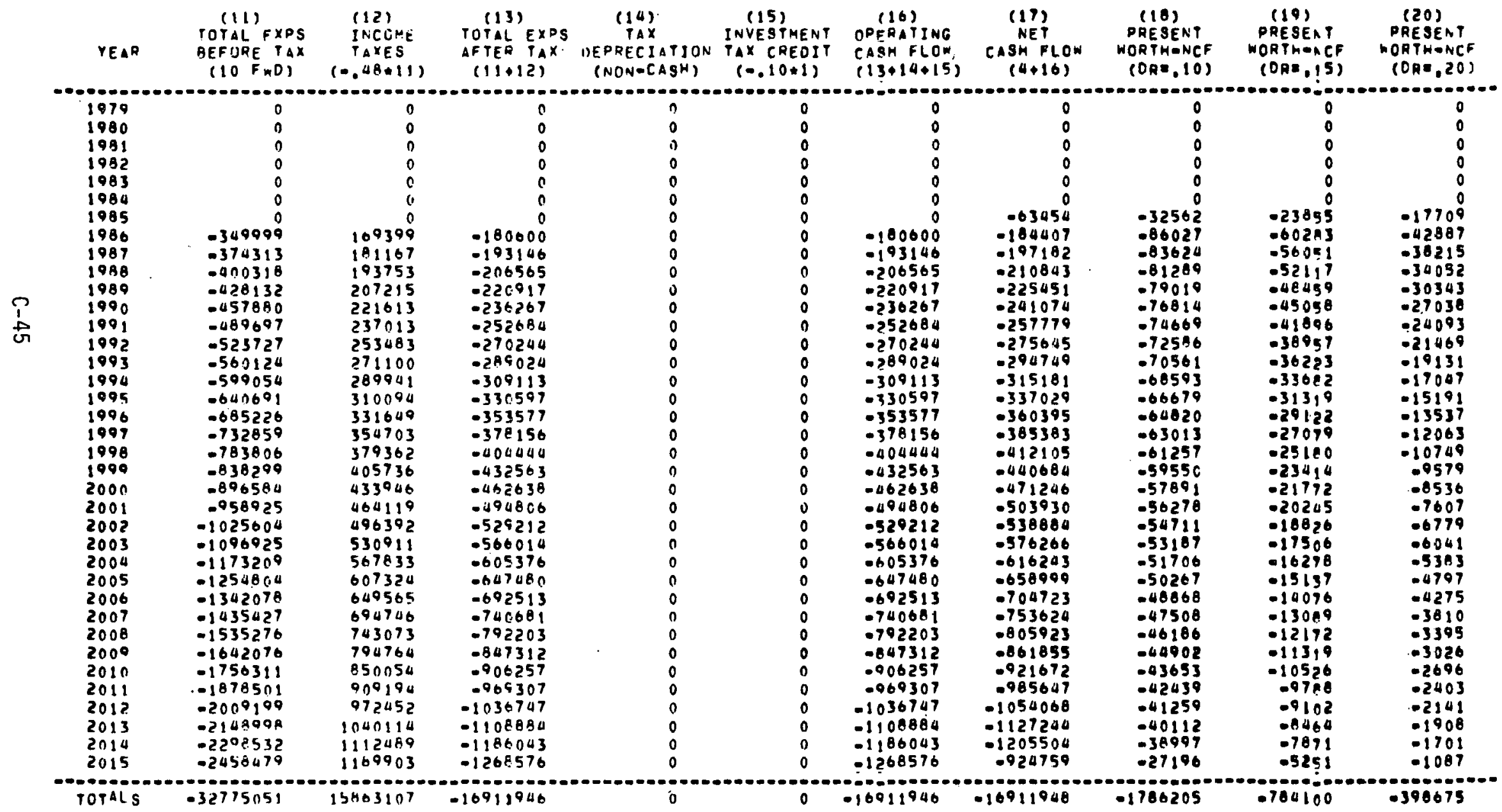


PRIIJECT COST ANALYSIS

CRESENT ORTH

UF ANVUAL CASH REDUIREMEATS

PHOJECTI GEISMAR COIEEVERATIONN

CASE IEXTST. PLANTS

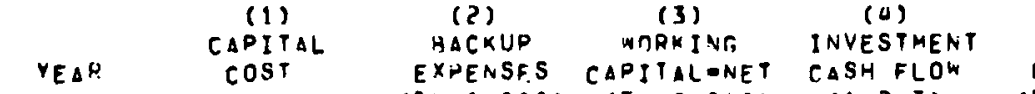
EXPENSFS CAPITALENET CASH FLO
$(E A .000)$ (ER P.OSO) $(1+2+3)$

(5)

FLEL
XPENSES

(6) (T)

DTHER OPER TAXES OTHER TAX

(9)

(10) (ER ..070) (ER $\$ .060)$

TOTAL EXPS

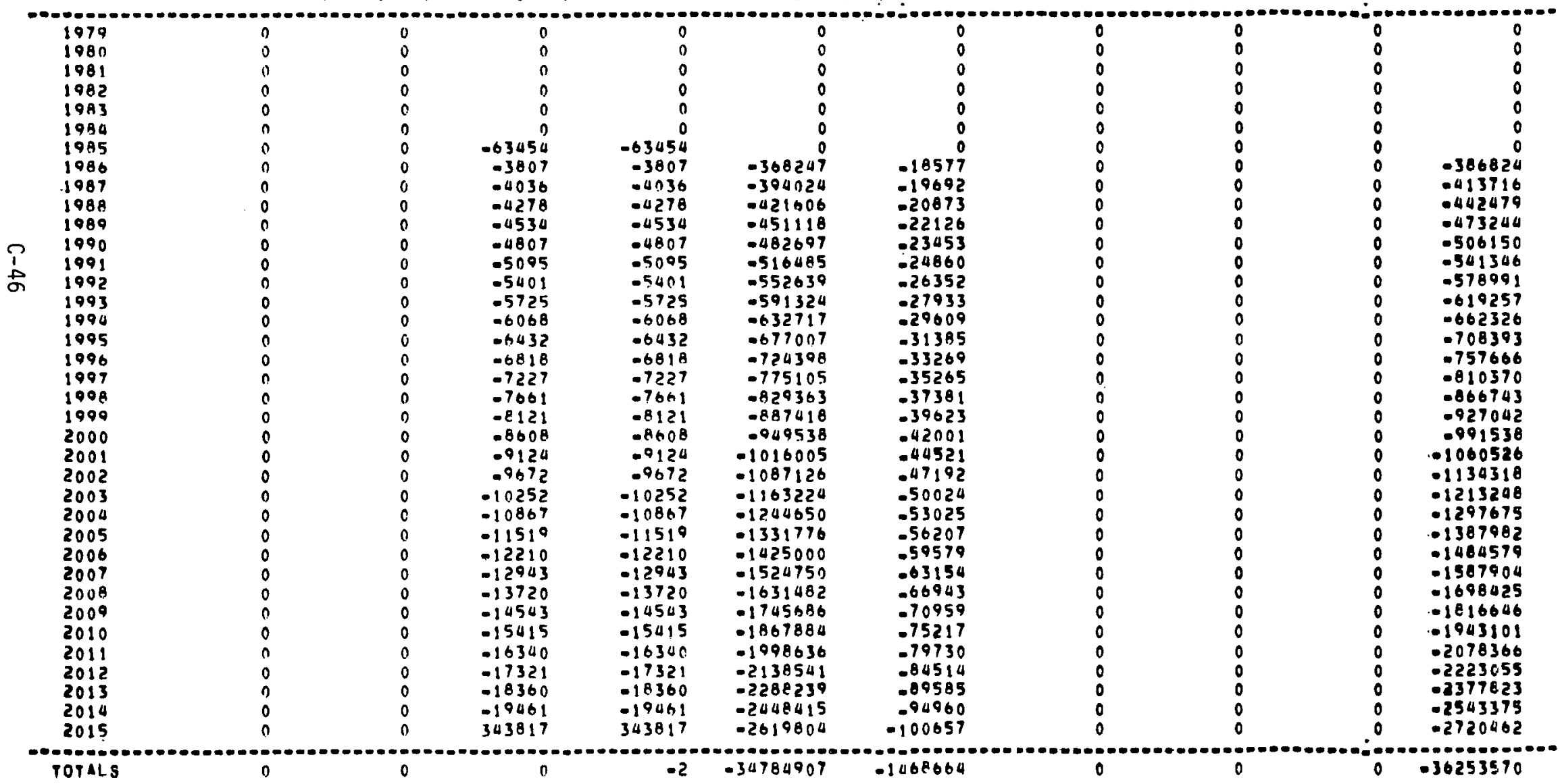


PROJECT COST AR:ALYSIS

OF ANALAL CAST REQLIREMEATS

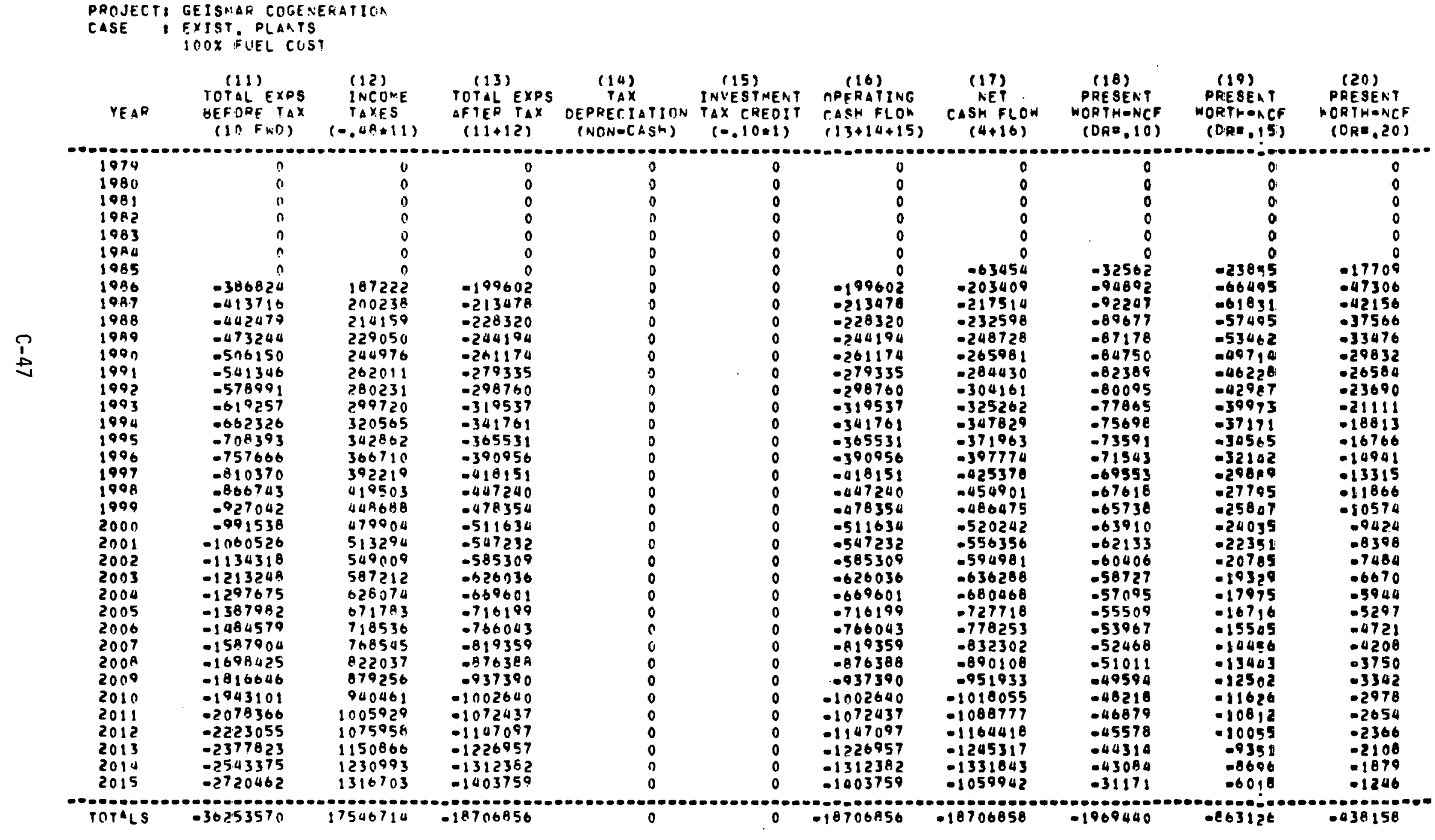


PRIJECT COST ANALYSIS

PROJFET I GEISMAR COGENFEATIOA

CASE I EXIST. PLARISS

1502 FUEL CUSI

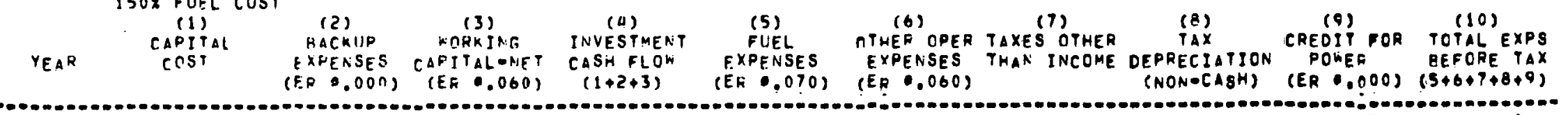

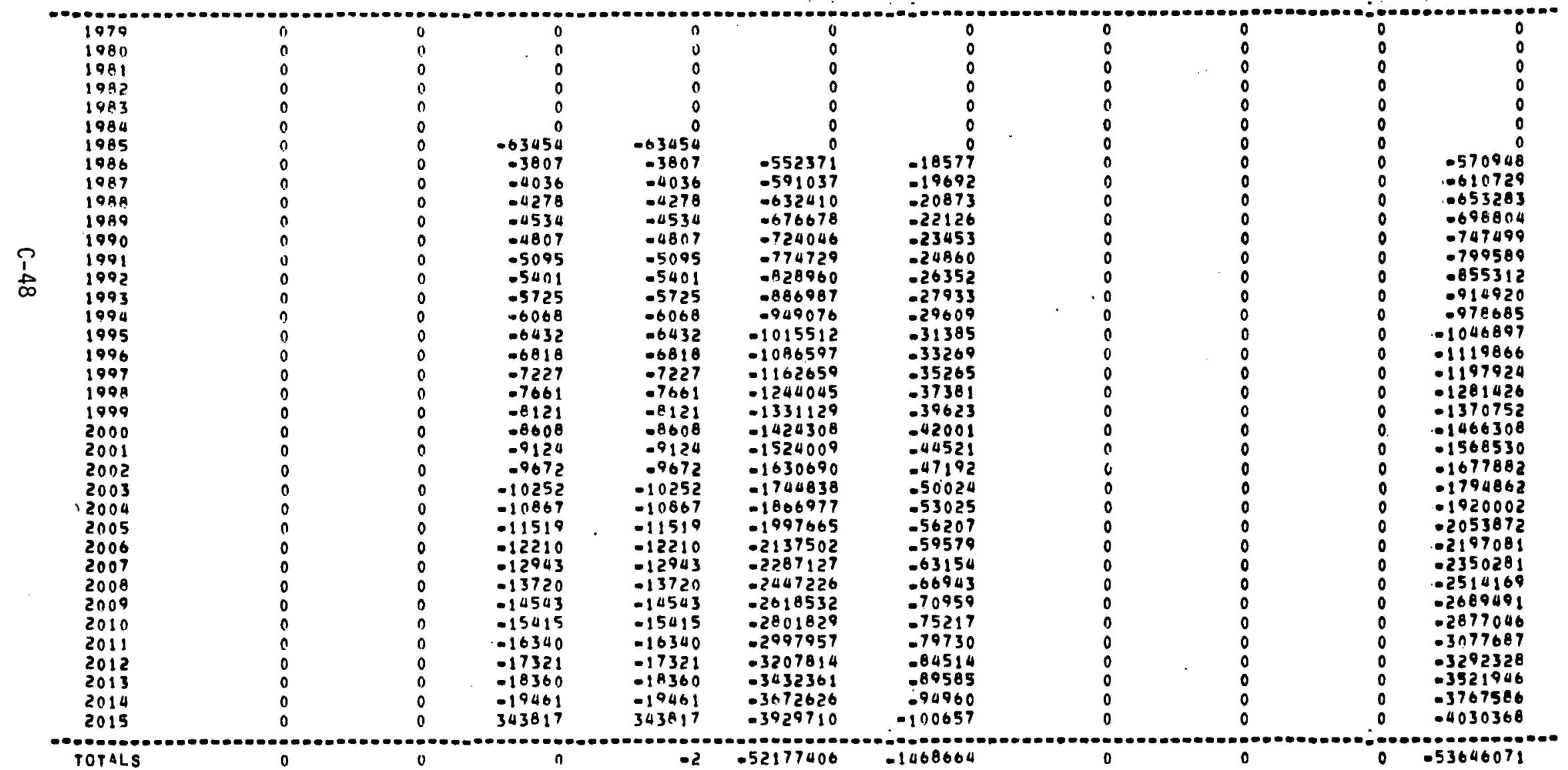


PKOJECT CUST ANALYSIS

PAGE 2 OF 2

IIF ANNUAL CAST REDUIREMFRTS

PROJECT, GEISNAR CIITENERATITH:

CASE IEXIST. PLANTS

$$
1502 \text { FIIEL CUST }
$$

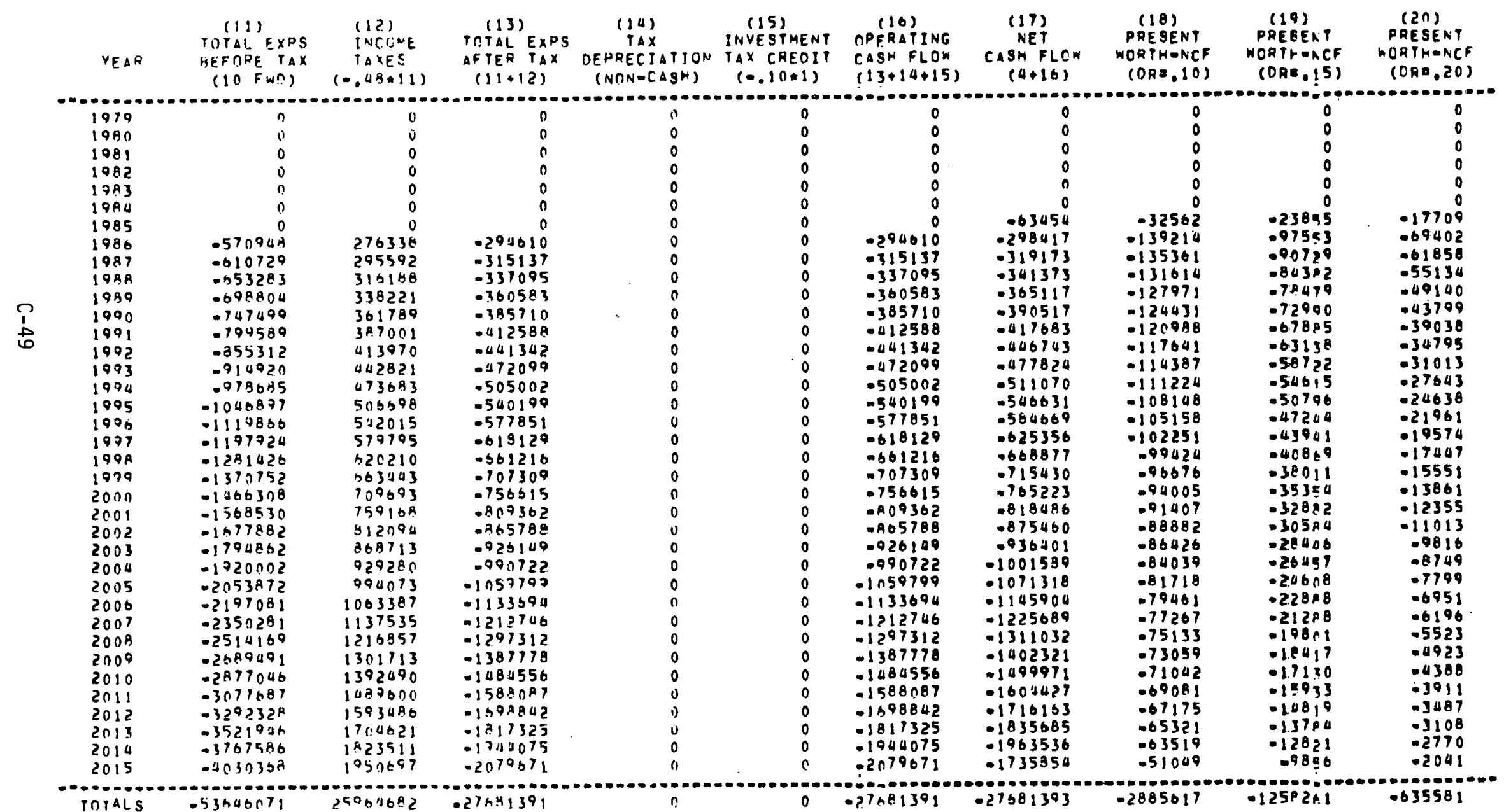




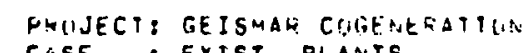
(4)
WORKING INVESTMEAT

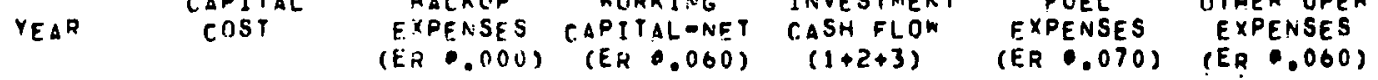

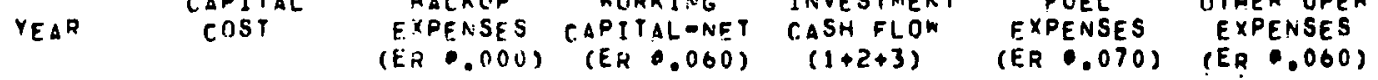

INVESTMENT (5)

(5) (6)
FUEL OTHER OPEF TAXES OTHER TI)
TAX

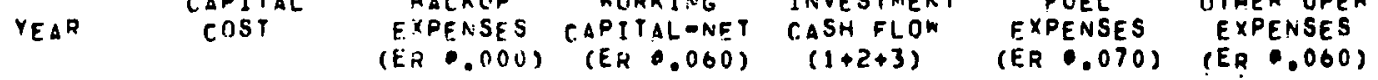
EXPENSES THAN INCOME DEPREEIATION (9) TOR CREOIT
POLEA (10)

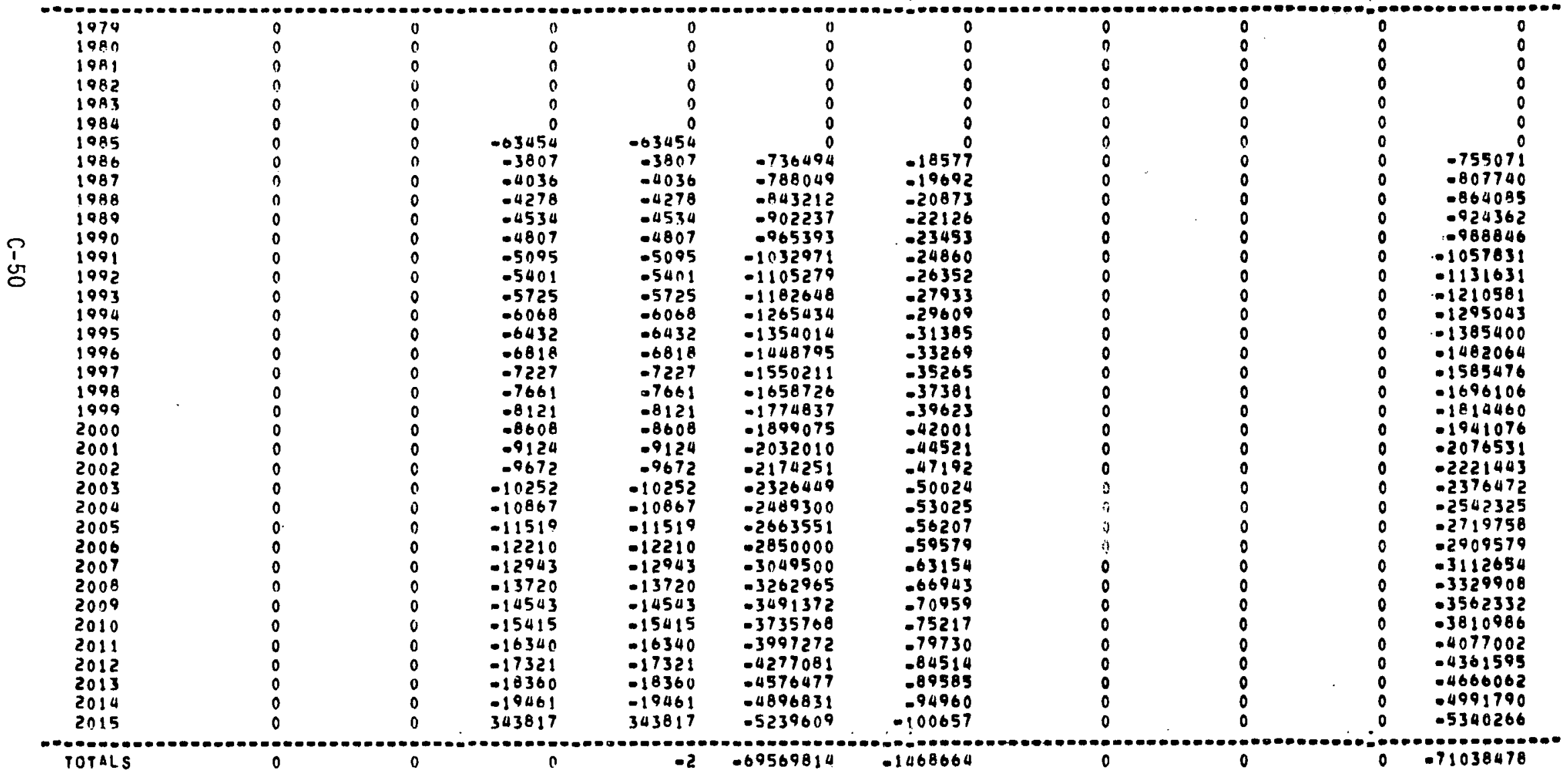


PKIIIECT: GEISWAR COGENERGTIOIN

CASE : EXIST PLANTS

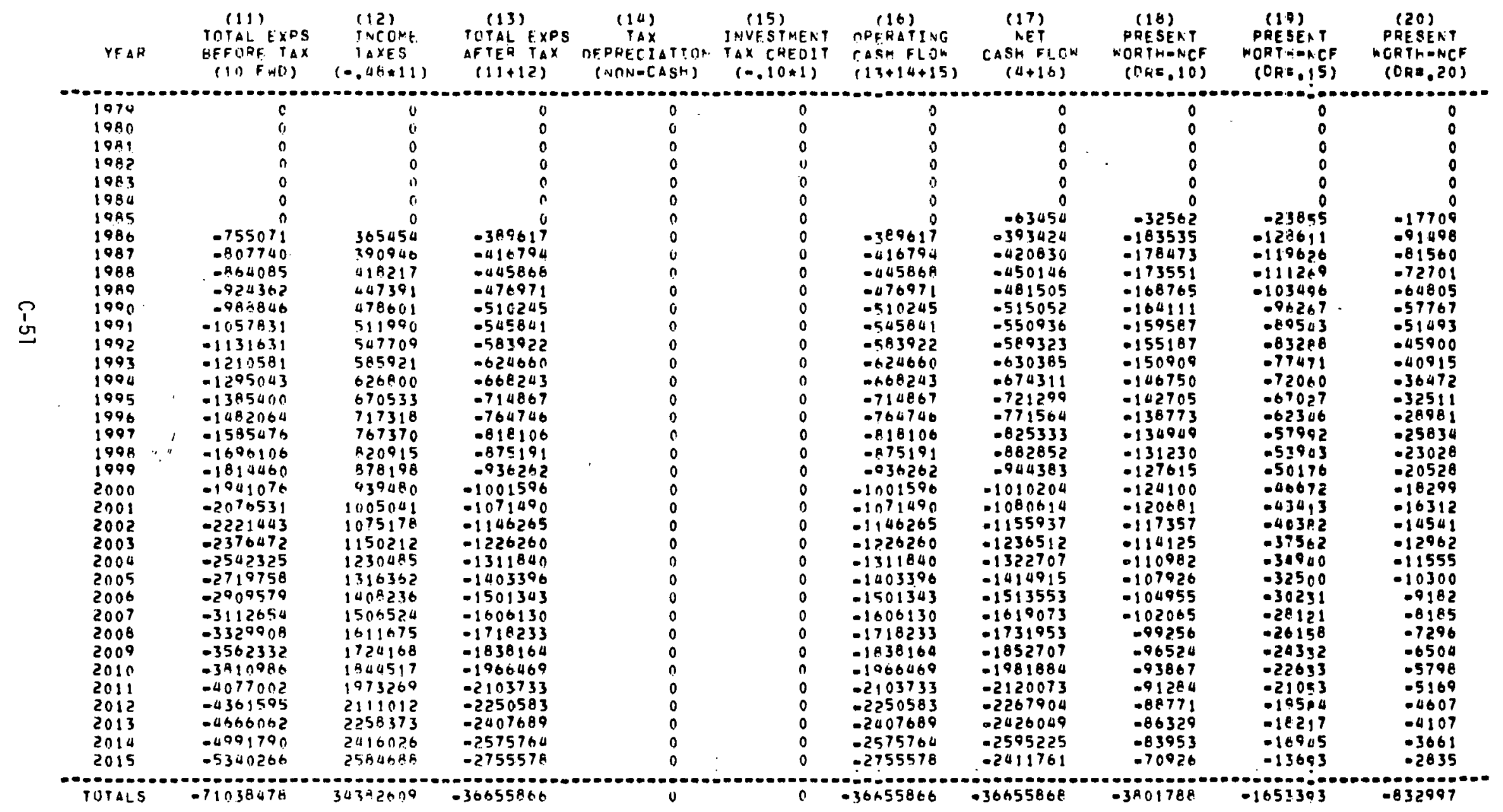


APPEADIX C

PRTJERT CUST ANALYSIS

HASED CN POESENT WOQTH

IIF INATiLL TASH REGLIIREMERTS

orange

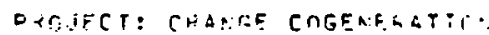

CASE : CASTEQH COAL

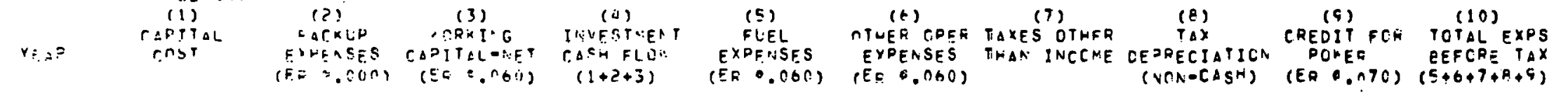

\begin{tabular}{|c|c|c|c|c|c|c|c|c|c|c|}
\hline 1077 & 0 & 0 & 0 & 0 & 0 & 0 & 0 & 0 & 0 & 0 \\
\hline $102 n$ & $-731=$ & $n$ & $n$ & -7316 & 0 & 0 & -73 & 0 & 0 & .73 \\
\hline $19 \times 1$ & -9055 & 0 & 0 & -8055 & $?$ & 0 & -237 & 0 & 0 & -237 \\
\hline $194 ?$ & $-17 \geq 03$ & 0 & $n$ & -17263 & 0 & 0 & -504 & 0 & 0 & -504 \\
\hline 1093 & -114011 & 0 & 0 & -114011 & 0 & $n$ & .1836 & 0 & 0 & -1836 \\
\hline 1950 & $-15: 1,2$ & a & $\therefore$ & -158102 & j & 0 & .4603 & 0 & 0 & $=4503$ \\
\hline 1909 & -130035 & 0 & $-100.3 j$ & -100036 & 0 & 0 & $.701 t$ & 0 & 0 & $-761 t$ \\
\hline 1996 & 0 & $i$ & $-t 00$ & -600 & $.52229=$ & -15168 & .9109 & -38925 & 47603 & $-t>B D E$ \\
\hline $10 \% 7$ & 0 & $c$ & -636 & -436 & -55363 & -16078 & .0190 & -35520 & $510 ? 1$ & -65049 \\
\hline $199 \%$ & 0 & 0 & -674 & -674 & .58685 & -17043 & -9109 & -33848 & 54542 & .64092 \\
\hline 1990 & 0 & (a) & .715 & -715 & -62206 & - 180h5 & .9109 & .32197 & $58 a_{1} a$ & $-t 3160$ \\
\hline $19 a_{0}$ & $a_{1}$ & 0 & -758 & .759 & -65039 & -19149 & $-9 i n a$ & -30506 & $6=503$ & .62240 \\
\hline 1991 & 0 & 0 & -803 & -803 & .69894 & -20298 & -9109 & -28895 & $6 \in 878$ & -61319 \\
\hline 1902 & $n$ & 0 & -251 & -851 & $.74 \cap 88$ & $-215: 6$ & -9109 & $\begin{array}{l}-27240 \\
\text { a }\end{array}$ & $715=9$ & .60398 \\
\hline 1003 & 0 & 0 & $-90 ?$ & -902 & .78533 & $\begin{array}{l}-52807 \\
0\end{array}$ & .9109 & .25593 & $7+5 \times 6$ & .59473 \\
\hline $199 \mathrm{~J}$ & $n$ & 0 & -956 & -056 & -83245 & -24175 & $-9 \operatorname{lng}$ & $-2394 ?$ & $819 ? 8$ & -58543 \\
\hline $\begin{array}{l}1545 \\
1095\end{array}$ & 0 & : & $\begin{array}{l}-1014 \\
-1075\end{array}$ & $\begin{array}{l}-1014 \\
-1075\end{array}$ & $\begin{array}{l}-80240 \\
-93534\end{array}$ & $\begin{array}{l}-25620 \\
-27160\end{array}$ & $\begin{array}{l}-9109 \\
.9109\end{array}$ & $\begin{array}{l}-22290 \\
-20639\end{array}$ & $\begin{array}{l}870+3 \\
936 \cap 0\end{array}$ & $\begin{array}{l}-57602 \\
-56606\end{array}$ \\
\hline 1097 & 0 & 0 & -1139 & -1070 & $\begin{array}{r}-993340 \\
-99146\end{array}$ & $\begin{array}{l}-28793 \\
-28\end{array}$ & $\begin{array}{r}-9108 \\
.9109\end{array}$ & $\begin{array}{r}-20054 \\
-18998\end{array}$ & $1003+6$ & $\begin{array}{r}-5600 \\
-55671\end{array}$ \\
\hline $190 \%$ & 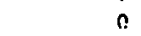 & a & -1207 & 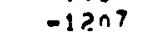 & -105095 & -30521 & -9109 & -17337 & 107301 & -54671 \\
\hline 1040 & 0 & 0 & -1280 & -12 \&0 & -111001 & -32352 & -9109 & $-1568 t$ & 114909 & .53639 \\
\hline $200 \mathrm{c}$ & $n$ & $n$ & -1357 & -1357 & -119085 & -34293 & -9109 & -14035 & $1229=2$ & .52570 \\
\hline $20 n 1$ & 0 & 0 & -1438 & -1438 & -125170 & .36351 & -9100 & $-1238 a$ & 131569 & .51455 \\
\hline 2002 & 0 & 0 & -1524 & .1524 & -132680 & $-3 \times 532$ & -9109 & -10732 & $1407 t 8$ & -50286 \\
\hline 2003 & 0 & 6 & -1316 & -1613 & -140641 & $-4084 a$ & .9109 & .9081 & 150622 & .09053 \\
\hline 20094 & $n$ & i & -1713 & -1713 & -149079 & -43295 & -9109 & .7430 & 101165 & .47748 \\
\hline 2005 & 0 & 0 & $-i \varepsilon i 6$ & $-1+10$ & -159024 & $-4589 ?$ & .9109 & .5779 & 172407 & .06357 \\
\hline 20196 & 0 & i & $-10 \geqslant 4$ & -1924 & -167505 & $.08640^{\circ}$ & $-910^{\circ}$ & -4128 & 1845,8 &.$\triangle 4870$ \\
\hline 2007 & 0 & 0 & -2040 & -2000 & .177550 & -51565 & .0109 & -2477 & 197484 & -43272 \\
\hline 2008 & ! & 0 & -2162 & -2162 & $-1 B 920^{\circ}$ & .54658 & .9109 & -926 & 211255 & - 01547 \\
\hline 2009 & $n$ & 0 & $\begin{array}{l}-550 ? \\
-550\end{array}$ & -2202 & -190502 & .57938 & -9109 & 0 & $22+003$ & $-4050 t$ \\
\hline 2010 & 0 & 0 & -2430 & -2.430 & -211472 & -61414 & .9109 & 0 & 241860 & .40129 \\
\hline $2 n 11$ & 0 & 0 & $-\hat{\varepsilon} 575$ & -2575 & -224160 & .05099 & -9109 & 0 & 258796 & .39572 \\
\hline 2012 & $n$ & i. & $-273 n$ & -2730 & -2376110 & -69005 & .0109 & 0 & $27+9,2$ & -39812 \\
\hline 2013 & 0 & 0 & -7894 & -2804 & $-25186 \mathrm{~A}$ & .73145 & .9109 & 0 & $29+206$ & -37825 \\
\hline 2014 & 0 & (i & $-300 ?$ & -3067 & -264978 & .77534 & .0109 & 0 & 317087 & .36505 \\
\hline ?ח15 & 13257 & i & 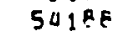 & $6744 t$ & -282997 & .82186 & -9109 & 0 & 335229 & -35063 \\
\hline
\end{tabular}


PARJFET: DHGNGF CHIEENENTTOOA

CASF : FASTER: COAL

$$
\text { one FuEL COST }
$$

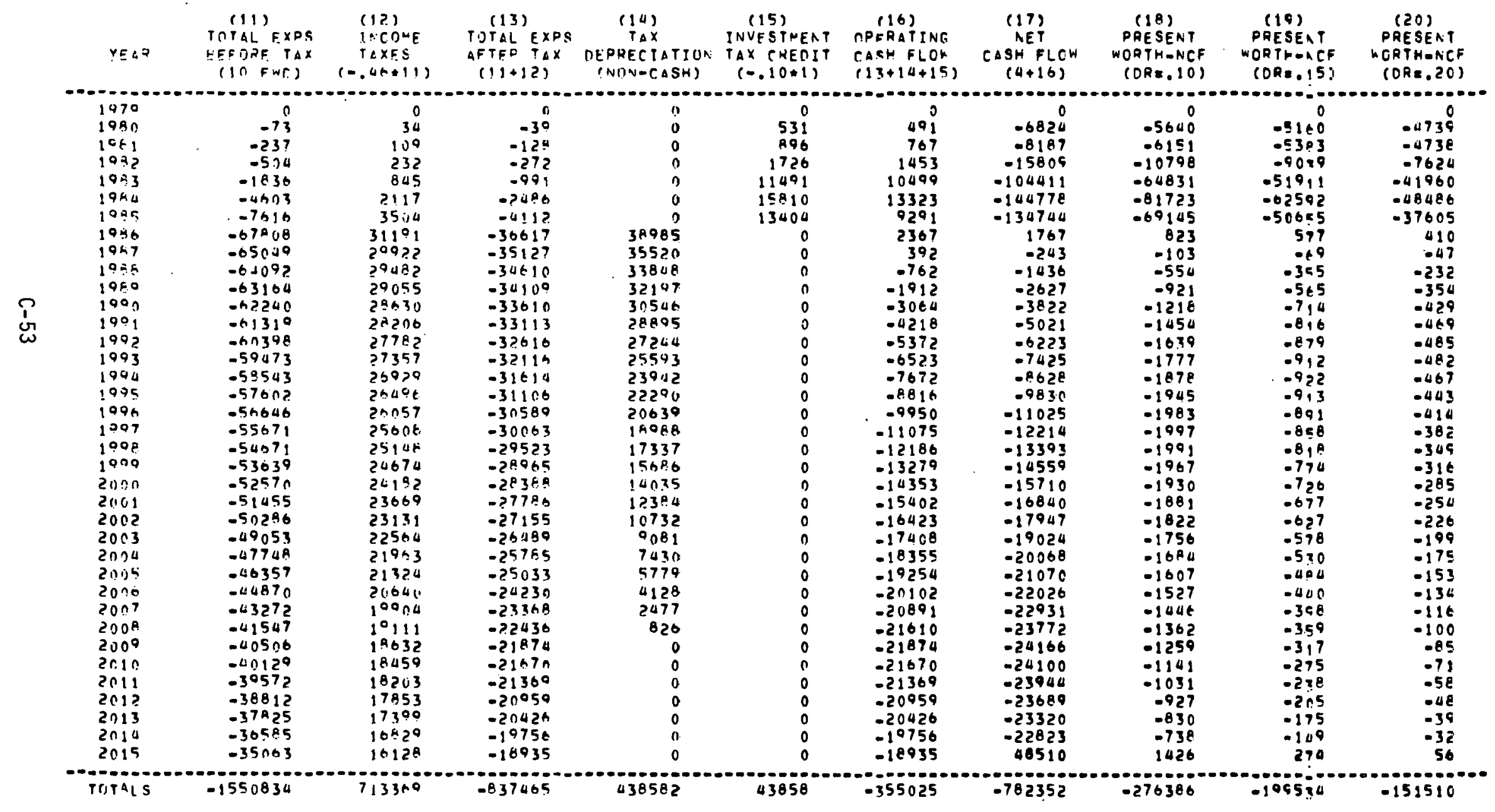


Proner.t: CFanige Cugfrenatio:

CAST : EASTEEAE CRAL
IOIDE FIIFL COST

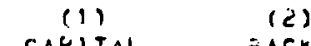

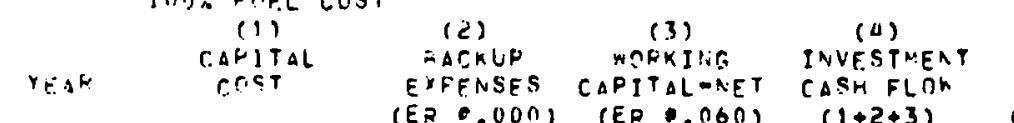

(s)

FL:EL
XPENSES (ER $\bullet .060)$

(

(7) EXPENSES (9) (9REIT FCR TOTAL EXPS POHEF EEFCRE TAX

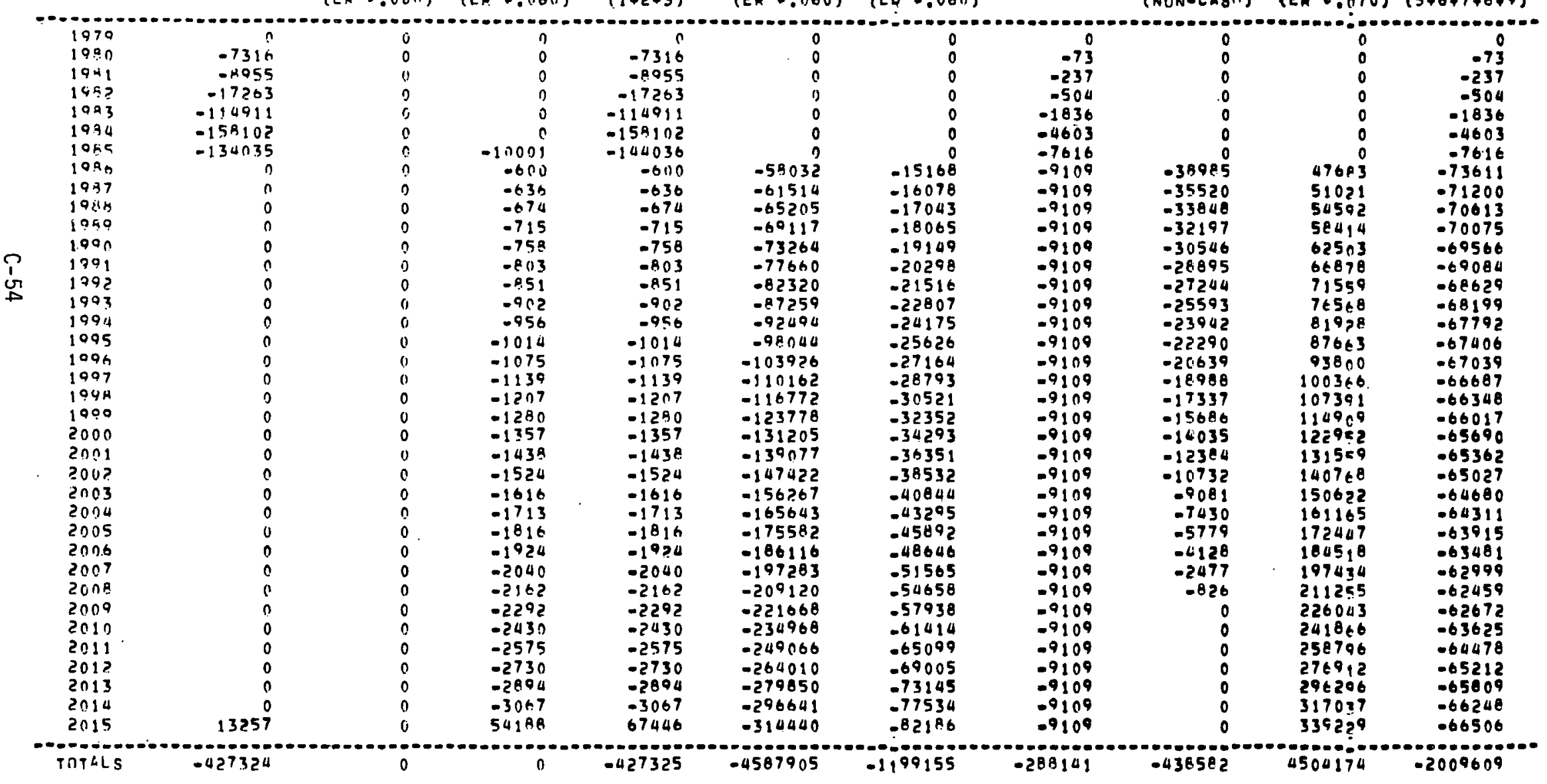


PRTJECT COST ABIAL YSIS

FERTECT: COANGE POEFNLFATIJH

CASE : EASTERN CIIAL

IIIOY FIFL CLST

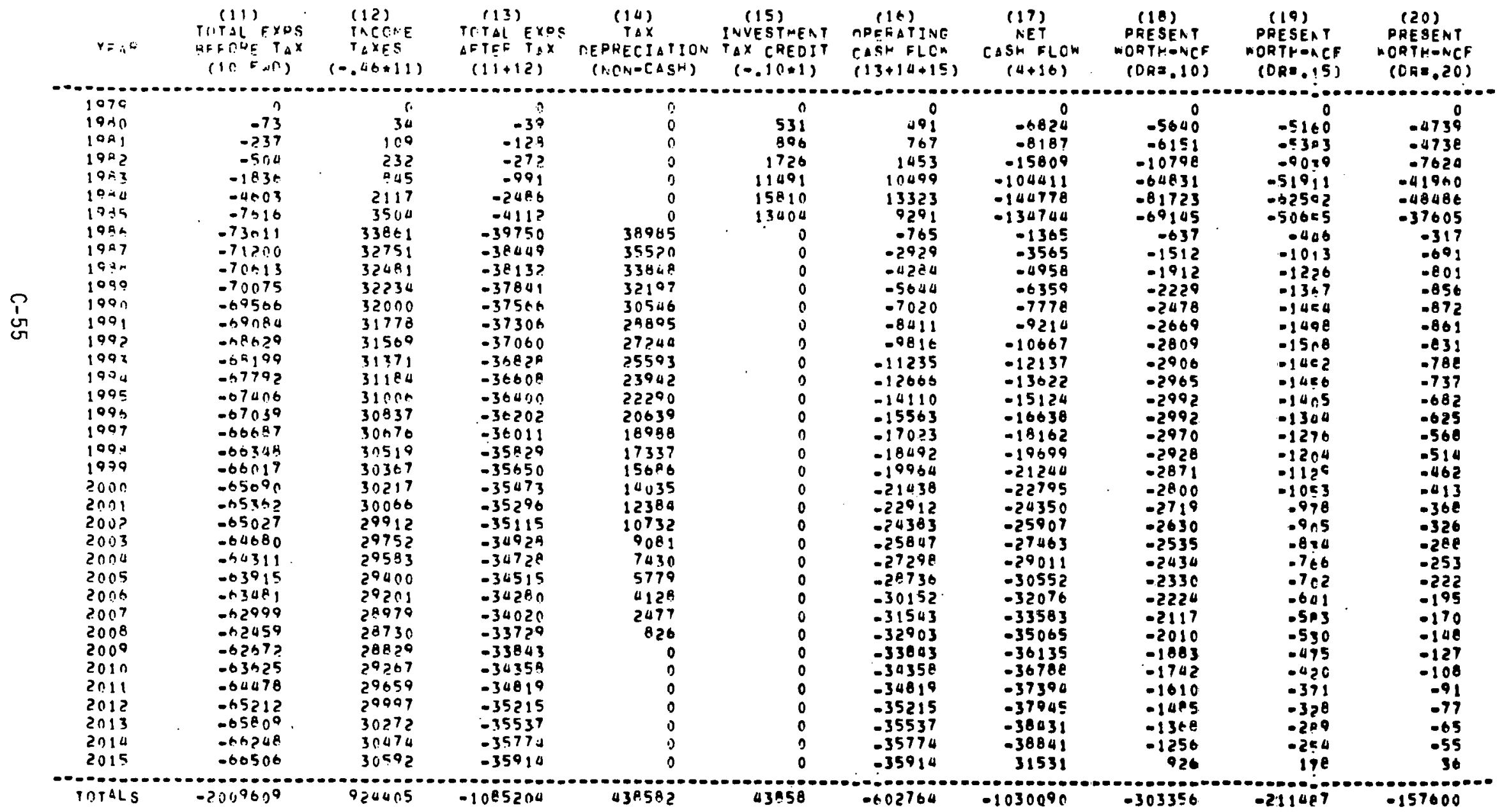


PROJECT COST ANALYSIS

OF ANRUAL CAST REOUIIPFMFATS

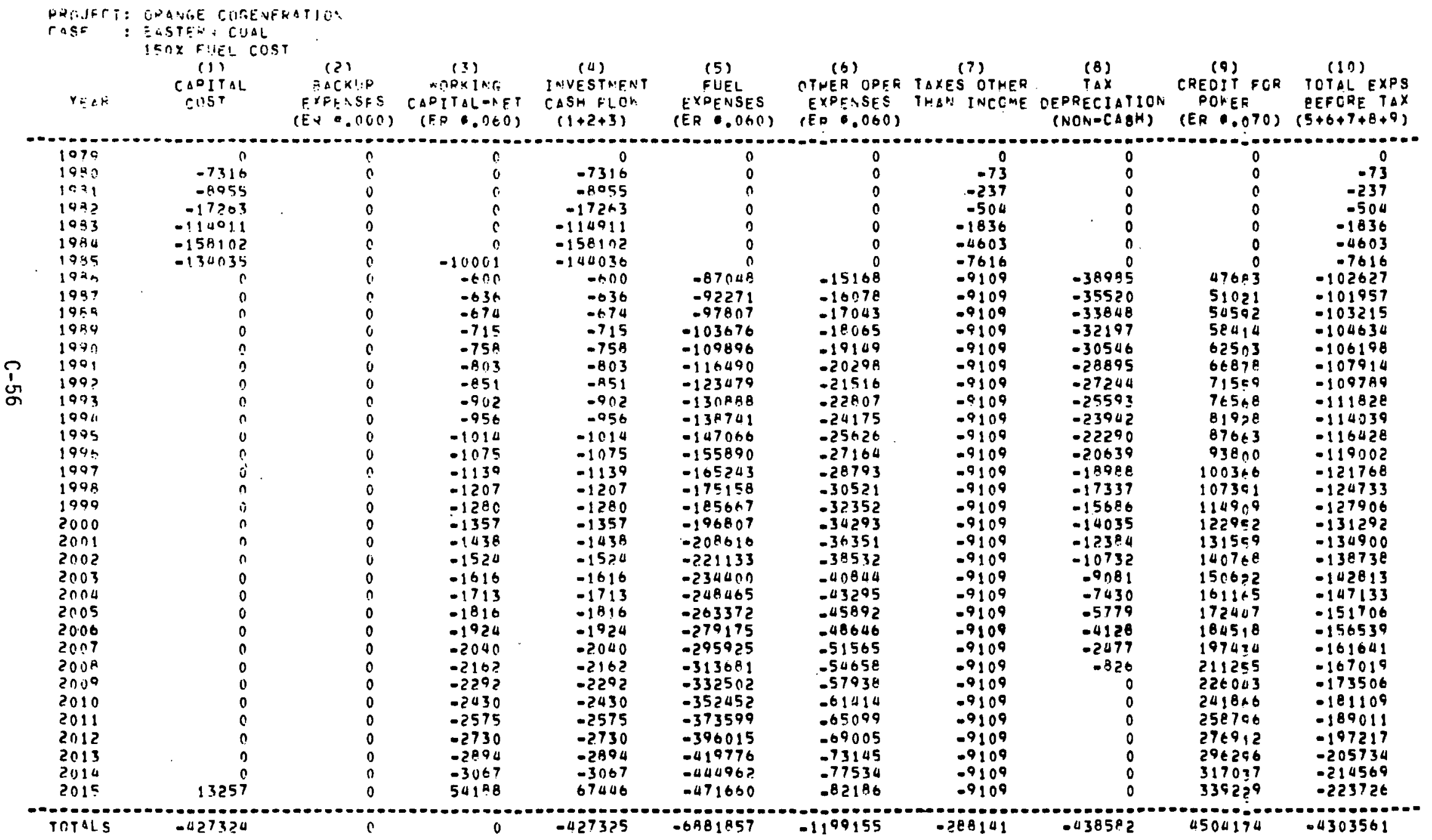


FROJECT COST ARALYSIO

PHOJFCT: DRANGF COGENERATIOA

CASF : FASTEUH COAL

ISNY FIIFL CUST

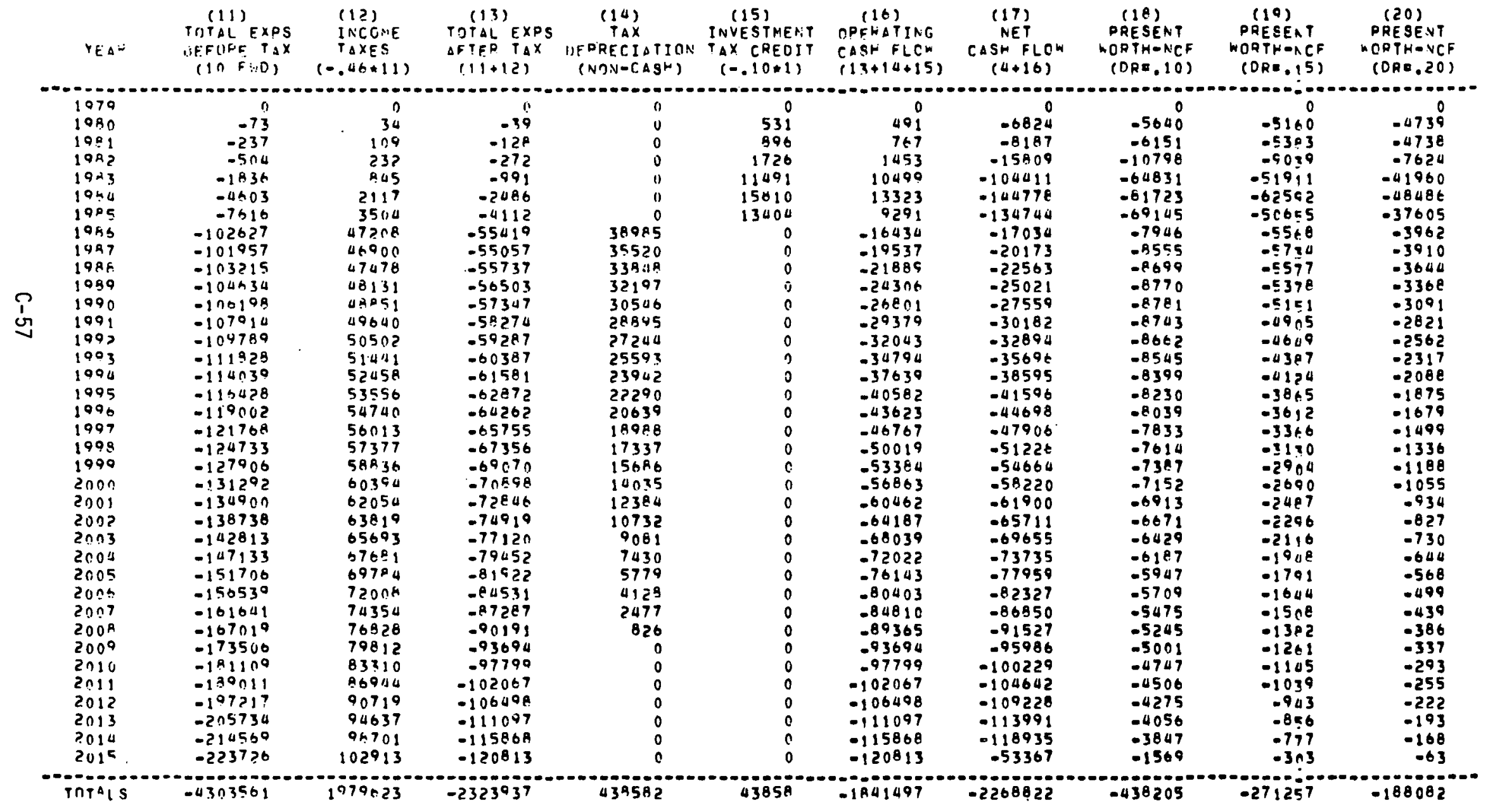




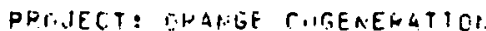

CASF : EASIEHH COAL

$$
\begin{gathered}
\text { ONOS FUFL CEST } \\
\text { (1) }
\end{gathered}
$$

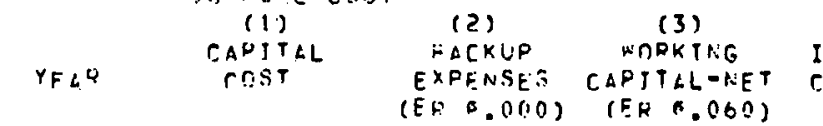

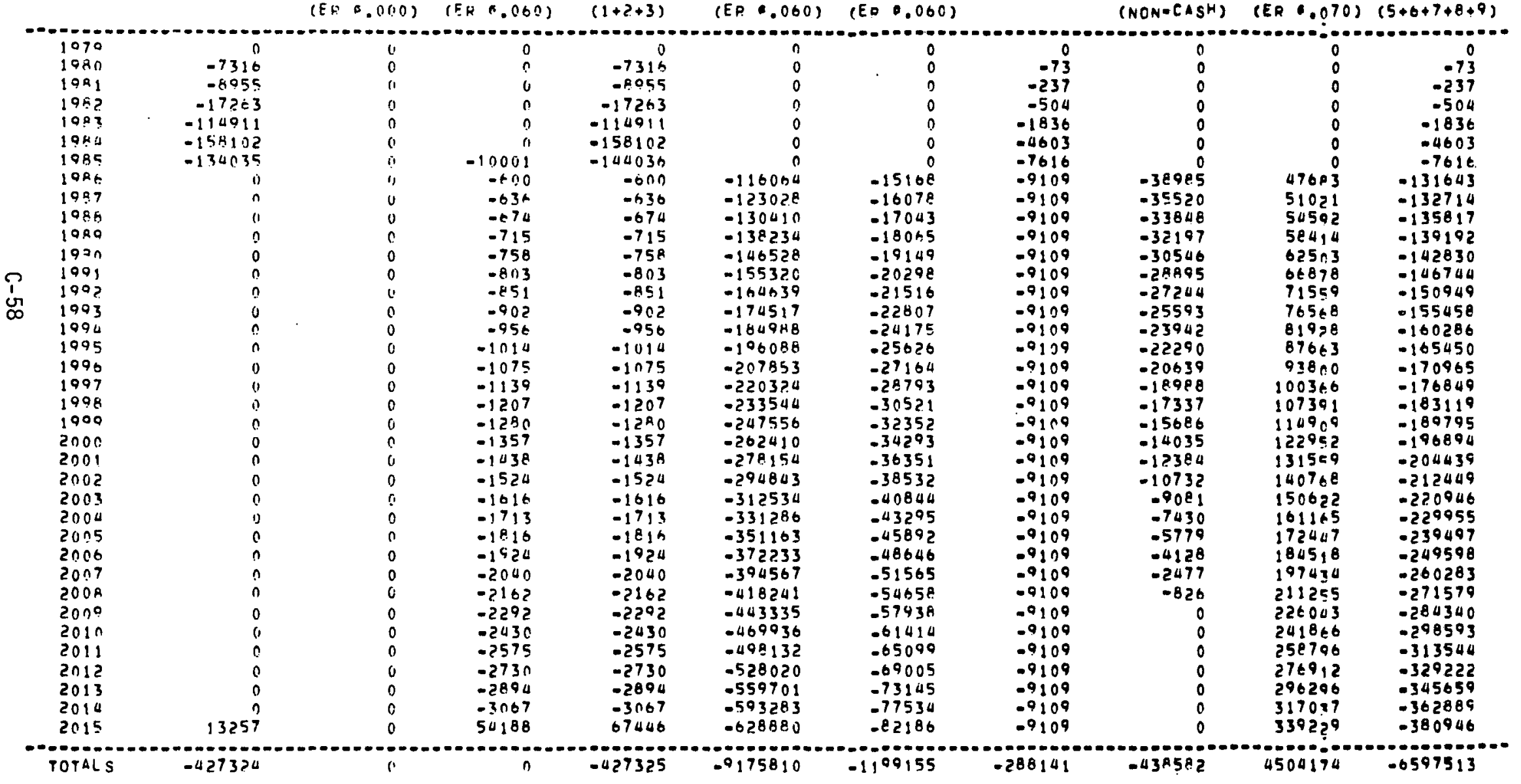


PROJFET: GHALGE COGEAFAATION CASF : FASTEDN COJLL

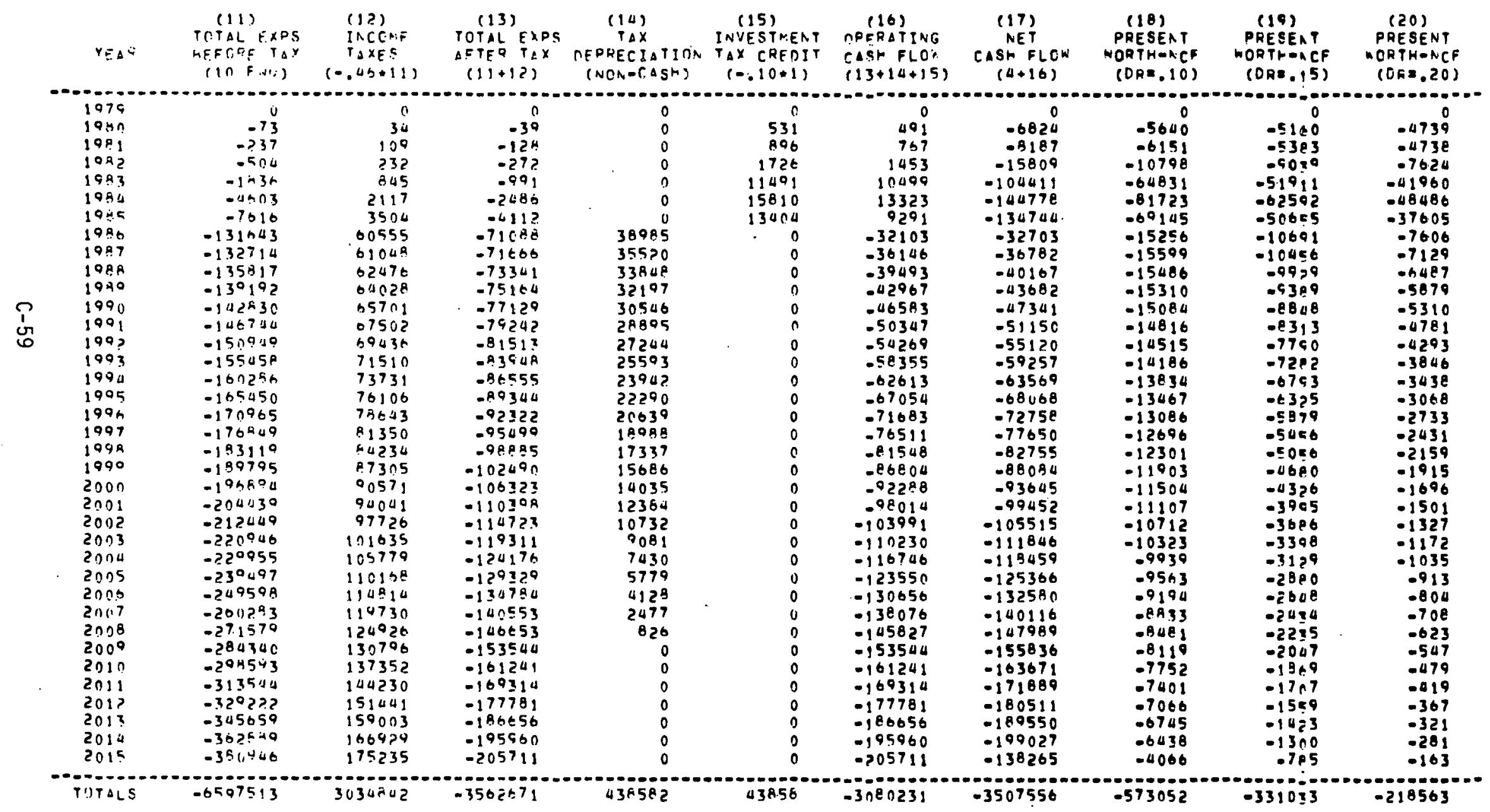


PROJECT: ERANGE COGENEOATITIN

CASE : WESTERN COAL

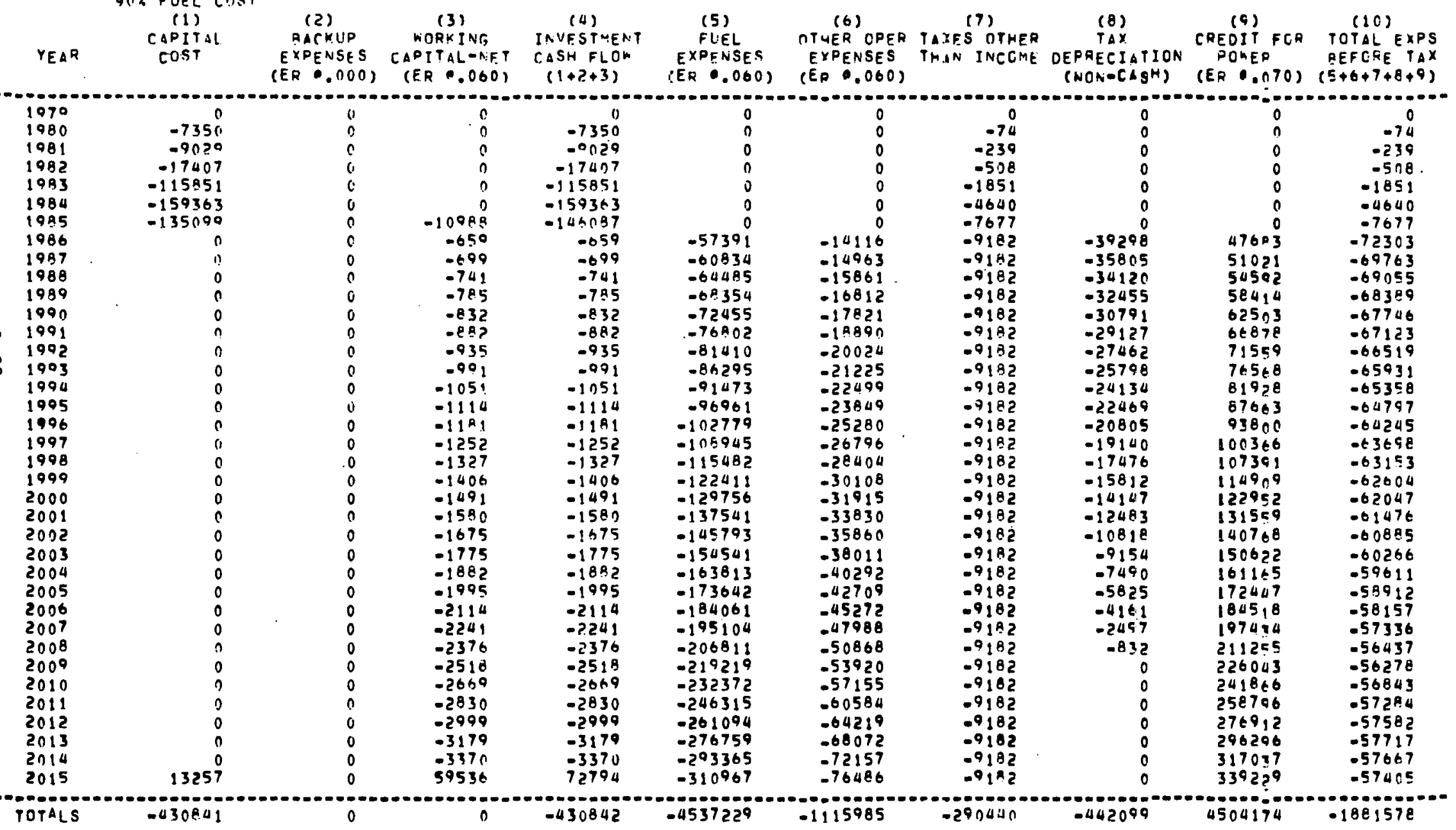


בHOJECT COST ANALYSIE

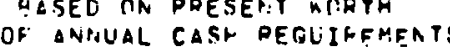

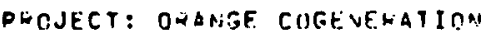

CASE : MESTENN COAL

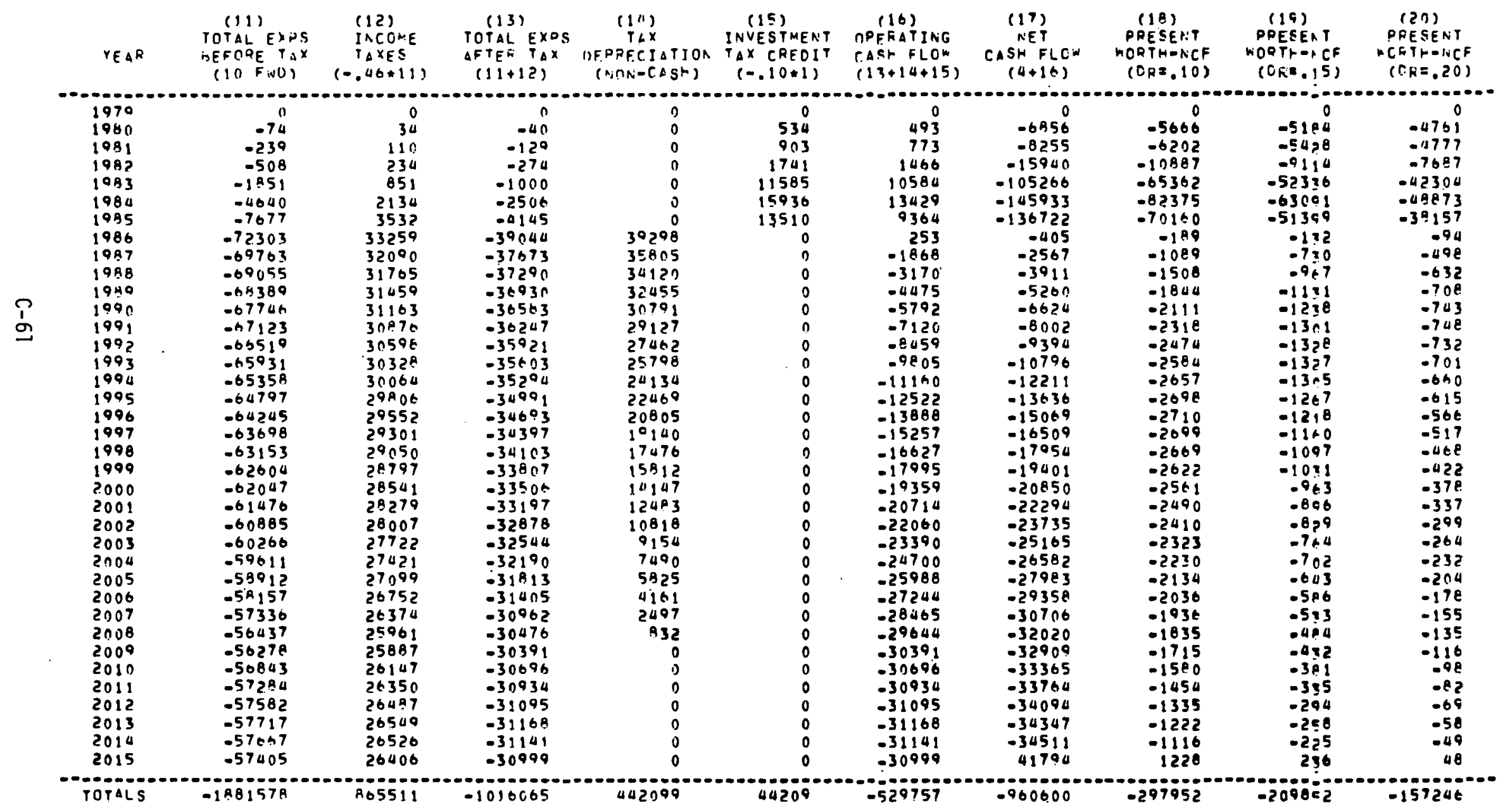


PROJECT COST ANALYSIS

OF LNHUULL CASH REQUIREMFNTS

PHOJECT: EHONGE COCESEFGTIGI

CASE : AESTEPN CIOL

$$
\text { 10O2 FUEL CLIST }
$$

$$
\text { (1) }
$$

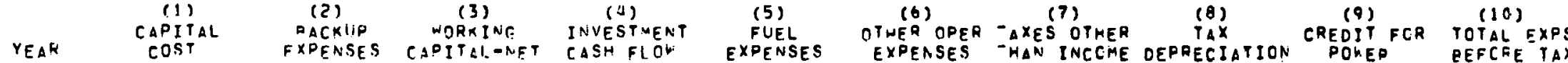

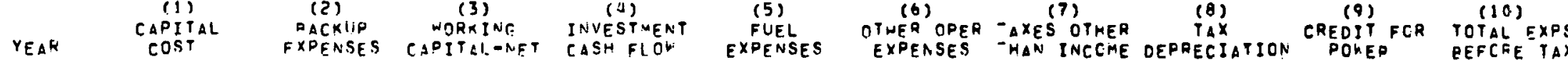

(6)

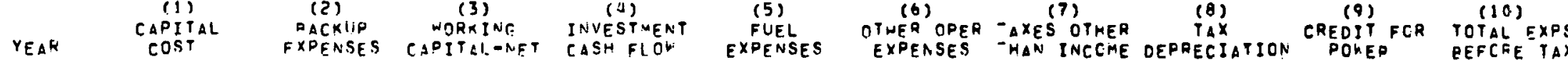

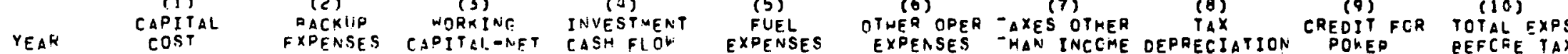

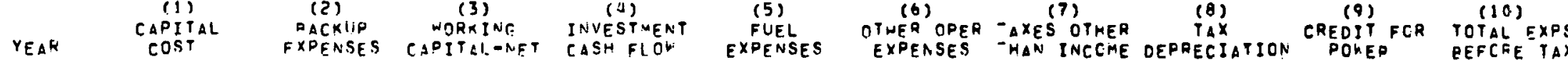

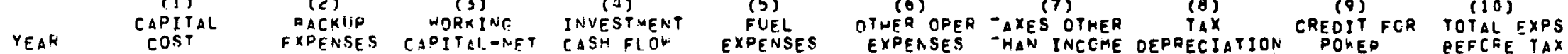

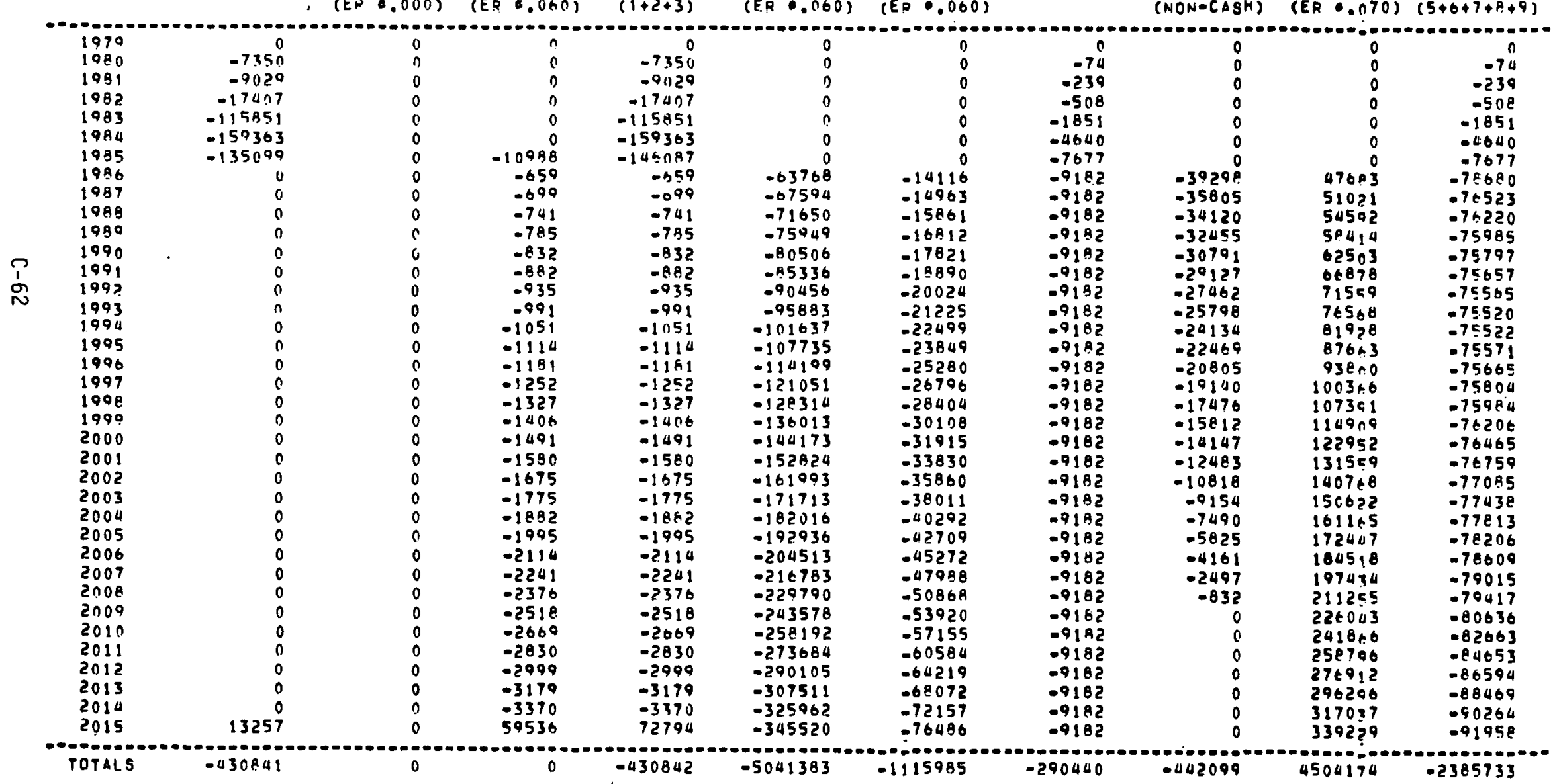


DROJECT CNST AMALYSIS

PAGE 2 OF 2

GF AVIUAL CASH PELLUIREMENTS

PROJECT ORANGE COGENEFATION

CASE : WESTERS COAL

IOOX FUEL COSI

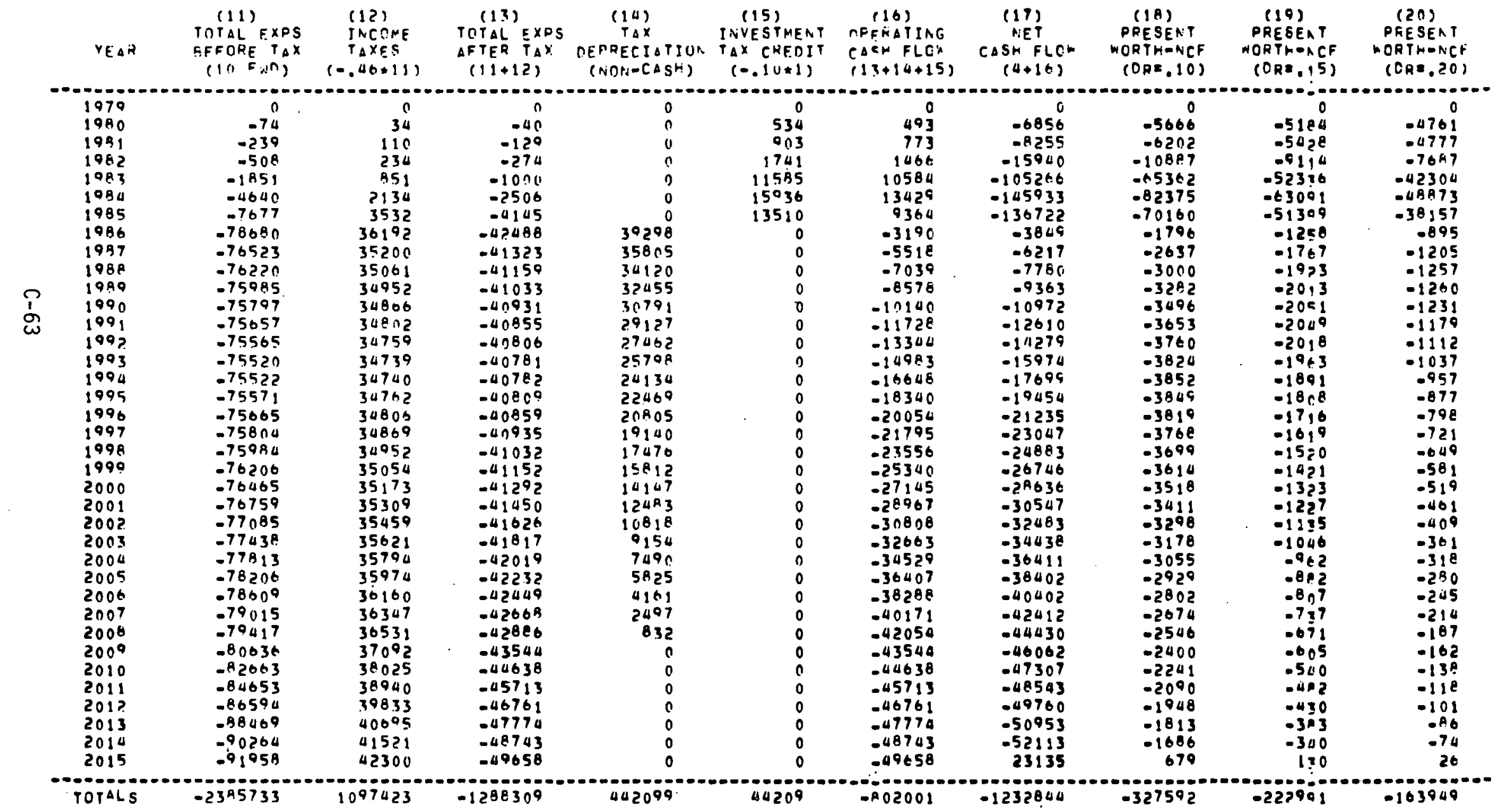


PROJECT COST AIIALYSIS

PAGE \& OF 2

PASED ON PRESENT WTRTH

UF ANNIJAL CASL REQUIKEMFNTS

PROJFCT: OAANTE COGEMEAGTION

CASE : MFSTER:: COAL

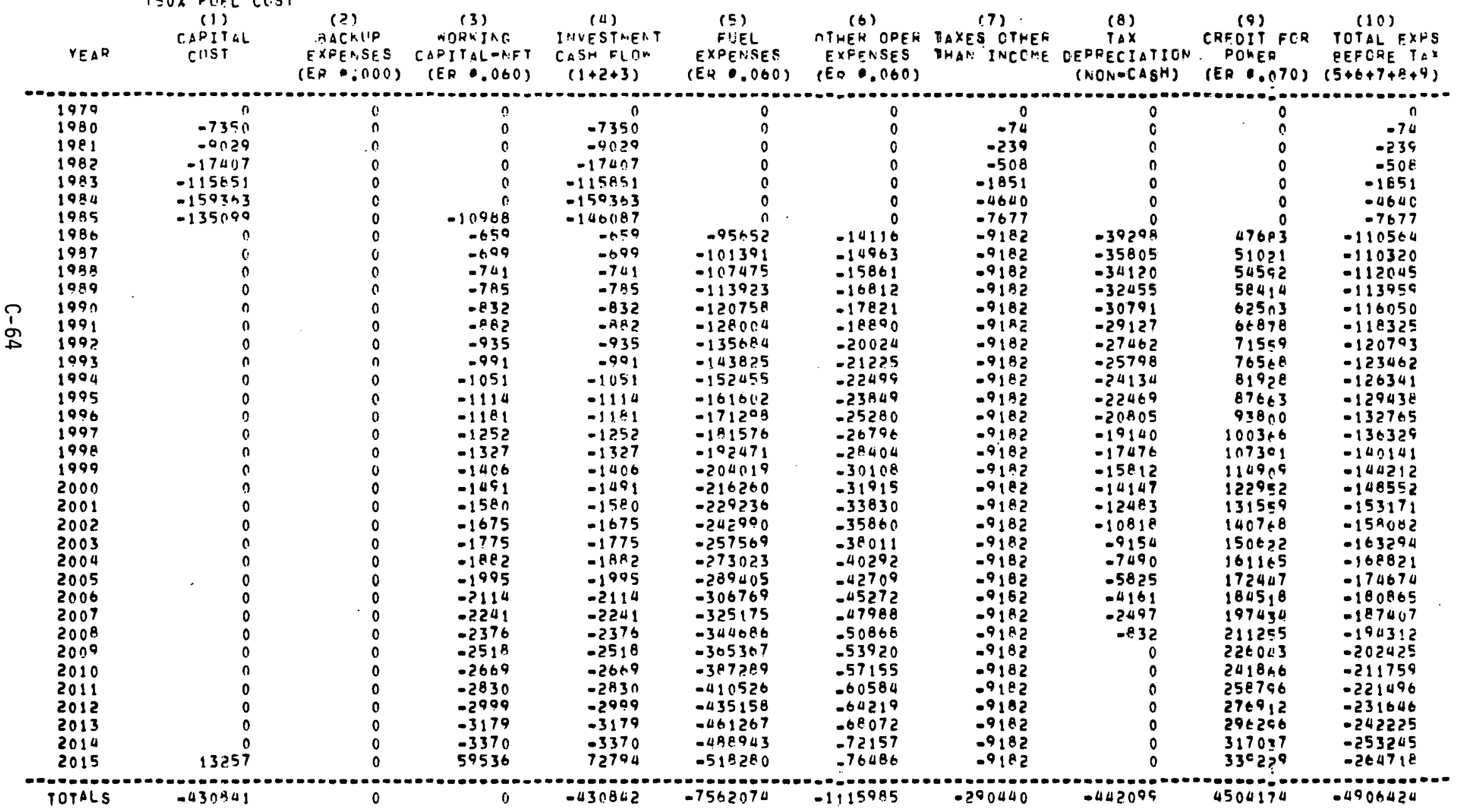


PRC.JECT CHST ARALYSIS

FASEC TH PDESENT RCRTH
UF ONALUL CASH FEDLIRENEATS

PROJECTI OHANGF COGENERATIOS

CASE I AESTER'" COAL

ISnX F:JFL ERST

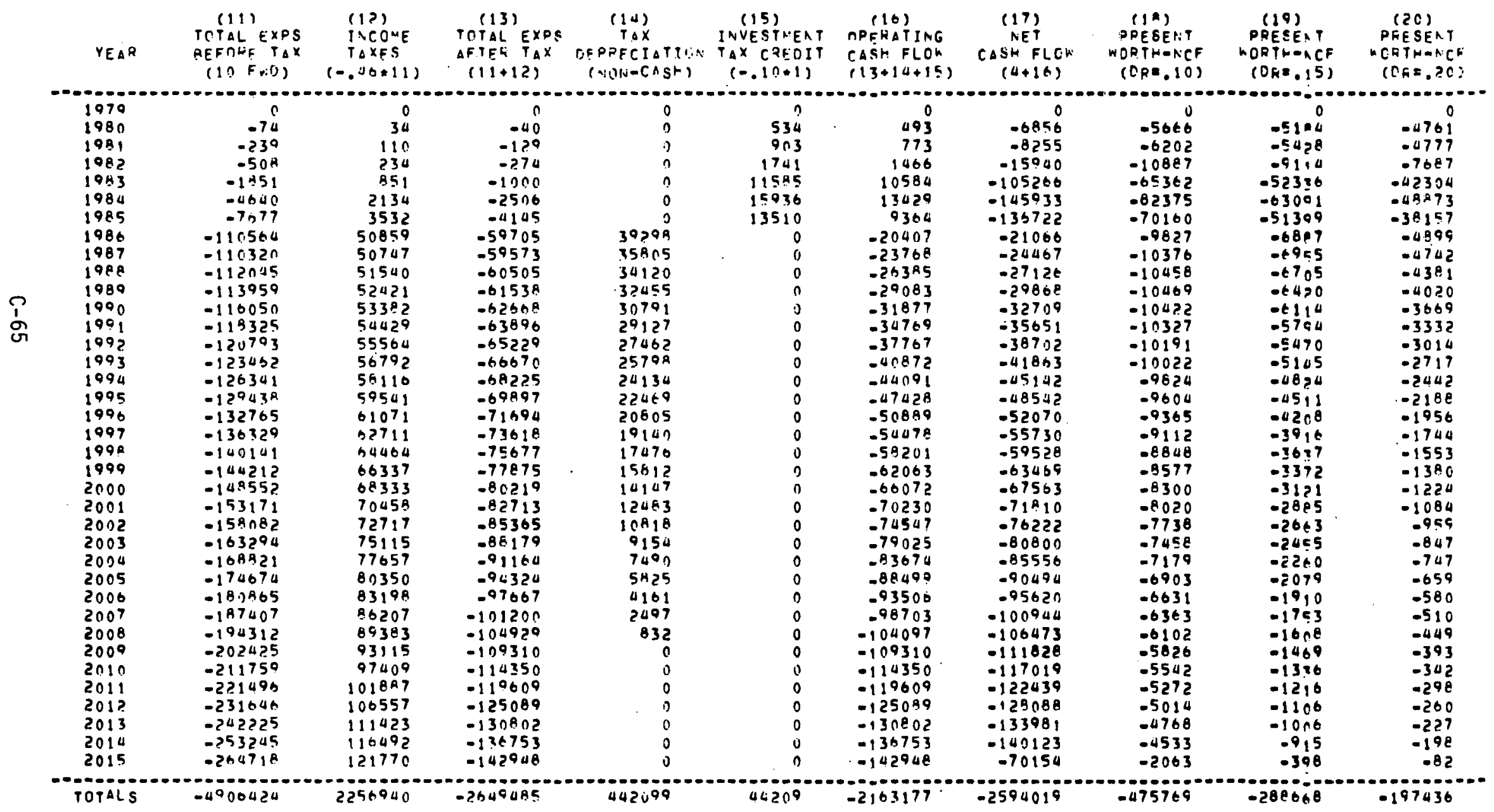


PROJETT: GFANCIE COGEAERTITIUR

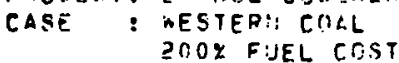

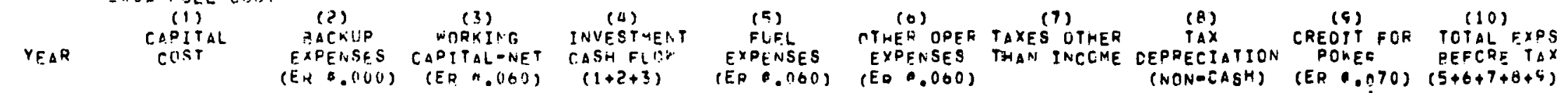

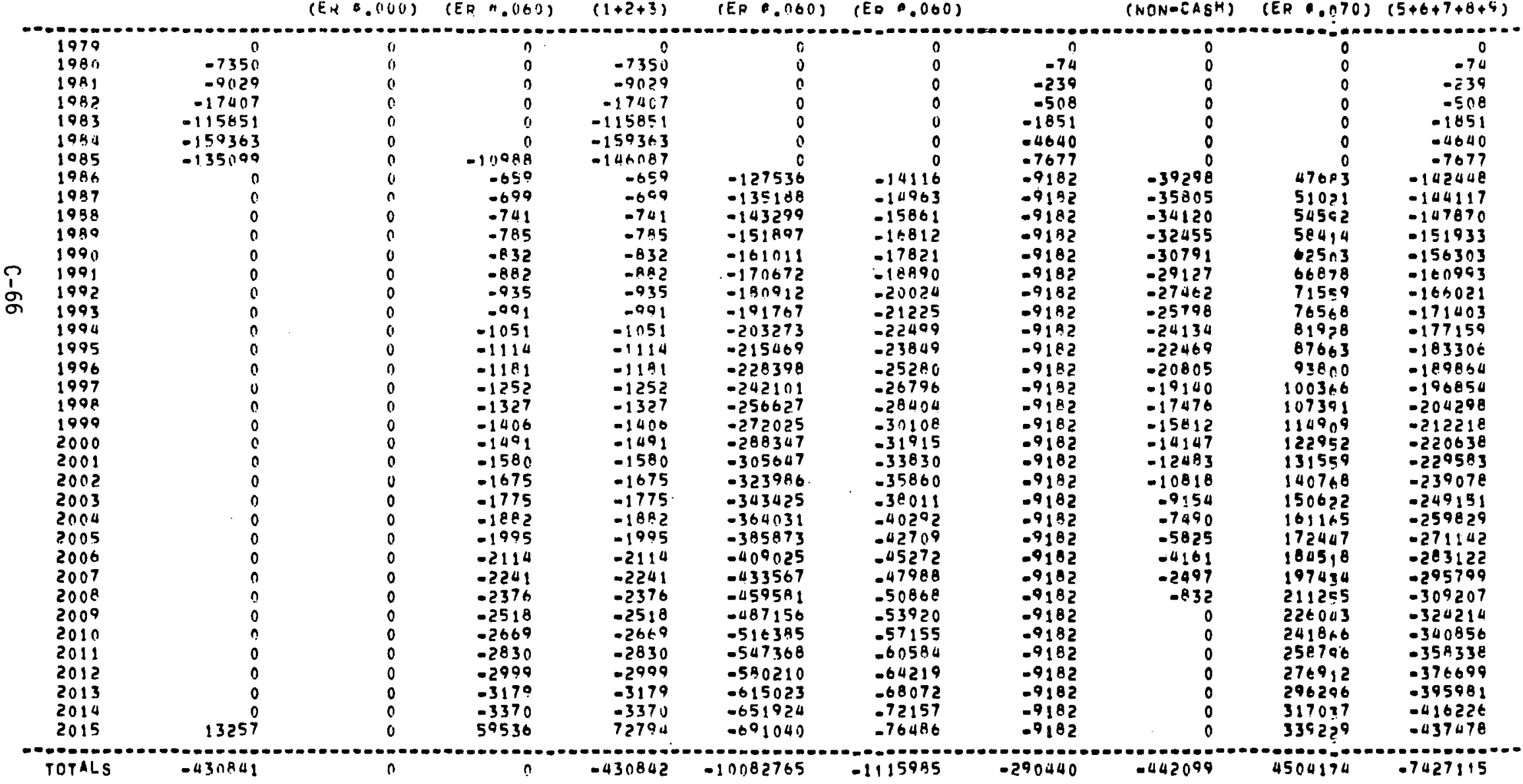


VRNJECT COST AHALYSIC

PAGE 2 CF 2

IIF AR: IAL CASE RELUIREMFA TS

PROJECT DRGMGF COCENERITIOS

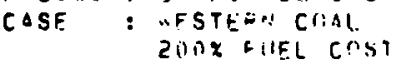

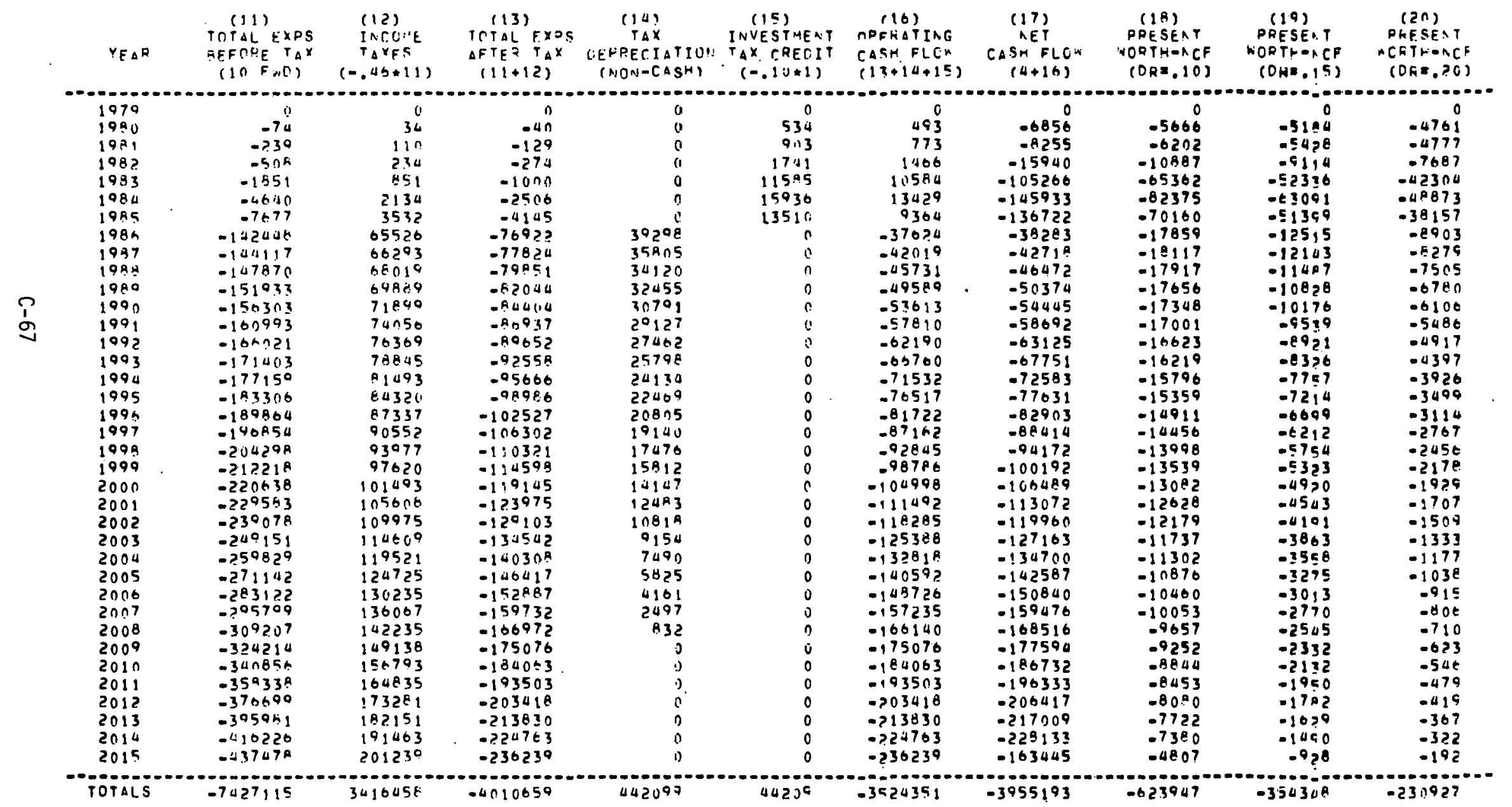




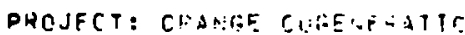

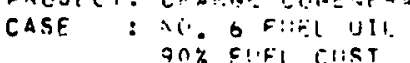

\begin{tabular}{|c|c|c|c|c|c|c|c|c|c|c|}
\hline$Y \in A R$ & $\begin{array}{c}\text { (1) } \\
\operatorname{coI} \text { CITSTL } \\
\text { CnST }\end{array}$ & 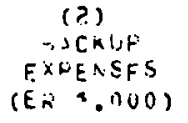 & $\begin{array}{c}(3) \\
\text { ADRKIAE } \\
\text { CAPITAL-NET } \\
(E R \quad 0.100)\end{array}$ & $\begin{array}{l}\text { (U) } \\
\text { I RVESTMEAT } \\
\text { CASH FLCK } \\
(1+2+3)\end{array}$ & $\begin{array}{c}\text { (5) } \\
\text { FUEL } \\
\text { EXPENSES } \\
(E R O .070)\end{array}$ & $\begin{array}{c}(0) \\
\text { OTWER CPER } \\
\text { EXFEASES } \\
\text { (ED O.OBO) }\end{array}$ & $\begin{array}{l}\text { (7) } \\
\text { TAXES OTHER } \\
\text { THA. INCCME }\end{array}$ & $\begin{array}{c}\text { (E) } \\
\text { TAXX } \\
\text { CEFDECIATIOA } \\
\text { (NONOCASH) }\end{array}$ & $\begin{array}{l}\text { (S) } \\
\text { CREDIT FCF } \\
\text { POKEF } \\
\text { (ER . OPO) }\end{array}$ & $\begin{array}{l}(10) \\
\operatorname{TOTAL} E x+S \\
\text { EEFCRF IOx } \\
(E+t+7+2+5)\end{array}$ \\
\hline 1979 & i & (1) & $\cdots$ & $\cdots \cdots a_{0}$ & $\cdots$ & $\cdots$ & 0 & 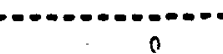 & $\cdots-\cdots$ & 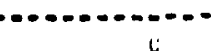 \\
\hline 1980 & 0 & 0 & 0 & $n$ & 0 & 0 & c & 0 & 6 & 0 \\
\hline 102.1 & $-1<506$ & r. & n? & -14550 & $c$ & 0 & -146 & 0 & 0 & -1 at \\
\hline 1022 & -25924 & c: & 0 & -25020 & ? & 0 & $-5 \subseteq 0$ & 0 & 0 & .554 \\
\hline 1933 & -07113 & G & 0 & -97113 & 0 & 0 & -1795 & 0 & 0 & -1705 \\
\hline 1084 & -126181 & 6 & $n$ & -126181 & 0 & 0 & -4064 & 0 & $a$ & -40014 \\
\hline 1985 & $-10 x 003$ & 0 & -19015 & -127474 & 0 & 0 & -6448 & 0 & i & $-644 \varepsilon$ \\
\hline 1986 & $n$ & ( & -1105 & -1165 & -101410 & -12042 & -7698 & -32876 & पseno & -104226 \\
\hline 1957 & (1 & 0 & -1235 & -1235 & $-10 \cos 0^{\circ}$ & -12745 & -7698 & -20953 & 53206 & -105639 \\
\hline 1999 & 0 & 0 & -1300 & -1309 & $-11 \in 1 \| 4$ & -13530 & -7698 & $-2 e 54 a$ & $570: 6$ & -10RACI \\
\hline 1950 & 0 & 0 & $=1387$ & -1327 & -124232 & -14342 & -7698 & -27152 & $610 \cap 7$ & -112410 \\
\hline 1990 & $n$ & 0 & -1471 & -1471 & -132928 & -15203 & .7698 & -25750 & 65278 & $-1153: 0$ \\
\hline 1991 & 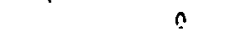 & 0 & -1559 & -1550 & -142233 & -10115 & $-760 E$ & -24367 & 698117 & -120565 \\
\hline $190 ?$ & $\theta$ & 0 & -1652 & -1652 & -152189 & -17082 & -7698 & -22974 & 74736 & -125207 \\
\hline 1093 & ! & $c$ & $-175 ?$ & -1752 & -162802 & -19107 & $-7+98$ & $-215+2$ & $749 \div 8$ & -130261 \\
\hline 1994 & 0 & $n$ & -1857 & -1957 & -174241 & -10193 & $.76^{\circ} 8$ & -20100 & BEsitt & $-13575 t$ \\
\hline 1995 & 0 & 8 & -1908 & -1908 & -1861138 & -20345 & -7598 & -18797 & 91555 & -141723 \\
\hline $\begin{array}{l}1996 \\
1997\end{array}$ & o & 0 & -2086 & -2056 & -199489 & -21565 & -7698 & -17405 & $979+4$ & $-14010 ?$ \\
\hline 1997 & $n$ & 0 & -2211 & -2211 & -213453 & -22859 & .7698 & -16012 & $1048 ? 2$ & -155201 \\
\hline 1909 & $n$ & 0 & $-23 \Delta 4$ & -2364 & -228345 & -24231 & $-769 A$ & -14620 & $\| \bar{c} \mid=0$ & -102785 \\
\hline 1909 & 0 & o & $-24 * 5$ & -2485 & -244382 & -25695 & -7698 & -13228 & 120010 & - 170942 \\
\hline 2000 & $n$ & 0 & .2634 & -2634 & .261489 & -27226 & .7698 & -11835 & 128491 & -179837 \\
\hline 2001 & 0 & 0 & -2792 & -2792 & -279703 & -29859 & -7698 & -10443 & 137400 & -180394 \\
\hline 2002 & 0 & 0 & -2950 & -2959 & -299379 & -30591 & $-7 n 98$ & -9051 & 147018 & -190701 \\
\hline 2003 & $n$ & 0 & -3137 & -3137 & -320335 & $-32420^{\circ}$ & -7698 & .7658 & $1573 \mathrm{Co}$ & $=210808$ \\
\hline 2000 & $n$ & 0 & $-3 \leq 25$ & -3325 & $-34=750$ & -34372 & .7099 & -6206 & 168331 & - 222774 \\
\hline 2005 & 0) & 0 & -3525 & -3525 & -300752 & .30434 & -7698 & .4873 & $180 \ln 3$ & -235055 \\
\hline 2006 & 0 & 0 & .3730 & -3736 & -392425 & -35620 & .7698 & -3481 & 192710 & -249514 \\
\hline 2007 & 0 & 0 & -3060 & -3960 & -419005 & .40938 & -7608 & -2080 & $20<200$ & .260419 \\
\hline 2008 & 0 & 0 & -4106 & $-a_{1} \circ \beta$ & -049287 & $-433^{\circ} 4$ & .7698 & -690 & 220624 & $-280 \Delta 41$ \\
\hline 2009 & 0 & $u$ & -4450 & $-4 u \leq n$ & .080737 & .45997 & .7698 & $n$ & 236078 & -290350 \\
\hline 2010 & 0 & $!$ & .4717 & -4717 & -510389 & -42757 & -7608 & 0 & $2526 n d$ & -318.240 \\
\hline 2011 & 0 & ! & -5000 & -5000 & -550390 & -51683 & -7698 & 0 & $2702 P 6$ & -330490 \\
\hline 2012 & 0 & 0 & -5300 & -5300 & $.5880 ? 4$ & $-5+784$ & -7698 & 0 & 289206 & -362199 \\
\hline 2013 & 0 & 0 & -5618 & -5613 & $-63 n 148$ & -58071 & -7098 & 0 & 305451 & $-38646 t$ \\
\hline 2014 & 0 & 0 & -5955 & -5955 & -674250 & .61555 & -7698 & n & 331112 & -412304 \\
\hline 2015 & 12450 & 0 & 105107 & 117648 & $-72: 457$ & .05248 & .7698 & 0 & 350200 & -400113 \\
\hline OTALS & 359000 & 0 & 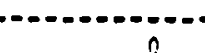 & 930413 & - & 2014 & 3 & 9851 & 704148 & -6440975 \\
\hline
\end{tabular}


C.RT.JERT COST ANALYSIS

PROJECT: OHANGE COGENEQATTS

CASE : NOD S FUFL UIL

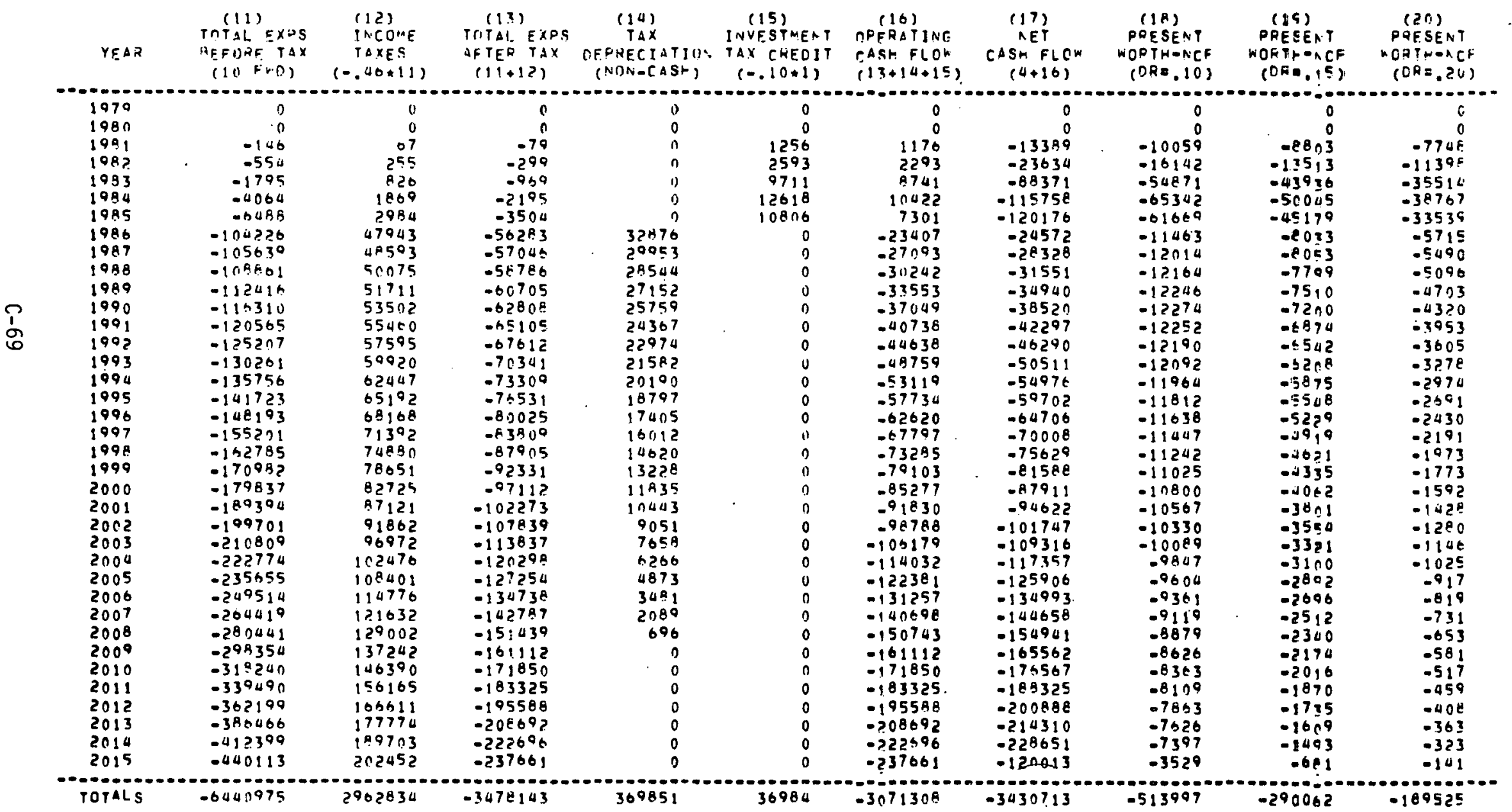


PROJECT: ORANGE EUGENERATION

CASE I AOD FUIEL OIL

\begin{tabular}{|c|c|c|c|c|c|c|c|c|c|c|}
\hline$Y \in A R$ & $\begin{array}{c}\text { (1) } \\
\text { CAPITAL } \\
\text { COST }\end{array}$ & $\begin{array}{c}\text { (2) } \\
Z A C K U P \\
\text { FPENSES } \\
(E \bar{F} .000)\end{array}$ & $\begin{array}{c}\text { (3) } \\
\text { MRRKING } \\
\text { CAPITALONET } \\
\text { (ER O.OBOS }\end{array}$ & $\begin{array}{l}\text { (4) } \\
\text { TAVESTMENT } \\
\text { CASH FLON } \\
(1+2+3)\end{array}$ & $\begin{array}{c}\text { (5) } \\
\text { FUEL } \\
\text { EXPENSES } \\
\text { (ER } .070)\end{array}$ & $\begin{array}{c}(6) \\
\text { RTHER OPER } \\
\text { EXPENSES } \\
(E P \bullet .060)\end{array}$ & $\begin{array}{l}\text { (7) } \\
\text { AXES OTHER } \\
\text { THAV INCOME }\end{array}$ & $\begin{array}{c}(E) \\
\text { TAX } \\
\text { DEPRECIATION } \\
\text { (NONOCASH) }\end{array}$ & $\begin{array}{l}\text { (S) } \\
\text { CREDIT FER } \\
\text { DOREP } \\
\text { (ER } .070)\end{array}$ & $\begin{array}{l}(10) \\
\text { TOTAL EXFS } \\
\text { EEFCRE TAX } \\
(5+6+7+8+9)\end{array}$ \\
\hline
\end{tabular}

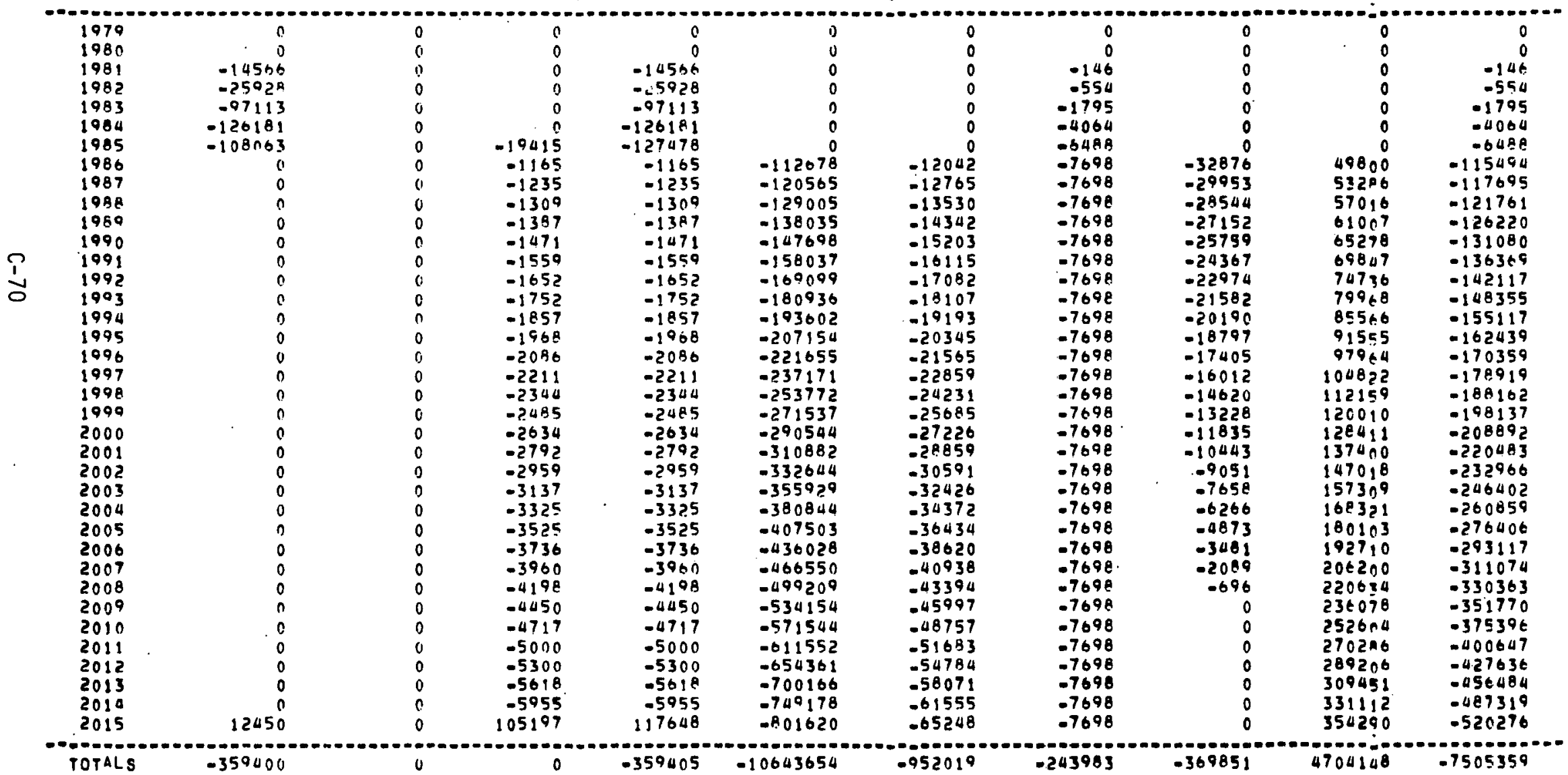


PROJECT O OPANGE CURENEHAITIMK

CASE : ANDG FIIEL UII

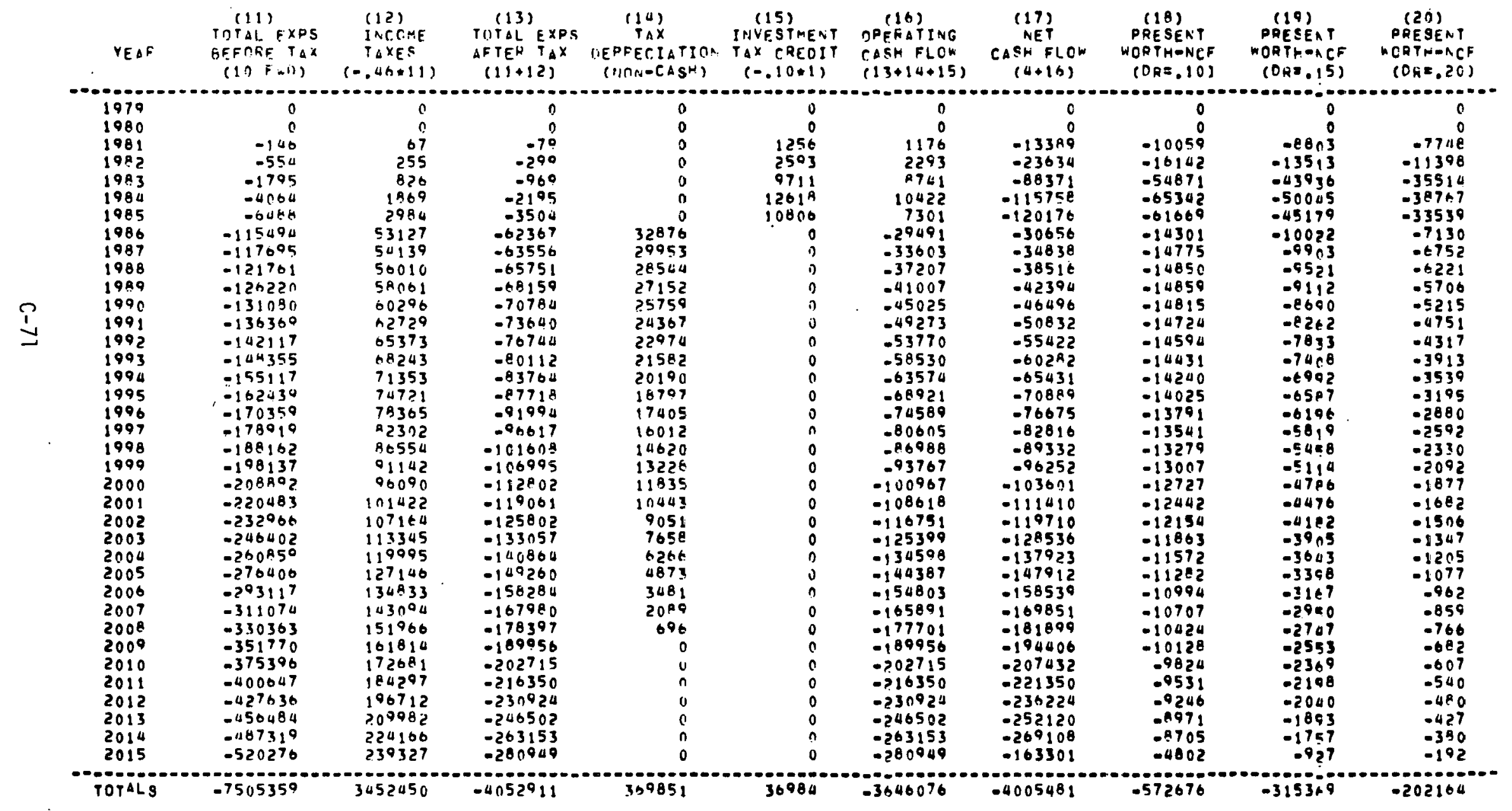


PROJECT: CHANGE COTEENERATIOR:

CASE : NO B FIJEL OIL

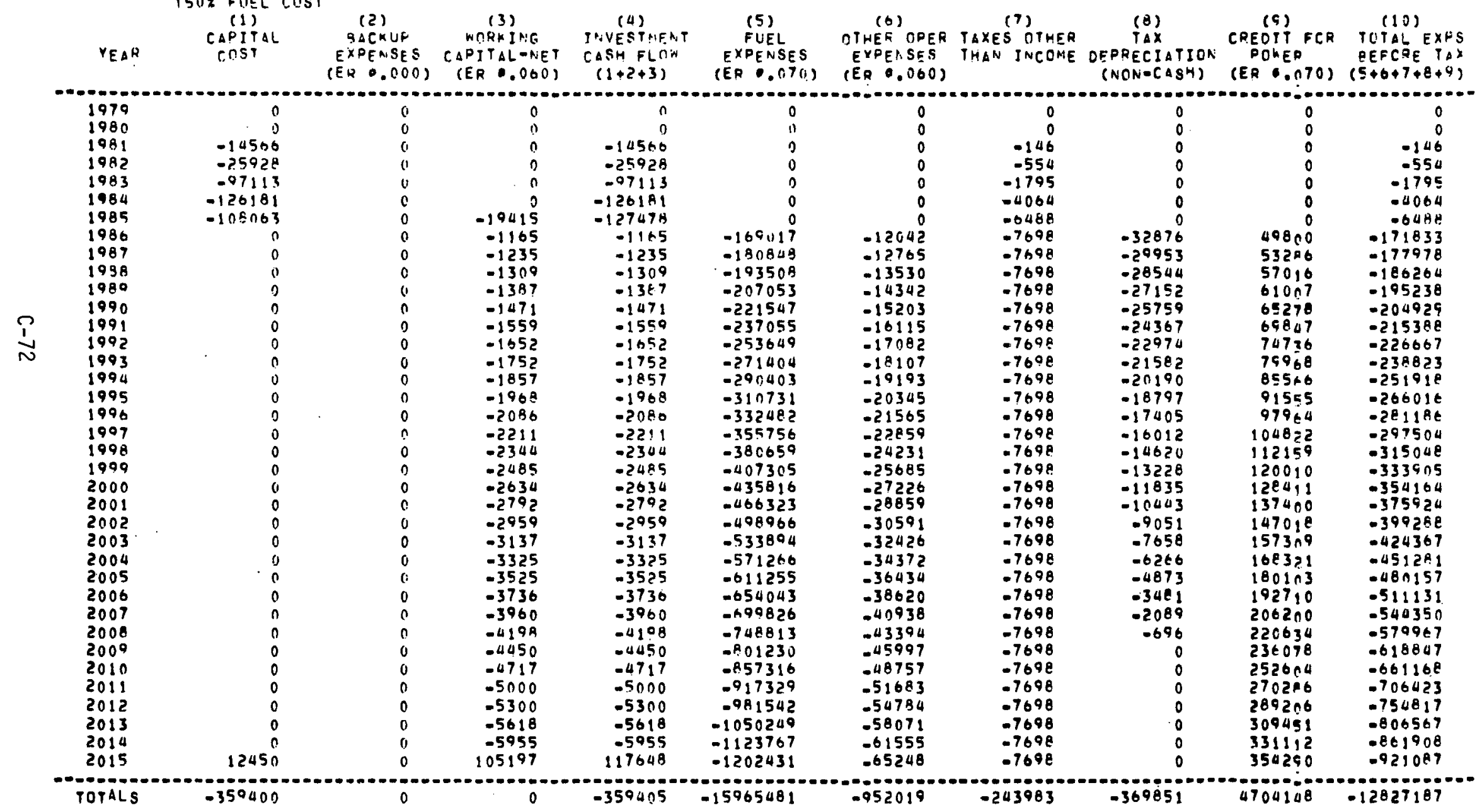


DRAJECT CAST AH:ALYSIS

DE SUNULL CASF FEGUIREMENTS

PROJECT: CrANGE COGENERATII!A

CASE : 90 . F FIEEL CIL

15 T2 FLIEL COST $^{3}$

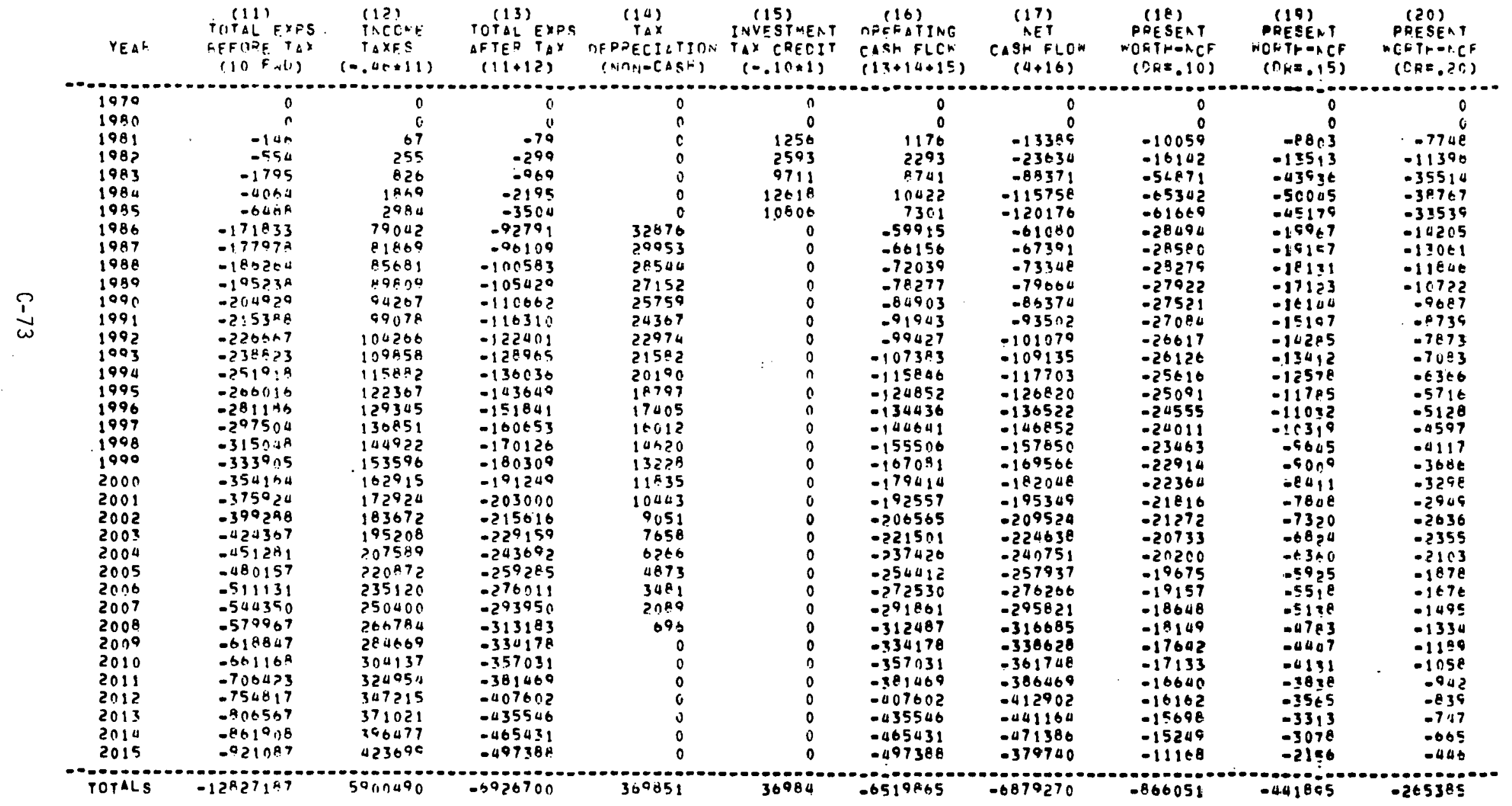


PNCJECT COST ANALYSTS

PASEC. CN PRESE:JT WDRTH

PAGE : OF 2

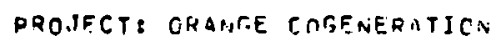

CASE I ARO FIIEI IJIL

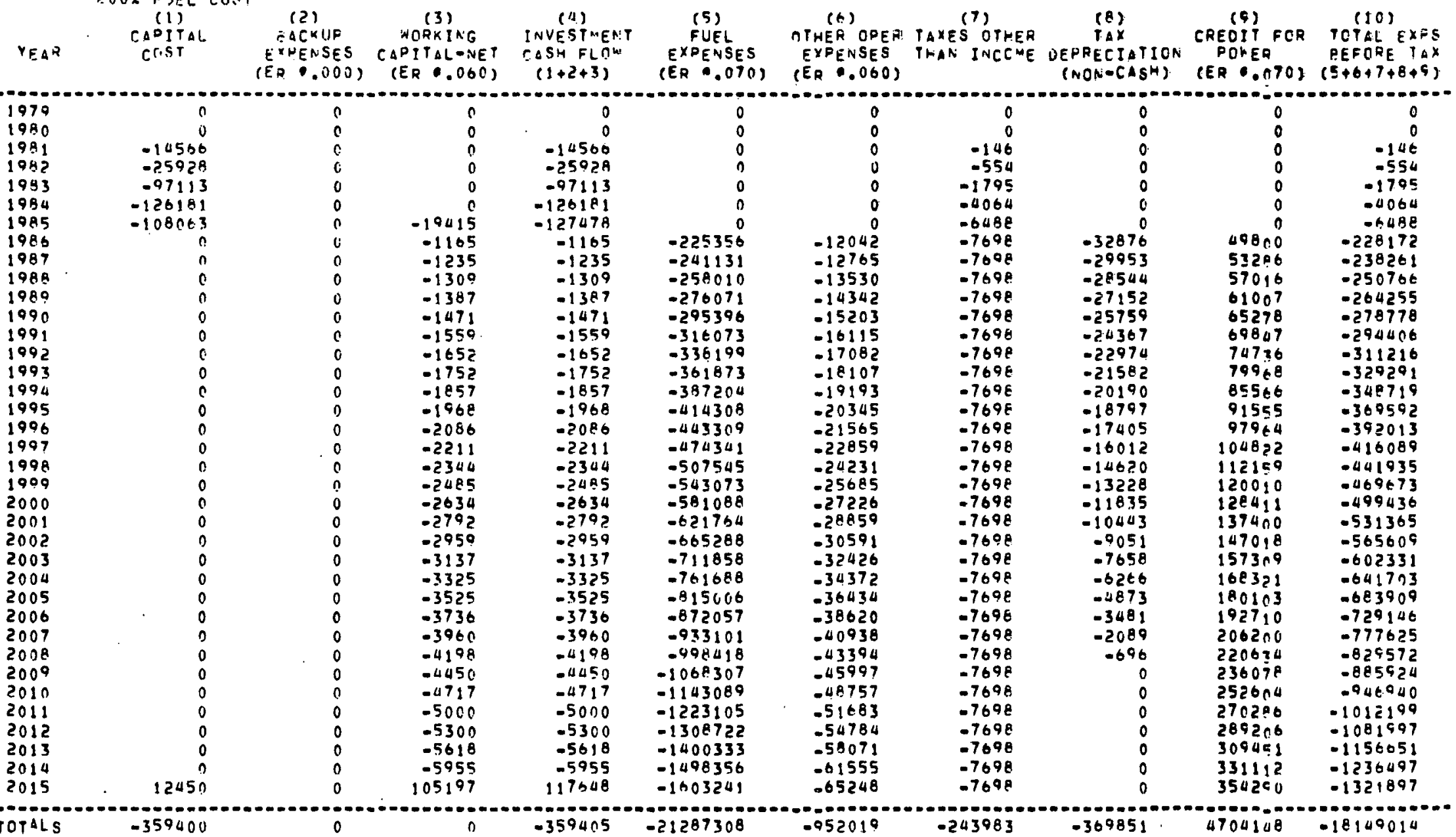


PROJECT: HFATGE CUGENERATITIF

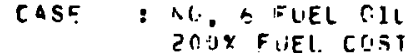

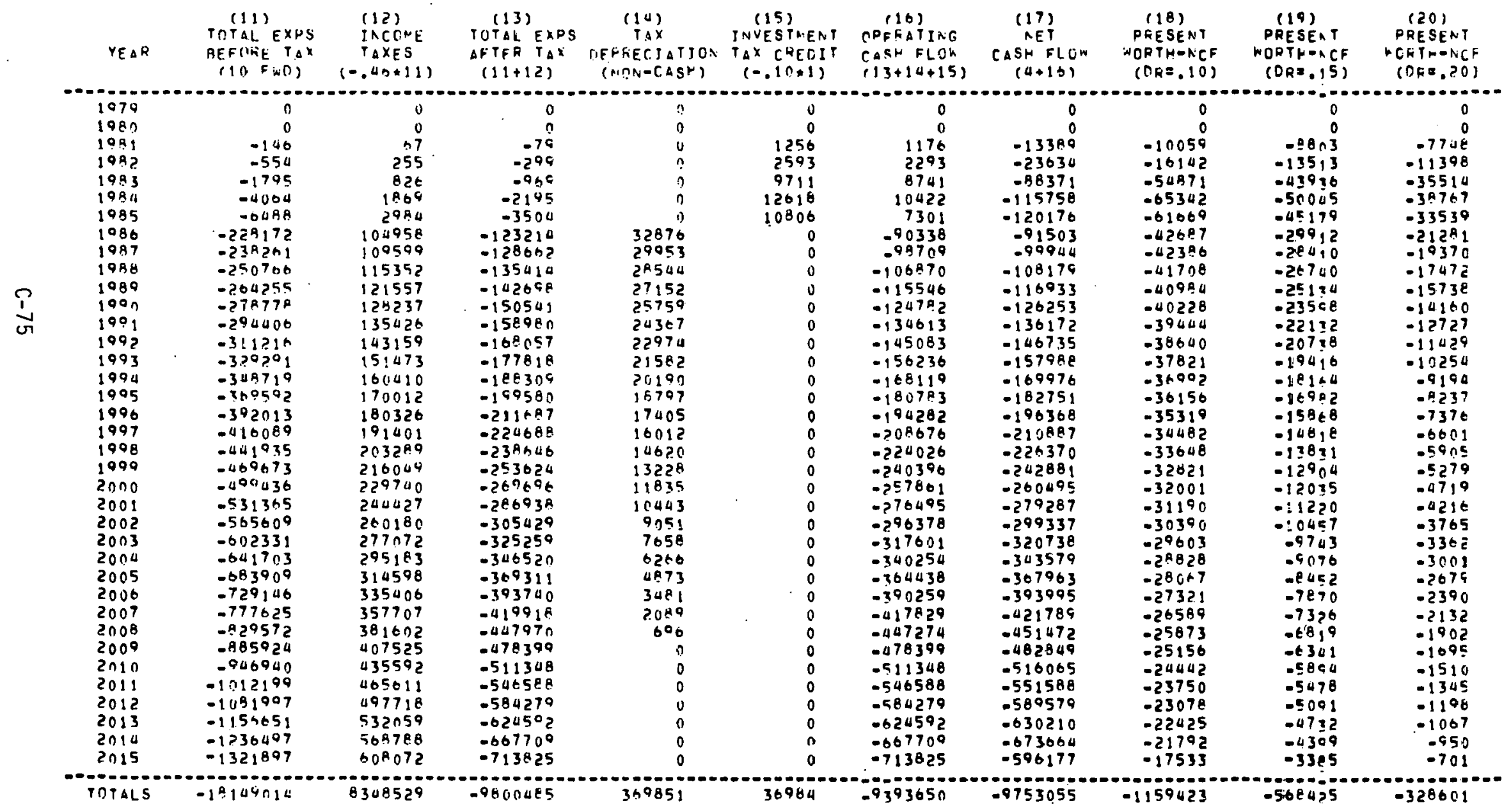


GF ANAUAL CASH REQUIREMFNTS

PFOJECT: UHA GIE COGEAEFATIGN

CASE: HTR :

GOY FUEL CIST

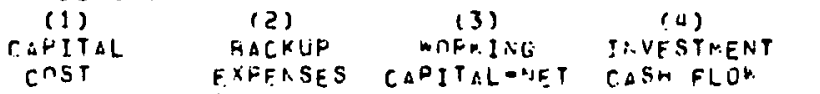

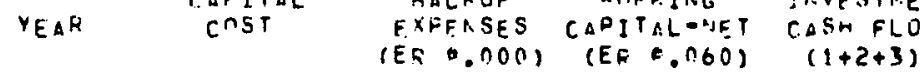

(5)

(5)
FLEL OTHEF OPEF TAXES OTHER (EP D.049) (ER

$(\Delta)$
$T A X$ (a) (10)

\begin{tabular}{|c|c|c|c|c|c|c|c|c|c|c|}
\hline$Y \in A R$ & COST & $\begin{array}{l}\text { EXFERSES } \\
\text { (ER D. DOOI) }\end{array}$ & $\begin{array}{l}\text { CAPITAL-AET } \\
\text { (EFE. TOOO) }\end{array}$ & $\begin{array}{l}(1+2+3) \\
\text { C.ASH FLO }\end{array}$ & $\begin{array}{l}\text { EXPFNSES } \\
(E P 0.049)\end{array}$ & $\begin{array}{l}\text { OXFEASES } \\
\text { (ER } .060)\end{array}$ & $\begin{array}{l}\text { TAXES DTHER } \\
\text { THAN INCEME }\end{array}$ & $\begin{array}{l}\text { DEPRECIATION } \\
\text { (NONOCABH) }\end{array}$ & $\begin{array}{l}\text { POHEF } \\
\text { (ER O. TO) }\end{array}$ & $\begin{array}{l}\text { TCIAL EXFS } \\
\text { EEFCEF TAX } \\
(5+6+7+9+9)\end{array}$ \\
\hline $\begin{array}{l}1970 \\
1940 \\
1031 \\
1982 \\
1983 \\
1994 \\
1905 \\
1990 \\
1987 \\
1989 \\
1989 \\
1990 \\
1091 \\
1992 \\
1993 \\
1094 \\
1995 \\
1996 \\
1997 \\
1998 \\
1999 \\
2000 \\
2001 \\
2002 \\
2003 \\
2004 \\
2005 \\
2006 \\
2007 \\
2009 \\
2009 \\
2010 \\
2011 \\
2012 \\
2013 \\
2014 \\
2015\end{array}$ & $\begin{array}{r}-1310 R \\
-45041 \\
-77851 \\
-12 \times 98 ? \\
-155262 \\
-110754 \\
-24565 \\
0 \\
0 \\
0 \\
0 \\
0 \\
0 \\
0 \\
0 \\
0 \\
0 \\
0 \\
0 \\
0 \\
0 \\
0 \\
0 \\
0 \\
0 \\
0 \\
0 \\
0 \\
0 \\
0 \\
0 \\
0 \\
0 \\
0 \\
0 \\
14121\end{array}$ & $\begin{array}{l}0 \\
0 \\
0 \\
0 \\
0 \\
0 \\
0 \\
0 \\
0 \\
0 \\
0 \\
0 \\
0 \\
0 \\
0 \\
0 \\
0 \\
0 \\
0 \\
0 \\
0 \\
0 \\
0 \\
0 \\
0 \\
0 \\
0 \\
0 \\
0 \\
0 \\
0 \\
0 \\
0 \\
0 \\
0 \\
0 \\
0\end{array}$ & $\begin{array}{l}0 \\
0 \\
0 \\
0 \\
0 \\
0 \\
n \\
n \\
n \\
0 \\
0 \\
0 \\
0 \\
0 \\
0 \\
0 \\
0 \\
0 \\
0 \\
0 \\
0 \\
0 \\
0 \\
0 \\
0 \\
0 \\
0 \\
0 \\
0 \\
0 \\
0 \\
0 \\
0 \\
0 \\
0 \\
0 \\
0\end{array}$ & $\begin{array}{r}-1310 \\
-45041 \\
-77851 \\
-124942 \\
-1552.02 \\
-110754 \\
-24508 \\
0 \\
0 \\
0 \\
0 \\
0 \\
0 \\
0 \\
0 \\
0 \\
0 \\
0 \\
0 \\
0 \\
0 \\
0 \\
0 \\
0 \\
0 \\
0 \\
0 \\
0 \\
0 \\
0 \\
0 \\
0 \\
0 \\
0 \\
0 \\
0 \\
14121\end{array}$ & $\begin{array}{r}0 \\
0 \\
0 \\
0 \\
0 \\
0 \\
0 \\
-23250 \\
-24389 \\
-25584 \\
-26838 \\
-28153 \\
-29533 \\
-30980 \\
-32498 \\
-34090 \\
-35760 \\
-37513 \\
-39351 \\
-41279 \\
-43302 \\
-45423 \\
-47649 \\
-49984 \\
-52433 \\
-55002 \\
-57698 \\
-60525 \\
-63490 \\
-66601 \\
-69865 \\
-73288 \\
-76879 \\
-81649 \\
-84598 \\
-88744 \\
-93092\end{array}$ & $\begin{array}{r}0 \\
0 \\
0 \\
0 \\
0 \\
0 \\
0 \\
-7319 \\
-7758 \\
-8224 \\
-8717 \\
-9240 \\
-9794 \\
-10382 \\
-111005 \\
-11665 \\
-12365 \\
-13107 \\
-13894 \\
-14727 \\
-15611 \\
-16548 \\
-17540 \\
-19593 \\
-19708 \\
-20891 \\
-22144 \\
-23473 \\
-23481 \\
-26374 \\
-219957 \\
-27969 \\
-29634 \\
-31412 \\
-33297 \\
-35295 \\
-37412 \\
-39659\end{array}$ & $\begin{array}{r}-131 \\
-734 \\
-1997 \\
-4105 \\
-7030 \\
-9830 \\
-11380 \\
-111853 \\
-111853 \\
-111853 \\
-111853 \\
-111853 \\
-111853 \\
-11853 \\
-111853 \\
-11853 \\
-11853 \\
-111853 \\
-11853 \\
-111853 \\
-111853 \\
-11853 \\
-111853 \\
-11853 \\
-111853 \\
-111853 \\
-111853 \\
-111853 \\
-111853 \\
-111853 \\
-111853 \\
-111853 \\
-111853 \\
-111853 \\
-11853 \\
-111853 \\
-11853\end{array}$ & $\begin{array}{r} \\
0 \\
0 \\
0 \\
0 \\
0 \\
0 \\
0 \\
-49375 \\
-44986 \\
-42869 \\
-40778 \\
-38687 \\
-36596 \\
-34504 \\
-37413 \\
-30327 \\
-28231 \\
-26140 \\
-24049 \\
-21957 \\
-10866 \\
-17775 \\
-15684 \\
-13593 \\
-11501 \\
-9410 \\
-7319 \\
-5228 \\
-3137 \\
-119 \\
-1046 \\
0 \\
0\end{array}$ & $\begin{array}{r}0 \\
0 \\
0 \\
0 \\
0 \\
0 \\
0 \\
528,7 \\
56514 \\
60470 \\
64703 \\
69232 \\
74079 \\
79244 \\
80813 \\
90749 \\
97102 \\
103899 \\
111172 \\
112954 \\
127281 \\
136100 \\
145724 \\
155920 \\
166899 \\
178518 \\
191094 \\
204395 \\
218692 \\
234001 \\
250391 \\
267907 \\
286061 \\
306797 \\
321198 \\
351172 \\
375754\end{array}$ & $\begin{array}{r}-131 \\
-734 \\
-1997 \\
-4105 \\
-7030 \\
-9830 \\
-11380 \\
-38940 \\
-32473 \\
-28060 \\
-23483 \\
-18701 \\
-13698 \\
-8450 \\
-6957 \\
2817 \\
8891 \\
15285 \\
22025 \\
29134 \\
36648 \\
44590 \\
52996 \\
61901 \\
71342 \\
81340 \\
91999 \\
103305 \\
115329 \\
129125 \\
140704 \\
153130 \\
165515 \\
180929 \\
195450 \\
213161 \\
231150\end{array}$ \\
\hline
\end{tabular}


FRRIJECT COST ANALLYSIS

PAGE 2 OF 2

i:P LNE:LIAL CASH REQUIKFMENTS

PRCJECT: CRANGE COGENEQATIOE

C.ASE : WTRR

oriz fuel cist

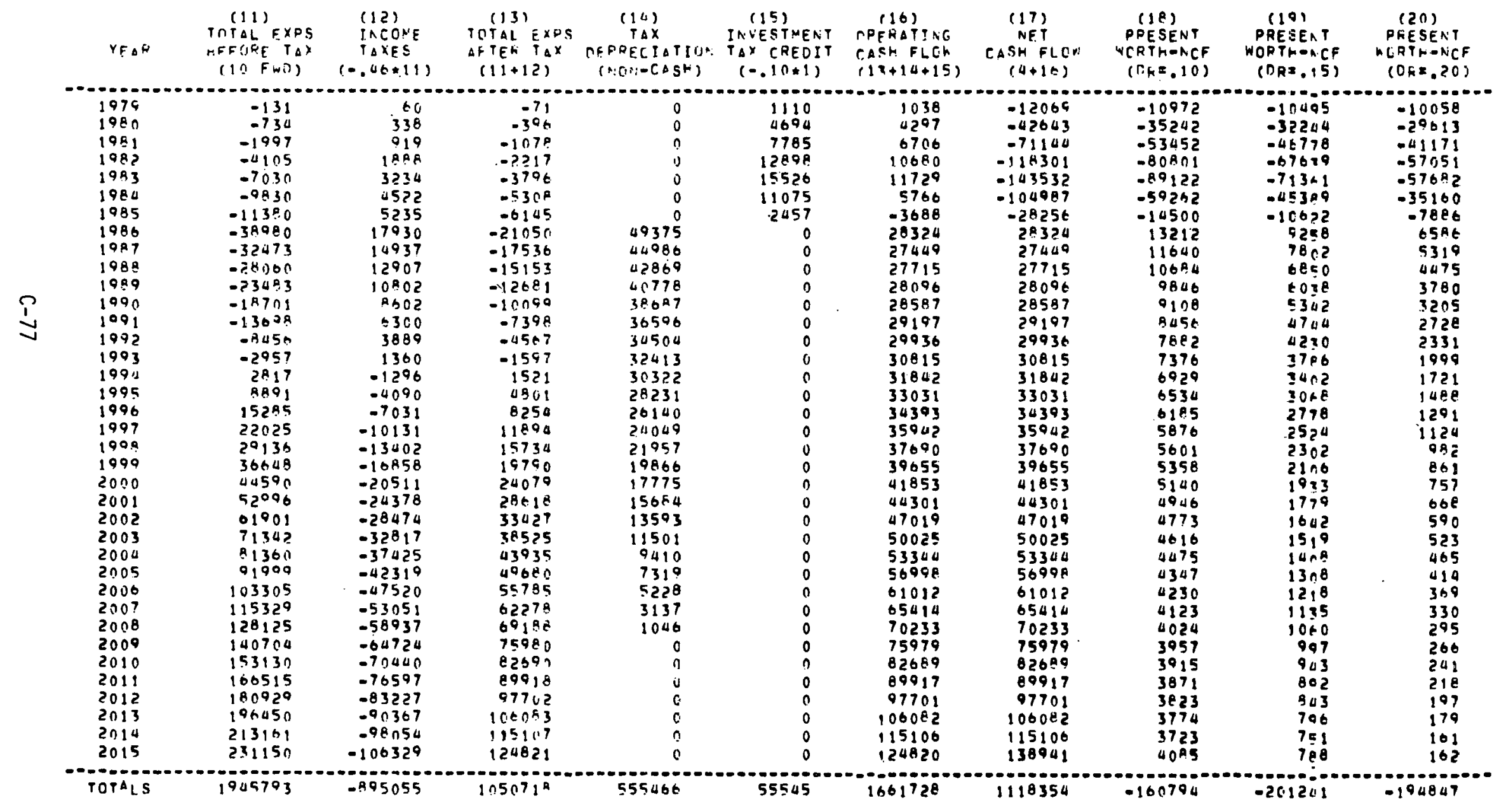


PQOJECT: OHA GEE CUTEREHATION

CASE : ATSO

$$
\text { ICOR F(IFL COS }
$$

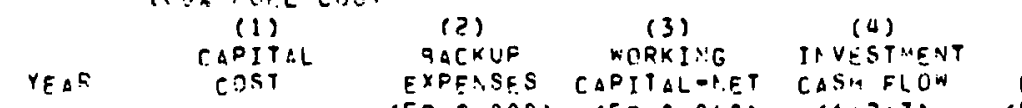
EXPEASES CAPITAL-TET CASIALLO

(6)

(7)

OTHER GPEK - AXES OTHEK

(0)

CREDIT (10)

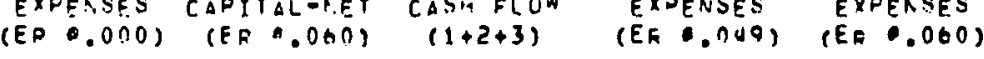

- HaA TnCONE DEPRECIATION

POHE 
PROIFCT: RNANGE CrITEMAFFATIOU

CASE : MIGR

luUz fuel cust

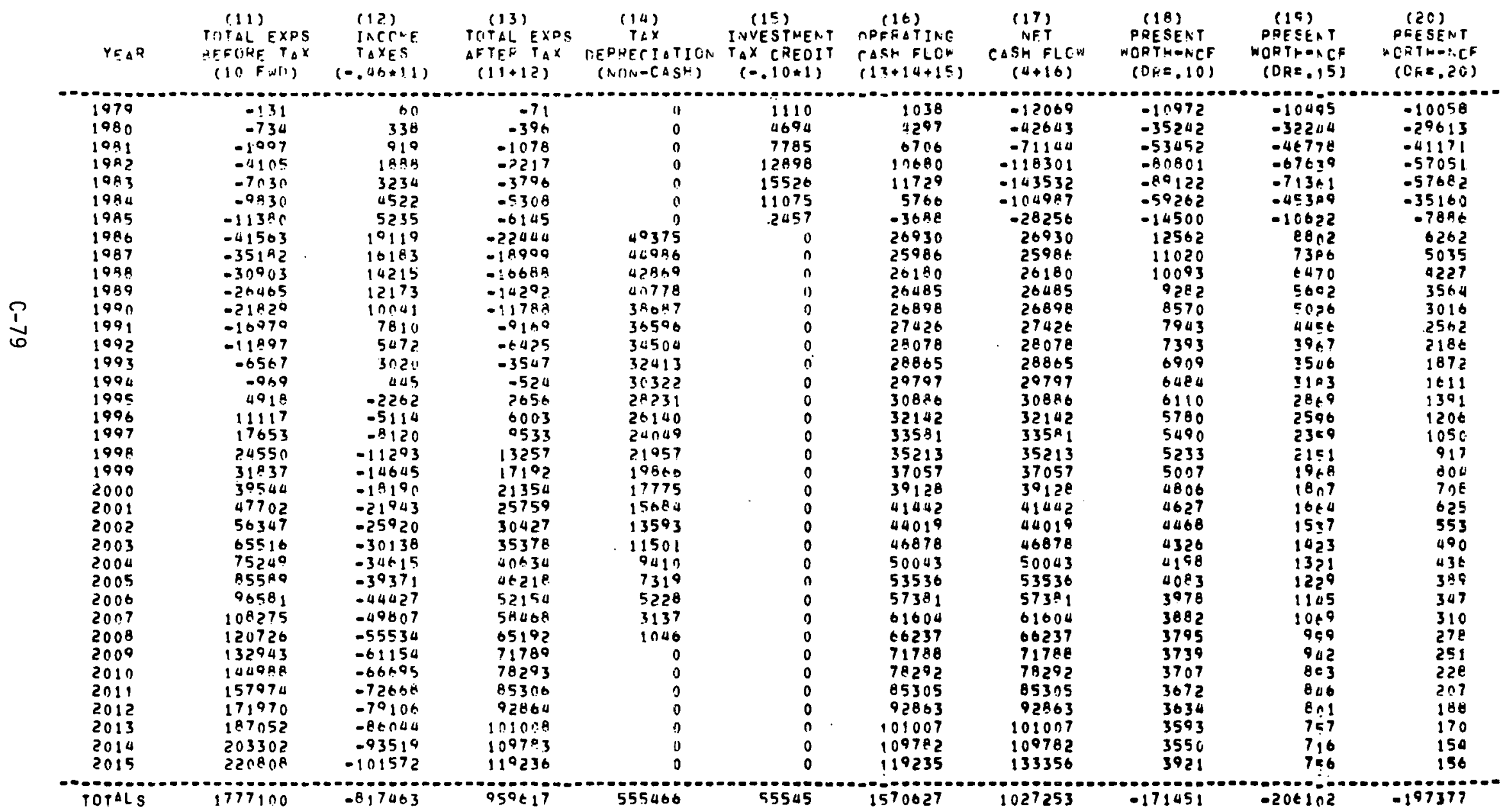


BPNJECT COST ANALYSIS

PAGE I GF 2

UF ANAUII CAST REQUIRFMEATS

PREJECT: ORARTE COCEREPATILO

COSE \& HTSE

$$
\text { TSOE FUEL COST }
$$

(1) (द)

(5) (3)

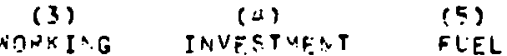

FIEL

(i)

(b) (

(B) (E) (10) EXPENSES THA INCCTE DEPRECIATICA POHER PEFCEE TAX

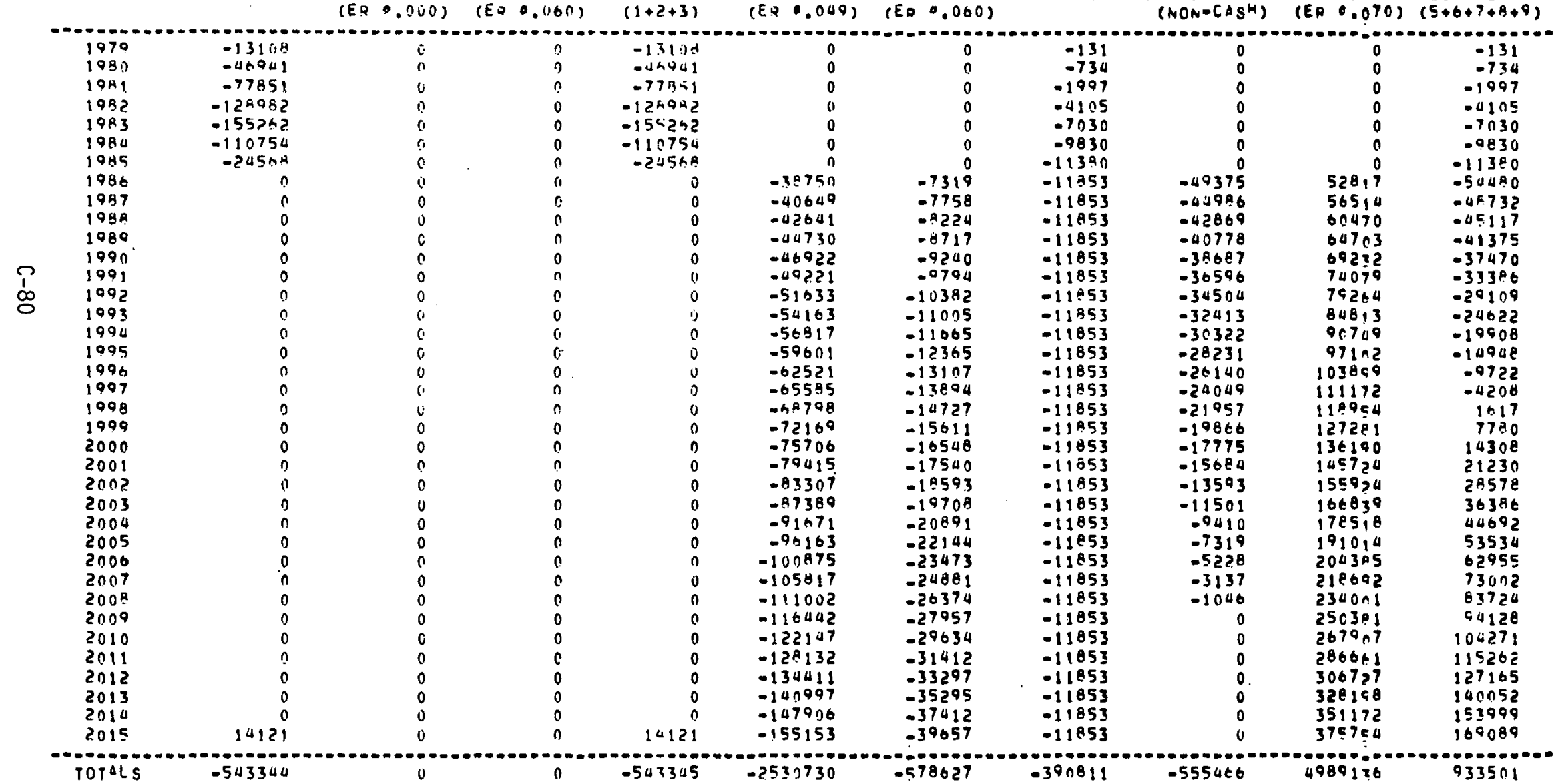


TE ANAUAL CASH PERLIREREATS

PROJFCT: TPANTEE CIIGEF:DOATICA.

CASE : HTGR

$$
\text { ISOR FIFL Crist }
$$

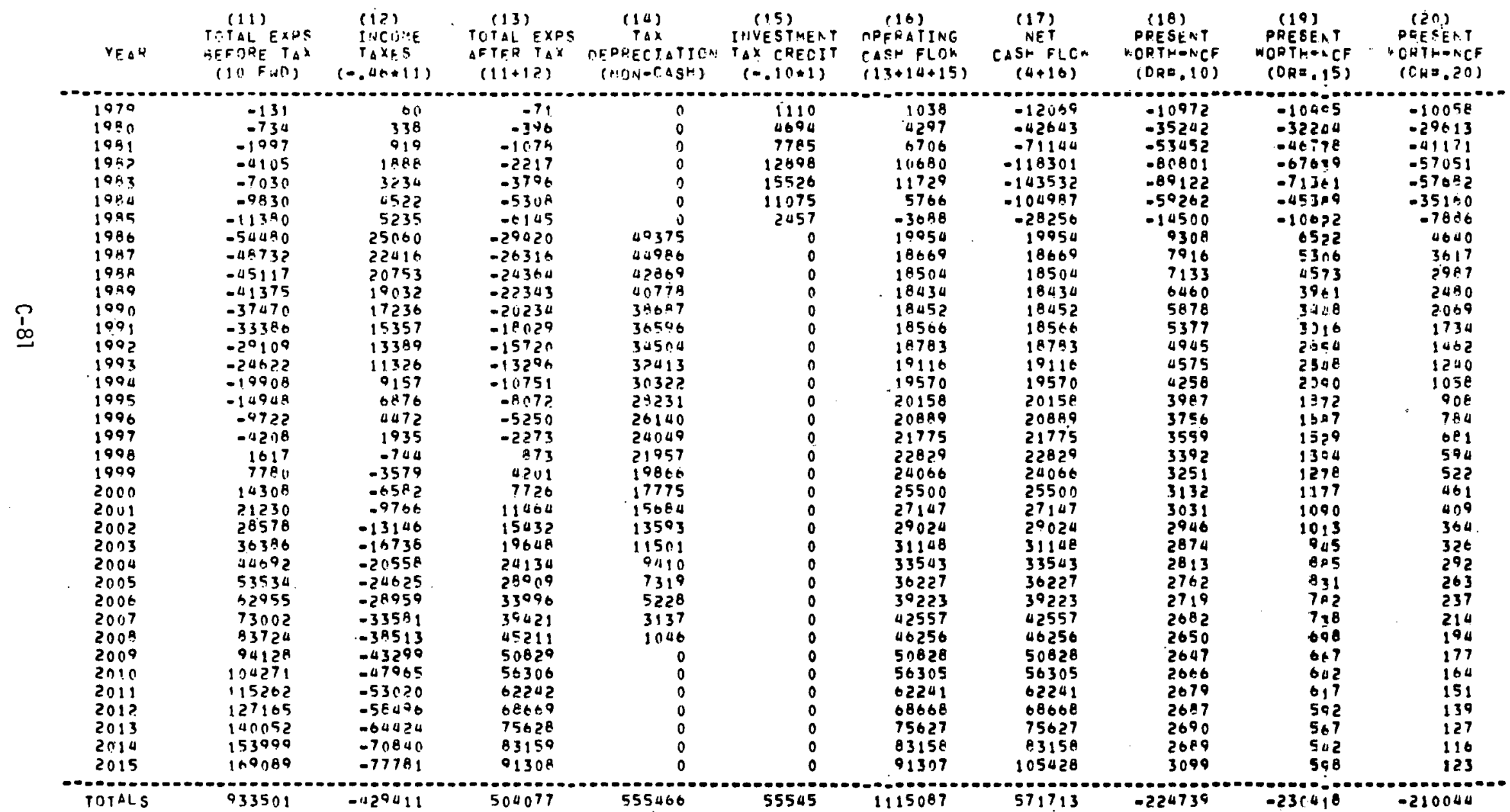


PHEJECT COST ANALYSIS

OF ANNUAL CAST REQUTREMEATS

PROJECT: IJKANGE COGENERAITON

CASE \& MTGP SOUZ FUFL COST

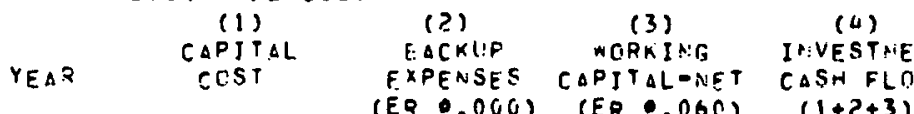

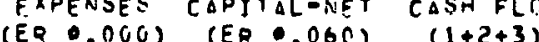

TTER

$(8$.

$(10)$

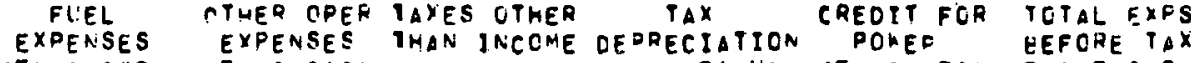
(ER .049$) \quad\left(E_{D} \cdot 0.060\right)$

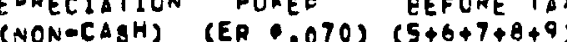

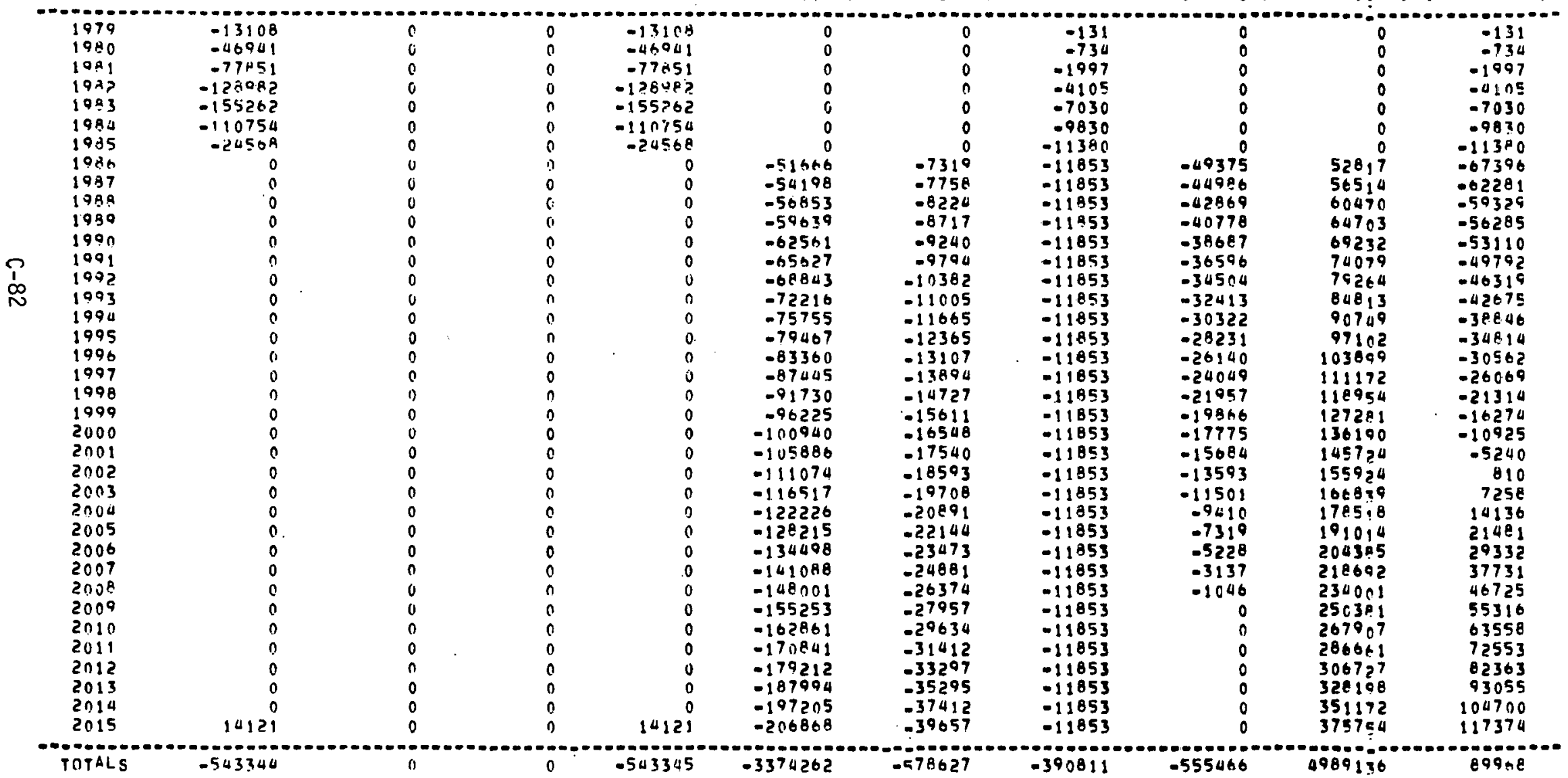


DPR.JECT COST ANALYSIS

(I) AIFALUL CASH REQUIHFMFATS

PAOJECT: URANGE CORENEHATION

CASE : HTGE

? HTSE FIELL COST

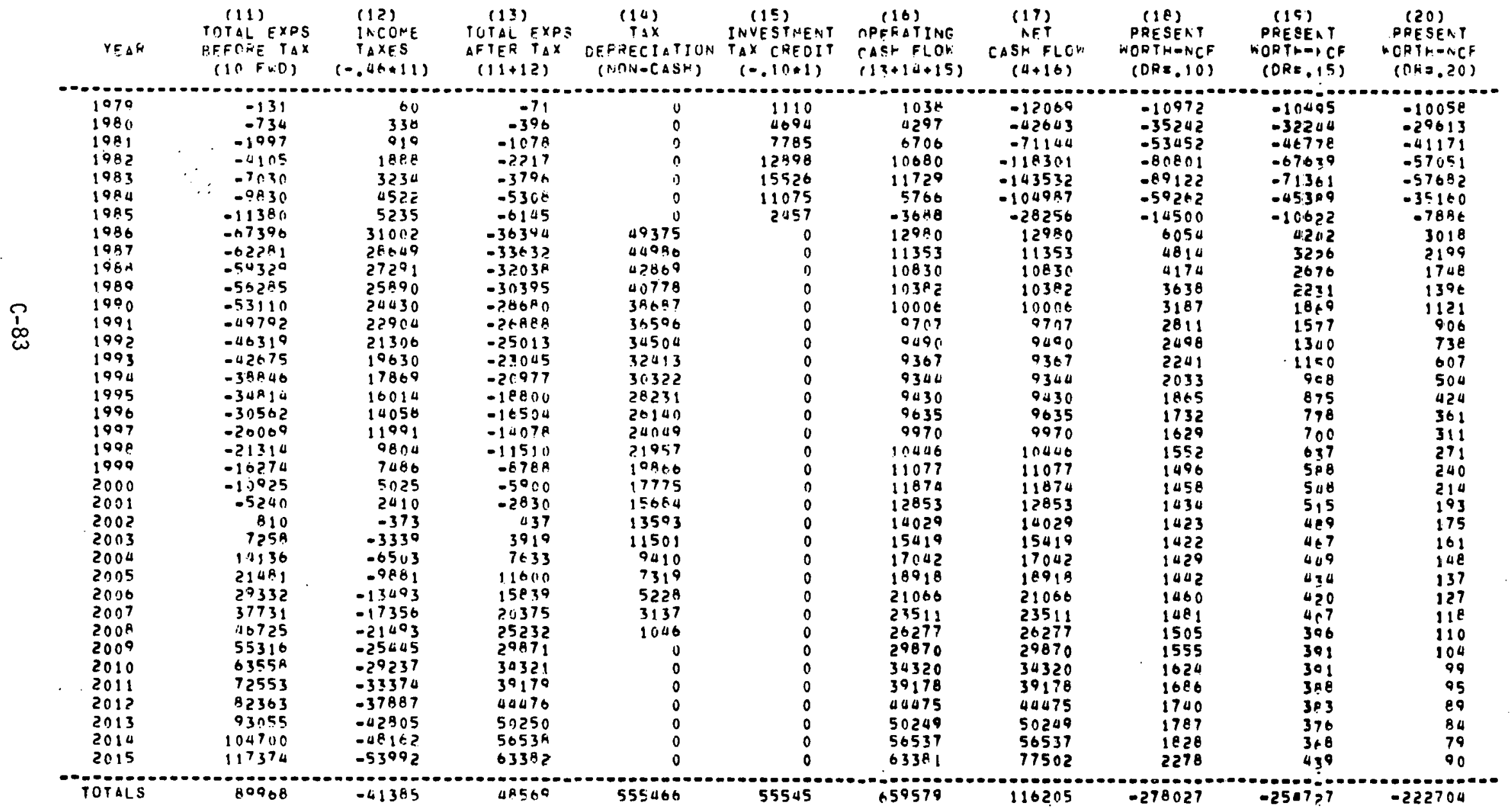


PNOJECT: CQLNAE CUGENEFUTION

CASE : COSS

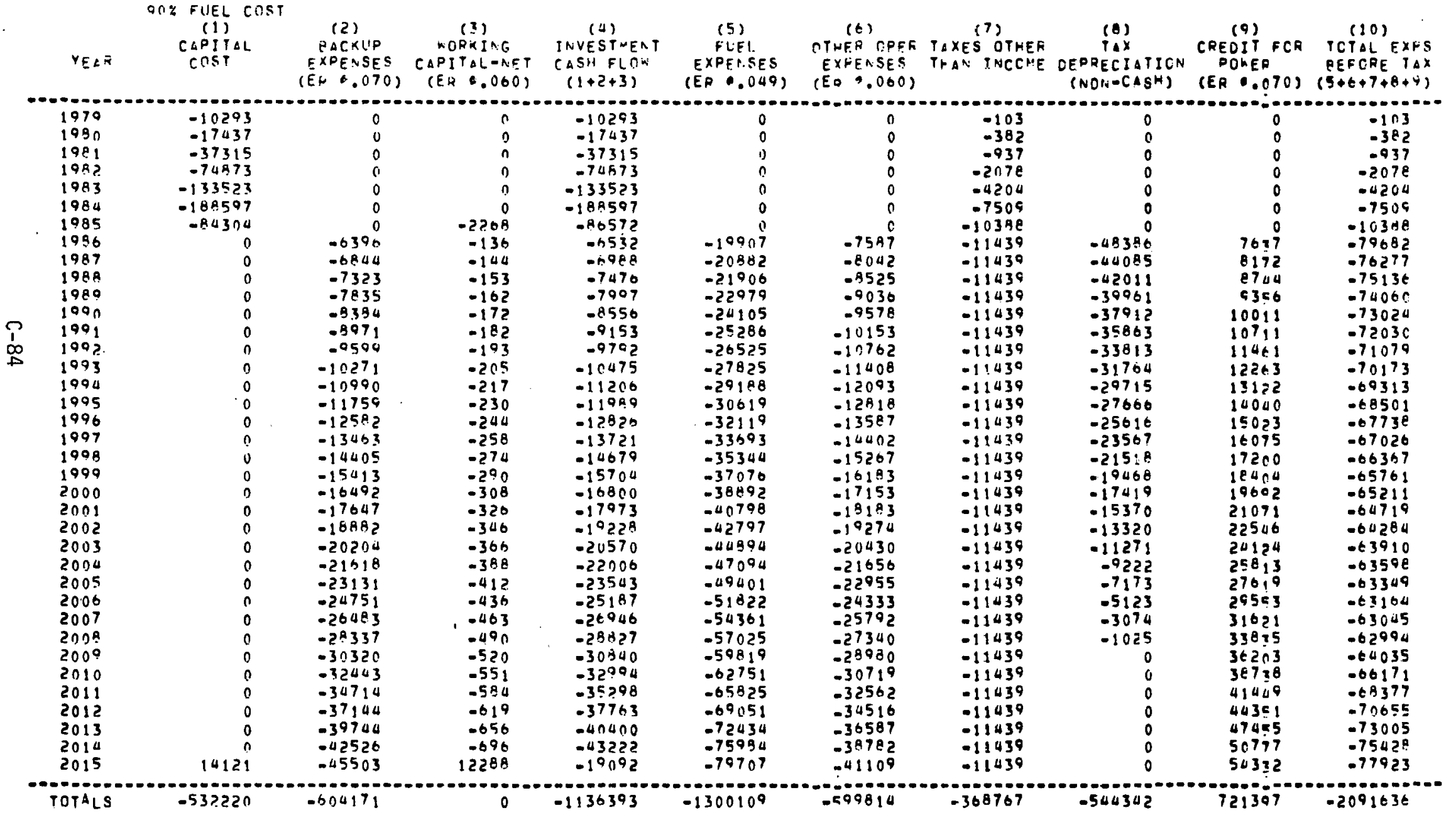


PRTIJFCT COST ANALYSIS

PAGE 2 OF 2

OF ANAIAL CEST REQUIREMENTS

PROJECT: OPANGE COSENENATIUL

CASF : C:SS

Ci) FIJFL COST

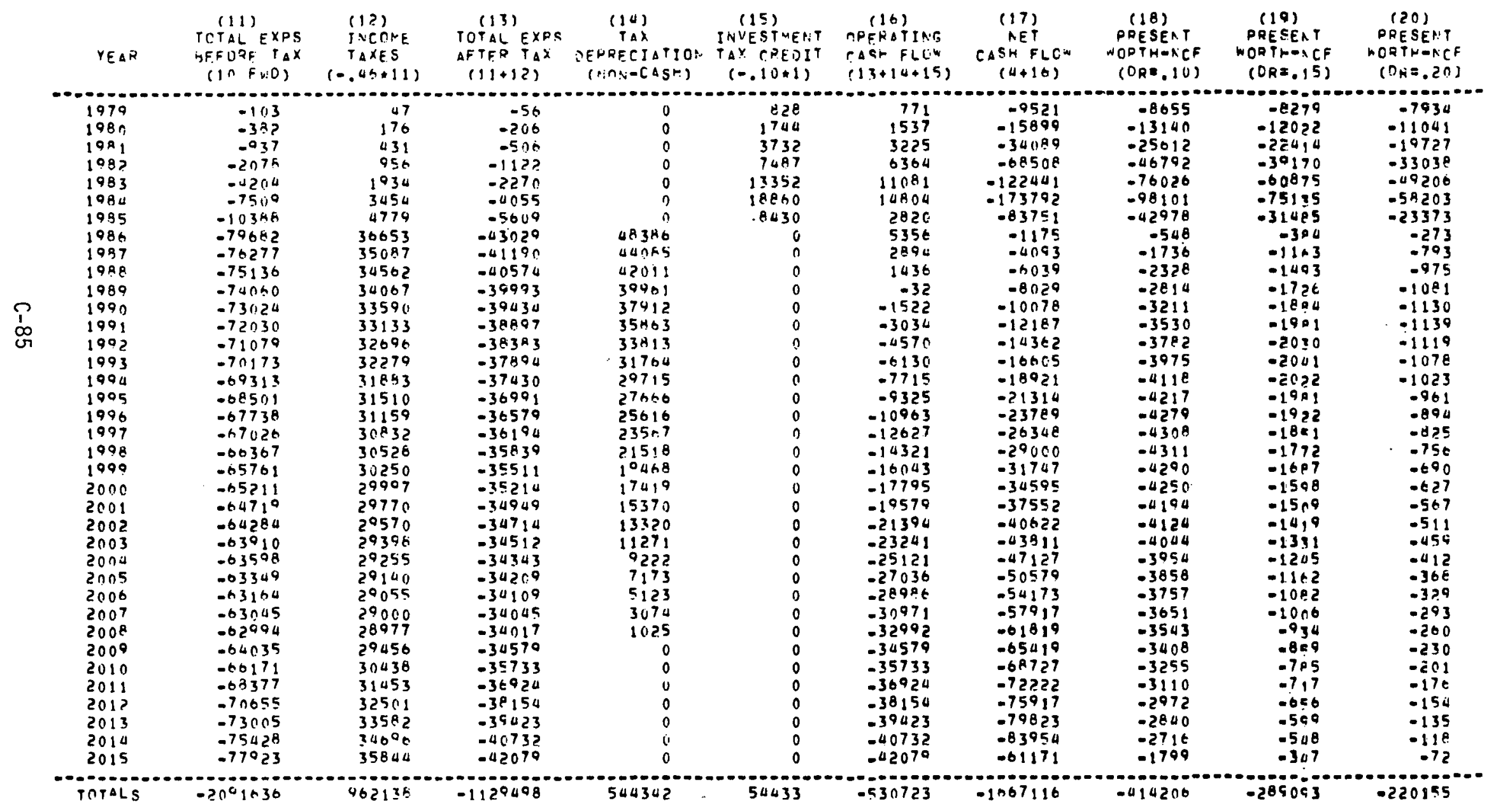


PROJECT: CFATIFE COGEMEFAIION

CASE : CHSS

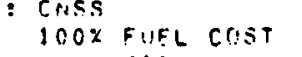

FACKUP WIRKING

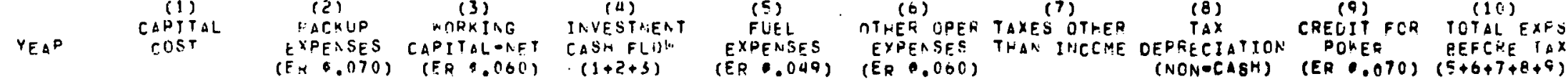

(A)

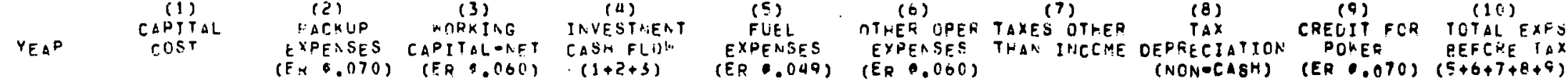

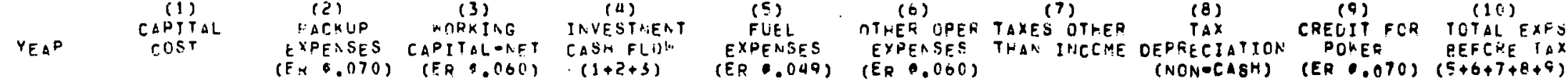

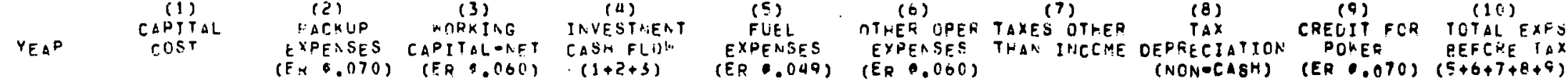
(1+2+3) (ER 0.049$)\left(\varepsilon_{P} 0.000\right)$

\begin{tabular}{|c|c|c|c|c|c|c|c|c|c|c|}
\hline 1979 & -10273 & 0 & 0 & -10203 & 0 & 0 & -103 & 0 & 0 & -103 \\
\hline 1940 & -17437 & i) & !) & -17437 & 0 & 0 & -382 & 0 & 0 & -382 \\
\hline 1081 & -37315 & 17 & 0 & -37315 & 0 & 0 & -037 & 0 & 0 & .937 \\
\hline 1987 & -74873 & 0 & 0 & .74873 & 0 & 0 & -2078 & 0 & 0 & -2078 \\
\hline 1993 & -133523 & 0 & 0 & -133523 & 0 & 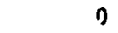 & -4204 & 0 & 0 & -4204 \\
\hline 1984 & $-18<5007$ & 0 & $n$ & -188597 & 0 & 0 & .7509 & 0 & 0 & .7509 \\
\hline 1985 & -64304 & 0 & -2268 & -80572 & i) & 0 & -10380 & 0 & 0 & $-1038 \mathrm{e}$ \\
\hline $199 \mathrm{~A}$ & 0 & -71 ij & -136 & -72.13 & -22119 & -7587 & -11439 & -48386 & 7687 & -81894 \\
\hline 1987 & 0 & .76010 & $-1 \Delta 4$ & $.77 \mathrm{do}$ & -23203 & -9042 & -11439 & $-\angle U O E S$ & 8172 & .78597 \\
\hline 1988 & 0 & -8137 & -153 & -8240 & - 24340 & -8525 & -11430 & -42011 & 8704 & .77570 \\
\hline 1989 & 0 & $-87 j 6$ & -102 & $-8 B 0^{\circ}$ & -25532 & -9036 & -11439 & -30961 & 9356 & -76613 \\
\hline 1990 & 0 & -9316 & -172 & -9488 & -26784 & -9578 & -11439 & -37912 & $100 i 1$ & .75702 \\
\hline 1991 & a & $-90 \mathrm{ng}$ & -182 & -10150 & -28096 & -10153 & -11439 & -35863 & 10711 & .74839 \\
\hline 1992 & 0 & -10000 & -193 & -10850 & -29473 & .10762 & -11439 & -33813 & 11461 & .74026 \\
\hline 1093 & 0 & -11412 & -205 & -11617 & -30917 & -11408 & -11439 & -31704 & $122+3$ & -73264 \\
\hline 1904 & 0 & -12211 & -217 & -12428 & -32432 & -12003 & $-11<39$ & -29715 & 13122 & .72556 \\
\hline 1095 & $n$ & -13000 & -230 & -13206 & -34021 & -12818 & -11439 & $-276 A 6$ & 14000 & .71903 \\
\hline $\begin{array}{l}1096 \\
1997\end{array}$ & 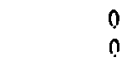 & $\begin{array}{l}-13951 \\
-14059\end{array}$ & $\begin{array}{l}-244 \\
-258\end{array}$ & $\begin{array}{l}-14234 \\
-15218\end{array}$ & $\begin{array}{l}-35688 \\
-37437\end{array}$ & $\begin{array}{l}-13587 \\
-14402\end{array}$ & $\begin{array}{l}-11439 \\
-11039\end{array}$ & $\begin{array}{l}-25616 \\
-23567\end{array}$ & $\begin{array}{l}1 \leq 023 \\
16075\end{array}$ & $\begin{array}{l}-71307 \\
.70770\end{array}$ \\
\hline 1998 & 0 & -16006 & -274 & $-162 \% 0$ & -39271 & $\begin{array}{r}-15267 \\
-15\end{array}$ & -11439 & $\begin{array}{l}-21518 \\
-\end{array}$ & 17200 & .70294 \\
\hline 1999 & 0 & -17127 & -290 & -17417 & -41195 & $-161^{83}$ & -11439 & -19468 & 18404 & .69881 \\
\hline 2000 & $?$ & -18326 & -308 & -18633 & -43214 & -17153 & -11339 & -17419 & 19642 & .69533 \\
\hline 2001 & 0 & -19600 & -326 & -10935 & -45331 & -18.183 & -11439 & -15370 & 21071 & -69252 \\
\hline 2002 & 0 & -20981 & .346 & -21327 & -47552 & -19274 & -11439 & -13320 & 225116 & .69040 \\
\hline 2003 & 0 & -22450 & .366 & $-22^{A_{10}}$ & -49823 & -20430 & -11430 & -11271 & 20120 & .08899 \\
\hline 2004 & $n$ & -24021 & -388 & $-24 \Delta 10$ & -52327 & -21650 & -11439 & 9222 & $258_{13}$ & .69831 \\
\hline 2005 & 0 & -25703 & -412 & $-2 b 114$ & -54801 & -22955 & -11439 & -7173 & 270,9 & -69838 \\
\hline 2006 & 0 & -27502 & .436 & -27938 & -57580 & -24333 & -11439 & -5123 & $295=3$ & .68922 \\
\hline 2007 & 0 & $-2^{0} 427$ & -463 & $-2^{0} 800$ & -60402 & .25702 & -12439 & -3074 & $316 ? 1$ & .69086 \\
\hline $200 \%$ & 0 & -31087 & .490 & -31977 & -63362 & -27340 & -11439 & -1025 & $338 \div 5$ & .69330 \\
\hline 2009 & 0 & -33691 & -520 & $-342: 1$ & -6640.6 & $-289 A_{0}$ & -11430 & 0 & $3 \in 203$ & -706 . \\
\hline 2010 & 0 & $-36 \cap 49$ & -551 & -366000 & $-697 \geqslant 3$ & -30719 & -11439 & 0 & $387,3^{\circ}$ & .73144 \\
\hline 2011 & 0 & -38573 & .584 & -39157 & .73100 & -32562 & -11439 & 0 & $414<9$ & .75692 \\
\hline 2012 & 0 & .41273 & .619 & -41802 & .76723 & -34516 & -11439 & 0 & 44351 & .78324 \\
\hline 2013 & 0 & -44162 & -656 & 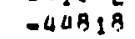 & $-8 \cap 483$ & -36587 & .11439 & 0 & 47465 & .81054 \\
\hline 2014 & 0 & -47253 & -696 & -47049 & -84427 & .38782 & -11439 & 0 & 50777 & -83871 \\
\hline 2015 & 14121 & $-505 \mathrm{hl}$ & 12288 & -24151 & .88563 & -41109 & -11439 & 0 & 54332 & .86780 \\
\hline
\end{tabular}


PRIDECT COST ANALYSIS

OF ANAUAL CGSH REQUIREMENTS

PROJECT: ORANGE COGEAEHATION

CASE I CNSS

IOOX FIJEL COST

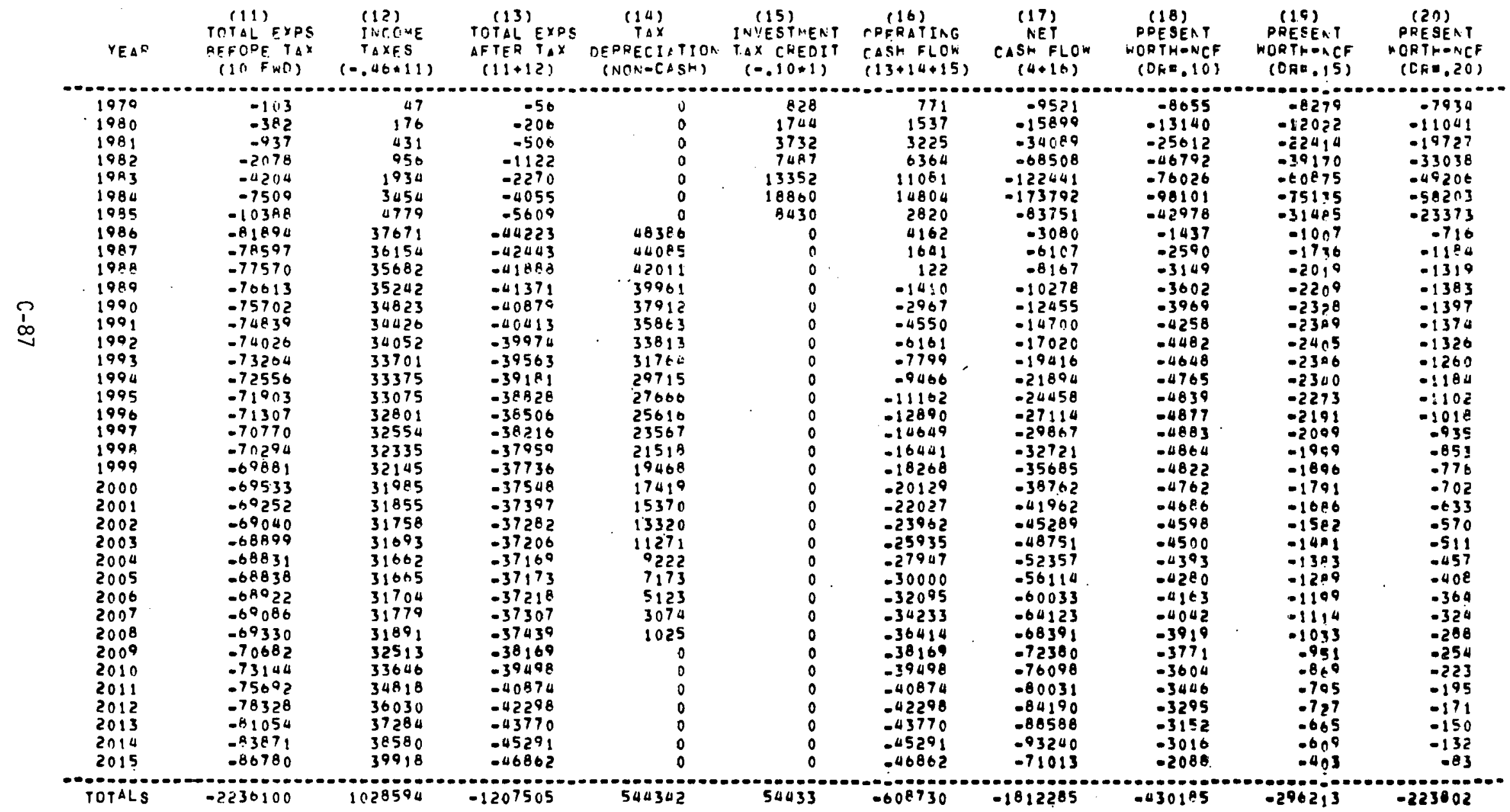


PROJECT COST ANALYSIS

page \& of 2

OF ANNIJAL CASH PEQUIREMENTS

PRCJECT: UHAHGE CIGENERATIOR

CASE: CHSS

$\begin{aligned} \text { : CNSS } & \text { ISOX FUEL COST }\end{aligned}$

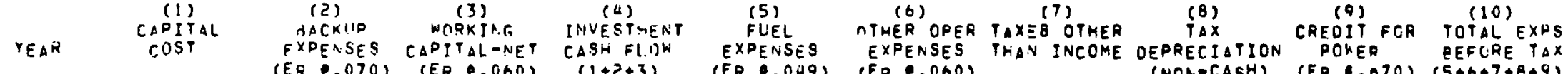

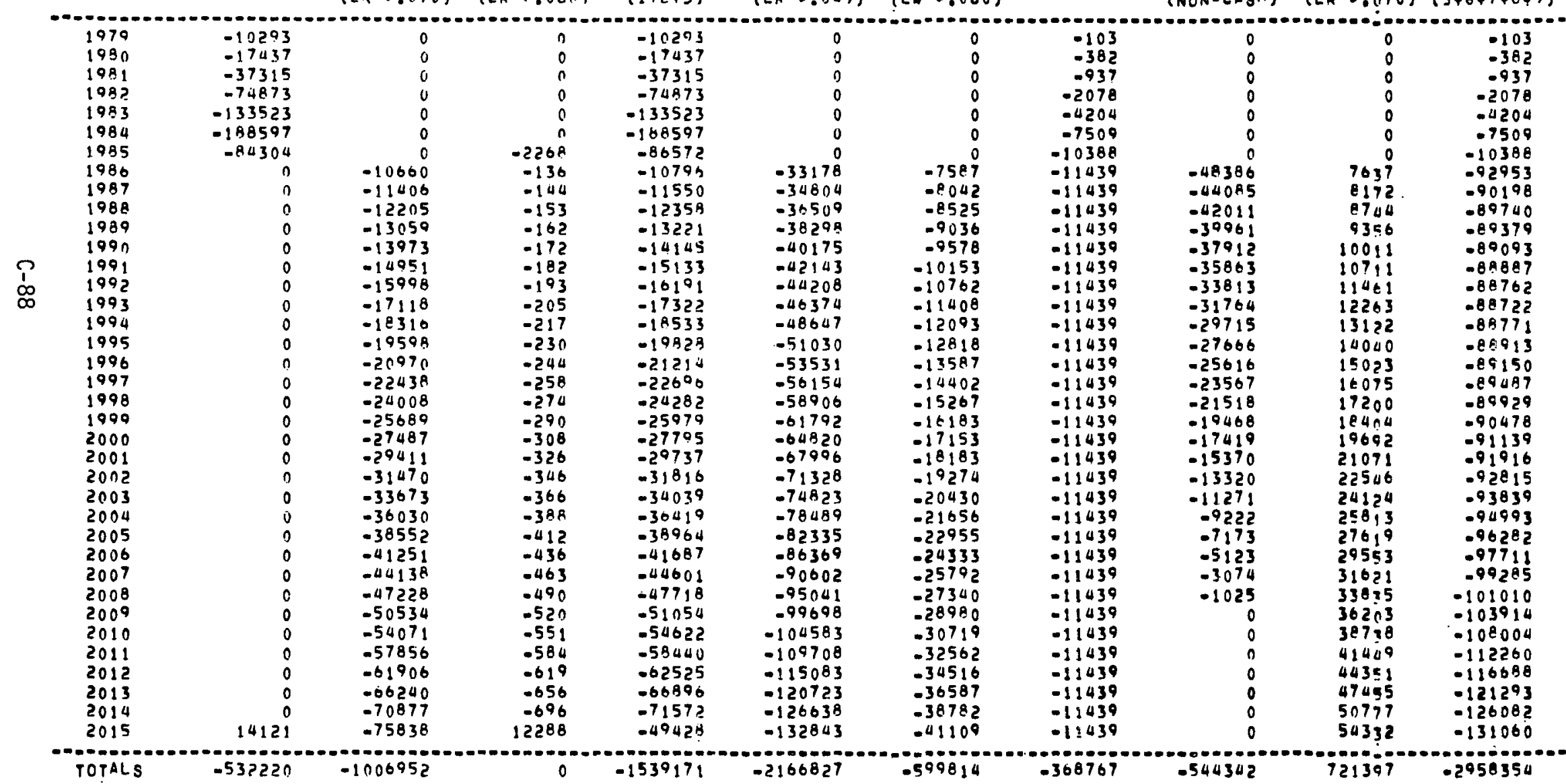


FRTIJECT COST ANALYSIS

PAGE 2 OF 2

OF ANNUAL CASH REOUIREMENTS

DROJECT: ORAHTEE COGENENATIOA CASE I CASS

15OX FUEL rost

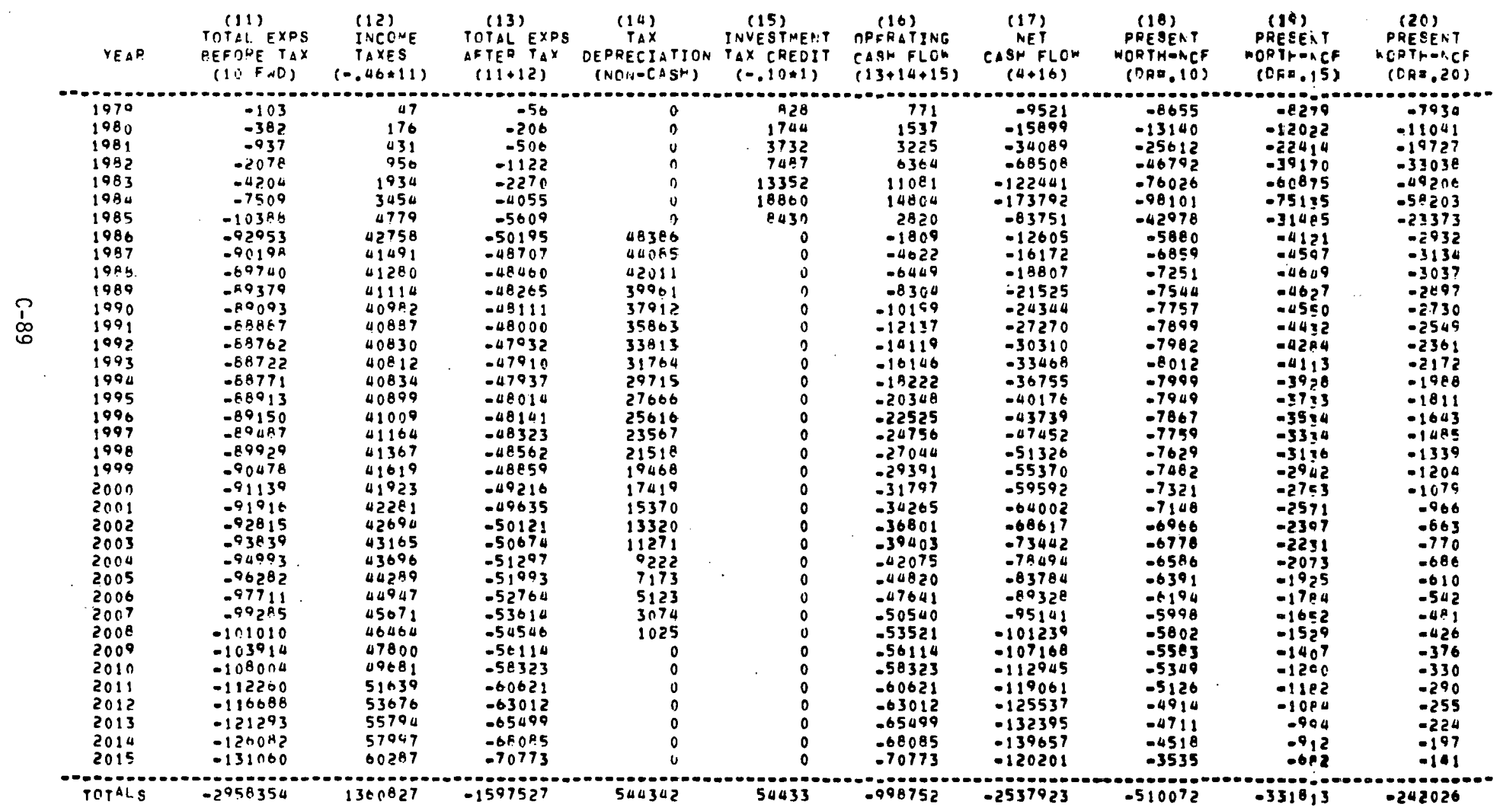


PRTIJECTI ORAROE CUGEREOATIUN

CASE : CHSS

$$
\text { ?ONY FLEL COST }
$$

$$
\begin{gathered}
\text { CPI } \\
\text { YEAR COPITAL }
\end{gathered}
$$

(3) (4) (5) (6)
IAVESTUEN

(6)

(7)

(e)
TaX
(a)

(c)

(10)

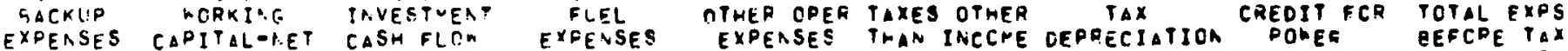

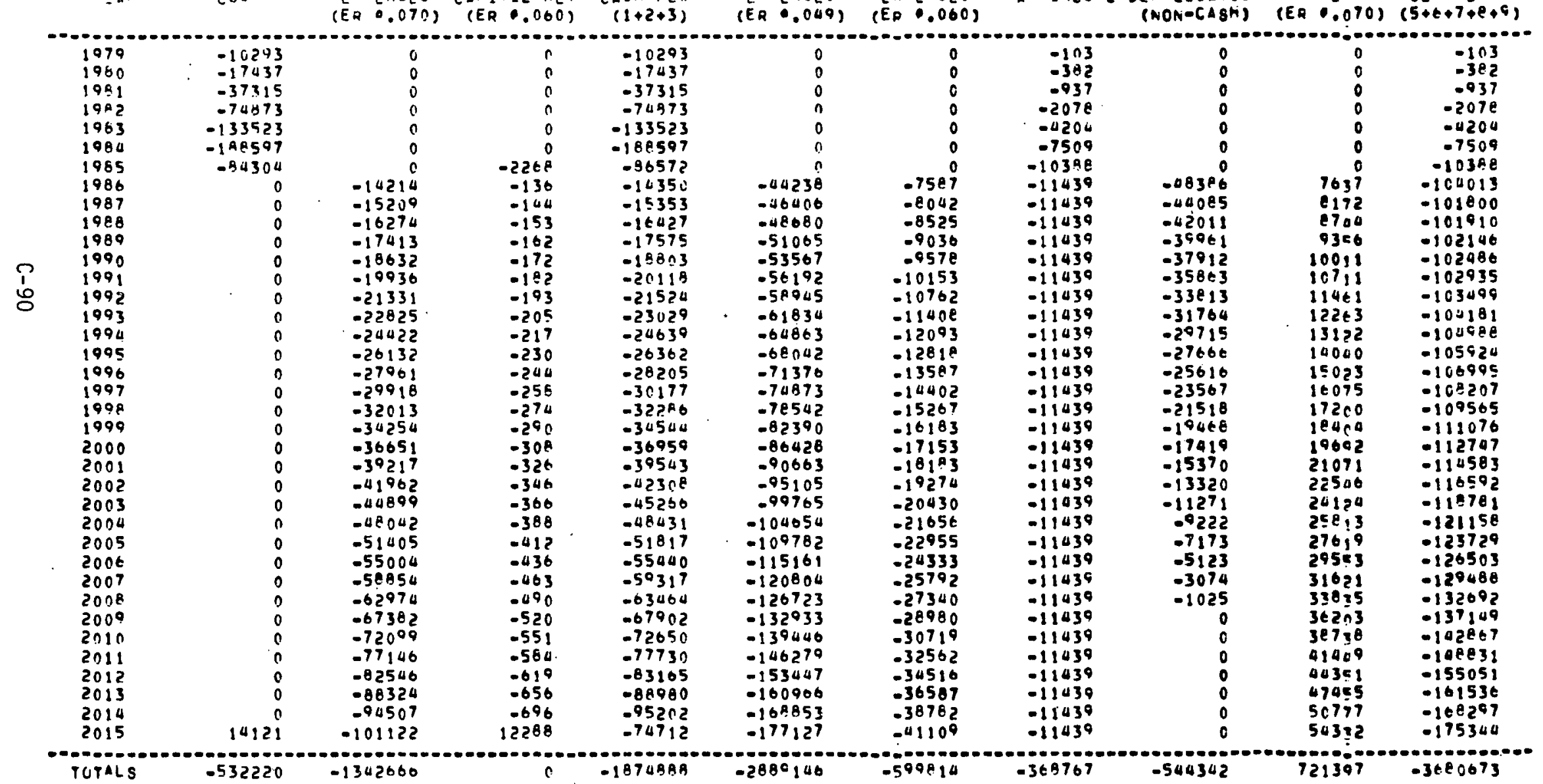


PROJECT COST ANALYSIS

PAGE 2 OF 2

OF ANAUAL CASH REOLIRFMENTS

PROJECT: ORANGE COCIENERATION

CASE I CHSS

$$
\text { ZONX FUEL COST }
$$

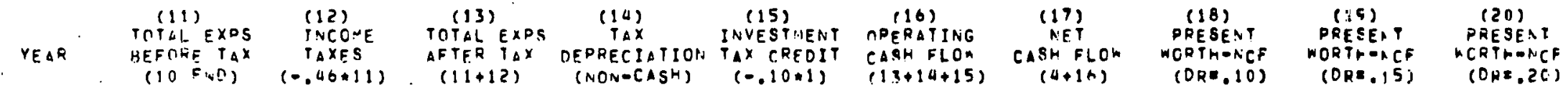

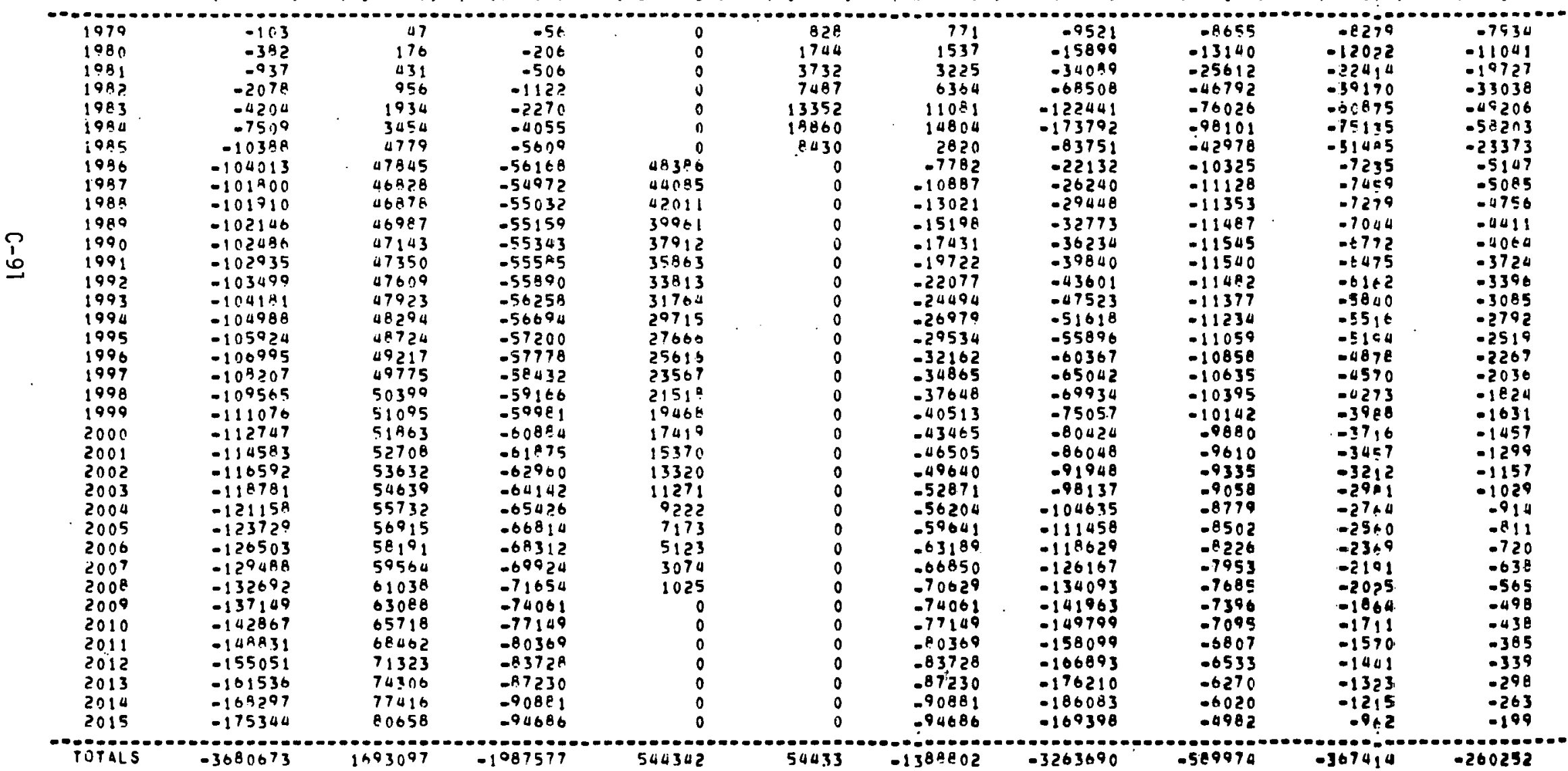


PROJECI: OHANGE COGENEKAIICA

CASE EXIST. PLANTS

$$
\begin{aligned}
& \text { EXIST PLANTS } \\
& \text { DOX FLIEL COST }
\end{aligned}
$$
CAPITAL (I) BACK

(द) (3) (4)

(4)

(5)

(5)
FUEL
XPENSES TTER OPEF TAXES OTHER TAX

(8) (o)

(9) TOR TOPAL (10)

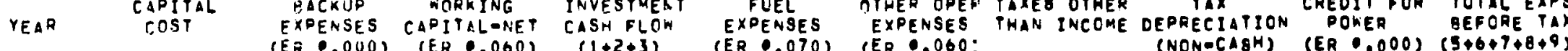

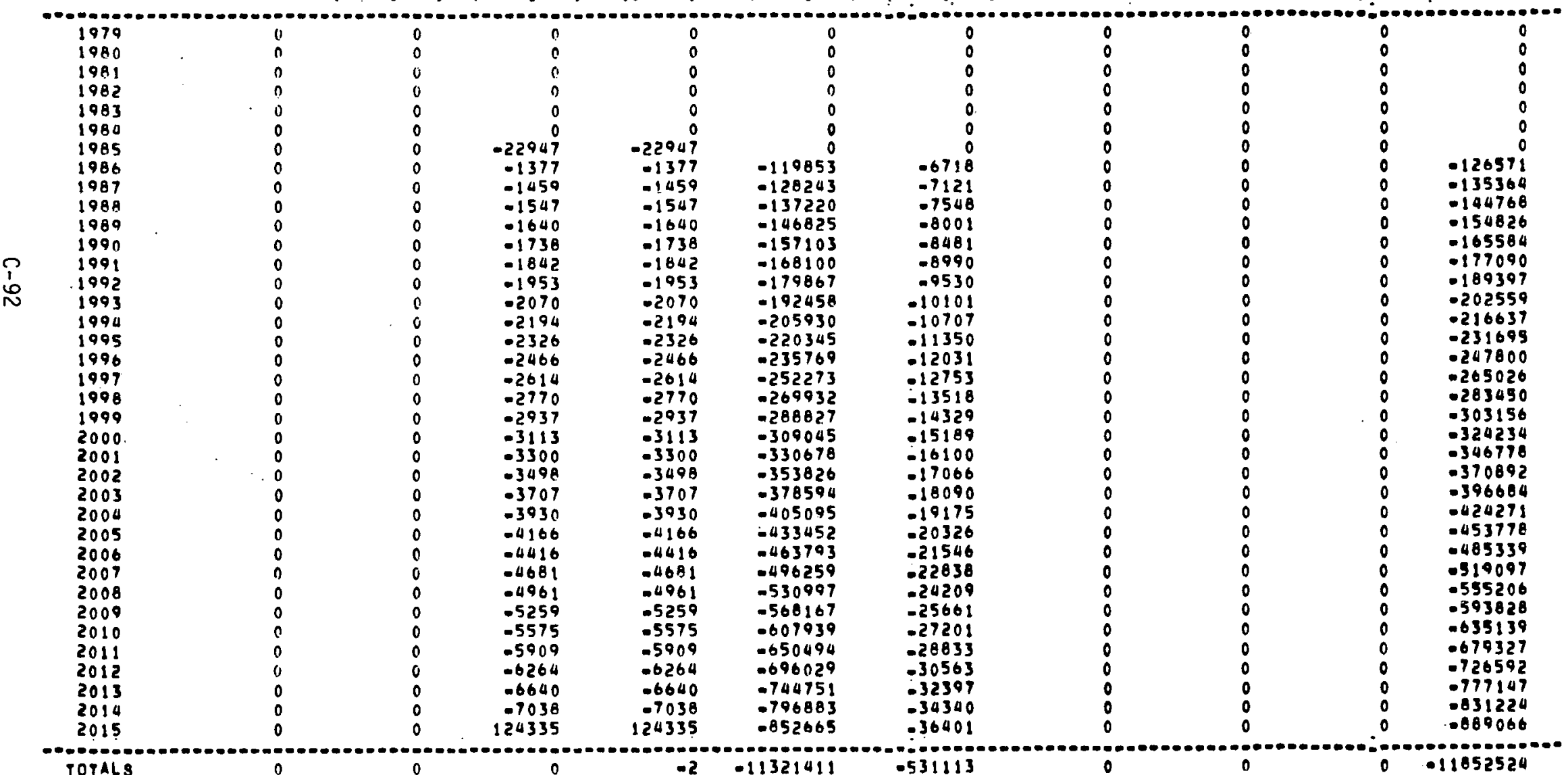


PROJECT COST ANALYSIS

OF. ANAUAL CASH REQUIREMENTS

PROJECTI ORAHGE COGENERATION

CASE EXIST. PLANT

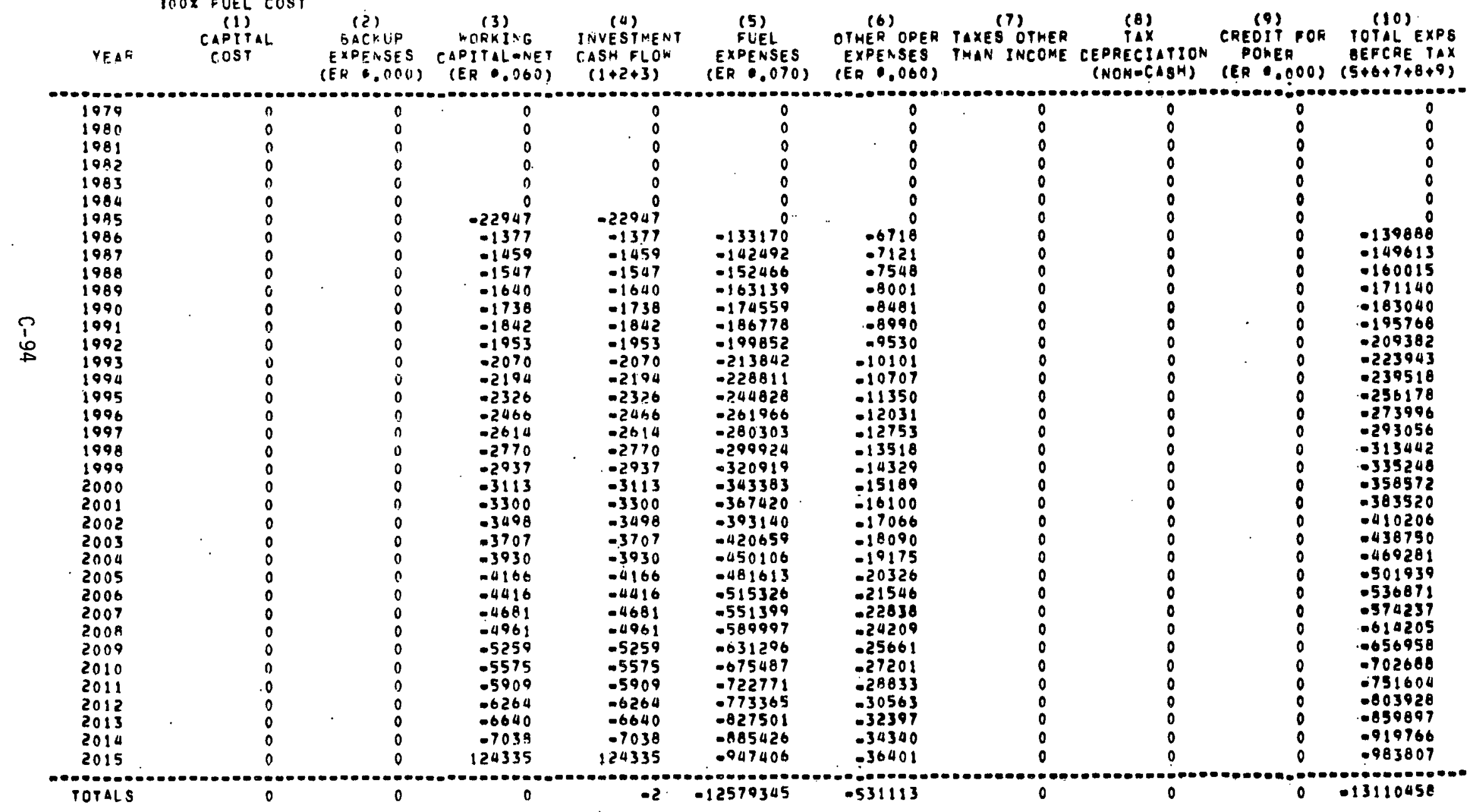


PROJECT ORANGE CUGENERATION

CASE IEXIST PLANT
ICOX FIJEL COST

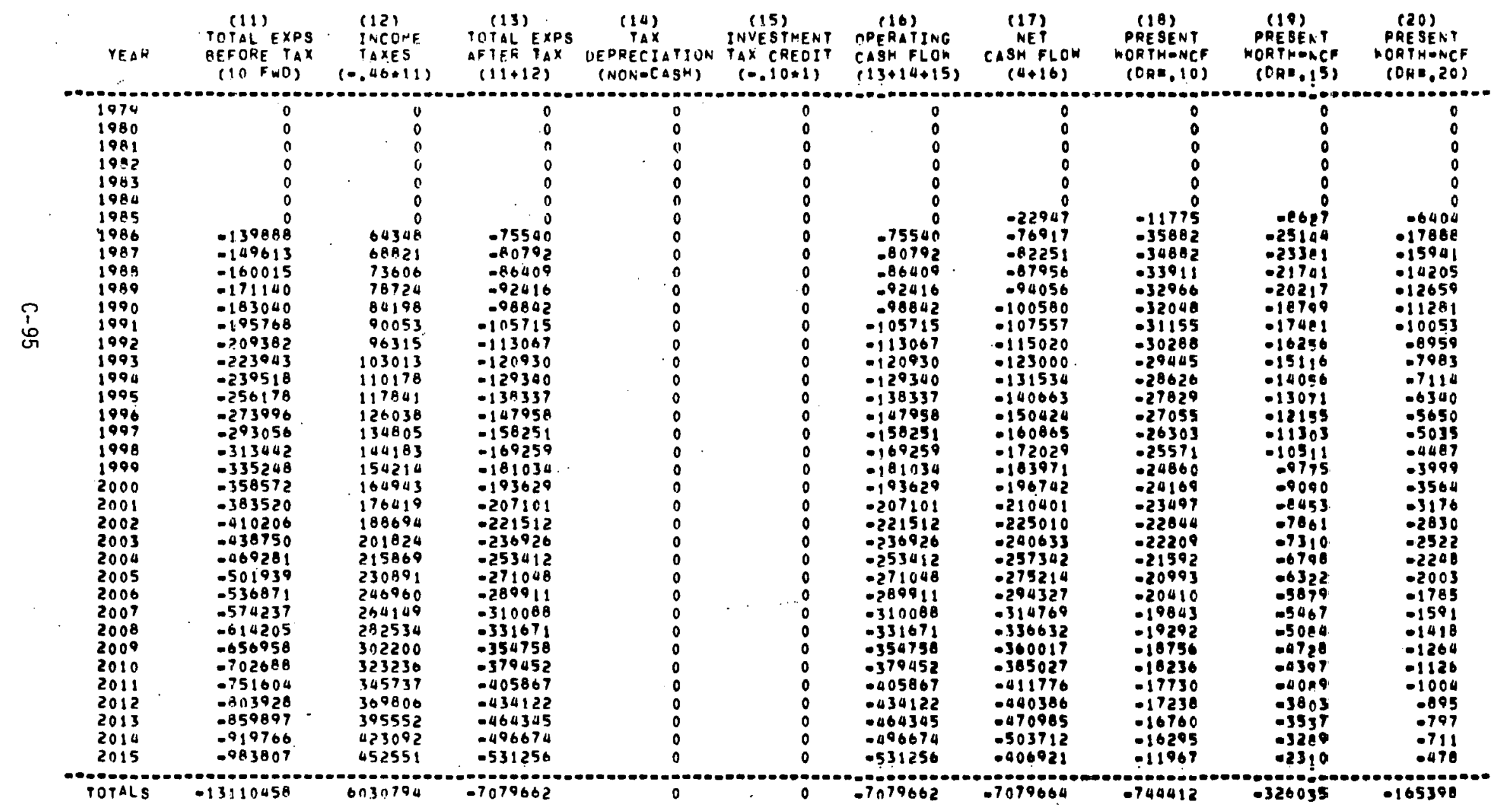


PROJECTI ORARGE COIEENERATITA

CASE IEXIST PLANTS
ISOE FUEL COST

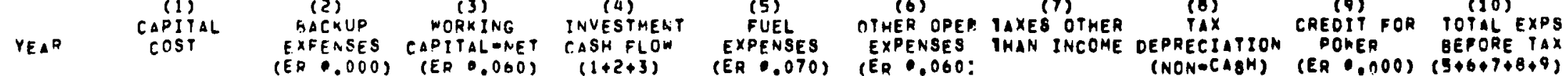

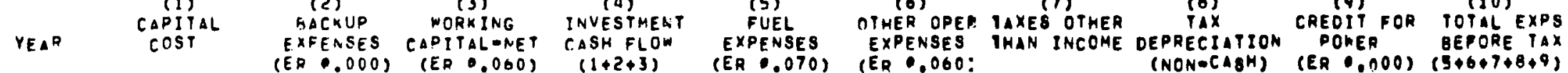

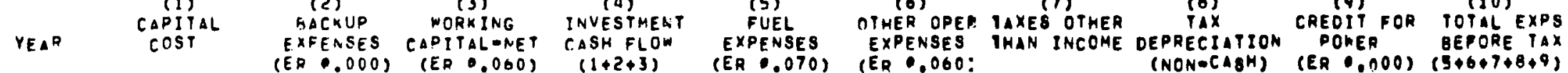

(6)

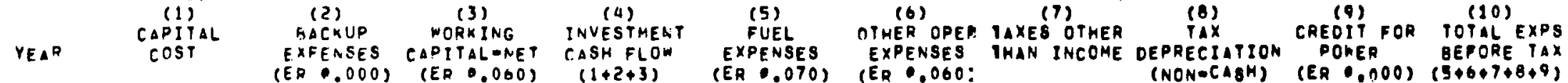

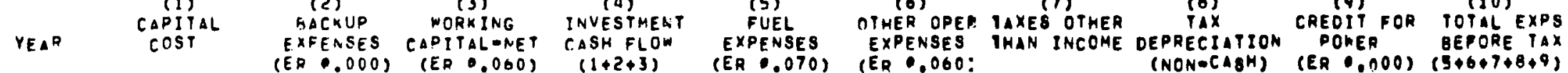

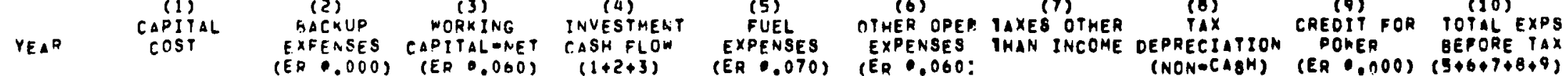

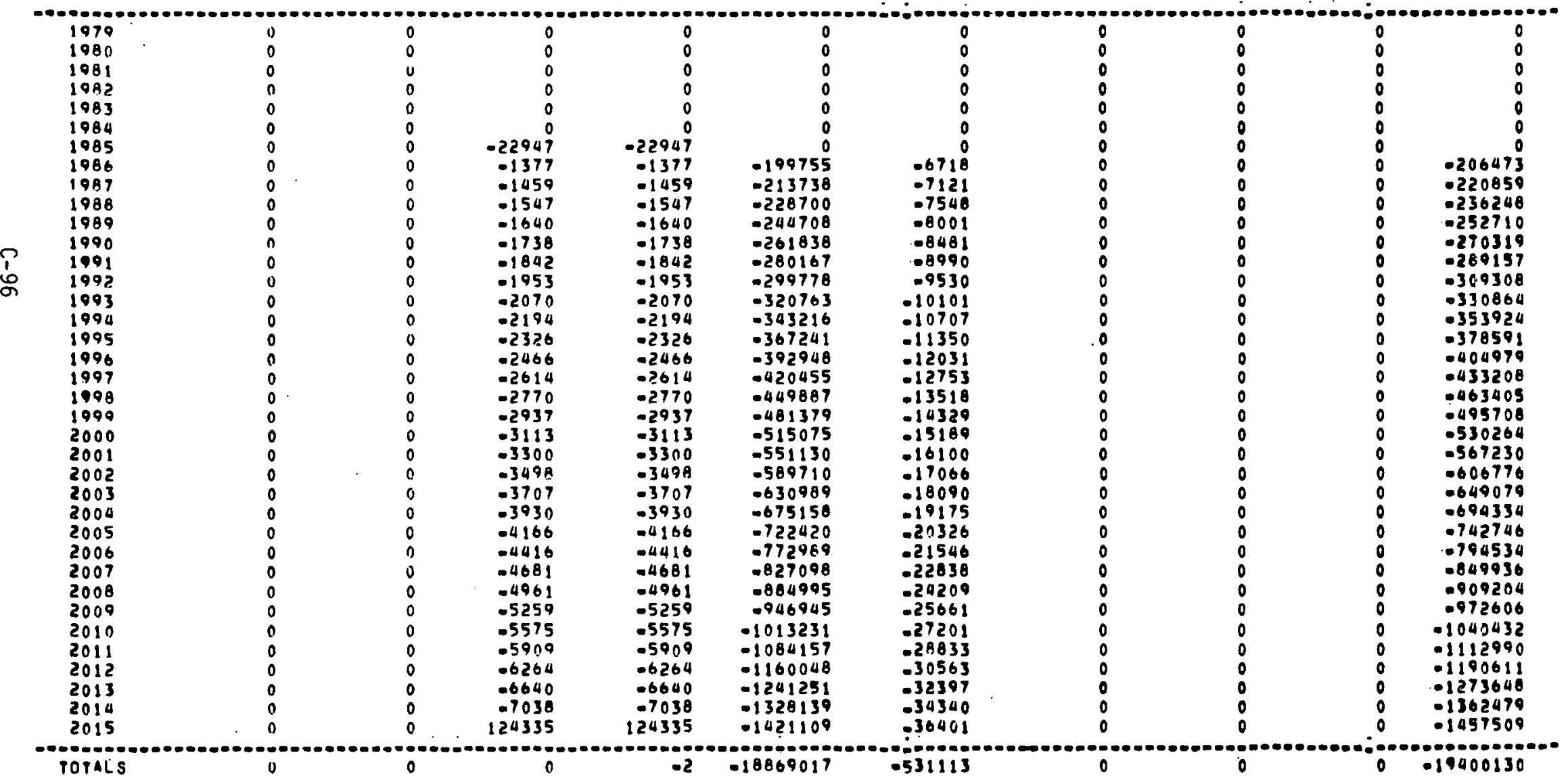


PROJECT COST ANALYSIS

PROJECT: ORANGE CUGENERATION

CASE EXIST. PLANTS

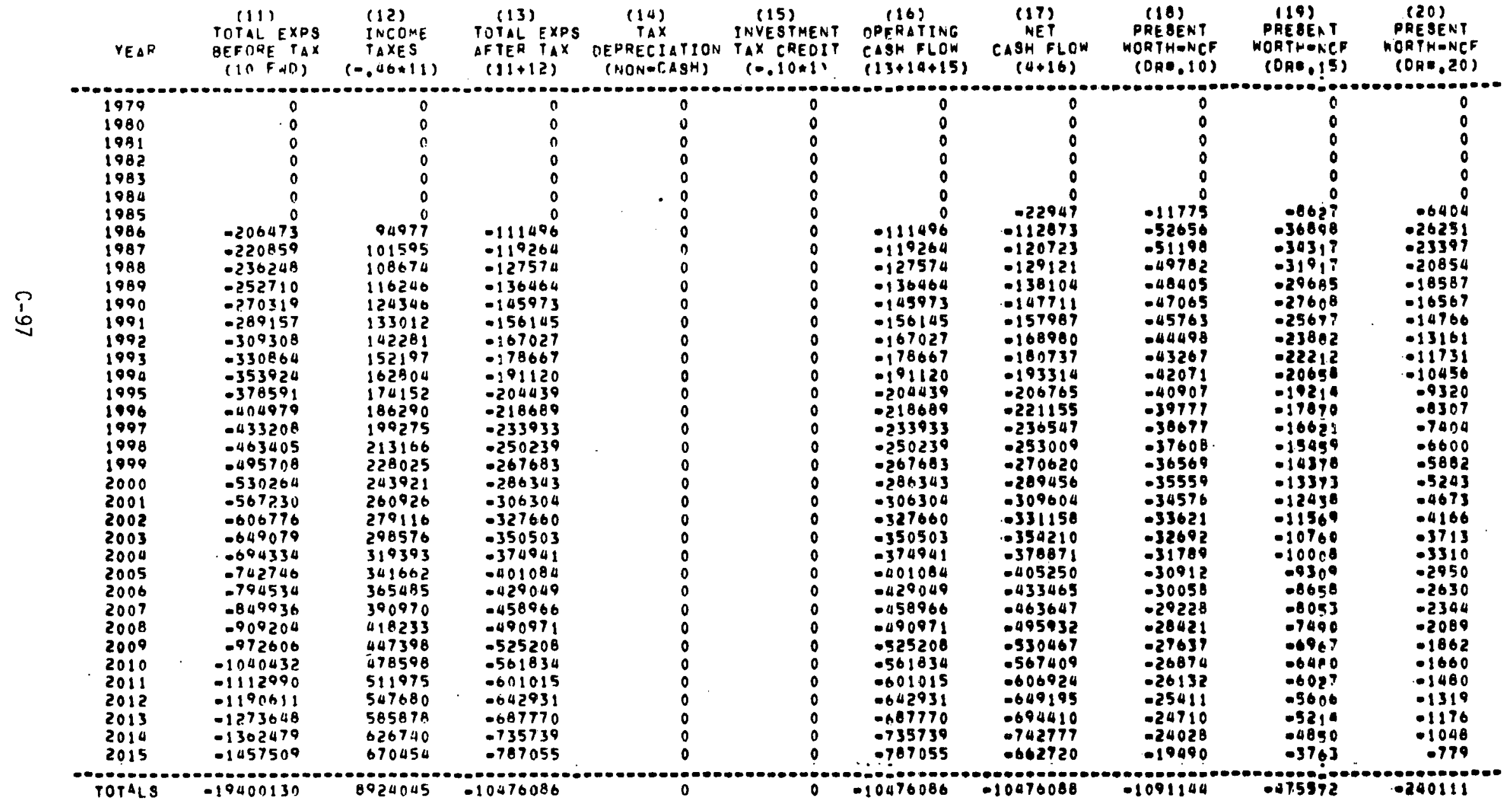


PROJECT COST ANALYSIS

OF ANIUUAL CASH REOUIREMEATS

PROJECI: RRANGE CUGENEFATIOA

CASE IEXIST. OLANTS

$$
\text { 200X FIJEL COST }
$$

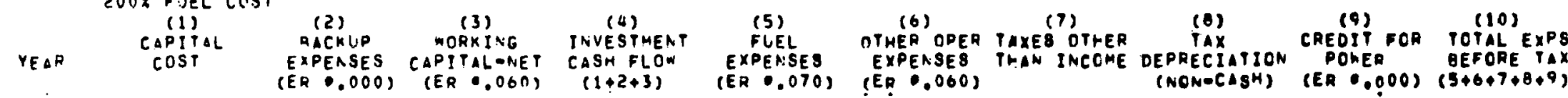

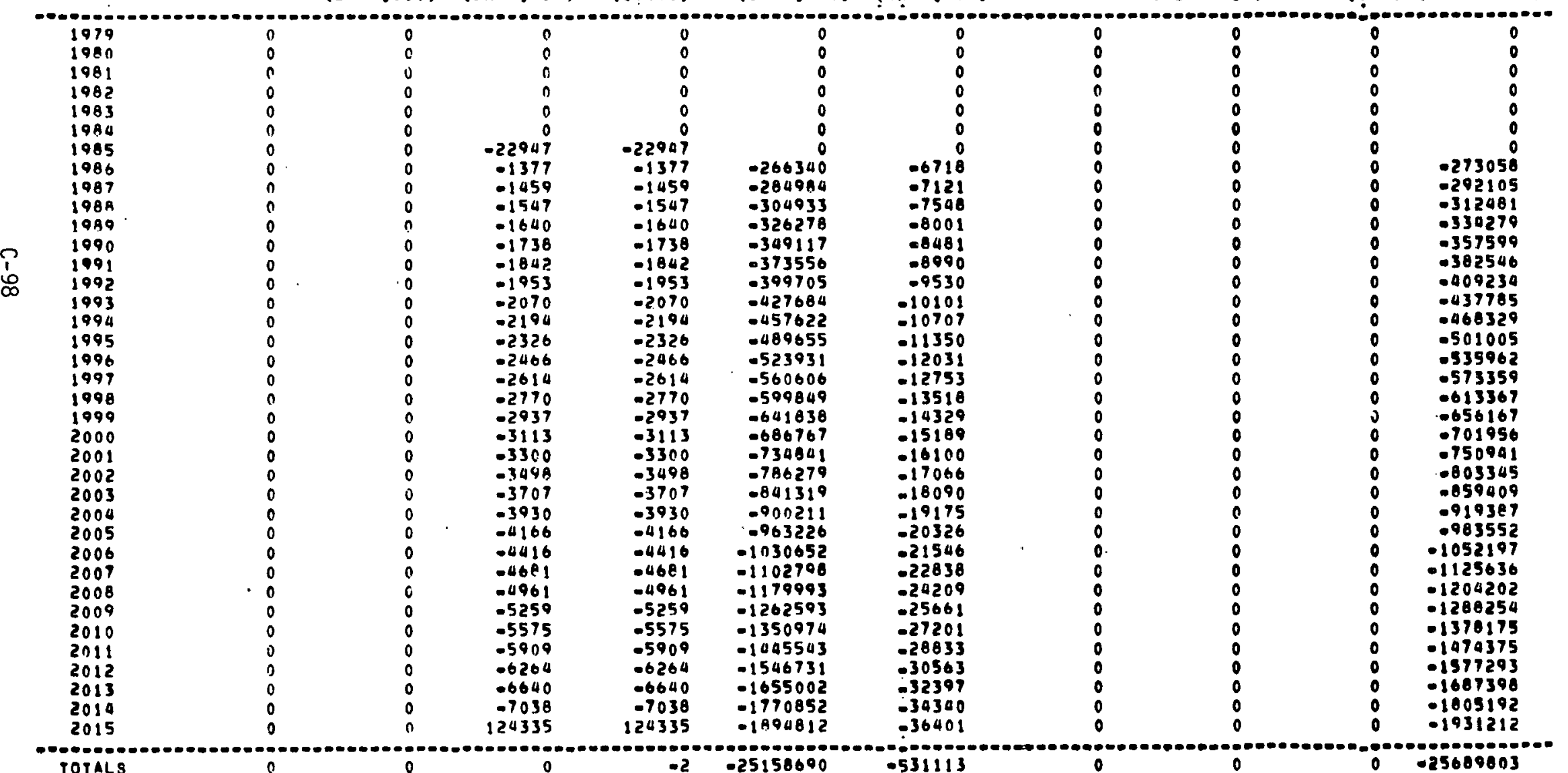


PRQJECT COST ANALYBIS

OF ANNUAL CASH REQUIREMENTS

PROJECT: ORANGE COGENERATICN

CASE IEXIST. PLANPS

$200 x$ FIJFL COST

\begin{tabular}{|c|c|c|c|c|c|c|c|c|c|c|c|}
\hline & $Y E A R$ & $\begin{array}{l}(11) \\
\text { TOTAL EXPS } \\
\text { AEFORE TAX } \\
(10 \text { FWD) }\end{array}$ & $\begin{array}{l}(12) \\
\text { INCONE } \\
\text { TAXES } \\
(0.46 .11)\end{array}$ & $\begin{array}{l}(13) \\
\text { TOTAL EXPS } \\
\text { AFTER TAX } \\
(11+12)\end{array}$ & $\begin{array}{c}(14) \\
\text { TAX } \\
\text { OEPRECIATION } \\
\text { (NON-CASH) }\end{array}$ & $\begin{array}{l}(15) \\
\text { INVESTMENT } \\
\text { TAX CREDIT } \\
(0.10 \otimes 1)\end{array}$ & $\begin{array}{l}(16) \\
\text { APERATING } \\
\text { CASH FLOW } \\
(13+14+15)\end{array}$ & $\begin{array}{c}(17) \\
\text { NEY } \\
\text { CASH FLOW } \\
(4+16)\end{array}$ & $\begin{array}{c}(1 A) \\
\text { PRESENT } \\
\text { WORTHENCF } \\
\text { (DRE, IO) }\end{array}$ & $\begin{array}{l}\text { (19) } \\
\text { PREgEAT } \\
\text { WORTHEACF } \\
\text { (OAH IS) }\end{array}$ & $\begin{array}{c}(20) \\
\text { PRESENT } \\
\text { WORTH-NCF } \\
\text { (OAE,2O) }\end{array}$ \\
\hline $\begin{array}{l}1 \\
0 \\
0\end{array}$ & $\begin{array}{l}1979 \\
1980 \\
1981 \\
1982 \\
1983 \\
1980 \\
1985 \\
1986 \\
1987 \\
1988 \\
1989 \\
1900 \\
1991 \\
1992 \\
1993 \\
1994 \\
1995 \\
1996 \\
1997 \\
1998 \\
1909 \\
2000 \\
2091 \\
2002 \\
2003 \\
2004 \\
2005 \\
2006 \\
2007 \\
2008 \\
2009 \\
2010 \\
2011 \\
2012 \\
2013 \\
2014 \\
2015\end{array}$ & $\begin{array}{r}0 \\
0 \\
0 \\
0 \\
0 \\
0 \\
-273058 \\
-292105 \\
-312481 \\
-334279 \\
-357599 \\
-382546 \\
-409234 \\
-437785 \\
-468329 \\
-501005 \\
-5535962 \\
-557359 \\
-613367 \\
-656167 \\
-771956 \\
-750941 \\
-803345 \\
-859409 \\
-9919387 \\
-983552 \\
-1052197 \\
-11125636 \\
-1204202 \\
-1288254 \\
-1378175 \\
-11474375 \\
-1577293 \\
-1687398 \\
-1805192 \\
-1931212\end{array}$ & $\begin{array}{r}0 \\
0 \\
0 \\
0 \\
0 \\
0 \\
125606 \\
134368 \\
143741 \\
153768 \\
169495 \\
175971 \\
188247 \\
201381 \\
215431 \\
230462 \\
246542 \\
263745 \\
282148 \\
301836 \\
322899 \\
305432 \\
369538 \\
395328 \\
422919 \\
452433 \\
484010 \\
517792 \\
553932 \\
592596 \\
633960 \\
678212 \\
725554 \\
776203 \\
830388 \\
888357\end{array}$ & $\begin{array}{r}0 \\
0 \\
0 \\
0 \\
0 \\
0 \\
0 \\
-149452 \\
-157737 \\
-168740 \\
-180511 \\
-193104 \\
-206575 \\
-220987 \\
-236404 \\
-252898 \\
-270543 \\
-289420 \\
-309614 \\
-331219 \\
-354331 \\
-379057 \\
-005589 \\
-433809 \\
-464081 \\
-496470 \\
-531119 \\
-568187 \\
-607804 \\
-650270 \\
-695658 \\
-740215 \\
-796163 \\
-851730 \\
-911195 \\
-9748114 \\
-1042855\end{array}$ & $\begin{array}{l}0 \\
0 \\
0 \\
0 \\
0 \\
0 \\
0 \\
0 \\
0 \\
0 \\
0 \\
0 \\
0 \\
0 \\
0 \\
0 \\
0 \\
0 \\
0 \\
0 \\
0 \\
0 \\
0 \\
0 \\
0 \\
0 \\
0 \\
0 \\
0 \\
0 \\
0 \\
0 \\
0 \\
0 \\
0 \\
0 \\
0\end{array}$ & $\begin{array}{l}0 \\
0 \\
0 \\
0 \\
0 \\
0 \\
0 \\
0 \\
0 \\
0 \\
0 \\
0 \\
0 \\
0 \\
0 \\
0 \\
0 \\
0 \\
0 \\
0 \\
0 \\
0 \\
0 \\
0 \\
0 \\
0 \\
0 \\
0 \\
0 \\
0 \\
0 \\
0 \\
0 \\
0 \\
0 \\
0 \\
0\end{array}$ & 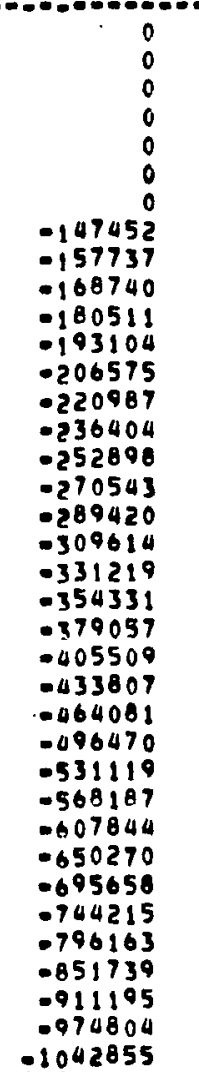 & 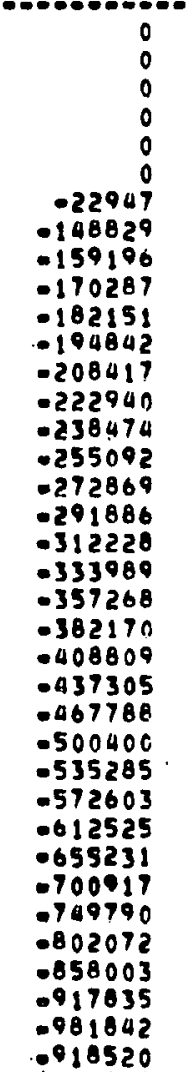 & 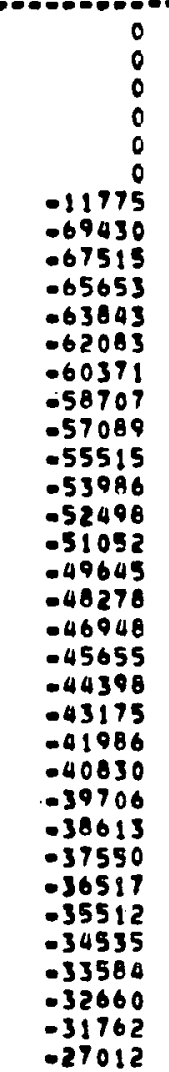 & 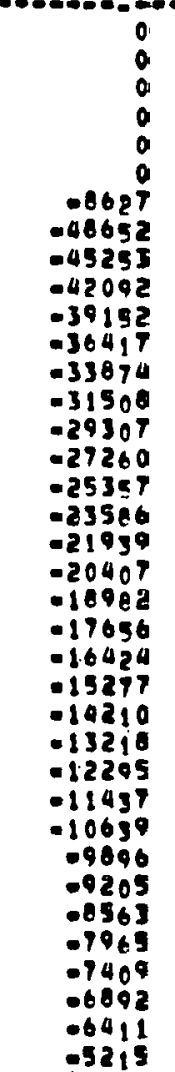 & 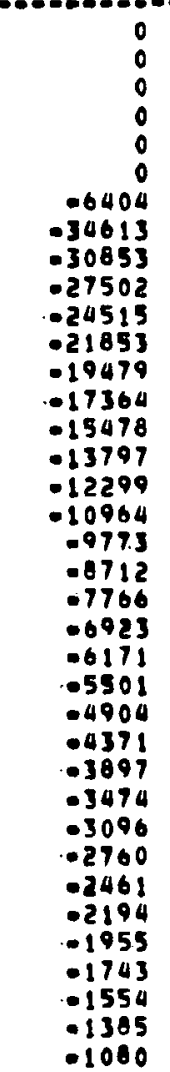 \\
\hline & TOTALS & 25680803 & 11917292 & -13872508 & 0 & 0 & -13872508 & -13872510 & -1437668 & $-625 \ln 9$ & $-314820^{\circ}$ \\
\hline
\end{tabular}

